\title{
\#USGS
}

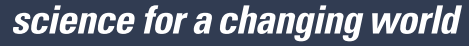

\section{Water, Energy, and Biogeochemical Model (WEBMOD), User's Manual, Version 1}

Chapter 35 of

Section B, Surface Water, of

Book 6, Modeling Techniques
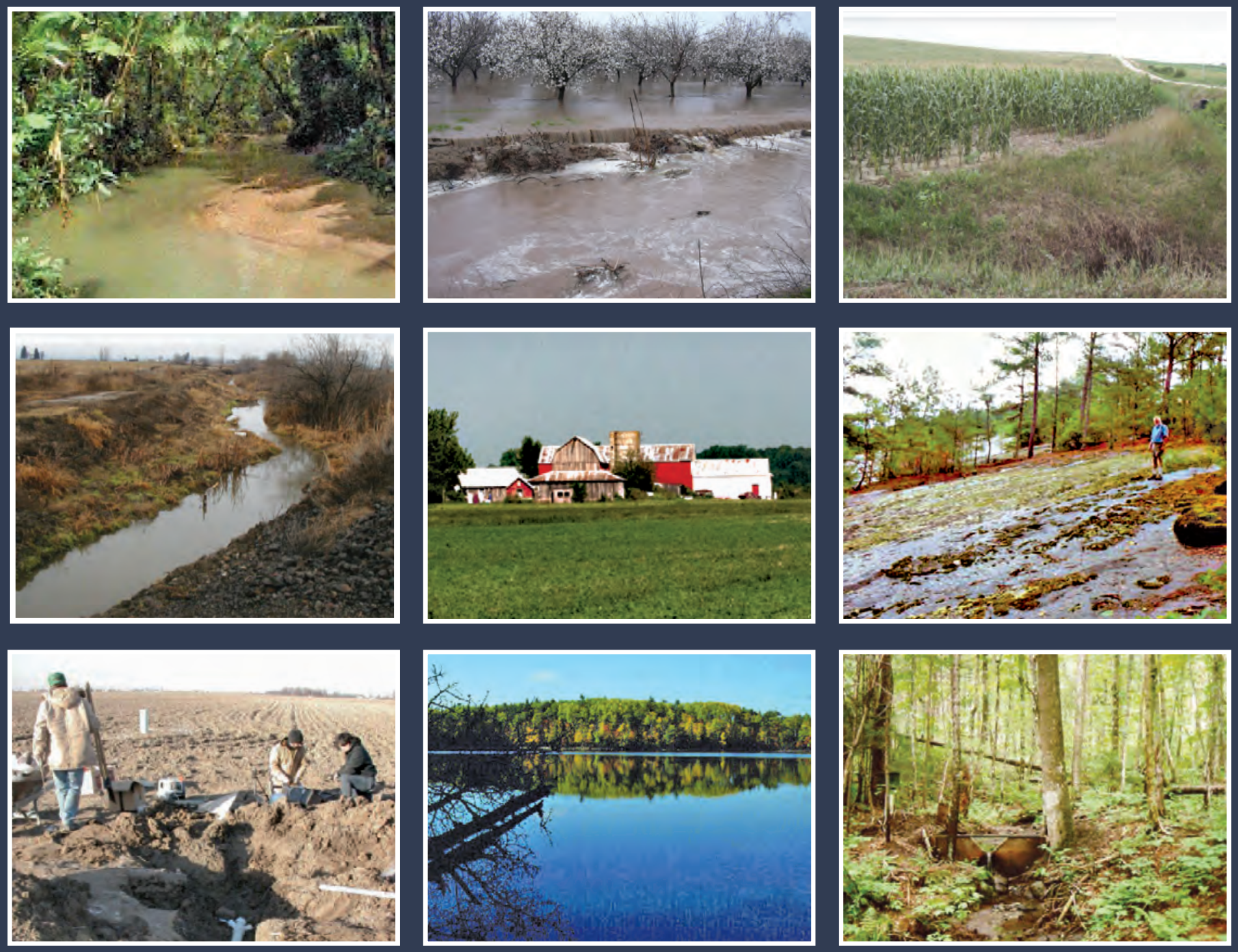

Techniques and Methods 6-B35

U.S. Department of the Interior

U.S. Geological Survey 

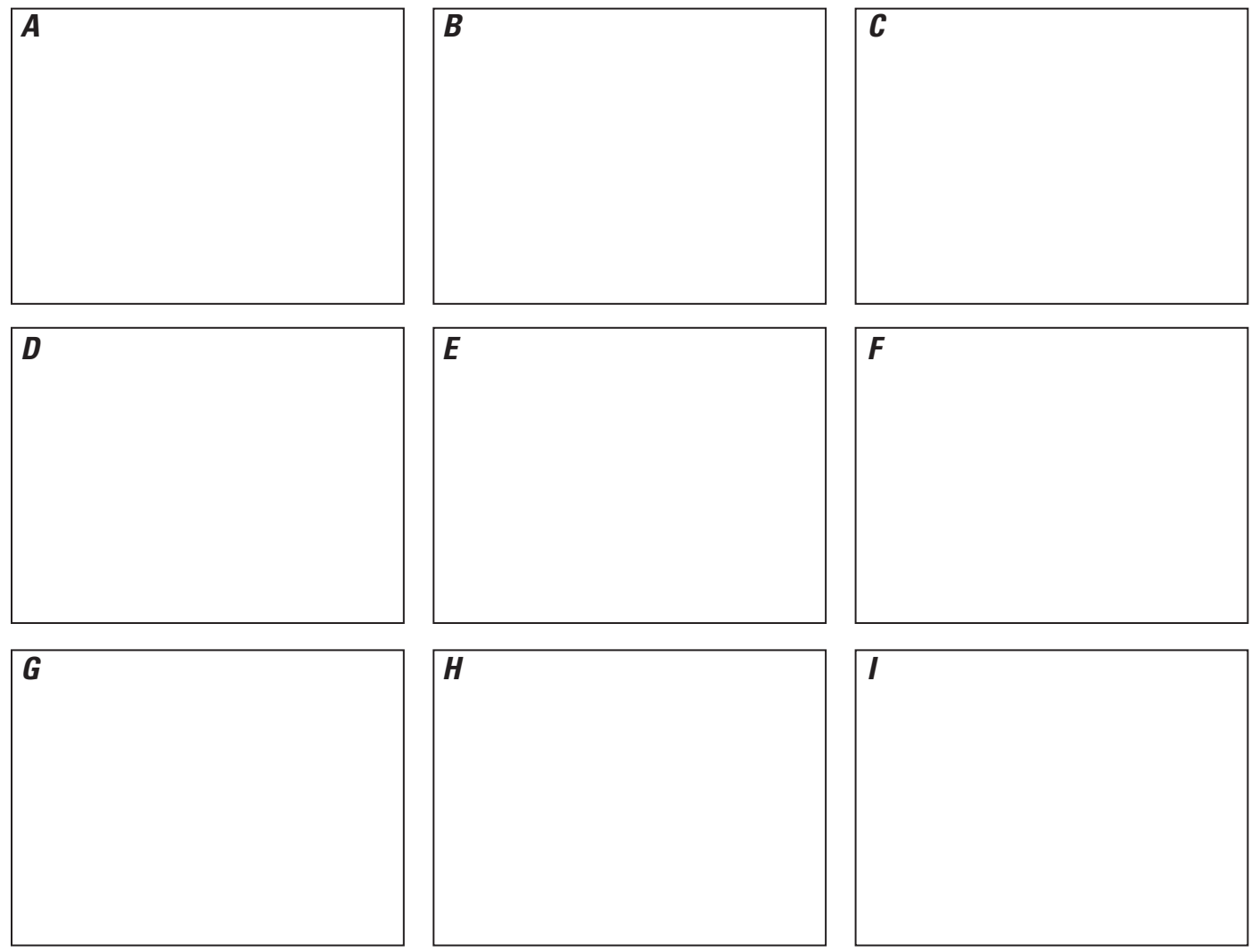

Front Cover. Forested upland watersheds of the Water, Energy, and Biogeochemical Budget Program $(A, F, H, I)$ and agricultural watersheds of the National Water Quality Assessment Agricultural Chemical Transport Studies $(B, C, D, E, G)$. $A$, Luquillo, Puerto Rico; $B$, Mustang River, California; $C$, Maple Creek, Nebraska; D, DR2 Drain, Washington; E, Morgan Creek, Maryland; F, Panola Mountain, Georgia; G, Sugar Creek, Indiana; $H$, Trout Lake, Wisconsin; I, Sleepers River, Vermont.

Back Cover. Loch Vale watershed, Rocky Mountain National Park, Colorado. Photograph by Austin Seeback, U.S. Geological Survey (Flickr, U.S. Geological Survey, public domain). 


\section{Water, Energy, and Biogeochemical Model (WEBMOD), User's Manual, Version 1}

By Richard M.T. Webb and David L. Parkhurst

Chapter 35 of

Section B, Surface Water

Book 6, Modeling Techniques

Techniques and Methods 6-B35 


\title{
U.S. Department of the Interior SALLY JEWELL, Secretary
}

\section{U.S. Geological Survey Suzette M. Kimball, Director}

\author{
U.S. Geological Survey, Reston, Virginia: 2017
}

For more information on the USGS - the Federal source for science about the Earth, its natural and living resources, natural hazards, and the environment—visit http://www.usgs.gov or call 1-888-ASK-USGS.

For an overview of USGS information products, including maps, imagery, and publications, visit http://store.usgs.gov.

Any use of trade, firm, or product names is for descriptive purposes only and does not imply endorsement by the U.S. Government.

Although this information product, for the most part, is in the public domain, it also may contain copyrighted materials as noted in the text. Permission to reproduce copyrighted items must be secured from the copyright owner.

Suggested citation:

Webb, R.M.T., and Parkhurst, D.L., 2017, Water, Energy, and Biogeochemical Model (WEBMOD), user's manual, version 1: U.S. Geological Survey Techniques and Methods, book 6, chap. B35, 171 p., https://doi.org/10.3133/tm6B35.

ISSN 2328-7055 (online) 


\section{Preface}

This report describes the U.S. Geological Survey Water, Energy, and Biogeochemical Model. The performance of the program has been tested in a variety of applications. Future applications, however, might reveal errors that were not detected in the test simulations. Users are requested to send notification of any errors found in this report or the model program to:

Office of Surface Water

U.S. Geological Survey

411 National Center

Reston, VA 20192

(703) 648-5001

The latest version of the model program and this report can be obtained using the Internet at address https://doi.org/10.5066/F7P26W9K. 



\section{Contents}

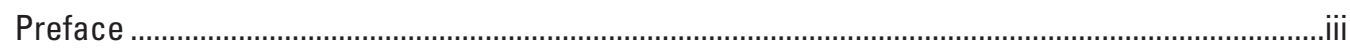

Abstract

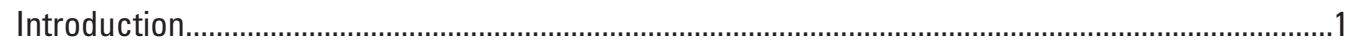

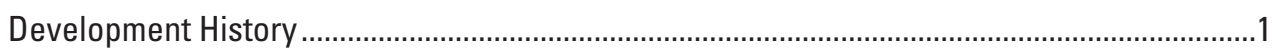

Representation of a Watershed in WEBMOD .....................................................................

Capabilities and Limitations ..................................................................................................

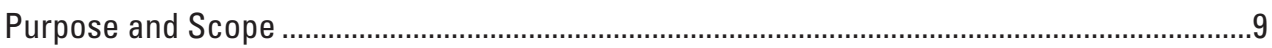

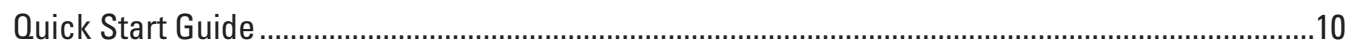

Obtaining, Installing, and Executing

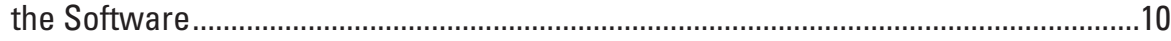

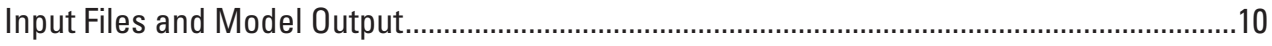

Dimensions, Parameters, and Variables................................................................... 10

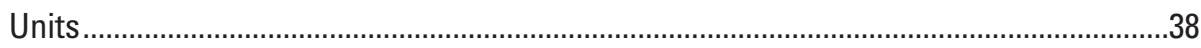

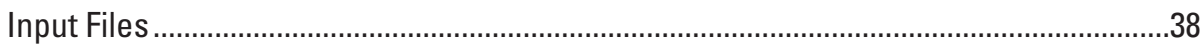

Control File (webmod.control) ................................................................................

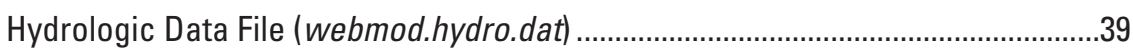

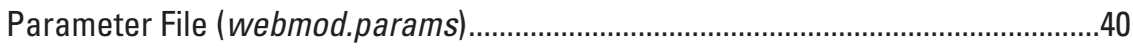

PHREEOC Database File (phreeqc_web_lite.dat) ..................................................40

PHREEQC Input File (webmod.pqi) ........................................................................40

PHREEOC Lookup Table (phreeq_lut) ......................................................................43

Solute Concentration File (webmod.chem.dat) ………..........................................43

Model Output.........................................................................................................

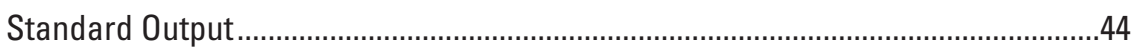

Custom Output and User-Defined Chemical Variables_Chemvars.....................47

Debug File (output/select_mixes) ......................................................................50

Spatial Properties and Topology of the Watershed ……......................................................

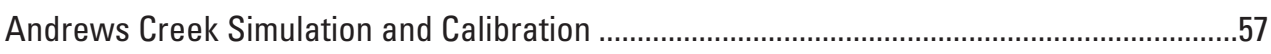

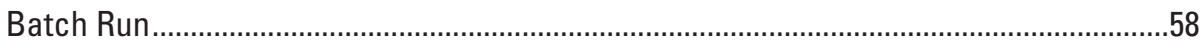

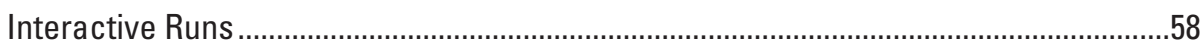

View Run Time Plots of Simulated and Observed Discharge

(steps 1-6; figs. 12A-12C) ....................................................................68

Add Plots for Snow-Water Equivalence for Two MRUs

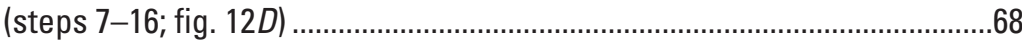

Adjust the Rain and Snow Undercatch Factors, rain_adj(nmru,nmonths) and snow adj(nmru,nmonths), and Evaluate Results (steps 17-31;

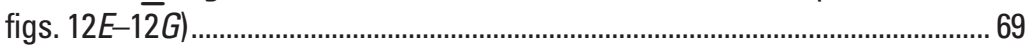

Activate Geochemical Simulations and View Variations in Concentrations of Sodium and Silica (steps 32-43; figs. 12G-12H) ..................................70

Increase Surface Area to Volume Ratio for Oligoclase and Evaluate Results (steps 44-45; fig. 12/)................................................................................71 


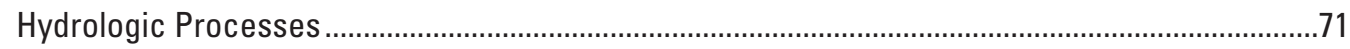

Initial Conditions......................................................................................................................... 72

Energy Balance, Temperature, and Precipitation ........................................................................73

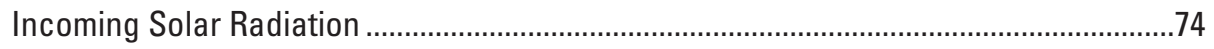

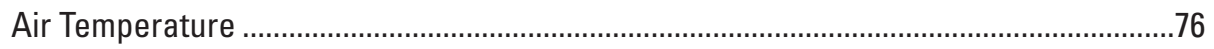

Relative Humidity .............................................................................................................. 77

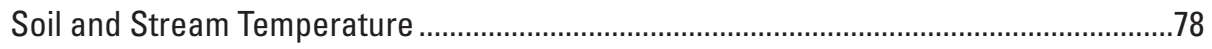

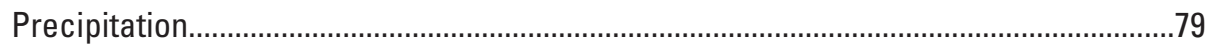

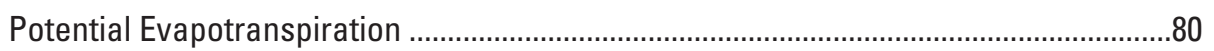

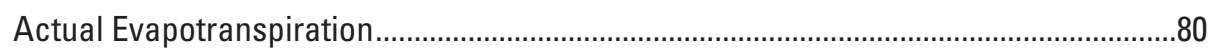

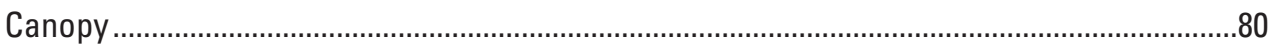

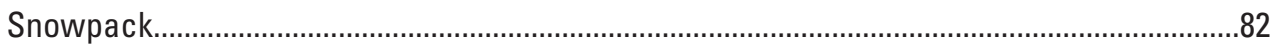

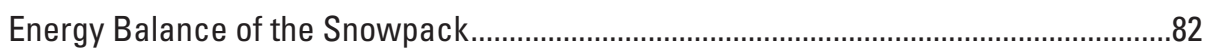

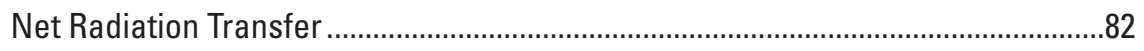

Latent and Sensible Heat Transfer......................................................................... 83

Heat Transfer by Mass Changes .......................................................................... 84

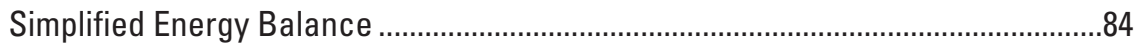

Computation of Snowmelt and Heat Deficits ......................................................................84

Precipitation Form and Melting as Functions of Air Temperature...........................85

Energy Exchange at the Snow-Air Interface .............................................................85

Melt Period with Little to No Rain ....................................................................86

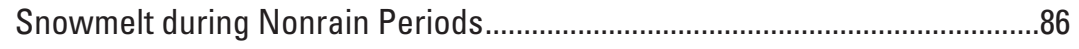

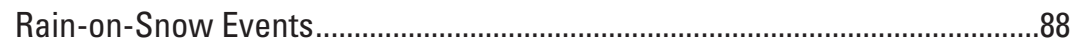

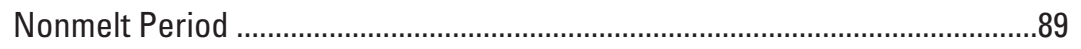

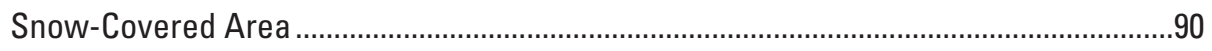

Other Snow Model Components ....................................................................................90

Initial Conditions and Accumulation..............................................................................90

Melting at the Snow-Soil Interface and Sublimation ...............................................92

Retention and Transmission of Liquid Water ..........................................................92

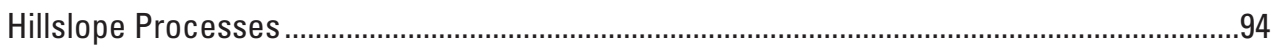

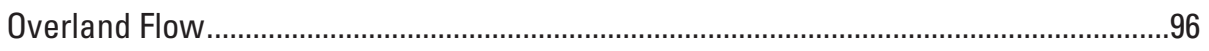

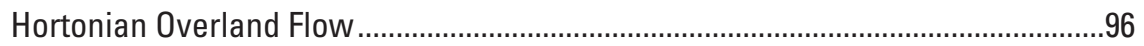

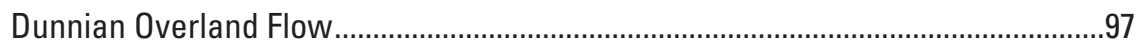

Preferential Flow Paths .......................................................................................................98

Vertical Preferential Flow in the Unsaturated Zone................................................99

Horizontal Preferential Flow in the Unsaturated Zone ............................................99

Preferential Flow in the Saturated Zone ..................................................................... 101

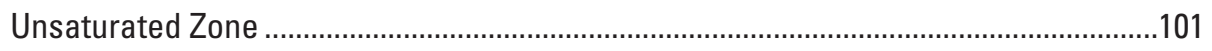

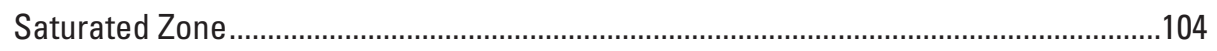

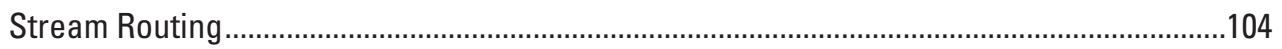

Leaky Canals and Upgradient Groundwater ...................................................................... 104

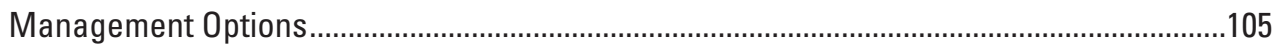

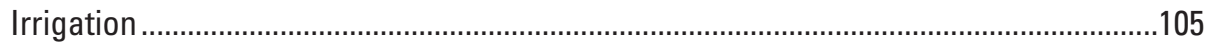

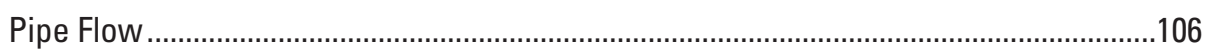




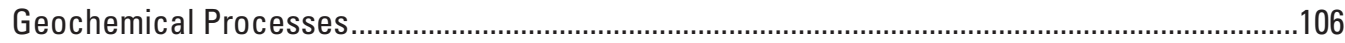

Initial Conditions................................................................................................................. 107

Geochemical Modules and Mixing Variables .......................................................................107

Incongruent Melting of Snowpack .......................................................................................110

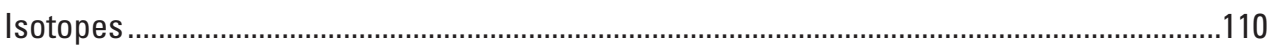

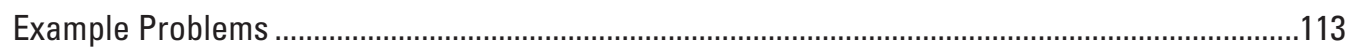

1. Hydrology, Weathering, and Isotopic Variations for the Andrews Creek Watershed...........113

Hydrologic Simulations ..................................................................................................118

Hydrologic Data File (webmod.hydro.dat) .............................................................118

Parameter File (webmod.params) ........................................................................ 118

Geochemical Simulations............................................................................................127

PHREEQC Input File (webmod.pqi) and Parameter File (webmod.params) ...........128

Assignment of Initial Solutions to the Reservoirs ...........................................128

Assignment of Geochemical Reactions to the Reservoirs (webmod.pqi and phreeqc_web_lite.dat) ........................................132

Kinetic Reactions............................................................................................132

Incongruent Melting of Snowpack ................................................................135

Solute Concentration File (webmod.chem.dat) .......................................................135

Model Calibration and Discussion .................................................................................137

2. Dryland Irrigation in the DR2 Watershed .......................................................................142

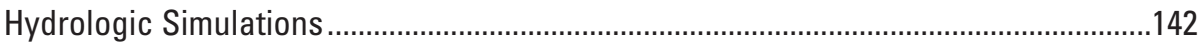

Hydrologic Data File (webmod.hydro.dat) ............................................................142

Parameter File (webmod.params) ........................................................................ 145

Geochemical Simulations.................................................................................................158

Model Calibration, Results, and Discussion................................................................164

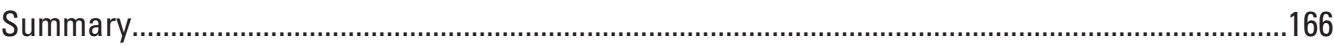

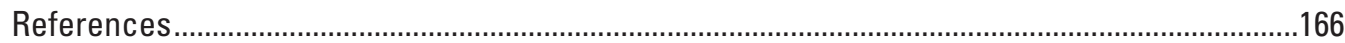

\section{Figures}

1. Forested upland watersheds of the Water, Energy, and Biogeochemical Budget Program.

2. Agricultural watersheds included in Cycle II of the National Water Quality Assessment Agricultural Chemical Transport Studies......................................................4

3. Reservoirs and fluxes of the Water, Energy, and Biogeochemical Model .............................5

4. Batch reactors simulated by the Water, Energy, and Biogeochemical Model along with reservoir indices to use for initializing geochemistry with entities described in the $\mathrm{pH}$-redox-equilibrium model ..................................................................6

5. File structure for the Water, Energy, and Biogeochemical Model ...................................11

6. Abridged view of Andrews Creek hydrologic data file.......................................................39

7. Abridged view of the dimension section of the 10 -model-response-unit Andrews Creek parameter file.

8. Abridged view of the parameter section of the 10-model-response-unit Andrews Creek parameter file. 
9. Shaded relief map of the Loch Vale watershed with solar illumination typical of noon on the day of equinox.

10. Subbasins of Loch Vale and the 10 model response units for the Andrews Creek model.

11. Map of the transformed topographic index for the Loch Vale watershed.

12. Screen images that demonstrate the execution and calibration of the Andrews Creek model using the Modular Modeling System Tool graphical user interface ..............59

13. Schematic diagram showing evapotranspiration at the interface between the water and energy cycles. .74

14. Hyperbolic relation between cloud cover and percent of clear-sky solar radiation .............. 76

15. Spatial distribution of $B$ values in the equation relating cloud cover to reduction

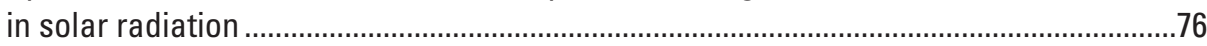

16. Run Time Plot of incoming solar radiation for model response unit 4 of the Andrews Creek model..

17. Decision tree used to determine portion of rain and snow in precipitation .79

18. Mean annual evapotranspiration as a percentage of precipitation for water years 1900-2008 for the conterminous United States

19. Synthetic variations in air temperature for four 6 -hour periods simulated in nwsmelt_topg.

20. Flowchart showing SNOW-17 algorithm to simulate snowpack dynamics including the exchange of heat across the snow-air interface for each of four 6-hour periods.

21. Seasonal variation in the melt factor for the northern hemisphere ................................88

22. Flowchart showing logic used to determine snow-covered area....................................91

23. The two default areal-depletion curves showing relation between snow-covered area, snow-water equivalence, and the areal index for low- and high-relief areas ............. 92

24. Snow-covered area, pack-water equivalence, and maximum accumulation simulated by using areal-depletion curve for low- and high-relief areas using the Andrews Creek model with data inputs from water years 1994 and 1995.

25. Three types of transmissivity profiles and resulting relations as derived by Ambroise and others and implemented in the Water, Energy, and Biogeochemical Model.

26. Green and Ampt infiltration model showing infiltration rate decreasing exponentially and asymptotically approaching the saturated hydraulic conductivity of the soils

27. Log-normal distribution of vertical hydraulic conductivity simulated for a model response unit with a median of 1.0 meter per hour and a coefficient of variation of 14.132

28. Variations of saturation deficits and water table with increasing nac index

29. Transformed topographic index bins for the parameters $\mathbf{T}$ _decay $(\circ n e)=0$; st (inac $=1-6, \mathrm{nmru})=18.4,14.2,10.1,6.0,1.6,0.76$; and ac $($ inac $=1-6, \mathrm{nmru})=0.0$, $0.018,0.025,0.275,0.484,0.198$.

30. Schematic showing different preferential flow mechanisms observed at pore, Darcian, and areal scales 100

31. Schematic diagram showing soil volumes from land surface down to bedrock 102 
32. Drainable porosity, available water capacity, and unavailable water for the twelve texture classes used by the National Resource Conservation Service 103

33. Relation of pump coefficient to saturation deficit..........................................................106

34. Depletion of deuterium and oxygen-18 in vapor over water and ice as a function of temperature..

35. Delta value for oxygen-18 for water and vapor simulated for evaporation fractions from 0 to 1.0 at 0 percent and 100 percent relative humidity at 25 degrees Celsius.

36. Descriptive map showing the location of the Loch, Andrews Creek, Icy Brook, and Main Weather Station in the Loch Vale watershed, Rocky Mountain National Park, Colorado.

37. Delta oxygen-18 measured in Andrews Creek along with that measured in rain and snow falling in the Loch Vale watershed from 1992 through 2009

38. Seasonal variations in delta oxygen-18 measured in Andrews Creek along with that measured in precipitation and snow pits in the Loch Vale watershed from 1992 through 2009

39. Simulated and observed discharge and adjusted precipitation for Andrews Creek for water years 1984 through 2012

40. Seasonal variations in snow-water equivalence and simulated and observed discharge for water years 2010 through 2012

41. Simulated and observed discharge for Andrews Creek for water years 2000 through 2012

42. Seasonal variations in daily delta oxygen-18, temperature, $\mathrm{pH}$, and solute concentrations for Andrews Creek averaged for water years 1993 through 2012.......140

43. The delta oxygen-18, temperature, $\mathrm{pH}$, and solute concentrations for Andrews Creek for water years 1992 through 2012

44. Map showing the Yakima River and the location of the Granger Drain 143

45. Map showing the Roza, Sunnyside, and Outlook Canals and the watershed boundaries for the DR2 and Granger watersheds 144

46. Map showing head weirs and delivery boxes used to regulate diversions of water from Sunnyside Canal to fields in the DR2 watershed

47. Depths of irrigation supplied by seven weirs that control deliveries of water from Sunnyside Canal to agricultural fields flowing to the DR2 drain from 2001 through 2005

48. Diagram showing 22 model response units in the DR2 model

49. Specific conductance versus chloride concentrations for water-quality samples collected at the DR2 gage at Yakima Highway from March 4, 2003, through October 24, 2004

50. Simulated discharge of the DR2 drain for calendar years 1988 through 2005, and measured discharge from March 1, 2003, through September 30, 2004, using a flume installed at the outlet. 164

51. Inputs and outputs for the DR2 watershed simulated for 2004-05................................165

52. Simulated and observed variations in specific conductance and chloride for the DR2 gage for calendar years 1998 through 2005 


\section{Tables}

1. Dimensions of the Water, Energy, and Biogeochemical Model

2. Parameters, by process and intent, used the Water, Energy, and Biogeochemical Model

3. Variables, categorized by property, observation, and process in the Water, Energy, and Biogeochemical Model....

4. Control File parameters that define the file names and contents of the Water, Energy, and Biogeochemical Model output....

5. Content of standard output files determined by the print_type(one) and print_vse(one) parameters.

6. Field labels and descriptions in webmod.hydro.out when detailed output is requested

7. Spatial metrics and topology in the Water, Energy, and Biogeochemical Model ...........51

8. Stream channel topology for a three-subbasin Loch Vale model ......................................53

9. Indices for assignment of model response units to precipitation, temperature, relative humidity, pan evaporation, irrigation, and diffuse groundwater along with indices used to assign water chemistry to watershed inputs..

10. Parameters describing initial states of irrigation, snowpack, soil moisture, and discharge

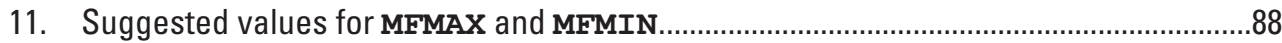

12. Geochemical entities that may be assigned to watershed reservoirs ............................108

13. Transformed topographic index (TTI) rule for row 6 in Entityset_table used to initialize TTI bins .108

14. Overview of model configuration for the Andrews Creek and the DR2 watersheds ........114

15. Dimensions of the Andrews Creek model ........................................................................119

16. Topographic and transmissivity parameters for the Andrews Creek model ..................120

17. Parameters to distribute incoming solar radiation, temperature, and precipitation in the Andrews Creek model.

18. Default parameters for irrigation ................................................................................ 123

19. Default parameters for groundwater inputs..........................................................................123

20. Evapotranspiration parameters for the Andrews Creek model .......................................124

21. Snowpack parameters for the Andrews Creek model ..................................................125

22. Hillslope parameters for the Andrews Creek model.........................................................126

23. Channel routing parameters for the Andrews Creek model..........................................127

24. Biogeochemical simulation switch and 11 solutes tracked in the Andrews Creek model.

25. Input dynamics, conversion factors, static reservoirs, and the transformed topographic index threshold that separates riparian from upland areas for the Andrews Creek model.

26. Initial assignments of inputs, hillslope reservoirs, and stream segments in the Andrews Creek model to the entities defined in webmod.pqi.

27. Minerals, weathering reactions, equilibrium constants, enthalpies of reaction, and surface areas listed in phreeqc_web_lite.dat and webmod.pqi to simulate weathering and precipitation of secondary minerals in the Andrews Creek model...

28. Parameters for incongruent melting of solutes and isotopes from snowpack for the Andrews Creek model 
29. Parameters for output and user-defined variables for the Andrews Creek model 137

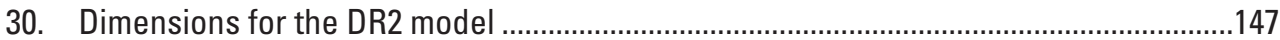

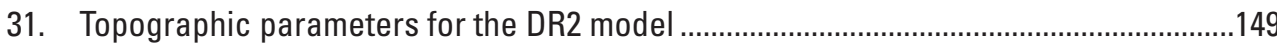

32. Channel routing parameters for the DR2 model .......................................................150

33. Parameters to distribute incoming solar radiation, temperature, and precipitation

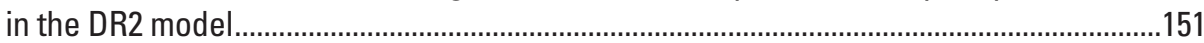

34. Parameters mapping irrigation for the DR2 model....................................................154

35. Parameters defining upgradient groundwater inputs for the DR2 model ......................155

36. Parameters for evapotranspiration in the DR2 model .................................................156

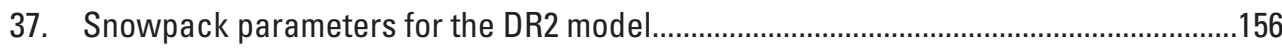

38. Hillslope parameters for the DR2 model ................................................................157

39. Biogeochemical simulation switch and single solute tracked for the DR2 model

40. Input dynamics, conversion factors, static reservoirs, and the transformed topographic index threshold that separates riparian from upland areas for the DR2 model

41. Initial assignments of inputs, hillslope reservoirs, and stream segments in the DR2 model to the entities defined in webmod.pqi.

42. Parameters for incongruent melting of solutes and isotopes from snowpack for the DR2 model

43. Parameters for output and user-defined variables for the DR2 model

\section{Conversion Factors}

Inch/Pound to International System of Units

\begin{tabular}{|c|c|c|}
\hline Multiply & By & To obtain \\
\hline \multicolumn{3}{|c|}{ Length } \\
\hline inch (in.) & 2.54 & centimeter $(\mathrm{cm})$ \\
\hline inch (in.) & 25.4 & millimeter $(\mathrm{mm})$ \\
\hline foot $(\mathrm{ft})$ & 0.3048 & meter $(\mathrm{m})$ \\
\hline \multicolumn{3}{|c|}{ Pressure } \\
\hline atmosphere (atm) & 101.325 & kilopascal $(\mathrm{kPa})$ \\
\hline millibar (mbar) & 0.1 & kilopascal (kPa) \\
\hline \multicolumn{3}{|c|}{ Flow rate } \\
\hline inch per day (in/d) & 2.54 & centimeter per day $(\mathrm{cm} / \mathrm{d})$ \\
\hline cubic foot per second $\left(\mathrm{ft}^{3} / \mathrm{s}\right)$ & 0.02832 & cubic meter per second $\left(\mathrm{m}^{3} / \mathrm{s}\right)$ \\
\hline gallon per minute (gal/min) & 0.06309 & liter per second $(\mathrm{L} / \mathrm{s})$ \\
\hline \multicolumn{3}{|c|}{ Energy } \\
\hline langley per day (ly/d) & 0.483333333 & watt per square meter $\left(\mathrm{W} / \mathrm{m}^{2}\right)$ \\
\hline \multicolumn{3}{|c|}{ Leakance } \\
\hline $\begin{array}{l}\text { cubic foot per second per mile } \\
\left(\left[\mathrm{ft}^{3} / \mathrm{s}\right] / \mathrm{mi}\right)\end{array}$ & 0.01756 & $\begin{array}{l}\text { cubic meter per second per kilometer } \\
\left(\left[\mathrm{m}^{3} / \mathrm{s}\right] / \mathrm{km}\right)\end{array}$ \\
\hline
\end{tabular}

Temperature in degrees Celsius $\left({ }^{\circ} \mathrm{C}\right)$ may be converted to degrees Fahrenheit $\left({ }^{\circ} \mathrm{F}\right)$ as follows:

$$
{ }^{\circ} \mathrm{F}=\left(1.8 \times{ }^{\circ} \mathrm{C}\right)+32 \text {. }
$$

Temperature in degrees Fahrenheit $\left({ }^{\circ} \mathrm{F}\right)$ may be converted to degrees Celsius $\left({ }^{\circ} \mathrm{C}\right)$ as follows:

$$
{ }^{\circ} \mathrm{C}=\left({ }^{\circ} \mathrm{F}-32\right) / 1.8 \text {. }
$$


To obtain the daily discharge in centimeters per day $(\mathrm{cm} / \mathrm{d})$, multiply the mean daily discharge in cubic feet per second ( $\left(\mathrm{ft}^{3} / \mathrm{s}\right)$ by 0.244658 then divide by the drainage area in square kilometers $\left(\mathrm{km}^{2}\right)$.

International System of Units to Inch/Pound

\begin{tabular}{|c|c|c|}
\hline Multiply & By & To obtain \\
\hline \multicolumn{3}{|c|}{ Mass } \\
\hline gram $(\mathrm{g})$ & 0.03527 & ounce (oz, avoirdupois) \\
\hline milligram (mg) & 0.00003527 & ounce (oz, avoirdupois) \\
\hline kilogram $(\mathrm{kg})$ & 2.2046 & pound (lb) \\
\hline \multicolumn{3}{|c|}{ Length } \\
\hline micrometer $(\mu \mathrm{m})$ & 0.00003937 & inch (in.) \\
\hline centimeter $(\mathrm{cm})$ & 0.3937 & inch (in.) \\
\hline millimeter (mm) & 0.03937 & inch (in.) \\
\hline meter $(\mathrm{m})$ & 3.281 & foot $(\mathrm{ft})$ \\
\hline kilometer (km) & 0.6214 & mile (mi) \\
\hline kilometer (km) & 0.5400 & mile, nautical (nmi) \\
\hline meter $(\mathrm{m})$ & 1.094 & yard $(y d)$ \\
\hline \multicolumn{3}{|c|}{ Area } \\
\hline square meter $\left(\mathrm{m}^{2}\right)$ & 0.0002471 & acre \\
\hline hectare (ha) & 2.471 & acre \\
\hline square centimeter $\left(\mathrm{cm}^{2}\right)$ & 0.001076 & square foot $\left(\mathrm{ft}^{2}\right)$ \\
\hline square meter $\left(\mathrm{m}^{2}\right)$ & 10.76 & square foot $\left(\mathrm{ft}^{2}\right)$ \\
\hline square centimeter $\left(\mathrm{cm}^{2}\right)$ & 0.1550 & square inch $\left(\mathrm{in}^{2}\right)$ \\
\hline hectare (ha) & 0.003861 & square mile $\left(\mathrm{mi}^{2}\right)$ \\
\hline square kilometer $\left(\mathrm{km}^{2}\right)$ & 0.3861 & square mile $\left(\mathrm{mi}^{2}\right)$ \\
\hline \multicolumn{3}{|c|}{ Volume } \\
\hline cubic centimeter $\left(\mathrm{cm}^{3}\right)$ & 0.061023 & cubic inch $\left(\right.$ in $\left.^{3}\right)$ \\
\hline liter $(\mathrm{L})$ & 33.82 & ounce, fluid (fl. oz) \\
\hline liter (L) & 2.113 & pint (pt) \\
\hline liter (L) & 1.057 & quart (qt) \\
\hline liter $(\mathrm{L})$ & 0.2642 & gallon (gal) \\
\hline cubic meter $\left(\mathrm{m}^{3}\right)$ & 264.2 & gallon (gal) \\
\hline cubic meter $\left(\mathrm{m}^{3}\right)$ & 0.0002642 & million gallons (Mgal) \\
\hline liter $(\mathrm{L})$ & 61.02 & cubic inch $\left(\mathrm{in}^{3}\right)$ \\
\hline cubic meter $\left(\mathrm{m}^{3}\right)$ & 35.31 & cubic foot $\left(\mathrm{ft}^{3}\right)$ \\
\hline cubic meter $\left(\mathrm{m}^{3}\right)$ & 1.308 & cubic yard $\left(\mathrm{yd}^{3}\right)$ \\
\hline cubic meter $\left(\mathrm{m}^{3}\right)$ & 0.0008107 & acre-foot (acre-ft) \\
\hline \multicolumn{3}{|c|}{ Density } \\
\hline gram per cubic centimeter $\left(\mathrm{g} / \mathrm{cm}^{3}\right)$ & 62.42796 & pound per cubic foot $\left(\mathrm{lb} / \mathrm{ft}^{3}\right)$ \\
\hline gram per cubic meter $\left(\mathrm{g} / \mathrm{m}^{3}\right)$ & 0.00006243 & pound per cubic foot $\left(\mathrm{lb} / \mathrm{ft}^{3}\right)$ \\
\hline \multicolumn{3}{|c|}{ Pressure } \\
\hline kilopascal & 0.1450377 & pound-force per square inch $\left(\mathrm{lb} / \mathrm{in}^{2}\right)$ \\
\hline kilopascal & 0.00986923 & atmosphere $(\mathrm{atm})$ \\
\hline kilopascal & 10.0 & millibar (mbar) \\
\hline \multicolumn{3}{|c|}{ Flow rate } \\
\hline millimeter per hour $(\mathrm{mm} / \mathrm{h})$ & 0.03937 & inch per hour \\
\hline centimeter per second $(\mathrm{cm} / \mathrm{s})$ & 0.3937 & inch per second \\
\hline centimeter per hour $(\mathrm{cm} / \mathrm{h})$ & 0.3937 & inch per hour \\
\hline meter per second $(\mathrm{m} / \mathrm{s})$ & 3.281 & foot per second $(\mathrm{ft} / \mathrm{s})$ \\
\hline meter per hour $(\mathrm{m} / \mathrm{h})$ & 3.281 & foot per hour $(\mathrm{ft} / \mathrm{h})$ \\
\hline meter per day $(\mathrm{m} / \mathrm{d})$ & 3.281 & foot per day $(\mathrm{ft} / \mathrm{d})$ \\
\hline kilometer per hour $(\mathrm{km} / \mathrm{h})$ & 0.62137 & mile per hour $(\mathrm{mi} / \mathrm{h})$ \\
\hline \multicolumn{3}{|c|}{ Energy } \\
\hline joule $(\mathrm{J})$ & 0.0000002 & kilowatthour (kWh) \\
\hline watts per square meter $\left(\mathrm{W} / \mathrm{m}^{2}\right)$ & 2.0689 & langleys per day (ly/d) \\
\hline \multicolumn{3}{|c|}{ Transmissivity* } \\
\hline square meter per hour $\left(\mathrm{m}^{2} / \mathrm{h}\right)$ & 10.76 & square foot per hour $\left(\mathrm{ft}^{2} / \mathrm{h}\right)$ \\
\hline
\end{tabular}




\section{Datum}

Vertical coordinate information is referenced to the North American Vertical Datum of 1988 (NAVD 88).

Horizontal coordinate information is referenced to the North American Datum of 1983 (NAD 83)].

Altitude, as used in this report, refers to distance above the vertical datum. The vertical datum is usually mean sea level with altitude expressed as meters above mean sea level (mamsl)

\section{Supplemental Information}

Transmissivity: The standard unit for transmissivity is cubic meter per hour per square meter times meter of aquifer thickness $\left[\left(\mathrm{m}^{3} / \mathrm{h}\right) / \mathrm{m}^{2}\right] \mathrm{m}$. In this report, the mathematically reduced form, meter squared per hour $\left(\mathrm{m}^{2} / \mathrm{h}\right)$, is used for convenience.

Specific conductance is given in microsiemens per centimeter at 25 degrees Celsius $(\mu \mathrm{S} / \mathrm{cm}$ at $\left.25^{\circ} \mathrm{C}\right)$.

Concentrations of chemical constituents in water are given in moles per liter $(\mathrm{mol} / \mathrm{L})$, moles per kilogram of water (mol/kgw), milligrams per liter $(\mathrm{mg} / \mathrm{L})$, micrograms per liter $(\mu \mathrm{g} / \mathrm{L})$, milliequivalents per liter (meq/L), or microequivalents per liter ( $\mu \mathrm{eq} / \mathrm{L})$.

Loads of chemical constituents in water entering or leaving the watershed are given in milligrams per square meter $\left(\mathrm{mg} / \mathrm{m}^{2}\right)$ or milliequivalents per square meter $\left(\mathrm{meq} / \mathrm{m}^{2}\right)$.

A water year is the 12-month period beginning 0 ctober 1 for any given year through September 30 of the following year. The water year is designated by the calendar year in which it ends.

Results for measurements of stable isotopes of an element in water, solids, and dissolved constituents commonly are expressed as the relative difference in $R_{\text {sample }}$ the ratio of the number of the less abundant isotope to the number of the more abundant isotope measured for a sample, with respect to $R_{\text {standard }}$ the same ratio in a measurement standard. This ratio of ratios is greater than 1.0 when the sample contains a greater proportion of the less abundant isotope than proportion measured in the standard, and less than 1.0 for the converse situation. The relative abundance of the light isotope is commonly expressed as delta, $\delta=\left(R_{\text {sample }} / R_{\text {standard }}-1\right) 1000$, in parts per thousand $(\%)$.

\section{Formatting Conventions}

The Modular Modeling System (MMS) represents Earth-system processes in modules that share parameters, variables, and dimensions. Parameters are user-specified values that do not change during a simulation. Variables are simulation states and fluxes that can vary with each time step. Dimensions define the array sizes of variables and parameters.

In this manual, consistent fonts and styles are used to distinguish file names, parameters, variables, constants, and Water, Energy, and Biogeochemcial Model (WEBMOD) modules and functions. The fonts and styles are simply an attempt to visually identify different elements; all files and file contents use standard American Standard Code for Information Interchange (ASCII) characters. 
- Directories and file names are typed in italic with an asterisk in front of the common extension where appropriate. The section "Input Files and File Output" will detail the locations and naming conventions of WEBMOD.

- Module dimensions, command lines in a Disk Operating System (DOS) or Unix command line window, and the names of process modules and module dimensions are typed in Courier New font. Module dimensions are listed and edited in the first section of the parameter file webmod.params.

- Module parameters are typed in bold Courier New font. Module parameters are listed and edited in the second section of the parameter file. Geochemistry is defined directly within webmod.pqi, the PHREEQC input file (Parkhurst and Appelo, 2013) and distributed throughout the watershed using parameters in the parameter file.

- Module variables are typed in bold italic Courier New font. Input variables are edited in webmod.hydro.dat and webmod.chem.dat.

The source code and graphical user interface (GUI) for the MMS were originally developed using X-Windows in the Unix operating system. As the source code and GUls were ported to the PC environment (both Windows and Linux operating systems), the term Modular Modeling Framework (MMF) was used to identify source code that contained an abridged version of the original MMS functions. During the port, some Java GUls were retitled with MMF instead of MMS. WEBMOD uses only the current MMF source code and GUls although MMS still appears as a legacy term in the tiles of some GUls including the root windows of the MMS tool.

\section{Abbreviations}

$\begin{array}{ll}\text { GUI } & \text { Graphical User Interface } \\ \text { MMF } & \text { Modular Modeling Framework } \\ \text { MMS } & \text { Modular Modeling System } \\ \text { MRU } & \text { Model Response Unit } \\ \text { NADP } & \text { National Atmospheric Deposition Program } \\ \text { NAWQA } & \text { National Water Quality Assessment } \\ \text { NWS } & \text { National Weather Service } \\ \text { PHREEC } & \text { pH-redox-equilibrium model in the C programming language } \\ \text { PRMS } & \text { Precipitation Runoff Modeling System } \\ \text { TOPMODEL } & \text { Topography-driven hydrologic model } \\ \text { TTI } & \text { Transformed Topographic Index } \\ \text { USGS } & \text { U.S. Geological Survey } \\ \text { WEBB } & \text { Water, Energy, and Biogeochemical Budget }\end{array}$




\title{
Water, Energy, and Biogeochemical Model (WEBMOD), User's Manual, Version 1
}

\author{
By Richard M.T. Webb and David L. Parkhurst
}

\section{Abstract}

The Water, Energy, and Biogeochemical Model (WEBMOD) uses the framework of the U.S. Geological Survey (USGS) Modular Modeling System to simulate fluxes of water and solutes through watersheds. WEBMOD divides watersheds into model response units (MRU) where fluxes and reactions are simulated for the following eight hillslope reservoir types: canopy; snowpack; ponding on impervious surfaces; O-horizon; two reservoirs in the unsaturated zone, which represent preferential flow and matrix flow; and two reservoirs in the saturated zone, which also represent preferential flow and matrix flow. The reservoir representing ponding on impervious surfaces, currently not functional (2017), will be implemented once the model is applied to urban areas. MRUs discharge to one or more stream reservoirs that flow to the outlet of the watershed. Hydrologic fluxes in the watershed are simulated by modules derived from the USGS Precipitation Runoff Modeling System; the National Weather Service Hydro-17 snow model; and a topography-driven hydrologic model (TOPMODEL). Modifications to the standard TOPMODEL include the addition of heterogeneous vertical infiltration rates; irrigation; lateral and vertical preferential flows through the unsaturated zone; pipe flow draining the saturated zone; gains and losses to regional aquifer systems; and the option to simulate baseflow discharge by using an exponential, parabolic, or linear decrease in transmissivity. PHREEQC, an aqueous geochemical model, is incorporated to simulate chemical reactions as waters evaporate, mix, and react within the various reservoirs of the model. The reactions that can be specified for a reservoir include equilibrium reactions among water; minerals; surfaces; exchangers; and kinetic reactions such as kinetic mineral dissolution or precipitation, biologically mediated reactions, and radioactive decay. WEBMOD also simulates variations in the concentrations of the stable isotopes deuterium and oxygen-18 as a result of varying inputs, mixing, and evaporation. This manual describes the WEBMOD input and output files, along with the algorithms and procedures used to simulate the hydrology and water quality in a watershed. Examples are presented that demonstrate hydrologic processes, weathering reactions, and isotopic evolution in an alpine watershed and the effect of irrigation on water flows and salinity in an intensively farmed agricultural area.

\section{Introduction}

The Water, Energy, and Biogeochemical Model (WEBMOD) is a semidistributed watershed-scale water-balance model that simulates hydrologic and geochemical storages and fluxes on a daily time step. WEBMOD is developed within the framework of the Modular Modeling System (MMS; Leavesley, Restrepo, and others, 1996; Leavesley, Markstrom, and others, 1996). MMS was developed to (1) support development, testing, and evaluation of physical-process models as compatible sets of computer code; (2) facilitate integration of user-selected codes into operational physical-process models; (3) facilitate the coupling of models for application to complex, multidisciplinary problems; and (4) provide utility software for optimization, sensitivity, forecasting, visualization, and statistical analyses (Leavesley and others, 2005, p. 160). An important benefit of WEBMOD development within MMS is the ability to link individual modules simulating processes such as canopy interception, snowpack dynamics, hillslope hydrology, and geochemistry and easily replace the modules with new or improved versions.

WEBMOD can be run in batch mode, or the MMS Tool can be used as a graphical user interface (GUI; Markstrom and Koczot, 2008) to configure simulations, view Run Time Plots, and specify custom output; however, some manual editing of input files may still be required. A feature of the MMS Tool GUI is the Parameter Tool GUI that can be run independently to modify WEBMOD model parameters. WEBMOD also can use automated procedures for data integration, calibration, and optimization of parameters developed for the Precipitation and Runoff Modeling System (PRMS) models. The most recent version of PRMS is PRMS-IV (Markstrom and others, 2015).

\section{Development History}

WEBMOD was developed in response to the needs of two programs in the U.S. Geological Survey (USGS)-The Water, Energy, and Biogeochemical Budget (WEBB) program and the National Water Quality Assessment (NAWQA).

The WEBB program was started in 1992 to better understand the fluxes of water and solutes through natural landscapes and to estimate how these fluxes may change 
given a variety of future climate scenarios. The following five sites have a history of watershed research and were selected for the WEBB program: (1) the granitic slopes flanking the Continental Divide that drain to Loch Vale, Colorado; (2) the sandy glacial outwash feeding Trout Lake, Wisconsin; (3) the forests and pastures draining through carbonates of Sleepers River, Vermont; (4) the hillslopes of Panola Mountain, Georgia; and (5) the weathered granodiorite in the rainforest of Luquillo Mountain, Puerto Rico (fig. 1). The hydrology and the net exports of solutes measured at the five sites during the first decade are presented by Peters and others (2006).

WEBMOD development began in 1999 with the goal of providing a robust and parsimonious numerical model to test conceptual and empirical models developed by the researchers at each WEBB site. The hydrologic core of WEBMODinitially named XTOP_PRMS (Webb and others, 2003) consists of temperature and precipitation distribution modules from the PRMS (Leavesley and others, 1983; Markstrom and others, 2015), the National Weather Service (NWS) Hydro-17 snow module (Anderson, 1973), and a multiplesubbasin version of the topography-driven hydrologic model (TOPMODEL; Beven and Kirkby, 1979; Beven, 1984, 1997; Beven and others, 1984; Wolock, 1993). Simple conservative mixing models can be used to estimate variations in specific conductance in watershed outflows if the concentrations and composition of the source waters remain constant; however, conservative mixing models are inadequate for simulating chemical and biological reactions. To understand how water quality varies in response to weathering, acid mine drainage, acid rain, biological transformations, and other chemical reactions, the $\mathrm{pH}$-redox-equilibrium model in the $\mathrm{C}$ programming language (PHREEQC; Parkhurst and others, 1980; Parkhurst and Appelo, 1999, 2013; Charlton and Parkhurst, 2011) was coupled to the hydrologic model.

The original TOPMODEL algorithms that simulate fluxes of water through the hillslope were modified in four ways as follows: (1) a fraction of recharge can become direct flow, routed directly to the stream to simulate interception and lateral transport of recharge funneled by low permeability layers or through macropores, such as worm borrows or roots (Piñol and others, 1997); (2) negative saturation deficits (artesian conditions) are used to replenish root-zone moisture deficits; (3) vertical hydraulic conductivities are modeled as having a log-normal distribution described by a median and a coefficient of variation; and (4) base-flow recession, originally simulated assuming an exponential decrease for the transmissivity profile, now has two additional options - a parabolic or linear decrease for the transmissivity profile - as described in Ambroise and others (1996a). With these modifications, WEBMOD could simulate the fluxes of water and solutes flowing through natural watersheds fed by rain and snow. WEBMOD was incapable, however, of simulating the hydrology of heavily managed agricultural watersheds such as those studied by NAWQA.
NAWQA began collecting data in 1991 to identify the sources, transport, and fate of agricultural contaminants across a range of space and time scales (Gilliom and others, 1995). In 2001, the following five NAWQA watersheds in diverse hydroclimatic regions and subject to a variety of agricultural management practices were selected for more detailed study: Mustang River, California (53 square kilometers $\left.\left[\mathrm{km}^{2}\right]\right)$; Granger Drain, Washington $\left(160 \mathrm{~km}^{2}\right)$; Maple Creek, Nebraska (950 km²); Sugar Creek, Indiana $\left(246 \mathrm{~km}^{2}\right)$; and Morgan Creek, Maryland (32 km²) (Capel and others, 2004) (fig. 2).

To address the needs of NAWQA, WEBMOD was further modified to simulate irrigation from surface water or wells with sources inside or outside the watersheds, leaky irrigation canals, field dewatering by tile drains (pipe flow), and the inputs of groundwater flowing from adjacent fields (Linard and others, 2009). The hydrologic reservoirs and fluxes in WEBMOD are shown schematically in figure 3 .

Finally, with the addition of tight coupling of the hydrologic model to the aqueous geochemical model PHREEQC, WEBMOD is now capable of simulating the fluxes of water, major ions, and agricultural chemicals in pristine and agricultural watersheds. Site measurements provide calibration targets for WEBMOD and other new-generation predictive watershed models. The models can be used to identify combinations of landscapes, soils, and land uses where impaired water quality can be expected. Watersheds susceptible to impairment can then be included in targeted monitoring programs to make the most efficient use of limited laboratory and human resources.

\section{Representation of a Watershed in WEBMOD}

In WEBMOD, a watershed is represented as one or more hillslopes, each with relatively homogenous altitude, aspect, soils, dominant plant cover, and (or) geochemistry. Each hillslope, or model response unit (MRU), is assigned to a channel, or subbasin, and all channels drain to a common outlet. When simulating geochemistry, the concentrations of solutes in precipitation, either constant or varying daily, describe the concentrations of solutes in precipitation deposited on all hillslopes. The temperature, amount, and form (rain/ snow) of precipitation, however, are properties distributed to each hillslope. Water can undergo chemical reactions in as many as eight types of hillslope reservoirs (numbered with reservoir indices 1-9 in figure 3, reservoir indices 5 and 6 are used to configure multiple unsaturated zone reservoirs) before being discharged to the stream reservoirs. Runoff and groundwater from all hillslopes are distributed to a simple one-dimensional stream model where waters mix and react, while being advected towards the outlet. The one-dimensional stream has no surface area and no water evaporates from its surface; losses of water and solutes from the stream are limited to leakage through the stream bottom, diversions for irrigation, or discharge from the basin outlet. 


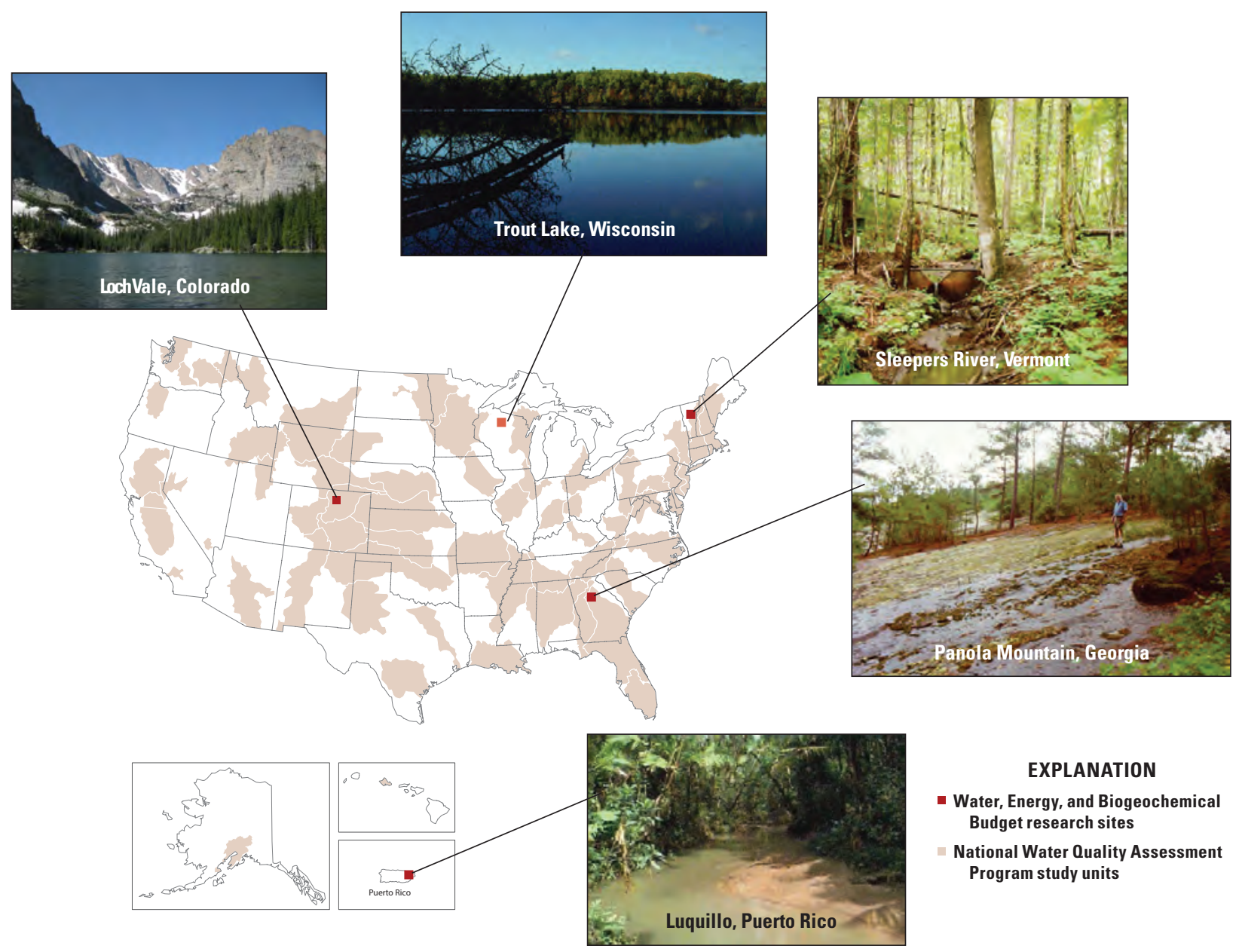

Figure 1. Forested upland watersheds of the Water, Energy, and Biogeochemical Budget Program. (Modified from Baedecker and Friedman, 2000)

Each MRU can have eight reservoir types, each with a dominant effluent — canopy (throughfall), snowpack (snowmelt), impermeable (storm drainage), O-horizon (overland flow), unsaturated zone (recharge), preferential flow paths through the unsaturated zone (direct flow), the saturated zone (base flow), and preferential flow paths through the saturated zone (pipe flow). The impermeable reservoir has not yet been implemented but will simulate ponding and delivery of precipitation and snowmelt from impervious surfaces directly to the stream. Preferential flow paths through the unsaturated and saturated zones may or may not be active depending on the parameters. Precipitation and irrigation can interact with one or more of these MRU reservoirs on its way to the stream reservoirs. Stream reservoirs collect and mix water flowing from each MRU and move the composite water towards the outlet of the watershed.

The canopy is represented as a single big leaf with userspecified capacities for holding rain or snow. On dry days, solutes are moved from the soil to the leaf surface during transpiration. On days with precipitation, the canopy intercepts rain and snow, and amounts exceeding a user-defined capacity are transferred to the ground or snowpack as throughfall. Canopy density, as a percent of MRU area, is assumed to be greater during the growing season, which begins on the day of "leaves on" and continues until the day of "leaves off." For accounting purposes, moisture that was on the canopy on the day of "leaves off" in the fall is added to the O-horizon for the winter and relocated from the O-horizon back up to the canopy surface on the day of "leaves on" the following spring.

As temperatures drop in the fall, precipitation can fall as snow. Snowpack may remain throughout the winter or melt completely during warm periods. As the snowpack melts, the snow-covered area (SCA) decreases as specified by a snowdepletion curve. Snowmelt, rainfall, irrigation, and throughfall are delivered immediately to the stream as overland flow or infiltrate into the soil.

Overland flow flushes the O-horizon reservoir. Other than the translocation of canopy moisture, the volume of the O-horizon is fixed such that the daily amount of overland flow entering the O-horizon equals the amount of flow exiting the O-horizon to the stream on that day.

Water that infiltrates the soil mixes with waters in the unsaturated and saturated zones. Soils above the water table are unsaturated and are discretized into multiple reservoirs beginning with reservoirs where the water table is at or near the surface 


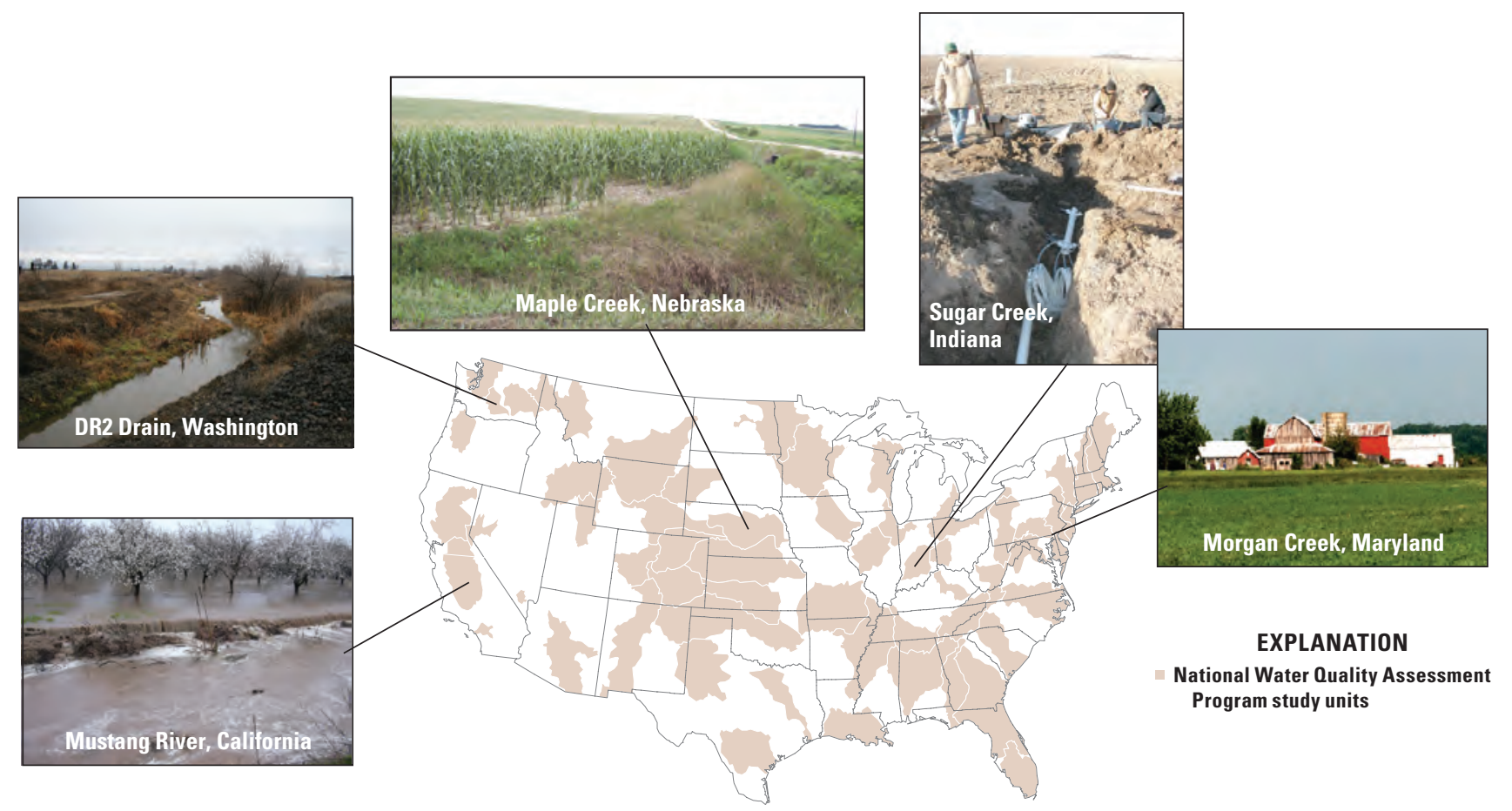

Figure 2. Agricultural watersheds included in Cycle II of the National Water Quality Assessment Agricultural Chemical Transport Studies. (Modified from Capel and others, 2004)

and continuing to reservoirs where the water table is deeper. This additional level of discretization for the unsaturated zone, which is related to hillslope position, allows the assignment and evolution of a soil catena. Water in the root zone can evaporate from the soil or transpire through the canopy. The cumulative amount of water sublimated from the snowpack, evaporated from the soils, and transpired through the canopy is referred to as evapotranspiration (ET). Water in excess of field capacity can be delivered to the stream as direct flow, or recharge the saturated zone either by matrix flow or preferential flow. Waters recharging the saturated zone mix in a single saturated-zone reservoir, which has an upper boundary at the water table and a lower boundary at bedrock. In reality, the lower boundary may be bedrock or it may be a regional aquitard. The key distinction is that losses into the bedrock or aquitard are tracked as exports from the model domain similar to losses through the bottom of stream reservoirs or discharge at the outlet. For brevity, the term bedrock will be used to refer to either actual bedrock or a regional aquitard.

The dynamic boundary between the unsaturated zone and the saturated zone is the water table. The water table will rise if inputs to the saturated zone exceed the outputs. Inputs to the saturated-zone reservoir include recharge through quick preferential flow from the surface, recharge that drains through the unsaturated zone, leaky irrigation canals, and upgradient groundwater. Outputs include pipe flow, base flow, losses into bedrock, wells, and ET in areas where the water table is near the surface. A rising water table will increase the volume of water in the saturated zone at the same time that the volume of water in the unsaturated zone decreases.
The unsaturated and saturated zones may have zones of preferential flow. Horizontal preferential flow in the unsaturated zone simulates lateral flow through worm borrows and root casts or on top of caliche layers. Vertical preferential flow can bypass the root zone or the entire unsaturated zone. When preferential flow is included in a model, a reservoir for waters along that flow path is assigned an initial volume, and that volume is static throughout the simulation. On any day, inputs and outputs through a preferential path are equal, resulting in a flushing of the reservoir. Preferential flow in the saturated zone simulates pipe flow at or below the water table. Pipe flow may be in response to high conductivity layers of sand and gravel or in response to the installation of tile drains. The volume of the saturated-zone preferential-flow mixing reservoir is also fixed and flushed (inputs equal outputs) with discharge proportional to the height of the water table above the base of the zone of preferential flow.

Overland flow, direct flow, pipe flow, and base flow are distributed to stream reservoirs by using the Clark unithydrograph approach (Clark, 1945). The unit hydrograph simulates one-dimensional transport with predictions of the quantity and quality of water at the outlet; the quantity and quality of water at interior points of the drainage are interpolated by using the cumulative area upstream from the outlet.

The transient aqueous geochemistry in the watershed is simulated as a network of forward-feeding batch reactors, each associated with a reservoir in the watershed (fig. 4). The chemical composition of precipitation and external sources of 


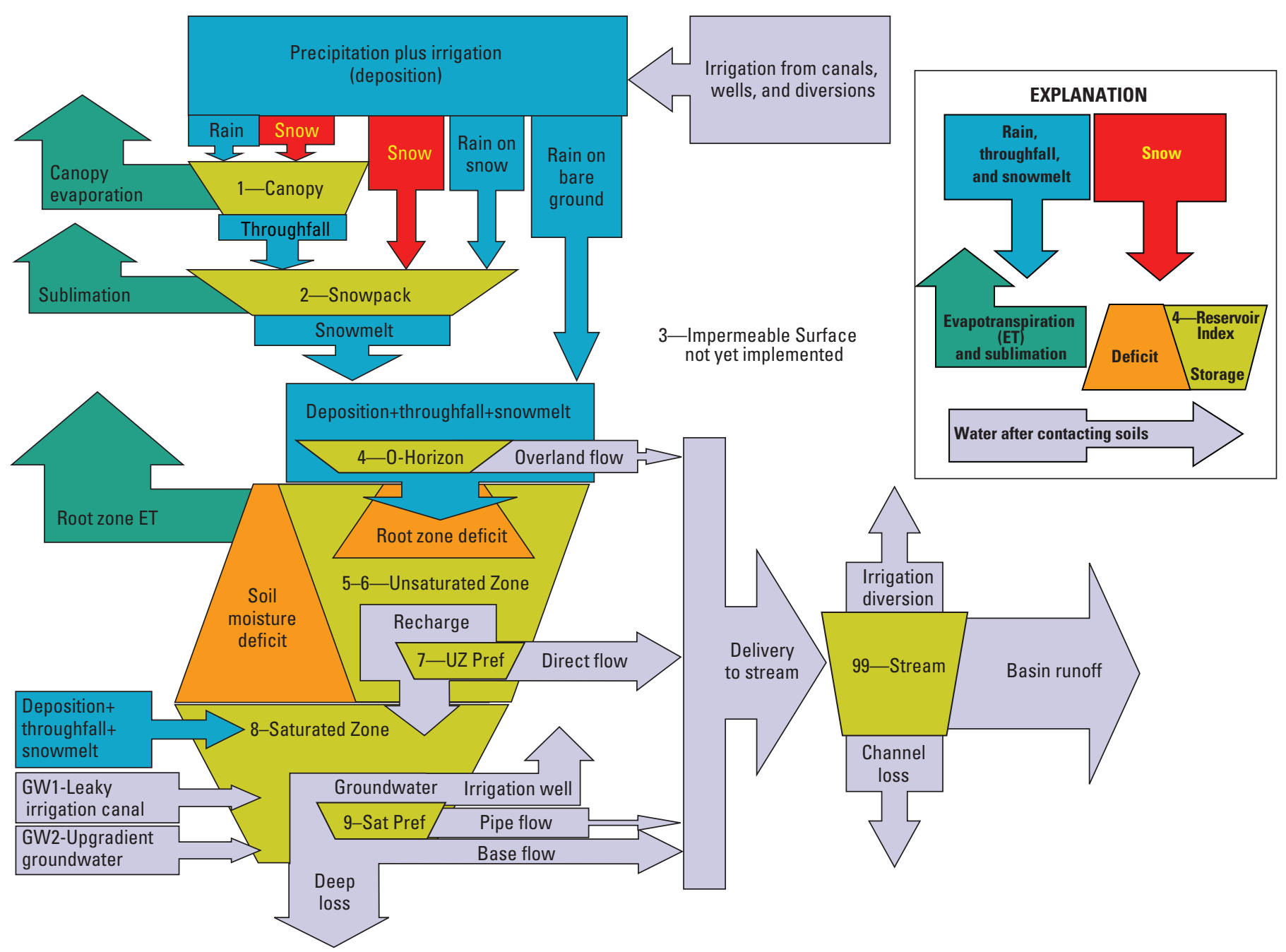

Figure 3. Reservoirs and fluxes of the Water, Energy, and Biogeochemical Model (WEBMOD). To simplify the schematic, infiltration, transpiration, and wetting of the root zone by groundwater are not shown. (UZ Pref, preferential flow through the unsaturated zone; Sat Pref, preferential flow through the saturated zone; GW1, leakage from irrigation canals; GW2, upgradient groundwater)

groundwater and irrigation can be assigned constant values, or daily concentrations can be read from a file. Inputs and initial solutions in the hillslope are mixed by using ratios derived from the hydrologic model and then are reacted. Reactions are described by standard PHREEQC input files and keywords, which can include ion exchange, surface complexation, equilibrium phases, stoichiometric chemical additions, or kinetic reactions. Reactions may be defined for each reservoir, including each of the transformed topographic index (TTI) bins that collectively represent the unsaturated zone. Snowpack melts incongruently, with snowmelt having a higher ionic strength and a lighter isotopic signature than the remaining snowpack. The results of PHREEQC mixing and reaction simulations are stored in tables of mass transfers for a set of solutes selected by the user. If the solutes of interest include oxygen-18 $\left({ }^{18} \mathrm{O}\right)$ or hydrogen-2 $\left({ }^{2} \mathrm{H}\right.$, deuterium, D), then the ratios of the rarer heavy isotope to the more common light isotope in each parcel of water is tracked through the various reservoirs of the watershed. Within the watershed, the isotopic composition of water is affected by evaporation of moisture from the canopy and soils and sublimation of the snowpack. Evaporated and sublimated water is isotopically lighter than the pool of water or snow left behind (Raleigh fractionation); water transpired to the canopy and then evaporated undergoes no fractionation.

Irrigation applied to an MRU can have an internal source or an external source. An internal source could be a stream reservoir or a well pumping from the saturated zone. Requested irrigation amounts are limited by the available water in the internal source; external sources have no limit on supply. Solute concentrations in irrigation from an internal source are tracked by PHREEQC; solute concentrations in external sources (precipitation, irrigation, or upgradient groundwater) are defined by the user as constant or are assigned daily values.

Small watersheds will have only a single stream reservoir that mixes and reacts with all hillslope discharges before exporting it at the end of the day as a single volume. In larger 


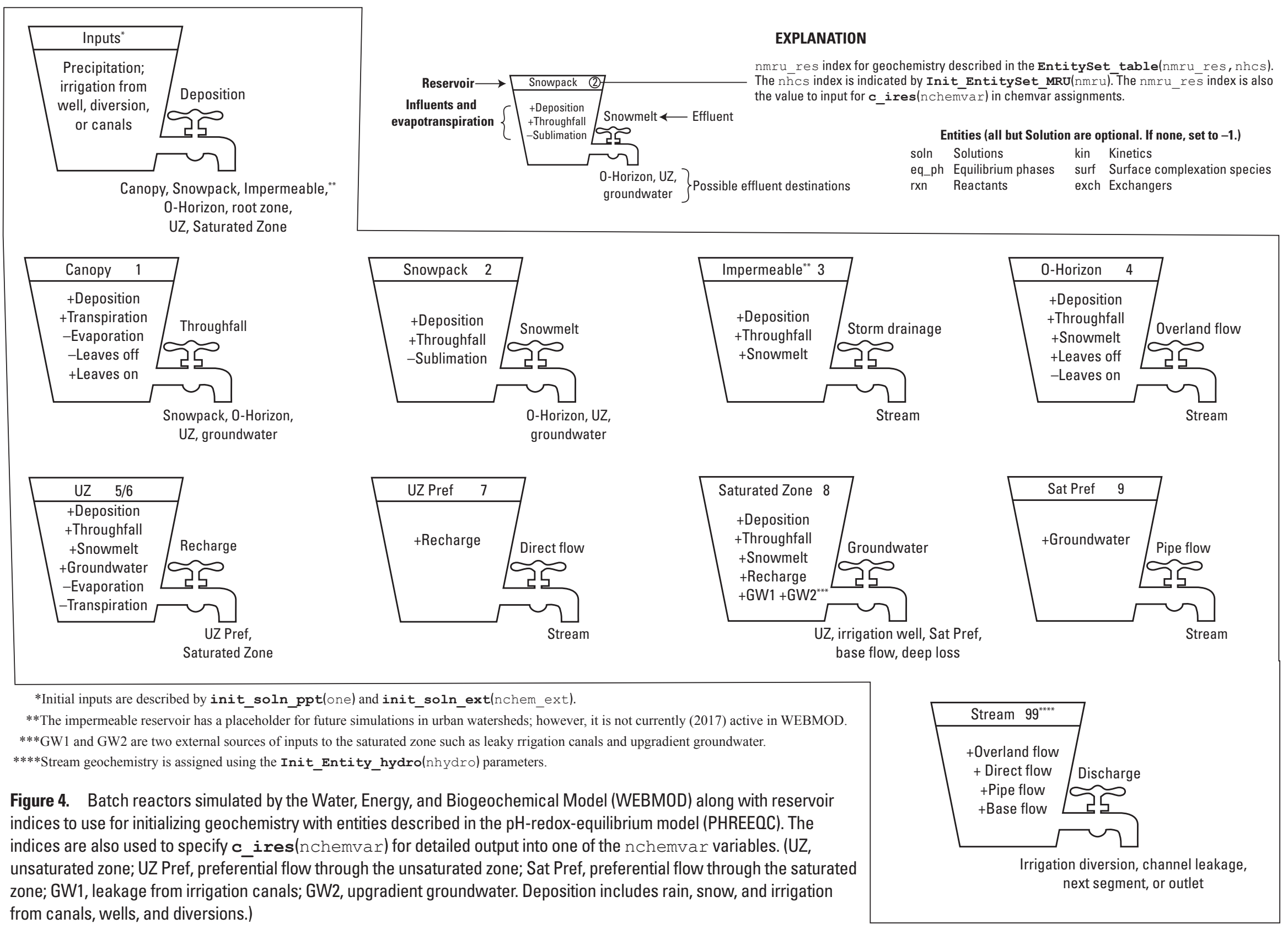


watersheds, a one-dimensional series of stream reservoirs is established with hillslope discharge apportioned to each on the basis of the average stream velocity and the distance of the hillslope from the watershed outlet. Discharge from the hillslopes mix with stream water, exchange carbon dioxide and oxygen with the atmosphere, and react with sediments and the streambed before being advected, without dispersion, to the next downstream reservoir. The stream reservoir closest to the outlet is exported from the watershed at the end of the day. The residence time for any given parcel of water entering the watershed could be as little as one day or as long as several decades.

\section{Capabilities and Limitations}

Throughout the development of WEBMOD, the objective has been to strike a balance between fine and coarse scales of time, space, and hydrologic and biogeochemical process details to develop a parsimonious, but robust, model. Some of the strengths and weaknesses of WEBMOD and the difficulties associated with watershed modeling include the following:

More parameters, but with more physical meaning.-One of the strengths of the original TOPMODEL is that simulations require few parameters. For example, the maximum water capacity available for ET, SRMAX, is provided as a single number by the user in the original TOPMODEL. In WEBMOD, the number of parameters was expanded, with the benefit that the user assigns values to parameters that have more physical meaning. Instead of SRMAX, the user of WEBMOD provides estimates of the three independent variables that determine SRMAX - field capacity, wilting point, and rooting depth, which have physical meaning and vary systematically with soil type. On the positive side, the additional parameters allow for tighter accounting of all moisture, such as residual moisture below wilting point, which is the volume of water where reactions take place during extended dry periods. On the negative side, the additional parameters increase the number of parameter sets that produce simulations that fit observations equally well.

Effective parameters. - Given the coarse temporal (daily) and spatial (tens to thousands of square kilometers) scale of the model, many model parameters become "effective" parameters that are calibrated such that simulated fluxes of water and solutes throughout the watershed match observed fluxes. The lumped and calibrated parameters may be close to the maximum, mean, or minimum of the statistical distribution for field measurements of a given physical property, such as canopy density, stream velocity, or vertical conductivity. Similarly, the surface-area parameters that produce weathering rates that fit observed yields of specific solutes may represent a single alteration zone or may represent crystals disseminated throughout the watershed. When final parameter values calibrate to values outside of the range of previously reported values, the user should pause to evaluate if the exceptional values indicate an error in input data or parameters or if the exceptional values are justified and therefore can be accepted.
Example of input error: Simulated streamflow greatly exceeds observed streamflow. The user sets precipitation corrections to values less than 1.0 (simulating gage overcatch rather than commonly observed undercatch) or increases ET parameters to unrealistic values to get a better fit. After further review, the mismatch is traced to erroneous inputs; precipitation, which was measured in centimeters, was erroneously assigned units of inches; or, the basin area, which was provided in hectares, was erroneously assigned units of square kilometers.

Example where exceptional values are justified: Streamflow and ET values simulated for a mountainous watershed are reasonable, but the water level measured in a well varies by several meters compared to simulated variations of several centimeters. The user justifies reducing the porosity, field capacity, and wilting point of the soil by two orders of magnitude because the well is drilled into fractured rock with extremely low porosity. At the same time, the user increases the rooting depth by the same two orders of magnitude to provide the same amount of available water capacity for ET.

Inputs. - Complete records of daily precipitation along with minimum and maximum temperature for one or more nearby meteorological observation stations are required. Simulations of water quality, isotopic fractionation, and stream temperature will also require daily records of relative humidity. If data are missing or are of poor quality, the user must interpolate and correct the data to the best of his or her ability. Adjustments to precipitation amounts and lapse rates of temperature are used to distribute station observations evenly for each MRU; gradients of precipitation, temperature, or topographic shading over parts of an MRU are not simulated. Similarly, irrigation, defined in the hydrologic data file, in inches per day, is applied evenly onto an MRU. If the source of the irrigation is a well within an MRU or a diversion from a stream segment, then the actual depth of irrigation will be reduced as limited by available volume of water and indicated pump capacity; external sources of irrigation, however, have no volume limits.

Canopy and land cover.-Plants only exist in the model as a big-leaf canopy with potential for interception and transpiration. In temperate climates, canopy density and transpiration rates are higher in summer and lower in winter. In tropical watersheds, continuous summer conditions may be simulated. Although transpiration relocates solutes to the canopy, where the solutes can be washed back to Earth in subsequent throughfall, no cycling of carbon and nutrients through growth and senescence are included in the current (2017) model. In temperate climates, moisture on the canopy on the last day of the growing season is moved into seasonal storage in the O-horizon and returned to the canopy on the first day of the growing season the following year. The four types of land cover used to describe canopy behavior are bare ground, grass, shrubs, and trees. If bare ground is assigned, a canopy is not simulated (all canopy parameters are ignored), and all precipitation will fall onto the snowpack or onto the ground where it will infiltrate or become overland flow. Grass, shrubs, and trees have the potential to 
intercept rain as described by their canopy density and canopy interception capacity. If the dominant vegetation is grass, no interception of snow is simulated for snow-covered areas, and snowmelt is delivered directly to the land surface. Trees and shrubs are functionally the same and have the ability to intercept rain and snow as described by summer and winter canopy densities and interception capacities. WEBMOD was developed for pristine upland watersheds and agricultural areas; simulation of flows in MRUs with predominant urban land cover is currently (2016) limited to assigning a cover type of bare ground with very low vertical conductivity.

Potential evapotranspiration (PET).-In WEBMOD, PET is set to pan evaporation if data are available, or, if pan evaporation data are not available, PET is estimated from daylight hours and average temperature (Hamon, 1961); the PET estimated using the Hamon method can be adjusted using monthly coefficients. Estimated actual evapotranspiration (AET) is removed from the canopy, the snowpack, and the soils, respectively, and will be less than or equal to PET depending on the moisture available on the canopy, in the snowpack, and in the soil.

Management options. - Irrigation can be supplied from the saturated zone, from streams, or from an external source. Additional inputs to groundwater from canal leakage or from upgradient groundwater can be simulated. All irrigation, diversions, and boundary inflows are defined in the hydrologic data file. Tile drains result in pipe flow, or preferential flow in the saturated zone.

Sublimation of snow from canopy.-The amount of snow sublimated and melted from the canopy is dependent on the net shortwave (less than 4 micrometers) and longwave (greater than 4 micrometers) radiation (Leavesley and others, 1983). Observations of incoming solar radiation - entirely in the shortwave spectrum - can be included in the hydrologic data file. If no observations are available, the potential incoming solar radiation on a clear-sky day is computed from the latitude, slope, and aspect of each MRU. The temperature range on a given day is used as a proxy for cloud cover over the entire watershed, with lesser temperature ranges indicative of cloudy skies. The potential incoming solar radiation on a clear-sky day for each MRU is reduced to account for the estimated cloud cover.

Snowpack.-Simulation of the accumulation of snow and the initiation and intensity of snowmelt requires a daily estimate of the energy balance of the snowpack. On days with rain on snow, WEBMOD completes a detailed energy balance (Anderson, 1968); however, on days with no precipitation, a simpler temperature index algorithm is used (Anderson, 1973). Depletion curves relating snow-water equivalence (SWE) to SCA during spring melt provide an approach to extend melting times by reducing the energy loading. This approach allows simulations of persistent snowpack observed well after air temperature exceeds 0 degrees Celsius $\left({ }^{\circ} \mathrm{C}\right)$.

Hortonian overland flow.-In TOPMODEL version 95.02 (Beven, 1995), infiltration excess is simulated with the Green and Ampt (1911) algorithm, which uses rainfall intensity and vertical infiltration rates to estimate time to ponding. In the original TOPMODEL algorithm, the soil properties in each MRU, including the vertical infiltration rate, are assumed to be homogeneous, resulting in ponding either nowhere or everywhere on a given time step. When water ponds over the entire MRU on the same time step, unreasonable spikes of overland flow are simulated. In WEBMOD, these unrealistic estimates of overland flow are mitigated by assigning a log-normal distribution of vertical infiltration rates to each MRU. However, given the 24-hour time step, the controlling parameters are still effective parameters calibrated such that local rainfall intensities and soil properties produce amounts of overland flow similar to that observed in the MRU.

Unsaturated zone.-With TOPMODEL (Beven and Kirkby, 1979; Wolock, 1993) as its foundation, streamflow is generated from overland flow, direct flow, and base flow. Water ponds and flows overland where precipitation and snowmelt exceed the infiltration capacity of the soils (Horton, 1939) and where soils are already saturated (Dunne and Black, 1970a, b). Direct flow is simulated as a percentage of the recharge to the saturated zone, and base flow increases as the water table rises.

Each TTI bin has its own unsaturated zone with an upper boundary of the land surface and a dynamic lower boundary at the water table. From the surface down to rooting depth, the moisture between field capacity and wilting point is available for ET. The unsaturated zone of each TTI bin, including the root zone, is well mixed and reacted during each time step. Instantaneous mixing implies infinite dispersion for the unsaturated zone (and saturated zone). To simulate vertical preferential flow, a fraction of infiltration can bypass the root zone to be delivered directly to the unsaturated-zone storage or can even bypass the unsaturated zone to be delivered directly to the saturated zone. Drainage from the unsaturatedzone storage is partitioned between lateral preferential flow and recharge to the saturated zone. For lateral preferential flow through the unsaturated zone, the chemistry of the water delivered to the stream is a recharge-weighted mixture of the unsaturated-zone chemistry for all TTI bins in an MRU; recharge is not possible in saturated TTI bins.

Groundwater flow.-Following the TOPMODEL concepts, base-flow discharge is estimated from the altitude of the water table by using relaxed assumptions of Darcy's Law with steady-state conditions and a spatially uniform recharge rate. Water tables in each MRU are independent and are not tied to the altitude of surrounding MRUs or stream altitudes. Groundwater may flow up into the unsaturated zone to meet evaporation demands when the water table is in the root zone; up through a well to be used for irrigation; downward, as leakage through the bottom of the domain; or horizontally toward the stream as pipe flow or base flow. In the real world, substantial amounts of groundwater can flow beneath a surface-water divide, especially in areas of porous soils and low relief. An approach to simulating streamflow in such areas is to define the watershed by using the water-table surface rather than the topography of the land surface. 
Stream routing.--Stream routing is simulated by using the Clark unit-hydrograph approach (Clark, 1945). This approach uses distances and flow accumulation for a branching drainage network along with an average stream velocity to create a simple one-dimensional advection model. The quantity and quality of water exported from each MRU is unique; however, the exports of all MRUs, even those that drain to separate tributaries flowing to the outlet, are mixed and transported toward the outlet in a single linear set of reservoirs.

Biogeochemistry.-Geochemical processes simulated in the two examples presented in this manual include mineral weathering, isotopic fractionation, and transpiration to a simple canopy. WEBMOD has access to the full suite of PHREEQC reactions that include aqueous, mineral, gas, surface, ion-exchange, solid-solution equilibria, and kinetic reactions, which provide the potential for modeling a wide range of biogeochemical processes in watersheds.

Model interface.-WEBMOD can be run in batch mode. Alternatively, the MMS Tool GUI (Markstrom and Koczot, 2008) can be used to configure simulations, view Run Time Plots, and specify custom output; however, some manual editing of input files may still be required. A feature of the MMS Tool GUI is the Parameter Tool GUI that can be run independently to inspect and modify WEBMOD model parameters or to compare the parameters with parameter defaults or the parameters of another model. WEBMOD also can use automated procedures for data integration, calibration, and optimization of parameters developed for PRMS models. The most recent version of PRMS is PRMS-IV (Markstrom and others, 2015). The MMS Tool GUI, however, does present certain limitations when running a WEBMOD model that has many two-dimensional and three-dimensional variables.

By using the MMS Tool GUI, developed for PRMS, oneand two-dimensional parameters can be edited, but variables selected for output or plotting are limited to one dimension. Therefore, if the user wishes to output WEBMOD variables with two dimensions (for example, depth to water table in a specific TTI bin in a specific MRU), the user cannot do this in the existing GUI and will need to manually edit the variable dimension indices in the control file. In addition, when simulating geochemistry, the solute names must be manually edited in the parameter file. The limit on dimensions required the introduction of suites of parameters to configure detailed output of fluxes of water and solutes through specific reservoirs and "one to many" assignment tables to initialize the geochemistry.

Model complexity.-The level of model complexity is dictated by which of 33 dimensions are not equal to zero. When simulating daily hydrologic processes with no geochemistry, no irrigation, and no interactions with regional groundwater, 21 dimensions, describing everything from the number of months in a year to the number of stream reservoirs, will be nonzero. Two of these, nrain and ntemp, which describe the number of stations recording precipitation and temperature, constrain three daily data values: the total precipitation, the minimum temperature, and the maximum temperature. The minimum model needs only these three variables to run hydrologic simulations. Approximately 100 parameters describing the topography, canopy, soils, and drainage are used to distribute the precipitation and temperature, estimate solar radiation and potential evapotranspiration, and simulate hydrologic processes for each hillslope. Even with the simplest hydrologic model, the user may select from any of 298 variables to view states and fluxes for volumes as small as the canopy moisture on a single hillslope to as large as the entire water content of the watershed on a given day. As complexity increases with the addition of irrigation, geochemistry, and interactions with regional groundwater, the number of dimensions not equal to zero can reach 33 , with 164 parameters that need to be assigned and 678 variables available for inspecting states and fluxes throughout the model domain.

Computation time.-A model for a given study could be simple, driven by daily precipitation and temperature, or could be more complicated with irrigation, diversions, and reactive transport. Increases in model complexity create concomitant demands on computing resources. On a modern computer, simulation of daily hydrologic fluxes for a small watershed (10 MRUs, each with 11 TTI bins) for 30 years is completed in less than 1 minute. In contrast, simulation of the hydrology and geochemical reactions for the same basin and time period may take several hours.

\section{Purpose and Scope}

The purpose of this manual is to present the theory, operation, and interpretation of the hydrologic and geochemical watershed model WEBMOD. The "Quick Start Guide" provides an introduction to the directory structure, dimensions, parameters, and variables used to discretize a watershed. The user then executes WEBMOD simulations in both batch and interactive modes. Following this quick introduction, the theory underlying WEBMOD is presented through the equations describing the movement of water and solutes through canopy, snowpack, O-horizon, unsaturated zone, saturated zone, and streams of a watershed. The "Example Problems" section includes detailed inputs and results for simulations of (1) the hydrology and geochemical reactions for Andrews Creek, which drains an alpine watershed in Rocky Mountain National Park, Colo., and (2) the effect of irrigation on streamflow and salinity at an agricultural area surrounding the DR2 drain near Yakima, Washington.

This first release of WEBMOD demonstrates how relatively simple representations of complex natural and managed systems are sufficient to reproduce a wide range of observed variations in hydrology and water quality. WEBMOD is intended to be used as a research tool to better understand processes common to all watersheds. With caution, WEBMOD can also be used to predict how certain hydrologic and biogeochemical processes may respond to changes in land use, land cover, climate, and atmospheric deposition of natural and anthropogenic compounds. 


\section{Quick Start Guide}

\section{Obtaining, Installing, and Executing the Software}

The latest version of WEBMOD can be download from the Web site at https://doi.org/10.5066/ F7P26W9K.

The download file is a zip file, and when the zip file is uncompressed, a directory will be created that contains a file README.TXT that describes how to install and run WEBMOD on your operating system (Windows or Linux).

Running the WEBMOD executable in batch mode does not require additional software installation; however, two associated GUIs, the MMS Tool and the Parameter Tool (Markstrom and Koczot, 2008), are distributed from the PRMS Web site (http://wwwbrr.cr.usgs.gov/projects/ SW_MoWS/PRMS.html, accessed August, 2015) and require Java ${ }^{\circledR}$ version 1.6 or later (http://www.oracle.com/ technetwork/java/index.html, accessed January, 2015). Derivation of spatial parameters using the geographic information system (GIS) Weasel (Viger and Leavesley, 2007) requires the Environmental Systems Research Institute Workstation GIS software (ESRI, Inc., 2001).

\section{Input Files and Model Output}

WEBMOD version 1 installs (unzips) into a directory, $\left|W E B M O D \_1.0\right|$, with the following four subdirectories: $\mid$ bin $\mid$ contains the model executable; $|d o c|$ contains model documentation, including this manual; $|l i b|$ contains Java libraries necessary to run the MMS Tool GUI and the Parameter Tool GUI; and $\mid$ projects $\mid$ has subfolders containing batch files, control files, input files, and output files for two versions of the Andrews Creek model and the DR2 model (fig. 5). The calibrated Andrews Creek model, presented as example 1 in the "Example Problems" section, is contained in the $\left|W E B M O D \_1.0\right|$ projects $\mid$ Andrews $\backslash$ directory. The calibrated DR2 model, presented as example 2 in the "Example Problems" section, is contained in the $\left|W E B M O D \_1.0\right|$ projects $|D R 2|$ directory. The directory $\mid W E B M O D \_1.0$ projects $\backslash$ Andrews_tutoriall contains a deliberately miscalibrated Andrews Creek model that is calibrated as described in the "Andrews Creek Simulation and Calibration" section. In this manual, a project model directory, like $\mid$ Andrews $\mid$, will be indicated as $\langle$ basin $>$. Although unique file name prefixes may be assigned, andcrk.hydro.dat for example, all projects included with the distribution use the same names for input and output files within a project model directory. For example, hydrologic inputs are provided in a file named webmod.hydro.dat, and geochemical summaries are output to webmod.chem.out. All control, input, and output files are formatted in American Standard Code for Information Interchange (ASCII) characters and can be viewed and edited with a text editor. The MMS Tool and the Parameter Tool are GUIs included to configure model runs, view Run Time Plots, and modify parameters. Data files containing meteorological observations or solute chemistry, or both, can be entered manually in a text editor or entered in Microsoft Excel and then exported to space-delimited ASCII files that can be read by WEBMOD. The Excel workbooks included in the $<$ basin $>\mid$ input $\mid$ directories for the $|D R|$ and $\mid$ Andrews $\mid$ example problems presented at the end of this manual contain a macro "ExportText" that will export the data to a space-delimited ASCII file.

A WEBMOD simulation starts by reading the webmod.control file that defines the model executable, input, and output files; the period to be simulated; and the variables selected for graphing or output to the statistics and animation files. The process modules are then called to simulate the application and movement of water and solutes throughout the watershed. Hydrologic simulations read meteorology, irrigation schedules, upgradient groundwater fluxes, and observed streamflow from the webmod.hydro.dat file. Basin topology, process parameters, and operational flags are then read from the webmod.params file. If the model is to include geochemical simulations [chem_sim(one)=1], then the webmod.pqi, phreeq_lut, and phreeqc_web_lite.dat files will also be read. If observed solute concentrations are to be plotted or if precipitation or irrigation data are to vary daily, then the webmod.chem.dat file will also be read. Output from the simulation will always include hydrologic summaries in webmod.hydro.out, summaries of TTI bins and stream routing in webmod.topout, and geochemical summaries in webmod.chem.out. If selected, additional output can be presented in Run Time Plots or can be sent to statistical (webmod.statvar) and multidimensional animation (webmod.aniout) files. Additional data on volumes $\left(v_{-}{ }^{*}\right.$ files), solutes ( $s_{-} *$ files), and entities ( $e_{-} *$ files) related to geochemistry for some or all reservoirs can be output. Finally, select_mixes can contain detailed PHREEQC output describing species and redox states of all solutes during initialization and after mixes and reactions for all reservoirs for selected days.

\section{Dimensions, Parameters, and Variables}

Dimensions define the array sizes of variables and parameters; for example, nmru defines the number of MRUs and is the dimension of all parameters related to MRUs. Other than fixed dimensions such as one or five, all dimensions begin with an $\mathrm{n}$ and represent a fixed number in the model configuration. The dimensions used in WEBMOD (table 1) are specified in the first section of the parameter file (webmod.params) and must be consistent with the topology of the watershed, the number and type of variables in the hydrologic data file (webmod.hydro.dat), and the number of chemically unique sources and sampling sites included in the chemical data file (webmod.chem.dat). The variables in the hydrologic data file, listed in parentheses in table 1, must be consistent with the named dimension that appears at the top of the parameter file. 


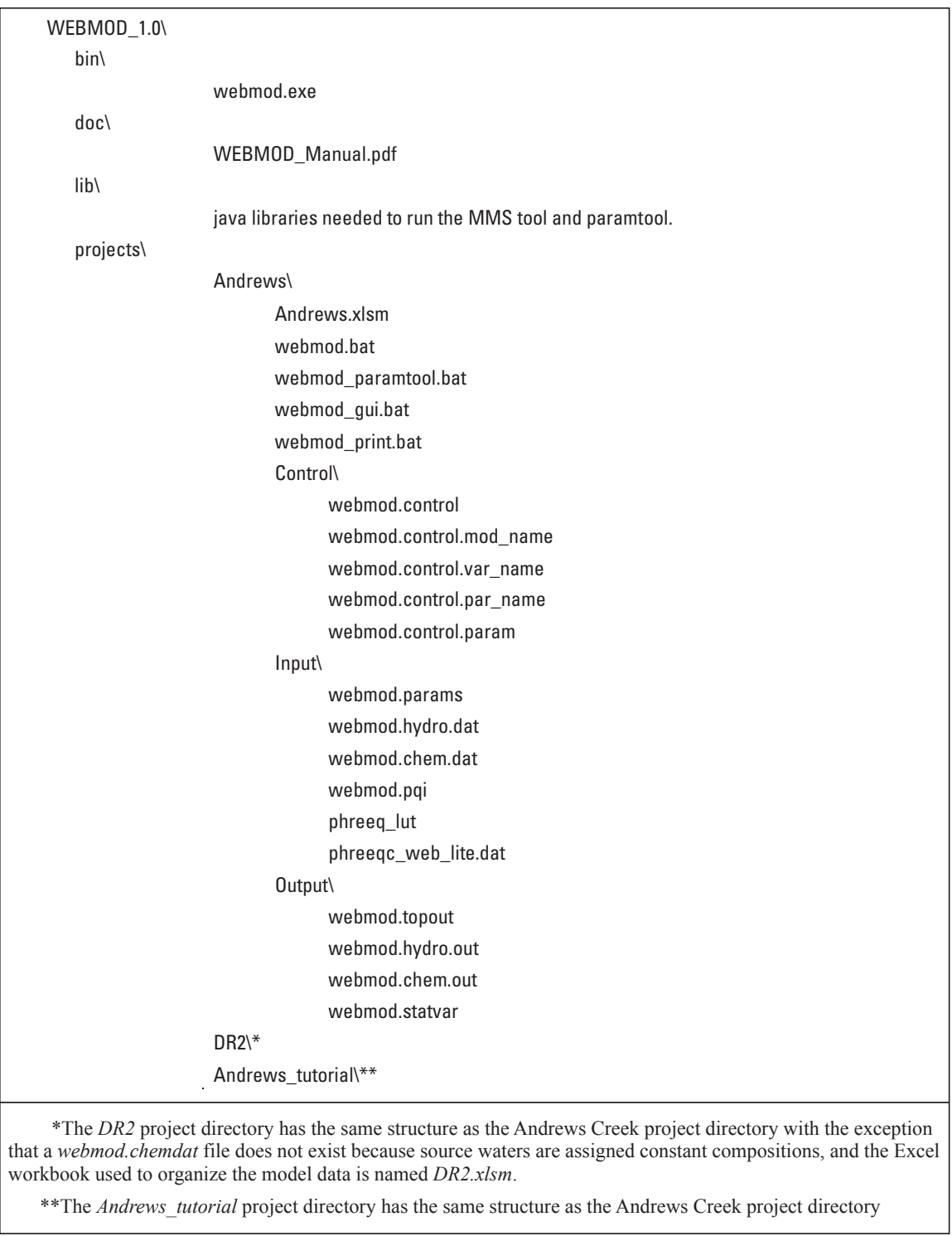

Figure 5. File structure for the Water, Energy, and Biogeochemical Model (WEBMOD).

Parameters are user-specified values that do not change during a simulation, such as the area of an MRU, mru_area(nmru), where the value in parentheses is the dimension of the parameter. Of the approximately 150 parameters in WEBMOD, about one-half is derivable from maps or site observations, or both, and the other onehalf is initial conditions, process thresholds, and operational flags. All parameters are defined as arrays. Scalar parameters, including basin descriptors and input and output flags, have an array size of one. The parameters used in WEBMOD are listed in table 2 .

Process algorithms use private internal variables that are invisible to the model user and public variables that can be viewed in plots or output to files. Public variables may be static or dynamic. Static variables are calculated during model initialization and then remain unchanged throughout the model run. Two examples of a static variable are the existence of the daily chemical input file, chemdat_flag(one), and the drainable porosity, $\boldsymbol{s}_{\text {_drain(nmru), computed }}$ as the saturated porosity, s_porosity(nmru), minus the moisture content at field capacity, s_theta_fc(nmru). Dynamic variables track any value that can change during the model run. Two examples of dynamic variables are the depth to the water table in a TTI bin in a given MRU, $z$ wt local(nac,nmru), and the daily maximum air temperature measured at a meteorological station, tsta_max_c(ntemp). Public variables may be viewed in Run Time Plots, appear in standard output files (for example, webmod.hydro.out or webmod.chem.out file), or be selected as custom output for statistical (webmod.statvar) and multidimensional animation (webmod.aniout) files. The public variables in WEBMOD are listed in table 3. 
Table 1. Dimensions of the Water, Energy, and Biogeochemical Model (WEBMOD).

[The formatting convention used in this report is to present file names in italic font, dimension names in Courier New font and variable names in bold italic Courier New font. Names and descriptions of all variables are presented in table 3. TTI, transformed topographic index]

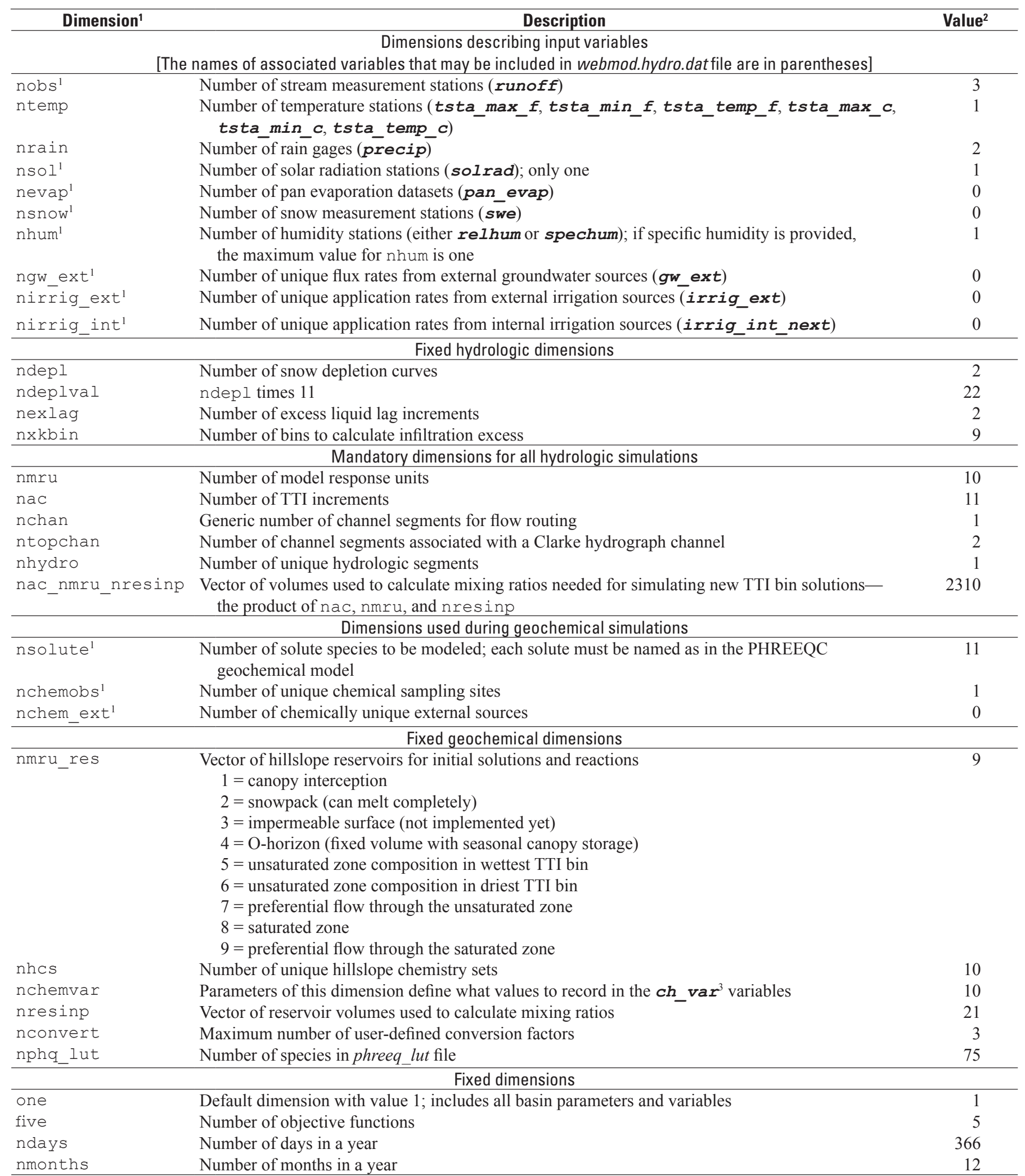

${ }^{1}$ Dimensions with this footnote control the presence or absence of certain parameters and variables.

${ }^{2}$ Dimension values are those of the Andrews Creek model described in the "Example Problems" section.

${ }^{3}$ The ch_var variables describe the chemistry of any reservoir in the model domain, as specified by the model user. 
Table 2. Parameters, by process and intent, used the Water, Energy, and Biogeochemical Model (WEBMOD).

[The formatting convention used in this report is to present file names in italic font, dimension names in Courier New font, variable names in bold italic Courier New font, and parameter names in bold Courier New font. Names and descriptions of all dimensions are presented in table 1; names and descriptions of all variables are presented in table 3.

$\mathrm{km}^{2}$, square kilometer; MRU, model response unit; m, meter; TTI, transformed topographic index; ccov, percent cloud cover; $\operatorname{ccov} /{ }^{\circ} \mathrm{C}$, percent cloud cover per degree Celsius; ${ }^{\circ} \mathrm{F}$, degree Fahrenheit; ${ }^{\circ} \mathrm{C}$, degree Celsius; ${ }^{\circ} \mathrm{C} / \mathrm{km}$, degree Celsius per kilometer]

\begin{tabular}{|c|c|}
\hline Parameter(Dimension) & Description \\
\hline \multicolumn{2}{|r|}{ Basin metrics } \\
\hline basin_area(one) & Total basin area, in $\mathrm{km}^{2}$ \\
\hline $\operatorname{dtinit}(o n e)$ & Initial time step for initialize function, in hours \\
\hline mru_area_frac(nmru) & Fractional area, mru_area divided by basin_area \\
\hline mru_elev(nmru) & Mean altitude of MRU, in $\mathrm{m}$ \\
\hline $\operatorname{nacsc}(\mathrm{nmru})$ & Number of TTI bins in the MRU \\
\hline riparian_thresh(nmru) & $\begin{array}{l}\text { TTI bins wetter than this value are riparian, TTI bins drier than this value are upslope, } \\
\text { in lambda; units for lambda depend on transmissivity profile model, T_decay }\end{array}$ \\
\hline s_rock_depth(nmru) & Average depth to bedrock for the MRU, in $\mathrm{m}$ \\
\hline \multicolumn{2}{|r|}{ Distribution of energy } \\
\hline mru_lat(nmru) & Latitude of MRU, in degrees \\
\hline \multicolumn{2}{|r|}{ Cloud cover } \\
\hline ccov_intcp(nmonths) & Intercept in temperature cloud cover relation, in ccov \\
\hline ccov_slope(nmonths) & Slope in temperature cloud cover relation, in $\operatorname{ccov} /{ }^{\circ} \mathrm{C}$ \\
\hline crad_coef(one) & Coefficient in cloud cover-solar radiation relation \\
\hline crad_exp(one) & Exponent in cloud cover-solar radiation relation \\
\hline \multicolumn{2}{|r|}{ Corrections for precipitation and aerosols } \\
\hline ppt_rad_adj(nmonths) & Radiation reduced if basin precipitation above this value, in inches \\
\hline radj_sppt(one) & Adjustment to solar radiation on precipitation day, summer \\
\hline radj_wppt(one) & Adjustment to solar radiation on precipitation day, winter \\
\hline mru_rhsta(nmru $)^{1}$ & Index of relative humidity station for MRU; must be same as mru_tsta \\
\hline mru_pansta $(n m r u)^{2}$ & Index of pan evaporation station for MRU \\
\hline \multicolumn{2}{|r|}{ Spatial parameters } \\
\hline rain_adj(nmru,nmonths) & Rain adjustment factor, by month for each MRU \\
\hline snow_adj(nmru,nmonths) & Snow adjustment factor, by month for each MRU \\
\hline tmax_allsnow_c(one) & All snow if $\operatorname{tmax}{ }_{-} c<$ this value; all rain if $\operatorname{tmin} \_c>$ this value, in ${ }^{\circ} \mathrm{C}$ \\
\hline tmax_adj(nmru) & MRU maximum temperature adjustment, in ${ }^{\circ} \mathrm{C}$ \\
\hline tmin_adj(nmru) & MRU minimum temperature adjustment, in ${ }^{\circ} \mathrm{C}$ \\
\hline \multicolumn{2}{|r|}{ Temporal parameters } \\
\hline tmax_allrain_c(nmonths) & Precipitation all rain if $\operatorname{tmax} \mathbf{x}_{\mathbf{c}} \boldsymbol{c}>$ this value, in ${ }^{\circ} \mathrm{C}$ \\
\hline tmax_lapse(nmonths) & Monthly maximum temperature lapse rate, in ${ }^{\circ} \mathrm{C} / \mathrm{km}$ \\
\hline tmin_lapse(nmonths) & Monthly minimum temperature lapse rate, in ${ }^{\circ} \mathrm{C} / \mathrm{km}$ \\
\hline
\end{tabular}


Table 2. Parameters, by process and intent, used the Water, Energy, and Biogeochemical Model (WEBMOD).—Continued

[The formatting convention used in this report is to present file names in italic font, dimension names in Courier New font, variable names in bold italic Courier New font, and parameter names in bold Courier New font. Names and descriptions of all dimensions are presented in table 1; names and descriptions of all variables are presented in table 3 .

MRU, model response unit; $\left(\mathrm{L}^{4} / \mathrm{M}\right) / \mathrm{T}^{3}$, length to the fourth power per mass per time cubed; ${ }^{\circ} \mathrm{C}$, degree Celsius; $n$, scaling factor for kinetic fractionation between 0.5 and 1.0, unitless; $\Theta$, weighting term inversely related to evaporative flux, unitless; ${ }^{\circ} \mathrm{F}$, degree Fahrenheit; $\left(\mathrm{mm} / 6\right.$-hour $/{ }^{\circ} \mathrm{C}$, millimeter of energy per 6-hour period per degree Celsius; h, hour; $(\mathrm{mm} / \mathrm{mb}) / 6$-hour, millimeter per millibar per 6-hour period]

\begin{tabular}{|c|c|}
\hline Parameter(Dimension) & Description \\
\hline \multicolumn{2}{|c|}{ Distribution of precipitation, temperature, and relative humidity —Continued } \\
\hline \multicolumn{2}{|c|}{ Rain/snow mix } \\
\hline adjmix_rain(nmonths) & Adjustment factor for rain in a rain/snow mix \\
\hline \multicolumn{2}{|r|}{ Units and indices } \\
\hline irrig_sched_ext(nmru $)^{3}$ & Index of external irrigation schedule for MRU; 0 if none \\
\hline irrig_sched_int(nmru $)^{4}$ & Index of internal irrigation schedule for MRU; 0 if none \\
\hline \multicolumn{2}{|r|}{ Initial application and pump capacity } \\
\hline irrig_int_init(nmru $)^{4}$ & Irrigation from an internal source to be applied on first day, in inches \\
\hline irrig_int_max $(\mathrm{nmru})^{4}$ & $\begin{array}{l}\text { Maximum discharge rate for a pump placed in a well or stream to provide irrigation to an MRU, } \\
\text { in gallons per minute }\end{array}$ \\
\hline \multicolumn{2}{|r|}{ Potential evapotranspiration-Canopy interception-Plant phenology } \\
\hline \multicolumn{2}{|r|}{ Cover type and transpiration } \\
\hline cov_type(nmru) & Cover type designation for MRU \\
\hline covìen_sum(nmru) & Summer vegetation cover density for major vegetation type, unitless fraction \\
\hline covden_win(nmru) & Winter vegetation cover density for major vegetation type, unitless fraction \\
\hline transp_beg(nmru) & Month to begin testing for transpiration $(1-12)$ \\
\hline transp_end(nmru) & End month of transpiration period (1-12) \\
\hline transp_tmax_c(nmru) & Tmax index to determine start of transpiration, in ${ }^{\circ} \mathrm{C}$ \\
\hline \multicolumn{2}{|r|}{ Canopy capacity } \\
\hline snow_intcp(nmru) & Snow interception storage capacity, in inches \\
\hline srain_intcp(nmru) & Summer rain interception storage capacity, in inches \\
\hline wrain intcp (nmru) & Winter rain interception storage capacity, in inches \\
\hline \multicolumn{2}{|r|}{ Spatial parameters } \\
\hline ALAT(one) & Average latitude of modeled region, in degrees \\
\hline DAYGM(nmru) & Average daily melt at the snow-soil interface during winter, in inches \\
\hline MBASE(nmru) & Base temperature for melt computations during nonrain periods, in ${ }^{\circ} \mathrm{F}$ \\
\hline MFMAX(nmru) & Maximum nonrain melt factor, in $(\mathrm{mm} / 6$-hour $) /{ }^{\circ} \mathrm{C}$ \\
\hline MFMIN(nmru) & Minimum nonrain melt factor, in $(\mathrm{mm} / 6$-hour $) /{ }^{\circ} \mathrm{C}$ \\
\hline NMF(nmru) & Negative melt factor, in $(\mathrm{mm} / 6$-hour $) /{ }^{\circ} \mathrm{C}$ \\
\hline PLWHC(nmru) & Fraction of liquid water holding capacity, unitless fraction \\
\hline $\operatorname{SI}(\mathrm{nmru})$ & Snow water equivalence above which snow-covered area reaches a maximum, in inches \\
\hline SUBRATE(nmru) & Average daily snowpack sublimation rate for each MRU, in inches per day \\
\hline $\operatorname{TIPM}(n m r u)$ & Antecedent temperature index parameter \\
\hline UADJ(nmru) & Average 6-h wind function during rain on snow events, in $(\mathrm{mm} / \mathrm{mb}) / 6$-hour \\
\hline
\end{tabular}


Table 2. Parameters, by process and intent, used the Water, Energy, and Biogeochemical Model (WEBMOD).-Continued

[The formatting convention used in this report is to present file names in italic font, dimension names in Courier New font, variable names in bold $i$ talic Courier New font, and parameter names in bold Courier New font. Names and descriptions of all dimensions are presented in table 1; names and descriptions of all variables are presented in table 3 .

MRU, model response unit; $h$, hour; ${ }^{\circ} \mathrm{C}$, degree Celsius; $\mathrm{m}$, meter; $\mathrm{L}^{3} / \mathrm{L}^{3}$, length cubed by length cubed; $\mathrm{m} / \mathrm{h}$, meter per hour; cm/s, centimeter per second; $\mathrm{m}^{2} / \mathrm{h}$, square meter per hour; TTI, transformed topographic index]

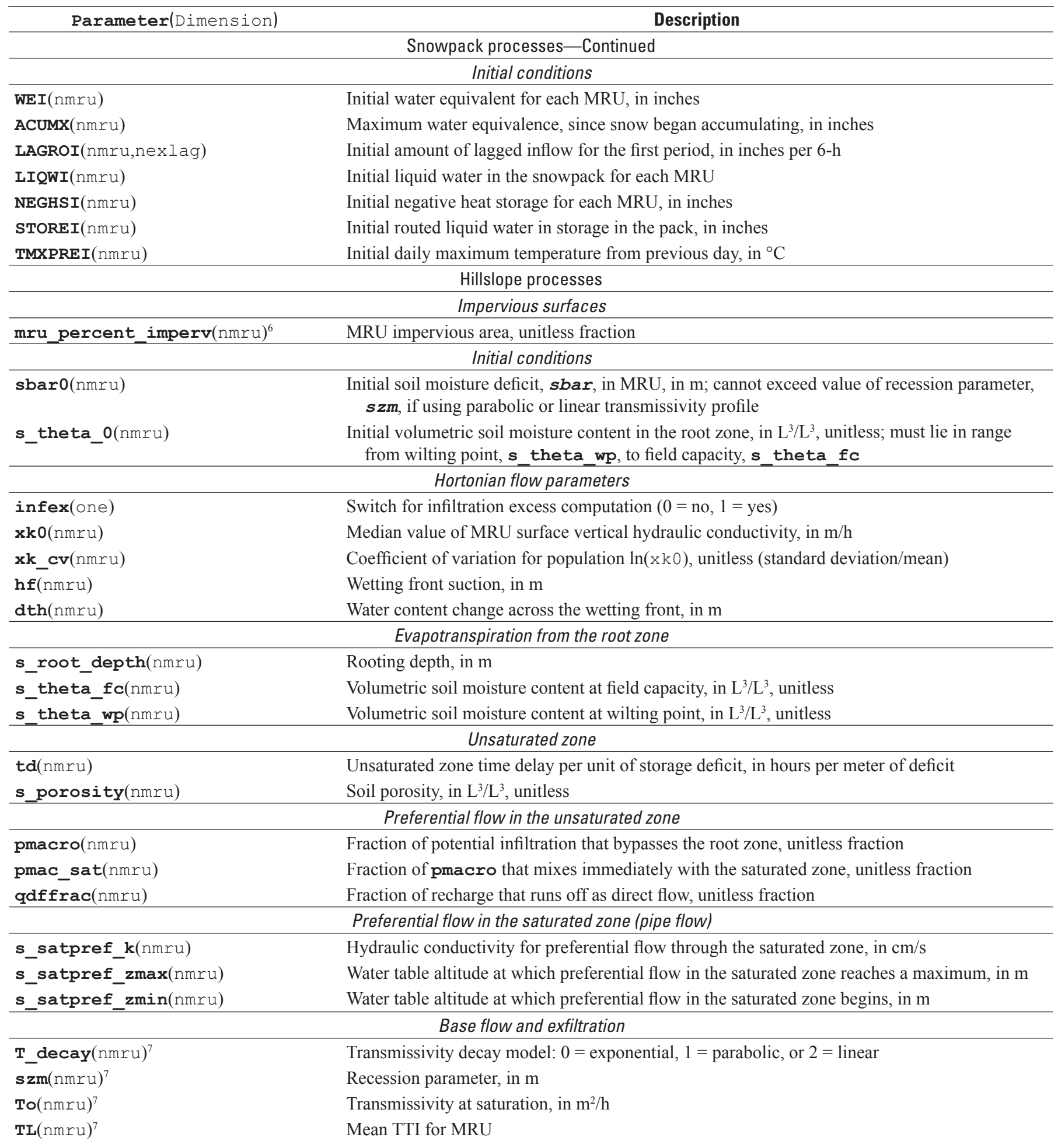


Table 2. Parameters, by process and intent, used the Water, Energy, and Biogeochemical Model (WEBMOD).-Continued

[The formatting convention used in this report is to present file names in italic font, dimension names in Courier New font, variable names in bold italic Courier New font, and parameter names in bold Courier New font. Names and descriptions of all dimensions are presented in table 1; names and descriptions of all variables are presented in table 3 .

MRU, model response unit; $\left(\mathrm{ft}^{3} / \mathrm{s}\right) / \mathrm{mi}$, cubic foot per second per mile; $\mathrm{m}$, meter; $\mathrm{cm} / \mathrm{s}$, centimeter per second; $\mathrm{m} / \mathrm{h}$, meter per hour; $\mathrm{m}^{3} / \mathrm{s}$, cubic meter per second; ID, integer identification of geochemical entity block in the $\mathrm{pH}$-redox-equilibrium model in the $\mathrm{C}$ programming language (PHREEQC) as described in the input file webmod.pqi; TTI, transformed topographic index]

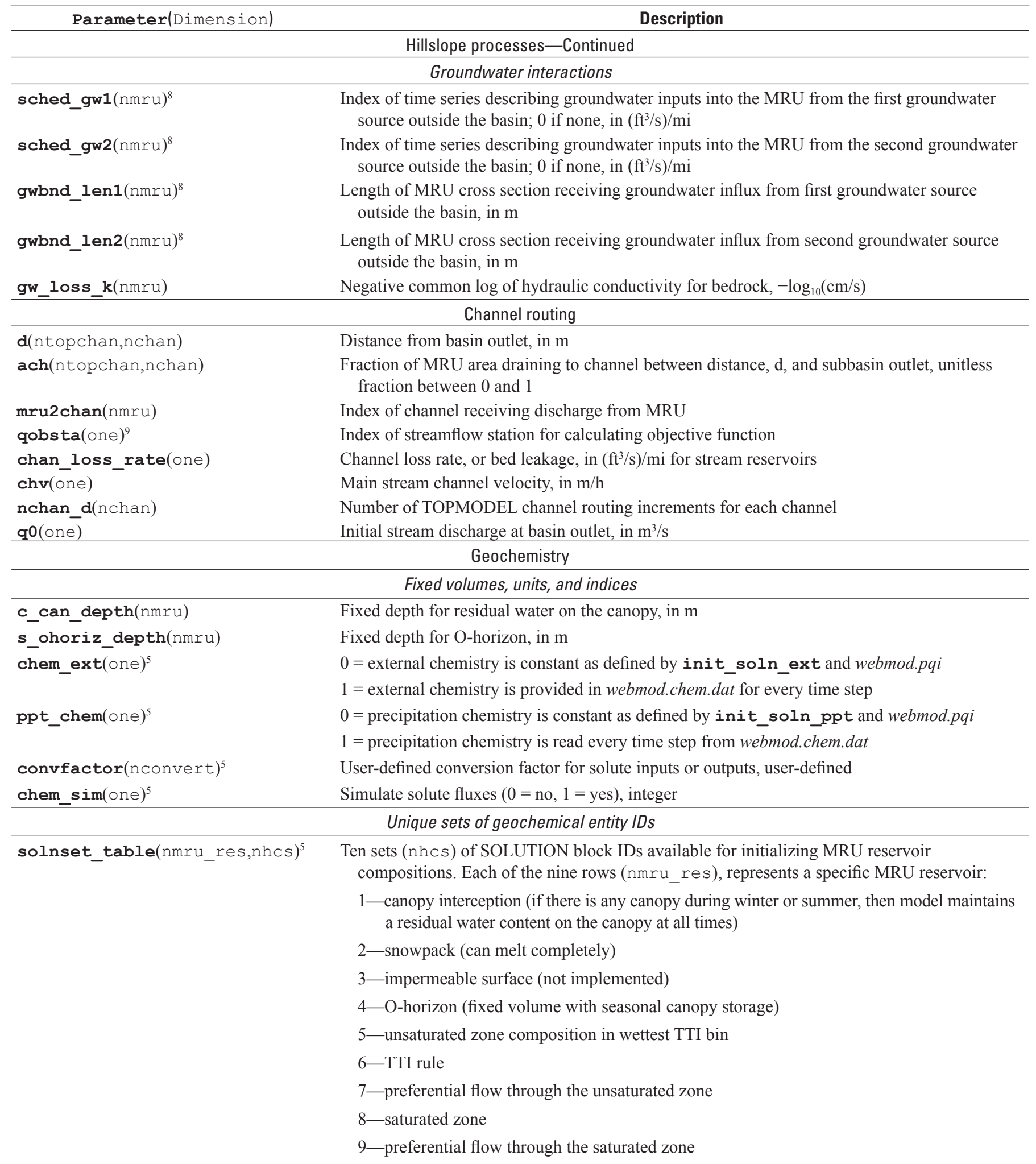


Table 2. Parameters, by process and intent, used the Water, Energy, and Biogeochemical Model (WEBMOD).-Continued

[The formatting convention used in this report is to present file names in italic font, dimension names in Courier New font, variable names in bold italic Courier New font, and parameter names in bold Courier New font. Names and descriptions of all dimensions are presented in table 1; names and descriptions of all variables are presented in table 3.

ID, integer identification of geochemical entity block in the pH-redox-equilibrium model in the $\mathrm{C}$ programming language (PHREEQC) as described in the input file webmod.pqi; MRU, model response unit]

\begin{tabular}{|c|c|}
\hline Parameter(Dimension) & Description \\
\hline \multicolumn{2}{|r|}{ Geochemistry-Continued } \\
\hline \multicolumn{2}{|r|}{ Unique sets of geochemical entity IDs_-Continued } \\
\hline rxnset_table(nmru_res,nhcs $)^{5}$ & $\begin{array}{l}\text { Ten sets of REACTION block IDs available for describing MRU reservoir geochemistry } \\
\text { ( }-1 \text { if none). Row indices of MRU reservoirs are those described in solnset_table } \\
\text { (nmru_res,nhcs). }\end{array}$ \\
\hline kinset_table(nmru_res,nhcs $)^{5}$ & $\begin{array}{l}\text { Ten sets of KINETICS block IDs available for describing MRU reservoir geochemistry } \\
\text { (-1 if none). Row indices of MRU reservoirs are those described in solnset_table } \\
\text { (nmru_res,nhcs). }\end{array}$ \\
\hline surfset_table(nmru_res,nhcs $)^{5}$ & $\begin{array}{l}\text { Ten sets of SURFACE block IDs available for describing MRU reservoir geochemistry } \\
\text { ( }-1 \text { if none). Row indices of MRU reservoirs are those described in solnset_table } \\
\text { (nmru_res,nhCs). }\end{array}$ \\
\hline \multicolumn{2}{|r|}{ Chemistry of inputs (precipitation, irrigation, and groundwater) } \\
\hline init_soln_ppt $(o n e)^{5}$ & SOLUTION block ID describing typical precipitation chemistry \\
\hline init_soln_ext $(\mathrm{nchem} \text { ext })^{10}$ & $\begin{array}{l}\text { SOLUTION block IDs to use for initializing the solute composition for each unique external } \\
\text { source (both irrigation and groundwater) }\end{array}$ \\
\hline atmos_eq_ph $(o n e)^{5}$ & EQULIBRIUM_PHASES ID describing atmospheric $\mathrm{O}_{2}$ and $\mathrm{CO}_{2}$ \\
\hline src_ext_irrig $(\mathrm{nmru})^{11}$ & Chemical source for external irrigation \\
\hline src_gw1(nmru $)^{12}$ & Chemical source for first groundwater influx (channel leakage) \\
\hline src_gw2 $(\mathrm{nmru})^{12}$ & Chemical source for second groundwater influx (upgradient) \\
\hline \multicolumn{2}{|r|}{ Incongruent melting of snowpack } \\
\hline \multicolumn{2}{|r|}{ Geochemistry of hillslopes reservoirs } \\
\hline init_solnset_mru(nmru $)^{5}$ & $\begin{array}{l}\text { Column number of solnset_table to use to assign an initial SOLUTION block ID to each } \\
\text { reservoir in an MRU }\end{array}$ \\
\hline init_eq_phset_mru(nmru $)^{5}$ & $\begin{array}{l}\text { Column number of eq_phset_table to use to assign an initial EQUILIBRIUM_PHASES } \\
\text { block ID to each reservoir in an MRU }\end{array}$ \\
\hline init_rxnset_mru(nmru $)^{5}$ & $\begin{array}{l}\text { Column number of rxnset_table to use to assign an initial REACTION block ID to each } \\
\text { reservoir in an MRU }\end{array}$ \\
\hline init_kinset_mru(nmru $)^{5}$ & $\begin{array}{l}\text { Column number of } \mathbf{k i n s e t} \text { table to use to assign initial KINETICS block IDs to each } \\
\text { reservoir in an MRU }\end{array}$ \\
\hline init_surfset_mru(nmru $)^{5}$ & $\begin{array}{l}\text { Column number of surfset_table to use to assign an initial SURFACE block ID to each } \\
\text { reservoir in an MRU }\end{array}$ \\
\hline init_exchset_mru(nmru $)^{5}$ & $\begin{array}{l}\text { Column number of exchset_table to use to assign an initial EXCHANGE block ID to each } \\
\text { reservoir in an MRU }\end{array}$ \\
\hline
\end{tabular}


Table 2. Parameters, by process and intent, used the Water, Energy, and Biogeochemical Model (WEBMOD).—Continued

[The formatting convention used in this report is to present file names in italic font, dimension names in Courier New font, variable names in bold italic Courier New font, and parameter names in bold Courier New font. Names and descriptions of all dimensions are presented in table 1; names and descriptions of all variables are presented in table 3 .

ID, integer identification of geochemical entity block in the pH-redox-equilibrium model in the $\mathrm{C}$ programming language (PHREEQC) as described in the input file webmod.pqi.; ${ }^{\circ} \mathrm{C}$, degree Celsius; MRU, model response unit; ch_var, one of 10 groups of user-defined chemical variables, or chemvars; TTI, transformed topographic index]

\begin{tabular}{|c|c|}
\hline Parameter(Dimension) & Description \\
\hline \multicolumn{2}{|r|}{ Geochemistry-Continued } \\
\hline \multicolumn{2}{|r|}{ Geochemistry of stream reservoirs } \\
\hline init_eq_ph_hydro(nhydro) $)^{5}$ & $\begin{array}{l}\text { EQUILIBRIUM PHASES block ID to use for initializing stream segment or water body } \\
(-1 \text { if none) }\end{array}$ \\
\hline init_kin hydro $(\text { nhydro) })^{5}$ & KINETICS block ID to use for initializing stream segment or water body ( -1 if none) \\
\hline init_surf_hydro(nhydro) & SURFACE species block ID to use for initializing stream segment or water body ( -1 if none) \\
\hline init_exch_hydro(nhydro) $)^{5}$ & $\begin{array}{l}\text { EXCHANGE block ID to use for initializing exchange sites for stream segment or water body } \\
(-1 \text { if none })\end{array}$ \\
\hline trxn_ohoriz_days $(o n e)^{5}$ & Temperature averaging window for O-horizon, in days \\
\hline trxn_uz_days $(o n e)^{5}$ & Temperature averaging window for the unsaturated zone, in days \\
\hline trxn_sat_days $(o n e)^{5}$ & Temperature averaging window for saturated zone, in days \\
\hline trxn_ohoriz_c_adj(nmru $)^{5}$ & Temperature adjustment to moving average of tmin, tavg, or tmax for O-horizon, in ${ }^{\circ} \mathrm{C}$ \\
\hline trxn_uz_c_adj(nmru $)^{5}$ & Temperature adjustment to moving average of tmin, tavg, or tmax for the unsaturated zone, in ${ }^{\circ} \mathrm{C}$ \\
\hline trxn_sat_c_adj(nmru $)^{5}$ & Temperature adjustment to moving average of tmin, tavg, or tmax for the saturated zone, in ${ }^{\circ} \mathrm{C}$ \\
\hline \multicolumn{2}{|c|}{ User-defined chemical variables_-Chemvars (MRU and basin fluxes available in standard variables) } \\
\hline c_ires(nchemvar) & $\begin{array}{l}\text { Reservoir type (1-9 or 99) to save to ch_var: } \\
\begin{aligned} 1 & =\text { canopy } \\
2 & =\text { snowpack } \\
3 & =\text { impermeable surface (not implemented) } \\
4 & =\text { O-horizon } \\
5 & =\text { unsaturated zone, TTI bin } \\
6 & =\text { unsaturated zone, composite, upslope or riparian } \\
7 & =\text { unsaturated preferential flow } \\
8 & =\text { saturated zone } \\
9 & =\text { saturated preferential flow } \\
99 & =\text { stream, pond, irrigation, or diversion }\end{aligned}\end{array}$ \\
\hline c_metric(nchemvar) $)^{5}$ & $\begin{array}{l}\text { Chemical metric }(1-5) \text { for } \text { ch_var: } \\
\qquad \begin{aligned} 1 & =\text { initial, } 2=\text { influent, } 3=\text { effluent } \\
4 & =\text { reaction gain }(+) \text { or loss }(-) \\
5 & =\text { final, or } 6=\text { net. }\end{aligned}\end{array}$ \\
\hline c_mru(nchemvar) $)^{5}$ & MRU for ch_var, 0 for basin sum for that reservoir \\
\hline c_hyd_indx(nchemvar) $)^{5}$ & Specific drainage segment or node for ch_var \\
\hline c_obs_indx $(\text { nchemvar })^{5}$ & Index of solute chemistry observation station. \\
\hline c_stindx(nchemvar) $)^{5}$ & Specific TTI bin for ch_var when c_res $=5$ \\
\hline c_rip $(\text { nchemvar })^{5}$ & Composite of TTI bins for $0=$ hillslope, $1=$ riparian, or $2=$ upland for ch_var when $c \_r e s=6$ \\
\hline
\end{tabular}


Table 2. Parameters, by process and intent, used the Water, Energy, and Biogeochemical Model (WEBMOD).—Continued

[The formatting convention used in this report is to present file names in italic font, dimension names in Courier New font, variable names in bold italic Courier New font, and parameter names in bold Courier New font. Names and descriptions of all dimensions are presented in table 1; names and descriptions of all variables are presented in table 3.

c_units(nchemvar), user-selectable unit; ch_var, one of 10 groups of user-defined chemical variables, or chemvars; MRU, model response unit; mg, milligram; meq, milliequivalent; $\mathrm{mmol}$, millimole; $\mathrm{mg} / \mathrm{m}^{2}$, milligram per square meter; $\mathrm{meq} / \mathrm{m}^{2}$, milliequivalent per square meter; $\mathrm{mmol} / \mathrm{m}^{2}$, millimole per square meter; $\mathrm{mg} / \mathrm{L}$, milligram per liter; meq/L, milliequivalent per liter; $\mathrm{mmol} / \mathrm{L}$, millimole per liter]

\begin{tabular}{|c|c|}
\hline Parameter(Dimension) & Description \\
\hline & Geochemistry-Continued \\
\hline \multicolumn{2}{|c|}{ User-defined chemical variables_-Chemvars (MRU and basin fluxes available in standard variables)_Continued } \\
\hline \multirow[t]{4}{*}{ c_units(nchemvar) } & Units for ch_var: \\
\hline & $1=\mathrm{mg}, \overline{2}=\mathrm{meq}, 3=\mathrm{mmol}$ \\
\hline & $4=\mathrm{mg} / \mathrm{m}^{2}, 5=\mathrm{meq} / \mathrm{m}^{2}, 6=\mathrm{mmol} / \mathrm{m}^{2}$ \\
\hline & $7=\mathrm{mg} / \mathrm{L}, 8=\mathrm{meq} / \mathrm{L}, 9=\mathrm{mmol} / \mathrm{L}$ \\
\hline \multicolumn{2}{|r|}{ Model outputs } \\
\hline print_vse(one) $)^{5}$ & Scope of detailed geochemical output files: $0=$ none, $1=$ basin and MRUs, $2=$ all reservoirs \\
\hline print_explanation(one) & Print detailed explanation of fields in hydrologic output file $(0=$ no, $1=$ yes $)$ \\
\hline print_freq(one) & $\begin{array}{l}\text { Frequency for output data file: sum of selected periods: } 16 \text {, event; } 8 \text {, daily; } 4 \text {, monthly; } \\
2 \text {, yearly; and } 1 \text {, entire run. Therefore, by summation, a value of } 15 \text { would print a summary } \\
\text { for each day, month, year, and entire run. Event summaries are not available at the daily time } \\
\text { step of WEBMOD. }\end{array}$ \\
\hline print_type(one) & Type of output data file: $0=$ minimal detail, $1=$ medium detail, or $2=$ very detailed \\
\hline iout(one) & Printed TOPMODEL output switch: $0=$ minimum, $1=$ summary, or $2=$ each time step \\
\hline \multicolumn{2}{|r|}{ Debugging and detailed PHREEOC output } \\
\hline xdebug_start(one) & Begin debugging on this step (0 if no debugging), integer \\
\hline xdebug_stop(one) & End debugging on this step, integer \\
\hline
\end{tabular}

${ }^{1}$ Must be present in parameter file when nhum, the number of stations recording relative humidity, is not equal to zero.

${ }^{2}$ Must be present in parameter file when nevap, the number of stations recording pan evaporation, is not equal to zero.

${ }^{3}$ Must be present in parameter file when nirrig_ext, the number of unique application rates from external irrigation sources, is not equal to zero.

${ }^{4}$ Must be present in parameter file when nirrig_int, the number of internal irrigation sources, is not equal to zero.

${ }^{5}$ Must be present in parameter file when nsolute, the number of solutes tracked, is not equal to zero.

${ }^{6}$ This parameter is inactive pending the development of process modules for impermeable surfaces.

${ }^{7}$ This parameter is dependent on the model selected for the decrease of transmissivity with depth.

${ }^{8}$ Must be present in parameter file when ngw_ext, the number of unique flux rates from external groundwater sources, is not equal to zero.

${ }^{9}$ Must be present in parameter file when nobs, the number of discharge records, is not equal to zero.

${ }^{10}$ Must be present in parameter file when nsolute, the number of solutes, and nchem_ext, the number of chemically unique external sources, are both not zero.

${ }^{11}$ Must be present in parameter file when nsolute, the number of solutes, and nirrig_ext, the number of unique application rates from external irrigation sources, are both not zero.

${ }^{12}$ Must be present in parameter file when nsolute, the number of solutes, and ngw_ext, the number of unique flux rates from external groundwater sources, are both not zero. 
Table 3. Variables, categorized by property, observation, and process in the Water, Energy, and Biogeochemical Model (WEBMOD).

[All variables not listed in the first block as static are dynamic, potentially having a different value each day. The formatting convention used in this report is to present file names in italic font, dimension names in Courier New font, variable names in bold italic Courier New font, and parameter names in bold Courier New font. Names and descriptions of all dimensions are presented in table 1; names and descriptions of all parameters are presented in table 2.

MRU, model response unit; $\mathrm{km}^{2}$, square kilometer; $\mathrm{L}^{3} / \mathrm{L}^{3}$, length cubed per length cubed; m, meter; $\mathrm{ft}^{3} / \mathrm{s}$, cubic foot per second; ${ }^{\circ} \mathrm{C}$, degree $\mathrm{Celsius;}{ }^{\circ} \mathrm{F}$, degree Fahrenheit; mol/L, mole per liter; NADP, National Atmospheric Deposition Program]

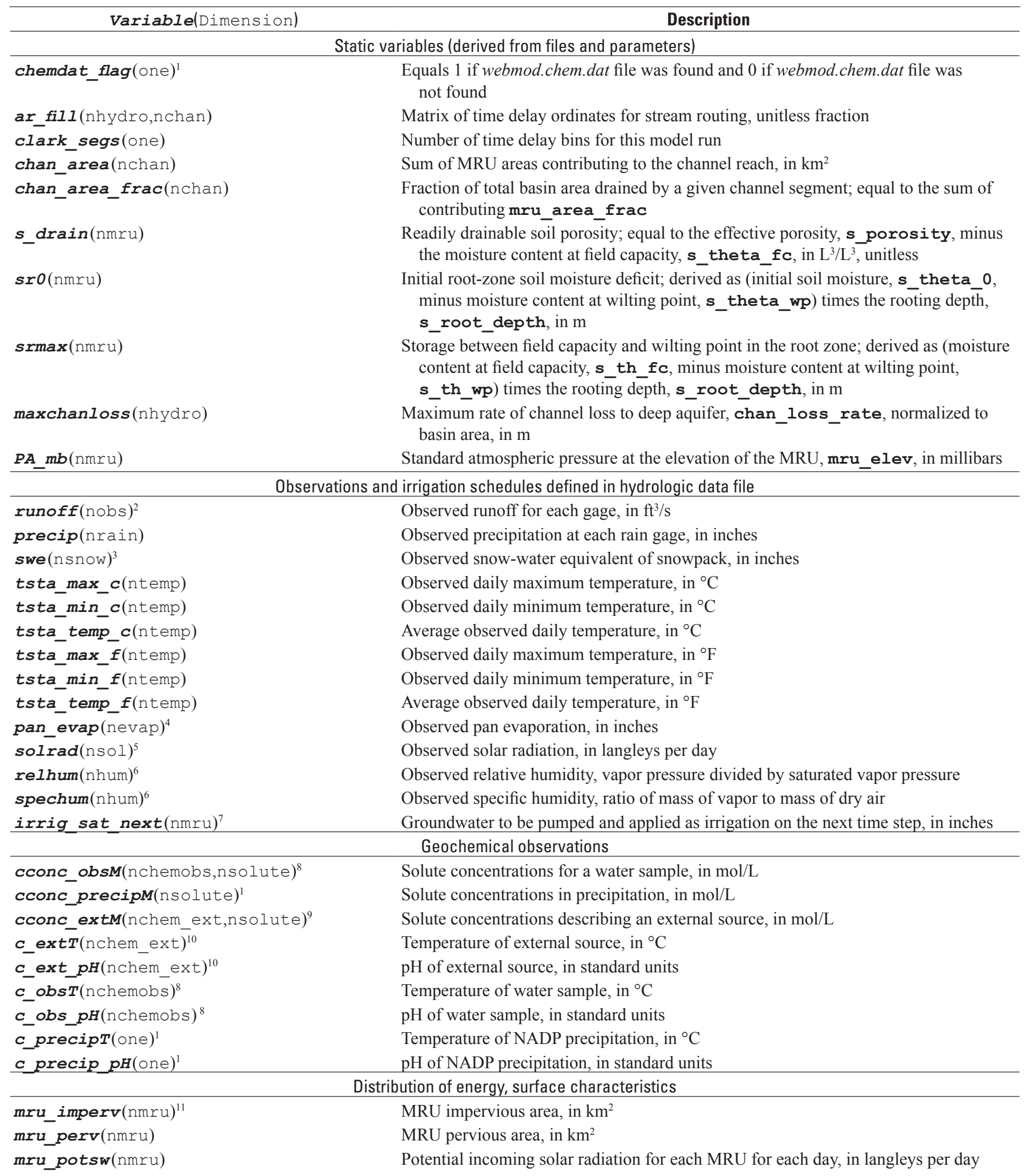


Table 3. Variables, categorized by property, observation, and process in the Water, Energy, and Biogeochemical Model (WEBMOD). -Continued

[All variables not listed in the first block as static are dynamic, potentially having a different value each day. The formatting convention used in this report is to present file names in italic font, dimension names in Courier New font, variable names in bold italic Courier New font, and parameter names in bold Courier New font. Names and descriptions of all dimensions are presented in table 1; names and descriptions of all parameters are presented in table 2.

MRU, model response unit; $\mathrm{h}$, hour; $\mathrm{W} / \mathrm{m}^{2}$, watt per square meter; ${ }^{\circ} \mathrm{C}$, degree Celsius; ${ }^{\circ} \mathrm{F}$, degree Fahrenheit; ET, evapotranspiration]

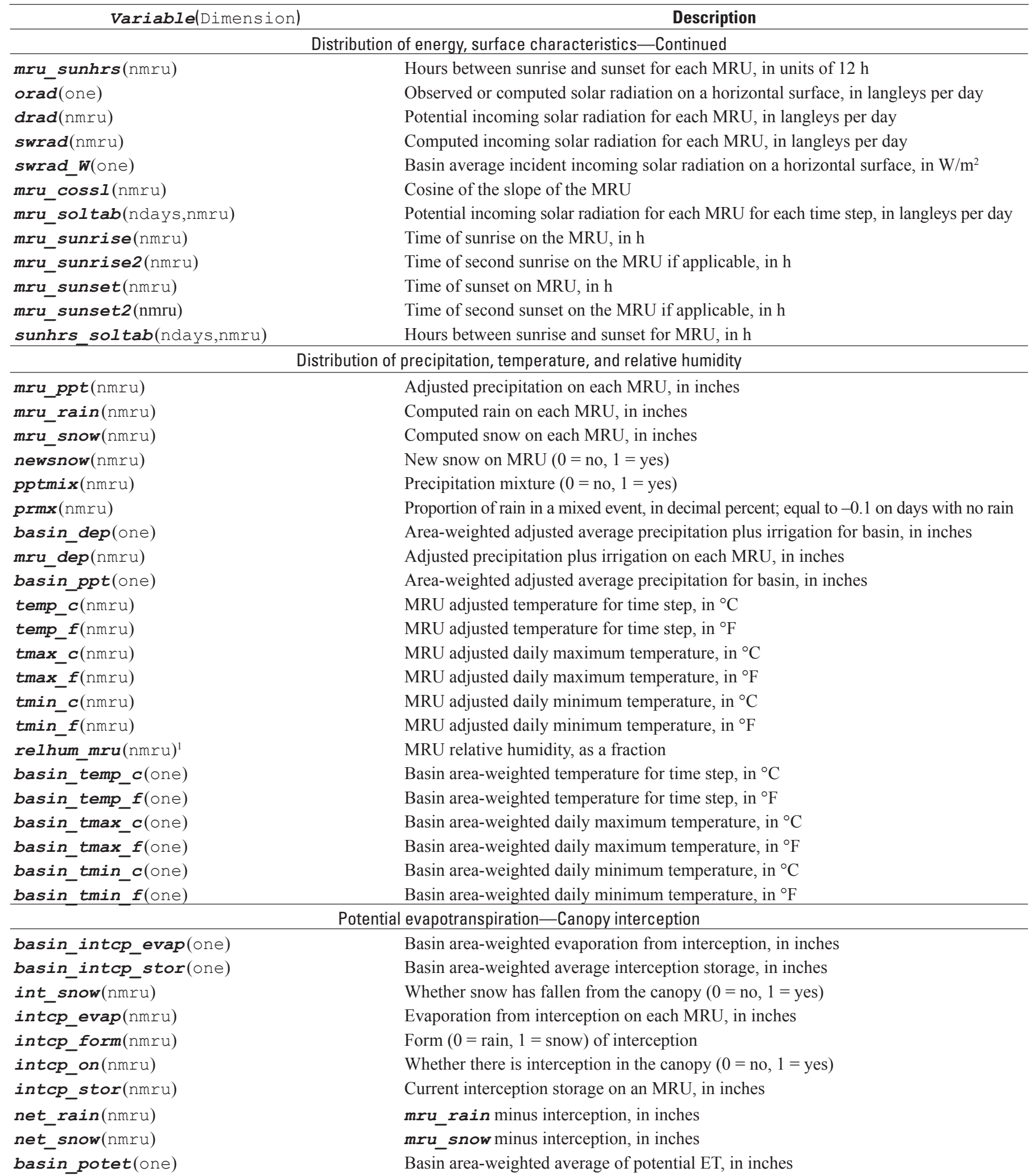


Table 3. Variables, categorized by property, observation, and process in the Water, Energy, and Biogeochemical Model (WEBMOD). -Continued

[All variables not listed in the first block as static are dynamic, potentially having a different value each day. The formatting convention used in this report is to present file names in italic font, dimension names in Courier New font, variable names in bold italic Courier New font, and parameter names in bold Courier New font. Names and descriptions of all dimensions are presented in table 1; names and descriptions of all parameters are presented in table 2.

ET, evapotranspiration; MRU, model response unit; ${ }^{\circ} \mathrm{F}$, degree Fahrenheit; $\left(\mathrm{ft}^{3} / \mathrm{s}\right) / \mathrm{mi}$, cubic foot per second per mile; $\mathrm{m}^{3}$, cubic meter; $\mathrm{m}$, meter]

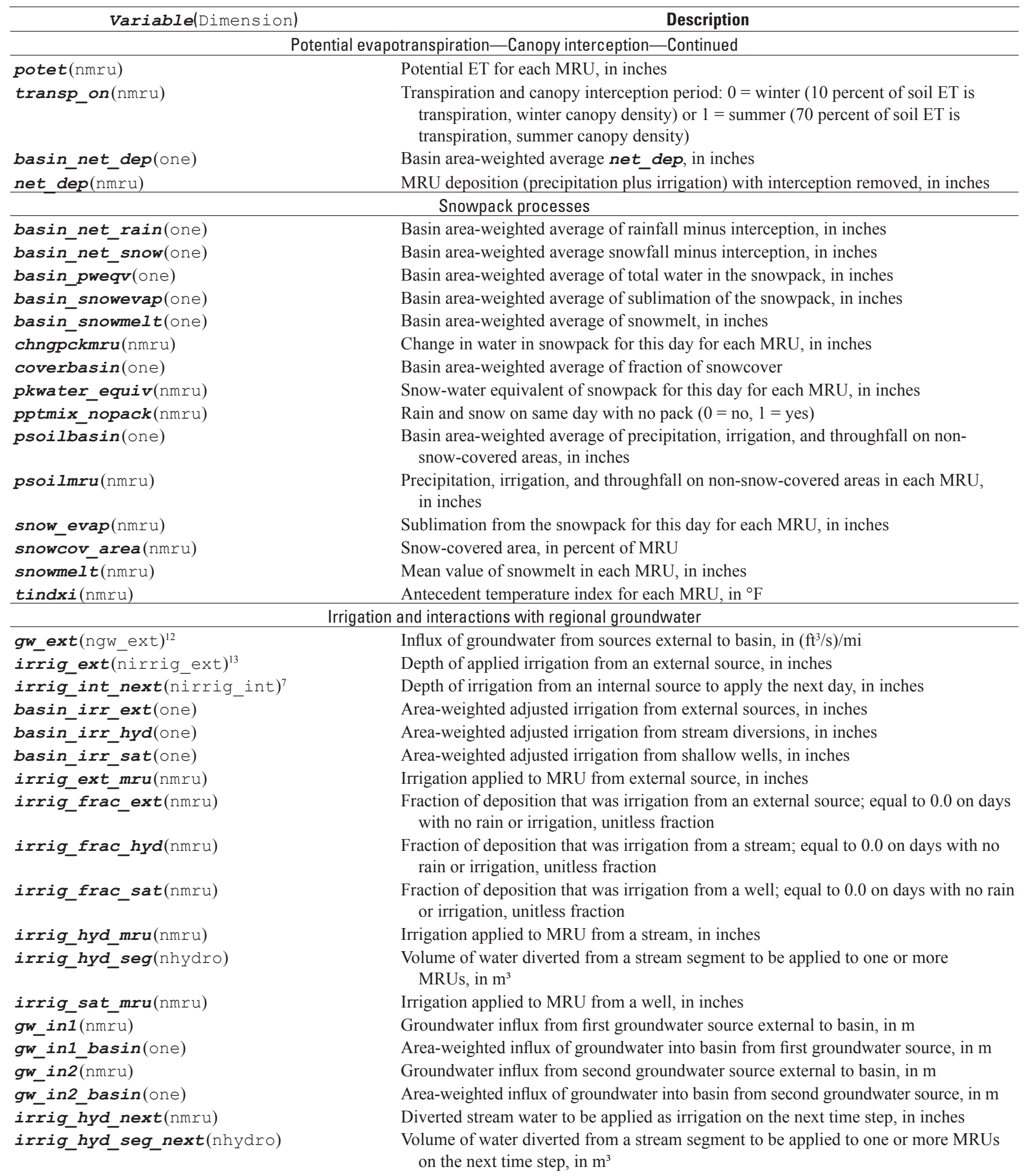


Table 3. Variables, categorized by property, observation, and process in the Water, Energy, and Biogeochemical Model (WEBMOD). -Continued

[All variables not listed in the first block as static are dynamic, potentially having a different value each day. The formatting convention used in this report is to present file names in italic font, dimension names in Courier New font, variable names in bold italic Courier New font, and parameter names in bold Courier New font. Names and descriptions of all dimensions are presented in table 1; names and descriptions of all parameters are presented in table 2.

MRU, model response unit; ET, evapotranspiration; m, meter; $\mathrm{m} / \mathrm{h}$, meter per hour; TTI, transformed topographic index]

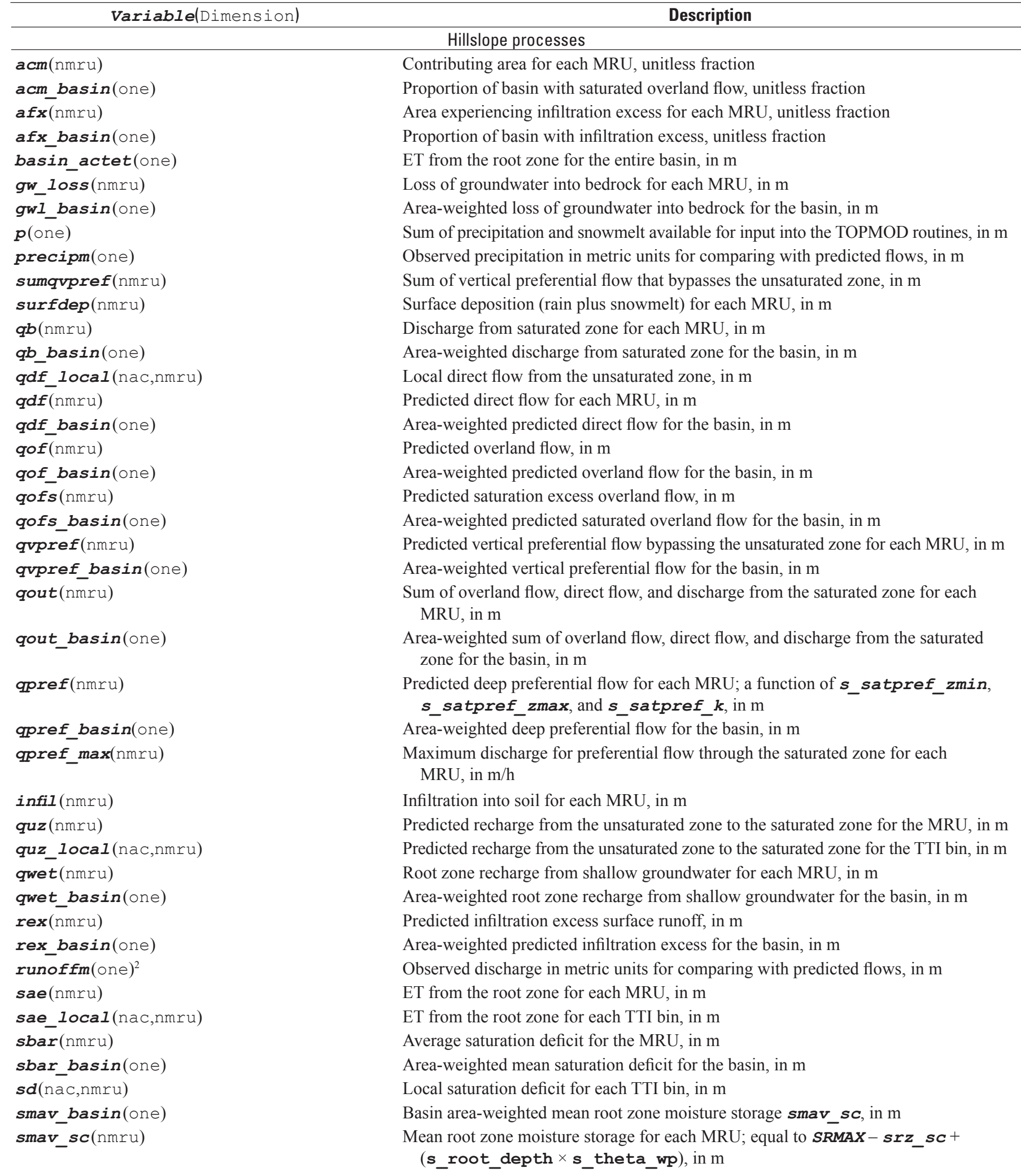


Table 3. Variables, categorized by property, observation, and process in the Water, Energy, and Biogeochemical Model (WEBMOD). -Continued

[All variables not listed in the first block as static are dynamic, potentially having a different value each day. The formatting convention used in this report is to present file names in italic font, dimension names in Courier New font, variable names in bold italic Courier New font, and parameter names in bold Courier New font. Names and descriptions of all dimensions are presented in table 1; names and descriptions of all parameters are presented in table 2.

$\mathrm{L}^{3} / \mathrm{L}^{3}$, length cubed per length cubed; MRU, model response unit; TTI, transformed topographic index; $\mathrm{m}, \mathrm{meter} ; \mathrm{m}^{3}$, cubic meter; $\mathrm{ft}^{3} / \mathrm{s}$, cubic foot per second]

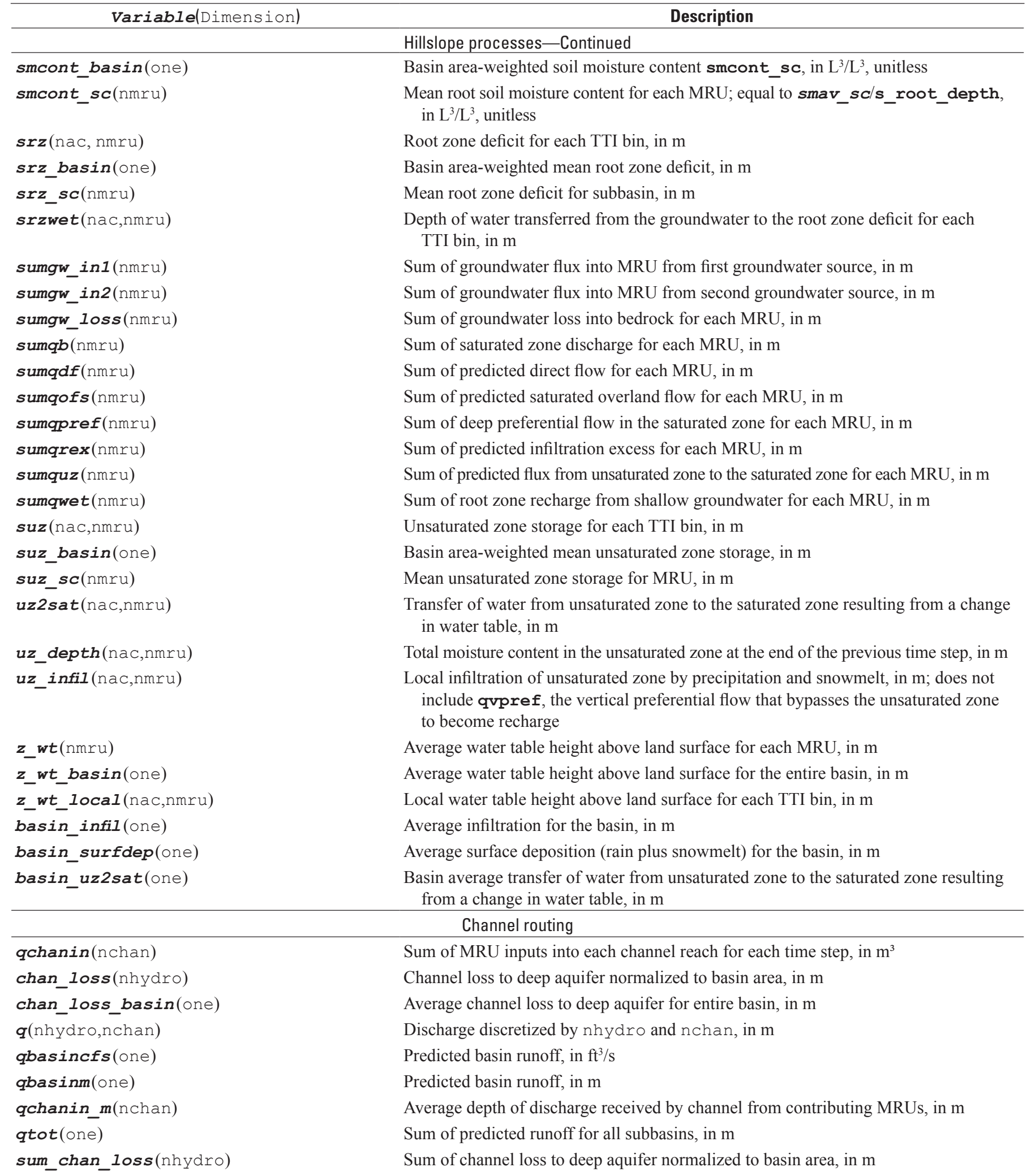


Table 3. Variables, categorized by property, observation, and process in the Water, Energy, and Biogeochemical Model (WEBMOD). - Continued

[All variables not listed in the first block as static are dynamic, potentially having a different value each day. The formatting convention used in this report is to present file names in italic font, dimension names in Courier New font, variable names in bold italic Courier New font, and parameter names in bold Courier New font. Names and descriptions of all dimensions are presented in table 1; names and descriptions of all parameters are presented in table 2.

ET, evapotranspiration; $\mathrm{cm}$, centimeter; $\mathrm{m}^{3} / \mathrm{s}$, cubic meter per second]

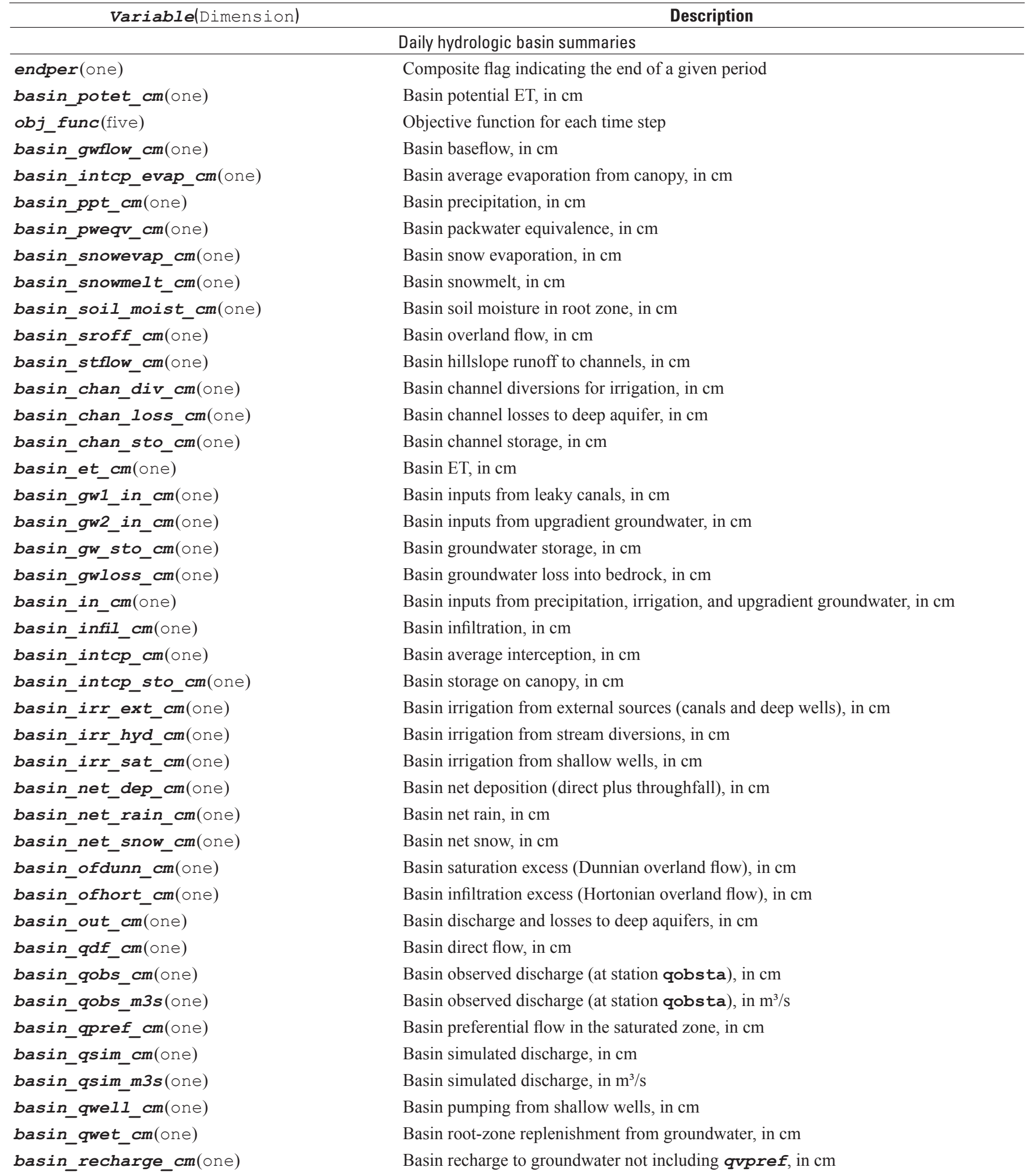


Table 3. Variables, categorized by property, observation, and process in the Water, Energy, and Biogeochemical Model (WEBMOD). - Continued

[All variables not listed in the first block as static are dynamic, potentially having a different value each day. The formatting convention used in this report is to present file names in italic font, dimension names in Courier New font, variable names in bold italic Courier New font, and parameter names in bold Courier New font. Names and descriptions of all dimensions are presented in table 1; names and descriptions of all parameters are presented in table 2.

$\mathrm{cm}$, centimeter; $\mathrm{W} / \mathrm{m}^{2}$, watt per square meter; ET, evapotranspiration; $\mathrm{m}^{3} / \mathrm{s}$, cubic meter per second]

\begin{tabular}{ll}
\hline \multicolumn{1}{c}{ Variable(Dimension) } & \multicolumn{1}{c}{ Description } \\
\hline basin_sat2uz_cm(one) & Daily hydrologic basin summaries_Continued \\
basin_sssto_cm(one) & Basin water left in unsaturated zone as water table lowers, in cm \\
basin_sto_cm(one) & Basin subsurface storage, in cm \\
& Storage in basin including streams, groundwater, subsurface storage, soil moisture, \\
basin_surfdep_cm(one) & snowpack, and interception, in cm \\
basin_thruf_cm(one) & Basin hillslope deposition (direct plus snowmelt), in cm \\
basin_transp_cm(one) & Basin average canopy throughfall, in cm \\
basin_uz2sat_cm(one) & Basin average transpiration, in cm \\
basin_uz_et_cm(one) & Basin unsaturated zone water added to the saturated zone as water table rises, in cm \\
basin_vpref_cm(one) & Basin evaporation from the soil, in cm \\
wat_bal_cm(one) & Basin infiltration delivered directly to groundwater, in cm \\
\hline
\end{tabular}

Cumulative hydrologic basin summaries

[Most of the following variables are vectors of length 5 with unit values averaged or accumulated for time step of (1) event, (2) day, (3) month, (4) year, or (5) entire run]

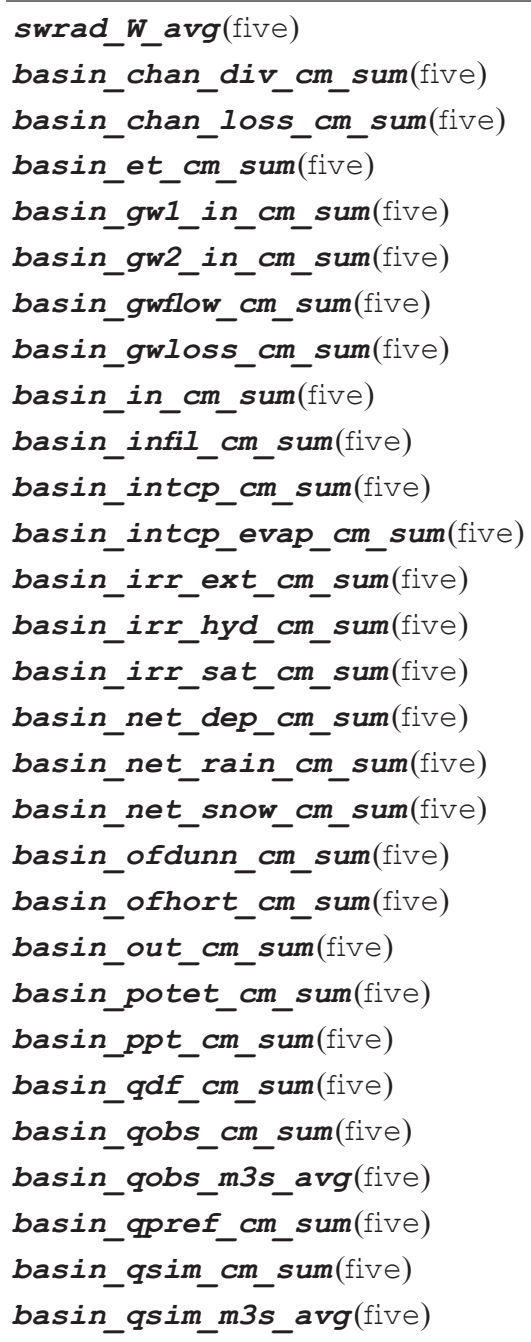

Average incoming solar radiation, in $\mathrm{W} / \mathrm{m}^{2}$

Sum of basin diversions for irrigation, in $\mathrm{cm}$

Sum of basin chan_loss, in cm

Sum of basin ET, in cm

Sum of inputs from leaky canals, in cm

Sum of inputs from upgradient groundwater, in $\mathrm{cm}$

Sum of basin baseflow, in $\mathrm{cm}$

Sum of basin groundwater loss into bedrock, in $\mathrm{cm}$

Sum of basin inputs from precipitation, irrigation, and upgradient groundwater, in $\mathrm{cm}$

Sum of basin infiltration, in $\mathrm{cm}$

Sum of basin interception, in $\mathrm{cm}$

Sum of evaporation from interception, in $\mathrm{cm}$

Sum of basin irrigation from external sources, in $\mathrm{cm}$

Sum of basin irrigation from stream diversions, in $\mathrm{cm}$

Sum of basin irrigation from shallow wells, in $\mathrm{cm}$

Sum of basin direct deposition plus throughfall (precipitation plus irrigation), in $\mathrm{cm}$

Sum of basin net rain, in $\mathrm{cm}$

Sum of basin net snow, in $\mathrm{cm}$

Sum of basin saturation excess, in $\mathrm{cm}$

Sum of basin infiltration excess, in cm

Sum of basin discharge and losses to deep aquifers, in $\mathrm{cm}$

Sum of potential ET, in $\mathrm{cm}$

Sum of basin precipitation, in $\mathrm{cm}$

Sum of basin lateral macropore flow, in $\mathrm{cm}$

Sum of basin observed discharge (at station qobsta), in cm

Average basin observed discharge (at station qobsta), in $\mathrm{m}^{3} / \mathrm{s}$

Sum of basin preferential flow through the saturated zone, in $\mathrm{cm}$

Sum of basin simulated discharge, in $\mathrm{cm}$

Average basin predicted runoff, in $\mathrm{m}^{3} / \mathrm{s}$ 
Table 3. Variables, categorized by property, observation, and process in the Water, Energy, and Biogeochemical Model (WEBMOD). - Continued

[All variables not listed in the first block as static are dynamic, potentially having a different value each day. The formatting convention used in this report is to present file names in italic font, dimension names in Courier New font, variable names in bold italic Courier New font, and parameter names in bold Courier New font. Names and descriptions of all dimensions are presented in table 1; names and descriptions of all parameters are presented in table 2.

$\mathrm{cm}$, centimeter; ${ }^{\circ} \mathrm{C}$, degree Celsius; $\mathrm{m}^{3}$, cubic meter; MRU, model response unit; UZ, unsaturated zone]

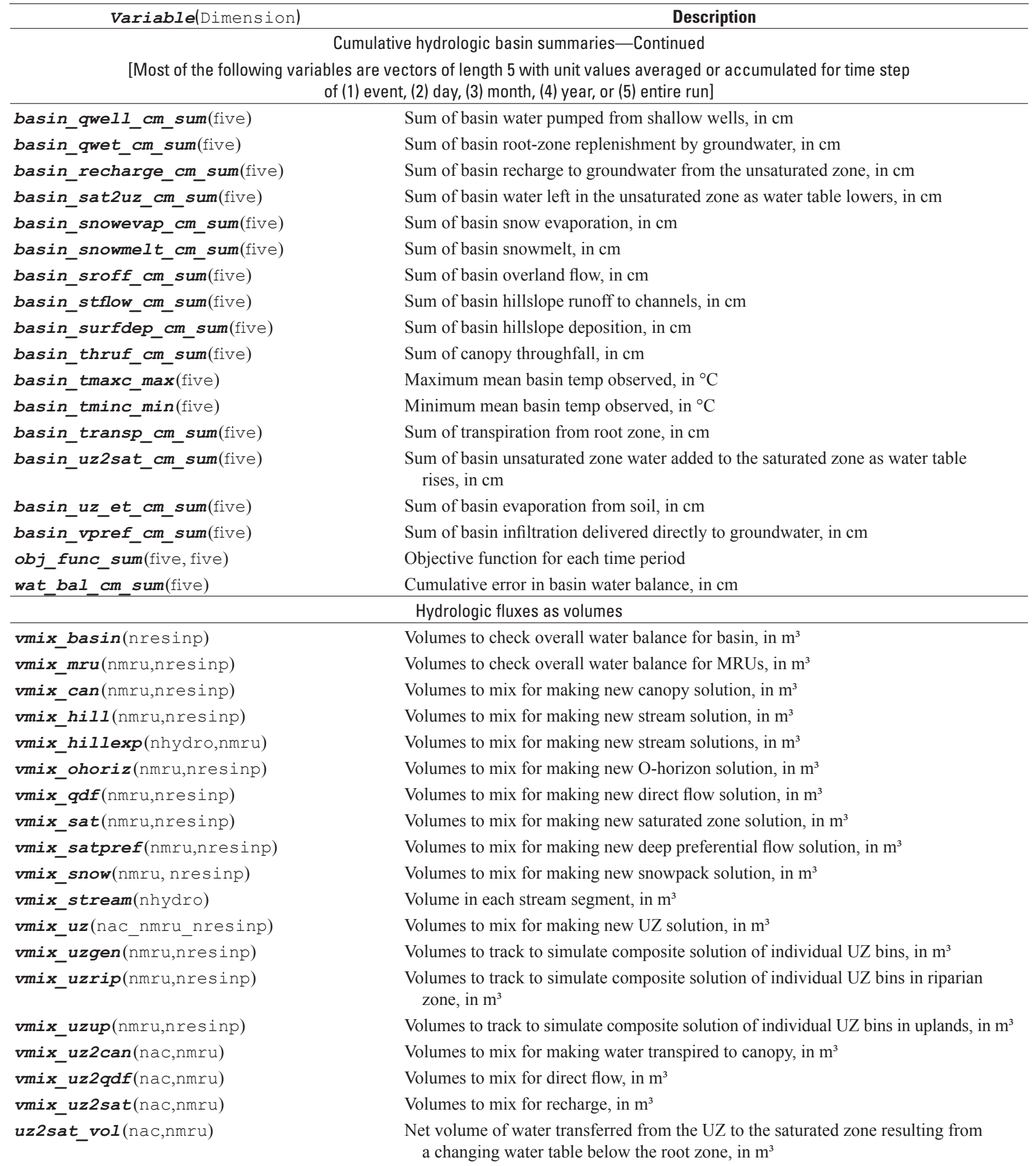


Table 3. Variables, categorized by property, observation, and process in the Water, Energy, and Biogeochemical Model (WEBMOD). -Continued

[All variables not listed in the first block as static are dynamic, potentially having a different value each day. The formatting convention used in this report is to present file names in italic font, dimension names in Courier New font, variable names in bold italic Courier New font, and parameter names in bold Courier New font. Names and descriptions of all dimensions are presented in table 1; names and descriptions of all parameters are presented in table 2.

$\mathrm{m}^{3} / \mathrm{s}$, cubic meter per second; $\mathrm{m}^{3}$, cubic meter; eq, equivalent; g, gram; mol, mole; ET, evapotranspiration; meq/L, milliequivalent per liter; meq $/ \mathrm{m}^{2}$, milliequivalent per square meter; $\mathrm{mg} / \mathrm{L}$, milligram per liter; $\mathrm{mg} / \mathrm{m}^{2}$, milligram per square meter; $\mathrm{mmol} / \mathrm{L}$, millimole per liter; $\mathrm{mmol} / \mathrm{m}^{2}$, millimole per square meter]

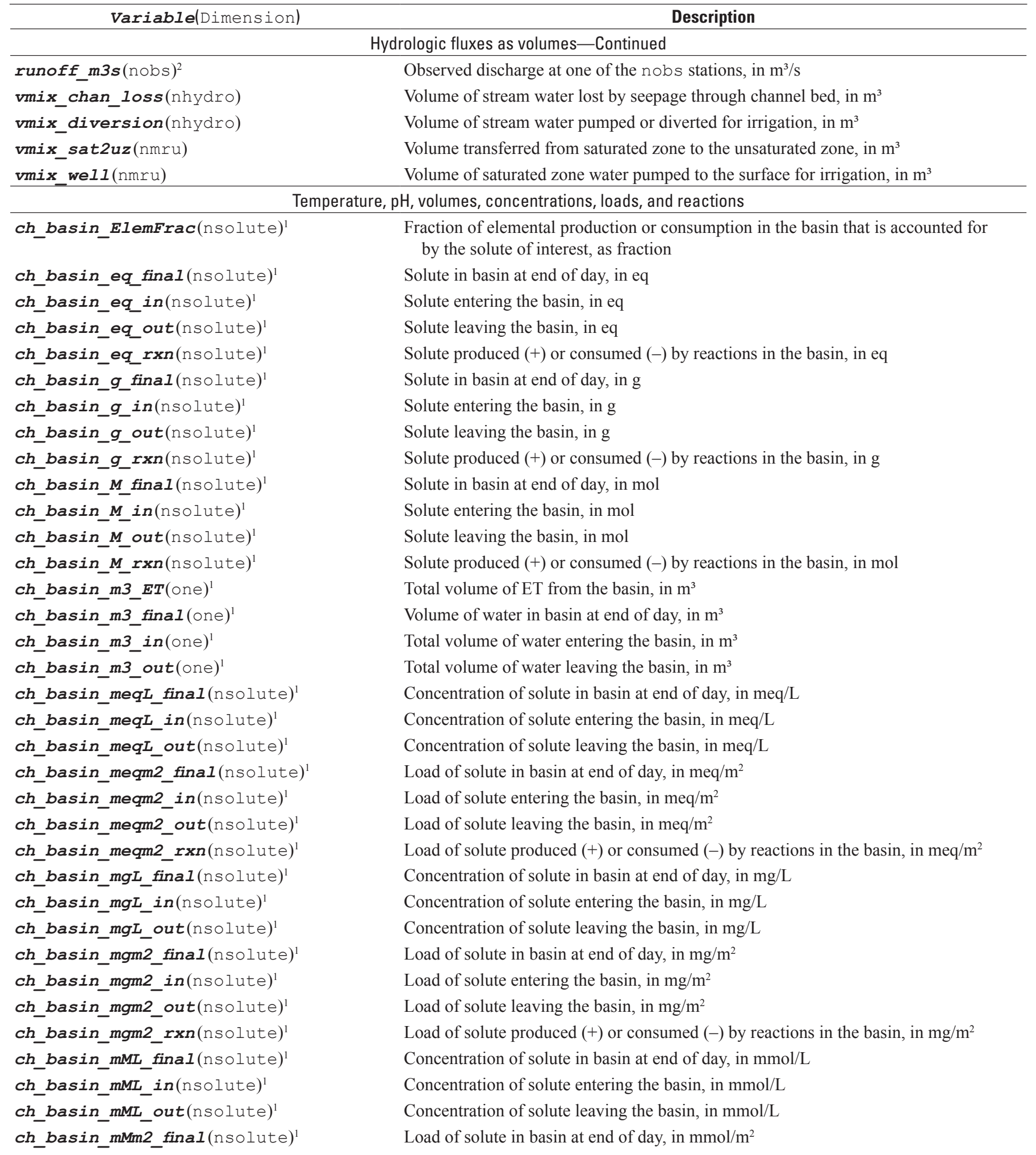


Table 3. Variables, categorized by property, observation, and process in the Water, Energy, and Biogeochemical Model (WEBMOD). -Continued

[All variables not listed in the first block as static are dynamic, potentially having a different value each day. The formatting convention used in this report is to present file names in italic font, dimension names in Courier New font, variable names in bold italic Courier New font, and parameter names in bold Courier New font. Names and descriptions of all dimensions are presented in table 1; names and descriptions of all parameters are presented in table 2.

$\mathrm{mmol} / \mathrm{m}^{2}$, millimole per square meter; ${ }^{\circ} \mathrm{C}$, degree Celsius; eq, equivalent; g, gram; mol, mole; $\mathrm{m}^{3}$, cubic meter; meq $/ \mathrm{L}$, milliequivalent per liter; meq $/ \mathrm{m}^{2}$, milliequivalent per square meter; $\mathrm{mg} / \mathrm{L}$, milligram per liter; $\mathrm{mg} / \mathrm{m}^{2}$, milligram per square meter]

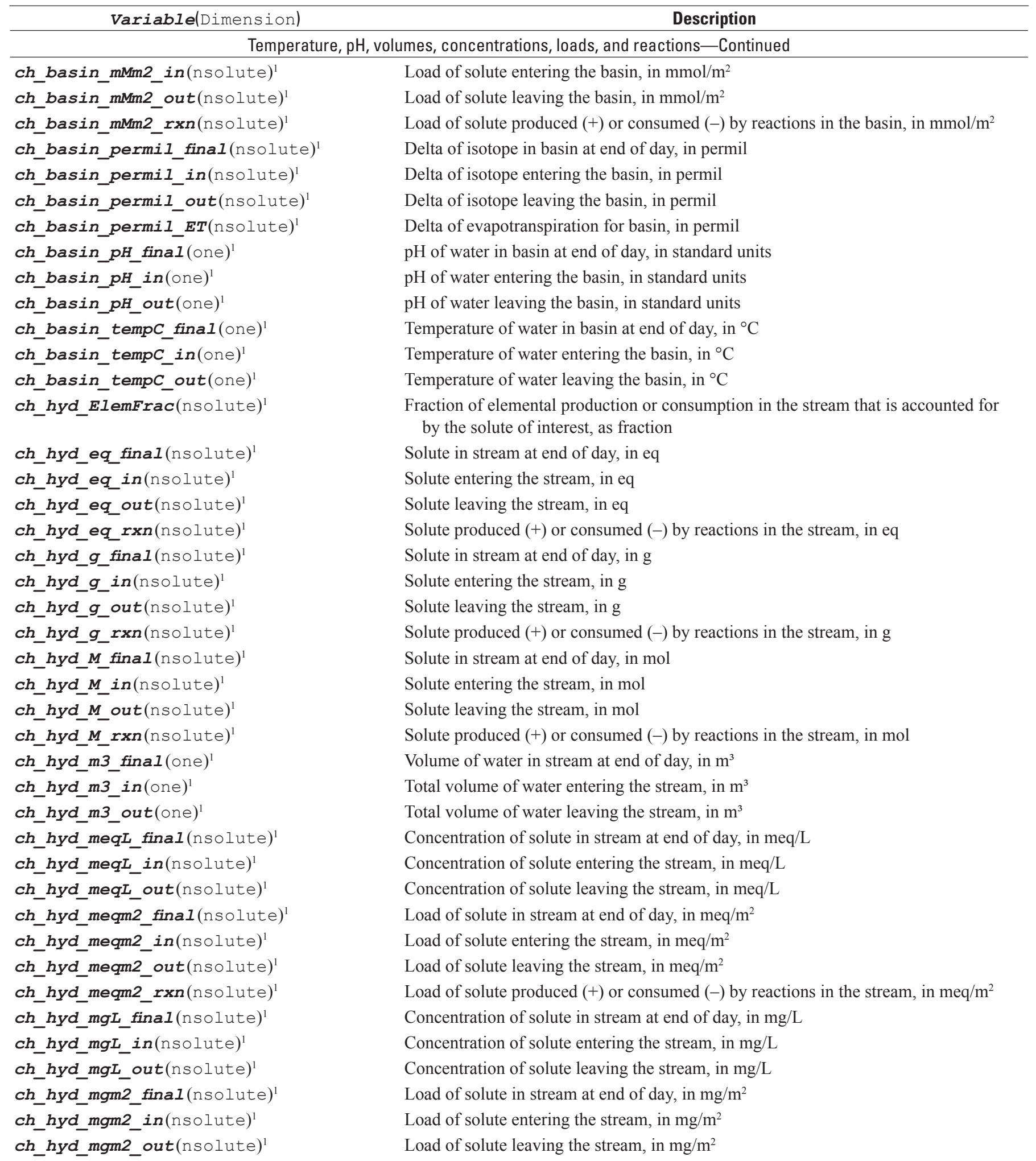


Table 3. Variables, categorized by property, observation, and process in the Water, Energy, and Biogeochemical Model (WEBMOD). -Continued

[All variables not listed in the first block as static are dynamic, potentially having a different value each day. The formatting convention used in this report is to present file names in italic font, dimension names in Courier New font, variable names in bold italic Courier New font, and parameter names in bold Courier New font. Names and descriptions of all dimensions are presented in table 1; names and descriptions of all parameters are presented in table 2.

$\mathrm{mg} / \mathrm{m}^{2}$, milligram per square meter; $\mathrm{mmol} / \mathrm{L}$, millimole per liter; $\mathrm{mmol} / \mathrm{m}^{2}$, millimole per square meter; ${ }^{\circ} \mathrm{C}$, degree Celsius; MRU, model response unit; eq, equivalent; g, gram; mol, mole; ET, evapotranspiration; $\mathrm{m}^{3}$, cubic meter; meq $/ \mathrm{L}$, milliequivalent per liter; meq $/ \mathrm{m}^{2}$, milliequivalent per square meter]

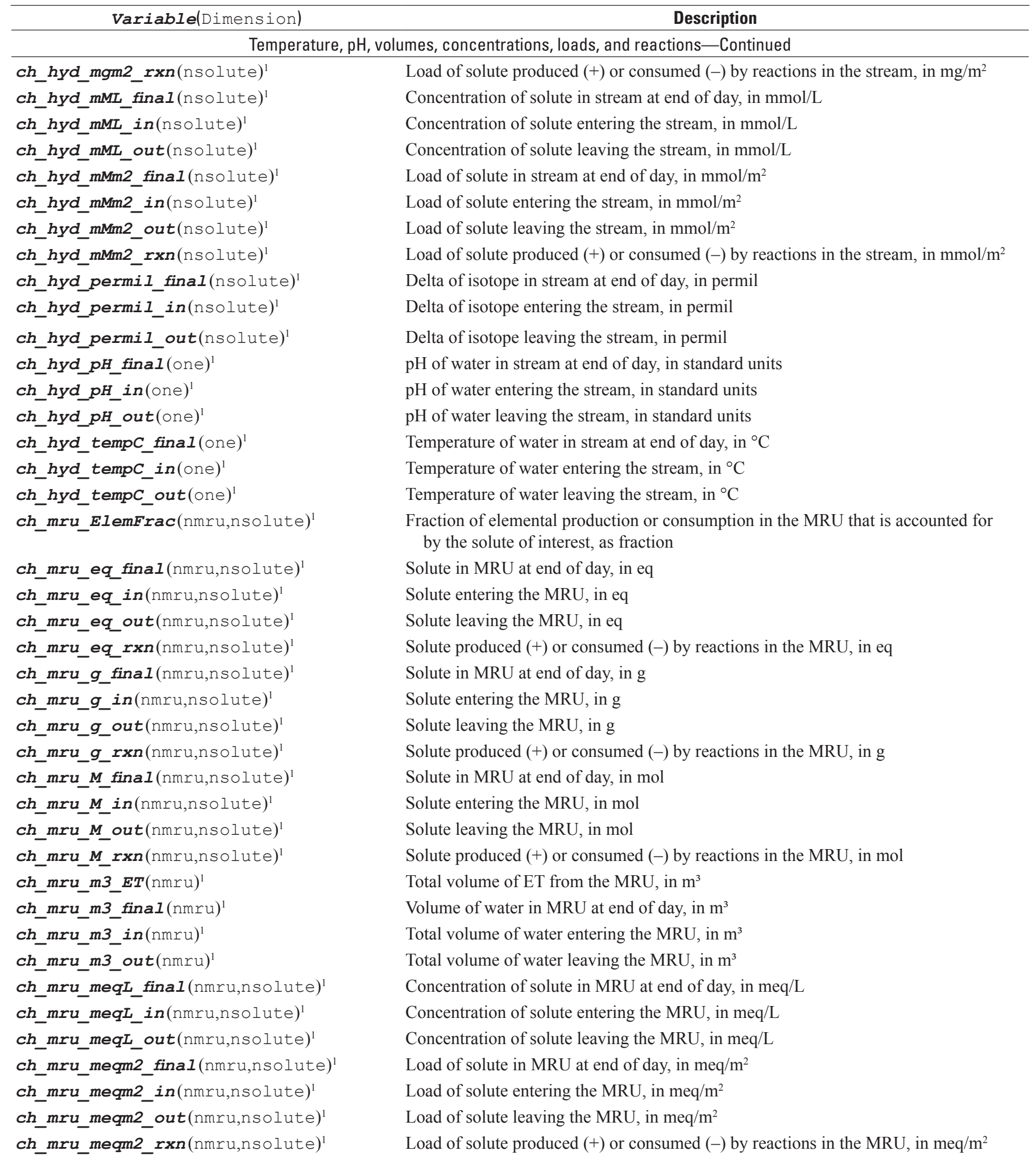


Table 3. Variables, categorized by property, observation, and process in the Water, Energy, and Biogeochemical Model (WEBMOD). -Continued

[All variables not listed in the first block as static are dynamic, potentially having a different value each day. The formatting convention used in this report is to present file names in italic font, dimension names in Courier New font, variable names in bold italic Courier New font, and parameter names in bold Courier New font. Names and descriptions of all dimensions are presented in table 1; names and descriptions of all parameters are presented in table 2.

$\mathrm{MRU}$, model response unit; $\mathrm{mg} / \mathrm{L}$, milligram per liter; $\mathrm{mg} / \mathrm{m}^{2}$, milligram per square meter; $\mathrm{mmol} / \mathrm{L}$, millimole per liter; ${ }^{\circ} \mathrm{C}$, degree Celsius; eq, equivalent; g, gram; mol, mole; $\mathrm{m}^{3}$, cubic meter; meq $/ \mathrm{L}$, milliequivalent per liter; $\mathrm{meq} / \mathrm{m}^{2}$, milliequivalent per square meter; $\mathrm{mmol} / \mathrm{m}^{2}$, millimole per square meter; UZ, unsaturated zone]

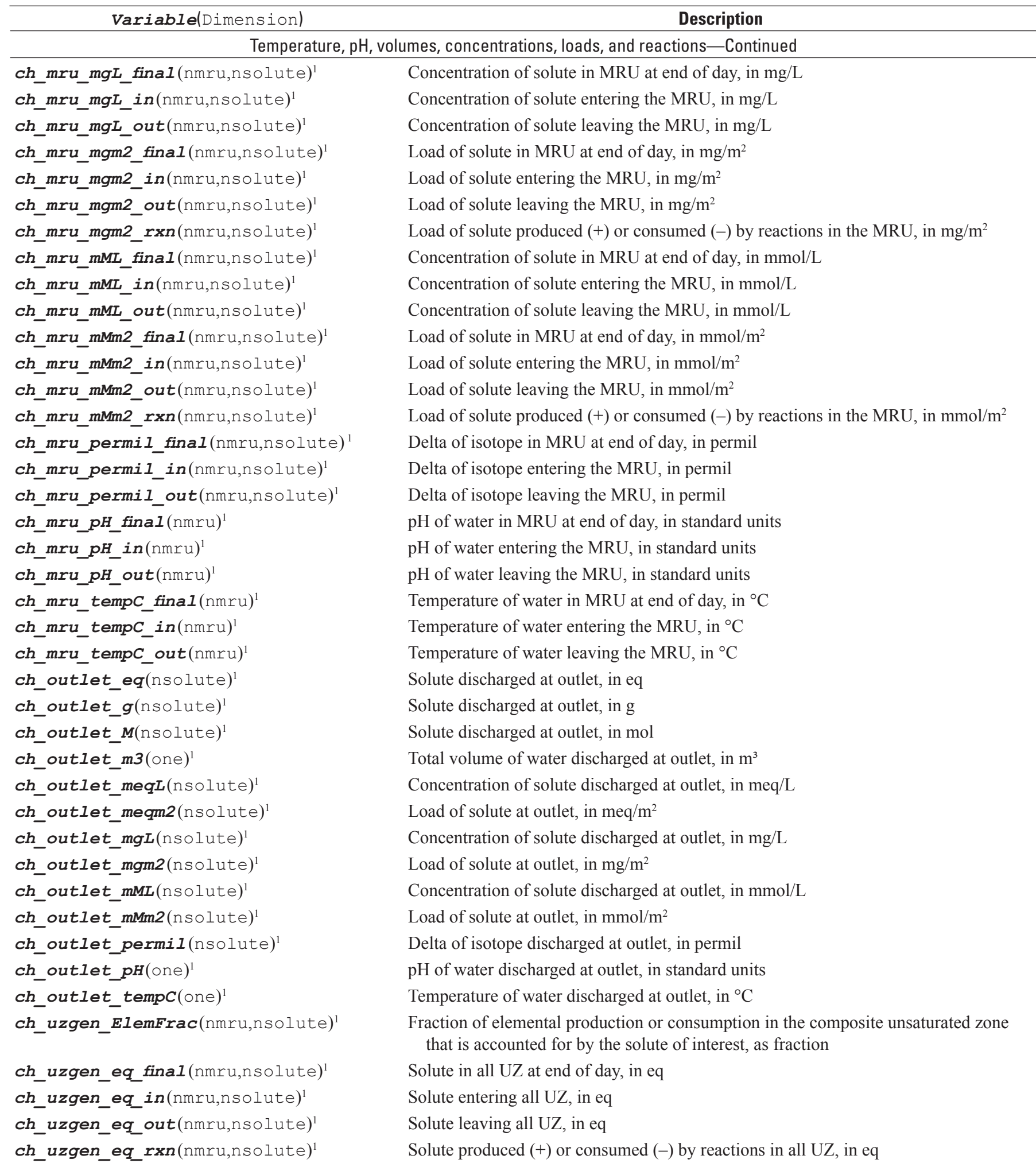


Table 3. Variables, categorized by property, observation, and process in the Water, Energy, and Biogeochemical Model (WEBMOD). -Continued

[All variables not listed in the first block as static are dynamic, potentially having a different value each day. The formatting convention used in this report is to present file names in italic font, dimension names in Courier New font, variable names in bold italic Courier New font, and parameter names in bold Courier New font. Names and descriptions of all dimensions are presented in table 1; names and descriptions of all parameters are presented in table 2.

UZ, unsaturated zone; g, gram; mol, mole; ET, evapotranspiration; $\mathrm{m}^{3}$, cubic meter; meq/L, milliequivalent per liter; meq $/ \mathrm{m}^{2}$, milliequivalent per square meter; $\mathrm{mg} / \mathrm{L}$, milligram per liter; $\mathrm{mg} / \mathrm{m}^{2}$, milligram per square meter; $\mathrm{mmol} / \mathrm{L}$, millimole per liter; $\mathrm{mmol} / \mathrm{m}^{2}$, millimole per square meter; ${ }^{\circ} \mathrm{C}$, degree Celsius]

\begin{tabular}{|c|c|}
\hline Variable(Dimension) & Description \\
\hline \multicolumn{2}{|c|}{ Temperature, pH, volumes, concentrations, loads, and reactions-Continued } \\
\hline ch_uzgen_g_final (nmru,nsolute $)^{1}$ & Solute in all UZ at end of day, in $g$ \\
\hline ch_uzgen_g_out(nmru,nsolute $)^{1}$ & Solute leaving all $\mathrm{UZ}$, in $\mathrm{g}$ \\
\hline ch_uzgen_g_rxn (nmru,nsolute $)^{1}$ & Solute produced $(+)$ or consumed $(-)$ by reactions in all $\mathrm{UZ}$, in $\mathrm{g}$ \\
\hline ch_uzgen_M_final(nmru,nsolute $)^{1}$ & Solute in all UZ at end of day, in mol \\
\hline ch_uzgen_M_out (nmru,nsolute $)^{1}$ & Solute leaving all UZ, in mol \\
\hline ch_uzgen_M_rxn (nmru,nsolute $)^{1}$ & Solute produced $(+)$ or consumed $(-)$ by reactions in all UZ, in mol \\
\hline ch_uzgen_m3_ET $(\mathrm{nmru})^{1}$ & Total volume of ET from all $\mathrm{UZ}$, in $\mathrm{m}^{3}$ \\
\hline ch_uzgen_m3_final $(\mathrm{nmru})^{1}$ & Volume of water in all $\mathrm{UZ}$ at end of day, in $\mathrm{m}^{3}$ \\
\hline ch_uzgen_m3_in $(\mathrm{nmru})^{1}$ & Total volume of water entering all $\mathrm{UZ}$, in $\mathrm{m}^{3}$ \\
\hline ch_uzgen_meqL_out(nmru,nsolute $)^{1}$ & Concentration of solute leaving all $\mathrm{UZ}$, in meq/L \\
\hline ch_uzgen_meqm2_final (nmru,nsolute $)^{1}$ & Load of solute in all UZ at end of day, in meq $/ \mathrm{m}^{2}$ \\
\hline ch_uzgen_meqm2_in(nmru,nsolute $)^{1}$ & Load of solute entering all $\mathrm{UZ}$, in $\mathrm{meq} / \mathrm{m}^{2}$ \\
\hline ch_uzgen_meqm2_out (nmru,nsolute $)^{1}$ & Load of solute leaving all $\mathrm{UZ}$, in $\mathrm{meq} / \mathrm{m}^{2}$ \\
\hline ch_uzgen_meqm2_rxn(nmru,nsolute $)^{1}$ & Load of solute produced $(+)$ or consumed $(-)$ by reactions in all $\mathrm{UZ}$, in $\mathrm{meq} / \mathrm{m}^{2}$ \\
\hline ch_uzgen_mgL_final (nmru,nsolute $)^{1}$ & Concentration of solute in all $\mathrm{UZ}$ at end of day, in $\mathrm{mg} / \mathrm{L}$ \\
\hline ch_uzgen_mgL_in (nmru,nsolute $)^{1}$ & Concentration of solute entering all $\mathrm{UZ}$, in $\mathrm{mg} / \mathrm{L}$ \\
\hline ch_uzgen_mgL_out(nmru,nsolute $)^{1}$ & Concentration of solute leaving all $\mathrm{UZ}$, in $\mathrm{mg} / \mathrm{L}$ \\
\hline ch_uzgen_mgm2_final(nmru,nsolute $)^{1}$ & Load of solute in all $\mathrm{UZ}$ at end of day, in $\mathrm{mg} / \mathrm{m}^{2}$ \\
\hline ch_uzgen_mMm2_final(nmru,nsolute $)^{1}$ & Load of solute in all $\mathrm{UZ}$ at end of day, in $\mathrm{mmol} / \mathrm{m}^{2}$ \\
\hline ch_uzgen_mMm2_in(nmru,nsolute $)^{1}$ & Load of solute entering all $\mathrm{UZ}$, in $\mathrm{mmol} / \mathrm{m}^{2}$ \\
\hline ch_uzgen_mMm2_out(nmru,nsolute $)^{1}$ & Load of solute leaving all $\mathrm{UZ}$, in $\mathrm{mmol} / \mathrm{m}^{2}$ \\
\hline ch_uzgen_mMm2_rxn(nmru,nsolute $)^{1}$ & Load of solute produced $(+)$ or consumed $(-)$ by reactions in all $\mathrm{UZ}$, in $\mathrm{mmol} / \mathrm{m}^{2}$ \\
\hline ch_uzgen_permil_final (nmru,nsolute $)^{1}$ & Delta of isotope in all UZ at end of day, in permil \\
\hline ch_uzgen_permil_in (nmru,nsolute $)^{1}$ & Delta of isotope entering all UZ, in permil \\
\hline ch_uzgen_permil_out $(\mathrm{nmru}, \mathrm{nsolute})^{1}$ & Delta of isotope leaving all UZ, in permil \\
\hline$c h \_u z g e n \_p H \_f i n a l(\mathrm{nmru})^{1}$ & $\mathrm{pH}$ of water in all $\mathrm{UZ}$ at end of day, in standard units \\
\hline$c h \_u z g e n \_p H \_i n(\mathrm{nmru})^{1}$ & $\mathrm{pH}$ of water entering all UZ, in standard units \\
\hline$c h \_u z g e n \_p H \_o u t(\mathrm{nmru})^{1}$ & $\mathrm{pH}$ of water leaving all UZ, in standard units \\
\hline ch_uzgen_tempC_final $(\mathrm{nmru})^{1}$ & Temperature of water in all $\mathrm{UZ}$ at end of day, in ${ }^{\circ} \mathrm{C}$ \\
\hline ch_uzgen_tempC_in $(\mathrm{nmru})^{1}$ & Temperature of water entering all $\mathrm{UZ}$, in ${ }^{\circ} \mathrm{C}$ \\
\hline
\end{tabular}


Table 3. Variables, categorized by property, observation, and process in the Water, Energy, and Biogeochemical Model (WEBMOD). -Continued

[All variables not listed in the first block as static are dynamic, potentially having a different value each day. The formatting convention used in this report is to present file names in italic font, dimension names in Courier New font, variable names in bold italic Courier New font, and parameter names in bold Courier New font. Names and descriptions of all dimensions are presented in table 1; names and descriptions of all parameters are presented in table 2.

$\mathrm{UZ}$, unsaturated zone; ${ }^{\circ} \mathrm{C}$, degree Celsius; eq, equivalent; g, gram; mol, mole; $\mathrm{m}^{3}$, cubic meter; meq $/ \mathrm{L}$, milliequivalent per liter; meq $/ \mathrm{m}^{2}$, milliequivalent per square meter; $\mathrm{mg} / \mathrm{L}$, milligram per liter; $\mathrm{mg} / \mathrm{m}^{2}$, milligram per square meter; $\mathrm{mmol} / \mathrm{L}$, millimole per liter; $\mathrm{mmol} / \mathrm{m}^{2}$, millimole per square meter]

\begin{tabular}{|c|c|}
\hline Variable(Dimension) & Description \\
\hline \multicolumn{2}{|c|}{ Temperature, $\mathrm{pH}$, volumes, concentrations, loads, and reactions-Continued } \\
\hline ch_uzgen_tempC_out $(\mathrm{nmru})^{1}$ & Temperature of water leaving all $\mathrm{UZ}$, in ${ }^{\circ} \mathrm{C}$ \\
\hline ch_uzrip_eq_final (nmru,nsolute $)^{1}$ & Solute in riparian $\mathrm{UZ}$ at end of day, in eq \\
\hline ch_uzrip_eq_in(nmru,nsolute $)^{1}$ & Solute entering the riparian $\mathrm{UZ}$, in eq \\
\hline ch_uzrip_eq_rxn(nmru,nsolute $)^{1}$ & Solute produced $(+)$ or consumed $(-)$ by reactions in the riparian UZ, in eq \\
\hline ch_uzrip_g_final(nmru,nsolute $)^{1}$ & Solute in riparian $\mathrm{UZ}$ at end of day, in $\mathrm{g}$ \\
\hline ch_uzrip_g_in(nmru,nsolute $)^{1}$ & Solute entering the riparian $\mathrm{UZ}$, in $\mathrm{g}$ \\
\hline ch_uzrip_g_out(nmru,nsolute $)^{1}$ & Solute leaving the riparian $\mathrm{UZ}$, in $\mathrm{g}$ \\
\hline ch_uzrip_g_rxn(nmru,nsolute $)^{1}$ & Solute produced $(+)$ or consumed $(-)$ by reactions in the riparian $U Z$, in $g$ \\
\hline ch_uzrip_M_rxn(nmru,nsolute $)^{1}$ & Solute produced $(+)$ or consumed $(-)$ by reactions in the riparian UZ, in mol \\
\hline Ch_uzrip_m3_ET(nmru $)^{1}$ & Total volume of ET from the riparian $\mathrm{UZ}$, in $\mathrm{m}^{3}$ \\
\hline ch_uzrip_m3_final $(\mathrm{nmru})^{1}$ & Volume of water in riparian $\mathrm{UZ}$ at end of day, in $\mathrm{m}^{3}$ \\
\hline ch_uzrip_m3_in $(\mathrm{nmru})^{1}$ & Total volume of water entering the riparian $\mathrm{UZ}$, in $\mathrm{m}^{3}$ \\
\hline ch_uzrip_m3_out $(\mathrm{nmru})^{1}$ & Total volume of water leaving the riparian UZ, in $\mathrm{m}^{3}$ \\
\hline ch_uzrip_meqL_final(nmru,nsolute $)^{1}$ & Concentration of solute in riparian $\mathrm{UZ}$ at end of day, in meq/L \\
\hline ch_uzrip_meqL_in (nmru, nsolute $)^{1}$ & Concentration of solute entering the riparian $\mathrm{UZ}$, in meq/L \\
\hline ch_uzrip_meqL_out (nmru,nsolute $)^{1}$ & Concentration of solute leaving the riparian $\mathrm{UZ}$, in meq/L \\
\hline ch_uzrip_meqm2_final(nmru,nsolute $)^{1}$ & Load of solute in riparian $\mathrm{UZ}$ at end of day, in $\mathrm{meq} / \mathrm{m}^{2}$ \\
\hline ch_uzrip_mgm2_in(nmru,nsolute $)^{1}$ & Load of solute entering the riparian $\mathrm{UZ}$, in $\mathrm{mg} / \mathrm{m}^{2}$ \\
\hline ch_uzrip_mgm2_out(nmru,nsolute $)^{1}$ & Load of solute leaving the riparian $\mathrm{UZ}$, in $\mathrm{mg} / \mathrm{m}^{2}$ \\
\hline ch_uzrip_mgm2_rxn(nmru,nsolute $)^{1}$ & Load of solute produced $(+)$ or consumed $(-)$ by reactions in the riparian UZ, in $\mathrm{mg} / \mathrm{m}^{2}$ \\
\hline ch_uzrip_mML_final(nmru,nsolute $)^{1}$ & Concentration of solute in riparian $\mathrm{UZ}$ at end of day, in $\mathrm{mmol} / \mathrm{L}$ \\
\hline ch_uzrip_mML_in(nmru,nsolute $)^{1}$ & Concentration of solute entering the riparian $\mathrm{UZ}$, in $\mathrm{mmol} / \mathrm{L}$ \\
\hline ch_uzrip_mML_out $(\mathrm{nmru}, \mathrm{nsolute})^{1}$ & Concentration of solute leaving the riparian $\mathrm{UZ}$, in $\mathrm{mmol} / \mathrm{L}$ \\
\hline ch_uzrip_mMm2_final(nmru,nsolute $)^{1}$ & Load of solute in riparian $\mathrm{UZ}$ at end of day, in $\mathrm{mmol} / \mathrm{m}^{2}$ \\
\hline ch_uzrip_mMm2_in (nmru,nsolute $)^{1}$ & Load of solute entering the riparian $\mathrm{UZ}$, in $\mathrm{mmol} / \mathrm{m}^{2}$ \\
\hline ch_uzrip_mMm2_out(nmru,nsolute $)^{1}$ & Load of solute leaving the riparian $\mathrm{UZ}$, in $\mathrm{mmol} / \mathrm{m}^{2}$ \\
\hline ch_uzrip_mMm2_rxn(nmru,nsolute $)^{1}$ & Load of solute produced $(+)$ or consumed $(-)$ by reactions in the riparian $\mathrm{UZ}$, in $\mathrm{mmol} / \mathrm{m}^{2}$ \\
\hline ch_uzrip_permil_final(nmru,nsolute) ${ }^{1}$ & Delta of isotope in riparian $\mathrm{UZ}$ at end of day, in permil \\
\hline ch_uzrip_permil_in(nmru,nsolute $)^{1}$ & Delta of isotope entering the riparian UZ, in permil \\
\hline
\end{tabular}


Table 3. Variables, categorized by property, observation, and process in the Water, Energy, and Biogeochemical Model (WEBMOD). -Continued

[All variables not listed in the first block as static are dynamic, potentially having a different value each day. The formatting convention used in this report is to present file names in italic font, dimension names in Courier New font, variable names in bold italic Courier New font, and parameter names in bold Courier New font. Names and descriptions of all dimensions are presented in table 1; names and descriptions of all parameters are presented in table 2.

UZ, unsaturated zone; ${ }^{\circ} \mathrm{C}$, degree Celsius; eq, equivalent; g, gram; mol, mole; $\mathrm{m}^{3}$, cubic meter; meq/L, milliequivalent per liter; meq $/ \mathrm{m}^{2}$, milliequivalent per square meter; $\mathrm{mg} / \mathrm{L}$, milligram per liter; $\mathrm{mg} / \mathrm{m}^{2}$, milligram per square meter; $\mathrm{mmol} / \mathrm{L}$, millimole per liter]

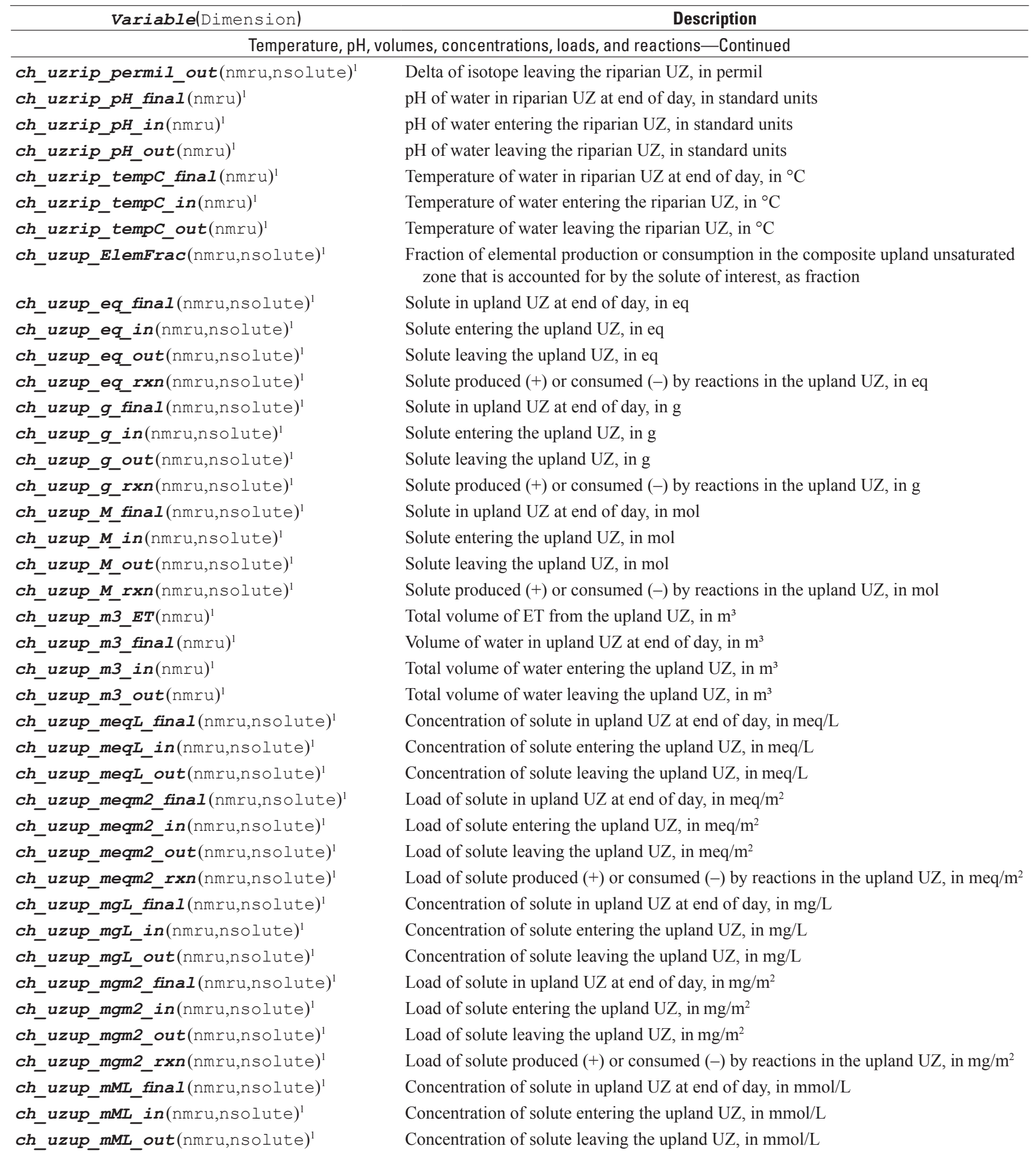


Table 3. Variables, categorized by property, observation, and process in the Water, Energy, and Biogeochemical Model (WEBMOD). -Continued

[All variables not listed in the first block as static are dynamic, potentially having a different value each day. The formatting convention used in this report is to present file names in italic font, dimension names in Courier New font, variable names in bold italic Courier New font, and parameter names in bold Courier New font. Names and descriptions of all dimensions are presented in table 1; names and descriptions of all parameters are presented in table 2.

UZ, unsaturated zone; $\mathrm{mmol} / \mathrm{m}^{2}$, millimole per square meter; ${ }^{\circ} \mathrm{C}$, degree Celsius; $\mathrm{m}^{3}$, cubic meter; c_units(nchemvar), user-selectable unit]

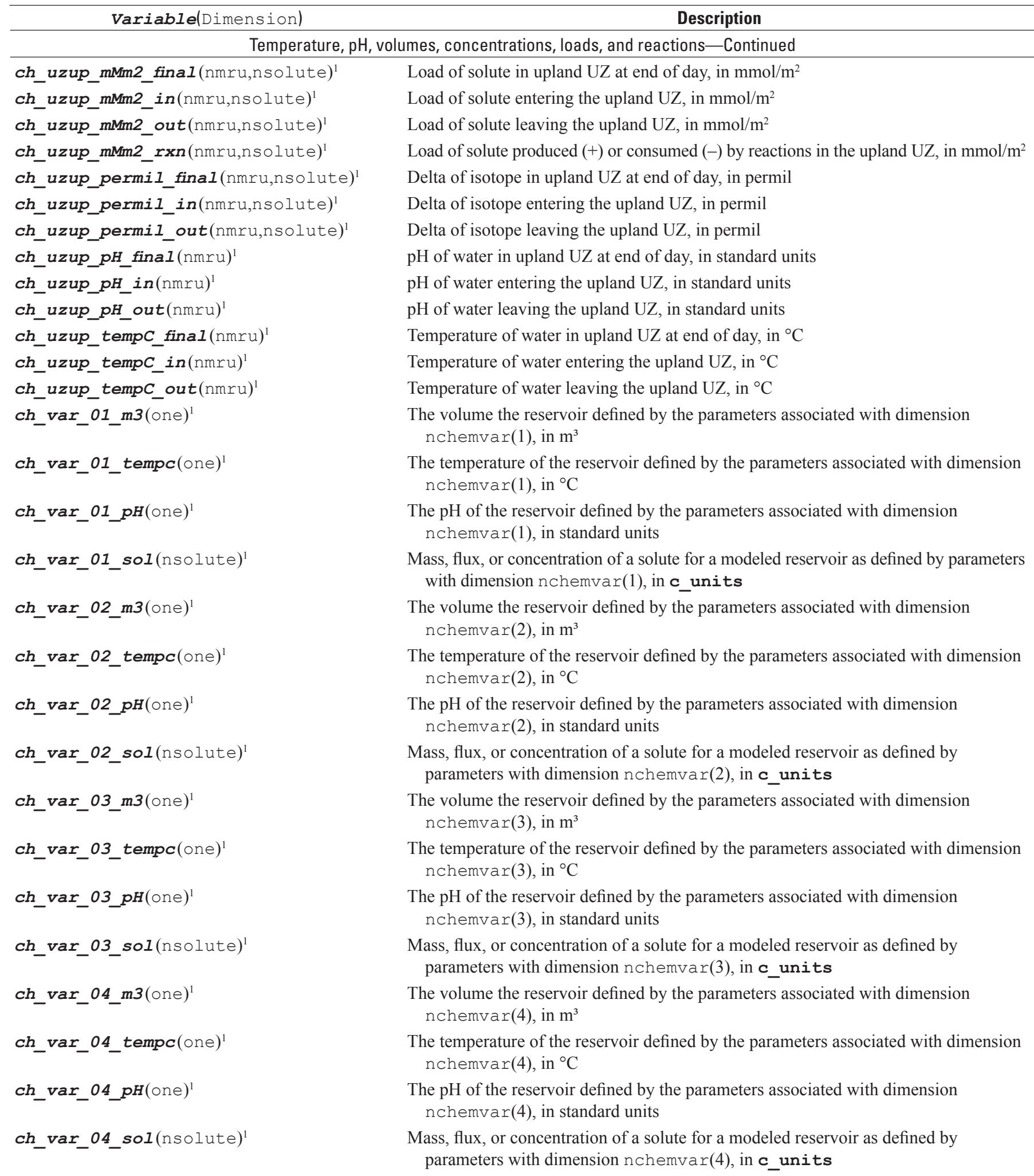


Table 3. Variables, categorized by property, observation, and process in the Water, Energy, and Biogeochemical Model (WEBMOD). -Continued

[All variables not listed in the first block as static are dynamic, potentially having a different value each day. The formatting convention used in this report is to present file names in italic font, dimension names in Courier New font, variable names in bold italic Courier New font, and parameter names in bold Courier New font. Names and descriptions of all dimensions are presented in table 1; names and descriptions of all parameters are presented in table 2.

$\mathrm{m}^{3}$, cubic meter; ${ }^{\circ} \mathrm{C}$, degree Celsius; c_units(nchemvar), user-selectable unit]

\begin{tabular}{|c|c|}
\hline Variable(Dimension) & Description \\
\hline \multicolumn{2}{|c|}{ Temperature, $\mathrm{pH}$, volumes, concentrations, loads, and reactions-Continued } \\
\hline ch_var_05_m3 $(o n e)^{1}$ & $\begin{array}{l}\text { The volume the reservoir defined by the parameters associated with dimension } \\
\text { nchemvar(5), in } \mathrm{m}^{3}\end{array}$ \\
\hline ch_var_05_tempc $(o n e)^{1}$ & $\begin{array}{l}\text { The temperature of the reservoir defined by the parameters associated with dimension } \\
\text { nchemvar }(5) \text {, in }{ }^{\circ} \mathrm{C}\end{array}$ \\
\hline$c h \_v a r \_05 \_p H(o n e)^{1}$ & $\begin{array}{l}\text { The } \mathrm{pH} \text { of the reservoir defined by the parameters associated with dimension } \\
\text { nchemvar(5), in standard units }\end{array}$ \\
\hline ch_var_06_m3 $(o n e)^{1}$ & $\begin{array}{l}\text { The volume the reservoir defined by the parameters associated with dimension } \\
\text { nchemvar(6), in } \mathrm{m}^{3}\end{array}$ \\
\hline ch_var_06_tempc $(o n e)^{1}$ & $\begin{array}{l}\text { The temperature of the reservoir defined by the parameters associated with dimension } \\
\text { nchemvar }(6) \text {, in }{ }^{\circ} \mathrm{C}\end{array}$ \\
\hline ch_var_07_m3(one $)^{1}$ & $\begin{array}{l}\text { The volume the reservoir defined by the parameters associated with dimension } \\
\text { nchemvar(7), in } \mathrm{m}^{3}\end{array}$ \\
\hline ch_var_07_tempc $(\text { one })^{1}$ & $\begin{array}{l}\text { The temperature of the reservoir defined by the parameters associated with dimension } \\
\text { nchemvar }(7) \text {, in }{ }^{\circ} \mathrm{C}\end{array}$ \\
\hline ch_var_07_pH(one $)^{1}$ & $\begin{array}{l}\text { The } \mathrm{pH} \text { of the reservoir defined by the parameters associated with dimension } \\
\text { nchemvar(7), in standard units }\end{array}$ \\
\hline ch_var_07_sol(nsolute) ${ }^{1}$ & $\begin{array}{l}\text { Mass, flux, or concentration of a solute for a modeled reservoir as defined by } \\
\text { parameters with dimension nchemvar(7), in c_units }\end{array}$ \\
\hline ch_var_08_m3 $(o n e)^{1}$ & $\begin{array}{l}\text { The volume the reservoir defined by the parameters associated with dimension } \\
\text { nchemvar(8), in } \mathrm{m}^{3}\end{array}$ \\
\hline ch_var_09_tempc $(\text { one })^{1}$ & $\begin{array}{l}\text { The temperature of the reservoir defined by the parameters associated with dimension } \\
\text { nchemvar }(9) \text {, in }{ }^{\circ} \mathrm{C}\end{array}$ \\
\hline ch_var_09_pH(one $)^{1}$ & $\begin{array}{l}\text { The } \mathrm{pH} \text { of the reservoir defined by the parameters associated with dimension } \\
\text { nchemvar(9), in standard units }\end{array}$ \\
\hline ch_var_09_sol(nsolute) ${ }^{1}$ & $\begin{array}{l}\text { Mass, flux, or concentration of a solute for a modeled reservoir as defined by } \\
\text { parameters with dimension nchemvar(9), in c_units }\end{array}$ \\
\hline ch_var_10_m3 $(\mathrm{one})^{1}$ & $\begin{array}{l}\text { The volume the reservoir defined by the parameters associated with dimension } \\
\text { nchemvar(10), in } \mathrm{m}^{3}\end{array}$ \\
\hline ch_var_10_tempc $(o n e)^{1}$ & $\begin{array}{l}\text { The temperature of the reservoir defined by the parameters associated with dimension } \\
\text { nchemvar(10), in }{ }^{\circ} \mathrm{C}\end{array}$ \\
\hline ch_var_10_pH(one $)^{1}$ & $\begin{array}{l}\text { The } \mathrm{pH} \text { of the reservoir defined by the parameters associated with dimension } \\
\text { nchemvar(10), in standard units }\end{array}$ \\
\hline
\end{tabular}


Table 3. Variables, categorized by property, observation, and process in the Water, Energy, and Biogeochemical Model (WEBMOD). - Continued

[All variables not listed in the first block as static are dynamic, potentially having a different value each day. The formatting convention used in this report is to present file names in italic font, dimension names in Courier New font, variable names in bold italic Courier New font, and parameter names in bold Courier New font. Names and descriptions of all dimensions are presented in table 1; names and descriptions of all parameters are presented in table 2.

c_units(nchemvar), user-selectable unit; ${ }^{\circ} \mathrm{C}$, degree Celsius; UZ, unsaturated zone; mol, mole; $\mathrm{m}^{3}$, cubic meter]

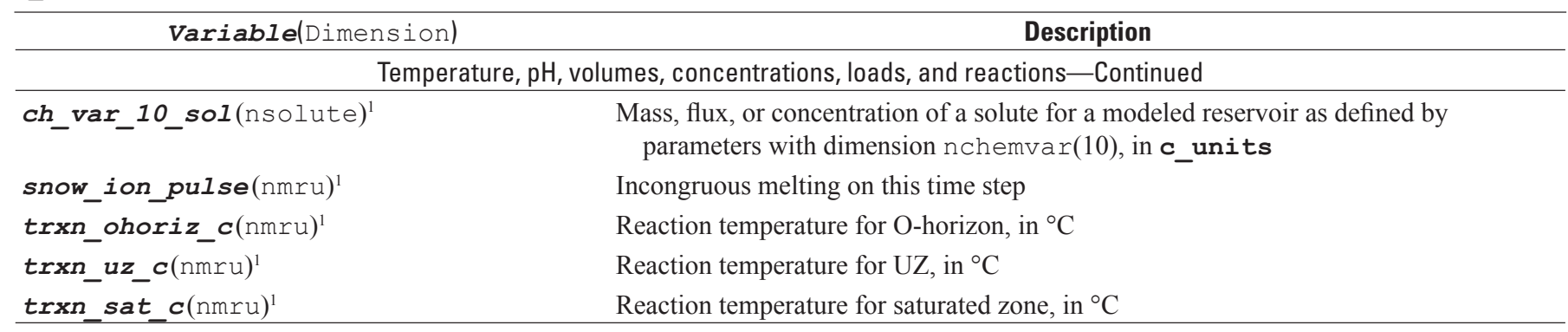

Cumulative geochemical basin summaries

[Most of the following variables are vectors of length 5 with unit values averaged or accumulated for time step of (1) event, (2) day, (3) month, (4) year, or (5) entire run]

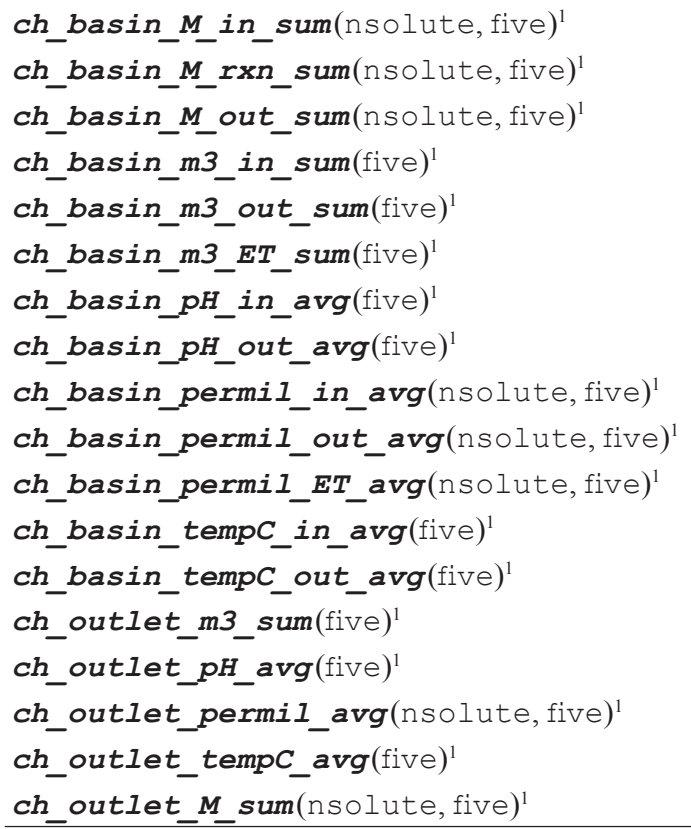

${ }^{1}$ Available when nsolute, the number of solutes tracked, is not equal to zero.

${ }^{2}$ Available when nobs, the number of discharge records, is not equal to zero.

${ }^{3}$ Available when nsnow, the number of snow measurement stations, is not equal to zero.

${ }^{4}$ Available when nevap, the number of pan evaporation stations, is not equal to zero.

${ }^{5}$ Available when nsol, the number of solar radiation stations, is not equal to zero. The dimension nsol has a maximum size of one.

${ }^{6}$ Available when nsolute, the number of solutes, and nhum, the number of humidity stations, chemically unique external sources, are both not zero.

${ }^{7}$ Available when nirrig_int, the number of internal irrigation sources, is not equal to zero.

${ }^{8}$ Available when nsolute, the number of solutes, and nchemobs, the number of unique chemical sampling sites, are both not zero.

${ }^{9}$ Available when nsolute, the number of solutes, and nchem_ext, the number of chemically unique external sources, are both not zero.

${ }^{10}$ Available when nsolute, the number of solutes, and nirrig_ext, the number of unique application rates from external irrigation sources, are both not zero.

${ }^{11}$ Impervious surfaces not active in this version of WEBMOD.

${ }^{12}$ Available when ngw_ext, the number of unique flux rates from external groundwater sources, is not equal to zero.

${ }^{13}$ Available when nirrig_ext, the number of unique application rates from external irrigation sources, is not equal to zero. 
This manual uses shorthand to describe generic and explicit assignments of values to parameters and variables. Parameters and variables are qualified with the dimension name in parentheses at the first mention and whenever used generically. For example, irrig_sched_ext(nmru) is the parameter (with dimension nmru) that links an MRU to one of nirrig_ext irrigation schedules in the hydrologic data file. To reference an array element, an instance number beginning with $i$ will be used in this report; for example, imru will refer to a specific MRU number. When parameter assignments of multiple MRUs to a single schedule are made, the set of specific MRUs will be listed as a set; for example,irrig_sched_ext $(i m r u=1,3-5,10)=2$ means that MRUs $1,3, \overline{4}, 5$, and $\overline{10}$ are assigned irrigation depths from the second irrigation schedule in the hydrologic data file. Similarly, the parameter tmax_lapse(nmonths), which describes lapse rates in degrees Celsius per kilometer $\left({ }^{\circ} \mathrm{C} / \mathrm{km}\right)$, has an array element for each month. An assignment of tmax_lapse(imonths $=1-12)=9.0$ assigns a lapse rate of $9^{\circ} \mathrm{C} / \mathrm{km}$ for all months of the simulation. Similarly, a request for time series and statistics for the chloride concentration of discharge from the 15th hillslope in the DR2 model (which has only one solute) would reference ch_mru_mgL_out(imru=15, isolute=1). Dimension qualifications for specific variables are described in ASCII characters in the control file; for this example, the entry in the section of "statVar_names" would be "ch_mru_mgL_out," and the entry in the section "statVar_element" would be " $15,1 . "$

\section{Units}

Metric units are the preferred units for WEBMOD outputs. As might be expected when coupling process modules from disparate sources, English units might be required by one module and metric units by another; precipitation in inches and soil-moisture deficit in meters are an example. To minimize errors resulting from unit conversions, process routines that use English units are provided inputs in their native units, and their outputs are converted to metric units after completion. Daily minimum and maximum temperatures are provided in the hydrologic data file as either degrees Fahrenheit $\left({ }^{\circ} \mathrm{F}\right)$ [tsta_min_f(ntemp) and tsta_max_f(ntemp)] or degrees $\bar{C}$ elsius $\left({ }^{\circ} \mathrm{C}\right)$ [tsta_min_c(ntemp) and tsta_max_c(ntemp)] and are available to modules in both

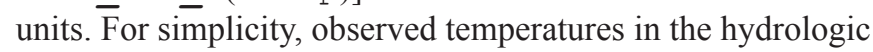
data file are degrees Celsius units in this manual.

The native unit for solute concentrations in PHREEQC is molality (moles per kilogram of water), which is nearly equal to molarity (moles per liter) for the dilute waters common in the surface waters of a watershed. By using gram molecular weights and valence states defined in the phreeq_lut file, users may input and request output in other concentration units including milligrams per liter $(\mathrm{mg} / \mathrm{L})$, milliequivalents per liter $(\mathrm{meq} / \mathrm{L})$, millimoles per liter $(\mathrm{mmol} / \mathrm{L})$, and permil (oxygen-18 and deuterium). Loads in milligrams per square meter $\left(\mathrm{mg} / \mathrm{m}^{2}\right)$ or milliequivalents per square meter $\left(\mathrm{meq} / \mathrm{m}^{2}\right)$ are computed by normalizing with area (hillslope, canopy, or SCA). User-defined conversion factors can also be assigned to convert concentrations; in this way, nitrate could be converted from the reported value in milligrams per liter as nitrogen $(\mathrm{N})$ to milligrams per liter as nitrate $\left(\mathrm{NO}_{3}\right)$.

\section{Input Files}

Simulations of hydrologic processes in the WEBMOD require three files - a control file (webmod.control), a hydrologic data file (webmod.hydro.dat), and the parameter file (webmod.params). Simulations of the aqueous geochemistry require three more input files - a PHREEQC database file (phreeqc_web_lite.dat), a PHREEQC solutes lookup table that defines all possible solutes of interest (phreeq_lut), and a PHREEQC input file that defines initial solutions and geochemical reactants (webmod.pqi). If observations of water quality are available, or if the solute concentrations of precipitation and irrigation change during the model run, then an additional file, the solute data file (webmod.chem.dat), is needed. Brief descriptions of each input file follow in the next sections and detailed descriptions of specific input files are included with the two examples.

\section{Control File (webmod.control)}

A WEBMOD control file, typically named $<$ basin $>\mid$ control webmod.control, describes the period to be simulated, the names of data and parameter files, and specifications for standard and custom output of selected public variables. Path names in the control file may be specified as absolute (beginning with a drive letter) or relative (beginning with a period and a slash) to the directory where the model is run (usually the $<$ basin $>$ directory). If a project directory is moved to a new location and absolute paths are used, these paths must be edited. The control files in the two examples use relative paths such that the first step in creating a new model could entail copying the $<$ basin $>$ directory of a similar model and then editing the content of the control, parameter, and data files to correspond to the basin of interest.

The name of the control file can be specified on the command line used to execute WEBMOD. For example, the user can begin a batch run of the simulation from the $<$ basin $>$ directory by executing webmod.bat for a batch run or webmod_gui.bat for an interactive run using the MMS Tool GUI. The batch files webmod.bat and webmod_gui.bat can be edited when an existing project is copied to a new directory. When executed, webmod.bat runs the WEBMOD executable with the name of the control file following the flag "-C," as follows: 


\section{..\..\bin\webmod -C.\control \\ webmod. control.}

If no control-file name is given with the -C option, MMS will look for a control file named webmod.control in the user's current directory. Additional self-documentation is provided in the file $<$ basin $>\mid$ control $\mid$ webmod.control.par_name for parameters and the file < basin $>\mid$ controllwebmod.control.var_name for variables; both files are created in the |controll directory with each run or if the $<$ basin $>$ |webmod print.bat file is executed.

\section{Hydrologic Data File (webmod.hydro.dat)}

The name webmod.hydro.dat is set with the parameter data_file in webmod.control. To simulate hydrologic processes, the hydrologic data file $<$ basin $>\mid$ input $\mid$ webmod.hydro.dat must contain a minimum of three data fields for each day of the simulation - precipitation [precip(nrain)], minimum temperature [tsta min c(ntemp)], and maximum temperature [tsta_max_c(ntemp)] (fig. 6). The first six fields in a row of daily observations are year, month, day, hour, minute, and seconds - the last three are always zero for the daily time step of WEBMOD. Multiple sets of daily observations (as specified by nrain and ntemp) can be used to include precipitation and temperature observations from other meteorological stations. Incoming solar radiation values [solrad(nsol)], pan evaporation [panevap(nevap)], humidity [either relhum(nhum) or spechum(nhum)], irrigation schedules [irrig_ext(nirrig_ext),

irrig_int_next(nirrig_int), or both], and groundwater inputs [ $g w_{-}$ext(ngw_ext)] can be also be defined in the hydrologic data file (table 3 ). If the model is to be calibrated, then daily discharge [runoff(nobs)] or observations of snow-water equivalence [swe(nsnow)], or both, from one or more stations can be included in the webmod.hydro.dat file.

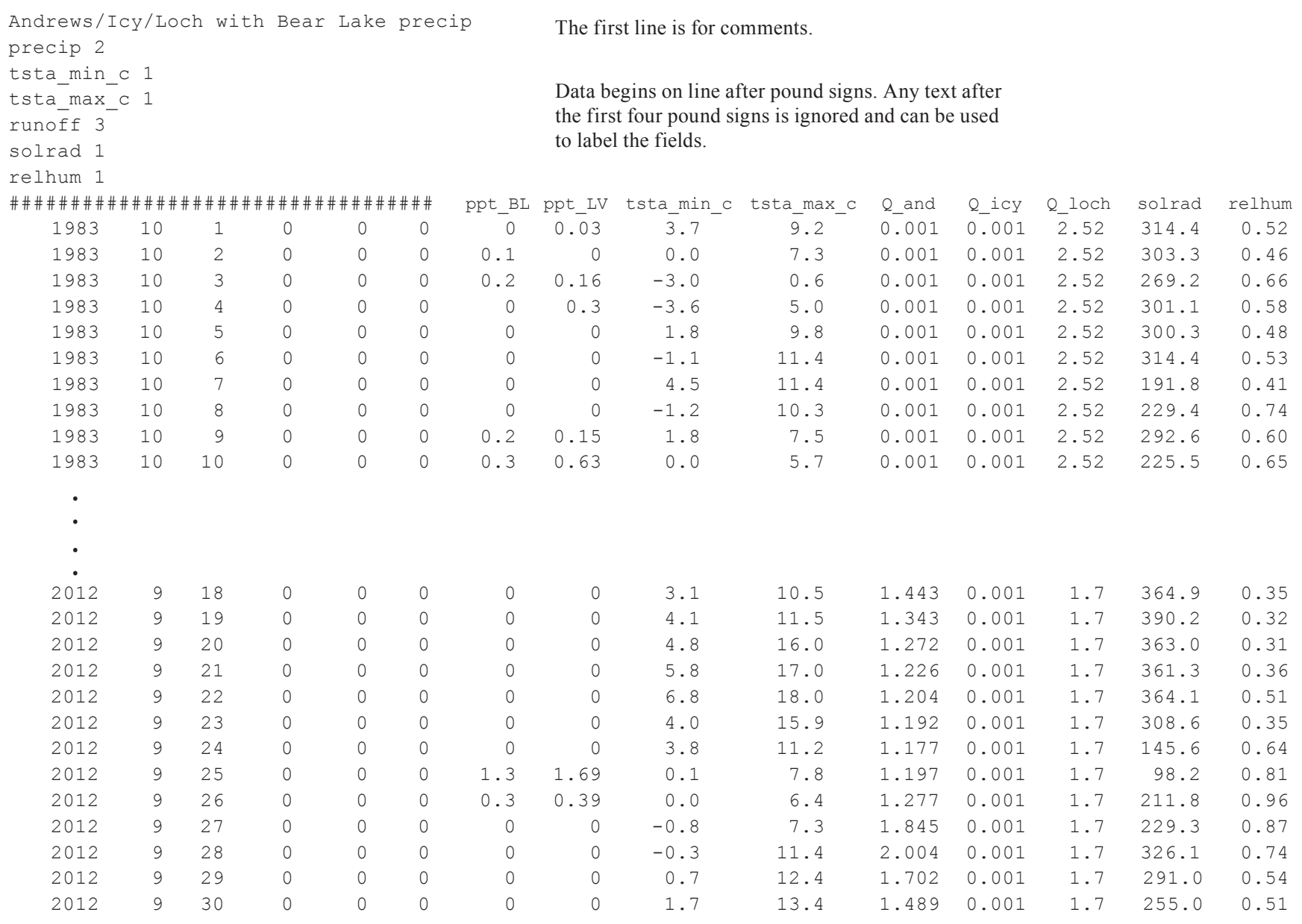

Figure 6. Abridged view of Andrews Creek hydrologic data file. The first six fields represent the time stamp followed by two fields of precipitation data, one field each of daily maximum and minimum temperature, three fields of runoff data, one field of daily incoming radiation, and one field of relative humidity. File contents are in Courier font. Comments are in Times font. Data fields are separated by one or more spaces. 


\section{Parameter File (webmod.params)}

The name of the parameter file is set with the parameter param file in the webmod.control file. The parameter file $<$ basin>linput|webmod.params defines the model dimensions (fig. 7) followed by the parameters (fig. 8). Together, the dimensions and parameters define the topology, process parameters, and operational flags that determine model output. Parameters that control output (table 2) include the level of detail [print_type(one)] and frequency [print_freq(one)] of model output in addition to seven parameters-c_ires(nchemvar), c_mru(nchemvar), c_stindx(nchemvar), c_rip(nchemvar), c_hyd_indx(nchemvar), c_metric(nchemvar), and c_units(nchemvar) - that assign a specific MRU reservoir and output type to any of 10 sets of chemical variables, referred to as chemvars (nchemvar $=10$ ). A chemvar set has four elements that describe the selected reservoir: solutes, volumes, $\mathrm{pH}$, and temperature. The chemvars ch_var_01_sol(nsolute) through ch_var_10_sol(nsolute), where nsolute is the number of solutes of interest, can be populated with concentrations or fluxes of a specified solute for any specified reservoir in the model domain. The other three elements of a chemvar set are water fluxes [ch_var_01_m3(one)], $\mathrm{pH}$ [ch_var_01_pH(one)], and temperature

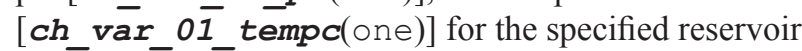
(table 3). All elements and element valence states in the PHREEQC input file $<$ basin $>\mid$ input $\mid<$ webmod.pqi are tracked by the PHREEQC geochemical model; however, the dimension nsolute at the top of the parameter file defines a subset of the elements known to PHREEQC (which can be elements, element valence states, isotopes, or defined compounds such as "alkalinity" or "Amm" [a proxy for ammonium]) to be tracked by WEBMOD.

\section{PHREEOC Database File (phreeqc_web_lite.dat)}

Thermodynamic data for aqueous species, exchangers, surfaces, and mineral and gas phases; gram formula weights of elements and element valence states; and rate expressions for kinetic reactions may be defined generically in the database file, phreeqc_web_lite.dat. These definitions may be modified or augmented in the PHREEQC input file, webmod.pqi.

The database file phreeqc_web_lite.dat is a synthesis of the two databases, phreeqc.dat and iso. $\overline{d a t}$, that are included in distributions of PHREEQC. Modifications include the following:

- $\mathrm{H}_{3} \mathrm{O}^{+}$is used instead of $\mathrm{H}^{+}$in stoichiometric equations to be consistent with iso.dat and to enable tracking of the isotopes deuterium (D) and oxygen-18 $\left({ }^{18} \mathrm{O}\right)$.

- Coefficients are added to describe the fractionation of $\mathrm{D}$ and ${ }^{18} \mathrm{O}$ during sublimation from snowpack.

The elements, species, minerals, and rate expressions defined in the database file are available to be used in the webmod.pqi file, and elements and element redox states defined in the database file can be included in the nsolute solutes of interest. Spelling of solutes in the webmod.chem.dat file and solute names in the parameter file (dimension nsolute) must match those in the second column of the phreeq_lut file, which also must match those in the phreeqc_web_lite.dat file.

\section{PHREEOC Input File (webmod.pqi)}

The name webmod.pqi is set with the parameter phreeq_file in webmod.control. The webmod.pqi file is used to define initial solution compositions for all of the reservoirs of the watershed and to define geochemical reactions for any reservoir of the watershed. The solution compositions of inputs - precipitation, irrigation, and upgradient groundwateralong with initial solution compositions of all stream and hillslope reservoirs are described in a PHREEQC input file $(<$ basin $>\mid$ input $\mid$ webmod.pqi). The file is a standard input file for PHREEQC, and the user is directed to the PHREEQC manual (Parkhurst and Appelo, 2013) for further description on the structure and format of the file. At a minimum, the file defines a limited number of solutions that are used to initialize the streams and hillslope reservoirs and to define the average concentrations of solutes in the precipitation. Without the inclusion of additional PHREEQC entities, such as reactions or kinetics, the model will simulate conservative transport of solutes described in the initial solutions. Concentrations of solutes will vary as dictated by mixing and evaporation.

In addition to solution compositions, geochemical reactants of PHREEQC can be assigned to the canopy, snowpack, O-horizon, unsaturated zone, unsaturated zone preferential flow, saturated zone, saturated zone preferential flow, and stream reservoirs. These reactants are defined with keyword data blocks of PHREEQC and include exchange reactions (EXCHANGE), surface reactions (SURFACE), mineral and gas equilibria (EQUILIBRIUM_PHASES), fixed stoichiometric reactions (REACTION), and kinetic reactions (KINETICS). For example, the Andrews Creek model simulates the weathering of feldspar, biotite, chlorite, calcite, and pyrite with KINETICS definitions and maintains equilibrium with secondary phases that include kaolinite, goethite, gibbsite, and smectite-illite in all subsurface reservoirs with additional EQUILIBRIUM_PHASES definitions. Equilibrium with specified partial pressures of oxygen and carbon dioxide are maintained in the unsaturatedzone and stream reservoirs by including these gases in the EQUILIBRIUM_PHASES definitions.

The database file can be augmented with additional elements, species, minerals, and rate expressions in the webmod.pqi file. Any PHREEQC data block can be included in the webmod.pqi file; however, not all PHREEQC data blocks have meaning for WEBMOD simulations (for example, INVERSE_MODELING and TRANSPORT keyword data blocks are not used in WEBMOD). Also, any solute of interest must appear in one of the solutions or geochemical reactants defined in the webmod.pqi file. 


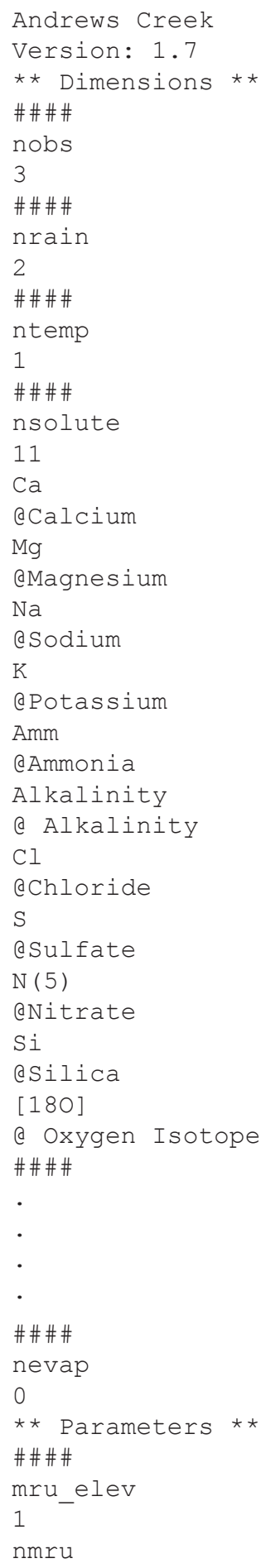

Figure 7. Abridged view of the dimension section of the 10-model-response-unit Andrews Creek parameter file. File contents are in Courier font. Comments are in Times font.
First two lines are comments.

Dimension definitions follow the ** Dimensions ** line. The definitions begin after 4 pound signs "\#\#\#\#” and continue until the next set of pound signs or the beginning of the ** Parameters $* *$ section.

A dimension delimiter consists of the following:

\#\#\#\# Delimiter

dimension (such as "nobs")

size (for example, 3 is the number of runoff observations in the data file) name for each dimension (optional except for nsolute)

@) full description (optional in all cases)

The solutes of interest in WEBMOD simulations of aqueous chemistry are named and indexed here. The names must match those in the phreeq_web_lite.dat file and the phreeq_lut file. The full names following the @ symbol are optional.

The ** Parameters ** line marks the end of the section defining the dimensions and the beginning of the sections defining the parameters. All dimension sizes in the Parameters section must equal those defined in the ** Dimensions ** section. 


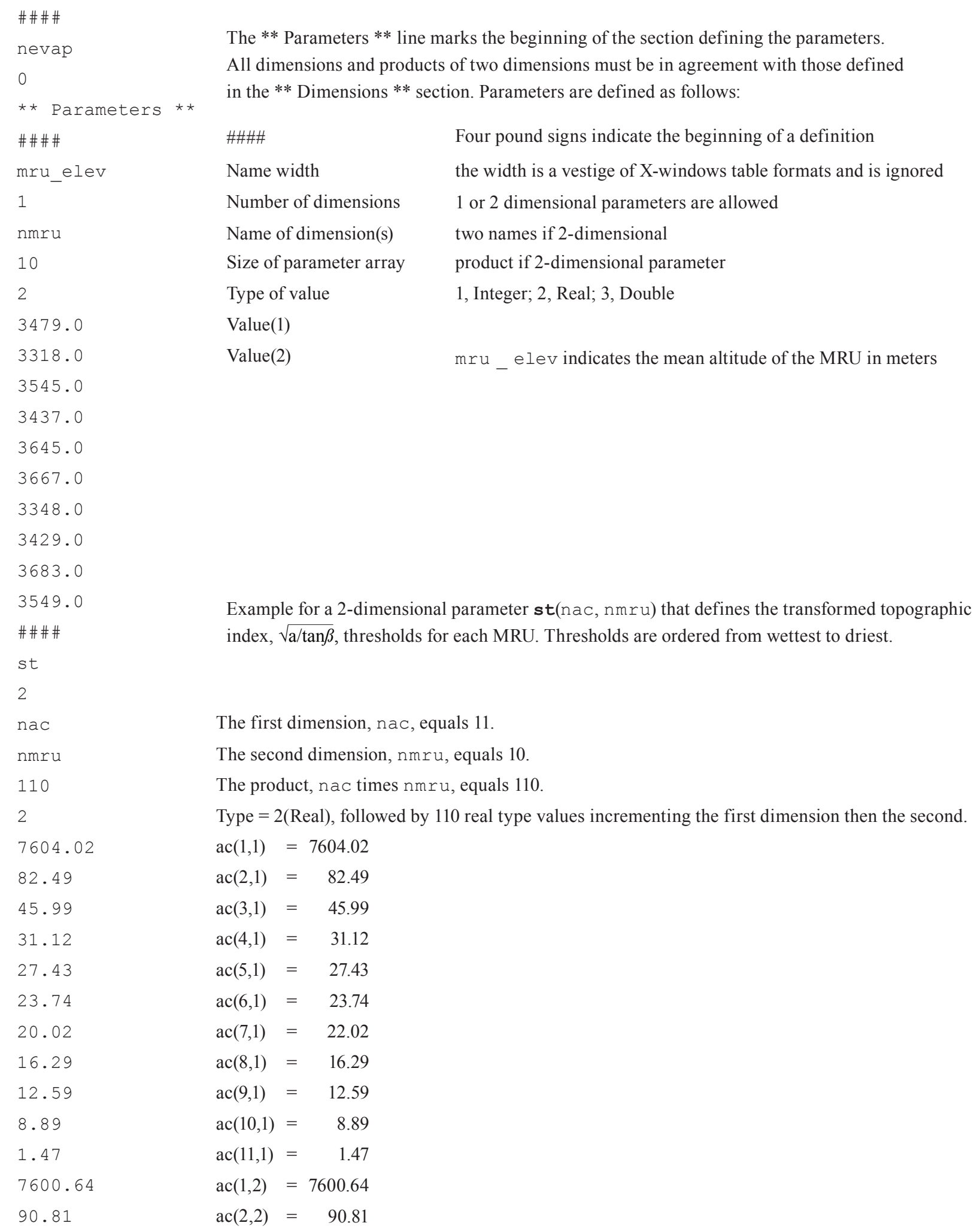

The ** Parameters ** line marks the beginning of the section defining the parameters. All dimensions and products of two dimensions must be in agreement with those defined in the ** Dimensions ** section. Parameters are defined as follows:

Number of dimensions Four pound signs indicate the beginning of a definition

Name of dimension(s) the width is a vestige of $\mathrm{X}$-windows table formats and is ignored

Size of parameter array 1 or 2 dimensional parameters are allowed

Type of value two names if 2-dimensional

Value(1)

Value(2) mru _ elev indicates the mean altitude of the MRU in meters

Example for a 2-dimensional parameter st(nac, $n m r u$ ) that defines the transformed topographic index, $\sqrt{\mathrm{a} / \tan \beta}$, thresholds for each MRU. Thresholds are ordered from wettest to driest.

The first dimension, nac, equals 11.

The second dimension, nmru, equals 10 .

The product, nac times nmru, equals 110 .

Type $=2($ Real $)$, followed by 110 real type values incrementing the first dimension then the second.

$\operatorname{ac}(1,1)=7604.02$

$\operatorname{ac}(2,1)=82.49$

$\operatorname{ac}(3,1)=45.99$

$\operatorname{ac}(4,1)=31.12$

$\operatorname{ac}(5,1)=27.43$

$\operatorname{ac}(6,1)=23.74$

$\operatorname{ac}(7,1)=22.02$

$\operatorname{ac}(8,1)=16.29$

$\operatorname{ac}(9,1)=12.59$

$\operatorname{ac}(10,1)=8.89$

$\operatorname{ac}(11,1)=1.47$

$\operatorname{ac}(1,2)=7600.64$

$\operatorname{ac}(2,2)=90.81$

Figure 8. Abridged view of the parameter section of the 10-model-response-unit Andrews Creek parameter file. File contents are in Courier font. Comments are in Times font. (MRU, model response unit) 


\section{PHREEOC Lookup Table (phreeq_lut)}

The file phreeq_lut contains a lookup table of the 75 elements, element redox states, and isotopes that may be selected as solutes of interest for output and plotting. Five of the definitions are user defined to accommodate additional elements such as "Amm" for the ammonium, one of the solutes included in the Andrews Creek model. Modifications to the list must be consistent with the spelling of element and element redox-state names in the database file and the PHREEQC input file (webmod.pqi file). The following list describes the 10 fields in the PHREEQC solutes lookup table:

1. Solute number (1 through 75).

2. Element name or element redox-state name, including valence. If valence is positive, no plus symbol should be used. Element and element redox-state names must be defined in the database file or the webmod.pqi file (SOLUTION_MASTER_SPECIES block). Alkalinity, Amm, and DOC are also included as special-case compounds that can be selected as one of the solutes of interest.

3. Chemical formula of the PHREEQC master species for the element or element redox state.

4. Moles-to-milligrams conversion factor. Multiply moles (mol) of solute by this factor to compute milligrams (mg).

5. Moles-to-milliequivalents conversion factor. Multiply moles of solute by this factor to compute milliequivalents (meq); use zero if uncharged.

6. Isotope units - "none," "permil" (parts per thousand), "TU" (tritium units), or "pmc" (percent modern carbon). Permil is used for ${ }^{18} \mathrm{O}$ and $\mathrm{D}$ (the only isotopes currently implemented, 2017); use "none" for nonisotopes.

7. Ratio of minor isotope to major isotope in the standard. For example, 0.0020052 for the ratio of ${ }^{18} \mathrm{O} /{ }^{16} \mathrm{O}$ in Vienna Standard Mean Ocean Water (Clark and Fritz, 1997); use 1 for nonisotopes.

8. PHREEQC named expression describing the log (base 10) of the temperature-dependent isotopic fractionation factor for equilibrium vapor above a liquid; use "none" if not applicable.

9. PHREEQC named expression describing the common $\log$ (base 10) of the temperature-dependent fractionation factor for equilibrium vapor above a solid; use "none" if not applicable.

10. The maximum diffusive isotope depletion, $\varepsilon_{\text {diff }}$, for a fully developed diffusive sublayer $\left(\mathrm{h}_{\mathrm{n}}=0, \Theta=1, n=1\right)$ (Craig and Gordon, 1965); Merlivat (1978) determined $\varepsilon_{\text {diff }}$ values of -28.5 permil for ${ }^{18} \mathrm{O}$ and -25.1 permil for D; use " 1 " if not applicable.
The fractionation factors are used to determine the equilibrium fractionation of deuterium and oxygen-18 in vapor above wet canopy and soils (field 8) and vapor above snow on the canopy and snowpack (field 9). The factor in field 10 is used to simulate kinetic, or diffusive, fractionation for conditions where relative humidity is less than 100 percent.

\section{Solute Concentration File (webmod.chem.dat)}

If solute concentrations in precipitation, external irrigation, or upgradient groundwater vary with time during the simulation, then the webmod.pqi file will be accompanied by a solute concentration file (webmod.chem.dat). Precipitation samples are routinely collected about every two weeks as part of the National Atmospheric Deposition Program (NADP; 2014). The webmod.chem.dat file contains the 2 -week average concentrations for all days of a period; these concentrations are used for any day within the period that had precipitation. In addition, the webmod.chem.dat file is used to define concentrations of analytes from periodic field samples of streams. The order of solutes and the specified units of concentration defined on the line following "** Species and Units **" in the header must be maintained for all inputs, including precipitation and external sources - irrigation and upgradient groundwater. The solution compositions defined in the webmod.chem.dat file are available for viewing, in molar units, by using the variables cconc_obsM(nchemobs,nsolute), cconc_precipM(nsolute), and cconc_extM (nchem_ext,nsolute).

Concentration values in the webmod.chem.dat file must be consistent with the conversion factors given in phreeq_lut. Thus, when milligrams per liter "as N" is defined in phreeq_lut for nitrate and ammonium, and concentrations in the NADP are "as $\mathrm{NO}_{3}$ " for nitrate and "as $\mathrm{NH}_{4}$ " for ammonium, the NADP data must be converted to milligrams per liter "as N" for the webmod.chem.dat file. The conversion entails multiplying the nitrate NADP values by 0.22589 $(14,007 / 62,007)$ and the ammonium NADP values by 0.77786 $(14,007 / 18,007)$. The conversion factor in phreeq_lut for alkalinity is $50,000 \mathrm{mg}$ of $\mathrm{CaCO}_{3}$ per equivalent (eq), silica is $60,084 \mathrm{mg} \mathrm{SiO} / \mathrm{mol}$, and sulfate is $96,064 \mathrm{mg} \mathrm{SO} / \mathrm{mol}$.

\section{Model Output}

WEBMOD simulations of hydrology and solutes produce standard and custom output. Standard output presents watershed mass balance of water and solutes by using a limited number of report formats and a limited number of variables. Custom output can be displayed as Run Time Plots or written as a flat file that can be imported into spreadsheets or databases for postprocessing. The file names and content of custom output, which include Run Time Plots, are determined by parameters in the webmod.control file (table 4). If the user is simulating 
Table 4. Control File parameters that define the file names and contents of the Water, Energy, and Biogeochemical Model (WEBMOD) output.

[The formatting convention used in this report is to present file names in italic font, dimension names in Courier New font, and parameter names in bold Courier New font. Names and descriptions of all dimensions are presented in table 1. Contents of volume, solute, and entity files are described in table 5. TOPMODEL, topography-driven hydrologic model (Beven and Kirkby, 1979); *, file name]

\begin{tabular}{lll}
\hline \multicolumn{1}{c}{ Parameter(Dimension) } & \multicolumn{1}{c}{ Information } & File name \\
\hline model_output_file(one) & Water budget file & webmod.hydro.out \\
model_topout_file(one) & TOPMODEL summary & webmod.topout \\
model_chemout_file(one) & Solute budget file & webmod.chem.out \\
written to output_dir(one) when & Detailed volume (v), solute (s), and entity files (e) & examples: \\
print_vse(one) is not equal to zero & & v_mru009_uz03, \\
& & s_mru004_snow, \\
& & e_mru001_sat \\
\hline
\end{tabular}

\begin{tabular}{|c|c|c|}
\hline \multirow{2}{*}{\multicolumn{3}{|c|}{ Custom output }} \\
\hline & & \\
\hline \multicolumn{3}{|c|}{ Runtime graphics ${ }^{1}$} \\
\hline ndispGraphs(one) & Number of Run Time Plots & \\
\hline dispVar_names $\left(\operatorname{Int}^{2}\right)$ & Names of runtime variables & \\
\hline dispVar_element $\left(\operatorname{Int}^{2}\right)$ & Indices of runtime variables & \\
\hline dispVar_plot $\left(\right.$ Int $\left.^{2}\right)$ & Run Time Plot number to receive variable & \\
\hline \multicolumn{3}{|c|}{ Indexed variables } \\
\hline stats_output_file(one) & Statistics of statistics variables & webmod.statistics \\
\hline nstatVars(one) & Number of statistics variables & \\
\hline statVar_names(nstatVars) & Names of statistics variables & \\
\hline statVar_elements(nstatVars) & Indices of statistics variables & \\
\hline aniOutON_OFF(one) & Print animation files $(0=$ no, $1=$ yes $)$ & \\
\hline ani_output_file(one) & $\begin{array}{l}\text { Root file name for daily values of all indices for } \\
\text { each animation variable with same dimension }\end{array}$ & $\begin{array}{l}\text { examples: } \\
\text { webmod.aniout.one } \\
\text { webmod.aniout.nmru }\end{array}$ \\
\hline naniOutVars(one) & Number of animation variables & \\
\hline anioutVar_names(naniOutVars) & Names of animation variables & \\
\hline
\end{tabular}

\footnotetext{
${ }^{1}$ Runtime graphics can be output to *.png format files after the model run terminates.

${ }^{2}$ Int is the total number of indexed variables to be plotted on all of the runtime graphs.
}

geochemistry, then manual editing of the control file permits custom output of two-dimensional geochemical variables: for example, the load of a solute produced or consumed by reactions in an MRU, ch_mru_meqm2_rxn(nmru,nsolute), in milliequivalents per square meter.

\section{Standard Output}

Standard output consists of at least three files-a hydrologic budget file < basin $>$ loutput|webmod.hydro.out, a TOPMODEL output file $<$ basin $>$ |output|webmod.topout, and a solute budget file $<$ basin $>$ loutput $\mid$ webmod.chem.out. The file names are declared in the control file (webmod.control). As with webmod.hydro.dat, the first six fields of simulated daily values in webmod.hydro.out are year, month, day, hour, minute, and seconds - the last three are always zero for the daily time step of WEBMOD; only year, month, and day are used to describe the day in webmod.chem.out.

The level of detail in standard output is configured by using print_type(one), as listed in table 5, and the frequency of summary data is configured by using print_freq(one). Detailed output for the hydrologic budget [print_type(one)=2] includes basin summaries for 54 storages and fluxes in the watershed (table 6). Printing the explanation of the 54 fields at the top of the file can be suppressed by setting print_explanation(one $)=0$. 
Table 5. Content of standard output files determined by the print_type(one) and print_vse(one) parameters.

[The formatting convention used in this report is to present file names in italic font, dimension names in Courier New font, and parameter names in bold Courier New font. The dimension one is used for most control parameters. MRU, model response unit; ET, evapotranspiration; *, component of file name reflecting a specific or composite reservoir]

\begin{tabular}{|c|c|c|c|}
\hline Output file & 0 & 1 & 2 \\
\hline \multicolumn{4}{|c|}{ print_type(one) } \\
\hline webmod.hyd.out & Observed and simulated discharge & $\begin{array}{l}\text { Storage, inputs, and outputs } \\
\text { for watershed }\end{array}$ & $\begin{array}{l}\text { Storage, inputs, and outputs, including } \\
\text { internal storages like canopy, } \\
\text { snowpack, and soil zone }\end{array}$ \\
\hline webmod.topout & $\begin{array}{l}\text { Soil properties, channel routing, } \\
\text { mass balance for the watershed }\end{array}$ & $\begin{array}{l}\text { Soil properties, channel routing, } \\
\text { mass balance for each MRU }\end{array}$ & $\begin{array}{l}\text { Soil properties, channel routing, and } \\
\text { mass balance for each MRU }\end{array}$ \\
\hline \multicolumn{4}{|c|}{ print_vse(one) } \\
\hline$v_{-}{ }^{*}, s_{-}{ }^{*}$, and $e_{-}{ }^{*}$ files & No $v_{-}{ }^{*}, s_{-}{ }^{*}$, and $e_{-}^{*}$ files created & $\begin{array}{l}\text { Volumes of water and moles of } \\
\text { solutes (initial, inputs, outputs, } \\
\text { reactions or ET, and final) for } \\
\text { basin, MRU, and stream }\end{array}$ & $\begin{array}{l}\text { Volumes of water and moles of solutes } \\
\text { (initial, inputs, outputs, reactions } \\
\text { or ET, and final) for basin, MRU, } \\
\text { stream, unsaturated zone composites, } \\
\text { and individual reservoirs }\end{array}$ \\
\hline
\end{tabular}

The field abbreviations at the top of each column are always printed. The value of print_freq(one) is the sum of each individual frequency desired as follows: 16 , event; 8 , daily; 4, monthly; 2 , yearly; and 1 , entire run. Thus, a value of seven for print_freq(one) prints a summary for each month, year, and entire run; a value of eight prints daily results with no summaries for month, year, or entire run. A value of 15 prints a summary for each day, month, year, and entire run. Event timing related to subdaily time steps is not implemented in WEBMOD; the minimum time step is daily.

When print_freq(one) includes summary periods other than daily, the user may print five objective functions for each summary period by setting print_objfunc(one) $=1$. Each objective function [obj_func(five)] is a unique description of the mismatch between $Q_{o b s}$, the observed discharge [runoff(nobs)] and $Q_{s i m}$, the simulated discharge [qbasincfs(one)], as described in the following equations:

$$
\begin{gathered}
o b j_{-} f u n c(1)=\sum\left|\Delta_{Q}\right|, \\
o b j_{-} f u n c(2)=\sum\left|\Delta_{Q}^{2}\right|, \\
o b j_{-} f u n c(3)=\sum\left|\log \left(Q_{o b s}+1\right)-\log \left(Q_{\text {sim }}+1\right)\right|, \\
o b j_{-} f u n c(4)=\sum\left|\log \left(Q_{o b s}+1\right)-\log \left(Q_{\text {sim }}+1\right)\right|^{2}, \text { and } \\
o b j_{-} f u n c(5)=\sum \Delta_{Q},
\end{gathered}
$$

where

obj_func $(i)$ is one of the five objective functions,

$\Delta_{Q} \quad$ is $Q_{s i m}-Q_{o b s}$,

$Q_{o b s} \quad$ is the observed discharge, in cubic feet per second - note that $Q_{o b s}$ is the discharge "observed" at the watershed outlet; its field number in the runoff(nobs) observations in the webmod.hydro.dat file is indicated by qobsta(one), and

$Q_{\text {sim }} \quad$ is the simulated discharge, in cubic feet per second.

If geochemistry is simulated [chem_sim(one)=1], the minimum output [print_type $(\circ \bar{e})=0$ ] written to file $<$ basin $>$ |output|webmod.chem.out is the basin discharge of water, in cubic meters $\left(\mathrm{m}^{3}\right)$, and the number of moles of each of the nsolute solutes of interest. Moles divided by cubic meters is equivalent to millimoles per liter. When print_type $(o n e)=1$, three additional files are written for the composite reservoirs - basin, MRU, and stream. Composite reservoirs are mathematical summations of individual reservoirs. Initial and final volumes and moles are extensive properties that are reported as the sum of the volumes and moles in the individual reservoirs. The total volume of water in an MRU will only increase in response to rain, snow, or external irrigation and only decrease in response to ET, runoff, base flow, or leakage. Similarly, moles of a solute produced in one reservoir may be consumed in another reservoir; the 
Table 6. Field labels and descriptions in webmod.hydro.out when detailed output is requested [print_type(one) =2].

[The formatting convention used in this report is to present dimension names in Courier New font, parameter names in bold Courier New font, and variable names in bold italic Courier New font. $\mathrm{W} / \mathrm{m}^{2}$, watt per square meter; ${ }^{\circ} \mathrm{C}$, degree Celsius; $\mathrm{cm}$, centimeter; $\mathrm{m}^{3} / \mathrm{s}$, cubic meter per second]

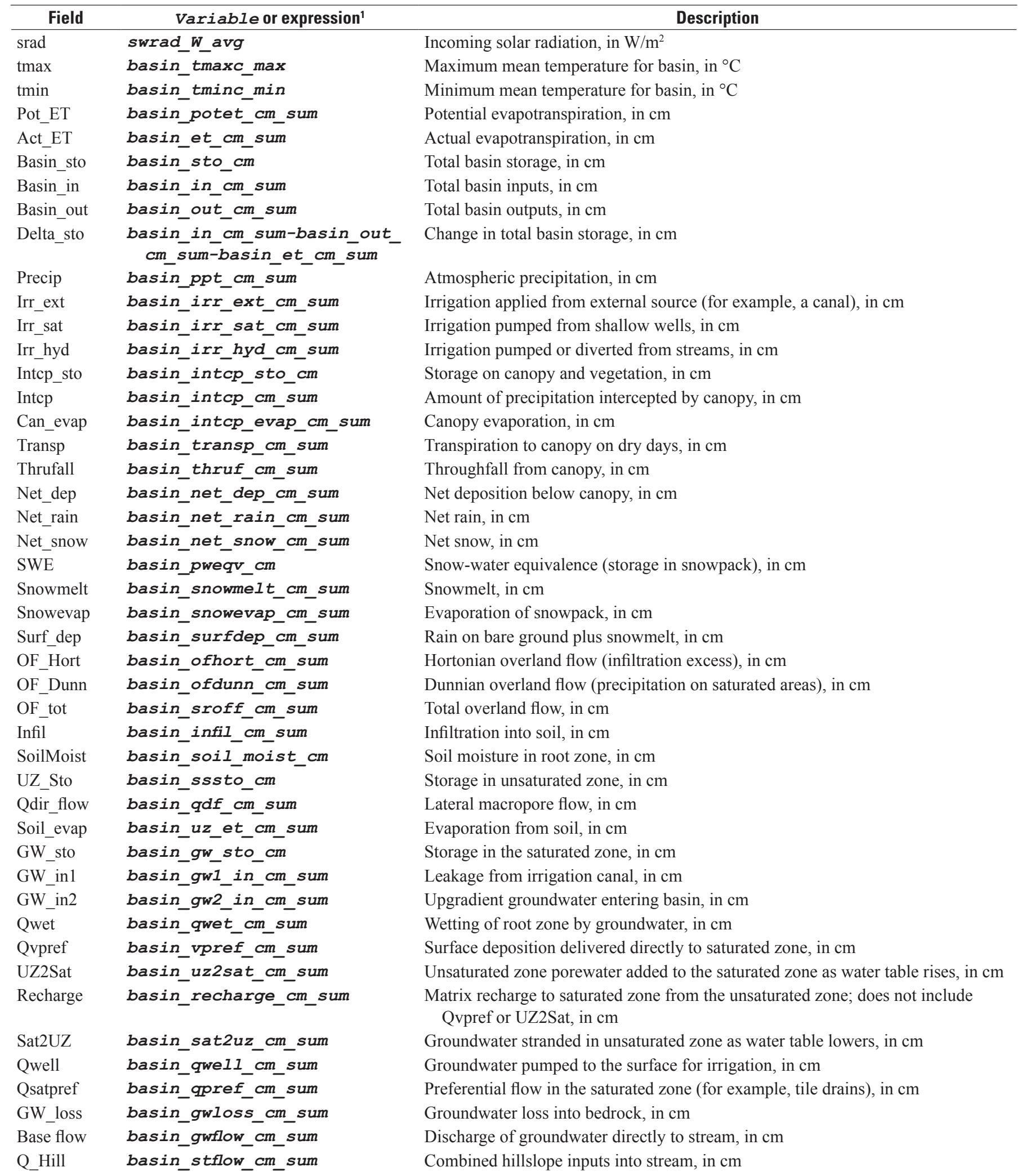


Table 6. Field labels and descriptions in webmod.hydro.out when detailed output is requested (print_type $(o n e)=2)$. - Continued

[The formatting convention used in this report is to present dimension names in Courier New font, parameter names in bold Courier New font, and variable names in bold italic Courier New font. $\mathrm{W} / \mathrm{m}^{2}$, watt per square meter; ${ }^{\circ} \mathrm{C}$, degree Celsius; $\mathrm{cm}$, centimeter; $\mathrm{m}^{3} / \mathrm{s}$, cubic meter per second]

\begin{tabular}{lll}
\hline \multicolumn{1}{c}{ Field } & \multicolumn{1}{c}{ Variableor expression } & \multicolumn{1}{c}{ Description } \\
\hline Chan_sto & basin_chan_sto_cm & Total water stored in channel, in cm \\
Diversion & basin_chan_div_cm_sum & Water diverted from stream for irrigation, in cm \\
Chan_loss & basin_chan_loss_cm_sum & Seepage through streambed, in cm \\
Q_sim $(\mathrm{cm})$ & basin_qsim_cm_sum & Simulated discharge at basin outlet, in cm \\
${ }^{2} \mathrm{Q}$ obs $(\mathrm{cm})$ & basin_qobs_cm_sum & Observed discharge at basin outlet, in cm \\
Q_sim $\left(\mathrm{m}^{3} / \mathrm{s}\right)$ & basin_qsim_m3s_avg & Simulated discharge at basin outlet, in $\mathrm{m}^{3} / \mathrm{s}$ \\
${ }^{2} \mathrm{Q}$ obs $\left(\mathrm{m}^{3} / \mathrm{s}\right)$ & basin_qobs_m3s_avg & Observed discharge at basin outlet, in $\mathrm{m}^{3} / \mathrm{s}$ \\
Wat_bal & wat_bal_cm_sum & Error in numerical closure of water balance, in cm \\
\hline
\end{tabular}

${ }^{1}$ All variables except for state variables such as basin_sto_cm or basin_pweqv_cm have a dimension of five representing averages, maximum, minimum, or sums for (1) event, (2) day, (3) month, (4) year, and (5) run. Because the model runs at a daily timestep, the values for event and day indices will be identical.

${ }^{2}$ Set to zero when nobs is equal to zero.

composite sum is simply the net result of production and consumption in all reservoirs. Intensive properties include temperature, $\mathrm{pH}$, concentrations, and delta values of isotopes. Where intensive properties are reported for composite reservoirs, the properties are volume weighted such that if $100 \mathrm{~m}^{3}$ of irrigation at $4{ }^{\circ} \mathrm{C}$ mix with $900 \mathrm{~m}^{3}$ of rain at $1{ }^{\circ} \mathrm{C}$, the temperature of water entering the hillslope would be reported as $1.3{ }^{\circ} \mathrm{C}[((100 \times 4)+(900 \times 1)) / 1,000]$. The prefix for each detailed geochemical output file indicates the content as follows: $v_{-}^{*}$ for volumes of water with identification (ID) of sources of all inputs; $s_{-}{ }^{*}$ for solutes, in moles; and $e_{-}{ }^{*}$ for entities that produce or consume solutes. The asterisk (*) is the name of the specific or composite reservoir. When detailed output is requested [print_type $(o n e)=2$ ], then additional $v_{-}^{*}, s_{-}{ }^{*}$, and $e_{-}{ }^{*}$ files are produced for additional composite reservoirs and each individual reservoir identified in figure 4. The additional composite reservoirs include all unsaturatedzone reservoirs in an MRU $\left(\right.$ mru $\times \times \_$uzgen $)$where $\times \times$is the MRU ID then, as determined with the user-assigned parameter riparian_thresh(nmru), the riparian unsaturated-zone reservoirs for each MRU ( $\left.\_m r u \times \times \_u z r i p\right)$ and the upland unsaturated-zone reservoirs for each MRU ( geochemistry is not simulated [chem_sim(one) $=0$ ], then the webmod.chem.out file will list the date and time of the model run with the statement "Geochemistry was not simulated for this model run"; no volume $\left(v_{-}^{*}\right)$, solute $\left(s_{-}^{*}\right)$, entity $\left(e_{-}^{*}\right)$, or select mixes files will be created.

Similar to the standard output file (webmod.hydro.out), the TOPMODEL output file (webmod.topout) contains a detailed daily water balance of the soil reservoirs for each time step if iout $(\circ n e)=2$ but only a run summary if iout (one) $=1$. The following key characteristics of TOPMODEL are written to webmod.topout: log-normal distribution of vertical infiltration rates, description of soil parameters and initial conditions, cumulative areas used in the Clark channel routing, a summary water balance for each MRU, and values of objective functions that describe how well the simulated discharge matched observed discharge.

\section{Custom Output and User-Defined Chemical Variables- Chemvars}

In addition to standard file outputs, the user can view Run Time Plots or write custom output consisting of daily values and statistics for any of almost 400 hydrologic and geochemical variables at a range of spatial and temporal scales (table 3). Run Time Plots and one-dimensional public variables for custom output are selected within the MMS Tool GUI (Markstrom and Koczot, 2008), which records the plot and output specifications in the webmod.control file. Selection of two-dimensional variables requires editing the webmod.control file to add comma-separated dimensions on the lines corresponding to the control parameters dispVar_element and statVar_element for Run Time Plots and statistical variable files, respectively.

The number of Run Time Plots is specified by the control parameter ndispGraphs. The variables to be plotted are specified as dispVar_names with the associated dimensions specified with dispVar_element. The variable is assigned to one of the ndispGraphs graphs with dispVar_plot. The number of days of data to be buffered before updating the plots is indicated by dispGraphsBuffSize.

The two most common custom outputs are the statistical variable file, webmod.statvar, and the animation files, webmod.aniout.variable. A webmod.statvar file consists of daily values for any number of variables specified by name 
and dimension. The first seven fields preceding values for daily data in webmod.statvar are the step number, year, month, day, hour, minute, and seconds, the last three of which are always zero for the daily time step of WEBMOD. For each variable selected for output to an animation file, a separate output file, webmod.aniout.variable, will contain daily values of that variable for all indices of the associated dimension(s). Additional information about the statistical variable and animation files is paraphrased from Markstrom and others (2015):

The webmod.statvar file is generated when parameter statsON_OFF is set to " 1 " in the webmod.control file. The name of the file is set by control parameter stat_var_file. The first line of the file is the number of variable values that are written in the file; this value is specified by using control parameter nstatVars. The next group of lines (nstatVars in number) lists the names and array index of each output variable; the output variables that are listed are specified by using control parameter statVar_name. Each output variable will have a corresponding row in the control parameter statVar_element that specifies the dimension index or indices. The remaining lines provide the model-calculated values of each variable for each simulation time step. These data lines have the following order: model time-step number, year, month, day, hour, minute, second, and each variable value in the order specified by the list of variable names. Each value is separated by a space.

A webmod.aniout.variable file consists of a time-series of spatial arrays that can be used with animation programs. A file is generated for each of naniOutVars when parameter aniOutON_OFF is set to " 1 " in the webmod.control file. These output variables are specified by using parameter anioutVar_names. The name of the prefix for the file (webmod.aniout) is set by parameter ani_output_file in webmod.control. The output variable names are appended as the suffix, which results in file names of webmod.aniout.variable. The first group of lines in the file, which start with hash characters (\#), describes the format of the file (that is, provides metadata that define the file format and contents); these lines can be used by external programs to reformat the file. The first line beyond the metadata is a tab-separated list of names of the output variables whose values are provided in a column in each data line. The next line is a tab-separated list of the field width and data type, defined as a single text string for each output variable in the same sequence as the list of variable names. Each value in the list is a single character appended to an integer value defining the field width. The single character designates the data type by using the following scheme: $d=$ date, $\mathrm{n}=$ number. The remaining lines contain the date and corresponding index number within the spatial feature dimension and variable values in the order specified by the list of variable names. A date value (or timestamp) is output as a 19-character string in the following format: YEAR-MO-DY:HR:MN:SE. The index number is an integer value using the next five characters. Data values are numbers written in a 10-character exponential format. All values are separated by tab characters.

At the coarsest scale, the MMS Tool GUI can be used to request a water balance of the accumulated inputs [basin_in_cm(one)], outputs [basin_out_cm(one)], or storage [basin_sto_cm(one)] for the watershed. With manual editing of the webmod.control file, the user can output two-dimensional variables such as the amount of ET from the root zone for a specific TTI bin for a specific MRU [sae_local(nac,nmru)] or the concentrations of solutes, in molar units, of precipitation [cconc_precipM(nsolute)]; external sources [cconc_extM(nchem_ext,nsolute)]; or observations [cconc_obsM(nchemōbs, nsolute)].

Describing geochemical fluxes in the unsaturated zone requires three dimensions (nac,nmru,nsolute) whereas the MMS limit for variables is two; therefore, 10 generic chemical variable groups or "chemvars" (nchemvar=10) were introduced. Each chemvar is a group of 4 variables; one for solutes, one for $\mathrm{pH}$, one for temperature, and one for volumes for water. Thus, 40 user-defined variables are available to describe states and fluxes in one or more reservoirs. The 10 variables that describe solutes, which can be output in various units, are ch_var_01_sol(nsolute) through ch_var_10_sol(nsolute) ; the 10 variables that describe $\mathrm{pH}$, in standard units, are ch_var_01_pH(one) through ch_var_10_pH(one); the 10 variables that describe temperature, in degrees Celsius, are ch_var_01_tempc(one) through ch_var_10_tempc(one); and the 10 variables that describe volumes of water, in cubic meters, are ch_var_01_m3(one) through ch_var_10_m3(one).

The values written to any of the 40 chemvars are determined by the integers assigned to seven chemvar flag parameters dimensioned by nchemvar C C_ires(nchemvar), C_metric(nchemvar), C_unit(nchemvar), c_mru(nchemvar), c_stindx(nchemvar), c_rip(nchemvar), and c_hyd_indx(nchemvar). The first character of the three parameters C_ires, C_metric, and C_unit are capitalized so they appear at the left when viewing the parameters by dimension nchemvar in the Parameter Tool GUI. The other four parametersc_mru, c_stindx, c_rip, and c_hyd_ind $x$-are used conditionally to define the specific reservoir, depending on the value of C_ires. The parameters can be edited in the Parameter Tool GUI by selecting the nchemvar dimension in the parameter tree. As an example, these flag parameters will be used to populate the following four variables in the 5th chemvar variable group: ch_var_05_sol(nsolute), ch_var_05_pH(one), ch_var_05_tempc(one), and ch_var_o5_m3(one); the same discussion applies equally to the 1st through the 10th chemvar variable groups. Five of the seven chemvar(5) 
flag parameters-C_ires(5), c_mru(5), c_stindx(5), c_rip(5), and c_hyd_indx(5) - specify the reservoir of interest; C_metric(5) specifies the desired metric (initial, inputs, outputs, reaction or ET, final, or net) that applies to all four chemvar variables; and C_unit(5) applies only to the solute variable ch_var_05_soln(nsolute).

The flag parameter C_ires(5) is used to specify one of the following reservoirs: 1, canopy; 2, snowpack; 4, O-horizon; 5, unsaturated zone; 7, preferential flow through the unsaturated zone; 8 , the saturated zone; 9 , preferential flow through the saturated zone; or 99, stream reservoirs. Index 3 is reserved for impermeable surfaces that are not implemented in this release but will be needed in future revisions to simulate urban watersheds. In addition, C_ires(5) can be assigned a value of 6 that is used to select a composite of unsaturated zone TTI bins - all, riparian, or upland bins. If C_ires(5) is any value other than 99 (stream reservoir), then the MRU of interest must be defined with the parameter index c_mru(5). The other three reservoir indices c_stindx(5), c_rip(5), and c_hyd_indx(5) are interpreted as follows:

- If C_ires $(5)=1,2,4,7,8$, or 9, then the corresponding hillslope reservoir is selected. The values of indices c_stindx(5), c_rip(5), and c_hyd_indx(5) are not relevant.

- If C_ires $(5)=5$, then a single TTI bin of the selected MRU is specified with c_stindx(5). The values of indices c_rip(5) and c_hyd_indx(5) are not relevant.

- If C_ires(5)=6, then a set of TTI bins for the selected MRU is specified with c_rip(5) as follows: c_rip $(5)=0$ selects all TTI bins, c_rip (5)=1 selects riparian TTI bins, and c_rip $(5)=2$ selects upland TTI bins. Riparian and upland TTI bins are distinguished by the parameter riparian_thresh(nmru). The values of indices c_stindx(5) and c_hyd_indx(5) are not relevant.

- If C_ires $(5)=99$, then a single stream reservoir is selected with c_hyd_indx(5). The values of indices c_stindx(5) and c_rip(5) are not relevant.

The metric for all four chemvars is defined with the parameter index c_metric(5). Values for c_metric(5) have the following meanings: $1=$ initial, $2=$ input, $\overline{3}=$ output, $5=$ final, and $6=$ net (final - initial). When c_metric $(5)=4$, reaction gain $(+)$ or loss $(-)$ will be stored in ch_var_05_sol(nsolute), volume of ET (-) will be stored in ch_var_05_m3, and $\mathrm{pH}$ and temperature of the final volume of the reservoir will be stored in ch_var_05_pH(one) and ch_var_05_tempc(one).

The units of ch_var_05_sol(nsolute) are defined with c_unit(5), which can have the following values: $1=$ milligram, 2 = milliequivalent, $3=$ millimole, $4=$ load in milligram per square meter, $5=$ load in milliequivalent per square meter, $6=$ load in millimole per square meter, $7=$ concentration in milligram per liter, $8=$ concentration in milliequivalent per liter, $9=$ concentration in millimole per liter, $10=$ user-defined concentrations using convfactor(1) in units per mole, 11 = user-defined concentrations using convfactor(2) in units per mole, 12 = user-defined concentrations using convfactor(3) in units per mole, and 13 = permil, when the solute of interest is either D or ${ }^{18} \mathrm{O}$. The variable ch_var_05_m3(one) is in cubic meters, ch_var_05_tempc(one) is in degrees Celsius, and ch_var_05_pH(one) is in $\mathrm{pH}$ units.

The user must take care to select compatible parameters for chemvars. If the metric of interest is "reaction gain" [c_metric (5)=4] or "net" [c_metric(5)=6], then c_unit(5) should be in the range of 1 through 6 (milligrams, milliequivalents, millimoles, or loads). Solute concentrations, delta values for isotopes, temperature, and $\mathrm{pH}$ are determined only for the metrics "initial," "input," "output," or "final." Similarly, requesting permil makes sense only if the solute of interest is $\mathrm{D}$ or ${ }^{18} \mathrm{O}$.

The areas used to compute loads are canopy area for canopy; SCA for snowpack; TTI area for an unsaturated zone bin; and MRU area for other hillslope reservoirs (O-horizon, saturated zone, and preferential flow through the unsaturated or saturated zones).

Conversion factors are available to report concentrations in nonstandard units. The conversion factors for milligram per mole $(\mathrm{mg} / \mathrm{mol})$ and milliequivalent per mole $(\mathrm{meq} / \mathrm{mol})$ are defined in the fourth and fifth fields in the phreeq_lut file. The native unit for internal computations is molality (moles per kilogram of water, or molal), which is assumed to be equal to molarity (moles per liter, or molar). User-defined units use convfactor(nconvert), where nconvert $=3$, such that moles per liter $\times$ convfactor $(1)=$ user-defined unit when c_unit $(5)=10$,

moles per liter $\times$ convfactor $(2)=$ user-defined unit when c_unit $(5)=11$, and

moles per liter $\times$ convfactor $(3)=$ user-defined unit when c_unit $(5)=12$.

For example, the mole-to-milligram conversion for nitrate $\mathrm{N}(5)$, the valence state of nitrate, in the phreeq_lut file is $14,007 \mathrm{mg} / \mathrm{mol}$, which gives results in milligrams per liter as $\mathrm{N}$. Nitrogen could be output in milligrams per liter as $\mathrm{NO}_{3}$ by entering convfactor $(1)=62,004$ and then setting c_unit $(5)=10$. Note that if multiple solutes of interest exist and if ch_var_05_sol(nsolute) is assigned c_unit $(5)=10,11$, or 12 , then the user-assigned conversion factor supersedes the conversion factors read from the phreeq_lut file; such that, all solutes referenced by ch_var_05_sol(nsolute) will have the same 
mole-to-user-defined-unit conversion factor applied. In the DR2 example in the "Example Problems" section, a userdefined conversion of $1,410,000$ microsiemens per centimeter per mole $((\mu \mathrm{S} / \mathrm{cm}) / \mathrm{mol})$ is used to convert moles of chloride to an approximate value of specific conductance in microsiemens per centimeter.

Because ch_var_05_sol(nsolute) is an array dimensioned by nsolute, once the chemvar flag parameters are setup as desired (and no user-defined conversion factors are used), ch_var_05_sol can address each of the nsolute solutes of interest. For example, if the parameter file defines nsolutes $=3$, with solute names of $\mathrm{Ca}, \mathrm{Mg}$, and $\mathrm{N}$, and if the chemvar flag parameters for the fifth chemvar designate groundwater output from MRU number 2 in milligrams per liter [c_ires (5) $=8$, c_mru(5) $=2$, c_metric $(5)=3$, c_unit $(\overline{5)}=7]$, then Run Time Plots of the concentrations in groundwater output for $\mathrm{Ca}$ and $\mathrm{N}$ can be viewed by adding ch_var_05_sol(1) and ch_var_05_sol(3) to the variable list. If viewing the webmod.control in a text editor, the section statVar_names will have two rows with "ch_var_05," and in the section statVar_element, the corresponding two rows will have values of " 1 " and "3."

\section{Debug File (output/select_mixes)}

Certain combinations of hydrologic and geochemical parameters may result in a failure to converge on a solution describing the waters after mixing and reacting, at which point PHREEQC will print an error statement and the run will terminate. The failure may happen during the initial assignment of solutions and geochemical entities or several years into a model run. A file, output/select_mixes, that details each mix and reaction performed by PHREEQC can be output to aid in identifying the reason for the failure. A file is not written when the two parameters xdebug_start(one) and xdebug_stop(one) are set to zero. Alternatively, select_mixes will contain detailed descriptions of all mixes and reactions during initial mixing and reactions for all reservoirs followed by all mixes and reactions

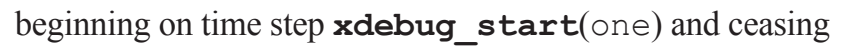
after time step xdebug_stop(one). The IDs of solutions and geochemical entities listed in select_mixes are those listed in the webmod.pqi file or assigned to specific reservoirs by WEBMOD during initialization. Specific reservoirs are described briefly in figure 4 and in more details in the "Geochemical Processes" section. Generally, initial numbers that identrify solutions and entities described in the webmod.pqi file that get distributed to the specific reservoirs in the model domain may be any integer with the following exceptions.

SOLUTION 1 must represent pure water that is removed during evaporation. Pure water consists only of hydrogen and oxygen and is assigned specific isotopic deltas whenever fractionation is being simulated.
Internally, WEBMOD copies the solution integer identification (ID) identified by init_soln_ppt(one) to SOLUTION 1001 that will represent the composition of all precipitation when ppt_chem $(\circ n e)=0$. When ppt_chem(one)=1, SOLUTION 1001 is created at the start of each day using the data in webmod.chem.dat. The SOLUTION number is increased by one (SOLUTION 1002, ...) for other prescribed sources such as upgradient groundwater or external irrigation [initialized with init_soln_ext(nchem_ext)] and water quality observations.

Initial solutions included in the webmod.pqi file are distributed to specific hillslope and stream reservoirs each with a unique ID. All geochemical entities for a reservoir, such as equilibrium phases and kinetics, are assigned the same ID as the SOLUTION ID whenever they are included in the initial conditions. The SOLUTION ID for hillslope reservoirs is a nine-digit integer beginning with either 1 or 2 :

\section{trrmmmnns}

where

$\mathbf{t}$ = Time stamp: 1 = beginning solution, or $2=$ ending solution. When snow melts incongruently, the remaining snowpack is assigned $\mathrm{t}=1$ and the melt assigned $\mathrm{t}=2$.

rr = Hillslope reservoir type:

$01=$ canopy interception

$02=$ snowpack

$03=$ impermeable surfaces

$04=$ O-horizon

$05=$ unique unsaturated zone

$06=$ composite reservoir for unsaturated zone

$07=$ unsaturated zone preferential flow (UZ Pref)

$08=$ saturated zone

$09=$ saturated zone preferential flow (Sat Pref)

$10=$ transient reservoir to mix overland flow, direct flow, pipe flow, and base flow before distributing to stream reservoirs

$11=$ transient reservoir for all hillslope deposition

$12=$ transient reservoir for transpiration

$13=$ transient reservoir for recharge

$14=$ transient reservoir for mixing inputs

$\mathbf{m m m}=$ MRU id for all hillslope reservoir types

$\mathbf{n n}=$ TTI bin, whenever the reservoir type is 05

$\mathrm{s}$ = optional flag for later use. Always zero now.

Transient reservoirs mix and equilibrate solutions only; they cannot be assigned any other geochemical entity.

The SOLUTION ID for stream reservoirs is a nine-digit integer beginning with either 3 or 4 : 


\section{txxxhhhhh}

where

$\mathbf{t}$ = Time stamp: 3 , beginning solution, 4 , ending solution.

$\mathbf{x x x}=$ placeholder for additional drainage dimension (000)

hhhhh = hydraulic segment (for example, stream, lake, and diversion)

\section{Spatial Properties and Topology of the Watershed}

Derivation of the spatial properties and topology of a watershed to be simulated by WEBMOD involves seven steps that can be done manually by using topographic maps and planimeters or by using a GIS operating on a digital elevation model. Whichever method is used, the dimensions and values for parameters listed in table 7 must be added to the parameter file. Dimensions are defined first in the parameter file followed by the parameter values. The parameter file can be created and edited with a text editor (all WEMBMOD input files are ASCII files) or with the Parameter Tool GUI launched by <basin >/webmod_paramtool.bat, which is in the project directory.

In this section, the Loch Vale watershed in Colorado is used to provide an overview of how to define the topology of a watershed. The "Example Problems" section presents (1) a model for the Andrews Creek watershed, a subbasin of Loch Vale, and (2) a model for the heavily managed agricultural fields that flow to the DR2 drain near Yakima, Wash. The details on the derivation of topography, distributed spatial data, and discussion of model results are presented there.

The following is an enumeration of the steps needed to define topology for a WEBMOD model.

1. Select the watershed.-All points upstream from the outlet belong to the watershed; the area (in square kilometers) of the watershed is defined as basin_area(one). In a GIS,

Table 7. Spatial metrics and topology in the Water, Energy, and Biogeochemical Model (WEBMOD).

[The formatting convention used in this report is to present dimension names in Courier New font and parameter names in bold Courier New font. See tables 1 and 2 for descriptions of dimensions and parameters. MRU, model response unit; TTI, transformed topographic index. Abbreviation of units: km², square kilometer; $\mathrm{m}$, meter; $\mathrm{m} / \mathrm{h}$, meter per hour]

\begin{tabular}{|c|c|}
\hline Parameter(Dimension) & $\begin{array}{r}\text { Description } \\
\end{array}$ \\
\hline $\operatorname{ALAT}(o n e)$ & Average latitude of modeled region, in decimal degrees \\
\hline basin_area(one) & Total basin area, in $\mathrm{km}^{2}$ \\
\hline mru_area(nmru) & MRU area, in $\mathrm{km}^{2}$ \\
\hline mru_area_frac(nmru) & MRU area/total basin area \\
\hline mru_slope(nmru) & MRU slope; vertical distance/horizontal distance, unitless \\
\hline mru_aspect(nmru) & MRU aspect, in degrees clockwise from north \\
\hline $\operatorname{ac}(n a c, n m r u)$ & Fractional area wetter than this TTI threshold \\
\hline mru_lat(nmru) & Latitude of MRU, in decimal degrees \\
\hline mru_percent_imperv(nmru) & MRU impervious area as a fraction of the total MRU area \\
\hline mru_psta(nmru) & Index of precipitation station used to compute rain and snow on MRU \\
\hline mru_tsta(nmru) & Index of temperature station used to compute MRU temperatures \\
\hline $\operatorname{mru} 2 \operatorname{chan}(\mathrm{nmru})$ & Index of channel receiving discharge from MRU \\
\hline d(ntopchan, nchan) & $\begin{array}{l}\text { Distance from basin outlet; } \mathrm{d}(1, \mathrm{nchan}) \text { should be the distance upstream from the basin outlet } \\
\text { to the most downstream point of the MRU such that } \operatorname{ach}(1, \mathrm{nchan})=0.0\end{array}$ \\
\hline $\operatorname{ach}(n t o p c h a n$, nchan) & $\begin{array}{l}\text { Fraction of MRU area draining to channel between distance, } \mathbf{d}(1, \mathrm{nchan}) \text {, and subbasin outlet; } \\
\operatorname{ach}(1, \operatorname{nchan})=0.0 \text { and ach }[\text { nchan_d(nchan }), \operatorname{nchan}]=1.0\end{array}$ \\
\hline $\operatorname{chv}(o n e)$ & Main stream channel velocity, in $\mathrm{m} / \mathrm{h}$ \\
\hline qobsta(one) $)^{3}$ & Index of streamflow station for calculating objective function \\
\hline
\end{tabular}

${ }^{1}$ Must be present in parameter file when nhum, the number of stations recording relative humidity, is not equal to zero.

${ }^{2}$ Must be present in parameter file when nevap, the number of stations recording pan evaporation, is not equal to zero.

${ }^{3}$ Must be present in parameter file when nobs, the number of discharge records, is not equal to zero. 
the watershed is conditioned by filling depressions in a digital elevation model to force flow to the outlet, after which grids of flow direction and flow accumulation are derived. The dimension of one means that the parameter is scalar and is defined by a single value. Scalar parameters that apply to the basin include radmax(one), the maximum percent of potential incoming solar radiation on a horizontal surface on a day with no clouds; radj_sppt(one) and radj_wppt(one), the decrease in potential incoming solar radiation on rainy days in the summer and winter, respectively; chv(one), the average channel velocity; chan_loss_rate(one), the bed leakage; and tmax_allsnow_c(one), the temperature threshold dividing rain and snow. The average channel velocity is a key parameter when converting the drainage network to a one-dimensional advection model. Some other parameters that apply to the basin as a whole have dimensions greater than one. For example, the lapse rates tmin_lapse(nmonths) and tmax_lapse(nmonths) provide distinct lapse-rate values for each month. See table 2 for a complete listing of basin parameters.

2. Delineate the drainage network.-The drainage network is a key component of watershed topology. The channels in the network are a natural boundary separating hillslopes with distinct slopes, aspects, and loadings of solar radiation. The channels and the riparian areas also form the conduit through which all hillslope discharge must flow on its journey to the outlet, and all MRUs must indicate one, and only one, channel to receive the runoff and base flow generated in that MRU [mru2 chan(nmru)]. A drainage network can be defined quantitatively as the convergence of flow directions and associated flow accumulation on a digital elevation model or qualitatively by perennial streams commonly drawn as blue lines on topographic maps. For a simple demonstration of the conversion of hillslope discharge to a one-dimensional advection model, the drainage network of the Loch Vale watershed will consist of three channels (nchan=3): the Loch Vale channel, the Andrews Creek channel, and the Icy Brook channel (fig. 9), each draining one of three subbasins. The blue lines shown on figure 9 include all points in the watershed where flow accumulation exceeds $1 \mathrm{~km}^{2}$. These lines approximate the blue lines, or perennial streams, shown on the topographic maps that include the Loch Vale watershed. Subbasins are not restricted to points of confluence; therefore, a subbasin can include the left bank, the right bank, or both banks of a channel, or even a single area that includes area upstream and downstream from a confluence. Whatever delineation is used, the distance from the outlet and flow accumulation must be computed for channel routing points in the channels that carry the runoff from the hillslopes to the basin outlet.

3. Define channel routing.-In WEBMOD, a twodimensional drainage network is reduced to a one-dimensional geomorphic unit hydrograph by computing contributing areas

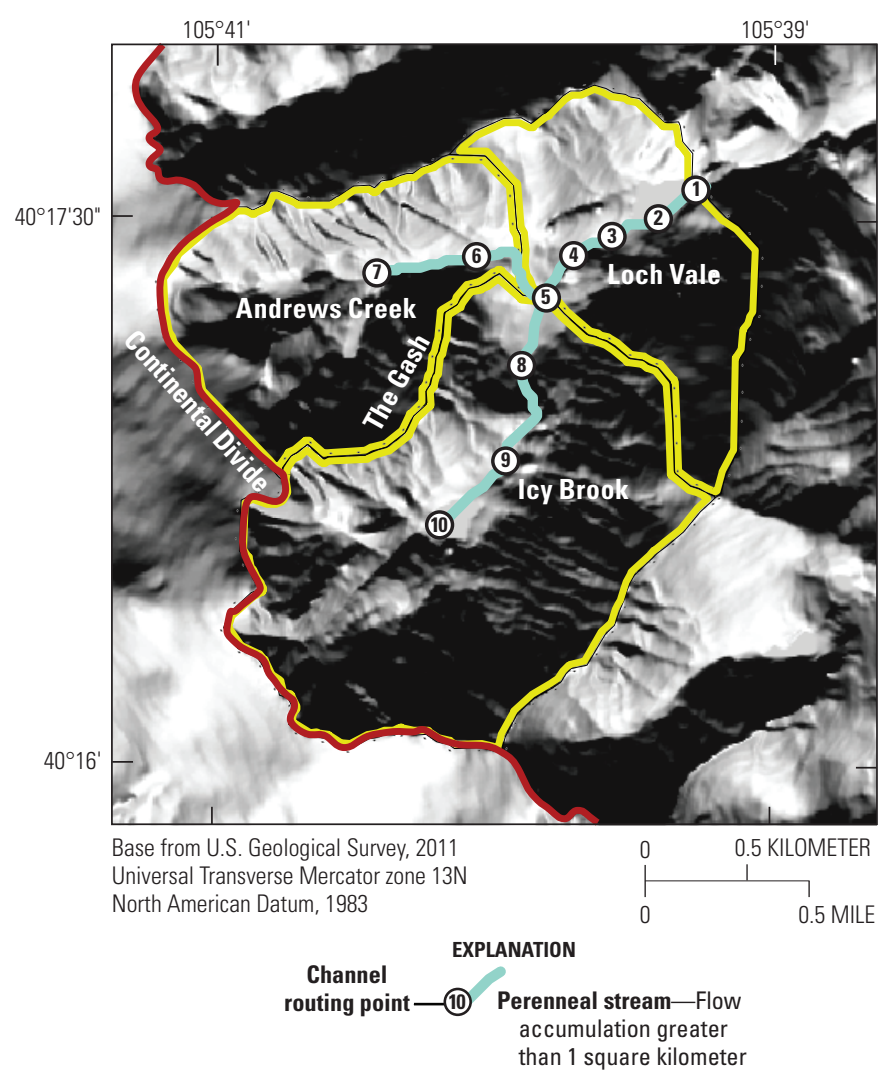

Figure 9. Shaded relief map of the Loch Vale watershed with solar illumination typical of noon on the day of equinox (from the south and a declination of 40 degrees). Blue stream lines are drawn where flow accumulation for the grid cells exceeds 1 square kilometer $\left(\mathrm{km}^{2}\right)$. Circled numbers are channel routing points.

and travel times to the outlet (Clark, 1945; Kirkby, 1976). Both the Andrews Creek watershed and the DR2 watershed in the "Example Problems" section are small enough that all hillslope runoff exits the watershed in less than a day; thus, a single stream reservoir (nhydro=1) is used to mix and react hillslope discharge and divert water for irrigation before exiting at the watershed outlet on the same time step. For larger watersheds, the time to reach the outlet may be greater than one day such that nhydro will be greater than one. The following methodology is used to determine nhydro: a series of stream channels (nchan) that drain to the outlet are defined. For several points on each channel [nchan-d(ntopchan)], determine the distance to the outlet, $\mathbf{d}(n c h a n, n t o p c h a n)$, and the cumulative fractional area of the subbasin draining between that point and the subbasin outlet, ach(nchan,ntopchan) (tables 2 and 8). The cumulative fraction for each routing point on a channel is computed as follows: 


$$
a c h_{\text {chan } \_d}=\left(f a c_{\max }-f a c_{d}\right) /\left(f a c_{\max }-f a c_{\min }\right)
$$

where

$$
\begin{gathered}
a c h_{\text {chan } d} \text { is the cumulative fraction of flow between } \\
\text { the point chan_d and the subbasin outlet, } \\
\text { dimensionless number between } 0.0 \text { and } 1.0 \\
\text { inclusive [ach(nchan,ntopchan)]; } \\
f a c_{\text {max }} \text { is the flow accumulation for the channel at the } \\
\text { subbasin outlet, in square meters; } \\
f a c_{d} \text { is the flow accumulation at the point chan_d; and } \\
f a c_{\text {min }} \text { is the flow accumulation at the most upstream } \\
\text { point in the subbasin, in square meters. }
\end{gathered}
$$

These two spatial parameters operate in conjunction with the average channel velocity, $\operatorname{chv}(o n e)$, to determine the volumes and timing of water moving from the hillslopes to the outlet. The number of points for each channel is a parameter nchan-d(nchan) and has a minimum value of two, the most downstream and the most upstream points on the channel, and a maximum value of $n t o p c h a n$. The cumulative fractional area $\operatorname{ach}(n c h a n, n t o p c h a n)$ is 0.0 at the first point, which is always at the most downstream point of the channel, and increases with each distance point until reaching 1.0 at the most upstream point on the channel. The maximum time, in hours (h), for water to travel from the farthest point in the watershed drainage to the outlet is determined by dividing the maximum distance $\mathbf{d}(\mathrm{nchan}, \mathrm{ntop}$ chan), in meters (m), by the average channel velocity $\operatorname{chv}(o n e)$, in meters per hour $(\mathrm{m} / \mathrm{h})$. The dimension nhydro must be set to the same integer value as the number of time-delay ordinates, computed as the constant variable CLARK_SEGS. CLARK_SEGS is equal to the integer greater than the maximum travel time divided by the computational time step of 24 hours. For example, in the Loch Vale watershed, the maximum distance from the outlet to the most upstream point of Icy Brook is 3,490 $\mathrm{m}$ (table 8). If the average channel velocity $\operatorname{chv}(\circ n e$ ) were $50 \mathrm{~m} / \mathrm{h}$, then the maximum travel time would be $69.8 \mathrm{~h}$ (2.9 days). Therefore CLARK_SEGS would equal 3. If the average channel velocity were $400 \mathrm{~m} / \mathrm{h}$, as estimated for Andrews Creek, then the maximum travel time would be $8.7 \mathrm{~h}$ and CLARK_SEGS would equal 1. The Andrews Creek channel-between channel routing points 6 and 7 on figure 9 - is $560 \mathrm{~m}$ long with an average channel velocity of $400 \mathrm{~m} / \mathrm{h}$ (Clow and others, 2003) so only a single stream reservoir is used and all MRU runoff is mapped to that reservoir [nhydro=1, and mru2chan(imru=1-10)=1]. If nhydro is not set equal to the computed value of CLARK_SEGS in the parameter file, the user will be notified, and the run will be stopped. Each of nhydro stream reservoirs can be assigned specific geochemical reactions and can be selected as a source of water
Table 8. Stream channel topology for a three-subbasin Loch Vale model.

[The formatting convention used in this report is to present dimension names in Courier New font and parameter names in bold Courier New font. See tables 1 and 2 for descriptions of dimensions and parameters. Parameter values for d(ntopchan, nchan) and ach(ntopchan, nchan) are grayed out where they exceed nchan_d(nchan), the number of $d$, ach pairs used to assign time-delay ordinates for routing for each channel (minimum of two pairs). Grayed out zeros pad the $\mathbf{d}$ and ach parameter arrays as the parameter file must contain ntopchan $\times$ nchan values. Figure 9 shows the following channels, channel routing points, and associated subbasins: (1) Loch Vale, (2) Andrews Creek, and (3) Icy Brook. Channel routing point 6 is at the location of the Andrews Creek streamgage. $\mathrm{km}^{2}$, square kilometer]

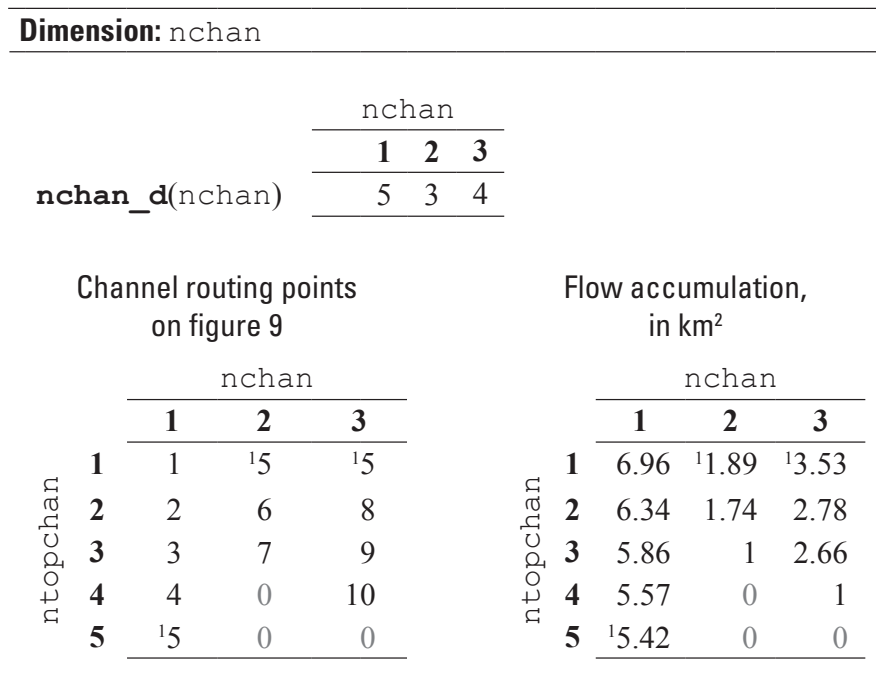

Dimension: ntopchan, nchan

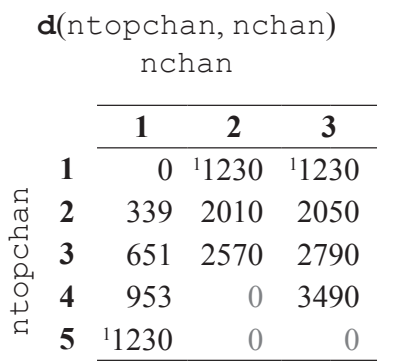

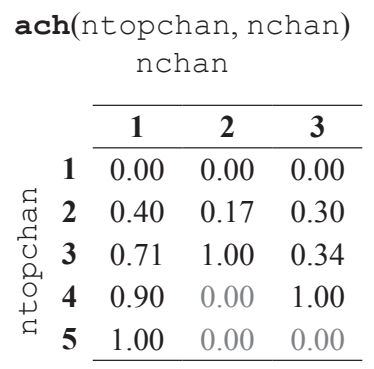

${ }^{1}$ Point 5 on figure 9 represents the most upstream point for the Loch Vale channel and the most downstream point for both the Andrews Creek and Icy Brook channels. Therefore, the flow accumulation for the most upstream point of the Loch Vale channel $\left(5.42 \mathrm{~km}^{2}\right)$ is the sum of the flow accumulations for Andrews Creek $\left(1.89 \mathrm{~km}^{2}\right)$ and Icy Brook $\left(3.53 \mathrm{~km}^{2}\right)$.

for irrigation. Whereas stream reservoirs in WEBMOD have volumes, they have no surface area and therefore receive no direct precipitation and lose no water to evaporation. The stream reservoirs may, however, exchange gas with the atmosphere as prescribed by init_eq_ph_hydro(nhydro). 
4. Identify MRUs.-The MRUs are hillslopes or areas that differ in aspect, soils, or dominant land cover. The number of MRUs is dimensioned nmru. In areas of high relief such as Loch Vale, MRUs are most commonly selected on the basis of aspect because slopes with southern exposure receive substantially more incoming solar radiation than slopes with northern exposure (in the northern hemisphere). For interior subbasins, the divide between MRUs is usually a stream or an extension of the perennial stream uphill to the divide. Ten MRUs were delineated for the Andrews Creek watershed (fig. 10).

5. Define TTI bins.-Each MRU is further discretized into areas with similar TTI. The topographic index (TI) is computed for each point in an MRU as a/tan $\beta$ (Kirkby, 1975; Beven and Kirkby, 1979; O'Loughlin, 1981), where "a" is the upslope contributing area, in square meters, and $\tan \beta$ is the tangent of the slope. Transmissivity of the soil at saturation, To(nmru), in square meters per hour, is assumed to be spatially homogenous for each MRU. As described in Ambroise and others (1996a), the nature of decreasing transmissivity with depth can be determined from observed discharge (Q)

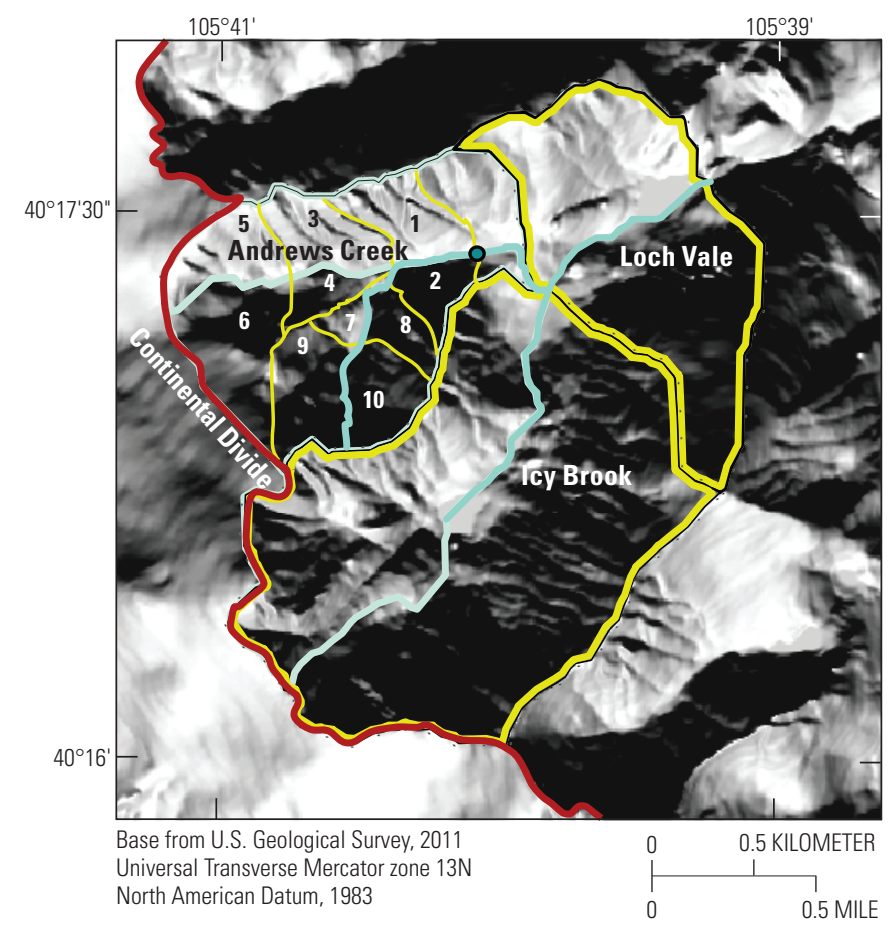

Figure 10. Subbasins of Loch Vale and the 10 model response units (MRUs) for the Andrews Creek model. Blue lines are along drainages, and yellow lines are on ridges or interfluves. The $10 \mathrm{MRUs}$ in the Andrews Creek subbasin above the Andrews Creek gage (green dot) are modeled in the "Quick Start Guide" and in example 1. The MRUs 1, $3,5,7$, and 9 have a warmer southern exposure, and the MRUs 2, 4, 6 , 8 , and 10 have cooler northern exposures. during recession periods. Where values of transformed discharge $1 / \mathrm{Q}, 1 / \sqrt{\mathrm{Q}}$, or $\ln (\mathrm{Q})$ are linear with time, the suggested transmissivity profile, T_decay (nmru), and associated TTI would be exponential [T_decay $(\mathrm{nmru})=0$, TTI $=\ln (\mathrm{TI})$; Beven and Kirkby (1979)], parabolic [T_decay $(\mathrm{nmru})=1$, $\mathrm{TTI}=\sqrt{\mathrm{TI}}$; Ambroise and others (1996b)] $\overline{\text {, or linear }}$ $[$ T_decay $(\mathrm{nmru})=2$, TTI=TI; O'Loughlin (1981)], respectively. When using the parabolic or linear profiles, the ratio of transmissivity at saturation [To(nmru)] to the recession parameter [ $\mathbf{s z m}(\mathrm{nmru})]$ is constrained by the slope of transformed discharge and the drainage area upstream from the measured discharge. When using the exponential profile, however, the ratio of transmissivity to the recession parameter is unconstrained. The relations are described further in the saturated zone section of "Hillslope Processes." Base-flow recessions observed in Andrews Creek from 2001 to 2009 were more linear when plotted as $1 / \sqrt{\mathrm{Q}}$ compared to $1 / \mathrm{Q}$ or $\ln (\mathrm{Q})$; therefore, a parabolic transmissivity curve [T_decay $(\mathrm{nmru})=1]$ was used. The surface of interest for st(nac,nmru) and TL(nmru) in the Andrews Creek model is therefore $\sqrt{\mathrm{a} / \tan \beta}$. The mean value of TTI for each MRU is then assigned to $\mathbf{T L}(\mathrm{nmru})$. The number of TTI bins in each MRU is defined by the parameter nacsc(nmru); the maximum number of TTI bins for all MRUs is defined by the dimension nac. The parameter nacsc(nmru) will equal nac for most models. Each bin is defined by a TTI threshold [st(nac,nmru)], in units of $\ln (\mathrm{TI}), \sqrt{\mathrm{TI}}$, or TI, and a fraction of the MRU area [ac(nac,nmru)] that is wetter (lower TTI value) than the threshold. The first TTI threshold $\mathbf{s t}$ (inac $=1, \mathrm{nmru}$ ) is the maximum value of TTI in the MRU such that the fractional area ac (inac $=1, \mathrm{nmru}$ ) that is wetter than the threshold is always equal to 0.0 . The sum of all ac(nac,nmru) for each MRU must equal 1.0. The spatial distribution of $\sqrt{\mathrm{TI}}(\sqrt{\mathrm{a} / \tan \beta})$ for the Loch Vale watershed is shown in figure 11 . Note the high values for $\sqrt{\mathrm{TI}}$ in the area south of the loch. This area is a broad ridge covered with alpine tundra where the water table is indeed close to the surface. This example highlights the fact that wet areas are not always nearest to the river.

6. Derive the parameters for each process.-For each MRU, derive the parameters described for each process in the "Hydrologic Simulations" and "Geochemical Simulations" sections. Each parameter should be reviewed to ensure that the parameter is appropriate for the region of interest. Certain scenarios can lead to parameters being inactive; in which case, the parameters are ignored. For example, when geochemistry is not simulated [chem_sim(one) $=0$ ], the initial solution assigned to precipitation [init_soln_ppt(one)] and all other geochemical parameters will be ignored. 


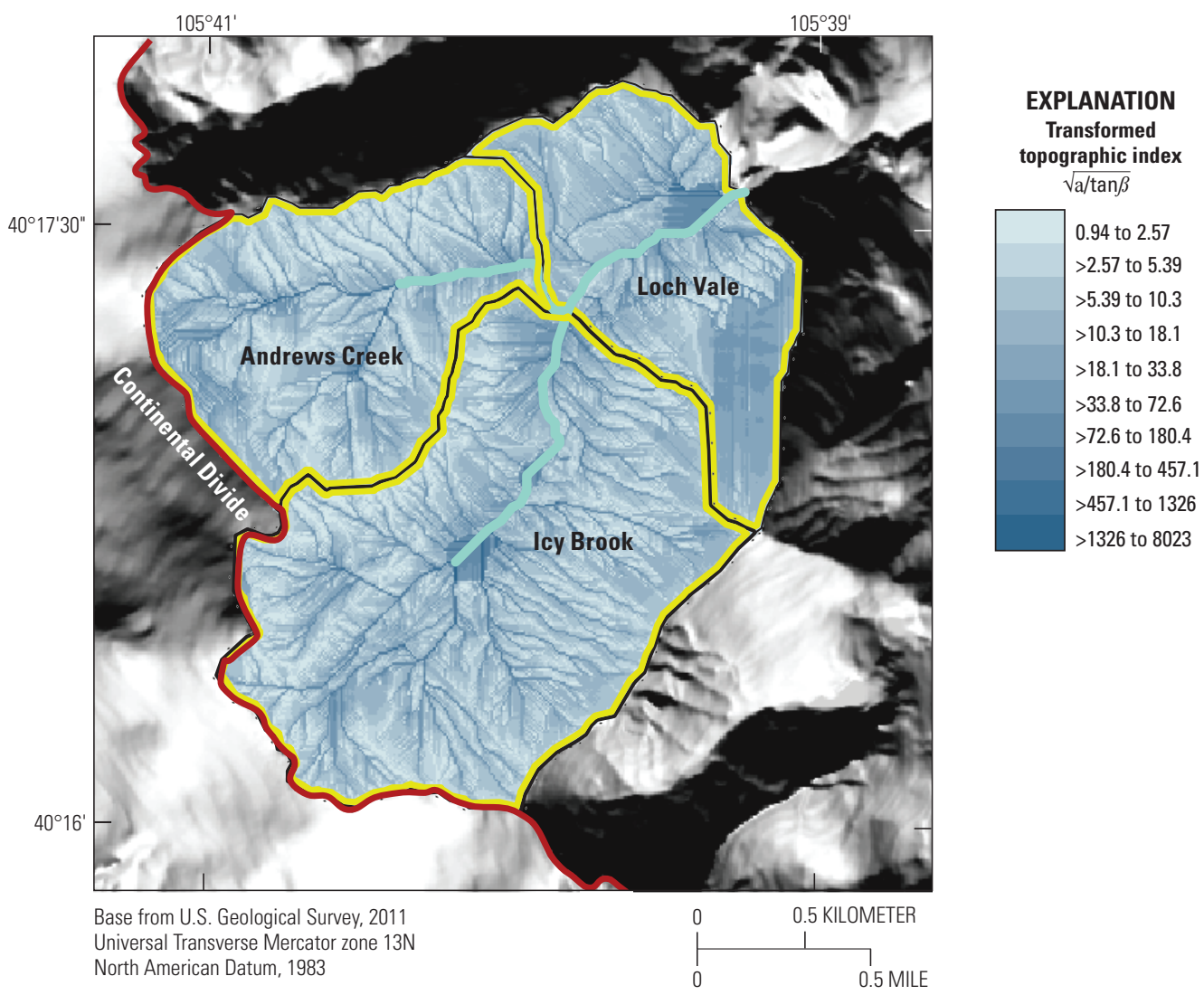

Figure 11. Map of the transformed topographic index (TTI), $\sqrt{\mathrm{a} / \tan \beta}$, for the Loch Vale watershed. (a, upslope area; $\beta$, tangent of the slope)

7. Transfer all dimensions and parameters to the parameter file.-Dimensions are in the first section followed by parameters in the second section. Four hash marks serve as a record delimiter. Dimensions or parameters are not required to be in a specific order. Note that the number of each type of observation in the hydrologic data file must be consistent with the dimension size listed in the parameter file.

8. Link MRUs to precipitation, temperature, irrigation, and diffuse groundwater sources.-The simplest WEBMOD model simulates hydrology for a single MRU driven by precipitation and temperature that are observed at a single meteorological station. For larger watershed areas, many MRUs could still be simulated with one set of meteorological observations. In keeping with the philosophy of only adding complexity where needed, the many-to-one approach is used throughout the design of WEBMOD. Many MRUs can rely on data from the same meteorological station and can be irrigated with the same irrigation schedule with water drawn from the same source. When simulating water quality, the concentrations of solutes in the precipitation, irrigation, and diffuse sources of groundwater can be used by multiple MRUs; additionally, the concentrations can be constant or can vary daily if the complexity can be justified. The parameters that connect each MRU to the data describing the precipitation, temperature, irrigation, and diffuse groundwater sources are listed in table 9. The last column in the table lists the variables that can be displayed in graphs or written to output files to verify that the watershed topology is defined correctly.

Although WEBMOD does some error checking, such as checking that the sum of the individual MRU areas equals the basin area, the model cannot detect some errors that can have profound effects on the model simulation. An example of an error that would be difficult to detect is if the altitude of a meteorological station was entered in meters and the altitude of the MRU was in feet. This inconsistency could possibly cause no generated runoff because the lapse-rate-corrected temperatures in the MRU would never be above freezing; therefore, all precipitation would fall as snow and would never melt. Another common error is assignment of the wrong meteorological station to an MRU, which would result in an erroneous distribution of precipitation and temperature. 
Table 9. Indices for assignment of model response units to precipitation, temperature, relative humidity, pan evaporation, irrigation, and diffuse groundwater along with indices used to assign water chemistry to watershed inputs.

[Geochemistry is simulated when the parameter chem $\operatorname{sim}(\circ n e)=1$. The formatting convention used in this report is to present file names in italic font, dimension names in Courier New font, variable names in bold italic Courier New font, and parameter names in bold Courier New font. See tables 1, 2, and 3 for descriptions of dimensions, parameters, and variables. MRU, model response unit]

\begin{tabular}{|c|c|c|c|c|}
\hline \multicolumn{5}{|c|}{ Indices } \\
\hline Parameter(Dimension) & Upper bound & Description & Source of data & $\begin{array}{c}\text { Example of dependent } \\
\text { Variable(Dimension) }\end{array}$ \\
\hline \multicolumn{5}{|c|}{ Precipitation and temperature } \\
\hline mru_psta(nmru) & nrain & Index of precipitation station for MRU & precip(nrain) field in webmod.hydro.dat file & mru_ppt(nmru) \\
\hline ppt_chem(one) & 0 & $\begin{array}{l}\text { Solute concentrations in precipitation } \\
\text { held constant }\end{array}$ & init_soln_ppt(one) in webmod.pqi file & cconc_precipM(nsolute) \\
\hline ppt_chem(one) & 1 & $\begin{array}{l}\text { Solute concentrations in precipitation } \\
\text { vary daily }\end{array}$ & Data field in webmod.chem.dat file & cconc_precipM(nsolute) \\
\hline mru_tsta(nmru) & ntemp & Index of temperature station for MRU & $\begin{array}{l}\text { tsta_min_c(ntemp) and tsta_max_c(ntemp) fields } \\
\text { in webmod.hydro.dat file }\end{array}$ & $\begin{array}{l}t \operatorname{tmin}-c(\mathrm{nmru}) \text { and } \\
t \max -c(\mathrm{nmru})\end{array}$ \\
\hline mru_rhsta(nmru) & nhum & Index of relative humidity station for MRU & $\begin{array}{l}\text { relhum(nhum) or spechum(nhum) fields in } \\
\text { webmod.hydro.dat file }\end{array}$ & relhum_mru(nmru) \\
\hline mru_pansta(nmru) & $\mathrm{n}$ & Index of temperature station for MRU & $\begin{array}{l}\text { tsta_min_c(ntemp) and tsta_max_c(ntemp) fields } \\
\text { in webmod.hydro.dat file }\end{array}$ & $\begin{array}{l}t \operatorname{tmin} c(\mathrm{nmru}) \text { and } \\
\operatorname{tmax} c(\mathrm{nmru})\end{array}$ \\
\hline \multicolumn{5}{|c|}{ Discharge } \\
\hline mru2chan(nmru) & nchan & $\begin{array}{l}\text { Index of channel receiving discharge } \\
\text { from MRU }\end{array}$ & None; directs MRU runoff to stream segment & qchanin_m(nchan) \\
\hline qobsta(one) & nobs & $\begin{array}{l}\text { Index of discharge at watershed outlet; } \\
\text { used for computing objective function }\end{array}$ & runoff(nobs) field in webmod.hydro.dat file & runoffm(one) \\
\hline & nchemobs & Ancillary water sample observations & conc_obs(nchemobs) field in webmod.chem.dat file & cconc_obsM(nchemobs,nsolute) \\
\hline \multicolumn{5}{|c|}{ Irrigation (active if irrig_sched_ext orirrig_sched_int is not zero) } \\
\hline irrig_sched_ext(nmru) & nirrig_ext & $\begin{array}{l}\text { Index of external irrigation schedule for MRU; } \\
\quad 0 \text { if none }\end{array}$ & irrig_ext(nirrig_ext) field in webmod.hydro.dat file & irrig_ext_mru(nmru) \\
\hline src_ext_irrig(nmru) & nchem_ext & Chemical source for external irrigation & & \\
\hline chem_ext(one) & 0 & $\begin{array}{l}\text { Solute concentrations for external sources } \\
\text { held constant }\end{array}$ & init_soln_ext(nchem_ext) in webmod.pqi file & cconc_extM(nchem_ext,nsolute) \\
\hline chem_ext(one) & 1 & $\begin{array}{l}\text { Solute concentrations for external sources } \\
\text { vary daily }\end{array}$ & conc_ext(nchem_ext) fields in webmod.chem.dat file & cconc_extM(nchem_ext,nsolute) \\
\hline irrig_sched_int(nmru) & nirrig_int & $\begin{array}{l}\text { Index of internal irrigation schedule for MRU; } \\
0 \text { if none }\end{array}$ & $\begin{array}{l}\text { irrig_int_next(nirrig_int) fields in } \\
\text { webmod.hydro.dat file }\end{array}$ & $\begin{array}{l}\text { irrig_sat_mru(nmru) if from well; } \\
\quad \text { irrig_hyd_mru(nmru) if from stream }\end{array}$ \\
\hline irrig_int_src(nmru) & nhydro & $\begin{array}{l}\text { If } 0 \text {, irrigation from well in MRU; if }>0 \text {, points } \\
\text { to one of nhydro segments as source }\end{array}$ & $\begin{array}{l}\text { Internally computed water chemistry of saturated zone or } \\
\text { one of nhydro stream segments }\end{array}$ & ch_mru_in_mg $(\mathrm{nmru}, \mathrm{nsolute})^{1}$ \\
\hline \multicolumn{5}{|c|}{ Diffuse groundwater inputs (active if sched_gw1 or sched_gw2 is not zero) } \\
\hline sched_gw1(nmru) & ngw_ext & $\begin{array}{l}\text { Index of time series describing groundwater in- } \\
\text { puts into the MRU from the } 1 \text { st groundwater } \\
\text { source outside the basin; } 0 \text { if none }\end{array}$ & gw_ext(ngw_ext) fields in webmod.hydro.dat file & gw_in1(nmru) \\
\hline src_gw1(nmru) & nchem_ext & $\begin{array}{l}\text { Chemical source for 1st groundwater influx } \\
\text { (channel leakage) }\end{array}$ & conc_ext(nchem_ext) fields in webmod.chem.dat file & $\begin{array}{l}\text { cconc_extM(nchem_ext,nsolute), } \\
\text { ch_mru in mgL(nmru,nsolute })^{1}\end{array}$ \\
\hline sched_gw2(nmru) & ngw_ext & $\begin{array}{l}\text { Index of time series describing groundwater in- } \\
\text { puts into the MRU from the } 2 \text { nd groundwater } \\
\text { source outside the basin; } 0 \text { if none }\end{array}$ & gw_ext(ngw_ext) fields in webmod.hydro.dat file & $g w_{-} \overline{i n} 2(n \bar{m} r u)^{-}$ \\
\hline src_gw2(nmru) & nchem_ext & $\begin{array}{l}\text { Chemical source for } 2 \text { nd groundwater } \\
\text { influx (upgradient) }\end{array}$ & conc_ext(nchem_ext) fields in webmod.chem.dat file & $\begin{array}{l}\text { cconc_extM(nchem_ext, nsolute), } \\
\text { ch mru in mgL(nmru,nsolute })^{1}\end{array}$ \\
\hline
\end{tabular}

${ }^{1} c h \_m r u \_$in_mgL(nmru,nsolute) is the average concentration of the precipitation, irrigation, and groundwater inputs combined. 


\section{Andrews Creek Simulation and Calibration}

The following sections demonstrate how to run and calibrate the 10-MRU Andrews Creek model contained in the $\mid$ WEBMOD_1.0|projects $\backslash$ Andrews_tutorial $\backslash$ directory. The objective is to simulate the discharge and chemistry of waters sampled at the Andrews Creek gage during 1991-2012. The demonstration is accompanied by a series of screen grabs that guide the user through specific steps without providing an exhaustive explanation of every option available.

Building and calibrating the model involved compilation and interpolation of data from a variety of sources described for Andrews Creek in the "Example Problems" section and was followed by adjustments to dozens of hydrologic and geochemical parameters. Similarly, the variables selected for output to Run Time Plots and to the webmod.statvar files changed as the role of different reservoirs and different processes in the watershed hydrology and geochemistry came into focus.

The calibration presented in this manual is intentionally simplified as follows: one hydrologic parameter [snow_adj (nmru,nmonths)] and the flag parameter to simulate geochemistry [chem_sim(one)] are changed in the webmod.params file; the surface area per volume parameter for oligoclase, a common feldspar, is changed for the unsaturated and saturated zones in the webmod.pqi file; and the simulation period and Run Time Plots are modified in the webmod.control file. The webmod.control file references the input and output files. For example, the parameter file is described in the webmod.control file with the parameter param_file(one), which is defined as.linput|webmod.params. Changes to webmod.control and webmod.params can be made in a text editor or in the MMS Tool GUI or Parameter Tool GUI. Use of the GUIs, whenever convenient, is recommended because files written by the GUIs will have consistent dimensions and parameters. However, some manual editing is required for geochemical simulations because the GUIs cannot assign the solute names to the nsolute dimensions, and the GUIs cannot add two dimensional variables to the Run Time Plots or webmod.statvar files.

After completion of this tutorial, the control file and input files in the .|Andrews_tutoriall directory should be almost identical to the final calibrated model in the. $\mid$ Andrews $\mid$ directory that is described in detail in the "Example Problems" section. The purpose of the "Example Problems" section is to demonstrate the basic steps in running and calibrating a WEBMOD model. The user can then copy the Andrews Creek or DR2 model to a separate |project 1 directory and modify input data and parameter files to begin constructing a model for the watershed of interest. All parameters and variables are described in the context of specific hydrologic and geochemical processes in subsequent sections.

Initial inspection of the miscalibrated Andrews Creek model directory (. Andrews_tutorial $)$ reveals the following files and directories.

The webmod.bat file opens a command window, writes model self-documentation (see webmod_print.bat) to the |control directory, and then executes WEBMOD as configured in webmod.control. Standard control files direct the model to read from the $\mid$ input $\mid$ directory and write to the $\mid$ output $\mid$ directory. Nominal descriptions and any errors or warnings are written either to the command window or to the file webmod.log. Model output is written to the loutput $\mid$ directory.

The webmod_gui.bat file opens a command window, writes model self-documentation to the $\mid$ control $\mid$ directory, reads input data and parameters files, and then opens the MMS Tool GUI. The MMS Tool GUI provides the user an interface to load and save standard data, parameters, and output files; edit dimensions and parameters; select the period of time to be simulated; and select variables for output to Run Time Plots or files for post-processing. Changes made in the MMS Tool GUI are usually written immediately to the webmod.control file without the need to specifically "Save" the file. In contrast, any changes made to parameters by using the Parameter Tool GUI, which can be accessed either within the MMS Tool GUI or by running the Parameter Tool GUI in standalone mode (see below), need to be "Saved" so that the changes will be included in the next model run. The MMS Tool GUI, developed as an interface with the PRMS watershed model, can also be used as an interface for WEBMOD. However, certain functions, such as naming the solutes for geochemical simulations and specifying output of two-dimensional variables, require modification of the webmod.control file in a text editor outside of the MMS Tool GUI.

The webmod paramtool.bat file opens a command window, writes model self-documentation to the $\mid$ control $\mid$ directory, reads the parameter file, and then opens the Parameter Tool GUI. The Parameter Tool GUI is useful for viewing and modifying model dimensions and parameters. The GUI can be accessed from the "Edit" menu in the MMS Tool GUI or can be opened in standalone mode. As model calibration proceeds, the user will likely be using the output files more than the Run Time Plots; therefore, the Parameter Tool provides a quick and easy way to modify selected parameters before running the model again in batch mode. The Parameter Tool GUI allows for editing of two-dimensional parameters and also provides descriptions of specific dimensions and parameters. The first time that a user clicks the Describe button with the cursor in the parameter table, the user will need to navigate to the $\mid$ control $\mid$ directory and select the webmod.control.par name file.

The webmod_print.bat file interrogates the model by using the -print option such that model self-documentation is written to the |control directory, but no hydrologic or geochemical simulations are run. The model self-documentation consists of four files.

- The webmod.control.mod_name file lists the modules in order of execution and ancillary coordinates that were used in earlier model GUIs. The order of modules is viewable in the MMS Tool GUI by clicking on the expander node (looks like a key) in the lower right pane of the initial MMS Tool GUI window. Pane dividers and field widths may have to be manually adjusted by using click and drag on divider bars to make the information viewable. 
- The webmod.control.par name file lists all parameters and their dimensions, the module they were first defined in, short and long descriptions, their units, acceptable range, and default values. This file is the source of information when the Describe button is pressed in the Parameter Tool GUI.

- The webmod.control.var_name file lists all variables and their dimensions, the module they were first defined in, descriptions, and their units.

- The webmod.control.param file is a copy of the input parameters used in the model. Values for nonintegers are printed in scientific notation with 12 decimal places (double precision); rounding errors may appear as artifacts for single precision variables.

The |control $\mid$ directory initially contains only the webmod.control file. After the first model run, or after running webmod print.bat, four additional files will be written as described earlier.

The |input $\mid$ directory is where hydrologic and geochemical inputs are stored along with files necessary to define the geochemical simulations.

- The webmod.hydro.dat file contains precipitation observations from Bear Lake; precipitation, minimum and maximum temperature, solar radiation, and relative humidity measured at USGS 401719105394311 Main Weather Station-Loch Vale-RMNP, CO, referred to as Main Weather Station; and discharge observed at Andrews Creek, Icy Brook, and the Loch Vale outlet.

- The webmod.chem.dat file contains solute concentrations measured in precipitation and Andrews Creek. Only the precipitation samples, which were collected by the NADP, affect the simulated model concentrations. All days between NADP sample collections are assigned the same $\mathrm{pH}$ and solute concentrations measured in the bulk sample. The concentration data from Andrews Creek are used for calibrating the geochemical processes.

- The webmod.params file contains the dimensions and parameters for a 10-MRU model of the Andrews Creek watershed.

- The phreeqc_web_lite.dat file is the generic PHREEQC database used to simulate aqueous geochemistry, which includes thermodynamic and kinetic rate definitions that can be used to model mineral weathering, secondary mineralization, and isotopic fractionation.

- The webmod.pqi file has two functions: (1) it amends the phreeqc_web_lite.dat file with initial solutions, specific mineral stoichiometry, equilibrium phases, and rates specific to the Andrews Creek watershed, and (2) it defines initial solutions and reactant entities that are distributed to the hillslopes of the Andrews Creek model.
- The phreeq_lut file is a list of solutes and their properties. Any solute of interest must be listed in this file. During initialization of a model run, a PHREEQC input file, phreeqmms.pqi, will be written to the $\mid$ input $\mid$ directory as part of the model run. This file lists specific instructions for PHREEQC to track the solutes of interest in the form of SELECTED_OUTPUT and USER_PUNCH data blocks that are placed above a copy of the webmod.pqi file. The phreeqmms.pqi file is rewritten with each model run and can be deleted once the simulation is completed.

The loutput $\mid$ directory initially does not contain output files. The parameters in the webmod.control and webmod.params files determine the names and content of the output files that are written to the $\mid$ output $\mid$ directory.

\section{Batch Run}

Execute webmod.bat in a command window while in the $<$ basin $>$ directory or by double-clicking on the file in a Windows Explorer window. The program will echo the start time and the list of modules included in WEBMOD_1.0; will indicate the initial volume of water in the watershed, in cubic meters; will notify the user that the variable for specific humidity, spechum(nhum), is not in the data file (this is okay since the relative humidity observed at the temperature station, relhum(nhum), is being used instead); will warn the user that no geochemistry will be simulated (chem_sim $=0$ ), so all chemical variables will uninitialized; will simulate hydrology for the Andrews Creek model for water years 1983 through 2012; will print the time of the end of the run; and then will pause for the user to hit Enter to dismiss the window. (A water year is the 12-month period beginning October 1 for any given year through September 30 of the following year. The water year is designated by the calendar year in which it ends.) The run should complete in less than 5 seconds, and if successful, the loutput $\mid$ directory will contain the hydrologic output file webmod.hydro.out, the TOPMODEL output file webmod.topout, a solute summary file webmod.chem.out, and the webmod.statvar file that contains 22 user-configured geochemical variables for each day. Because the parameter file included with the tutorial has the parameter chem_sim(one) initially set to zero, no geochemistry is simulated and all geochemical variables in the webmod.statvar file remain at the initial value of zero.

\section{Interactive Runs}

The following exercise presents 45 steps to run the model in interactive mode, to view and amend Run Time Plots, and to adjust parameters affecting the run period and the hydrologic and geochemical simulations (fig. 12). 
$\boldsymbol{A}$

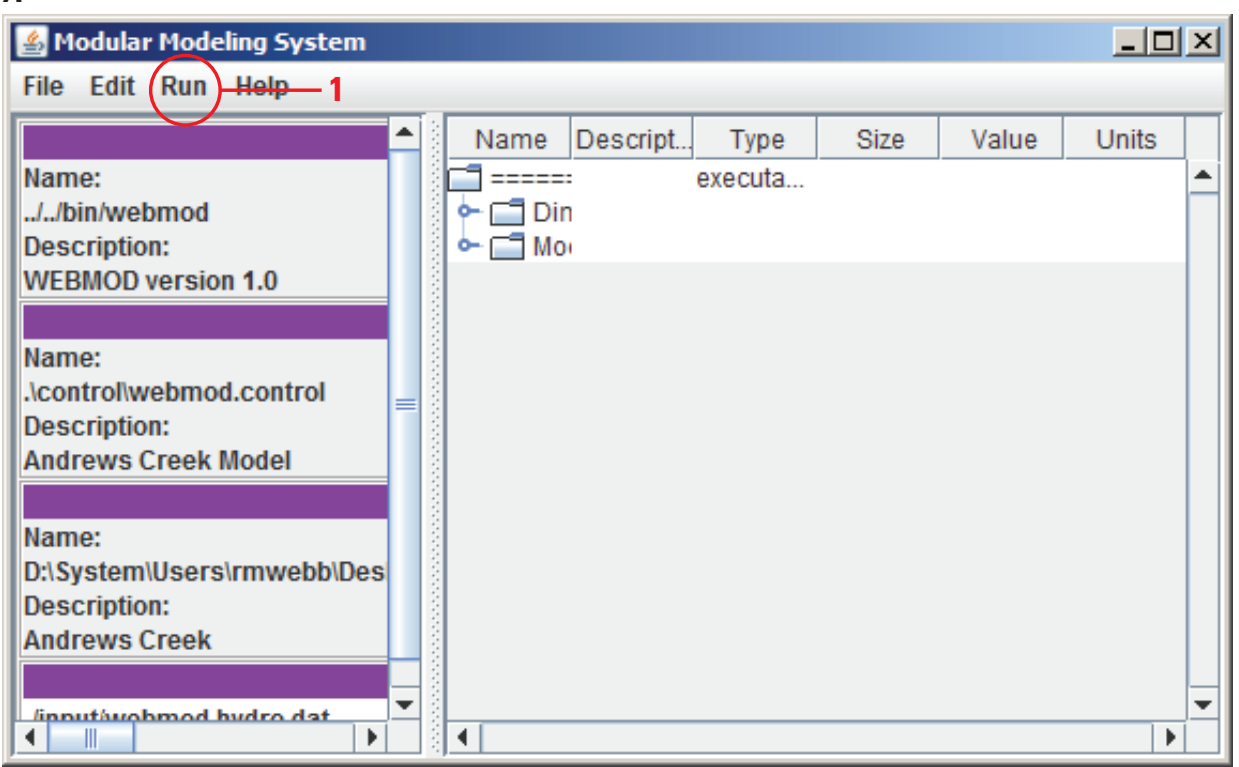

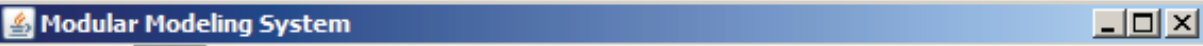

File Edit Run Help

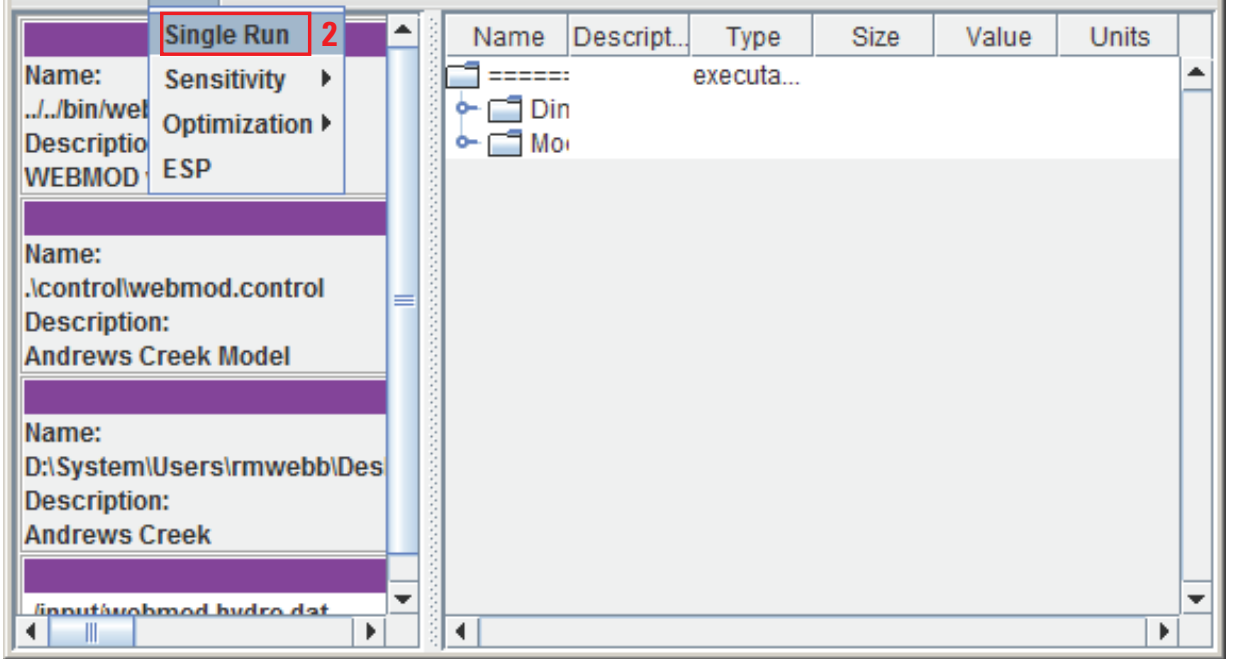

Figure 12. Screen images that demonstrate the execution and calibration of the Andrews Creek model using the Modular Modeling System Tool graphical user interface. A, Steps 1-2. B, Steps 3-4. C, Steps 5-6. D, Steps 7-16. E, Steps 17-18. F, Steps 19-30. G, Steps 31-38. H, Steps 39-43. I, Steps 44-45. 
B

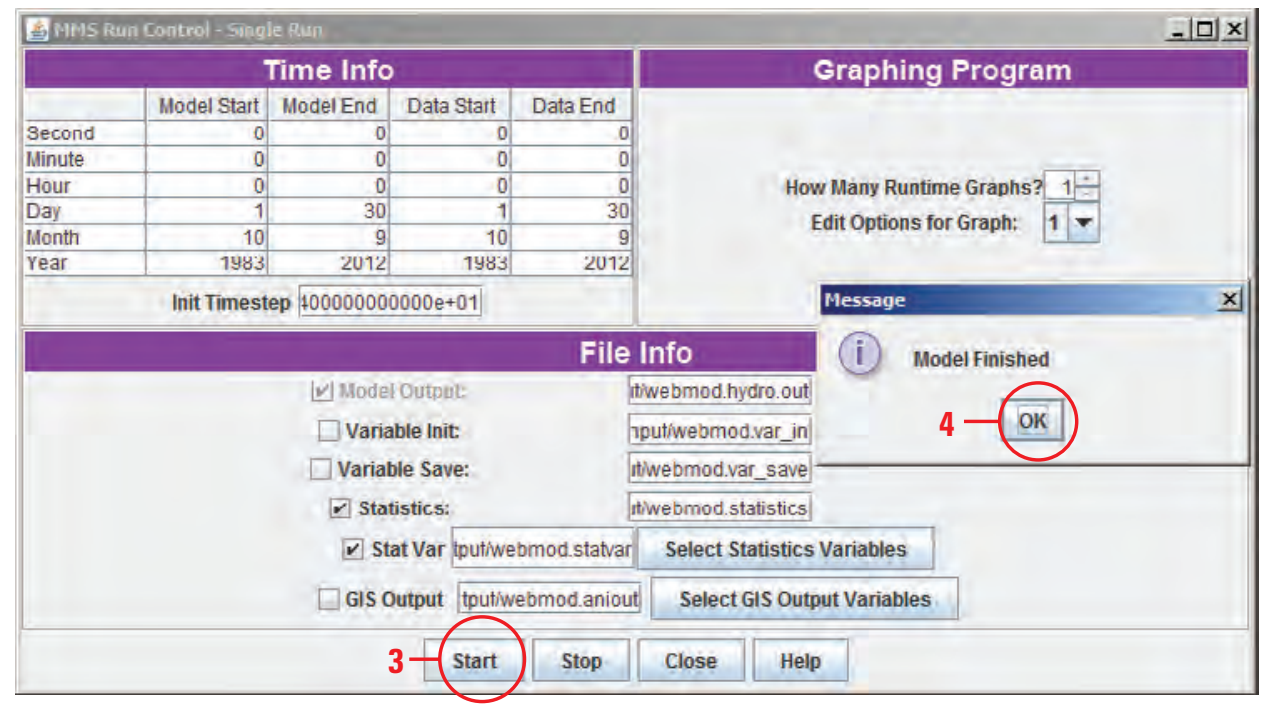

@MF Run Time Plots $\quad$ - $|\square| \underline{x}$

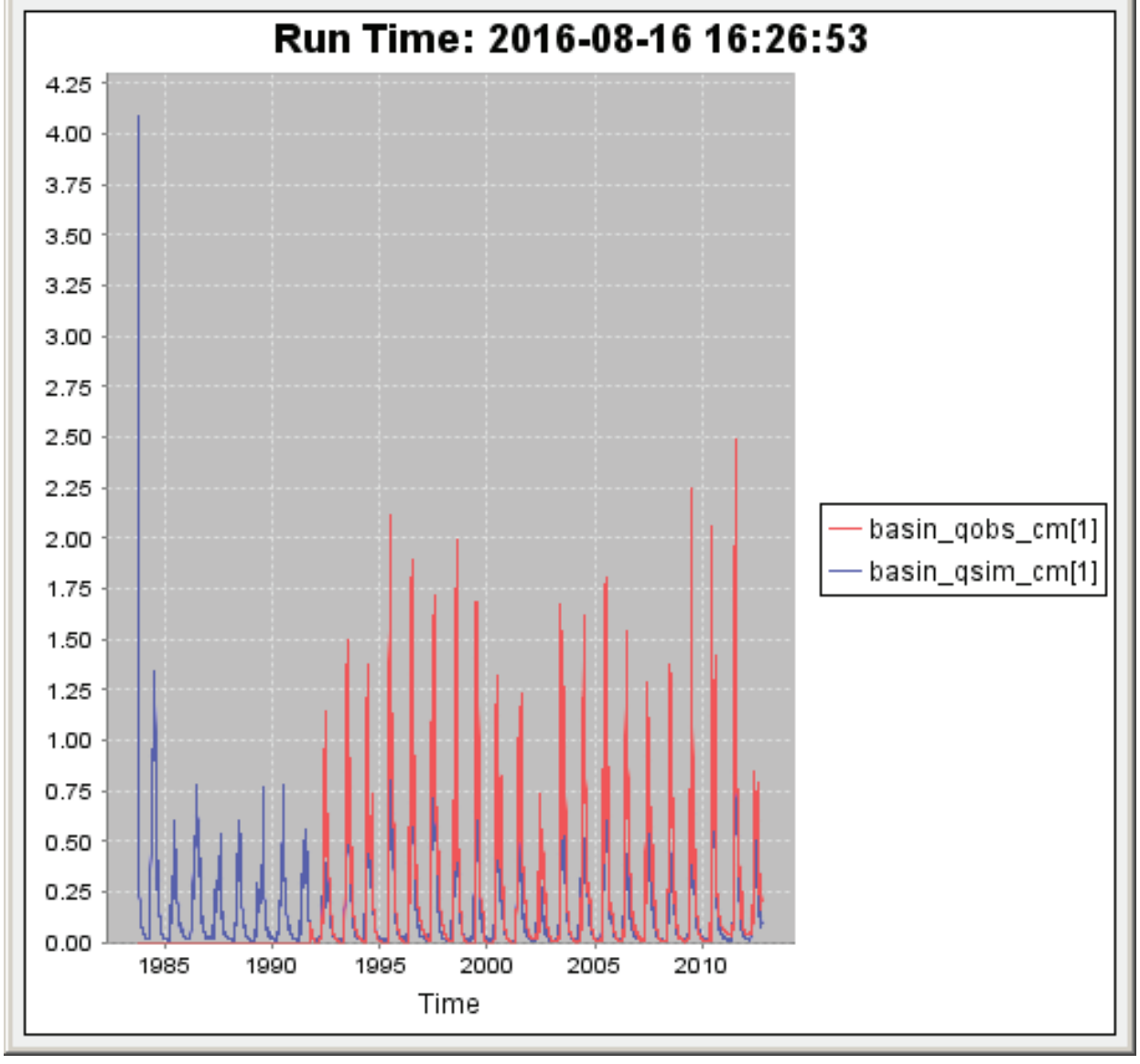

Figure 12. Screen images that demonstrate the execution and calibration of the Andrews Creek model using the Modular Modeling System Tool graphical user interface. A, Steps 1-2. B, Steps 3-4. C, Steps 5-6. D, Steps 7-16. E, Steps 17-18. F, Steps 19-30. G, Steps 31-38. $H$, Steps 39-43. I, Steps 44-45.-Continued 
C
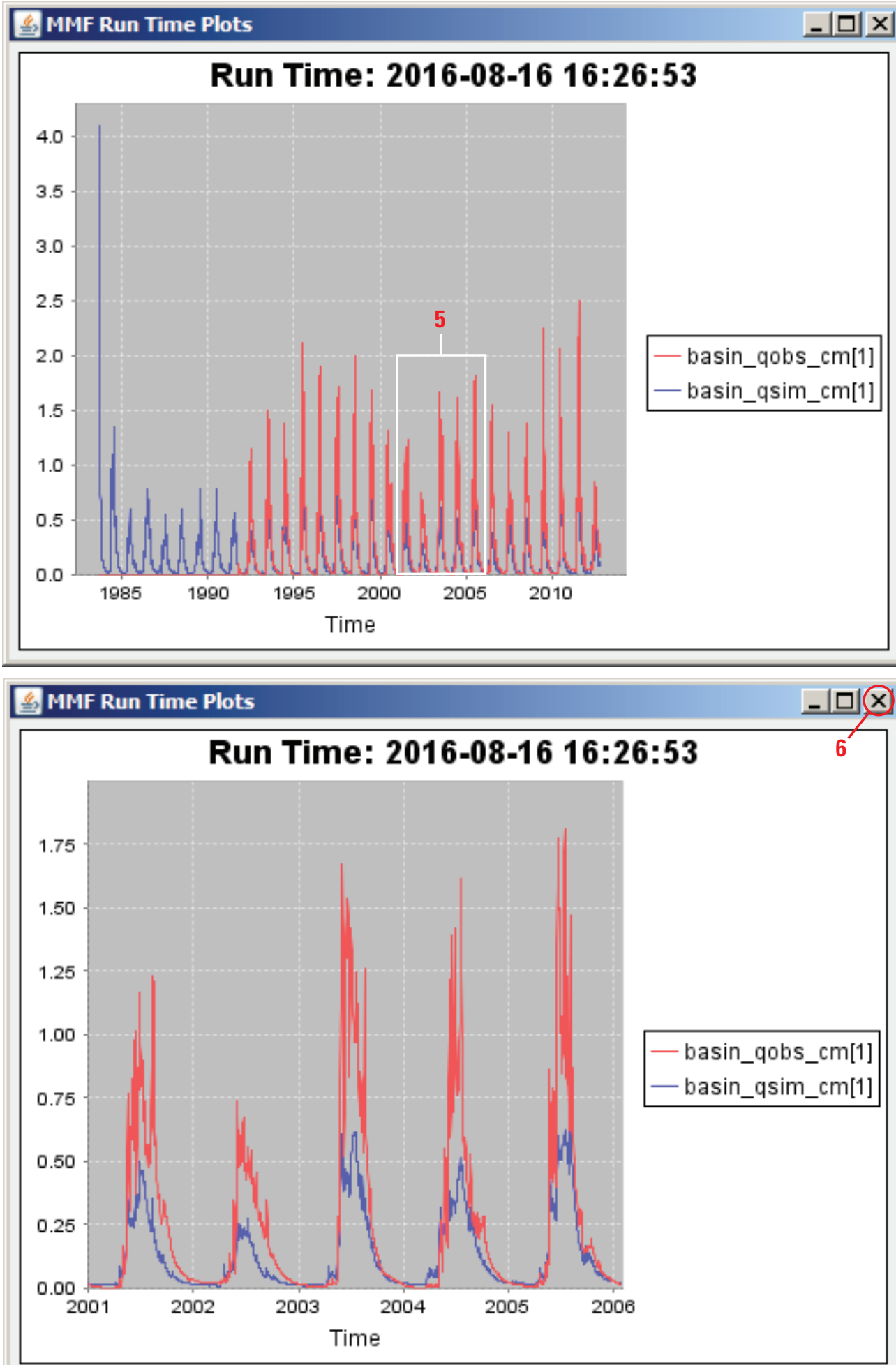

Figure 12. Screen images that demonstrate the execution and calibration of the Andrews Creek model using the Modular Modeling System Tool graphical user interface. A, Steps 1-2. B, Steps 3-4. C, Steps 5-6. D, Steps 7-16. E, Steps 17-18. F, Steps 19-30. G, Steps 31-38. H, Steps 39-43.

I, Steps 44-45.-Continued 


\section{D}

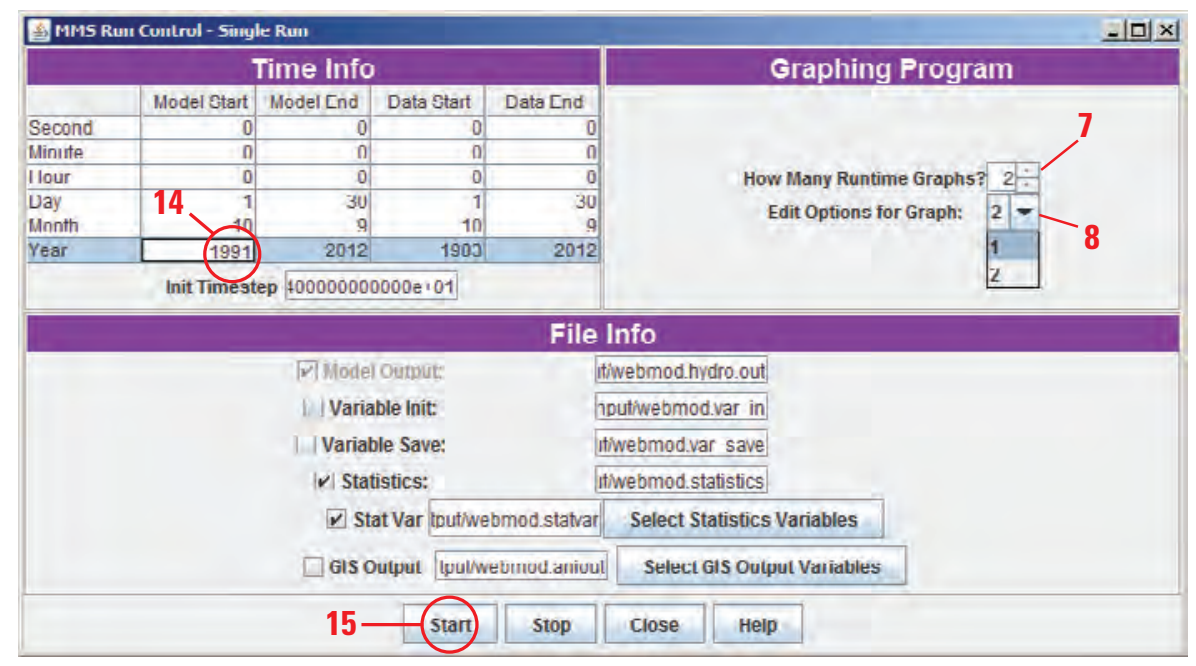

\begin{tabular}{|c|c|c|c|}
\hline MMS - Select Variables for Run Tí & & & $-|\square| x \mid$ \\
\hline Available Variables & & Selected Variables & \\
\hline newsnow & $\Delta$ & pkwater_equiv[3] & \\
\hline obj_func & & pkwater_equiv[10] & \\
\hline obj_func_sum & & & \\
\hline orad & 9 & & \\
\hline p & & & \\
\hline pkwater_equiv 10 & $\downarrow$ & & \\
\hline potet & $\equiv$ & & \\
\hline pptmix & & & \\
\hline pptmix_nopack & $=$ & & \\
\hline Describe & & Select To Delete & \\
\hline & ex & (10) $>11,12$ & \\
\hline $13-\mathrm{OK}$ & Can & cel & \\
\hline
\end{tabular}

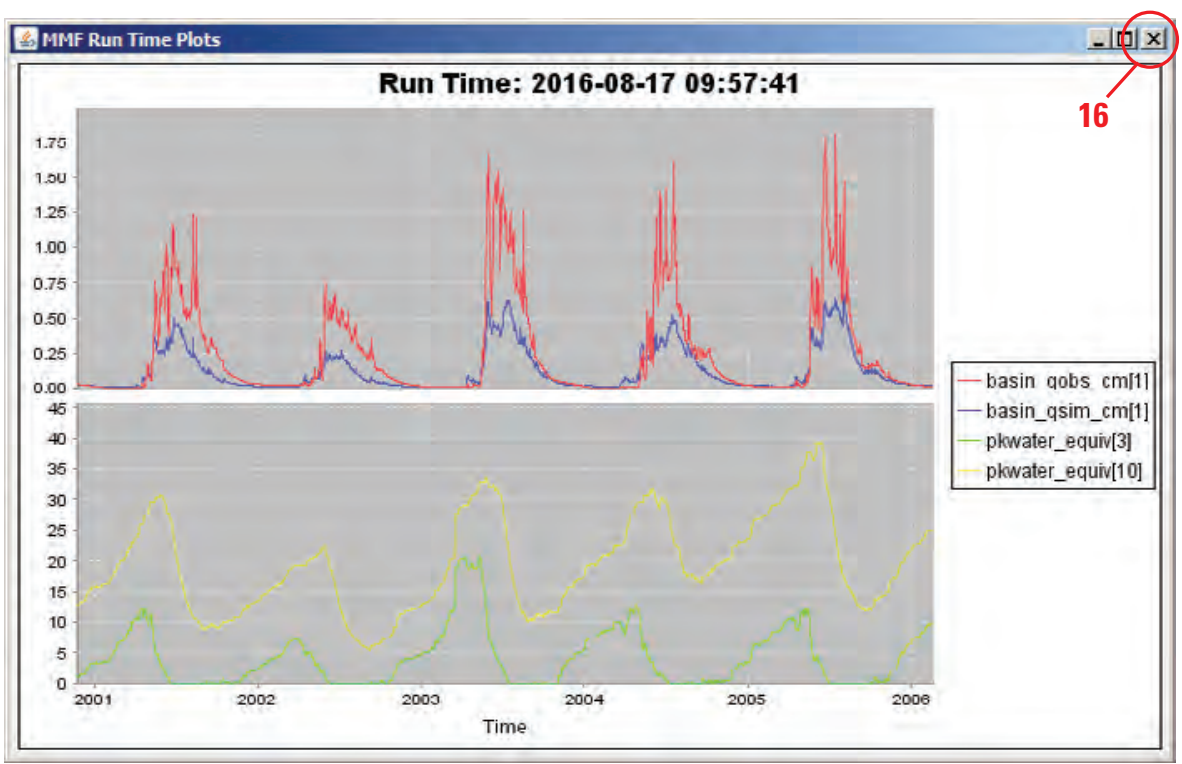

Figure 12. Screen images that demonstrate the execution and calibration of the Andrews Creek model using the Modular Modeling System Tool graphical user interface. A, Steps 1-2. B, Steps 3-4. C, Steps 5-6. D, Steps 7-16. E, Steps 17-18. F, Steps 19-30. G, Steps 31-38. H, Steps 39-43. I, Steps 44-45.-Continued 

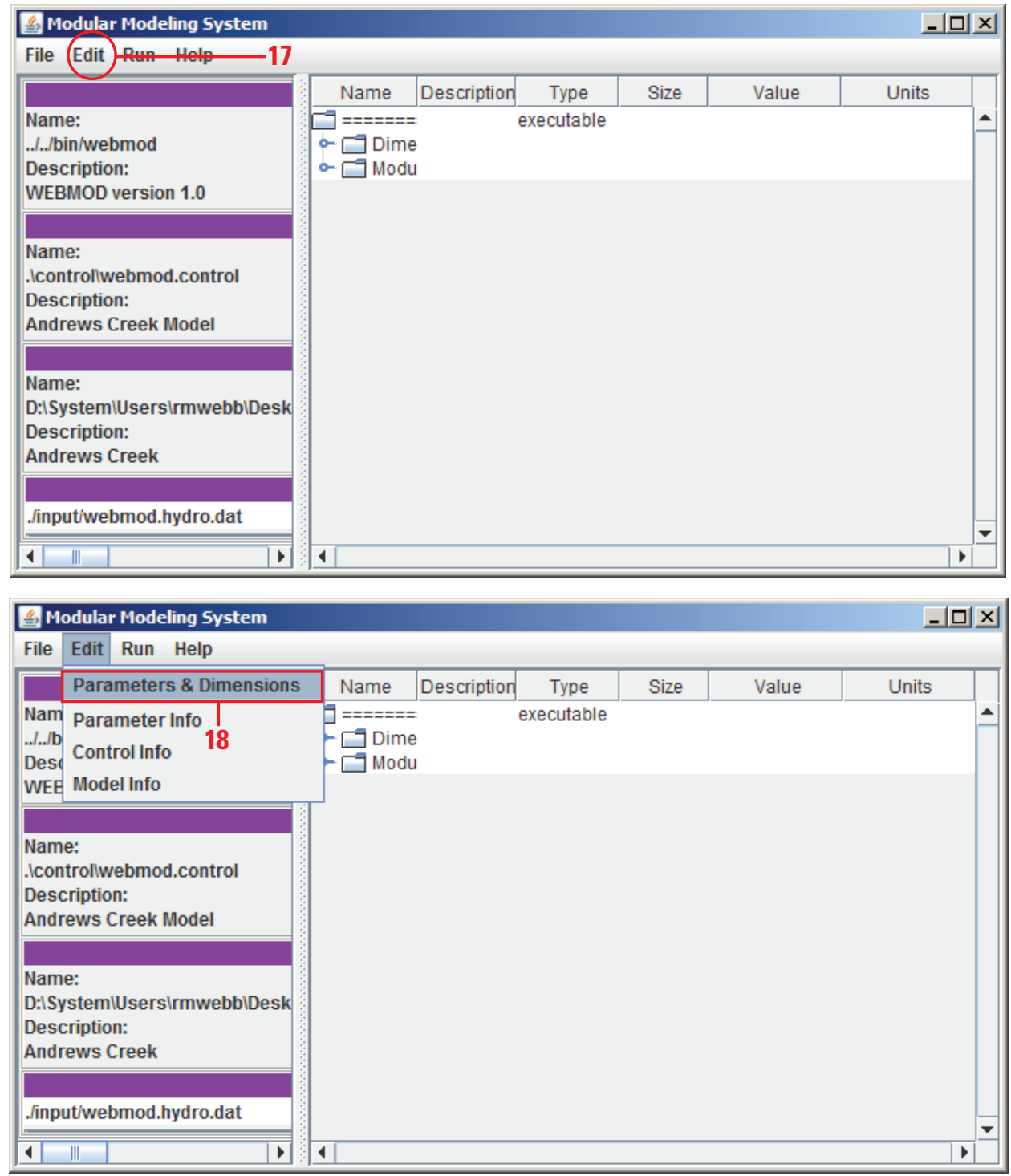

Figure 12. Screen images that demonstrate the execution and calibration of the Andrews Creek model using the Modular Modeling System Tool graphical user interface. A, Steps 1-2. B, Steps 3-4. C, Steps 5-6. D, Steps 7-16. E, Steps 17-18. F, Steps 19-30. G, Steps 31-38. H, Steps 39-43. I, Steps 44-45.-Continued 
$\boldsymbol{F}$
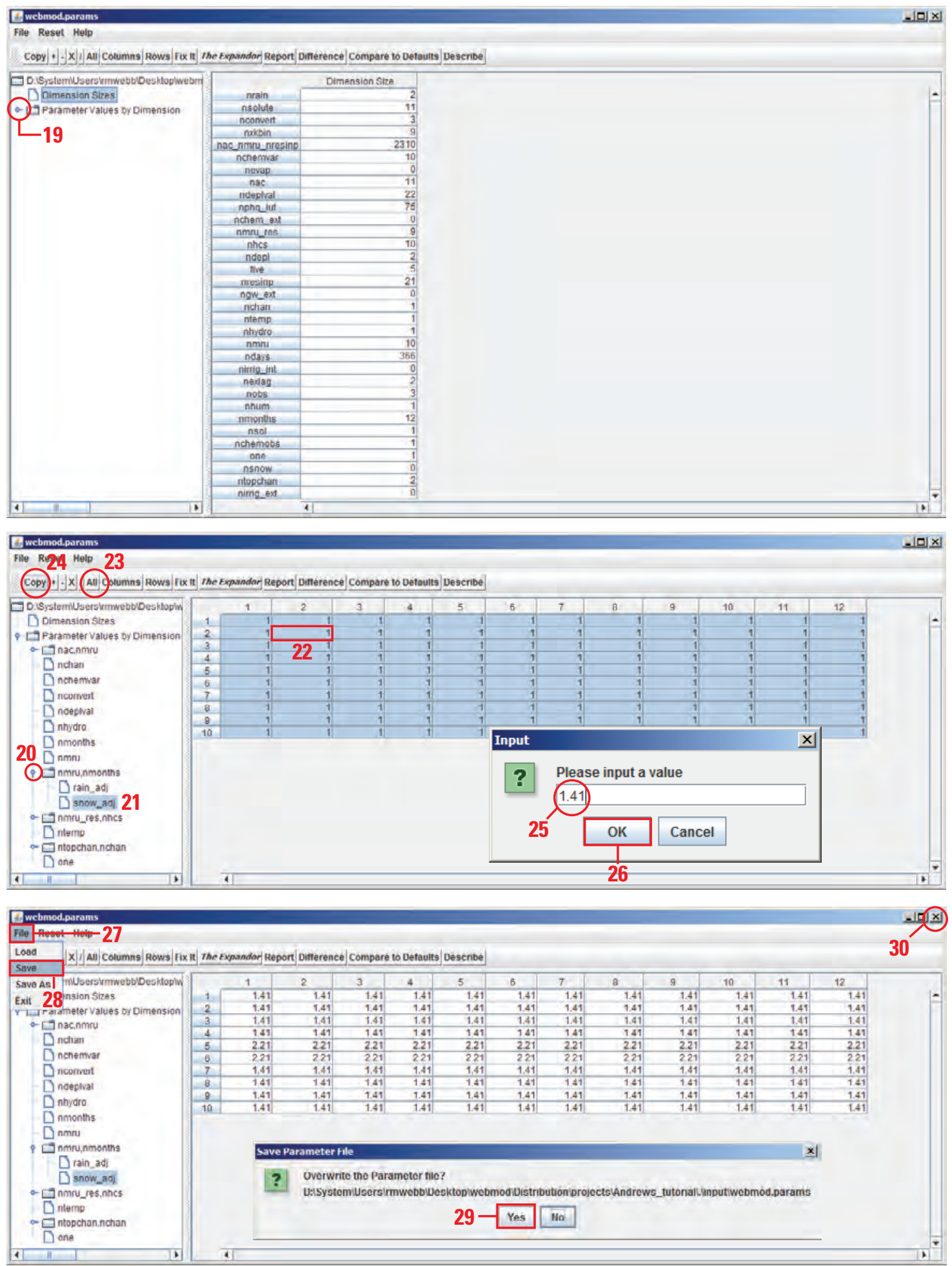

Figure 12. Screen images that demonstrate the execution and calibration of the Andrews Creek model using the Modular Modeling System Tool graphical user interface. A, Steps 1-2. B, Steps 3-4. C, Steps 5-6. D, Steps 7-16. E, Steps 17-18. F, Steps 19-30. G, Steps 31-38. H, Steps 39-43. I, Steps 44-45.-Continued 
G
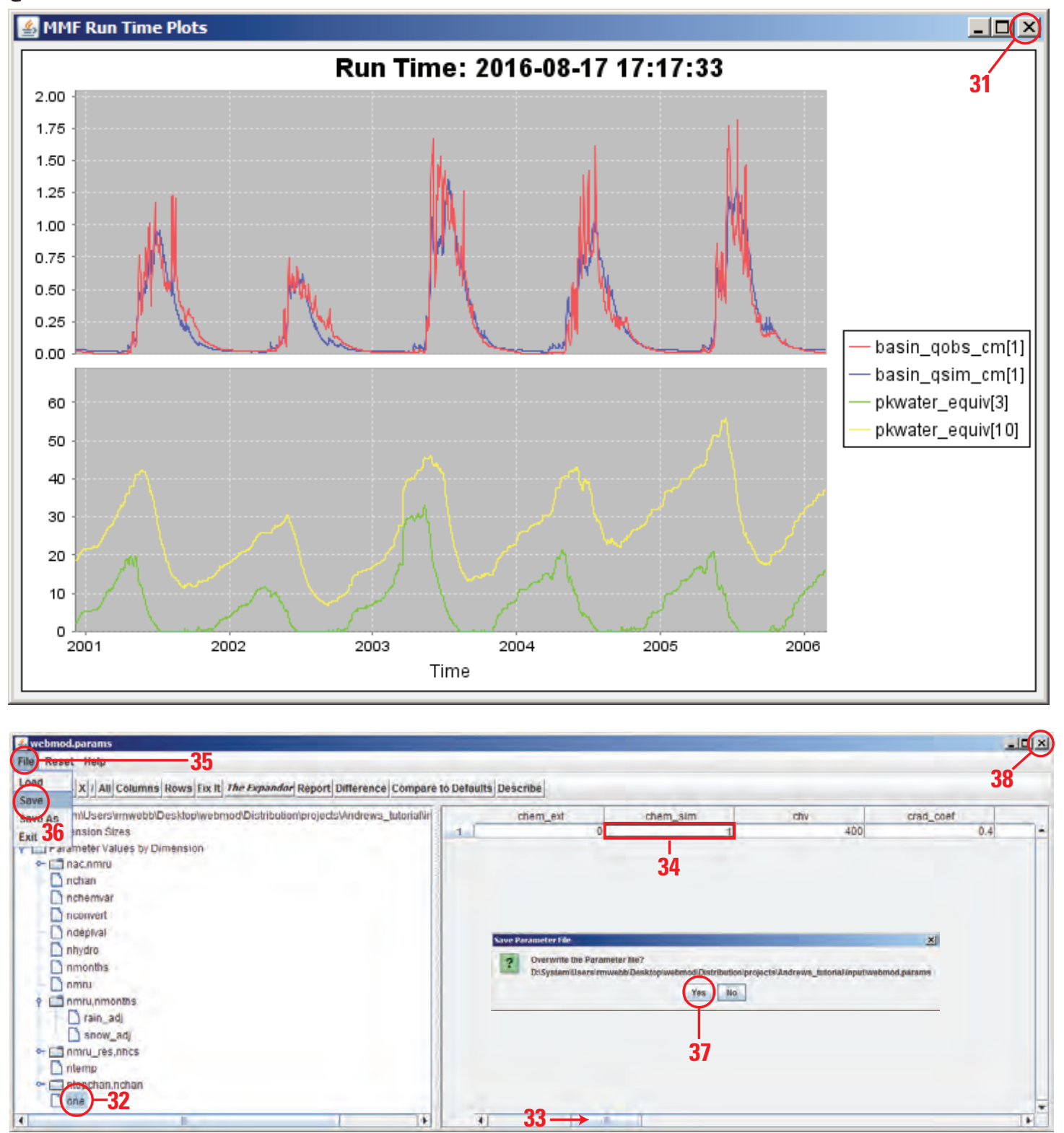

Figure 12. Screen images that demonstrate the execution and calibration of the Andrews Creek model using the Modular Modeling System Tool graphical user interface. A, Steps 1-2. B, Steps 3-4. C, Steps 5-6. D, Steps 7-16. E, Steps 17-18. F, Steps 19-30. G, Steps 31-38. H, Steps 39-43. I, Steps 44-45.-Continued 


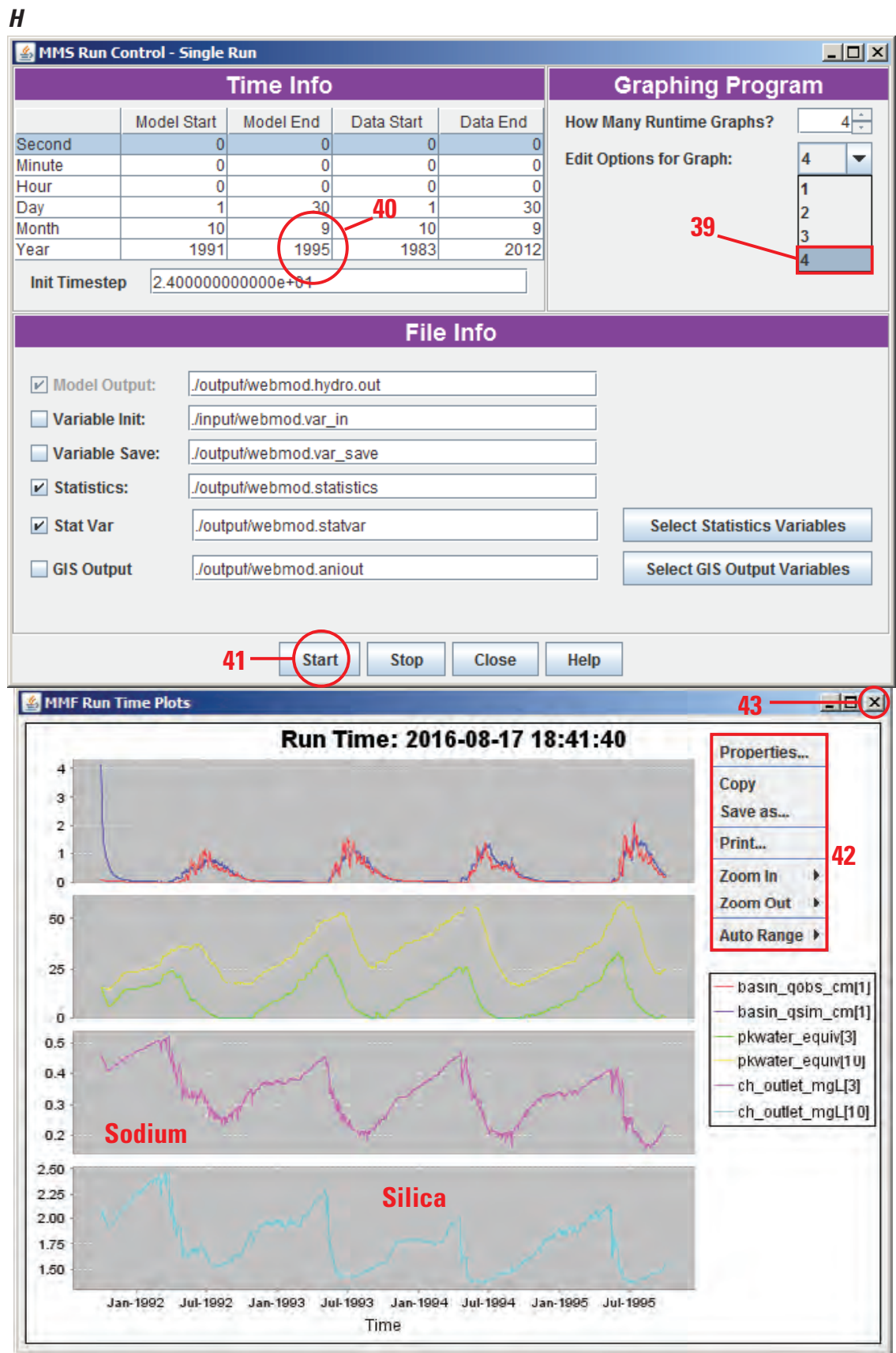

Figure 12. Screen images that demonstrate the execution and calibration of the Andrews Creek model using the Modular Modeling System Tool graphical user interface. A, Steps 1-2. B, Steps 3-4. C, Steps 5-6. D, Steps 7-16. E, Steps 17-18. F, Steps 19-30. $G$, Steps 31-38. H, Steps 39-43. I, Steps 44-45.-Continued 
I
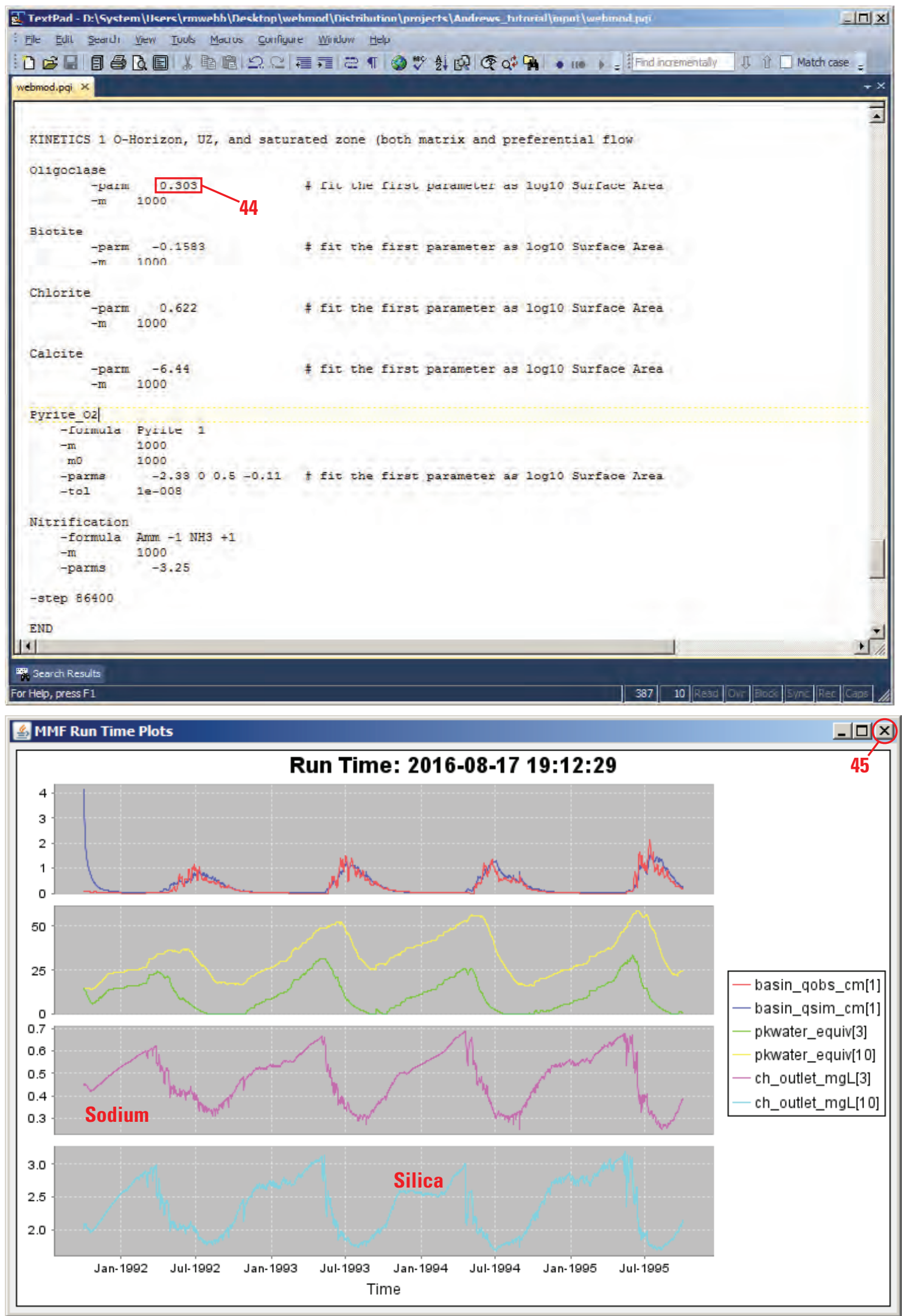

Figure 12. Screen images that demonstrate the execution and calibration of the Andrews Creek model using the Modular Modeling System Tool graphical user interface. A, Steps 1-2. B, Steps 3-4. C, Steps 5-6. D, Steps 7-16. E, Steps 17-18. F, Steps 19-30. G, Steps 31-38. H, Steps 39-43. I, Steps 44-45.-Continued 
To begin, double-click on webmod gui.bat. Similar to the batch runs, a command window will open with a description of the modules that will be run and notification that the data and parameter files have been read. The names of the input and output files along with the number and contents of Run Time Plots are read from the control file by the MMS Tool GUI. The MMS Tool GUI is a Java application that initializes a command window from which the GUI is launched. A menu of options is available at the top; however, many options have not yet been ported to Java from the original version that was written for Unix-based X-Windows System. Model information and model inputs are seen in the left pane. Dimensions and module information are available by clicking on the expander nodes (key icons) in the right pane. Window borders, pane dividers, and column widths can be adjusted to view content. Unless otherwise specified, "click" indicates a click with the left button of a personal computer mouse.

\section{View Run Time Plots of Simulated and Observed Discharge (steps 1-6; figs. 12A-12C)}

1. If the Single Run window does not autimatically pop up, then click Run in the top menu to open a drop-down menu (fig. 12A).

2. Click Single Run to open the Single Run GUI that will open in a separate window. This GUI is referred to as the Single Run window (fig. 12B). The Time Info pane in the upper left shows the Model Start and End times, which can be adjusted to simulate specific periods, and the Data Start and End times, which are determined by MMS after reading the hydrologic data file. The Init Timestep field is set to $2.400000000000 \mathrm{e}+01$ ( 24 hours in scientific notation) and should not be changed. The Graphing Program pane in the upper right contains a spinner box to define the number of Run Time Plots and a drop-down menu to select which plots will be assigned specific variables. The File Info pane, the bottom pane of the window, contains the names of output files and buttons to select specific variables for output to the Stat Var file (webmod.statvar) or the GIS output file (webmod.aniout). The Stat Var file contains daily values for a specific dimension index of the selected variables and the GIS output file contains daily values for all indices of a given dimension.

3. Click Start at the bottom of the Single Run window to run the model and plot observed [basin_qobs_cm(1)] versus simulated [basin_qsim_cm(1)] discharge. The variables and line colors are shown in the legend of the Run Time Plots window on the right along with their dimension index.
4. Click $\mathrm{OK}$ in the Message window to acknowledge run completion, thereby freeing up the focus to work with any of the visible windows-MMS, Single Run, or the MMF Run Time Plots. The screen image shows that observations of discharge began when the Andrews Creek gage became operational in the spring of 1992. The hindcast discharge was simulated by using precipitation observations from the Bear Lake snow telemetry (SNOTEL) station and temperatures measured at Main Weather Station; both sets of data are read from the webmod.hydro.dat hydrologic data file.

5. In the Run Time Plots window (fig. 12C), click and drag from upper left to lower right beginning at an $\mathrm{x}, \mathrm{y}$ coordinate of $(2001,2.0)$ to a coordinate of $(2006,0.0)$ to zoom in on a 5-year period of the plot. If the resulting zoomed-in view is not as desired, the plot can be reset by choosing "autorange > both axes" in the right-click menu box or by any left-click and upward drag in the plot area.

6. The zoomed-in view shows that simulated discharge is much less than observed discharge during the summers. Run Time Plots of snowpack for various hillslopes may reveal a reason for the mismatch. Click the $\mathrm{X}$ to close the Run Time Plots window (or it can be left open for later comparisons).

\section{Add Plots for Snow-Water Equivalence for Two MRUs (steps 7-16; fig. 12D)}

7. Increase the number of Run Time Plots from one to two by clicking the top arrow of the spinner in the Graphing Program pane. The user should be aware that whenever the spinner is used to reduce the number of Run Time Plots, the list or lists of variables previously assigned to plots with greater numbers are deleted; an "undo" feature is not available, so the list of variables would need to be reentered to recreate the plots.

8. Click the drop-down arrow and select 2. This command will open the MMS-Select Variables for Run Time Plots 2 window, one instance of a variable selection window. All variable selection windows operate identically for assigning variables to Run Time Plots, the Stat Var file (webmod.statvar), or the GIS file (webmod.aniout); the only differences are the title assigned to the window and the parameter names used in the webmod.control file (table 4).

9. In the variable selection window, slide the scroll button down until the variable pkwater_equiv is in view in the left pane. The variable pkwater_equiv tracks 
the simulated SWE, in inches, of the snowpack for each MRU. A warm and cool MRU will be selected to evaluate the simulated snowpack throughout the years.

10. Click pkwater_equiv. If the variable is scalar (dimension of one), then the variable and dimension will appear in the Selected Variables pane. However, pkwater_equiv has a dimension of nmru, so the Index drop-down menu must be used to select the specific MRU.

11. Click the Index drop-down arrow and select 3. As shown in figure 10, MRU 3 includes the warm south-facing slopes upstream from the Andrews Creek gage. The variable pkwater_equiv(3) will appear in the Selected Variables pane.

12. Click the Index drop-down arrow and select 10 to add pkwater equiv(10) to plot the SWE for MRU 10, an MRU of similar size to MRU 3. MRU 10 includes cold, high-relief shaded areas with northwest-facing slopes in a tributary to Andrews Creek. The temperature assigned to an MRU will be a function of the vertical lapse rate and a temperature adjustment that includes differences in incoming solar radiation between the temperature measurement station and the MRU. The temperature adjustment for daily maximum temperature, tmax_adj(nmru), in the parameter file is $2.2^{\circ} \mathrm{C}$ for MRU $\overline{3}$ and $-3.6{ }^{\circ} \mathrm{C}$ for MRU 10 .

13. Click $\mathrm{OK}$ in the variable selection window to return to the Single Run window.

14. Under Model Start, click the Year field and change the value from 1983 to 1991, which is the start of the water year that the Andrews Creek gage became operational. Use the backspace or delete keys as needed. Always hit Enter to complete the editing of a field in the GUIs to ensure that the change is registered in the webmod.control file. The user should be careful whenever changing the Model Start date because the values of hydrologic and geochemical variables are highly sensitive to initial conditions, particularly during the initial days and years of a simulation. In this example, the initial SWE, WEI(nmru), is set to 15 inches for all MRUs with the understanding that several years may need to be simulated before a dynamic equilibrium of snowpack accumulation and snowmelt is attained for each MRU.

15. Click on Start to run the simulation, and then zoom in on the period 2000-2006 for Run Time Plot number 2 (as previously described in step 5). The user may note that the annual maximum SWE values near 10 inches for MRU 3 and 30 inches for MRU 10 are much less than the SWE estimated from springtime snow surveys. The user may then decide that the amount of snow being distributed to the MRUs is insufficient.

16. Close the Run Time Plot windows.

\section{Adjust the Rain and Snow Undercatch Factors, rain adj(nmru,nmonths) and snow adj(nmru,nmonths), and Evaluate Results (steps 17-31; figs. 12E-12G)}

17. A review of webmod.params in a text editor indicates that the snow and rain adjustments [snow_adj (nmru,nmonths) and rain_adj(nmru,nmonths)] are set to their default value of 1.0 , which indicates that the measured snow and rain are the true values. Studies have determined that as little as 50 percent of the total amount of snow may be recorded in gages affected by high winds, such as those near the Continental Divide. Also, the primary snow measurements in the data file are those measured at Bear Lake, which is at a lower altitude than Andrews Creek and, thus, is expected to receive less precipitation. Finally, unmeasured snow blows into the watershed from the west side of the continental divide into the areas of MRU 5 and 6, contributing to the perennial existence of Andrews Glacier. Therefore, to correct the bias to measured snow and rain, the parameters snow_adj(nmru,nmonths) and rain_adj(nmru,nmonths) will be increased until the simulated discharge more closely fits the observed discharge. For purposes of this example, snow_adj(imru=1-4,7-10; imonths $=1-12)=1.41$ for all areas without blown-in snow, resulting in a catch efficiency of 71 percent (1.0/1.41); snow_adj $(i \operatorname{mru}=5,6$; imonth $s=1-12)=2.21$ for the two MRUs with blown-in snow, resulting in a catch efficiency of 45 percent (1.0/2.21); and rain_adj (imru=1-10; imonths $=1-12)=1.28$ for all MRUs when it rains, resulting in a catch efficiency of 78 percent (1.0/1.28). Editing the 120 values (nmru $\times$ nmonths) in webmod.params by hand will likely introduce errors, so the Parameter Tool GUI will be used. Begin by clicking on Edit in the MMS Tool GUI (fig. 12E).

18. Click on Parameters and Dimensions. This command will open the Parameter Tool GUI in a separate window (fig. 12F). Menu options (File, Reset, and Help) are available at the top of the window. The left pane presents a "tree" structure of the dimensions and parameters included in the parameter file. The right pane presents the values of either the dimensions or the parameter values. 
19. Click the expander node (key icon) to the left of the folder labeled Parameter Values by Dimension. Parameters are grouped by dimension. For example, clicking on nmru will display all parameters dimensioned by nmru in the right pane with parameter names at the top of the columns and MRU indices as row labels. Two-dimensional parameters, such as snow_adj(nmru,nmonths), require an extra branch on the tree.

20. Click on the expander node for nmru,nmonths, which is the dimension for rain_adj and for snow_adj.

21. Click on the parameter snow_adj. The parameter values are now viewable in the right pane. Month labels are at the top of the columns, and MRU indices are the row labels to the left. To reproduce the view in figs. $12 A-12 I$, the windows, panes, and field widths will need to be adjusted by clicking and dragging pane dividers or the border lines between month labels.

22. Click on any value in the table. If data, such as detailed wind fields during the course of the year, are available to indicate unique undercatch factors for each MRU for each month, the parameters can be individually assigned. If such data are not available, the same undercatch factor will be assigned to all MRUs for all months. Note that the snow undercatch factor is applied only when snow is the predicted form of precipitation for that MRU; therefore, on the same day, lower altitude MRUs may simulate rain with rain_adj(nmru,nmonths), while higher-altitude, or shaded MRUs simulate snow with snow_adj(nmru,nmonths).

23. Click the All button to select all fields in the table. Similarly, the Columns and Rows buttons are available to select all fields in those directions.

24. Click the Copy button to open an input window where a value can be entered to be copied to all selected fields.

25. Enter the value of 1.41 .

26. Click OK to copy the value to all selected fields. Click and drag on two cells in the fifth and sixth rows (MRUs 5 and 6), then select Rows, then Copy, then enter 2.21 and $\mathrm{OK}$ to assign additional snow correction for the two MRUs. Repeat this procedure for rain_adj (selecting All cells), assigning a value of 1.28 to all MRUs and all months. Although the values are changed in the table, the values will not be used in a model run until the new values are saved to the parameter file.

27. Click File in the top menu.

28. Click Save.

29. Click Yes when asked if you want to overwrite the parameter file.
30. Click the $\mathrm{X}$ at the top right of the window to close the Parameter Tool GUI (or choose Exit from the File menu). If desired, the Parameter Tool GUI can be left open for editing parameters of subsequent model runs.

31. Run the simulation again by clicking Run in the Single Run window (step 3), then zoom in on the period 2001-2006 (step 5). The SWE simulated for MRU 10 in the spring of 2003 now exceeds 40 inches, compared to 30 inches before the adjustment (fig. 12G). The match between the simulated and observed discharge values (plot 1) is now much improved. Close the window by clicking $\mathrm{X}$ at the top right.

Activate Geochemical Simulations and View Variations in Concentrations of Sodium and Silica (steps 32-43; figs. $12 G-12 H)$

32. Now that the hydrologic simulation has been changed, the simulated solute concentrations will be reviewed, and if necessary, the geochemical reactions will be adjusted. Reopen the Parameter Tool GUI (steps 17-19) and click on dimension one (fig. 12G). The right pane will now display all scalar parameters, including most operational flags and spatial parameters for the basin.

33. Slide the horizontal scroll button until parameter chem_sim is in view.

34. Click on the chem_sim field and change the value from 0 to 1 . This will activate geochemical simulations. Be sure to hit Enter or Tab after editing the value.

35. Click File in the menu bar.

36. Click Save.

37. Click Yes when asked if you want to overwrite the parameter file.

38. Exit the Parameter Tool GUI by clicking on the $\mathrm{X}$ at the top right.

39. Increase the number of Run Time Plots from 2 to 4 (fig. 12H). Click on Edit Options for Graph 3 to add ch outlet mgL(3) to plot 3 and then add ch_outlet_mgL(10) to plot 4 (steps 7-12). The geochemical variable ch_outlet_mgL(nsolute) tracks the concentration of all solutes simulated at the watershed outlet. The index (3) selects sodium because $\mathrm{Na}$ is the third solute listed for the nsolute dimension at the top of the parameter file. Similarly, the index (10) selects silica because $\mathrm{Si}$ is the 10th solute listed for the nsolute dimension. Sodium and silica are assigned to separate plots to make their variance comparable. Waters sampled from Andrews Creek from 1991 through 2012 have an average of $2.3 \mathrm{mg} \mathrm{SiO} 2$ per liter, almost five times greater than the average of $0.5 \mathrm{mg} \mathrm{Na}^{+}$per liter. 
40. Change the value of the Model End Year from 2012 to 1995. Be sure to hit Enter to register the revised simulation period in the webmod.control file. To verify that the change was recorded, open the webmod.control file in an editor and check the values for the parameter end_time. The time required to simulate daily geochemistry from 1982 to 2012 for the 2,000 reservoirs in the 10-MRU, 11-TTI Andrews Creek model is approximately 3 hours on a current (2017) personal computer. By limiting the model simulation to 4 years (October 1, 1991, to September 30, 1995), less than 30 minutes will be needed, and the user can determine if trends in the simulated mean annual concentrations indicate that geochemical parameters need to be adjusted. The user should be careful when changing the Model Start date because initial conditions are assigned values expected for a specific time of year.

41. Click the Start button. In contrast to the previous runs that simulated only hydrology, the first Run Time Plots with simulated geochemistry can take about 1 minute before initial data are plotted, and the "Model Finished" message can take about one-half hour to appear in the message window. Click OK to dismiss the window (step 4). Open the webmod.statvar file to see that the fields of geochemical variables are now populated with the values of the simulated concentrations, along with $\delta^{18} \mathrm{O}$ values, for streams, snowpack, snowmelt, the O-horizon, the unsaturated zone, and the saturated zone.

42. Concentrations of sodium and silica in the Run Time Plots drift lower from initial values, which were initially set to be similar to concentrations observed in stream samples in the fall. Right-click in the plot area to reveal a menu with options to Save, Print, Zoom in or out, or reset the range of the axes.

43. Click the $\mathrm{X}$ at the upper right to exit the Run Time Plot windows.

\section{Increase Surface Area to Volume Ratio for Oligoclase and Evaluate Results (steps 44-45; fig. 12/)}

44. Open the webmod.pqi file in an editor (fig. 12I) and scroll to the KINETICS 1 block near the bottom. Increase the surface area-to-volume ratio for the most abundant mineral, oligoclase, in the O-horizon, the unsaturated zone, and the saturated zone by changing the "-parm" value from 0.303 to 0.603 . As described in the BASIC code defining the moles produced in the RATE block, the -parm parameter for the oligoclase kinetics is the surface area-to-volume ratio in log units, so an increase of $0.3 \log$ units will double the simulated weathering rate. Save the webmod.pqi file and begin another run in the Single Run window.

45. The simulated discharge matches observed discharge, and the simulated solute concentrations now vary near mean values of $2.3 \mathrm{mg} \mathrm{SiO} 2$ per liter and $0.5 \mathrm{mg} \mathrm{Na}^{+}$per liter for waters sampled from Andrews Creek. The simulation period may now be extended to 1983-2012. The model performance that indicates the match between simulated and observed solute concentrations for 1983-2012 is presented in more detail in the workbook $\mid$ WEBMOD_1.0|projects $\backslash$ Andrews $\backslash$ Andrews.xlsm.

This completes the Quick Start Guide that uses the Andrews Creek model, which is presented in more detail as the first example in the "Example Problems" section. The second example in the "Example Problems" section simulates discharge and conservative transport of chloride in the DR2 watershed near Yakima, Wash. The methods presented in these sections, "Batch Run" and "Interactive Runs," of the Andrews Creek model are applicable to the DR2 model or any other WEBMOD model.

\section{Hydrologic Processes}

The following sections detail the algorithms used in WEBMOD to simulate the fluxes of water among atmosphere, canopy, snowpack, soils, and stream on a daily time step. Dimensions, parameters, and variables listed in tables 1,2, and 3 will be included in discussions of the governing equations and model configurations. The hydrology is defined as the interaction of precipitation and temperature with the geology, soils, and vegetation of the watershed. The hydrology is assumed to be independent of solute concentrations and geochemical reactions; in contrast, transport and fate of solutes are sensitive to hydrology for conservative and reactive solutes. One biologic process is simulated in a simple fashion with WEBMOD without use of geochemical reactions - a bimodal (summer/winter) canopy density is simulated, which affects canopy interception, evaporation, and transpiration.

The computational sequence for hydrologic and geochemical processes in WEBMOD is as follows:

- Read the hydrologic data file and distribute precipitation, incoming solar radiation, and irrigation to each MRU.

- Assign solute concentrations for all reservoirs, precipitation, external sources, and observations. Inputs may be constant or vary daily as described in the webmod. chem.dat.

- Complete the following steps for each MRU:

- Check if the day is the "leaves on" day in the spring or the "leaves off" day in the fall. Change canopy storage capacity and move residual moisture between the canopy and the O-horizon as indicated.

- Compute PET.

- Simulate canopy interception, evaporation, throughfall, and transpiration.

- Simulate snowpack accumulation, sublimation, and melt. 
- Determine the amount of Hortonian overland flow by using a log-normal distribution of vertical conductivity.

- If there is rain or snowmelt, determine how much vertical preferential flow is added directly to the saturated zone.

- For each TTI bin, in sequence from the wettest to the driest, route water as follows:

- Remove ET from the root zone.

- If the ground is saturated, and there is rain or snowmelt, then allocate rain or snowmelt to the root zone to offset any ET demand. Any remaining water is tagged as Dunnian overland flow. If there is no rain or snowmelt, move water from the saturated zone into the root zone to offset any ET demand.

- If the ground is not saturated, add infiltration to the unsaturated zone storage.

- Determine the amount of transient unsaturatedzone storage that will recharge the saturated zone by using a simple time-delay function. The deeper the unsaturated zone, the longer recharge will take to reach the saturated zone.

- Assign a fraction of the recharge to direct flow.

- Accumulate direct flow from all TTI bins. This ends the loop on TTI bins.

- Mix recharge from all TTI bins, subtract direct flow, and deliver the remaining recharge to the saturated zone.

- Add any canal leakage or upgradient groundwater inputs to the saturated zone.

- Account for losses from the saturated zone to the regional aquifer.

- Pump any irrigation from the saturated zone.

- Drain the soils if pipe flow is being simulated and the water table is sufficiently high.

- Discharge groundwater as base flow to the stream as determined by transmissivity and saturation deficit.

- Use mass balance to establish a new water table.

- Flush the O-horizon reservoir with the sum of Hortonian and Dunnian overland flow. Mix overland flow with direct flow, pipe flow, and base flow. This ends the loop on MRUs.

- Distribute discharge from all MRUs to the stream reservoirs.

- Remove any bed leakage and irrigation demands from the stream, and then advect remaining stream water toward the outlet. The export from the last stream reservoir is the discharge from the watershed.

When the parameter chem_sim(one)=1, use mixing fractions derived from the hydrologic simulations to simulate the geochemistry of the watershed as a network of forwardfeeding batch reactors (fig. 4).

\section{Initial Conditions}

Simulated flows and concentrations respond to the initial conditions, especially in the first days and months of a model run. For example, the observed water table is expected to rise during spring melt or after summer storms and then drop afterwards, but the observed water table will fluctuate around an annual average. The simulated water table, however, may drop steadily for the first several years of simulation if the initial water table was set too high or rise steadily for several years if the initial water table was set too low. Similarly, solute concentrations in the soils, which are expected to vary about an annual mean concentration, may instead change steadily because the initial concentrations were set too high or too low. Common modeling practice is to let a model "spin up" until a time period equal to several times the longest residence time for any reservoir in the model domain. That reservoir is usually the saturated zone, where the residence time is defined as the average volume of the groundwater divided by the average base-flow discharge. The spin-up allows reservoirs and reactions to approach a dynamic equilibrium that responds to seasonal variations in precipitation and temperature. Results from the spin-up period are commonly removed from post-run analysis. Knowledge of the simulated seasonal variations will help assign better initial conditions for the successive model runs, and knowledge of residence times will help to determine the length of the spin-up period.

Soil moisture in the root zone is initialized at field capacity. Other initial hydrologic conditions of a WEBMOD simulation are defined with 14 parameters as follows: 1 defines the initial soil moisture in the root zone, 1 defines the initial saturation deficit in the unsaturated zone below the root zone, 10 define the water equivalence and energy balance of the snowpack, 1 defines initial discharge (and, therefore, initial volume of the nhydro stream reservoirs), and 1 defines the depth of irrigation from internal sources to be applied on the first day (table 10). The three most important parameters for hydrologic initial conditions are the initial root zone soil moisture [s_theta_0(nmru)], the saturation (soil moisture) deficit [sbaro(nmru)], and the initial snowpack water equivalence $[\operatorname{WEI}(\mathrm{nmru})]$; the state variables defined by the other parameters will equilibrate within the first few days of the model run, so the initial values of the parameters may be set to zero without much consequence. The nuances of the initial snowpack conditions are presented in the snowpack section below.

Some initial conditions are intuitive, such as the initial water equivalence of the snowpack [ $\mathrm{WEI}(\mathrm{nmru})]$ in temperate regions. Simulations that start in the winter may begin with substantial snowpack; however, no such snowpack would be assigned if the simulation starts in summer. Other initial conditions, however, are less intuitive, such as the initial saturation deficit for each MRU [sbar0(nmru)]. Together with the value for saturated porosity [s_porosity(nmru)], sbar0(nmru) determines the initial depth to the water table. In practice, all initial conditions are assigned estimated values and then calibrated by using the following two criteria: (1) matching simulated values with observations of timing and magnitude of water discharge and solute concentrations and (2) obtaining 
Table 10. Parameters describing initial states of irrigation, snowpack, soil moisture, and discharge.

[The formatting convention used in this report is to present dimension names in Courier New font, variable names in bold italic Courier New font, and parameter names in bold Courier New font. See tables 1, 2, and 3 for descriptions of dimensions, parameters, and variables. Min, minimum; Max, maximum]

\begin{tabular}{|c|c|c|c|c|c|}
\hline Parameter & $\begin{array}{c}\text { Associated } \\
\text { state variable }\end{array}$ & Description & Minimum & Maximum & Default \\
\hline \multicolumn{6}{|c|}{ Root zone } \\
\hline s_theta_0(nmru $)^{1}$ & smcont_sc(nmru) & $\begin{array}{l}\text { Root zone soil moisture content, } \\
\text { in centimeters per centimeter }\end{array}$ & 0.01 & 0.7 & 0.23 \\
\hline \multicolumn{6}{|c|}{ Unsaturated zone } \\
\hline sbar0(nmru) $)^{2}$ & sbar(nmru) & Saturation (soil moisture) deficit, in meters & 0 & 10 & 0.001 \\
\hline LIQWI(nmru) & Internal variable & Liquid water in the snowpack, in inches & 0 & 100 & 0 \\
\hline $\operatorname{SBAESCI}(\mathrm{nmru})$ & snowcov_area(nmru) & $\begin{array}{l}\text { Areal extent of snow cover prior to the new } \\
\text { snowfall, as fraction }\end{array}$ & 0 & 1 & 0 \\
\hline $\operatorname{SBI}(\mathrm{nmru})$ & pkwater_equiv(nmru) & $\begin{array}{l}\text { Water equivalence just prior to the snowfall, } \\
\text { in inches }\end{array}$ & 0 & 1,000 & 0 \\
\hline NEGHSI(nmru) & Internal variable & Negative heat storage in snowpack, in inches & 0 & 100 & 0 \\
\hline STOREI(nmru) & Internal variable & $\begin{array}{l}\text { Routed liquid water in storage in the pack, } \\
\text { in inches }\end{array}$ & 0 & 100 & 0 \\
\hline TMXPREI(nmru) & tindxi(nmru) & $\begin{array}{l}\text { Daily maximum temperature from previous } \\
\text { day, in degree Celsius }\end{array}$ & 0 & 50 & 7 \\
\hline \multicolumn{6}{|c|}{ Stream } \\
\hline q0(one) & basin_qsim_m3s(one) & $\begin{array}{l}\text { Stream discharge at basin outlet, in cubic } \\
\text { meters per second }\end{array}$ & 0 & 100,000 & 1 \\
\hline \multicolumn{6}{|c|}{ Irrigation } \\
\hline
\end{tabular}

\footnotetext{
${ }^{1}$ Value has a minimum of the wilting point, s_theta_wp(nmru), and a maximum of the field capacity, s_theta_fc(nmru).

${ }^{2}$ Value has a minimum of zero. Maximum value must be less than the value of the recession parameter [s zm(nmru)] when the transmissivity profile is set to parabolic or linear [T_decay $(\mathrm{nmru})=1$ or T_decay $(\mathrm{nmru})=2$, respectively].
}

internal storages that vary seasonally about a mean value rather than increasing or decreasing monotonically. Monotonic trends indicate initial conditions far from the steady-state values or parameters that produce unbalanced gains or losses from a given reservoir. Adjusting static parameters that affect the rate of gain or loss in a reservoir - such as the recession parameter [ $\mathbf{s z m}(\mathrm{nmru})]$ and saturated transmissivity [To(nmru)], which determine base flow given the saturation deficit [sbar(nmru)]-will likely require that the initial saturation deficit $[\operatorname{sbar0}(n m r u)]$ be readjusted to the match the dynamic equilibrium between recharge and base flow.

\section{Energy Balance, Temperature, and Precipitation}

The water and energy cycles in a watershed are intrinsically linked by transfers of both mass and energy that are manifested as evapotranspiration and changes in temperature of the soils and waters flowing through them (fig. 13). On a given hillslope, precipitation and net radiation (sum of incoming and outgoing broadband radiation) vary seasonally, daily, and even with the passing of each cloud. Where precipitation exceeds ET, the excess water can increase soil moisture and flow out of the hillslope as runoff. Similarly, when net radiation exceeds the energy lost by latent (ET) and sensible heat flux, the excess energy can increase the temperature of the soils and porewaters. Above the surface, shifts in the energy balance result in changes in air temperature, the form of precipitation (rain, snow, or mixture), and snowpack dynamics.

A WEBMOD simulation requires three meteorological observations on a daily time step - total precipitation, minimum air temperature, and maximum air temperature. If available, observations of incoming solar radiation (shortwave, or radiation with a wavelength less than 4 micrometers) 


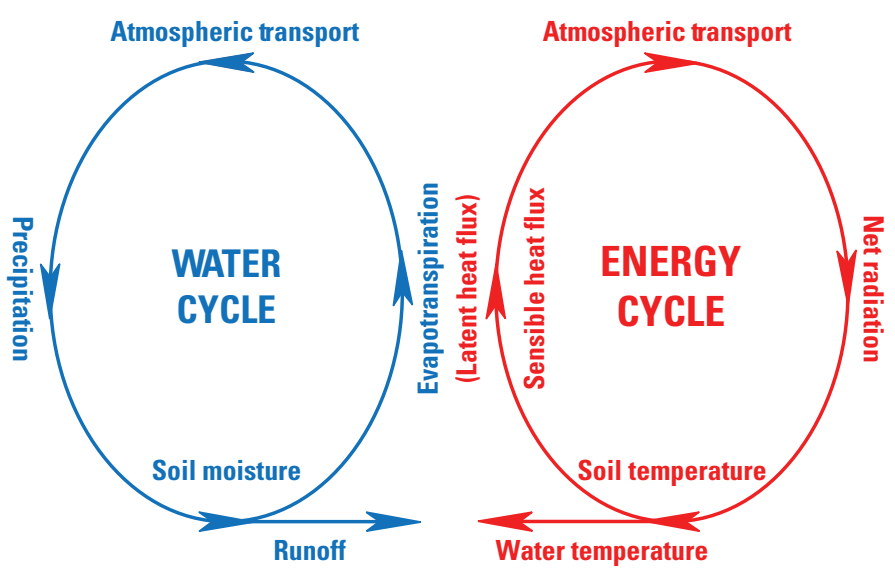

Figure 13. Schematic diagram showing evapotranspiration at the interface between the water and energy cycles. (Modified from concepts in Stannard and others, 2013)

and pan evaporation, a proxy for PET, can be included in the webmod.hydro.dat file. If observations of incoming solar radiation are not available, solar radiation will be estimated by using the geometry of the Earth's orbit; the latitude, slope, and aspect of the MRU; and estimates of cloud cover. Cloud cover is estimated by using temperature range as an inverse proxy; smaller temperature ranges indicate greater cloud cover. If pan evaporation data are not available, then PET is estimated by using the Hamon method described below.

Incoming solar radiation and precipitation are the primary drivers of hydrologic systems. However, in the current version (2017) of WEBMOD, the observed or calculated values of incoming solar radiation affect only one process directly, the melt rate of snow on the canopy. The simulations of the form of precipitation, PET, snowpack dynamics, and the temperatures of reactions in the soils depend only on temperature as a proxy for incoming solar radiation; therefore, it is important to carefully calibrate the parameters affecting the distribution of temperature. Indirectly, the seasonal variations of solar radiation on each MRU should also be taken into consideration when deriving the minimum and maximum melt factors for snowpack (Mizukami and others, 2008). Parameters affecting the simulation of incoming solar radiation would be sensitive if PET were estimated by a method that explicitly uses net radiation data, such as the Jensen and Haise method (Jensen and Haise, 1963). Temperatures simulated for geochemical reactions for the O-horizon, unsaturated zone, and saturated zone are set to the air temperature averaged over a period of days, months, and years, respectively.

\section{Incoming Solar Radiation}

Daily estimates of potential incoming solar radiation and daylight hours for clear-sky days are computed in the module soltab_prms (listed in webmod.control.mod_name file; Leavesley and others, 1983) from values of the axial tilt, or obliquity " $E$ "; the declination of the Sun " $D M$ "; and estimates of slope, aspect, and latitude of each MRU by using a combination of methods described in Frank and Lee (1966) and Swift (1976), as discussed in Leavesley and others (1983). Daylight length is computed in radians, converted to hours, and multiplied by the hourly solar constant. The potential incoming solar radiation on each MRU, $R s p_{\text {mru }}$ is calculated according to the following equations:

$$
\begin{gathered}
R S P_{m r u}=S C\left(C 1_{P S R}+C 2_{P S R}\right), \\
C 1_{P S R}=\frac{\sin \left(D M_{m r u}\right) \sin \left(l a t_{m r u}\right)\left(s s_{m r u}-s r_{m r u}\right) 24}{2 \pi}, \text { and } \\
C 2_{P S R}=\frac{\cos \left(D M_{m r u}\right) \cos \left(l a t_{m r u}\right)\left[\sin \left(s s_{m r u}\right)-\sin \left(s r_{m r u}\right)\right] 24}{2 \pi},
\end{gathered}
$$

where

$R s p_{m r u}$ is the potential solar radiation on a horizontal surface in the MRU, in calories per square centimeter per day, converted to mru_potsw(nmru), in langleys per day;

$S C$ is the 60-minute-period solar constant, in calories per square centimeter per hour;

$D M_{\text {mru }}$ is the solar declination at the MRU, in radians [derived from mru_slope(nmru) and mru_aspect(nmru)];

lat $_{m r u}$ is the latitude of the MRU centroid, positive values are north and negative values are south, in radians [converted from mru_lat(nmru), in degrees];

$s s_{m r u}$ is the hour angle of sunset on the MRU measured from solar noon, morning values are negative and evening values are positive, in radians [converted to mru_sunset(nmru), in hours]; and

$s r_{m r u}$ is the hour angle of sunrise on the MRU measured from solar noon, morning values are negative and evening values are positive, in radians [converted to mru_sunrise(nmru), in hours].

The hour angles at time of sunrise and sunset converted to hours of daylight for each MRU are computed by the following:

$$
s s r_{m r u}=\cos ^{-1}\left[-\tan \left(l a t_{m r u}\right) \tan \left(D M_{m r u}\right)\right],
$$

where

$s s r_{m r u}$ is the hour angle, either sunrise or sunset on the MRU, which is used to compute the daytime length, in multiples of 12 hours [mru_sunhrs(nmru)]. 
Daily estimates of obliquity are described in Meeus (1998) as follows:

$$
E=1-[E C \cdot \cos (j d-3) \cdot r a d]
$$

where

$E \quad$ is the obliquity of the Sun's ecliptic, in angular degrees;

$E C$ is the eccentricity of the Earth's orbit ( 0.01671), in radians;

$j d$ is the Julian day number ( 3 is subtracted because the solar year begins on December 29), in days; and

$\mathrm{rad}$ is the revolution speed of the Earth $(\sim 0.0172)$, in radians per day.

Daily estimates of solar declination are computed as described in Meeus (1998) as follows:

$$
\begin{aligned}
D M= & 0.006918-0.399912 \cdot \cos \left(E_{r t}\right)+0.070257 \\
& \cdot \sin \left(E_{r t}\right)-0.006758 \cdot \cos \left(E_{r t}\right)+0.000907 \\
& \cdot \sin \left(2 \cdot E_{r t}\right)-0.002697 \cdot \cos \left(3 \cdot E_{r t}\right)+0.00148 \\
& \cdot \sin \left(3 \cdot E_{r t}\right),
\end{aligned}
$$

where

$D M \quad$ is the solar declination, in angular degrees, and

$E_{r t}$ is the revolution speed of the Earth $(\sim 0.0172)$, in radians per day, multiplied by the Julian day minus 1 .

The potential incoming solar radiation predicted for clear-sky days on each MRU may be reduced in the module ccsolrad_web to account for estimates of cloud cover. Cloud cover is assumed to be homogenous over the entire watershed on a given day. In the absence of weather fronts moving across the watershed, the temperature range observed at a given station on a cloudy day will be less than the temperature range observed on a clear-sky day, making temperature range a useful proxy for incoming solar radiation (Tangborn, 1978). The hyperbolic relation between observations of cloud cover and solar radiation established by Thompson (1976) for 43 stations in and around Oklahoma City, Oklahoma, is shown in figure 14. The procedure is applicable to humid regions with variable cloud cover. The final incoming solar radiation is calculated by the following equations:

$$
\begin{gathered}
\operatorname{Rasw}_{\text {mru }}=\frac{\operatorname{Rah}_{\text {mru }}}{\cos \left(\text { slope }_{\text {mru }}\right)}, \\
R a h_{\text {mru }}=\left\lfloor B+(1.0-B)(1.0-C C)^{c r r}\right\rfloor R s p_{\text {mru }} \text {, and } \\
C C=c r n_{\text {month }}\left(T m x_{\text {basin }}-T m n_{\text {basin }}\right)+c r b_{\text {month }},
\end{gathered}
$$

where

$$
\begin{aligned}
& \text { Rasw }_{\text {mru }} \text { is the incoming solar radiation assigned to } \\
& \text { the MRU; } \\
& R a h_{\text {mru }} \text { is the measured basin average incoming } \\
& \text { solar radiation on a horizontal surface } \\
& \text { [solrad(nsol); nsol must equal } \\
& \text { one], or computed as cloud-corrected } \\
& \text { clear-sky radiation by equation } 14 \text { using } \\
& \text { Rsp } \\
& \text { day_- mru_potsw(nmru), in langleys per } \\
& \text { swrad_W(nmru) in watts per square meter; }
\end{aligned}
$$

slope $_{m r u}$ is the slope of the MRU, in radians [derived from mru_slope(nmru), unitless];

$B$ is the best fit coefficient obtained by Thompson (1976) (fig. 15), dimensionless [crad coef(one)];

$C C$ is the estimated cloud cover over the watershed, as unitless fraction;

cre is suggested by Thompson (1976) to be 0.61 , dimensionless [crad_exp(one)];

$\mathrm{crn}_{\text {month }}$ is the slope for the cloud cover to daily airtemperature range relation by month, in cloud cover per degree Celsius [ccov_slope(nmonths)];

$T m x_{\text {basin }}$ is the average maximum temperature for the watershed as computed using maximum temperatures distributed to each MRU and weighted by MRU area, in degrees Celsius [basin_tmin_c(one)];

$T m n_{\text {basin }}$ is the average minimum temperature for the watershed as computed using minimum temperatures distributed to each MRU and weighted by MRU area, in degrees Celsius [basin_tmin_c(one)]; and

$c r b_{\text {month }}$ is the intercept for the cloud cover to daily air temperature range relation by month, in cloud cover fraction [ccov_intcp(nmonths)].

The estimated incoming solar radiation has a maximum value of radmax(one) fraction of potential incoming solar radiation. The estimated incoming solar radiation is further reduced on days when the average basin precipitation [basin_ppt(one)] exceeds the threshold ppt rad adj(nmonths), in inches. The adjustment factor is radj_sppt(one) in the summer (May through September) and radj wppt(one) in the other seasons (October through April). A simulation of seasonal changes in incoming solar radiation is shown in figure 16. The upper limit of the envelope represents simulated incoming solar radiation on clear-sky days; the lower limit represents days with predicted cloud covers near 100 percent. 


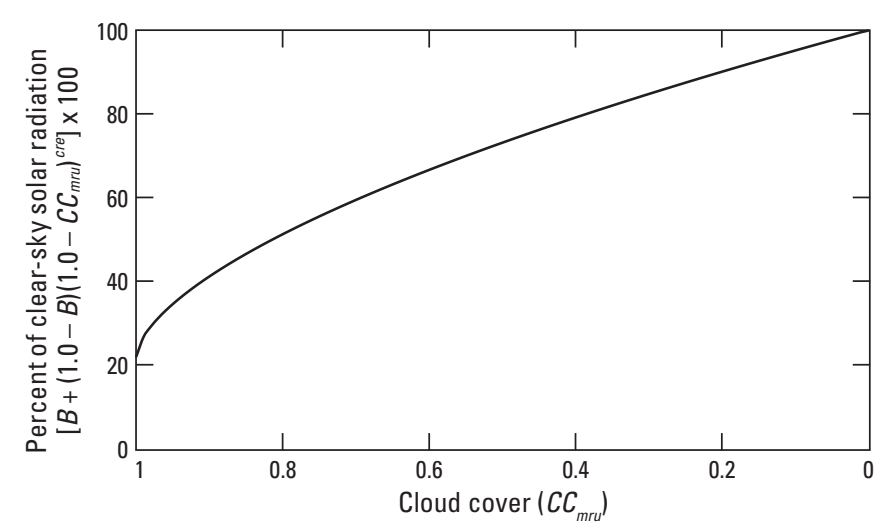

Figure 14. Hyperbolic relation between cloud cover $\left(C C_{m r u}\right)$ and percent of clear-sky solar radiation using exponent (cre) value of 0.61 (43-station average) and $B$ value of 0.22 (best fit for station). The values for cre and $B$ are Thompson's (1976) best values fit to observations of cloud cover and solar radiation made at 43 stations in and around Oklahoma City, Oklahoma.

\section{Air Temperature}

The units for temperature observations in the hydrologic data file are indicated by the parameter temp_units(one), which is set to 0 for degrees Fahrenheit and to 1 for degrees Celsius. The temperature units must match the variable names in the hydrologic data file. For example, the hydrologic data file will contain tsta $\max \boldsymbol{f}(n t e m p)$ if observed temperatures are in degrees Fahrenheit [temp_units(one)=0] or tsta_max_c(ntemp) if temperatures are in degrees Celsius [temp_units(one)=1]. In the possibility of a mismatch, the user will be asked to correct the temp_units(one) to match the temperature variable name in the hydrologic data file. The maximum and minimum daily air temperatures are extrapolated from the meteorological observation station to each MRU by using mean monthly lapse rates and an adjustment parameter to account for slope, aspect, topographic shading, and other local considerations by using the following equation.

$$
T_{m r u}=T_{t s t a}-b_{m o n t h}\left(\frac{Z_{m r u}-Z_{t s t a}}{1000}\right)-t a f_{m r u},
$$

where

$T_{m r u}$ is the maximum (or minimum) temperature distributed to the MRU for the day, in degrees Celsius [tmax_c(nmru) or tmin_c(nmru)];

$T_{\text {tsta }}$ is the maximum (or minimum) temperature observed during the day at the meteorological station assigned to the MRU by mru_tsta(nmru), in degrees Celsius [tsta_max_c(ntemp) or tsta_min_c(ntemp)];

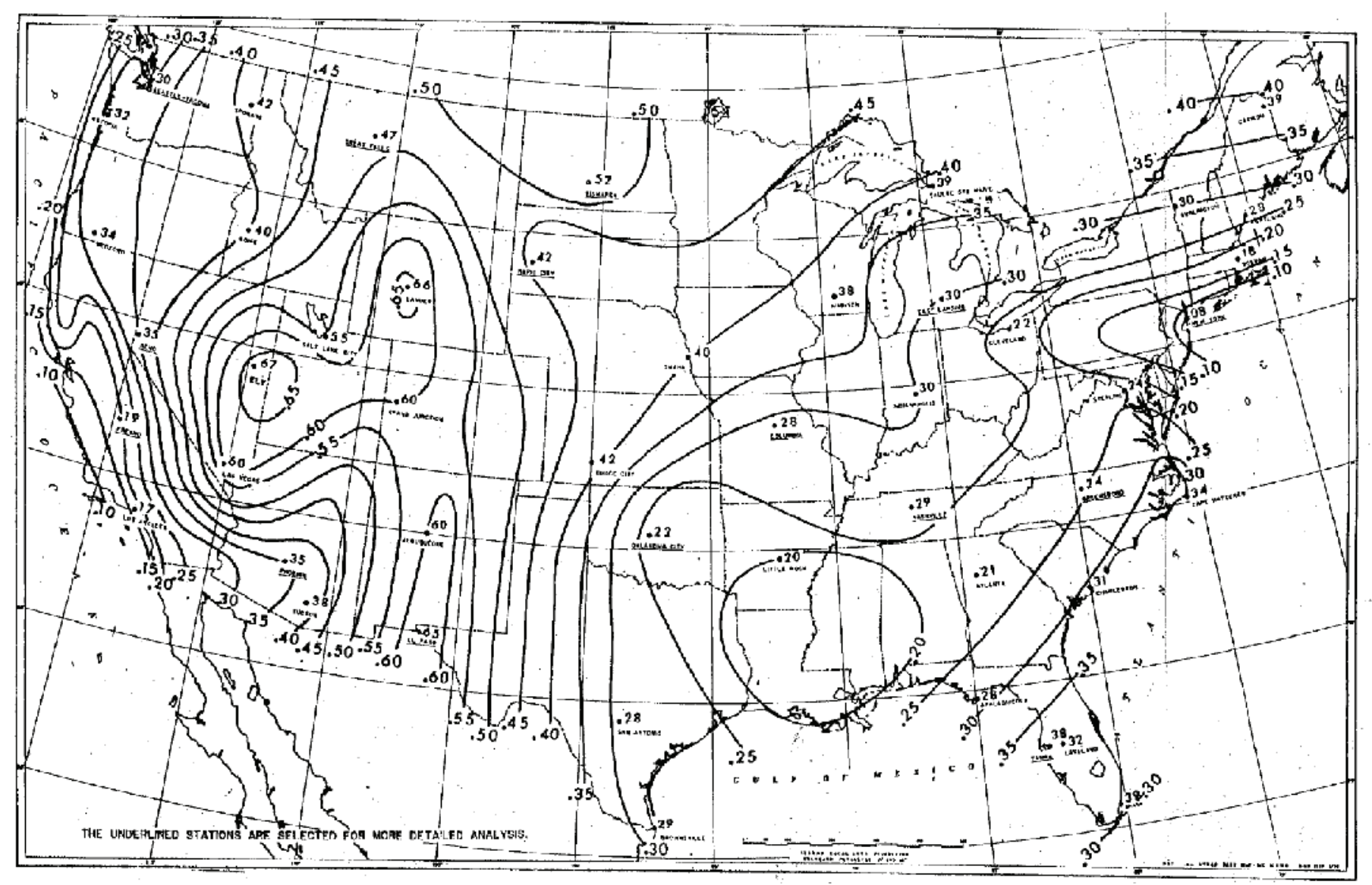

Figure 15. Spatial distribution of $B$ values in the equation relating cloud cover to reduction in solar radiation. (From Thompson, 1976) 


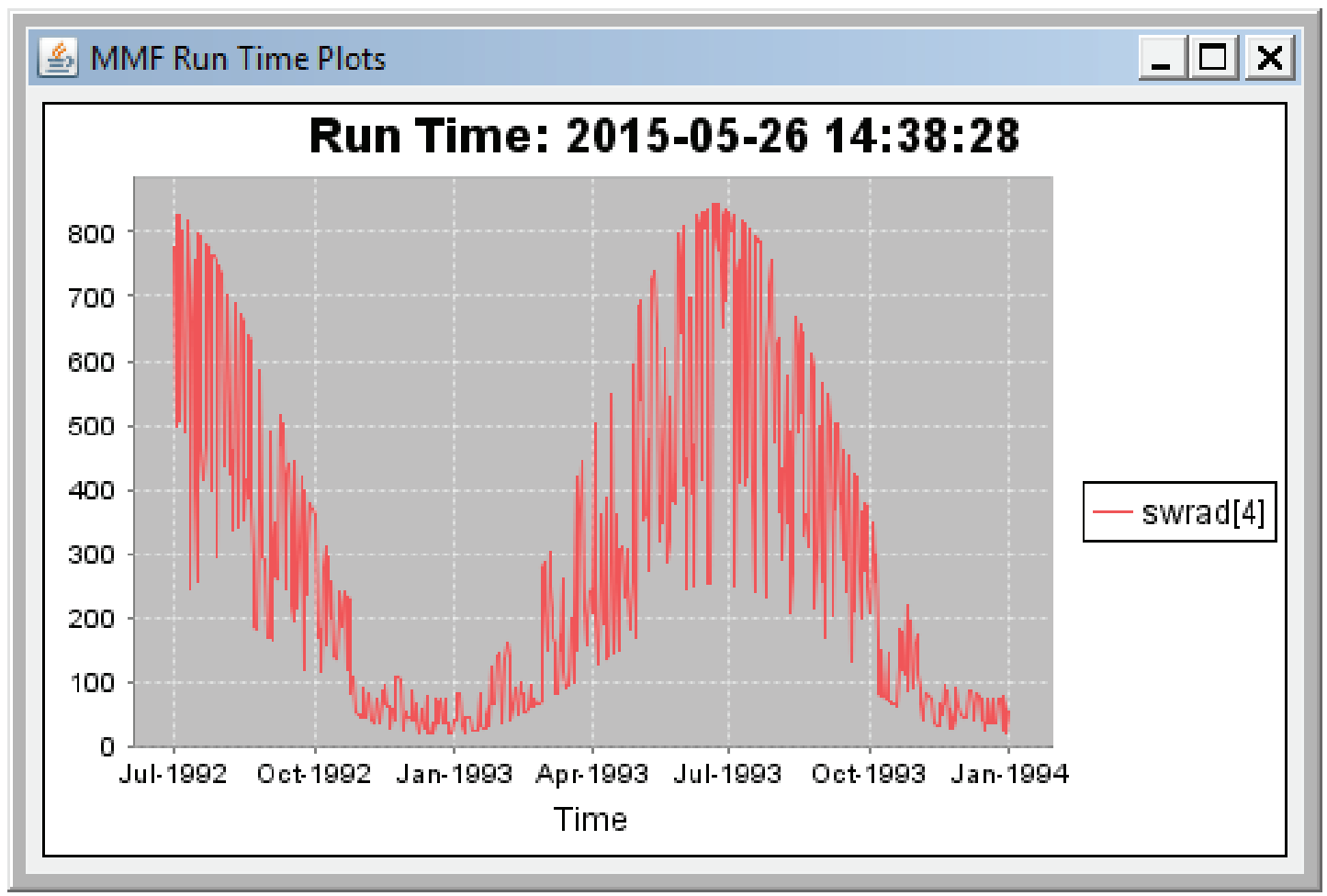

Figure 16. Run Time Plot of incoming solar radiation for model response unit 4 of the Andrews Creek model, in langleys per day. Temperature range is used as an inverse proxy for cloud cover.

$b_{\text {month }}$ is the mean lapse rate for daily maximum (or minimum) temperatures in the watershed for the month, in degree Celsius per kilometer [tmax_lapse(nmonths) or tmin_lapse(nmonths)];

$Z_{\text {rru }}$ is the altitude of the MRU, in meters [mru_elev(nmru)];

$Z_{\text {tsta }}$ is the altitude of the temperature station assigned to the MRU by mru_tsta(nmru), in meters [tsta_elev(ntemp)]; and

$t a f_{m r u}$ is the temperature adjustment parameter, which takes into account the effects of slope, aspect, and topographic shading on daily MRU temperatures, in degrees Celsius [tmax_adj(nmru) or tmin_adj(nmru)].

Additional temperature variables include the average of the maximum and minimum temperatures for each MRU [temp_c(nmru) or temp_f(nmru)] and the basin average temperature computed from the area-weighted statistics of the MRUs [basin_tmax_c(one), basin_tmin_c(one), or basin_temp_c(one) for degrees Celsius].

\section{Relative Humidity}

The relative humidity is a measure of the amount of moisture in the air expressed as a fraction of the total moisture needed to saturate the air at a given temperature. If the user is simulating only hydrology, then observations of relative humidity are not needed as the snowpack routines assume a relative humidity of 90 percent on days with precipitation and estimates of potential evapotranspiration use only day length and saturated water-vapor density at the average temperature for the day; the dimension for the number of humidity fields, nhum, in webmod.hydro.dat can equal zero. When the user is simulating geochemistry, then nhum must be set to one or more as observations of relative humidity are distributed to each hillslope to assign a wet-bulb temperature to precipitation, and to compute the amount of kinetic fractionation of isotopes. Relative humidity is not a conservative property; warm air can hold more moisture than cold air, so as air with a given moisture content, or vapor pressure, warms through the day, the relative humidity drops. Vapor pressure and specific humidity, in comparison, are assumed to be relatively constant on a given day, independent of the air temperature but dependent on the moisture content of overlying air masses. Therefore, the distribution of daily relative humidity to each hillslope is derived from one of two sources: (1) observations of relative humidity at one or more nearby meteorological stations [relhum(nhum)], or (2) the daily mean specific humidity [spechum(nhum)] for the watershed. WEBMOD determines which source is used by attempting to read both variables, relhum and spechum, from webmod.hydro.dat. WEBMOD will print an error message that one or the other is not in the data file and continue the model run. 
In the first case, when observations of relative humidity are included, the data must be from the same meteorological station that temperature was measured. The observations of relative humidity measured at that meteorological station are distributed as follows:

where

$$
h_{m r u}=h_{r h s t a} \cdot \frac{e S_{t s t a}}{e S_{m r u}},
$$

$$
\begin{gathered}
h_{m r u} \text { is the relative humidity of the air assigned to the } \\
\text { MRU [relhum_mru(nmru), fraction]; }
\end{gathered}
$$

$h_{r h s t a}$ is the relative humidity measured at the meteorological station \{relhum[mru_rhsta(nmru), fraction]\}, the same station where temperature \{tsta_temp_c[mru_tsta $(\mathrm{nmru})]$ in degrees Celsius was measured;

$e s_{t s t a}$ is the saturated vapor pressure at the average temperature \{tsta_temp_c[mru_tsta $(\mathrm{nmru})]\}$ for the meteorological station, in kilopascals; and

$e s_{m r u}$ is the saturated vapor pressure at the average temperature [temp_c(nmru)] of the MRU, in kilopascals;

The saturated vapor pressure at a given temperature is computed using the 6th-order polynomial approximation of Lowe (1976).

In the second case, one, and only one, field of daily estimates of the mean specific humidity [spechum(nhum=1)], such as those available from high resolution gridded datasets of surface meteorological variables (Abatzoglou, 2013), is included in webmod.hydro.dat and distributed as follows (modified from Fritschen and Gay, 1979, equation 5.12):

$$
h_{m r u}=\frac{P_{k p a} \cdot h q}{(E+(1-E) \cdot h q) \cdot e s_{\text {nrru }}},
$$

where

$h_{m r u}$ is the relative humidity of the air assigned to the MRU, unitless [relhum_mru(nmru)];

$P_{k p a}$ is the standard atmospheric pressure, in kilopascals, at the elevation of the MRU mru_elev(nmru);

$h q$ is the specific humidity, spechum[mru_rhsta

$(n m r u)]$, averaged for the cells that include the watershed, unitless;

$E \quad$ is the ratio of the molecular weight of moist air to the molecular weight of dry air, equal to 0.622 ; and

$e s_{m r u}$ is the saturated vapor pressure at the average temperature [temp_c(nmru)] of the MRU, in kilopascals.

For watersheds with areas less than a few hundred square kilometers, it should suffice to provide temperature and relative humidity data from a single meteorological station, but relative humidity from multiple stations or specific humidity for the watershed may be provided for larger watersheds. Just as relative humidity is important in determining the fractionation of isotopes and the wet-bulb temperature of the precipitation, reaction rates and equilibrium constants are dependent on the temperature of the water as it moves through the soils and streams.

\section{Soil and Stream Temperature}

Soil temperatures vary in response to the net energy balance. During the day, the temperature of the soil will rise as shortwave solar radiation and downwelling longwave radiation exceed outgoing longwave radiation and energy lost as sensible and latent heat. After 12 p.m. local time, energy gains decrease and, by midafternoon, the energy gains roughly equal energy losses until the energy losses dominate and the air and soils temperatures begin to drop. During a 24-hour period, temperatures of the air and soil surface can vary tens of degrees Celsius. Variations in soil temperatures decrease with depth until soil temperatures become constant at a temperature equal to the average annual air temperature. Below the depth that temperatures become constant, temperatures increase along a geothermal gradient of approximately $25^{\circ} \mathrm{C} / \mathrm{km}$.

Stream temperatures are simulated in WEBMOD as mixtures of upstream stream water, overland flow from the O-horizon, direct flow from macropores in the unsaturated zone, and pipe flow and base flow from the saturated zone. Waters in the O-horizon mix conservatively, such that the overland flow contribution to the stream has a temperature equal to the volume-weighted mean temperature of the precipitation, throughfall, snowmelt, and antecedent moisture. For the O-horizon and all reservoirs in the unsaturated zone and the saturated zone, inputs mix with the antecedent reservoir solution before exporting a fraction of the mix. After the export, geochemical reactions take place in the final volume of the day at a temperature equal to a moving average of air temperature.

$$
\operatorname{Trxn}_{m r u}=\overline{T_{m r u}}-t a f_{m r u},
$$

where

$$
\begin{gathered}
\operatorname{Trxn}_{\text {mru }} \text { is the temperature of reaction distributed to that } \\
\text { O-horizon [trxn_ohoriz_c(nmru)], } \\
\text { unsaturated zone [trxn_uz_c(nmru)], or } \\
\text { saturated zone [trxn_sat_c(nmru)] for } \\
\text { the MRU on that day, in degrees Celsius; }
\end{gathered}
$$

$\overline{T_{m r u}}$ is the running average temperature of one of the daily temperature metrics, in degrees Celsius. The metric is the minimum temperature tmin_c(nmru) when trxn_ohoriz_stat(nmru), trxn_uz_stat(nmru), or trxn_sat_stat(nmru) equals 1; the average temperature temp_c(nmru) when the trxn_**_stat(nmru) 
parameter equals 2; and the maximum temperature tmax_c(nmru) when the trxn_**_stat(nmru) parameter equals 3 . The averaging periods are specified by trxn ohoriz days (one), trxn_uz_days(one), and trxn_sat_days(one). The averaging period has been declared as a real number to facilitate calibration, which would not be possible with an integer or categorical parameter; and

$t a f_{m r u}$ is the temperature adjustment parameter

trxn_ohoriz_c_adj(nmru), trxn_uz_c_adj(nmru), or trxn_sat_c_adj(nmru). The temperature metric and adjustment parameters permit the use of tmin_c(nmru) with an offset instead of the average temperature. The reason for this added flexibility is that the minimum temperature with a positive offset has been documented to more closely track average soil temperatures than tmax c(nmru) with a negative offset because tmax_c(nmru) is more sensitive to cloud cover.

\section{Precipitation}

Each MRU receives precipitation depths adjusted from the rainfall station indicated by psta_mru(nmru). Temperatures distributed to the MRUs determine whether precipitation falls in the form of rain, snow, or a mixture of both. The form of precipitation affects the maximum depth of canopy interception, the contributions to snowpack, and the energy balance of the snowpack on days when rain falls on snow. The form of precipitation also applies to irrigation, which allows snowmaking activities to be simulated. The form of precipitation is dependent on the distributed temperature along with the thresholds tmax_allsnow_c(one) and tmax_allrain_c(nmonths) as shown in figure 17.

If the precipitation is simulated as all rain or all snow, the depth measured at the meteorological station is adjusted to account for altitude, spatial variation, topography, precipitationgage location, deficiencies in gage-catch because of the effects of wind, and other factors by using the following equation:

$$
P_{m r u}=P_{p s t a} C F_{m r u, m o n t h s},
$$

where

$P_{m r u}$ is the daily total precipitation at the MRU, in inches [mru ppt(nmru), mru_rain(nmru), or mru_snow(nmru); with irrigation added, the total deposition is mru_dep(nmru)];
$P_{p s t a}$ is the measured precipitation at the station psta_mru(nmru), in inches [precip(nrain)]; and

$C F_{\text {mru,months }}$ is the specified monthly rain (or snow) correction factor for each MRU, dimensionless [rain adj(nmru,nmonths) or snow_adj(nmru,nmonths)].

If the precipitation is a mixture of rain and snow, the fraction of precipitation falling as rain is computed as follows:

$$
P R M X_{m r u}=\left(\left(\text { Tmax }_{m r u}-T_{\text {snow }}\right) / T_{m r u} \cdot C M X_{\text {month }},\right.
$$

where

$P R M X_{m r u}$ is the fraction of precipitation falling as rain in the MRU [prmx(nmru)]—prmx(nmru) equals -0.1 on days with no precipitation;

$\operatorname{Tmax}_{m r u}$ is the maximum daily temperature assigned to the MRU, in degrees Celsius [tmax_c(nmru)];

Tsnow is the threshold temperature separating rain and snow, in degrees Celsius [tmax_allsnow_c(one)];

$T_{m r u}$ is the average daily temperature assigned to the MRU, in degrees Celsius [temp_c(nmru)]; and

$C M X_{\text {month }}$ is the specified monthly correction factor for rain and snow mixtures, dimensionless [adjmix_rain(nmonths)].

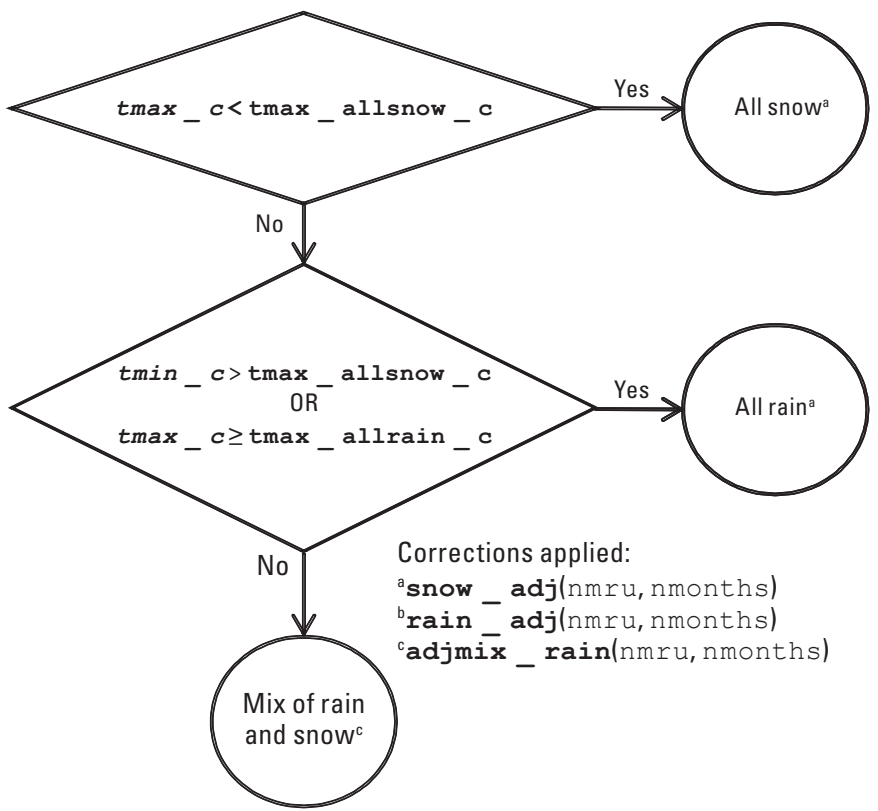

Figure 17. Decision tree used to determine portion of rain and snow in precipitation. 
The amount and form of precipitation is readjusted on days with snowpack in response to an imposed synthetic diurnal temperature variation.

\section{Potential Evapotranspiration}

The PET for each MRU, potet(nmru), is assigned the free-water-surface rate, which is set to the values entered as pan evaporation, pan_evap[mru_pansta(nmru)] when available (nevap greater than zero). Pan evaporation is sensitive to the surrounding ground cover, terrain and objects that can alter the relative humidity, wind, and insolation on the pan (Doorenbos and Pruitt, 1977). WEBMOD applies no adjustment for daily variations of land cover, wind velocity, or humidity. Therefore, observations of pan-evaporation should be adjusted for any known bias before including in the webmod.hydro.dat file.

When pan evaporation data are not available (nevap equals zero), the PET for each MRU is computed in the module potet_hamon_prms as a function of daily mean air temperature and hours of sunshine (Hamon, 1961; Murray, 1967; Federer and Lash, 1978) by the following equations:

$$
\begin{gathered}
E_{m r u}^{\text {Hamon }}=C_{m o n t h s}^{\text {Hamon }}\left(s h_{m r u}\right)^{2} \rho_{m r u}, \text { and } \\
\rho_{m r u}=216.7 \frac{6.108 e^{\frac{17.26939 * \bar{T}_{m r u}}{\overline{\bar{T}}_{m r u}+237.3}}}{\bar{T}_{m r u}+273.2}
\end{gathered}
$$

where

$$
\begin{aligned}
& E_{\text {mru }}^{\text {Hamon }} \text { is the PET for the MRU estimated using the } \\
& \text { Hamon method, in inches per day; } \\
& C_{\text {months }}^{\text {Hamon }} \text { is the empirical Hamon calibration coefficient, in } \\
& \text { length to the fourth power per mass per time } \\
& \text { cubed [hamon_coef(nmonths)]; } \\
& s h_{m r u} \text { is the daytime period for the MRU, in multiples } \\
& \text { of } 12 \text { hours [mru_sunhrs(nmru)]; } \\
& \rho_{\text {mru }} \text { is the saturated water-vapor density (absolute } \\
& \text { humidity), in grams per cubic meter; and } \\
& \overline{T_{m r u}} \text { is the daily mean temperature on the MRU, } \\
& \text { in degrees Celsius [temp_c(nmru)]. }
\end{aligned}
$$

The PET estimated by the Hamon method can be corrected each month to better match observed pan evaporation by using the following equation:

$$
E_{m r u}^{p}=\frac{E_{m r u}^{\text {hamon }}}{C_{\text {months }}^{\text {pan }}},
$$

where

$$
\begin{gathered}
E_{m r u}^{p} \quad \begin{array}{c}
\text { is the potential evaporation for the MRU, } \\
\text { in inches [potet }(\operatorname{nmru})] ;
\end{array} \\
E_{m r u}^{\text {Hamon }} \quad \begin{array}{c}
\text { is the potential evapotranspiration computed } \\
\text { by using the Hamon method; and }
\end{array}
\end{gathered}
$$

$$
\begin{gathered}
C_{m r u}^{p a n} \text { is the coefficient by which the potential } \\
\text { evaporation rate computed using the } \\
\text { Hamon method is divided to approximate } \\
\text { observed pan evaporation for each month } \\
\text { [epan_coef(nmonths)]. }
\end{gathered}
$$

Inspection of equations 22 and 24 shows that the Hamon calibration coefficient and the pan coefficient are redundant and correlated, so it is recommended to fix the pan coefficient at its default value of 1.0 and focus calibration efforts on the Hamon coefficient instead. McCabe and others (2015) completed such a calibration for 109,951 hydrologic units across the conterminous United States, and the coefficients derived for the area of Rocky Mountain National Park are used for the Andrews Creek model presented in the "Example Problems" section. Locally derived estimates of daily PET were available for the DR2 watershed that is the second model in the "Example Problems" section, and those daily values were used as is.

\section{Actual Evapotranspiration}

The PET [potet(nmru)] is WEBMOD's estimate of the upper limit of the AET for a given day. The AET [sae(nmru)] is limited by precipitation that provides moisture to the canopy, the snowpack, and the root zone. Using a monthly waterbalance model driven by weather observations for the last century, McCabe and Wolock $(2008,2010)$ determined that the AET averages 60-70 percent of precipitation over much of the eastern United States and exceeds 90 percent of precipitation over much of the western United States (fig. 18).

\section{Canopy}

Interception of rain and snow by the plant canopy in each MRU is computed in the module intcp_prms as a function of plant-cover density and the storage available on the predominant plant-cover type [cov_type(nmru)] (Leavesley and others, 1983). Precipitation and irrigation are intercepted by the canopy up to available storage; any volume in excess of storage capacity is added to any snowmelt from the canopy to become throughfall. On days with no precipitation, water stored on the canopy, or translocated there by transpiration, is then evaporated up to the PET value. Transpiration is assumed to be negligible on days of precipitation. If canopy evaporation is less than PET, the additional demand is provided by sublimation of snowpack and evaporation of soil moisture, in that order.

Net precipitation is the sum of rain falling on bare ground and throughfall, which is water in excess of canopy storage that is derived from rain that falls on the canopy and snow that melts from the canopy. Net precipitation will be less than total precipitation, $P_{m r u}$, for all days except days of substantial snowmelt from canopy storage; net precipitation is calculated from the following equation: 


$$
P_{m r u}^{\text {net }}=P_{\text {mru }}\left(1.0-\rho_{\text {mru }}^{\prime}\right)+\left(P_{m r u}^{t f} \rho_{m r u}^{\prime}\right),
$$

where

$P_{m r u}^{\text {net }}$ is the net precipitation that reaches the ground in the MRU, in inches [net dep(nmru), basin_net_dep(one)];

$P_{m r u}$ is the total precipitation on the MRU, in inches

[mru_ppt(nmru)];

$\rho_{m r u}^{\prime} \quad$ is the plant canopy density of the MRU, as

a fraction [covden_sum(nmru) and

covden_win(nmru)]; and

$P_{m r u}^{t f} \quad$ is the throughfall in the MRU, in inches.

Throughfall is the amount of precipitation and snowmelt that exceeds the canopy-storage capacity and is calculated by using the following equations:

$$
\begin{gathered}
P_{m r u}^{t f}=P_{m r u}^{*}-\frac{S p c a_{m r u}}{\rho_{m r u}^{\prime}} \text { when } P_{m r u}^{*}>\frac{S p c a_{m r u}}{\rho_{m r u}^{\prime}}, \\
P_{m r u}^{t f}=0.0 \text { when } P_{m r u}^{*} \leq \frac{S p c a_{m r u}}{\rho_{m r u}^{\prime}} \text {, and } \\
S p c a_{m r u}=S p c m x_{m r u}-S p c_{m r u},
\end{gathered}
$$

where

$S p c a_{m r u}$ is the available storage in the plant canopy of the MRU at the beginning of the day, in inches;

Spcmx $_{m r u}$ is the maximum storage on the plant canopy of the MRU, in inches

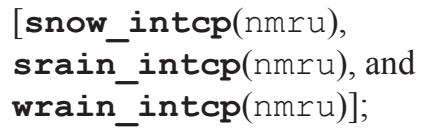

$S p c_{m r u}$ is the storage in the plant canopy (winter or summer) of the MRU, in inches [intcp_stor(nmru)]; and

$P_{m r u}^{*} \quad$ is the total precipitation, irrigation, and snowmelt from the canopy, in inches [mru_dep(nmru)].

Plant-cover density can vary by season and type. The types of plant cover that can be specified are bare ground (no cover), grass, shrubs, and trees. Bare ground has no canopy; the fate of precipitation is limited to snowpack, runoff, or infiltration. Trees and shrubs are functionally identical and able to intercept rain and snow in summer and winter. Grass can intercept rain but not snow because grass lies below the snowpack, which is simulated separately.

Precipitation and canopy snowmelt in excess of canopystorage capacity mix with the canopy storage on the way to the ground or snowpack. Canopy snowmelt is simulated
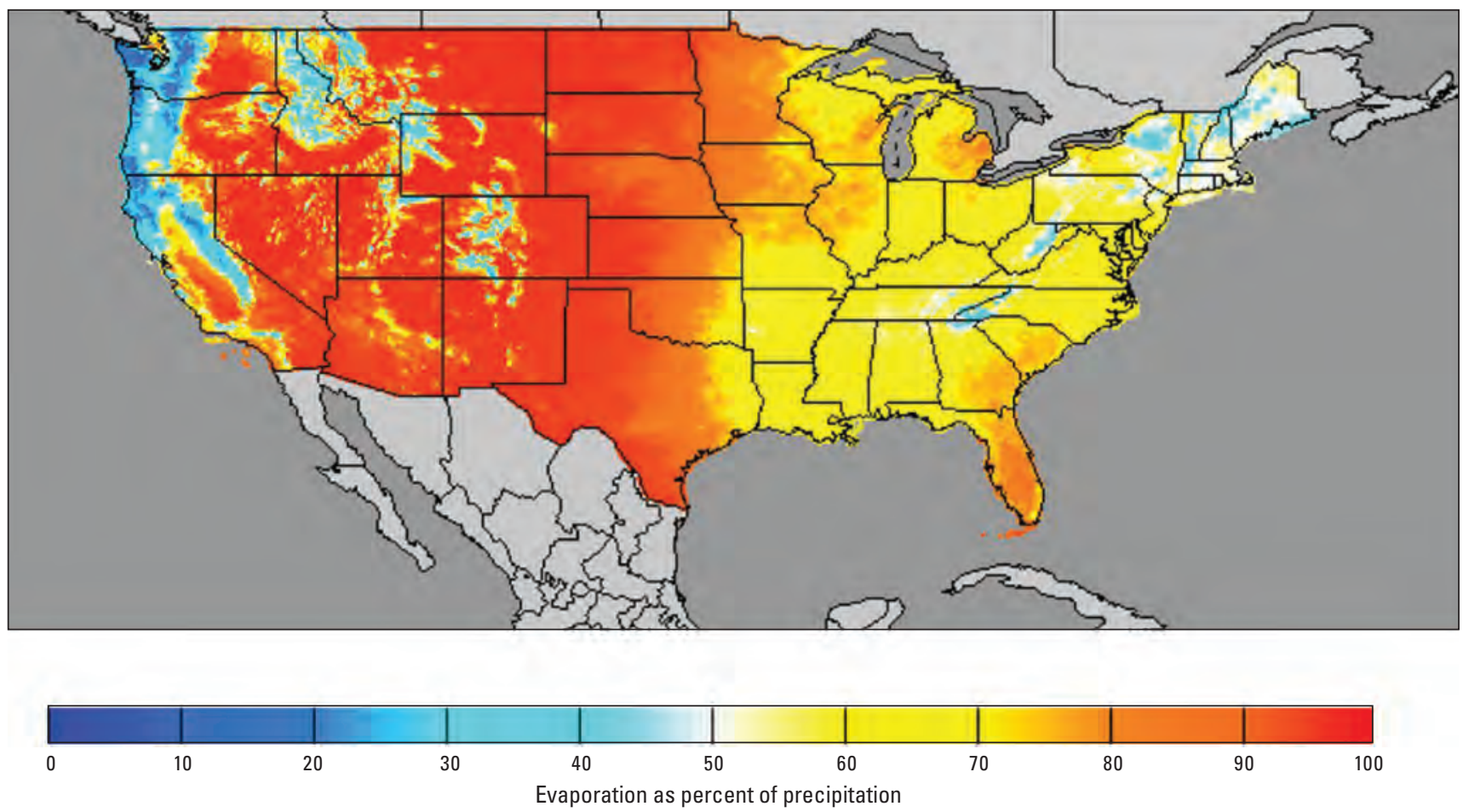

Figure 18. Mean annual evapotranspiration as a percentage of precipitation for water years 1900-2008 for the conterminous United States. (From McCabe and Wolock, 2010) 
by using a modified energy balance that considers short and longwave components of the energy balance for each time step. For 24-hour time steps, the energy balance is computed for an assumed 12-hour daylight period. If the energy balance is negative or zero, the snow will not melt. When the energy balance is positive, the snowmelt in excess of the liquid storage capacity is added to the throughfall, and the remaining snowmelt is available to satisfy canopy evaporation demands.

Canopy storage [intcp_stor(nmru)] and evaporation rates [intcp_evap(nmru)] are normalized to canopy density. For example, if the moisture on the canopy equals the maximum storage capacity of $0.1 \mathrm{inch}$, and the canopy density is equal to 0.25 , then the reported intercept storage for the MRU will be 0.025 inch. Storages and rates are then weighted by the MRU area to compute basin averages.

In reality, as moisture in the canopy evaporates, salts and secondary minerals precipitate on the surface of the leaves. In WEBMOD, simulation of the extremely high concentrations and tracking masses of precipitates is computationally taxing; therefore, a fixed arbitrary residual depth of water [c_can_depth(one)] is assigned to the canopy to ensure that ions remain in solution. This residual canopy water mixes with precipitation and water transpired from the root zone at each time step but is not available for evaporation.

\section{Snowpack}

Rain and snow are combined with throughfall from the canopy to provide the net precipitation for the snow module nwsmelt_topg. WEBMOD simulates snowpack dynamics by using the temperature index method documented in the National Oceanic and Atmospheric Administration (NOAA) Technical Memorandum NWS-HYDRO-17 (Anderson, 1973), referred to as SNOW-17 in Anderson (2006). The following is a summary of the SNOW-17 documentation and information on how SNOW-17 was implemented in WEBMOD. The user is referred to the NOAA documentation for more details and discussion of the direct and indirect methods to estimate the snowpack energy balance.

The sections below describe how WEBMOD includes (1) the energy balance when simulating snowpack dynamics, (2) the simplified methods used to compute snowmelt or adjust the heat deficit on any day, and (3) other snow model components. Other snow model components include accumulation; variation of SCA during accumulation and melt; routing of liquid water; and the incongruent melting of the snowpack, which results in an ionic pulse and fractionation of stable isotopes.

Observations of SWE swe(nsnow) can be included in the data file for comparison to simulated values of SWE [pkwater_equiv(nmru)]. A variable is not available for SCA observations to compare with the simulated values of SCA [snowcov_area(nmru)]. The snow process module of the NWS River Forecasting System (Anderson, 1973) operates with a variety of inputs, each with its own sampling period. In the discussion below, $\Delta t_{p}$ refers to the sampling period for precipitation and $\Delta t_{t}$ refers to the sampling period for temperature, in hours. Because daily temperature and precipitation are subdivided into four 6-hour periods in the snowpack algorithms, the sampling period for both is equal to 6 hours. If no subscript $t$ or $p$ is indicated, then the time step will be specified.

\section{Energy Balance of the Snowpack}

The energy balance per unit area of the snowpack can be expressed as follows:

$$
\Delta Q=Q_{n}+Q_{e}+Q_{h}+Q_{g}+Q_{m}
$$

where

$\Delta Q$ is the change in the heat storage of the snowpack,

$Q_{n}$ is the net radiation transfer,

$Q_{e}$ is the latent heat transfer (evaporation),

$Q_{h}$ is the sensible heat transfer (heating of the air),

$Q_{g}$ is the heat transfer across the snow-soil interface, and

$Q_{m}$ is the heat transfer by mass changes (advected heat).

The units for each term are millimeters of energy $\left(\mathrm{mm}_{\mathrm{e}}\right)$, which is the amount of heat required to melt 1 millimeter of ice (or the heat required to be removed to freeze 1 millimeter of water) over an area of 1 square centimeter. At $0{ }^{\circ} \mathrm{C}$, a millimeter of energy is equal to approximately 8 calories per square centimeter. The unit " $\mathrm{mm}_{\mathrm{e}}$ " will be used to distinguish millimeters of energy from millimeters of length $(\mathrm{mm})$.

\section{Net Radiation Transfer}

Net radiation is computed from the relative contributions of incoming solar radiation and longwave radiation emitted from clouds, surrounding landscape, and the snowpack. When the sun is overhead on a clear day in Rocky Mountain National Park, incoming solar radiation ranges from about 1,000 watts per square meter $\left(\mathrm{W} / \mathrm{m}^{2}\right)$ in the summer to less than $500 \mathrm{~W} / \mathrm{m}^{2}$ in the winter (National Renewable Energy Laboratory, 1995). If completely absorbed, an energy flux of $1,000 \mathrm{~W} / \mathrm{m}^{2}$ will melt approximately $10 \mathrm{~mm}$ of ice per hour. However, new snow is highly reflective to incoming solar radiation, so as much as 90 percent of the incident energy will be reflected back into space. As the snowpack ages, dust and soot settle on the surface, reducing the albedo (reflectance) and increasing the net absorption of energy. The net radiation transfer for the snowpack can be expressed as the sum of incoming minus reflected solar radiation and incoming minus outgoing long-wave radiation as follows:

$$
Q_{n}=Q_{i} \cdot(1.0-A)+Q_{a}-\Delta t \cdot 1.0 \cdot \sigma \cdot\left(T_{s}+273\right)^{4},
$$


where

$Q_{n} \quad$ is the net radiation transfer, in millimeters of energy; where the terms for incoming energy include

$Q_{i}$ incoming solar radiation, in millimeters of energy;

$A$ albedo, unitless fraction; and

$Q_{a}$ incoming longwave radiation from the atmosphere, in millimeters of energy; and

where the terms for outgoing energy include

$\Delta t$ computation time interval, in seconds;

$\sigma \quad$ Stefan-Boltzman constant, $1.17 \cdot 10^{-13}$ millimeter per Kelvin per second; and

$T_{s} \quad$ snow-surface temperature, in degrees Celsius, which is assumed to equal the air temperature at the snow surface.

For the 6-hour time steps used in WEBMOD, the equation can be written as follows:

$$
Q_{n}=Q_{i} \cdot(1.0-A)+Q_{a}-3.67 \cdot 10^{-9} \cdot\left(T_{s}+273\right)^{4} .
$$

\section{Latent and Sensible Heat Transfer}

Latent and sensible heat are transferred between the atmosphere and snowpack by way of turbulent eddies. Latent heat is transferred when water vapor enters and condenses in the snowpack, which causes the snowpack to warm, and when water sublimates from the snowpack, which causes the snowpack to cool. The rate at which water vapor is transferred as a function of wind and vapor pressure gradient is described in Dalton (1808) as follows:

$$
V=f\left(u_{a}\right) \cdot\left(e_{a}-e_{s}\right)
$$

where

$V \quad$ is the water vapor transfer, in millimeters;

$f\left(u_{a}\right)$ is a function of the wind speed, $u_{a}$, at a height, $z_{a}$, above the snow surface, in millimeters per millibar [UADJ(nmru)];

$e_{a}$ is the vapor pressure of the air at $z_{a}$, in millibars; and

$e_{s}$ is the vapor pressure at the snow surface, in millibars (assumed equal to the saturation vapor pressure at the snow surface temperature).

The wind function [UADJ(nmru)], in millimeters per millibar ( $\mathrm{mm} / \mathrm{mbar}$ ), is an empirical relation used to compute the transfer of latent and sensible heat during rain-onsnow events. The following equation is used to calculate the wind function:

$$
\mathrm{UADJ}=0.002 \cdot u_{1},
$$

where

UADJ is the wind function, in millimeters per millibar [UADJ(nmru)],

0.002 is the coefficient calibrated to observations of snowpack processes by Anderson (1976), in millimeters per millibar per kilometer, and

$u_{1}$ is the wind travel distance, in kilometers, at $1 \mathrm{~m}$ above the snow surface for the time period, 6 hours in this case.

Typical values for UADJ range from $0.03 \mathrm{~mm} / \mathrm{mbar}$ per 6-hour period (wind speed of 2.5 kilometers per hour $[\mathrm{km} / \mathrm{h}]$ ) to $0.2 \mathrm{~mm} / \mathrm{mbar}$ per 6 -hour period (wind speed of $\sim 17 \mathrm{~km} / \mathrm{h}$ ).

The amount of latent heat transferred between the atmosphere and the snowpack is equal to $V$, the amount of water vapor transferred, times $L_{s}$, the latent heat of sublimation $\left(8.5 \mathrm{~mm}_{\mathrm{e}} / \mathrm{mm}\right)$ :

$$
Q_{e}=L_{s} \cdot V=8.5 \cdot f\left(u_{a}\right) \cdot\left(e_{a}-e_{s}\right) .
$$

The rate of sensible heat transfer $\left(Q_{h}\right)$, also a turbulent process, is assumed to have an analogous transport mechanism as latent heat, and the turbulent transfer coefficients for heat and water vapor are assumed to be the same. With this assumption, the ratio of $Q_{h} / Q_{e}$, commonly referred to as Bowen's ratio (Bowen, 1926), can be expressed as follows:

$$
\frac{Q_{h}}{Q_{e}}=\gamma \cdot \frac{T_{a}-T_{s}}{e_{a}-e_{s}},
$$

where

$T_{a}$ is the temperature of the air at $z_{a}$, in degrees Celsius;

$T_{s}$ is the temperature of the air and snow at the snow surface, in degrees Celsius; and

$\gamma$ is the psychrometric constant, in millibars per degree Celsius, which is equal to $0.00057 \cdot P_{a}$, where $P_{a}$ is the atmospheric pressure, in millibars, computed by using the "standard atmosphere" altitude versus pressure relation

$$
P_{a}=1012.4-11.34 \cdot H_{e}+0.00745 \cdot H_{e}^{2.4}
$$

where

$P_{a}$ is the atmospheric pressure, in millibars, and

$H_{e}$ is the altitude, in hundreds of meters

[mru_elev(nmru)/100].

Substituting $Q_{e}$ into the Bowen ratio, the transfer of sensible heat is as follows:

$$
Q_{h}=8.5 \cdot \gamma \cdot f\left(u_{a}\right) \cdot\left(T_{a}-T_{s}\right)
$$

The expressions describing the transfer of latent and sensible heat may be further simplified for a melting snowpack by assigning $0{ }^{\circ} \mathrm{C}$ for the surface of the snowpack, $T_{s}$, and 6.11 millibars for saturated vapor pressure at $0{ }^{\circ} \mathrm{C}$. 


\section{Heat Transfer by Mass Changes}

The mass balance per unit area of a snowpack can be expressed as follows:

$$
\Delta W E_{t}=P_{x}-O_{s}+V+V_{g}
$$

where

$\Delta W E_{t} \quad$ is the change in the total water equivalent of the snowpack or SWE, in millimeters, where the total water equivalent comprises ice, liquid water, and water vapor in the snowpack;

$P_{x} \quad$ is the water equivalent of precipitation, in millimeters;

$O_{s}$ is the liquid-water outflow from the bottom of the snowpack, in millimeters;

$V \quad$ is the vapor transfer between the snow and the air, in millimeters; and

$V_{g} \quad$ is the vapor transfer between the snow and the soil, in millimeters.

The base temperature $0{ }^{\circ} \mathrm{C}$ is generally used for heatstorage computations in a snowpack because the snow must warm up to $0{ }^{\circ} \mathrm{C}$ before it can melt. If the mean temperature of snowpack is below $0{ }^{\circ} \mathrm{C}$, a heat deficit exists. Additional heat must be added to the snowpack to raise the temperature to $0{ }^{\circ} \mathrm{C}$ before meltwater can be generated.

If the temperature of the snowpack melt is assumed to be $0{ }^{\circ} \mathrm{C}$ and the heat content of the transferred vapor is assumed negligible, then only the heat transferred by precipitation needs to be considered. The quantity of heat transferred to the snowpack by precipitation is dependent on the amount, temperature, and specific heat of the precipitation. The wetbulb temperature is a good approximation of the temperature of precipitation because of the analogy between falling precipitation and a ventilated wet-bulb thermometer. Thus, the advected heat transfer resulting from mass changes can be expressed as follows:

$$
Q_{m}=\frac{c}{80} P_{x} T_{w}
$$

where
$Q_{m} \quad$ is the advected heat transfer, in millimeters of energy; $c$ is the specific heat, in calorie per gram per degree
Celsius, equal to 0.5 for snow and 1.0 for rain;
$P_{x}$ is the water equivalent of precipitation, in millimeters; and
$T_{w}$ is the wet-bulb temperature, in degrees Celsius.

\section{Simplified Energy Balance}

By using the preceding derivations, the energy balance of the snowpack in response to net radiation, to exchanges of latent and sensible heat, and to gains and losses of mass, can be expressed as follows:

$$
\begin{aligned}
\Delta Q & =Q_{i} \cdot(1.0-A)+Q_{a}-\Delta t \cdot 1.0 \cdot \sigma \\
& \cdot\left(T_{s}+273\right)^{4}+8.5 \cdot f\left(u_{a}\right) \cdot\left[\left(e_{a}-e_{s}\right)\right. \\
& \left.+\gamma \cdot\left(T_{a}-T_{s}\right)\right]+\frac{c}{80} \cdot P_{x} \cdot T_{w}+Q_{g}
\end{aligned}
$$

To use equation $40, Q_{i}, A, Q_{a}, u_{a}, e_{a}, T_{a}, P_{x}$, and $T_{w}$ must be measured or estimated, and $T_{s}, \Delta Q$, and $Q_{g}$ are unknowns. Expressions for the exchange at the snow-soil interface, $Q_{g}$, and the net exchange, $\Delta Q$, can be formulated, but the algorithms are complex and rarely are data available for all the observations.

The solution to the energy balance can be simplified for an isothermal snowpack undergoing melt; in which case, $T_{s}$ equals $0^{\circ} \mathrm{C}, Q_{g}$ is small compared to the energy at the snow surface, and $\Delta Q$ is equal to the melt. Precipitation during the melt period will likely be rain. The cumulative melt, in millimeters per 6-hour period ( $\mathrm{mm} / 6-\mathrm{h})$, is simulated as follows:

$$
\begin{aligned}
M & =Q_{i} \cdot(1.0-A)+Q_{a}-20.4 \cdot 0.125 \cdot P_{x} \cdot T_{w} \\
& +8.5 \cdot f\left(u_{a}\right) \cdot\left[\left(e_{a}-6.11\right)+0.00057 \cdot P_{a} \cdot T_{a}\right]
\end{aligned}
$$

where

$M$ is the cumulative melt, in millimeters per 6-hour period.

Even this special case requires observations of radiation, wind speed, temperature, and relative humidity that are rarely available for each MRU in a watershed. Therefore, Anderson (1973) developed the temperature index method where the heat exchange is estimated from air temperature and the annual variation in solar radiation. On days when rain falls on the snowpack, equation 41 is further simplified by assuming cloudy conditions (no incoming solar radiation), 90 percent relative humidity, and an average wind function.

North of the tropics, incoming solar energy varies from a maximum at summer solstice to a minimum at winter solstice. Maximum and minimum air temperatures will lag by about 1 month in response to atmospheric and oceanic circulation and thermal inertia of the land and water. Therefore, the melt energy on a given day can be estimated by using only the day of the year and the air temperature. SNOW-17 uses this seasonal variation in melt energy to estimate the energy exchange at the snow-air interface.

\section{Computation of Snowmelt and Heat Deficits}

SNOW-17 includes most of the important physical processes that are considered in the previously described pointscale model of energy and mass balance (Anderson, 1968, 1976); however, the physical processes are in a simpler form that simulates the snowpack as a single mass of ice, water, and vapor. The model has three main concepts that are based on using the season, air temperature, and precipitation to estimate heat exchange of the snowpack. The following is a list of the main concepts. 
- During periods close to the winter solstice and when the air temperature is less than the snowpack temperature, the snowpack temperature will decrease, creating a heat deficit that must be overcome before any snow melts. The snowpack will remain frozen until the snowpack becomes isothermal at $0{ }^{\circ} \mathrm{C}$. At $0{ }^{\circ} \mathrm{C}$, the snowpack is "ripe," and any additional heat will produce outflow of meltwater from the snowpack as ice is converted to liquid.

- Most of the energy is exchanged at the snow-air interface. The energy exchange is computed differently for each of the following three conditions: (1) when the air temperature is below the threshold (usually $0{ }^{\circ} \mathrm{C}$ ), the condition is considered a nonmelt period; (2) when the air temperature is above the threshold and precipitation is recorded, a more complete energy balance is computed; and (3) when the air temperature is above the threshold, but little to no precipitation is recorded $(<1.5$ $\mathrm{mm} / 6-\mathrm{h}$ ), a seasonal melt factor is used. A constant daily amount of melt at the snow-soil interface and sublimation at the snow-air interface may be assigned, but the energy equivalent of the melting and sublimation is assumed to be minor compared to the energy exchange at the snow-air interface. The ground melt and sublimation are independent of all other conditions and will continue until the snowpack is completely melted or sublimated.

- The surface area of the snowpack subject to energy exchange decreases during the melt period according to a user-defined relation between pack-water equivalence and SCA.

On days with no snowpack and no precipitation or irrigation, the snowpack module does no computations. Otherwise, net deposition and temperature are distributed into four 6-hour periods.

\section{Precipitation Form and Melting as Functions of Air Temperature}

Temperatures measured at meteorological stations are distributed in temp_1sta_prms to each MRU by using lapse rates [tmax_lapse(nmonths) and tmin_lapse(nmonths)] and corrections for aspect and topographic shading [tmax adj(nmru) and tmin adj(nmru)]. The final MRU temperatures [tmax_c(nmru) and

tmin_c(nmru)] are then provided to nwsmelt_topg where the temperatures are redistributed temporally to produce a synthetic diurnal variation. Those temporary temperatures are then compared with tmax allsnow_c(one), the WEBMOD parameter equivalent to the original SNOW-17 parameter PXTEMP, to determine the form of precipitation for each of four 6-hour periods. Each period receives one-quarter of the daily net deposition.
The synthetic diurnal variation of temperature results in minimum temperatures from midnight to 6 a.m. and maximum temperatures from noon to 6 p.m. (fig. 19) as follows:

$$
\begin{gathered}
\overline{\mathrm{T}}_{m r u}^{12 \mathrm{am}-6 \mathrm{am}}=0.95 \mathrm{~T}_{m r u}^{\min }+0.05 \mathrm{Tprev}_{m r u}^{\max }, \\
\bar{T}_{m r u}^{6 \mathrm{am}-12 \mathrm{pm}}=0.4 T_{m r u}^{\min }+0.6 T_{m r u}^{\max },
\end{gathered}
$$

$$
\begin{aligned}
\bar{T}_{m r u}^{12 \mathrm{pm}-6 \mathrm{pm}}= & 0.925 T_{m r u}^{\max }+0.025 T_{m r u}^{\mathrm{min}}+0.05 \text { Tpst }_{m r u}, \text { and } \\
& \bar{T}_{m r u}^{6 \mathrm{pm}-12 \mathrm{am}}=0.33 T_{m r u}^{\max }+0.67 \text { ppst }_{m r u},
\end{aligned}
$$

where

$\bar{T}_{m r u}^{6-\mathrm{h}}$ is the average temperature for snowpack accumulation and melt in the MRU for that 6-hour period, in degrees Celsius - referred to with the symbol $T_{n}$ in following sections;

$T_{m r u}^{\max (\min )} \quad$ is the maximum or minimum temperature distributed to the MRU, in degrees Celsius [tmax_c(nmru) and tmin_c(nmru)];

Tprev $_{\text {mru }}^{\max }$ is the maximum temperature distributed to the MRU for the previous day, in degrees Celsius [initialized on day zero as TMXPREI(nmru)]; and

$T p s t_{m r u}$ is an estimate of the minimum temperature on the next day, determined by $T_{m r u}^{\min }-T_{m r u}^{\max }+$ Tprev $_{m r u}^{\max }$, in degrees Celsius.

In the original SNOW-17 algorithm, the term Tpst ${ }_{m r u}$ was equal to the minimum temperature on the next day. As data from a future date are not available in MMS, the form presented here is an estimate using the maximum and minimum temperature of the time step and the maximum temperature of the previous day.

The procedure for each 6-hour period is as follows: (1) calculate melt at the snow-soil interface; (2) determine the energy exchange at the snow-air interface; (3) route any liquid water through the snowpack; (4) account for any melting at the snow-soil interface, lagged water, and rain on bare ground for delivery as potential infiltration; and (5) update states, including the heat storage of the snowpack, the pack-water equivalence, and the SCA (fig. 20).

\section{Energy Exchange at the Snow-Air Interface}

The temporally distributed air temperature, $T_{n}$, and net deposition of snow, $P_{n}$, will determine if each 6-hour period is a melt period with little to no rain, a melt period with rain on snow, or a nonmelt period. 


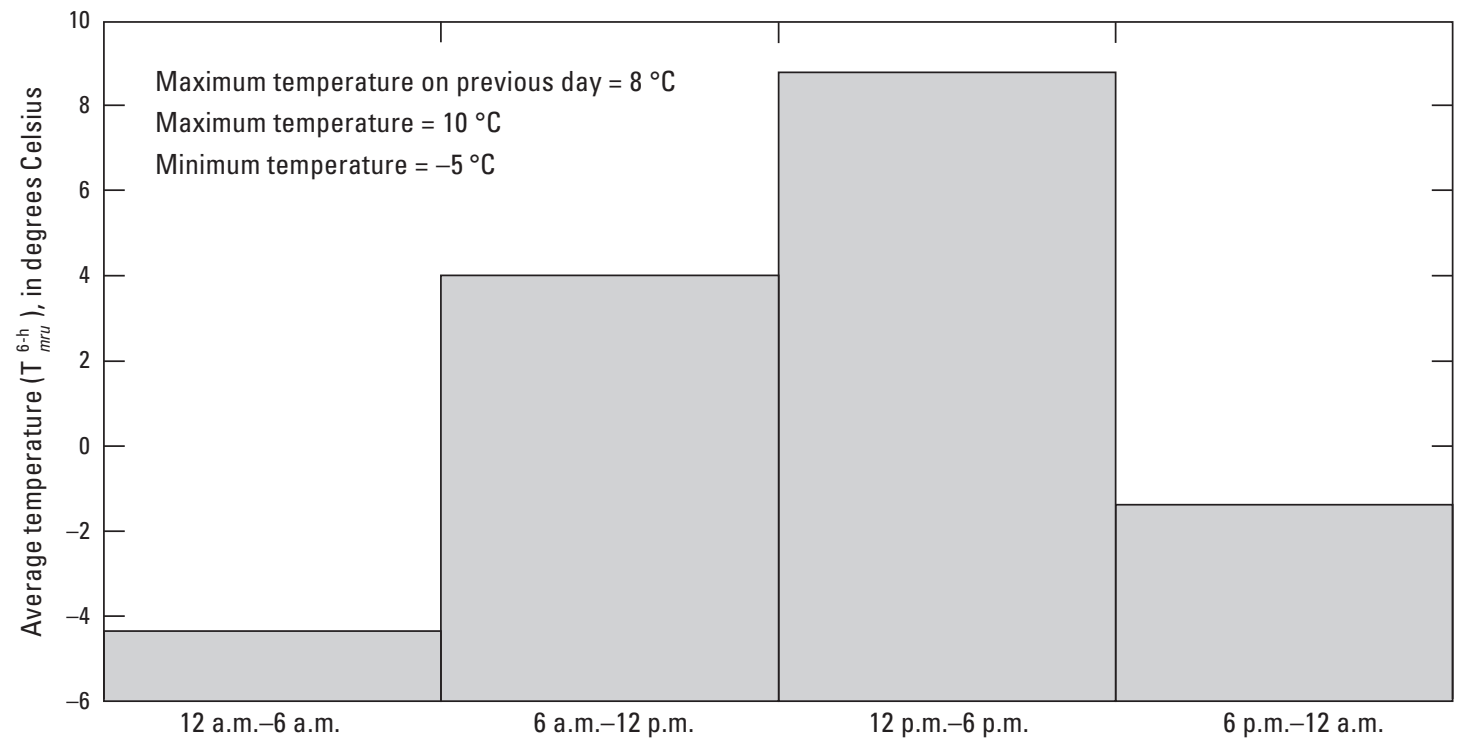

Figure 19. Synthetic variations in air temperature for four 6-hour periods simulated in nwsmelt_topg. $\left(T_{m r u^{\prime}}^{6-h}\right.$ average temperature for snowpack accumulation and melt in a model response unit [mru] for a 6-hour [6-h] period; ${ }^{\circ} \mathrm{C}$, degrees Celsius)

\section{Melt Period with Little to No Rain}

If the temperature is above tmax_allsnow_c(one) and net deposition for the 6-hour period $\left[\operatorname{mru} \operatorname{de}_{\bar{p}}(\mathrm{nmru}) / 4\right]$ is less than or equal to $1.5 \mathrm{~mm}$, heat is added to the snowpack by using the melt factor that is a function of the 6-hour temperature; the base temperature for melt [MBASE(nmru)]; the day of year; the maximum melt factor, which is on June 21 [MFMAX(nmru)]; and the minimum melt factor, which is on December 21 [MFMIN(nmru)]. Suggested initial values for the minimum and maximum melt factors for different terrains and forest types are listed in table 11. Within a watershed, hillslopes with steep southern exposures should be assigned values near the maximum of a given range, and hillslopes with steep northern exposures should be assigned values near the minimum of the given range.

If temporal estimates of solar radiation on the MRUs are available, then the following equations presented by Mizukami and others (2008) can be used to compute MFMAX and MFMIN to account for the effect of forest cover and topography:

$$
M F M A X=\frac{1.03 \cdot(1-g) \cdot R_{D B}+2.04+0.42 \cdot u}{2(R+1)}
$$

$$
M F M I N=R \cdot M F M A X
$$

where

MFMAX is the maximum melt factor (June 21), in millimeters per degree Celsius per 6-hour period $[\operatorname{MFMAX}(\mathrm{nmru})]$;

$g \quad$ is the fraction of forest cover;

$R_{D B} \quad$ is the ratio of radiation on the MRU with a given slope and aspect to the radiation on a horizontal surface, both measured on the equinox (March 21);

$u$ is the wind speed $10 \mathrm{~m}$ above land surface, in meters per second;

$R \quad$ is the ratio of radiation on the MRU on winter solstice (December 21) to the radiation on the MRU on the summer solstice (June 21); and

MFMIN is the minimum melt factor (December 21), in millimeters per degree Celsius per 6-hour period [MFMIN(nmru)].

\section{Snowmelt during Nonrain Periods}

On days with less than $6 \mathrm{~mm}$ of rain, a seasonally varying melt factor (fig. 21) is used in conjunction with the airtemperature data to estimate snowmelt. Trace amounts of rain are added as advected heat. 


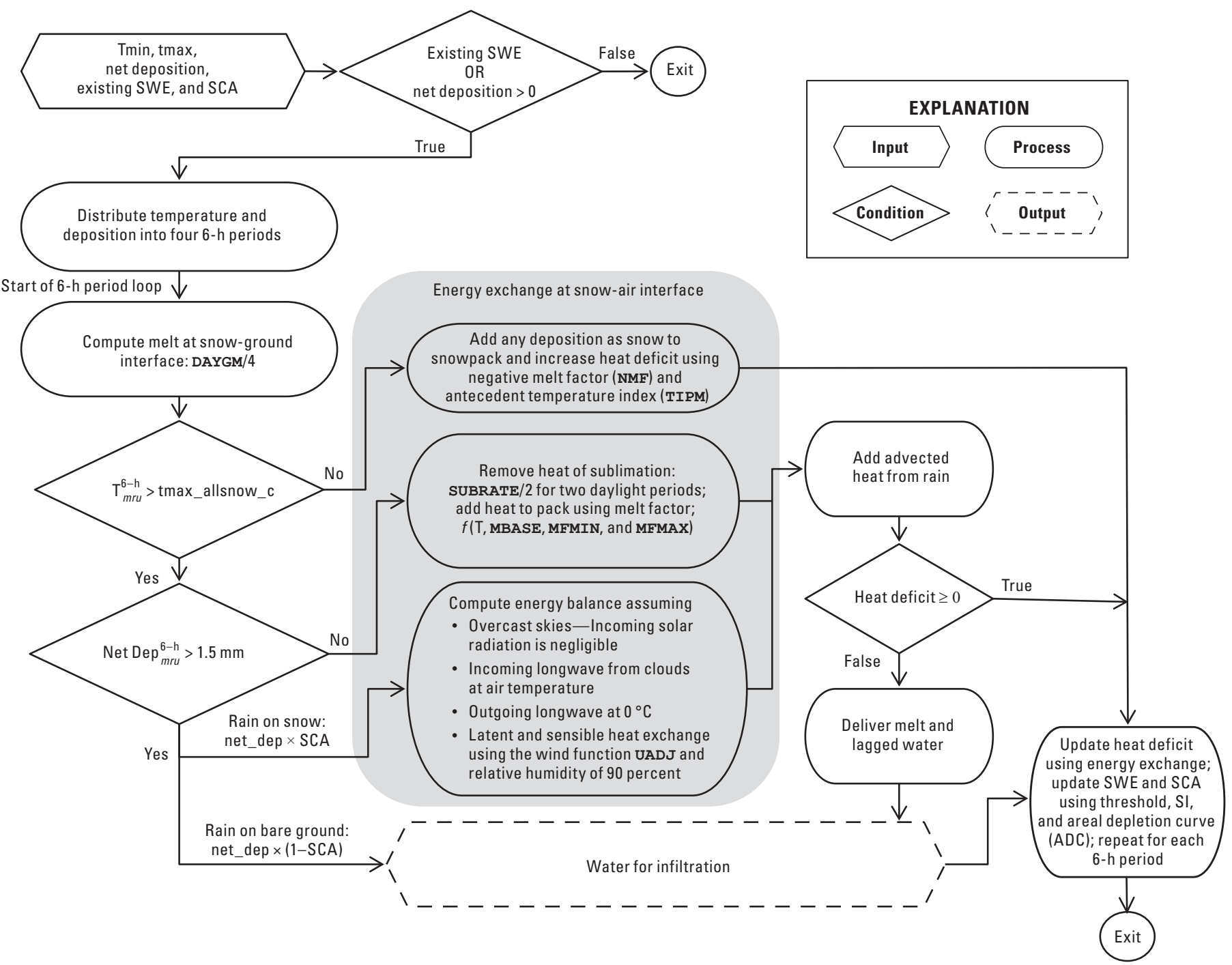

Figure 20. Flowchart showing SNOW-17 algorithm to simulate snowpack dynamics including the exchange of heat across the snow-air interface for each of four 6-hour periods. (Tmin, minimum temperature [tmin_c]; tmax, maximum temperature [ $t$ max_c]; SWE, snowwater equivalent [pkwater equi v]; SCA, snow-covered area [snowcov area]; 6-h, 6-hour; DAYGM, daily total melt at snow-ground interface; MRU, model response unit; $T_{m r u}^{6-h}$, average temperature distributed to MRU for this 6-h period; tmax allsnow c, snow/rain temperature threshold; NMF, negative melt factor, TIPM, antecedent temperature index; Net $\operatorname{Dep}_{m r u}^{6-\mathrm{h}}$, net deposition for this 6-h period; mm, millimeter; net_dep, net deposition; SUBRATE, sublimation rate; T, temperature; MBASE, base temperature for melt; MFMIN, minimum melt factor; MFMAX, maximum melt factor; ${ }^{\circ} \mathrm{C}$, degrees Celsius; UADJ, average 6-h wind function; SI, SWE above which SCA reaches a maximum; ADC, areal depletion curve) 
Table 11. Suggested values for MFMAX and MFMIN, in millimeters per degree Celsius per 6-hour period.

[The formatting convention used in this report is to present dimension names in Courier New font and parameter names in bold Courier New font. See tables 1 and 2 for descriptions of dimensions and parameters. MFMAX, maximum value for melt factor; MFMIN, minimum value for melt factor]

\begin{tabular}{lrr}
\hline \multicolumn{1}{c}{ Description of area } & $\begin{array}{r}\text { MFMAX } \\
\text { (nmru) }\end{array}$ & $\begin{array}{c}\text { MFMIN } \\
\text { (nmru) }\end{array}$ \\
\hline $\begin{array}{l}\text { Dense conifer forest or persistent cloud cover } \\
\text { Mixed cover - conifer, deciduous, open }\end{array}$ & $0.5-0.7$ & $0.2-0.4$ \\
$\begin{array}{l}\text { Mostly deciduous } \\
\text { Mostly open }\end{array}$ & $0.8-1.2$ & $0.1-0.3$ \\
& $1.0-1.4$ & $0.2-0.6$ \\
Flat terrain & $1.5-2.2$ & $0.2-0.6$ \\
Mountainous terrain & $0.9-1.3$ & $0.1-0.3$ \\
\hline
\end{tabular}

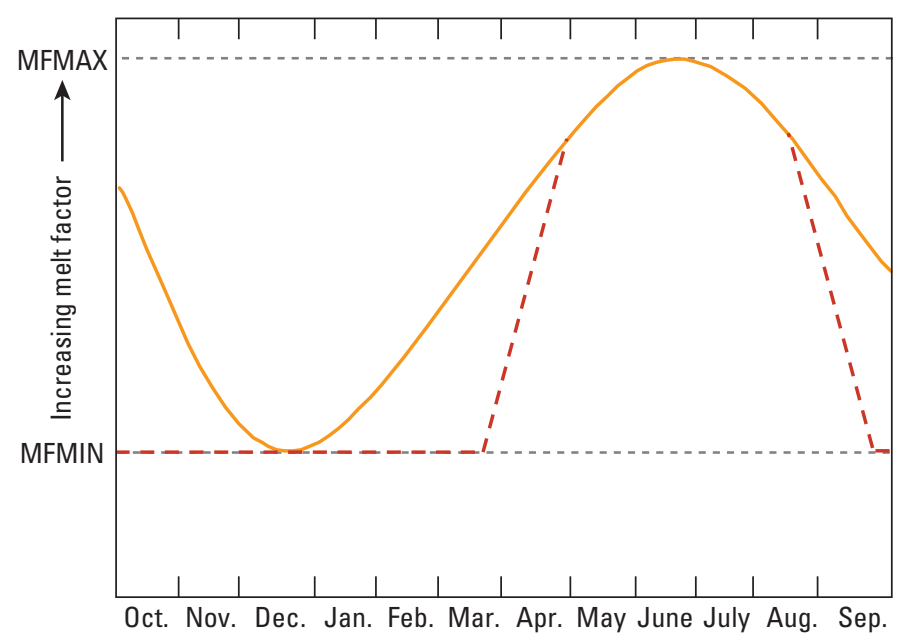

Figure 21. Seasonal variation in the melt factor for the northern hemisphere. The segmented curve is used for all areas north of latitude $54^{\circ} \mathrm{N}$. (all of Alaska). (MFMAX, maximum melt factor, June 21; MFMIN, minimum melt factor, December 21)

For the 6-hour melt period during nonrain periods, $M_{n r}$ is calculated as follows:

$$
M_{n r}=M_{f} \cdot\left(T_{a}-M B A S E\right)+0.0125 \cdot P \cdot T_{r},
$$

where

$M_{n r} \quad$ is the melt during nonrain periods, in millimeters;

$M_{f}$ is the melt factor, in millimeters per degree

Celsius per 6-hour period;

$M B A S E \quad$ is the base temperature for melt, in degrees

Celsius [MBASE(nmru)];

$P \quad$ is the net precipitation, in millimeters; and

$T_{r}$ is the temperature of the rain (air temperature), in degrees Celsius.
The seasonal variation in the nonrain melt factor is as follows:

$$
\begin{gathered}
M_{f}=\frac{\Delta t_{t}}{6} \cdot\left\{S_{v} \cdot A_{v} \cdot(\text { MFMAX }- \text { MFMIN })+\text { MFMIN }\right\} \\
S_{v}=0.5 \cdot \sin \left[\frac{(N \cdot 2 \cdot \pi)}{366}\right]+0.5,
\end{gathered}
$$

where

$\Delta t_{t}$ is the sampling period for temperature, in hours (6 h);

$N$ is the day number (1-366) with day 1 equal to March 21;

MFMAX is the maximum melt factor (June 21), in millimeters per degree Celsius per 6-hour period [MFMAX $(\mathrm{nmru})]$;

MFMIN is the minimum melt factor (December 21), in millimeters per degree Celsius per 6-hour period [MFMIN(nmru)]; and

$A_{v} \quad$ is the seasonal variation adjustment, which is defined as follows:

when latitude $<54^{\circ} \mathrm{N}$., $A_{v}=1.0$;

when latitude $\geq 54^{\circ} \mathrm{N}$.,

$A_{v}=0.0$ from September 24 to March 18,

$A_{v}$ varies linearly between 0.0 and 1.0 from March 19 through April 26, $A_{v}=1.0$ from April 27 to August 15, and

$A_{v}$ varies linearly between 1.0 and 0.0 from August 16 through September 23.

\section{Rain-on-Snow Events}

If $T_{n}$ is above tmax_allsnow_c(one) and net deposition is greater than $1.5 \mathrm{~mm}$, a rain-on-snow event is simulated with a more complete energy balance that has the following assumptions:

- incoming solar radiation is negligible because overcast conditions prevail;

- incoming longwave radiation is equal to black-body radiation at the temperature of the bottom of the cloud cover, which should be close to the air temperature; and

- the relative humidity is high (90 percent is assumed).

The melt during these periods is described in the following equation:

$$
\begin{aligned}
M_{r} & =\sigma \cdot \Delta t_{p} \cdot\left[\left(T_{a}+273 .\right)^{4}-273 .{ }^{4}\right]+0.0125 \cdot P \cdot T_{r} \\
& +8.5 \cdot \mathrm{UADJ} \cdot\left[\left(0.9 \cdot e_{\text {sat }}-6.11\right)+0.00057 \cdot P_{a} \cdot T_{a}\right],
\end{aligned}
$$

where

$M_{r} \quad$ is the melt during rain-on-snow time intervals, in millimeters;

$\sigma \quad$ is the Stefan-Boltzman constant, $6.12 \cdot 10^{-10}$ millimeters per Kelvin per hour; 
$\Delta t_{p} \quad$ is the time interval of precipitation data, in hours;

$T_{a}$ is the air temperature, in degrees Celsius;

273. is $0{ }^{\circ} \mathrm{C}$ on the Kelvin scale;

$T_{r} \quad$ is the temperature of rain, in degrees Celsius

( $=T_{a}$ or $0^{\circ} \mathrm{C}$, whichever is greater);

UADJ is the average wind function, in millimeter per millibar per 6-hour time period;

$e_{s a t}$ is the saturated vapor pressure, in millibars, at $T_{a}$, which is computed from $e_{\text {sat }}=2.7489 \cdot 10^{8} \cdot e^{\left(-4278.63 /\left(T_{a}+242.792\right)\right)} ;$ and

$P_{a} \quad$ is the atmospheric pressure, in millibars.

The snowpack becomes ripe when energy exchange results in an isothermal snowpack at $0{ }^{\circ} \mathrm{C}$ (heat deficit $=0$ ). Any additional heat will melt snow resulting in liquid that is simulated as ponding on the snow surface. Although the negative heat

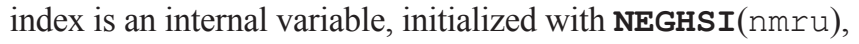
the temperature of the snowpack [TINDXI(nmru)] is a public variable that may be tracked to observe how ripe the snowpack is during a simulation. The liquid water will be retained in the snowpack up to the percent liquid-water holding capacity as described in the "Retention and Transmission of Liquid Water" section. The liquid water may refreeze if temperatures drop below freezing during a subsequent 6-hour period. Once the liquid water exceeds the holding capacity, the water will be routed out of the bottom of the snowpack.

\section{Nonmelt Period}

If $T_{n}$ is below tmax_allsnow_c(one), then the form of precipitation is set to snow, the net deposition is added to the snowpack, and the heat deficit (internal variable) of the snowpack is adjusted. The heat deficit may increase or decrease depending on the temporally distributed air temperature, $T_{n}$, and the gradient of temperature in the upper parts of the snowpack. The temperature of the surface of the snowpack, $T_{s}$, is set to $0^{\circ} \mathrm{C}$ or $T_{a}$, whichever is less. The temperature at some distance below the surface is described by the antecedent temperature index (ATI), in degrees Celsius, which weights the most recent temperatures more heavily than those in the past. If new snow is falling at a rate more than 1.5 millimeters per hour, then the antecedent temperature is reset to the air temperature during the snowfall. The following equation describes the logic used when updating the antecedent temperature index for the next 6-hour period:

$$
A T I=A T I+T I P M_{m r u} \cdot\left(T_{n}-A T I\right)
$$

where

ATI is the antecedent temperature index, in degrees

Celsius, which is set with the criteria

$$
\begin{aligned}
& A T I=0{ }^{\circ} \mathrm{C} \text {, if } A T I>0{ }^{\circ} \mathrm{C}, \\
& \text { or } A T I=T_{n} \text {, if } P_{n}>1.5 \cdot \Delta t_{p} ;
\end{aligned}
$$

$T I P M_{m r u}$ is the antecedent temperature index parameter that controls how much weight is put on temperatures from previous time intervals when computing $A T I$ - the smaller the value of TIPM, the more previous time intervals are weighted $(0.0<\operatorname{TIPM}(\mathrm{nmru})]<1.0)$; and

$T_{n} \quad$ is the temporally distributed air temperature, in degrees Celsius.

If the temperature at the surface of the snowpack, $T_{s}$, is colder than $A T I$, then the heat deficit is increasing; if $T_{s}$ is warmer than ATI, then the heat deficit is decreasing. The magnitude of the change in heat deficit will depend on the seasonally varying negative melt factor, which has a maximum value equal to $\mathbf{N M F}(n m r u)$.

$$
\begin{gathered}
\Delta D_{t}=N M_{f} \cdot\left(A T I-T_{s}\right)= \\
N M F \cdot\left(\Delta t_{p} / 6\right) \cdot \frac{M_{f}}{M F M A X} \cdot\left(A T I-T_{s}\right),
\end{gathered}
$$

where

$\Delta D_{t} \quad$ is the change in heat deficit because of a temperature gradient, in millimeters;

$N M_{f}$ is the negative melt factor, in millimeter per degree Celsius per 6-hour period; and

$N M F \quad$ is the maximum negative melt factor, in millimeter per degree Celsius per 6-hour period [NMF(nmru)].

The following two paragraphs are based on the SNOW-17 documentation (Anderson, 2006):

The TIPM parameter is used to compute an ATI that represents the temperature inside the snowpack near the surface. Anderson (2006) suggests a value 0.05 for areas where the snow depth is usually $1 \mathrm{~m}$ or more. A value of 0.20 is appropriate for areas with shallow (generally less than $0.3 \mathrm{~m}$ ) or intermittent snowpack. Intermediate values should be used for other areas.

The negative melt factor determines the amount of energy that is exchanged when snow is not melting at the snow surface. The negative melt factor equals NMF on June 21, when $M_{f}$ is equal to MFMAX(nmru). A seasonal variation is needed because density is the primary factor that affects the thermal conductivity of the snow, and the snow density generally varies in a seasonal manner. The density is lowest during periods of accumulation and increases as the snow ages throughout the winter. Simplified heat-transfer calculations indicate that a reasonable value for NMF is about 0.15 millimeters per degree Celsius per 6-hour period $\left(\left(\mathrm{mm} /{ }^{\circ} \mathrm{C}\right) / 6-\mathrm{h}\right)$. This value is generally independent of the amount of snow in an area and is 
based on a maximum snow density of 0.3 gram per cubic centimeter $\left(\mathrm{g} / \mathrm{cm}^{3}\right)$ for a shallow snowpack and $0.5 \mathrm{~g} / \mathrm{cm}^{3}$ for a deep snowpack. If an area generally has a maximum density less than $0.3 \mathrm{~g} / \mathrm{cm}^{3}$, NMF should be decreased, and if the maximum density is greater than $0.5 \mathrm{~g} / \mathrm{cm}^{3}, \mathbf{N M F}$ should be increased. A maximum reasonable range for the NMF parameter is from 0.05 to $0.30\left(\mathrm{~mm} /{ }^{\circ} \mathrm{C}\right) / 6-\mathrm{h}$.

\section{Snow-Covered Area}

The energy exchange at the snowpack surface and melting at the snow-soil interface (ground melt) is directly related to the SCA [snowcov_area(nmru), As in figure 22]. Similarly, the SCA determines the fraction of the MRU area where throughfall and rain falls on snow and, by subtraction, the area where throughfall and rain falls on open ground.

Conceptually, the SCA on any given day is determined by conditional logic; either the SCA is 100 percent because of recent snowfall, or the SCA is established on an areal depletion curve by using the ratio of SWE or pack-water equivalence [pkwater_equiv(nmru), Ws in figure 22] to an areal index, Ai (fig. 22). The areal index is the smaller of (1) the maximum SWE during the accumulation period, Wmax, or (2) the SWE threshold above which the SCA is always 100 percent [SI(nmru)]. Therefore, during the accumulation phase, $\mathrm{Ws} / \mathrm{Ai}$ is at or close to 1.0 because Wmax is reset to Ws with each new snowfall. The maximum SWE is reset to zero whenever the snowpack melts completely or to the total SWE when the snowfall on a given day exceeds three times the SWE from the previous day. If available, observations of SWE, included in webmod.hydro.dat as swe(nsnow), can be plotted against simulated SWE, pkwater_equiv(nmru), to assist in calibrating snowpack parameters.

Watersheds with high relief may rarely have 100 percent SCA because new snow is quickly redistributed by avalanches and wind. In WEBMOD, the parameter MRUDEPL(nmru) determines which of two areal-depletion curves for SWE in the snowpack is to be used for a given MRU-curve 1, which describes the behavior observed in low-relief areas, where SCA remains close to 100 percent throughout the winter; or curve 2 , which describes the behavior observed in high-relief areas, where SCA quickly becomes patchy after each snowfall as snow is redistributed by wind and mass movements (fig. 23).
Areas assigned the high-relief depletion curve will simulate greater maximum snowpack and an extended melt season when compared to simulations of areas assigned the low-relief depletion curve (fig. 24). If more detailed observations describing the relation between SWE and SCA are available for a basin, the areal-depletion curves defined for the parameter ADC(ndeplval) can be modified. The dimension ndeplval is fixed at 22 with $\mathrm{ADC}$ (ndeplval) describing the two curves, each with 11 fractions of SCA that correspond to values of $\mathrm{Ws} / \mathrm{Ai}$ from 0.0 to 1.0 in increments of 0.1 .

\section{Other Snow Model Components}

As winter begins in montane and alpine watersheds, snowpack cover quickly rises to 100 percent after the initial snowfalls, with occasional decreases on warm days and on wind-blown steep slopes. After reaching a peak in April or May, snowpack begins a monotonic decline until the snowpack melts entirely or reaches a seasonal minimum. In WEBMOD, a new accumulation period begins with the first snowfall following the disappearance of the snowpack or, for MRUs that maintain residual snowpack, when the SWE in an MRU triples on a single day.

\section{Initial Conditions and Accumulation}

The initial SWE in an MRU is defined by WEI(nmru). If the model starts during the accumulation season in fall or winter, the initial maximum SWE [ACUMX(nmru)] should be set to zero so that each new snowfall will become a new maximum. To initialize a colder snowpack, the initial negative heat storage can also be set higher, but not higher than one-third of $\operatorname{WEI}(n m r u)$. If the model starts during the melt season, ACUMX (nmru) should be set to the usual spring maximum so that the SCA begins on and continues down the areal-depletion curve. During the melt season, the initial negative heat storage [NEGHSI(nmru)], in inches, should also be set to zero.

The parameters SCF and PXTEMP are two of the most important parameters in the NWS implementation of SNOW17. The parameter SCF is used to correct gage undercatch, which can be significant in windy areas, and the parameter PXTEMP is the air-temperature threshold used to determine whether the precipitation will be simulated as rain or snow. In WEBMOD, SCF and PXTEMP parameters have proxies 


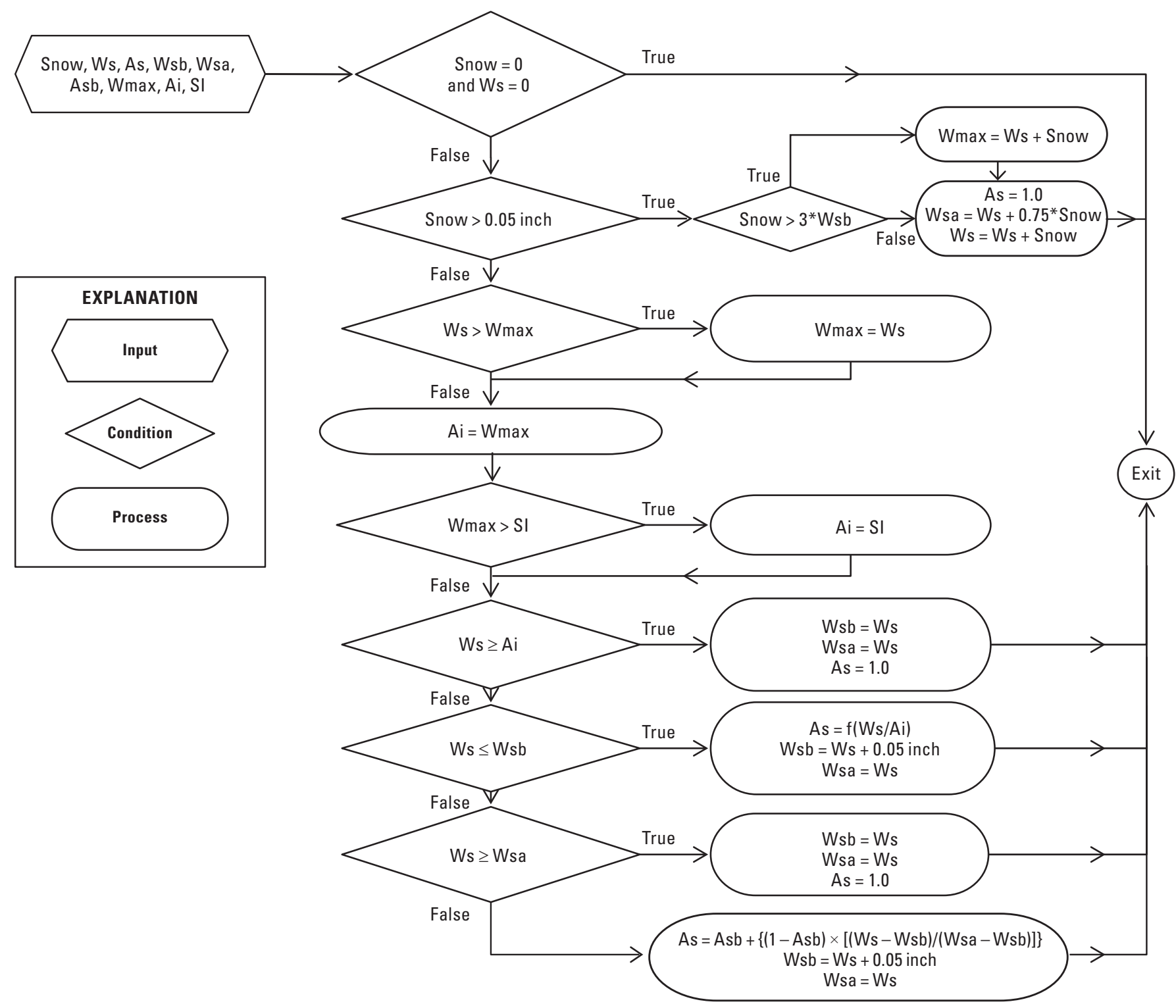

Figure 22. Flowchart showing logic used to determine snow-covered area. (Snow, water-equivalence of new snow; Ws, snowwater equivalence (SWE) of the snowpack; As, snow-covered area (SCA); Wsb, SWE index before a snowfall; Wsa, SWE index after a snowfall; Asb, SCA before a snowfall; Wmax, maximum SWE during current snow season; Ai, areal index that is the lesser of either Wmax or SI, the threshold above which SCA is always equal to 1.0. The areal-depletion curve is a function of Ws/Ai, written $\mathrm{f}(\mathrm{Ws} / \mathrm{Ai})$.) 


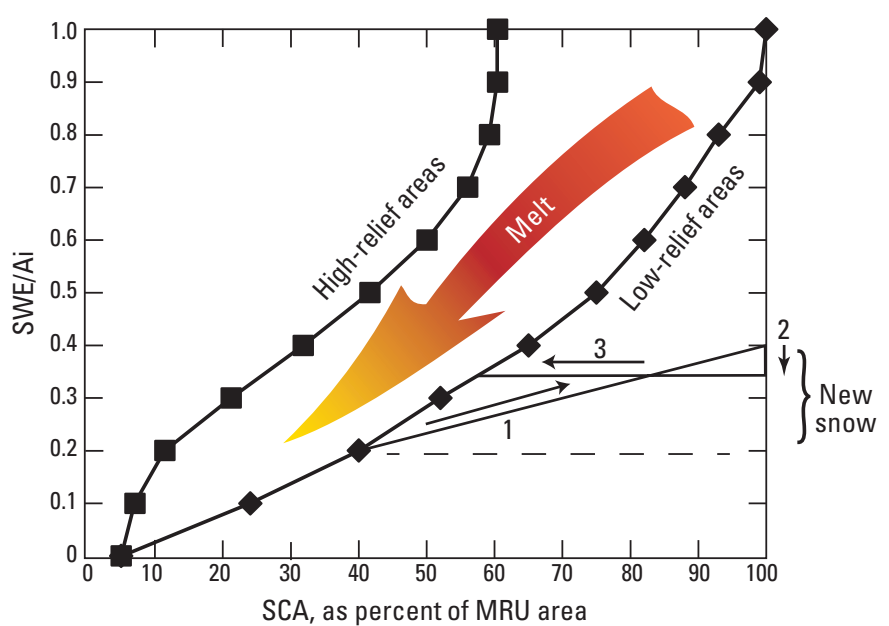

Figure 23. The two default areal-depletion curves showing relation between snow-covered area (SCA), snow-water equivalence (SWE), and the areal index (Ai) for low- and high-relief areas [MRUDEPL(nmru) $=1$ and 2, respectively]. The Ai is the smaller of (a) the maximum SWE since the start of snowpack accumulation and (b) the SWE above which the SCA always equals 100 percent [SI(nmru)]. With each new snow, (1) SCA is set to 100 percent until (2) 25 percent of the new snow melts or sublimates, and at which point (3) SCA is computed again using the curve. Each curve is defined by 11 points that define SCA, as a decimal fraction, for 0.1 increments of SWE/Ai between 0 and 1.0. (MRU, model response unit)

(related parameters) in the modules that distribute precipitation and temperature to each MRU. Precipitation missed because of gage undercatch can be added back in precip_web by using the corrections for rain [rain_adj(nmru)] and snow [snow_adj(nmru)]. The resulting total precipitation is then reduced by canopy interception in intcp_prms with the rain and snow that was not intercepted joining the throughfall as net deposition for nwsmelt_topg. The parameter tmax_allsnow_c(one), described earlier, is the proxy for the rain-snow temperature threshold.

\section{Melting at the Snow-Soil Interface and Sublimation}

Compared to the heat exchange and conversion of ice to water at the air-snow interface, the energy exchanges resulting from melting at the snow-soil interface and sublimation are small. Melting at the snow-soil interface and sublimation are simulated with constant rates in WEBMOD. Although the rates are small compared to the heat exchange at the snow-air interface, the total volume of snowpack lost over the winter can be substantial.

When the temperature of the ground is greater than the base of the snowpack and greater than $0{ }^{\circ} \mathrm{C}$, snow at the base of the snowpack will melt. The amount of melt [DAYGM(nmru)], in inches per day, is a parameter that should be assigned a value ranging from 0.0 for MRUs with thin snowpacks and long cold winters to 0.02 for MRUs with thick snowpacks, moderate winters, and many days above freezing (Anderson, 1973). The melt at the snow-ground interface for the 6-hour computational period, converted to millimeters, is as follows:

$$
M_{g}=D A Y G M \cdot 25.4 / 4
$$

where

$M_{g} \quad$ is the amount of ground melt during each precipitation data interval, in millimeters, which is equal to the existing pack-water equivalence $W_{s}$ [pkwater_equiv(nmru)], if $M_{g}>W_{s}$, and

$D A Y G M \quad$ is the amount of ground melt, in inches per day [DAYGM(nmru)].

Ground melt is simulated whenever SWE is greater than zero, independent of the air temperature or the heat deficit of the snowpack. Similarly, sublimation is assigned a constant rate [SUBRATE(nmru)], in inches per day.

$$
V=S U B R A T E,
$$

where

$V$ is the amount of sublimated snow during the day, in inches per day [SUBRATE(nmru)], which is equal to the existing pack-water equivalence $W_{s}$ [pkwater_equiv(nmru)], if $V>W_{s}$.

Internally, SUBRATE(nmru) is divided by two and applied to the two 6-hour time periods from 6 a.m. to 6 p.m.

Melting at the snow-soil interface is removed from the snowpack before simulations of the energy exchange at the snow-air interface. Sublimation is simulated for any snowpack remaining after the simulations of melting at the snow-soil interface and energy exchange at the snow-air interface.

\section{Retention and Transmission of Liquid Water}

When the heat deficit of the snowpack is zero, ice and liquid water can be present. The pack-water equivalence, $W_{s}$, is the sum of both forms of water.

$$
W_{s}=W_{i}+W_{q}
$$

where

$W_{s}$ is the pack-water equivalence

[pkwater_equiv(nmru)], in inches;

$W_{i}$ is the frozen water in snowpack, in inches; and

$W_{q}$ is the liquid water in snowpack, in inches.

The amounts of liquid and frozen water in the snowpack are tracked internally, but only the total is available as a public variable. Liquid water in the snowpack is held against gravity up to a user-specified limit.

$$
W_{q x}=\mathrm{PLWHC} \cdot W_{i}
$$

where

$W_{q x}$ is the maximum amount of liquid in snowpack, in inches;

PLWHC is the liquid-water holding capacity, unitless fraction [PLWHC(nmru)]; and

$W_{i}$ is the water equivalent of the ice portion of the snowpack, in inches. 


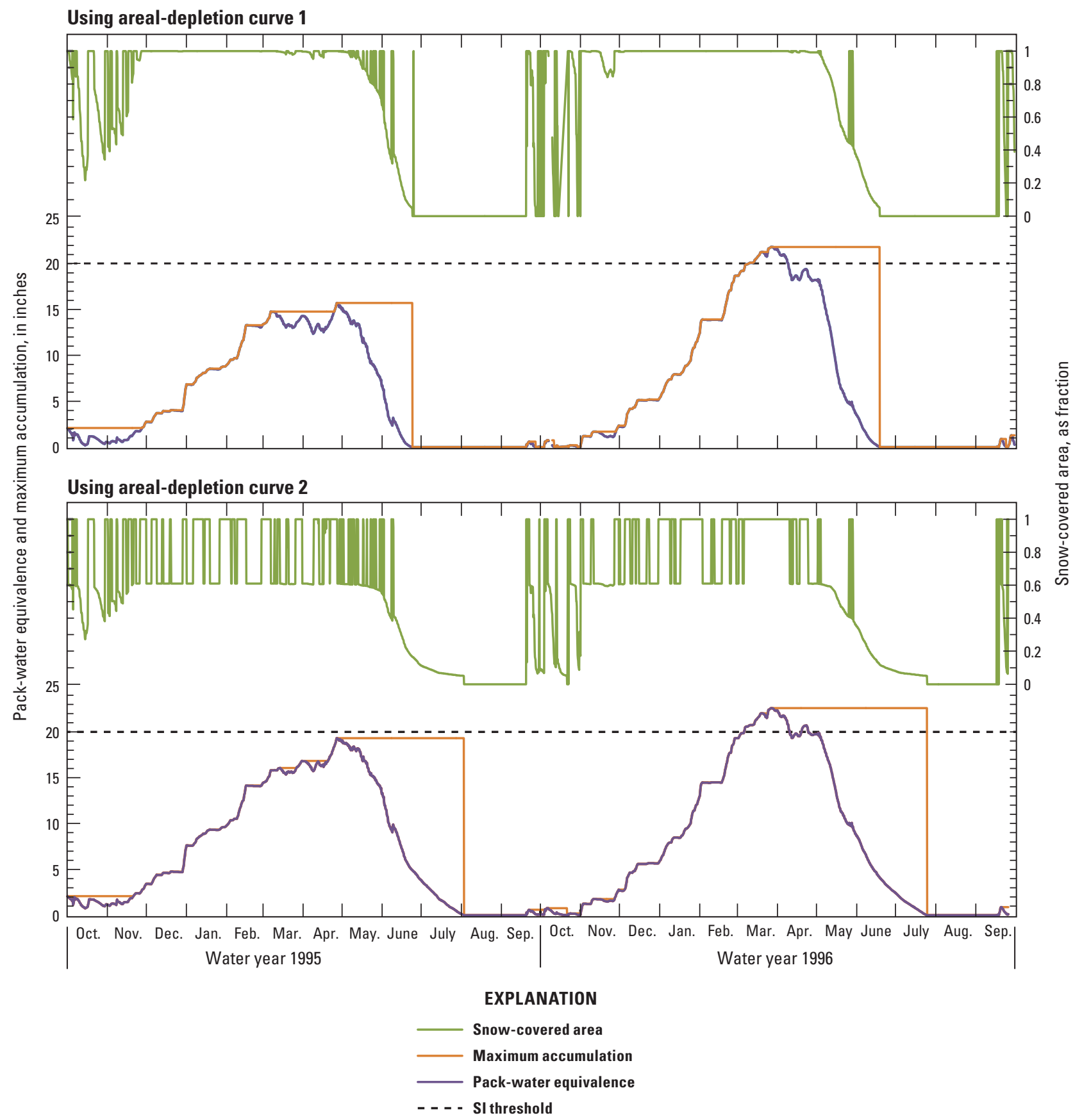

Figure 24. Snow-covered area, snowcov_area(nmru); pack-water equivalence, pkwater_equiv(nmru); and maximum accumulation [initialized with ACCMAX $(\mathrm{nmru})$ ] simulated by using areal-depletion curve for low- and high-relief areas [MRUDEPL(nmru)=1 and 2, respectively] using the Andrews Creek model with data inputs from water years 1994 and 1995. During much of the accumulation period, the pack-water equivalence is equal to the maximum accumulation. Curve 2 , used in the Andrews Creek model, simulates less energy exchange at the air-snow interface, resulting in greater pack-water and a longer melting season when compared with curve 1 . The areal index, Ai, on any given day is the smaller of the maximum accumulation or the value of pack-water equivalence [SI, SI(nmru)] above which snow-covered area is always 100 percent. $\mathrm{SI}$ is set here to 20 inches to demonstrate its role in seasonal variations in the snow-covered area. The SI is set to 999 inches in the Andrews Creek model to allow for some bare areas soon after each snowfall. 
The PLWHC is intended to represent the overall liquidwater holding capacity of a ripe snowpack near isothermal conditions. The maximum allowed value of PLWHC is 0.4 . Once the liquid water exceeds the PLWHC threshold, the excess water is routed to the ground surface beneath the snowpack, where the water is added to the melt at the snow-soil interface to simulate the total snowmelt [snowmel $t$ (nmru)], in inches. The thickness of the snowpack is a function of the snow density, the SWE, and the SCA. The lag time could be significant if thick snowpacks were simulated on an hourly time step. For the 6-hour time periods used in the WEBMOD implementation of SNOW-17, the number of lag periods is fixed at two, and estimates are not made of snow density or snowpack thickness. Given two lag periods for routing excess water through the snowpack, the maximum residence time of excess water above water holding capacity is 12 hours; that is, excess water will be delivered to the ground either on that day or the next day if the heat deficit does not increase and refreeze water in the snowpack. The user is directed to Anderson (2002) for further details on the lag and outflow of meltwater for shorter time periods. The user may assume that when the temperature of the snowpack [TINDXI(nmru)] is 0 ${ }^{\circ} \mathrm{C}$, then some fraction of the snowpack is water.

Final lagged water amounts are summed with ground melt, throughfall, and rain on bare ground to arrive at the total potential infiltration at the land surface. The heat exchange and melting at the snow-soil interface computed in the previous sections are used to estimate the changes in net depth in SWE for a single point in the MRU. The changes in net depth are multiplied by the SCA $(0.05-1.0)$ to arrive at the final flux values for the MRU. The minimum value of 0.05 for SCA allows a nominal amount of energy exchange to melt small amounts of snow that remain late in the melt season.

\section{Hillslope Processes}

Rain, irrigation, throughfall, and snowmelt combine to run off or infiltrate the land surface. The water that infiltrates the land surface, combined with inputs from upgradient groundwater, can return to the atmosphere by ET or follow hydraulic gradients to local streams or regional aquifers. The total contribution of the hillslope to streamflow is a combination of overland flow and hillslope discharge as follows:

$$
q_{\text {tot }}=q_{\text {overland }}+q_{\text {hillslope }}
$$

where

$q_{\text {tot }}$ is the total discharge from the MRU, in meters [qout(nmru)];

$q_{\text {overland }}$ is the sum of Dunnian and Hortonian overland flow, in meters [ $q \circ f(\mathrm{nmru})]$; and

$q_{\text {hillslope }}$ is the sum of direct flow $[q d f(\mathrm{nmru})]$, pipe flow [qpref(nmru)], and base flow [qb(nmru)], all in meters.

Overland flow and hillslope processes are simulated by using algorithms of the TOPMODEL demonstration program version 95.02 (Beven and Kirkby, 1979). TOPMODEL is a popular hillslope hydrology model because the model is computationally efficient, flows and fluxes are based on physical processes, and initial model setup requires only topographic data. An analysis of the watershed topography identifies areas where the depth to the water table should be similar. The water table should be shallower in areas where the upslope contributing area (a, in length squared) is greater and the local slope ( $\beta$, in change in altitude per change in horizontal distance) is less than in areas where the contributing area is less and the local slope is greater. An analysis of the base-flow recession provides estimates of the effective soil transmissivity at the saturated thickness ( $T_{0}$, in length squared per time) and the shape of the decrease in transmissivity with depth (Tallaksen, 1995). Where thick aquifers are drained by little-incised streams, as in the watersheds of the northern United Kingdom where TOPMODEL was developed, an exponentially decreasing transmissivity may be appropriate (Beven and others, 1984). Where shallow aquifers are well drained by streams, a parabolic or linear decrease in transmissivity may be more appropriate (Ambroise and others, 1996a, b). The shape of the decrease in transmissivity also constrains which transformation of the TI $(a / \tan \beta)$ should be distributed in the MRU to simulate the correct recession for the MRU- $\ln (\mathrm{TI})$ for the exponential profile [T_decay $(\mathrm{nmru})=0], \sqrt{\mathrm{TI}}$ for the parabolic profile [T_decay $(\mathrm{nmru})=1]$, or simply TI for the linear profile [T_decay (nmru) $=2$ ] (fig. 25). The correct transformation is critical for consistent simulations of all hillslope processes including overland flow, preferential flows, and base-flow generation. The recession parameter $[\mathbf{S Z M}(\mathrm{nmru})]$ is a sensitive parameter in TOPMODEL and WEBMOD. In keeping with the high priority for model parsimony, the original TOPMODEL uses the recession parameter to control the recession curve and also to describe an exponential decrease in vertical saturated conductivity, $\mathbf{x k 0}$ (nmru) (Beven, 1984). This use of a single parameter results in unrealistic spikes in overland flow because the MRU will experience overland flow whenever 


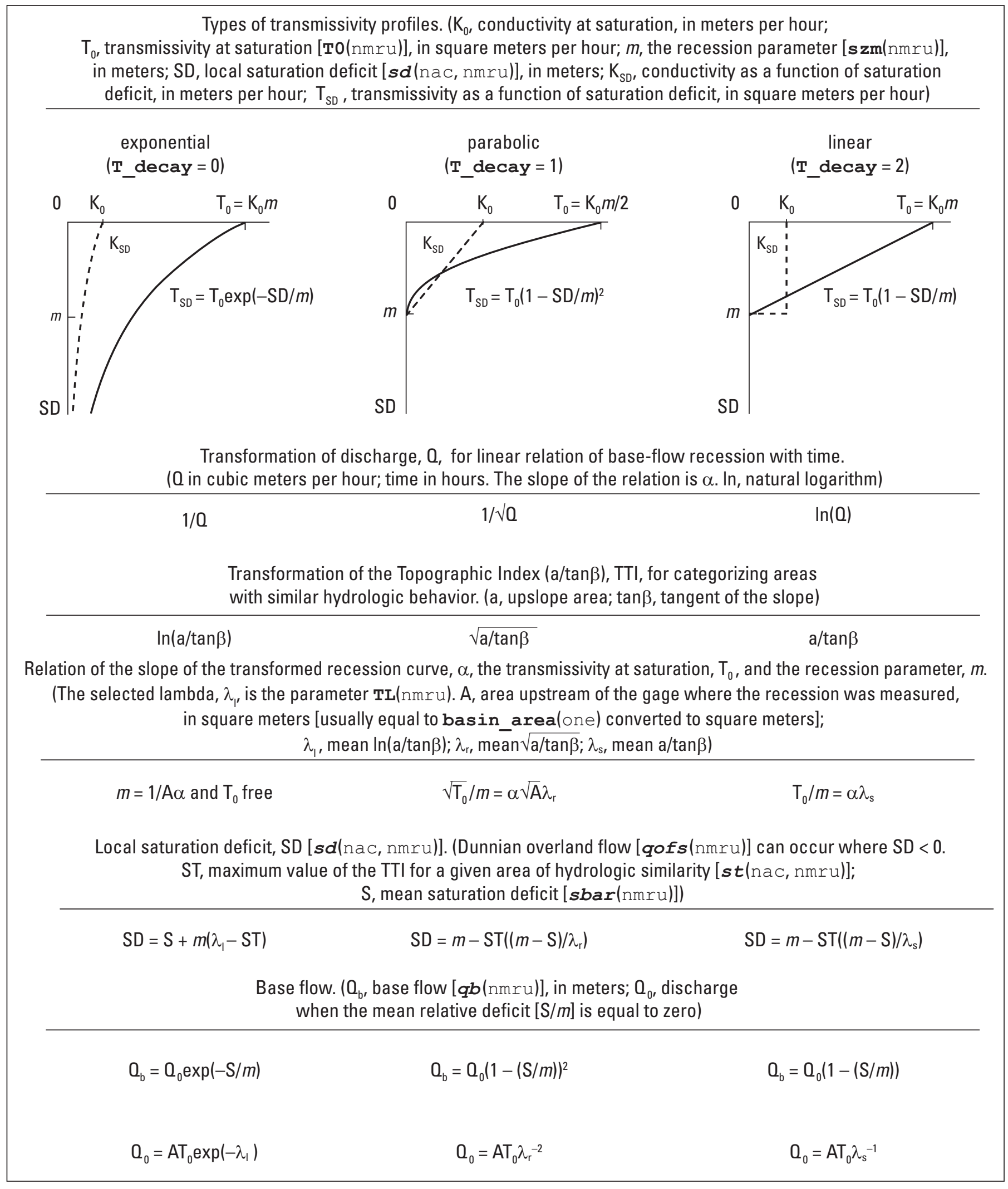

Figure 25. Three types of transmissivity profiles [T_decay (nmru)] and resulting relations as derived by Ambroise and others (1996a) and implemented in the Water, Energy, and Biogeochemical Model (WEBMOD). 
surface deposition exceeds the vertical saturated conductivity. WEBMOD provides for spatial heterogeneity of overland flow by assuming a log-normal distribution of vertical saturated conductivity with median $\mathbf{x k}$ _cv(nmru) and coefficient of variation $\mathbf{x k} \mathbf{c v}(\mathrm{nmru})$. To avoid problems with the correlated parameters $\mathbf{S Z M}(n m r u)$ and $\mathbf{x k} \mathbf{C} \mathbf{c v}(\mathrm{nmru})$, the user should calibrate and fix SzM(nmru) and To(nmru) to match baseflow recession and then fix these values before calibrating the log-normal distribution of the vertical saturated conductivity to match overland flow.

\section{Overland Flow}

Water ponds and flows toward the stream when the rate of rainfall, irrigation, and snowmelt is greater than the infiltration rate of the soil (Hortonian overland flow) or when no additional soil storage is available because the water table has risen to the surface (Dunnian overland flow). Hortonian and Dunnian overland flows are simulated in WEBMOD when $\operatorname{infex}(o n e)$ is set to 1 . When $\operatorname{infex}(o n e)$ is set to 0 , only Dunnian overland flow is simulated.

\section{Hortonian Overland Flow}

Horton and others (1934) determined that the dominant source of streamflow in the arid southwest of the United States was infiltration excess. Infiltration excess refers to water that ponds when the precipitation rate exceeds the infiltration rate of the soils. The work of Horton and others (1934) built upon the work of Green and Ampt (1911), which recognized that the infiltration rate into soils is initially much greater than the saturated hydraulic conductivity of the soils because the capillary action pulls water into the unsaturated soils (fig. 26).

Mein and Larson (1973) presented the model as follows:

$$
f_{p}=K_{s}[1+(\Delta \theta \cdot \Delta \Psi / F)]
$$

where

$f_{p} \quad$ is the infiltration capacity, in meters per hour;

$K_{s} \quad$ is the vertical saturated conductivity

[xk0(nmru)], in meters per hour;

$\Delta \theta \quad$ is the saturated porosity, $\theta_{s}$, minus the initial porosity, $\theta_{i}[\mathrm{dth}(\mathrm{nmru})]$, in length cubed per length cubed, unitless;

$\Delta \Psi \quad$ is the effective wetting front suction or capillary drive $[\mathrm{hf}(\mathrm{nmru})]$, in meters; and

$F \quad$ is the cumulative infiltration since the beginning of the event, in meters.

In the TOPMODEL implementation of the Green and Ampt model, Beven developed a numerical solution for time-varying rainfall on nonuniform soils where the saturated hydraulic conductivity decreases with depth (Beven, 1984). To obtain an analytical solution, Beven made the assumption that the suction factor, $C=\Delta \theta \Delta \Psi$, is constant with depth. Morel-Seytoux and Khanji (1974, as described in Beven,

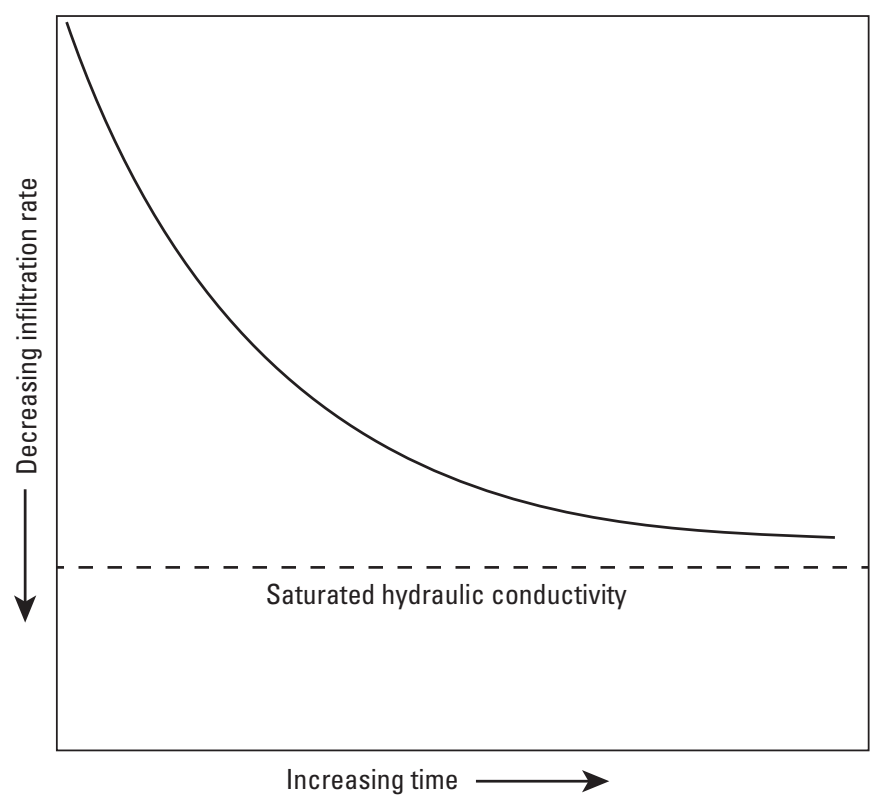

Figure 26. Green and Ampt infiltration model showing infiltration rate decreasing exponentially and asymptotically approaching the saturated hydraulic conductivity of the soils. (Modified from Green and Ampt, 1911)

1984) suggest that $C$ should vary over the narrow range from 0 to $0.1 \mathrm{~m}$ and, except at short times, predictions should be relatively insensitive to the value of $C$. Beven (1984) suggests that the default values of 0.35 (unitless fraction) and $0.01 \mathrm{~m}$ for $\Delta \theta$ and $\Delta \Psi$ are reasonable values that need not be changed. The vertical hydraulic conductivities at the surface may be on the order of meters per hour (Childs and Bybordi, 1969, as described in Beven, 1984) and decrease with depth according to TOPMODEL assumptions. These large vertical hydraulic conductivities are in contrast to much smaller conductivities measured by Holtan and others (1968, as described in Beven, 1984) for confined soil specimens in the laboratory, where the effect of secondary porosity is greatly reduced.

The infiltration excess algorithm used in WEBMOD (Beven, 1984) determines the time to ponding, given the inputs (precipitation, irrigation, throughfall, and snowmelt); the cumulative infiltration, $F$; and the parameters $\mathbf{s} \mathbf{z m}(\mathrm{nmru})$, $\mathbf{x k 0}$ (nmru), $\mathbf{d t h}(\mathrm{nmru})$, and $\mathbf{h f}(\mathrm{nmru})$. The time to ponding is less, and overland runoff is more, when any of these four parameters are reduced. The cumulative infiltration is subtracted from the total surface deposition to compute the depth of ponded water that is tagged as Hortonian overland flow $[\operatorname{rex}(\mathrm{nmru})]$. Hortonian overland flow is mixed with Dunnian overland flow [qofs(nmru)] and moisture in the $\mathrm{O}$-horizon and is delivered to the stream reservoirs. The sum of Hortonian and Dunnian overland flow is tracked in the variable $q \circ f(n m r u)$.

The parameters $\mathbf{x k} 0(\mathrm{nmru}), \mathbf{d t h}(\mathrm{nmru})$, and $\mathbf{h f}(\mathrm{nmru})$ are constant for each MRU in TOPMODEL version 95.02, which results in the generation of unrealistic amounts of overland flow once infiltration capacity is exceeded. In WEBMOD, 
heterogeneity is introduced by assuming that vertical hydraulic conductivity has a log-normal distribution with median $\mathbf{x k} \mathbf{0}(\mathrm{nmru})$ and a coefficient of variation of $\mathbf{x k} \mathbf{c} \mathbf{c v}(\mathrm{nmru})$. A coefficient of variation of 14.132 will result in an order of magnitude change in hydraulic conductivity for each of the nine fractional areas (median \pm 4 standard deviations) that sum to the total MRU area (fig. 27). A coefficient of variation of zero will assign the value of $\mathbf{x k 0}(\mathrm{nmru})$ to all areas of the MRU, thereby reproducing the original TOPMODEL behavior. The fraction of the MRU area that experiences infiltration excess at any time step is reported as $\boldsymbol{a f} \mathbf{x}(\mathrm{nmru})$. The recession parameter [ $\mathbf{s z m}(\mathrm{nmru})]$, which becomes small as the rate of decrease in conductivity gets large, is also a sensitive parameter for Hortonian overland flow. When Hortonian overland flow is the dominant process and rates of infiltration excess are known through direct or indirect methods, then the vertical hydraulic conductivity [ $\mathbf{x k 0}(\mathrm{nmru})]$ and its coefficient of variation [ $\left.\mathbf{x k} \_\mathbf{c v}(\mathrm{nmru})\right]$ should be the primary target of calibration efforts.

All infiltration estimated by using the Green-Ampt algorithms is potential infiltration because, where the water table is at the surface, all surface deposition will become overland flow. For further discussion see the "Dunnian Overland Flow" section.

\section{Dunnian Overland Flow}

Dunnian overland flow (Dunne and Black, 1970a, b) is a key component of TOPMODEL, one of several "variable source area" models (Wolock, 1993). The area of saturated soils (source areas) will vary with every time step, expanding as the water table rises with recharge events and shrinking as the water table drops between recharge events. For example, a quicker streamflow response is generated by a storm during a wet period when the water table is higher and the saturation deficit is smaller than by an equivalent storm during a dry period when the water table is lower and the saturation deficit is greater.

The saturation deficit is calculated for each TTI bin as follows:

$$
\begin{gathered}
s d_{i}=s b a r+\left(s z m \cdot\left(T L-s t_{i}\right)\right) \\
\quad \text { for exponential decay, or } \\
\left.s d_{i}=s z m-s t_{i}((s z m-s b a r) / T L)\right) \\
\text { for parabolic or linear decay, }
\end{gathered}
$$

where

$s d_{i} \quad$ is the saturation deficit [ $\left.\boldsymbol{s d}(\mathrm{nac}, \mathrm{nmru})\right]$ for transformed topographic index bin $i$ in a given MRU, in meters;

sbar is the average soil moisture deficit for the MRU

[sbar(nmru)], in meters;

szm is the recession parameter for the MRU

$[\mathbf{s z m}(\mathrm{nmru})]$, in meters;

$s t_{i} \quad$ is the maximum value of the transformed

topographic index for the bin $i-$

st(nac,nmru). The transformation is

$\ln (\mathrm{TI})$ for exponential decay

[T_decay $(\mathrm{nmru})=0]$,

$\sqrt{\mathrm{TI}}$ for parabolic decay [T_decay $(\mathrm{nmru})=1]$, and

TI for linear decay [T_decay $(\mathrm{nmru})=2]$; and

$T L \quad$ is the mean $s t_{i}$ value for the MRU [TL(nmru)],

equivalent to the zonal mean of

st(nac,nmru), usually computed in a

geographic information system.

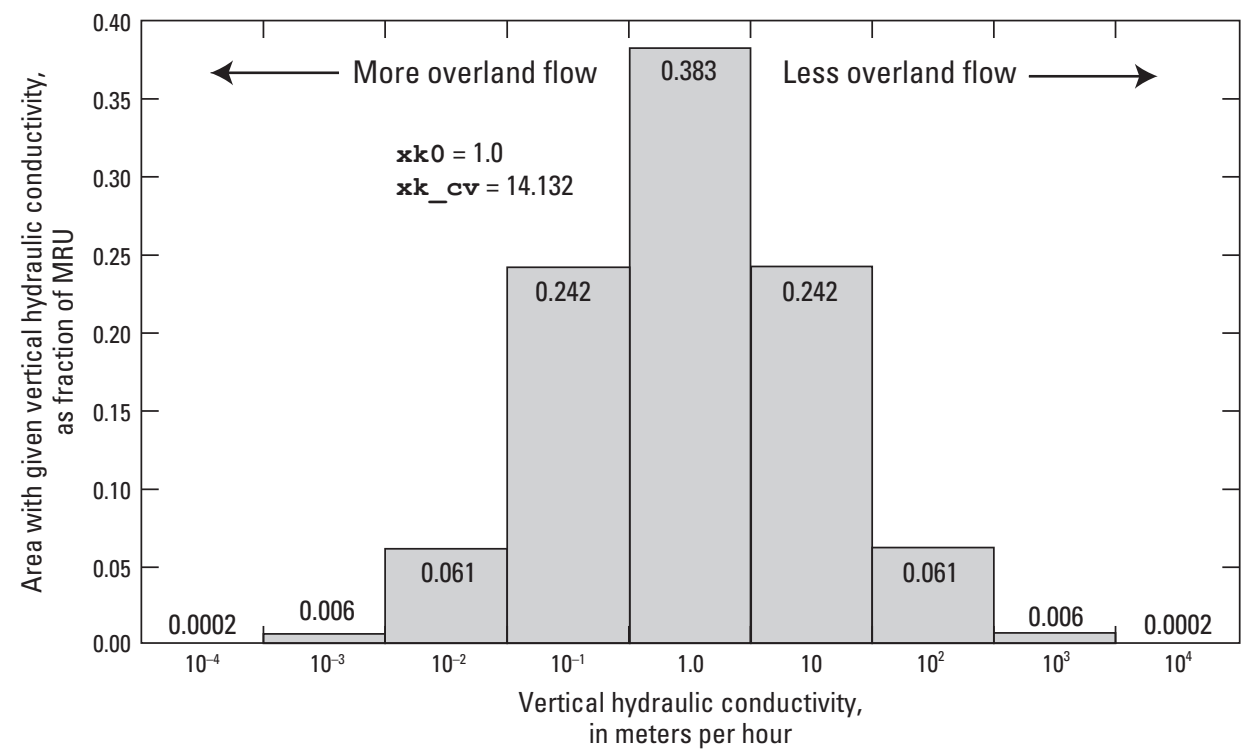

Figure 27. Log-normal distribution of vertical hydraulic conductivity simulated for a model response unit (MRU) with a median, $\mathbf{x k} 0(n m r u)$, of 1.0 meter per hour and a coefficient of variation, $\mathbf{x k} \_\mathbf{c v}(\mathrm{nmru})$, of 14.132 . The maximum predicted infiltration is always limited by the available precipitation, throughfall, irrigation, and snowmelt. 
The simulation of exponential decay has no limit on the maximum saturation deficit, and the saturated transmissivity [To(nmru)] is unconstrained. When simulating parabolic or linear decay, the saturation deficit has a maximum value equal to the recession parameter [s zm(nmru)], and the ratio of $\mathbf{s z m}(\mathrm{nmru})$ to To(nmru) is constrained by the slope of the recession curve as explained in the "Saturated Zone" section. WEBMOD also differs from the original TOPMODEL in the way negative saturation deficits are handled (fig. 28). The calculated saturation deficit, $s d_{i}$, is the maximum amount of water that can infiltrate in soils of a given TTI bin (in excess of that needed to fill the root zone to capacity). During periods with no precipitation in the original TOPMODEL, ET from the root zone could produce substantial deficits, even in bins with negative values of $s d_{i}$. In WEBMOD, surpluses identified by negative $s d_{i}$ values are used to satisfy the root-zone deficit for that bin. Any surplus after filling the root zone is then truncated by setting $s d_{i}$ to zero.

The amount of water transferred from the saturated zone to the root zone [srzwet(nac,nmru)] is equal to the hypothetical artesian head or the root-zone deficit, whichever is less, multiplied by the total hillslope area within that TTI bin. The area of a TTI bin, as a fraction of the MRU, is assigned as $[\operatorname{ac}(i)+\operatorname{ac}(i+1)] / 2$ with the final bin assigned an area of $\operatorname{ac}(\mathrm{nac}) / 2$ as shown in figure 29. Processing of hillslope contributions to the stream reservoirs begins with the saturated areas with the highest topographic index and proceeds to the unsaturated areas with lowest index.
The total area experiencing Dunnian overland flow at a given time step is reported as acm(nmru). The fraction of rain, irrigation, throughfall falling on bare ground [psoilmru(nmru)], and snowmelt(nmru) that does not become overland flow can be delivered directly to the saturated zone as vertical preferential flow [qvpref(nmru)] or can infiltrate into the unsaturated zone to evaporate and transpire $[\mathbf{s a e}(\mathrm{nmru})]$, to recharge groundwater [quz(nmru)], or to flow directly to the stream reservoirs along horizontal preferential flow paths [qdf(nmru)].

The wettest TTI bin $\mathbf{s t}$ ( inac $=1, \mathrm{nmru}$ ) will almost always be simulated as saturated with the unsaturated zone for that bin limited in volume and scope to just the root zone. Inputs to the root zone for the wettest TTI bin are limited to surface deposition or groundwater to offset evaporation, and the only output simulated is transpiration; no recharge or preferential flow leaves the root zone. As a result, the concentrations of solutes simulated for the unsaturated zone of the wettest TTI bin could be several orders of magnitude higher than the concentrations simulated for other TTI bins as evaporation concentrates the mass of solutes that enter the root zone.

\section{Preferential Flow Paths}

In homogenous soils, water flows uniformly downward through the unsaturated zone behind a wetting front as described by the Green-Ampt model, and then water in the saturated zone moves towards the stream as described by Darcy's law. However,

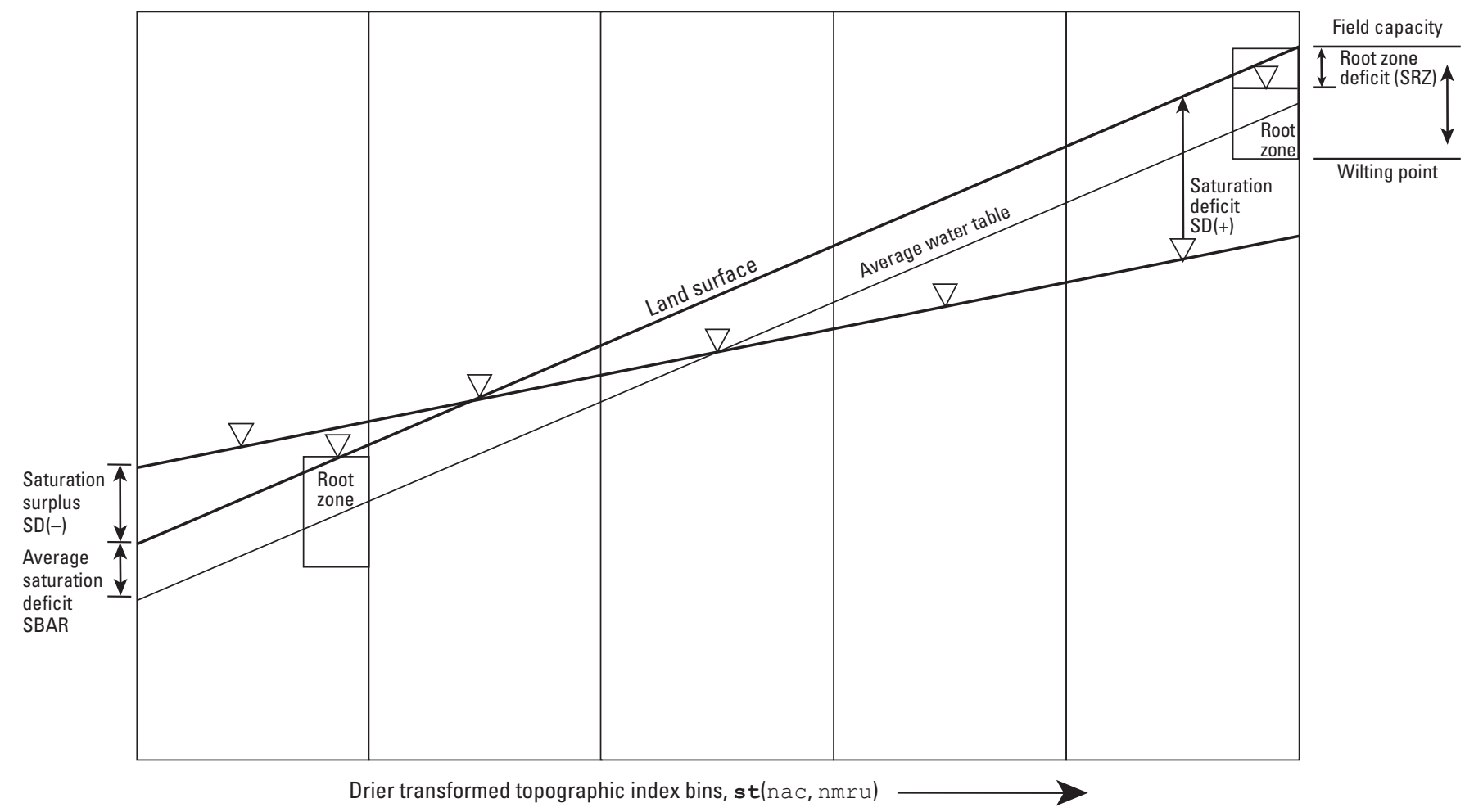

Figure 28. Variations of saturation deficits and water table with increasing nac index (decreasing transformed topographic index [TTI], wet to dry). Where negative saturation deficits are predicted, the Water, Energy, and Biogeochemical Model (WEBMOD) will satisfy any root zone deficit before setting the saturation deficit to zero. 


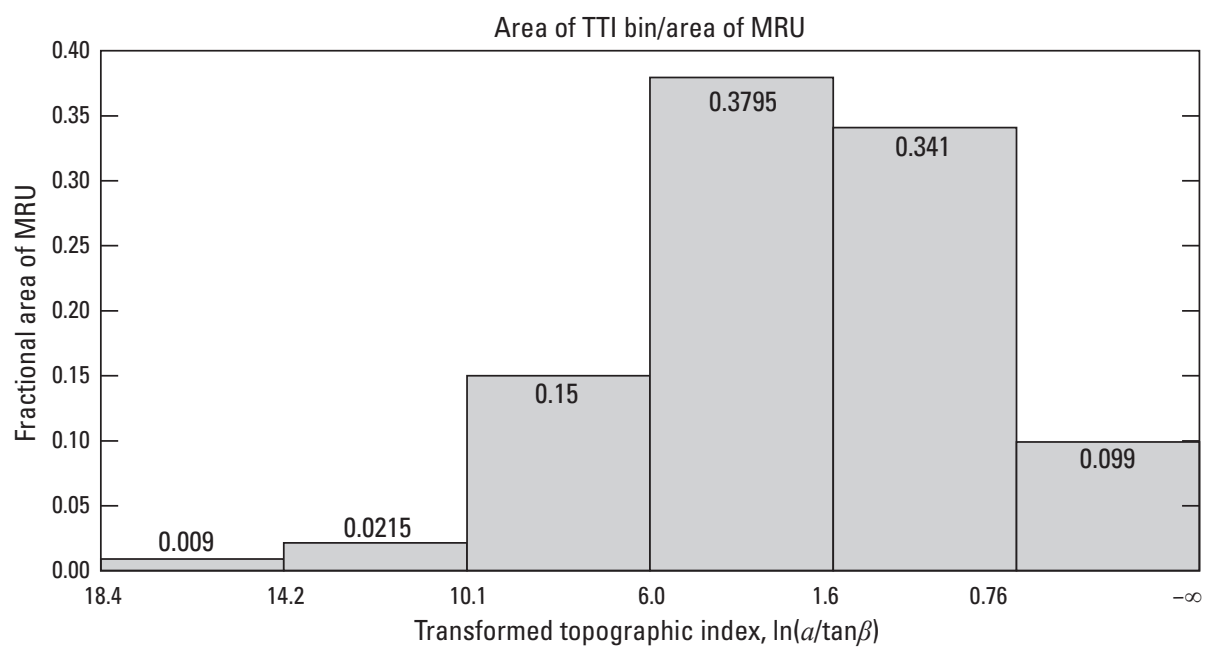

Figure 29. Transformed topographic index (TTI) bins for the parameters $\mathbf{T}$ _decay $($ one $)=$ 0 ; st (inac $=1-6, \mathrm{nmru})=18.4,14.2,10.1,6.0,1.6,0.76$; and ac (inac $=1-6, \mathrm{nmru})=0.0,0.018$, $0.025,0.275,0.484,0.198$. Limits of each TTI bin are given on the $x$-axis and the fractional area of each model response unit (MRU) is given on the $y$-axis. (a, upslope area; $\beta$,tangent of the slope)

soils are rarely homogenous; from macropore to areal scales, waters preferentially flow under areas of focused recharge, through burrows, along roots, and through zones of high hydraulic conductivity (fig. 30; Hendrickx and Flury, 2001). The flow paths can be either natural, such as layers of sand and gravel or macroporosity of karst systems, or anthropogenic, such as those related to focused vertical recharge below retention ponds or horizontal pipe flow through tile drains. Although the direction of flow can be at any angle, WEBMOD will simulate preferential flows as vertical, horizontal, or both.

\section{Vertical Preferential Flow in the Unsaturated Zone}

Vertical preferential flow plays an important role in the movement of water and solutes to depth. In extreme cases, vertical preferential flow can cause landslides (Simon and others, 1990) or high concentrations of pesticides beneath the root zone (Hancock and others, 2008). The parameters pmacro(nmru) and pmac_sat(nmru) determine the fractions of water that bypass the root zone and the unsaturated zone. The amount of potential infiltration is equal to $m r u \quad d e p(n m r u)$, which is the sum of rain, irrigation, throughfall on bare ground, and snowmelt. The amount of vertical preferential flow that bypasses the root zone is qupref(nmru):

$$
\text { qvpref }_{\text {mru }}=\text { pmacro }_{\text {mru }} \cdot \text { mru_dep }_{\text {mru }},
$$

where

$$
\begin{array}{cc}
\text { qvpref }_{\text {mru }} & \begin{array}{c}
\text { is the amount of vertical preferential flow } \\
\text { that bypasses the root zone, in meters } \\
\text { [qvpref(nmru)], }
\end{array} \\
\text { pmacro }_{\text {mru }} & \text { is the fraction of water that bypasses the root } \\
& \text { zone, in meters [pmacro(nmru)], and } \\
m r u \_ \text {dep }_{m r u} & \text { is the amount of potential infiltration, in } \\
\text { meters [mru_dep(nmru)]. }
\end{array}
$$

Similarly, the fraction of water that bypasses the root zone and also bypasses the unsaturated zone is pmac_sat(nmru). When pmac_sat $(\mathrm{nmru})=1.0$, all vertical preferential flow will be delivered directly to the saturated zone; conversely, when pmac_sat $(\mathrm{nmru})=0.0$, all vertical preferential flow will bypass the root zone and be added to the unsaturated zone if storage capacity exists.

\section{Horizontal Preferential Flow in the Unsaturated Zone}

Snowmelt and precipitation on bare ground that do not run off as overland flow or do not immediately reach the water table as vertical preferential flow will infiltrate the soil. Of the water that infiltrates, some will recharge the saturated zone, and some may become direct flow, travelling laterally to the stream along preferential flow paths, such as macropores, root casts, and shallow impermeable soil lenses (Piñol and others, 1997). The total recharge plus direct flow is estimated for each TTI bin by using a simple time-delay function as follows:

$$
u z_{i}=\left(s u z_{i} \cdot d t\right) /\left(s d_{i} \cdot t d\right),
$$

where

$u z_{i} \quad$ is the amount of recharge plus direct flow for transformed topographic index bin $i$ during a given time step, in meters;

$s u z_{i} \quad$ is the unsaturated zone storage, or transient drainage, for the bin [suz_local(nac,nmru)] (an amount less than the saturation deficit $s d_{i}$ ), in meters;

$d t \quad$ is the time step [dt(one)], in hours;

$s d_{i} \quad$ is the saturation deficit for the bin [sd(nac,nmru)], in meters; and

$t d$ is the time-delay constant [ $\operatorname{td}(n m r u)]$, in hours per meter of saturation deficit. 

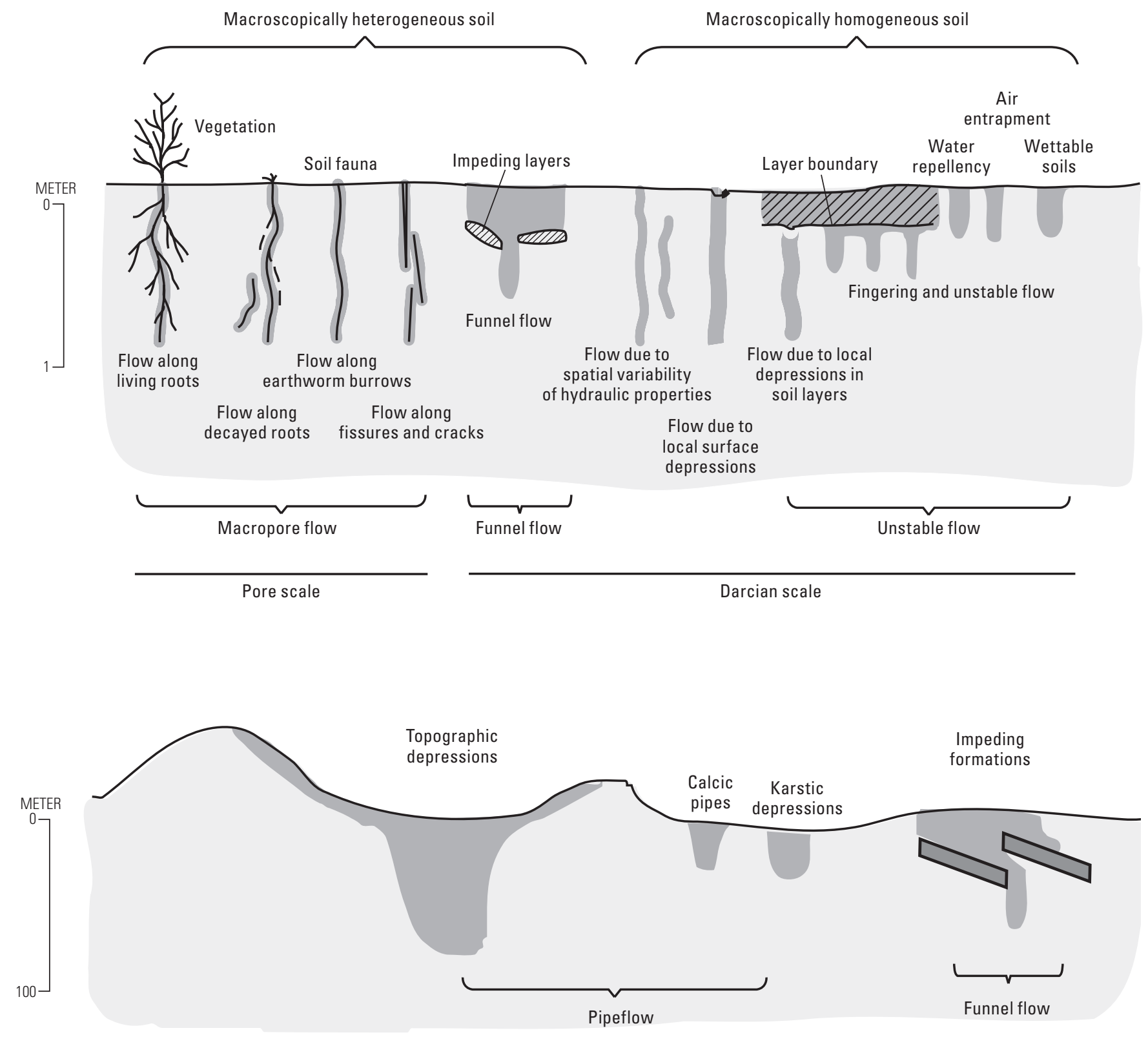

Areal scale

Figure 30. Schematic showing different preferential flow mechanisms observed at pore, Darcian, and areal scales. (From Hendrickx and Flury, 2001) 
The total recharge plus direct flow for each topographic index bin, $u z_{i}$, is partitioned into direct flow [qdf local(nac,nmru)] and recharge to the saturated zone [quz_local(nac,nmru)] as follows:

$$
\begin{gathered}
q d f=u z \cdot q d f f r a c, \text { and } \\
q u z=u z-q d f
\end{gathered}
$$

where

$q d f$ is the direct flow through macropores in the unsaturated zone, qdf_local(nac,nmru), delivered to the stream, in meters;

$u z$ is the total recharge plus direct flow, in meters;

qdffrac is the user-specified proportion of recharge, qdffrac(nmru), that is delivered to streams as direct flow for each MRU, dimensionless; and

$q u z$ is the amount of recharge to the saturated zone, quz_local(nac,nmru), in meters.

The direct flow and recharge are multiplied by the fractional area of each TTI bin and summed to yield the total direct low and recharge for the hillslope [ $q d f(n m r u)$ and quz(nmru)]. After delivery of direct flow and recharge from each TTI bin, all moisture and solutes above the water table in each bin, including the residual moisture below wilting point, are mixed and reacted in the unsaturated zone volume at the end of each time step. Vertical and horizontal preferential flows through the unsaturated zone are included to build models where these flow paths are supported by hydrologic or geochemical evidence.

\section{Preferential Flow in the Saturated Zone}

Just as burrows, roots, and planes of high hydraulic conductivity create preferential flow in the unsaturated zone, natural layers of high hydraulic conductivity or manmade tile drains can result in pipe flow, or preferential flow in the saturated zone. Caves are a natural conduit, and tile drains are manmade conduits commonly installed to lower water tables in agricultural fields where the water table is near the surface either naturally or as a result of irrigation. Pipe flow can be an important conduit for transporting recently applied pesticides to streams (Stone and Wilson, 2006). WEBMOD provides a simple representation of pipe flow resulting from natural horizontal preferential flow through the saturated zone or tile drains, as explained in the "Management Options" section.

\section{Unsaturated Zone}

As in the original TOPMODEL, WEBMOD simulates an unsaturated zone and a saturated zone, with the water table as the boundary between the two zones; the root-zone soil moisture exists as a subdomain of the unsaturated zone. Differing from the original TOPMODEL, WEBMOD keeps track of moisture in all pore spaces between bedrock and the land surface (fig. 31), including the saturated zone volume and soil moisture below the wilting point, volumes not relevant to the hydrologic simulations of TOPMODEL but necessary for the geochemical simulations of WEBMOD.

During dry periods, the water table will drop, and the overall volume of the unsaturated zone will increase as the volume of the saturated zone decreases; conversely, when recharge exceeds base-flow discharge, the water table will rise and entrain pore water that was previously in the unsaturated zone. Maximum soil moisture is limited by the saturated porosity $\left[\theta_{\text {sat }}, \mathbf{s}\right.$ _porosity $\left.(\mathrm{nmru})\right]$, and the maximum volume of the saturated zone is assigned as the saturated porosity times the depth to bedrock $\left[d_{\mathrm{b}}, \mathbf{s} \_\right.$rock_depth(nmru)].

Water evaporates and transpires from the root zone [sae(nmru)] at the residual potential rate [the residual rate after canopy evaporation and snow sublimation are removed first from the potential evaporation, potet(nmru)] when soils are at field capacity. ET decreases linearly to zero as soils dry to the wilting point. The maximum available water capacity for ET in the original TOPMODEL is SRMAX, a single parameter. In WEBMOD, the user provides estimates of three independent variables that determine SRMAX - field capacity [ $\theta_{\text {fc }}, \mathbf{s}$ _theta_fo(nmru)], wilting point $\left[\theta_{\mathrm{wp}}, \mathbf{s}_{-}\right.$theta_wp $\left.(\mathrm{nmru})\right]$, and rooting depth $\left[d_{\mathrm{r}}\right.$, s_root_depth(nmru)]. These parameters have physical meaning and vary systematically with soil type (fig. 32) and vegetation. The volume of residual moisture below wilting point will affect residence time and, therefore, the rates of chemical reactions; reaction rates will decrease as ions in solution approach mineral saturation.

In addition to soil moisture below field capacity, WEBMOD maintains a residual moisture pool in the canopy [c_can_depth(one)] and in a soil organic horizon, or O-horizon [s_ohoriz_depth(nmru)]. The residual canopy reservoir contains the solutes from transpired water in a volume of water that is limited to an arbitrary minimum value, thereby easing the numerical burden of computing extremely high equilibrium concentrations on the surface of a drying leaf. Similarly for the O-horizon reservoir, a residual volume is maintained where compounds can be generated in shallow soil and flushed by overland flow. The O-horizon 


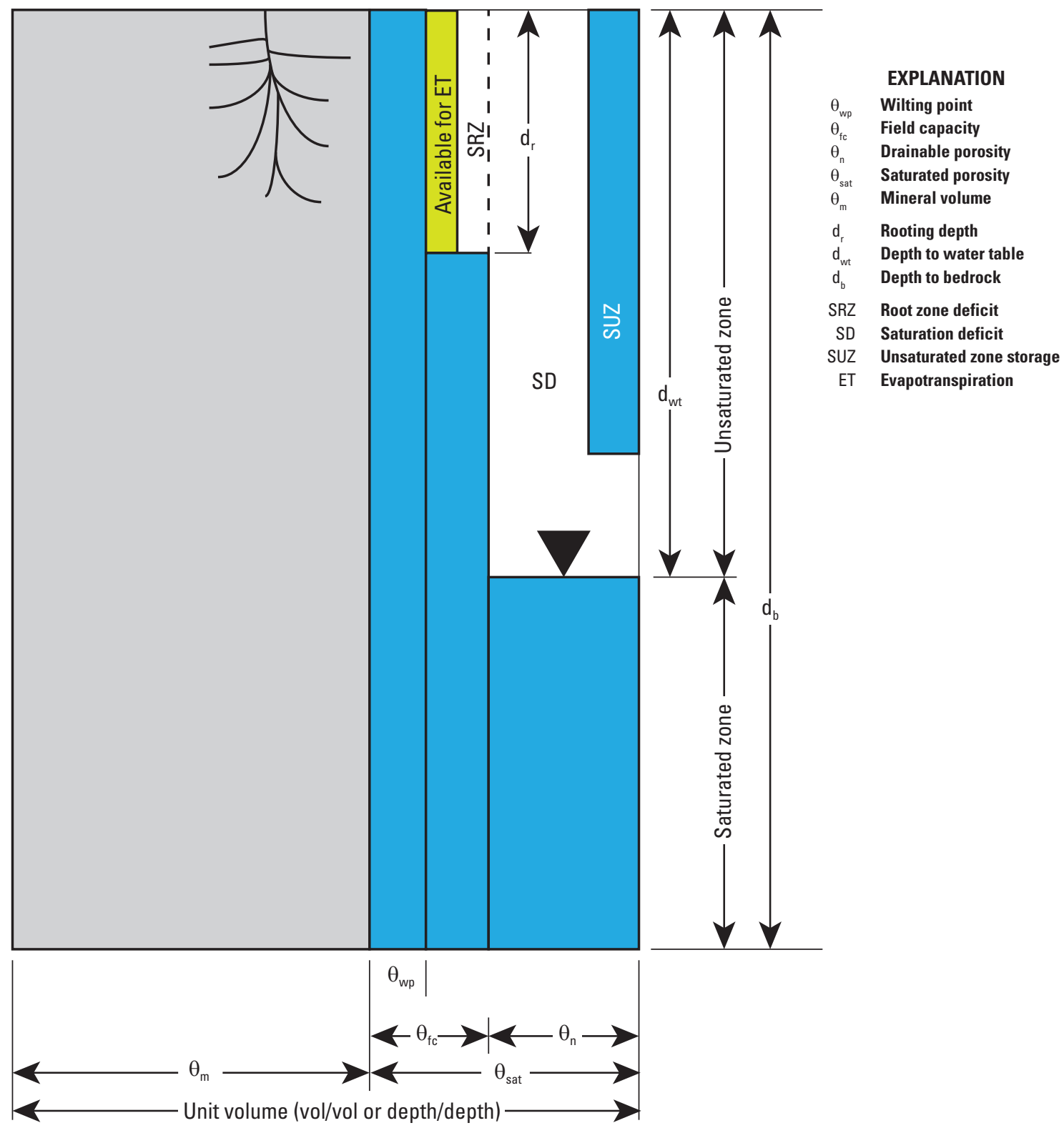

Figure 31. Schematic diagram showing soil volumes from land surface down to bedrock. The water in the unsaturated zone includes root-zone water, water at field capacity above the water table (indicated by the black triangle) but below the root zone, and infiltrated water that is draining to the water table (unsaturated zone storage). Infiltration in excess of field capacity is stored in the unsaturated zone [suz(nac,nmru)] to become recharge at a later time. The total depth of available unsaturated-zone storage is equal to the saturation deficit, $s d_{i j}$ for each transformed topographic index (TTI) bin. The volume of water in the saturated zone is the height of the water table above bedrock times the saturated porosity. 


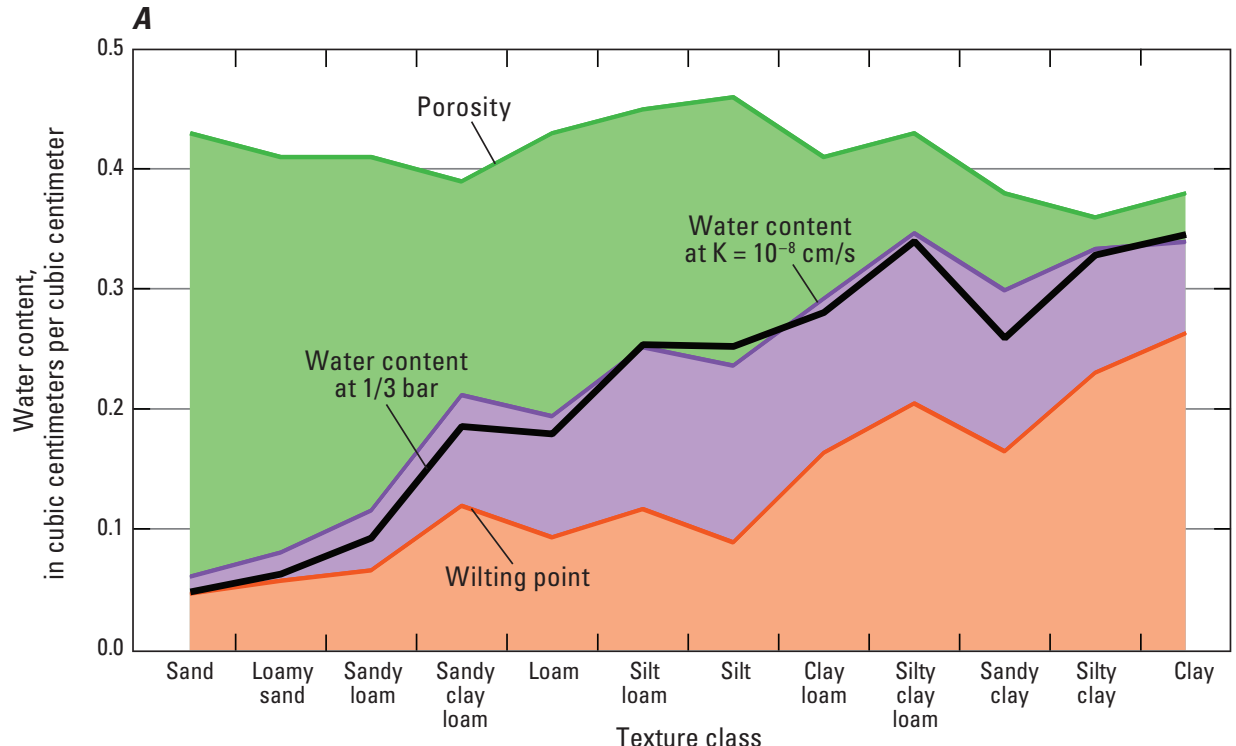

EXPLANATION

Drainable porosity

Plant available water capacity

Unavailable wate

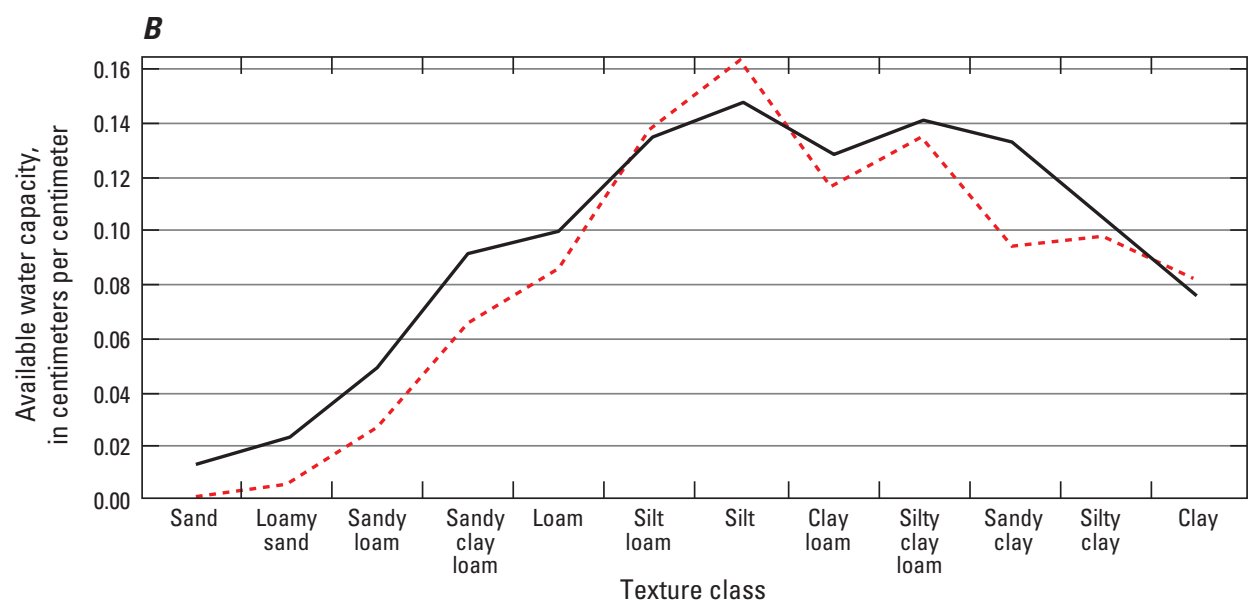

\section{EXPLANATION}

- Using $\theta$ at $\mathrm{K}=10^{-8} \mathrm{~cm} / \mathrm{s}$

...... Using $\theta$ at $1 / 3$ bar

Figure 32. Drainable porosity, available water capacity, and unavailable water for the twelve texture classes used by the National Resource Conservation Service. A, Calculation of field capacity as (1) the water content $(\theta)$ at a hydraulic conductivity of $10^{-8}$ centimeters per second $(\mathrm{cm} / \mathrm{s}$ ) versus (2) the water content at a tension of $1 / 3$ bar. $B$, Resulting available water capacities. (Modified from Meyer and others, 1997) 
also serves as a source of residual canopy moisture on the day of "leaves-on" and the destination for the canopy moisture on the day of "leaves-off." The residual canopy depth is a volume in addition to the original PRMS canopy storage available on the canopy. PRMS canopy storage is a fixed depth, in inches, for snow, snow_intcp(nmru); for rain in the summer, srain_intcp(nmru); and for rain in the winter, wrain_intcp(nmru).

\section{Saturated Zone}

In TOPMODEL, three main assumptions are used to determine the discharge of groundwater (Wolock, 1993; Beven, 1997). The assumptions are as follows:

- the dynamics of the water table can be approximated by subsurface runoff production per unit area over an upslope contributing area, a, draining through a point;

- the hydraulic gradient of the water table can be approximated by the local hillslope, $\tan \beta$; and

- the transmissivity decreases as the average saturation deficit increases.

The topographic index $(\mathrm{TI}=\mathrm{a} / \tan \beta)$ is computed by using equations of continuity and Darcy's law (Beven and Kirkby, 1979; Freeze and Cherry, 1979; Wolock, 1993). If the transmissivity at saturation, $T_{0}$, is distributed in the MRU, then the metric becomes the soil-topographic index, a $/ T_{0} \tan \beta$, (Beven, 1984; Ambroise and others, 1996a); WEBMOD assumes only a homogenous distribution of $T_{0}$ in each MRU, distributing unique values of TI to each point in the watershed. As described in Ambroise and others (1996a), the appropriate transmissivity model for a subbasin can be determined from observed discharge during recession periods. Where values of $1 / \mathrm{Q}, 1 / \sqrt{\mathrm{Q}}$, or $\ln (\mathrm{Q})$ are linear with time, the suggested transmissivity profile would be exponential, parabolic, or linear. Areas with similar TI within an MRU are assumed to have similar saturation deficits, as described in equation 60 if using the exponential transmissivity profile or in equation 61 if using the parabolic or linear transmissivity profiles. Each profile is associated with a distinct transformation of TI- $\ln (\mathrm{TI})$ for the exponential profile [T_decay $(\mathrm{nmru})=0], \sqrt{\mathrm{TI}}$ for the parabolic profile [T_decay $(\mathrm{nmru})=1$ ], or TI for the linear profile [T_decay $(\mathrm{nmru})=2]$. The correct transformation is critical for consistent simulations of all hillslope processes including overland flow, preferential flows, and base-flow generation. Areas in the same transformed topographic index (TTI) bin are treated as hydrologically and geochemically similar whether the areas are contiguous or the areas are separated in space. All TTI bins drain to the same groundwater reservoir but maintain unique unsaturated zones with individual soil moisture and chemistry. As detailed in figure 25, the base flow for any selected transmissivity model, $Q_{\mathrm{b}}$, is computed using the discharge at saturation, $Q_{0}$, the mean hillslope saturation deficit $[S, \operatorname{sbar}(\mathrm{nmru})]$, and the recession parameter $[m, \mathbf{s z m}(n m r u)]$. The mean hillslope saturation deficit is updated each time step to reflect all gains and losses of the saturated zone including any withdrawals for irrigation.

\section{Stream Routing}

Water flowing in streams can be described by complex shallow-water equations or by simple one-dimensional advection models. WEBMOD uses a one-dimensional advection model, which employs a modification of the unit-hydrograph algorithm developed by Clark (1945) as implemented in TOPMODEL version 95.02. The fraction of a channel draining downstream [ach(ntopchan,nchan)] and distance from the outlet [d(ntopchan,nchan)] for each point on a channel that drains an MRU are converted into time-delay ordinates by using an average channel velocity [chv(one)], in meters per hour. Discharge from hillslopes at similar distances from the outlet are mixed and moved together toward the outlet; the mixing of water from channels is strictly on the basis of flow time to the outlet and is independent of where the channels are in a branching network. This approach will simulate the quantity and quality of water at the basin outlet but not at interior nodes in the drainage network that are located upstream from the first confluence. Using a spatially constant velocity of 1 meter per second $(\mathrm{m} / \mathrm{s})$ for all flow stages, Kirkby (1976) determined that peak discharge in random networks with 50 first-order streams would be reached within 24 hours (1 day) for basins smaller than $10,000 \mathrm{~km}^{2}$.

Stream reservoirs can be used to simulate irreversible leakage to groundwater by using the chan_loss_rate(nhydro), in cubic foot per second per mile. Stream reservoirs can also be a source of water for irrigation. Note that leakage from internal stream reservoirs are tracked as a loss from the model domain, distinct from the inputs of water and solutes from leaky irrigation canals and groundwater through the upgradient boundary of the model domain.

\section{Leaky Canals and Upgradient Groundwater}

The discharge from a watershed could possibly exceed the total amount of precipitation, irrigation, and snowmelt on the watershed (see the DR2 example) because of additional 
water inputs. To simulate additional inputs to a watershed from leaky irrigation canals and upgradient groundwater, each MRU may be linked to gw_ext(ngw_ext) fields in the hydrologic data file. Because these are inputs from linear canals or border segments, or both, the units for the gw_ext fields are in cubic foot per second per mile, a common unit used to describe leaky canals in western irrigation systems. Any MRU can have two, one, or none of the groundwater inputs as indicated by the schedules sched_gw1(nmru) and sched_gw2(nmru); the inputs are inactive if set to zero or active if indexed to one of the gw_ext fields in the hydrologic data file. The schedule, in cubic foot per second per mile, is converted into meters of deposition [ $g w_{-}$in $1(n m r u)$ and gw_in2(nmru)] by multiplying by the lengths of the features [gwbnd_len1(nmru) and gwbnd_len2(nmru)], in meters, and making the proper unit conversions.

The temperature [c_ext $\mathbf{c}$ (nchem_ext)], $\mathrm{pH}$ [c_ext_pH(nchem_ext)], and concentrations of solutes [cconc_extM(nchem_ext)] for any external source, including the two groundwater inputs, are defined in the webmod.chem.dat file. The indices src_gw1(nmru) and src_gw2(nmru) specify which of the nchem_ext fields describes the solute concentrations of groundwater entering a specific MRU.

\section{Management Options}

As watersheds are developed for agriculture, anthropogenic inputs and withdrawals may replace the natural rain-fed system and determine the hydrology and water chemistry of the watershed discharge. To simulate the quantity and quality of water in managed watersheds, the user must specify the depths of irrigation from internal (saturated zones and stream reservoirs) or external (irrigation canals and deep wells) sources, estimates of inflows from leaky irrigation canals and groundwater through upgradient basin boundaries, and the efficiency of any tile drains.

\section{Irrigation}

The source of the irrigation for an MRU can be external, internal, or both. External sources can be applied at any rate and can have any chemical composition; internal sources are constrained by the available volume of the saturated zone or stream reservoir. Irrigation is applied to an MRU by specifying an application schedule [irrig_sched_ext(nmru) or irrig_sched_int(nmru), or both]; an index of zero indicates no irrigation, and a positive integer points to one of the nirrig ext or nirrig int fields in the hydrologic data file. If the source is external [irrig_ext (nirrig_ext)], the depths are applied on that day. If the source is internal [irrig_int_next(nirrig_int)], the volume of next-day irrigation is retained from the last step of flux calculations for the day and applied as the first step of flux calculations the following morning. An internal source must be specified as either pumping from the saturated zone of the MRU [irrig_int_src(nmru) $=0$ ] or pumping from one of the nhydro stream reservoirs [irrig_int_src $(n m r u)>0$ ], but not both. If internal irrigation is to be applied on day 1 of the model run, that depth is specified with irrig_int_init(nmru). The actual depths of irrigation from internal sources to the MRU are constrained by the available water and by the pumping rate [irrig_int_max(nmru)], in gallons per minute. The pumping rate is constant for a stream reservoir; however, the pumping rate decreases in the saturated zone as the water table approaches bedrock. The maximum water available for pumping from the saturated zone is as follows:

$$
\text { max_avail }=d_{\text {bedrock }} \cdot \text { sdrain, }
$$

where

$$
\begin{gathered}
\text { max_avail is the maximum water available for pumping } \\
\text { from the saturated zone, in meters; } \\
d_{\text {bedrock }} \text { is the depth to bedrock, in meters; and } \\
\text { sdrain } \\
\begin{array}{l}
\text { is the readily drainable porosity, equal to the } \\
\text { saturated porosity minus the field capacity, } \\
\text { unitless. }
\end{array}
\end{gathered}
$$

Note that max avail is also equal to the maximum value for the saturation deficit [sbar(nmru)] as explained in the "Initial Conditions" section of "Hydrologic Processes" and in the "Dunnian Overland Flow" and "Saturated Zone" sections describing soil moisture. On any given time step, the pumping rate will be throttled as the saturation deficit sbar approaches max_avail as follows:

$$
R_{\text {pump }}=C_{\text {pump }} R_{\max }
$$

where

$R_{p u m p}$ is the pumping rate, in gallons per minute;

$C_{\text {pump }}$ is the pump coefficient determined by using the quadratic function as shown in figure 33, unitless; and

$R_{\max }$ is the maximum pump delivery rate [irrig_int_max(nmru)], in gallons per minute. 


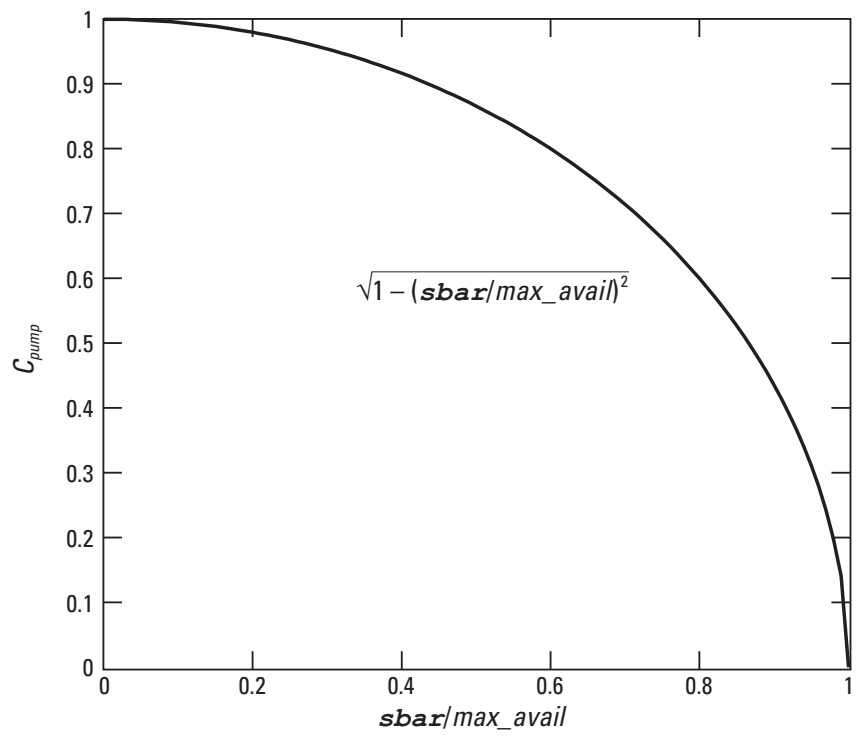

Figure 33. Relation of pump coefficient, $C_{\text {pump }}$ to saturation deficit, sbar. The pump coefficient decreases from 1.0 when the water table is at the surface (saturation deficit equal to zero), to 0.0 as the water table drops to bedrock (saturation deficit, sbar, equal to maximum water available for pumping, max_avail).

If sufficient water is available in the saturated zone and the throttled pumping rate is sufficient to meet the requested irrigation demand, then the full scheduled irrigation depth is applied. If there is insufficient water or the computed pumping rate is insufficient to meet the demand, the applied depth will be less than the scheduled irrigation depth.

The composition of water from an internal source is computed for each time step; however, the composition of water from one or more external sources either can be constant or can vary daily. The composition of an external irrigation source is initialized to the solution in the webmod.pqi file pointed to by init_soln_ext(nchem_ext). If chem_ext $(o n e)=0$, then the concentrations of all external irrigation sources remain constant as described by init_soln_ext(nchem_ext). If chem_ext(one) $=1$, then the concentrations vary daily as described by one of the external chemistry fields [cconc_extM(nchem_ext)] in the webmod.chem.dat file. Any nchem_ext solution composition can be assigned to any external source, be it an external irrigation source [src_ext_irrig(nmru)], a leaky irrigation canal [src_gw1(nmru)], or influx from upgradient groundwater [src_gw2(nmru)].

Irrigation prescribed for the land surface will be deposited as either snow or rain depending on the air temperature. This dependence on temperature permits the model to be used to determine potential effects of snowmaking operations in addition to standard irrigation of agricultural fields.

\section{Pipe Flow}

Pipe flow through tile drains is simulated as a horizon of enhanced permeability rather than simulating multiple individual pipes. Pipe flow becomes active once the mean water table [z_wt(nmru)] rises above a datum [s_satpref_zmin(nmru)]; preferential drainage increases linearly with water-table height above the datum to a maximum discharge when the water table reaches s_satpref_zmax(nmru). The maximum discharge [qpref_max $\overline{\text { n }}$ mru $)]$, in meters per hour, is equal to the thickness of the region of enhanced permeability, in meters, multiplied by the saturated hydraulic conductivity [s_satpref_k(nmru)], in centimeters per second, multiplied by 36.0. The preferential flow discharge [qpref(nmru)] from the saturated zone is described as follows:

$$
Q_{s p}=\left(z_{w t}-z_{\min }\right) /\left(z_{\max }-z_{\min }\right) \cdot Q_{\text {spmax }}
$$

where

$Q_{s p} \quad$ is the pipe flow from preferential flow paths in the saturated zone [qpref(nmru)], in meters per day;

$z_{w t}$ is the water table $\left[\boldsymbol{z} \_\boldsymbol{w} t(n m r u)\right]$, in meters above the land surface;

$z_{\min } \quad$ is the lower boundary of enhanced permeability [s_satpref_zmin(nmru)], in meters above the land surface;

$z_{\max }$ is the upper boundary of enhanced permeability [s_satpref_zmax(nmru)], in meters above the land surface; and

$Q_{\text {spmax }}$ is the maximum pipe flow for the saturated zone preferential flow, either qpref_max(nmru), in meters per hour, or a lesser amount such that the discharge, $Q_{s p}$, drops the water table to the lower boundary of enhanced permeability, but no further.

\section{Geochemical Processes}

Simulations of mixing, isotopic fractionation, and geochemical reactions are completed by using the interface version of PHREEQC (Charlton and Parkhurst, 2011). Mixing and isotopic fractionation use the MIX keyword of PHREEQC, and reactions in the various reservoirs of WEBMOD may use any of the following six reaction entities that are defined by PHREEQC keywords: (1) EQUILIBRIUM_PHASES allows equilibration with a set of minerals and fixed-pressure gases; (2) EXCHANGE allows equilibrium exchange reactions between the solution 
and an ion (usually a cation) exchanger; (3) SURFACE allows equilibrium between the solution and mineral surfaces using a surface-complexation model (diffuse double layer or Charge Distributed MUltiSIte Complexation model [CD-MUSIC]); (4) SOLID_SOLUTION allows formation and dissolution of one or more solid solutions; (5) GAS_PHASE allows multiphase equilibration of the solution with a fixed-pressure or fixed-volume gas phase (seldom used); and (6) KINETICS allows implementation of any set of kinetic reactions, which could include kinetic mineral dissolution or precipitation, biologically mediated reactions, and radioactive decay, among others.

Each WEBMOD reservoir can be initialized with a set of these reaction entities. Although only one keyword data block for each kind of entity is allowed for any given reservoir, that block may be quite diverse, containing multiple minerals or equilibrium phases, for example. The reservoir solution initially will be equilibrated with each of the equilibrium entities (all except KINETICS) defined for the reservoir and will remain in equilibrium for the course of the simulation, unless a reactant is completely depleted. Kinetic reactants will react according to a rate equation defined in the RATES keyword data block.

\section{Initial Conditions}

For geochemical simulations, concentrations of solutes in precipitation, external sources, and all hillslope and stream reservoirs are defined in the webmod.pqi file by using the PHREEQC keyword SOLUTION followed by an ID number; a solution composition is one type of PHREEQC entity used by WEBMOD. The solution compositions identified by the ID number can be distributed to the various hillslope and stream reservoirs by definitions in the parameter file. Geochemical reactions for hillslope and stream reservoirs may be defined through five additional PHREEQC entitiesirreversible reactions, kinetic reactions, surface complexation, ion-exchange, and equilibrium with pure mineral phases and gases (table 12). For brevity, Entity is used generically as a component of a parameter name in text where in practice, the parameter names would include one of the following six WEBMOD entity abbreviations: soln, rxn, kin, surf, exch, or eq_ph.

The partial pressures of carbon dioxide and oxygen in precipitation are assumed to be in equilibrium with the atmosphere; the index specified for atmos_eq_ph(one) refers to an ID number for an EQUILIBRIUM_PHASES data block in the webmod.pqi file describing those partial pressures. Similarly, the index specified for init_soln_ppt(one) refers to an ID number for a SOLUTION data block defined in the webmod.pqi file that is used for the initial solute concentrations in precipitation. The webmod.pqi file can also contain SOLUTION data blocks with ID numbers that are referenced by init_soln_ext(nchem_ext) to define the solute concentrations of external sources applied as irrigation, leakage from a canal, or upgradient groundwater.

Each MRU uses init_Entityset_MRU(nmru) to reference a unique hillslope chemistry set ( $\overline{\mathrm{h}} \mathrm{CS}$ ) that distributes individual enitity ID numbers to all hillslope reservoirs in an MRU. The number of available unique hillslope chemistry sets for any entity is arbitrarily set to 10 in this initial version of WEBMOD (2017) (nhcs=10), each set with the potential to represent the unique geochemistry for groups of hillslopes that share common minerology, such as limestone or granitic terranes. Both of the watershed models in the "Example Problems" section use only a single hillslope chemistry set for all MRUs_init_Entityset_MRU(imru=1-10)=1 for Andrews Creek and init_Entityset_MRU(imru=1-22)=1 for DR2 - but any MRU may be assigned the geochemistry from any of the 10 available hillslope chemistry sets. The index specified for init_Entityset_MRU(imru) points to a column in Entityset_table(nmru_res,nhcs). For example, if init_solnset_mru(2) $=\overline{3}$, then the initial webmod.pqi SOLUTION ID numbers for all hillslope reservoirs in MRU 2 are defined in the third column of the solnset_table(nmru_res,nhcs) data. The nine rows (nmru_res=9) of solnset_table(nmru_res,nhcs) describe (1) canopy, (2) snowpack, (3) impermeable surface (not used), (4) O-horizon, (5) wettest TTI bin, (6) TTI rule, (7) preferential flow through the unsaturated zone, (8) saturated zone, and (9) preferential flow through the saturated zone. The value in index 6 determines which of three ways will be used to fill the nac TTI bins (table 13). The init_Entityset_MRU and Entityset_table parameters are used to define solutions and reactants for the hillslope reservoirs; initial solute concentrations and geochemical characterization of stream reservoirs are defined by init_Entity_hydro(nhydro), which references the ID numbers of data blocks in the webmod.pqi file to initialize solution composition and geochemical entities in the stream reservoirs.

After initialization with PHREEQC entities from the webmod.pqi file, the chemistry of each reservoir evolves independently. The following sections present the processes of hydrology and geochemistry that are simulated on a daily time step by WEBMOD along with the parameters and variables used to constrain and track the various processes and solute concentrations in reservoirs.

\section{Geochemical Modules and Mixing Variables}

The three main geochemical modules are (1) obs_chem, which reads daily values of solute concentrations in precipitation and external sources; (2) webmod_res, which converts hydrologic storages and fluxes described as area-normalized depth units into volumes; and (3) phreeq_mms, which simulates equilibrium and kinetic geochemical reactions for all 
Table 12. Geochemical entities that may be assigned to watershed reservoirs.

[The formatting convention used in this report is to present file names in italic font, dimension names in Courier New font, and parameter names in bold Courier New font. See tables 1 and 2 for descriptions of dimensions and parameters. Solute concentrations in each reservoir solution must be established; all other entities are optional. If an entity is not simulated in a reservoir, the Entityset_table will have a value of -1 for that reservoir. ID, integer identification of geochemical entity block in the pH-redox-equilibrium model in the C programming language (PHREEQC); TTI, transformed topographic index]

\section{Purpose of PHREEQC Entity}

Define the temperature and chemical composition of initial solutions

Define irreversible reactions that transfer specified amounts of elements to or from the aqueous solution during batch reactions

Identify kinetic reactions and specify reaction parameters for batch reactions

Define the amount and composition of each surface in a surface assemblage

Define the amount and composition of an assemblage of exchangers

Define the amounts of an assemblage of pure phases that can react reversibly with the aqueous phase

\section{PHREEOC keywords for entity data blocks in webmod.pqi}

SOLUTION [ID]

REACTION [ID]

KINETICS [ID] and RATES [ID]

SURFACE [ID]

EXCHANGE [ID]

EXCHANGE $[\mathrm{ID}]$

EQUILIBRIUM_PHASES [ID]

\section{Initialization parameters in WEBMOD that point to entity data blocks} in webmod.pqi

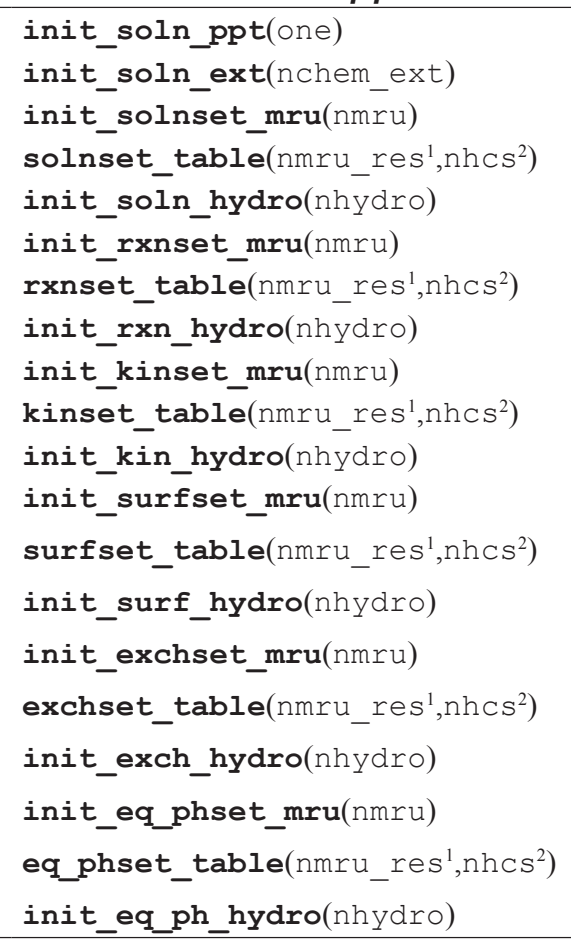

${ }^{1}$ nmru_res indices: (1) canopy, (2) snowpack, (3) impermeable surface, (4) O-horizon, (5) wettest TTI bin, (6) TTI rule, (7) preferential flow through the unsaturated zone, (8) saturated zone, and (9) preferential flow through the saturated zone.

${ }^{2}$ nhes is fixed at 10 geochemically-distinct hillslope chemistry sets in this initial release.

Table 13. Transformed topographic index (TTI) rule for row 6 in Entityset_table used to initialize TTI bins.

[The formatting convention used in this report is to present dimension names in Courier New font and parameter names in bold Courier New font. See tables 1 and 2 for descriptions of dimensions and parameters. Entity may be solution (soln), equilibrium phase (eq_ph), reaction (rxn), kinetics (kin), surface complex (surf), or exchange (exch). ID, integer identification]

\begin{tabular}{|c|c|}
\hline $\begin{array}{l}\text { Row (6) in } \\
\text { Entityset_table }\end{array}$ & $\begin{array}{c}\text { TTI bin } \\
\text { initialization }\end{array}$ \\
\hline Same value as in (5) & All bins are assigned that Entity ID \\
\hline$-1 *$ & Wettest bin is assigned Entity ID (5), then the Entity ID is incremented by one for each successively drier bin \\
\hline $\begin{array}{l}\text { Positive value different } \\
\text { than (5) }\end{array}$ & $\begin{array}{l}\text { Binary distribution: All TTI bins with mean TTI value wetter than or equal to riparian_thresh(nmru) are } \\
\text { assigned Entity ID (5); all other, drier TTI bins are assigned Enti ty ID (6) }\end{array}$ \\
\hline
\end{tabular}


reservoirs in the watershed. Following initialization, flows into and out of each of the nine reservoir types are computed in webmod res. For all reservoirs but snowpack, flows into the reservoir are mixed conservatively with the existing reservoir solution, any evaporated water is fractionated and removed, then the resulting mixture is exported. Snow melts incongruently, with the melt having higher concentrations of solutes and lighter isotopes than the remaining snowpack. Reactions take place in the final volume for 24 hours once all mixing and exports have been completed.

Specific input volumes and fluxes for most reservoirs, in cubic meters, can be traced by using volume-mixing (vmix) variables, such as vmix_can(nmru,nresinp) for the canopy or vmix_snow(nmru,nresinp) for the snowpack. The second dimension, nresinp, is fixed currently (2017) at 21 vmix indices; the first 4 indices describe states and total flux, and the last 17 indices describe inputs from specific sources. The $21 \mathbf{v m i x}$ indices for nresinp are as follows: (1) initial volume, (2) total inputs, (3) total outputs, (4) final volume, (5) precipitation, (6) evaporation (considered a negative input by PHREEQC), (7) impervious surface (not implemented), (8) throughfall, (9) snowmelt, (10) O-horizon (transient storage for canopy moisture and overland flow), (11) unsaturated zone, (12) preferential flow through the unsaturated zone (direct flow), (13) saturated zone (groundwater), (14) exfiltration (accounted for as 13, groundwater), (15) preferential flow in the saturated zone (pipe flow), (16) hillslope mixture that feeds stream reservoirs, (17) irrigation from a well, (18) irrigation from a stream reservoir, (19) irrigation from an external source (canal or deep aquifer), (20) groundwater from the first source (leaky canal in the DR2 example), and (21) groundwater from the second source (upgradient groundwater in the DR2 example). Given steady-state conditions, the volume and discharge of a reservoir will determine the residence time during which the equilibrium and kinetic reactions take place.

Volume mixing fractions, $F$, are computed as ratios of volumes (all in cubic meters):

$$
\begin{gathered}
F_{\text {init }}=V_{\text {init }} / V_{\text {tot }}, \\
F_{i}=V_{i} / V_{\text {tot }}, \text { and } \\
F_{\text {Evap }}=-V_{\text {Evap }} / V_{\text {tot }},
\end{gathered}
$$

where

$F_{\text {init }}$ is the mixing fraction of water with the initial chemistry;

$F_{i} \quad$ is the mixing fraction assigned to water from source $i$;

$F_{\text {Evap }}$ is the mixing fraction of evaporated water (assigned an isotopic signature as described below);

$V_{\text {init }}$ is the volume of water in the reservoir at the beginning of the day, which is equal to vmix index 1;

$V_{\text {tot }}$ is equal to $V_{\text {init }}+\Sigma_{5,7}^{21} V_{i}-V_{\text {Evap }}-\mathbf{v m i x}$ index 5 is the contribution from precipitation, index 6 is evaporation, and indices 7 through 21 represent all other possible inputs;

$V_{i} \quad$ is the volume of water entering the reservoir from source $i$ during the day, equal to vmix indices 5 and 7 through 21 - the sum of inputs is recorded in vmix index 2; and

$V_{\text {Evap }}$ is the volume of water evaporated from the canopy, snowpack, or root zone during the day, which is equal to vmix index 6-transpired water is considered an output from the unsaturated zone that is translocated to the canopy along with solutes.

The sum of all mixing fractions will always equal 1.0. For example, if a reservoir had an initial volume of 425 cubic meters $\left(\mathrm{m}^{3}\right)$, total inputs of $100 \mathrm{~m}^{3}$, and $25 \mathrm{~m}^{3}$ of evaporation, $V_{\text {tot }}$ would equal $500 \mathrm{~m}^{3}$ and the mixing fractions would equal $0.85,0.2$, and -0.05 for $F_{\text {init }}, \Sigma F_{i}$, and $F_{\text {Evap }}$, respectively.

The volume-mixing variables are read by phreeq_mm, which uses PHREEQC to simulate all geochemical mixing, equilibrium, and kinetic reactions. PHREEQC computes the amount of each solute of interest that was consumed or produced by each geochemical reaction. The solutes in each reservoir can be output as totals, loads, or concentrations for the watershed, for each MRU, or for any individual reservoir. Variables describing solute masses, concentrations, and loads for the basin and MRUs are standard variables; ch_basin_mass_g(nsolute) and ch_mru_mass_g(nmru,nsolute) are two examples. The 10 chemvars are convenient for reporting water quality and volumes for specific reservoirs. 


\section{Incongruent Melting of Snowpack}

As the snowpack builds throughout the winter, the snowpack composition is affected by atmospheric deposition and canopy throughfall. In the absence of melting, solute concentrations will increase slightly as a result of sublimation. On warm winter days or with the onset of spring melt, snow commonly melts during the day and refreezes at night. With each thaw-freeze cycle, solutes and lighter isotopes fractionate into the melt leaving behind a snowpack that is more dilute and isotopically heavier than the original snowpack. During the main spring melt, as much as 80 percent of the solutes deposited over the winter may be contained in the initial 20 percent of the meltwater, a phenomena commonly referred to as the ionic pulse (Johannessen and Henriksen, 1978; Bales and others, 1993).

This incongruent melting is simulated by using a parameter describing the concentration factor for melt [snow_ion_factor(nmru)] and parameters describing the fractionation of $\mathrm{D}$ and ${ }^{18} \mathrm{O}$ [snowmelt_D_depl(nmru) and snowmelt_180_depl(nmru)]. Snowmelt has a concentration of solutes equal to the concentration in the final snowpack times the concentration factor. The delta value of an isotope is equal to the delta of the final snowpack plus the fractionation factor. Snowmelt is isotopically lighter than the remaining snowpack, so snowmelt D depl(nmru) and snowmelt_180_depl(nmru) must be assigned negative values.

The chemistry of the melt and the remaining snowpack is computed by using equations of mass balance as follows:

$$
\begin{gathered}
M_{\text {pack }}=M_{\text {init }}(1-f+f \cdot I F) \text { and } \\
M_{\text {melt }}=M_{p a c k} \cdot I F,
\end{gathered}
$$

where

$$
\begin{aligned}
& M_{\text {pack }} \text { is the molar concentration in the remaining } \\
& \text { snowpack, } \\
& M_{\text {init }} \text { is the molar concentration in the snowpack } \\
& \text { at the beginning of the day, } \\
& f \text { is fraction of the snowpack that melts, } \\
& I F \quad \text { is the snow ion factor } \\
& \text { [snow_ion_factor(nmru)], } \\
& \text { and }
\end{aligned}
$$

$M_{\text {melt }}$ is the molar concentration in the snowmelt.

Stable isotopes are treated similarly with the necessary translations of delta values to molar concentrations of the isotopes, which require using the absolute isotope ratios of the standards.

If more than 90 percent of the snowpack melts on a given time step, no ionic pulse or isotopic fractionation is simulated. Similarly, no ionic pulse is simulated if the concentration factor is set to 1.0 .

\section{Isotopes}

The temporal and spatial variations of stable isotopes deuterium and ${ }^{18} \mathrm{O}$ can elucidate hydrologic processes in a watershed. Snow is isotopically lighter than rain, and evaporation produces isotopically lighter vapor, leaving behind isotopically heavier snow, water, or soil moisture. The isotopic signature of the stable isotopes of hydrogen and oxygen in unsaturated and saturated zones changes predominantly in response to mixing of water from different sources, changes secondarily from evaporation (unsaturated zone), and changes little from other biological and geochemical reactions (Kendall and McDonnell, 1998).

Most of the water molecules on Earth have a molecular weight of $18\left({ }^{1} \mathrm{H}_{2}{ }^{16} \mathrm{O}\right)$, consisting of two atoms of protonium (hydrogen atoms with only one proton in the nucleus) bound to one atom of oxygen-16 (oxygen with eight neutrons and eight protons). A small fraction of water molecules are heavier, with deuterium $\left({ }^{2} \mathrm{H}\right.$, or $\left.\mathrm{D}\right)$ in place of a protonium $\left({ }^{1} \mathrm{HD}^{16} \mathrm{O}\right)$ or ${ }^{18} \mathrm{O}$ in place of the ${ }^{16} \mathrm{O}\left({ }^{1} \mathrm{H}_{2}{ }^{18} \mathrm{O}\right)$. Rather than report absolute concentrations of the heavy isotopes, common practice is to report the ratio of the less common heavy isotope to the more common light isotope in a sample divided by the ratio in a standard. Because the ratio of ratios is close to 1 , the value is commonly reported as the deviation from 1.0, and because the deviation is small, the number is multiplied by 1,000 and reported as permil as follows:

$$
\delta=\left(R_{\text {sample }} / R_{\text {standard }}-1\right) 1000,
$$

where

$$
\begin{aligned}
& R \quad \text { is the ratio of the heavy to light isotope in the } \\
& \text { sample or standard. }
\end{aligned}
$$

The international standard for hydrogen and oxygen isotopes in water is the Vienna Standard Mean Ocean Water, which has approximately $156 \mathrm{D}$ atoms and $2,005{ }^{18} \mathrm{O}$ atoms in every million water molecules (Clark and Fritz, 1997).

In WEBMOD, the total ET consists of evaporation, which undergoes fractionation of the isotopes, and transpiration, which does not undergo fractionation. Evaporation is treated as a Rayleigh process such that the $\delta$ of the remaining water or ice, in permil, can be described as follows:

$$
\delta=\left(1+\delta_{0}\right) f^{\varepsilon}-1,
$$

where

$\delta \quad$ is the isotopic composition of the remaining water;

$\delta_{0} \quad$ is the initial isotopic composition of the water;

$f \quad$ is the ratio of the volume of evaporated water to the initial volume of water or ice; and

$\varepsilon \quad$ is the isotopic fractionation between the two phases, in permil, usually vapor over liquid or vapor over ice. 
For vapor over liquid, the isotope fractionation is defined as follows:

$$
\varepsilon=\left(R_{v} / R_{l}-1\right) 1000
$$

where

$R_{v} \quad$ is the isotopic ratio measured in the vapor, and

$R_{l} \quad$ is the isotopic ratio measured in the liquid.

Similar to $\delta, \varepsilon$ is a small number that is usually reported in permil. Functionally, the total isotopic fractionation is the sum of equilibrium fractionation, $\varepsilon_{e q}$, and kinetic or diffusive fractionation, $\varepsilon_{\text {diff }}$.

The equilibrium fractionation (fig. 34) for $\mathrm{D}$ and ${ }^{18} \mathrm{O}$ among liquid, vapor, and solid water has been described by Majzoub (1971, as translated and presented in Clark and Fritz, 1997) as follows:

$$
\varepsilon_{e q}=e^{c_{0}+\frac{c_{1}}{T}+\frac{c_{2}}{T^{2}}}-1
$$

where

$$
\begin{aligned}
& \varepsilon_{e q} \text { is the equilibrium fractionation, in permil; } \\
& T \text { is temperature, in Kelvin; } \\
& c_{0}=2.0667 \times 10^{3}, c_{1}=0.4156 \text {, and } c_{2}=-1.137106 \times 10^{3} \\
& \text { for oxygen-18 in vapor over liquid; } \\
& c_{0}=-52.612 \times 10^{3}, c_{1}=76.2 \text {, and } c_{2}=-2.48 \times 10^{4} \text { for } \\
& \text { deuterium in vapor over liquid; and } \\
& c_{0}=0.0945, c_{1}=0 \text {, and } c_{2}=-1.6289 \times 10^{4} \text { for deuterium } \\
& \text { in vapor over ice (Merlivat and Nief, 1967). }
\end{aligned}
$$

For ${ }^{18} \mathrm{O}$ in vapor over ice, the same equation is used as ${ }^{18} \mathrm{O}$ in vapor over water but with an offset of -3 permil as obtained by O'Neil (1968) according to the approximation proposed by Gonfiantini (1971) as cited in Fritz and Fontes (1980).

The kinetic fractionation resulting from diffusion, in permil, is derived from the Craig and Gordon (1965) model (as presented in Mook, 2000) as follows:

$$
\varepsilon_{\text {diff }}=n \Theta\left(1-h_{n}\right)\left(1-\Delta_{\text {diff }}\right) \text {, }
$$

where

$$
\begin{aligned}
& \varepsilon_{\text {diff }} \quad \text { is the kinetic fractionation, in permil; } \\
& n \quad \text { is a factor between } 0.5 \text { and 1.0, unitless } \\
& \text { [iso_n(nmru)]; }
\end{aligned}
$$

Values for $\Delta_{\text {diff }}$ are 1.0251 for $\mathrm{D}$ and 1.0285 for ${ }^{18} \mathrm{O}$ (Merlivat, 1978, as cited in Mook, 2000). These values are input into WEBMOD as the last field of the solute list in the phreeq_lut file. A value of $n=0.5$ [iso_ $\mathrm{n}(\mathrm{nmru})$ ] was determined by Vogt (1978) to be appropriate for open water such that

$$
\begin{gathered}
\varepsilon_{\text {diff }}=-12.5\left(1-h_{n}\right) \text { for } \mathrm{D}, \text { and } \\
\varepsilon_{\text {diff }}=-14.2\left(1-h_{n}\right) \text { for }{ }^{18} \mathrm{O} .
\end{gathered}
$$

The weighting term $\Theta$ [iso_theta(nmru)] is assumed to equal 1 for small bodies of water where evaporation flux does not substantially modify the ambient atmospheric moisture. The value for $\Theta$ has been determined to be 0.88 for the North American Great Lakes (Gat and others, 1994) and about 0.5 for evaporation in the eastern Mediterranean Sea (Gat, 1996). The default values for $n$ and $\Theta$ in WEBMOD are 0.5 and 1.0, respectively. In a closed system, both the residual water and the evaporated water become isotopically heavier as the ratio of evaporated volume to initial volume, $f$, increases. The simulated fractionation of ${ }^{18} \mathrm{O}$ as water evaporates into dry and moist air is shown in figure 35. Light rains falling on a canopy can evaporate completely such that $f$ approaches 1.0 resulting in little to no fractionation (no water left; vapor returned with same delta as the delta of the deposited water).

The fractionation models apply to areas of open water or snowpack in a watershed, generally only a small fraction of the total area. Therefore, the sum of equilibrium and diffusive fractionation is reduced by using an areal factor correlated with the amount of wetlands, riparian areas, and open water in the watershed as follows:

$$
\varepsilon=A F_{m r u}\left(\varepsilon_{e q}+\varepsilon_{d i f f}\right),
$$

where

$$
\begin{array}{cl}
\varepsilon & \text { is the effective fractionation, in permil, and } \\
A F_{m r u} & \text { is the areal correction factor [iso_fac(nmru)], }
\end{array}
$$
unitless.

Many factors will affect the variations of the stable isotopes of hydrogen and oxygen simulated for the stream. These factors include input signatures, rain and snow adjustments, PET, and residence times in the various reservoirs as water flows through the landscape. The areal correction factor is the only factor that has an effect only on the amount of fractionation and no other hydrologic or geochemical process.

The dynamics of hydrogen and oxygen fractionation are similar, such that the covariance of measurements in precipitation samples from around the world can be described by $\delta \mathrm{D}=8$ $\delta^{18} \mathrm{O}+10$ (Craig, 1961). The line defined by this equation has been given the term "global meteoric water line" and can be explained by equilibrium and kinetic fractionation as atmospheric moisture condenses into precipitation (Dansgaard, 1964).

In WEBMOD, isotopes are treated similarly to other solutes. Deuterium is listed as D and oxygen-18 is listed as $\left[{ }^{18} \mathrm{O}\right]$ in the dimension names listed at the top of the parameter file. Initial isotopic values, in permil, for precipitation, 


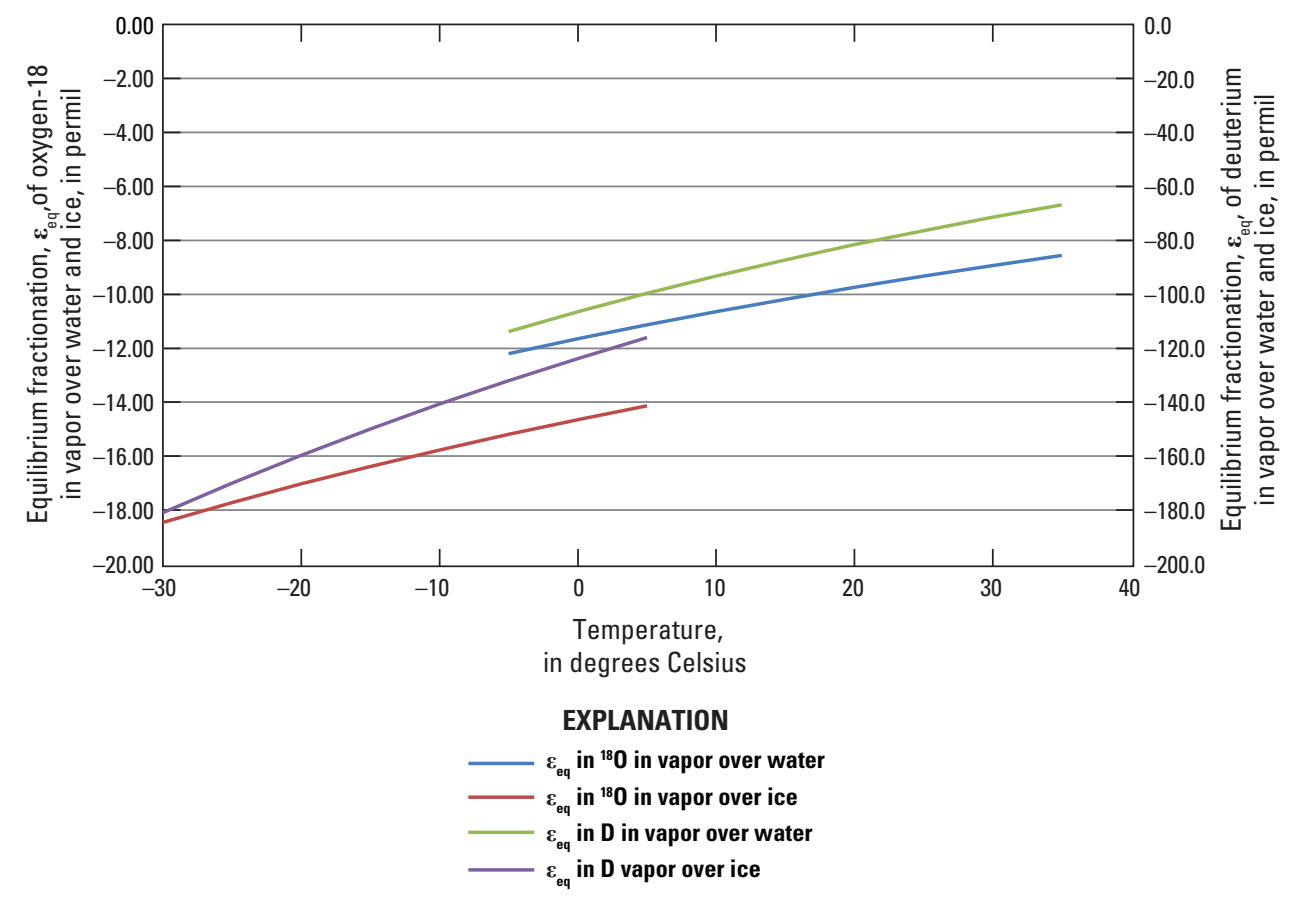

Figure 34. Depletion of deuterium (D) and oxygen-18 $\left({ }^{18} 0\right)$ in vapor over water and ice as a function of temperature. Curves constructed from equations from Majzoub (1971) as presented in Clark and Fritz (1997).

external sources, and hillslope reservoirs are defined in SOLUTION data blocks in the webmod.pqi file, and daily variations for precipitation and external sources are defined in the webmod.chem.dat file. Isotopic values at the end of the day for hillslope reservoirs are simulated by using mixing and fractionation. Because $\delta \mathrm{D}$ and $\delta^{18} \mathrm{O}$ are highly correlated, the user can save time by supplying values for only one isotope; only $\delta^{18} \mathrm{O}$ values are used in subsequent discussions and in the Andrews Creek example problem.

Temporal variations in ratios of stable isotopes of hydrogen and oxygen provide an important calibration target for a watershed model for several reasons. The residence time of water in the subsurface for watersheds with annual snowpacks can be deduced from the amplitude and lag time of the isotopically light snowmelt measured in the streams. Even in watersheds without substantial snowfall, estimating residence time is possible if the isotopic composition of precipitation from large convective storms is much lighter than the precipitation from storms with less convection, and evaluating the relative importance of evaporation compared to transpiration also is possible. Evaporation from saturated soils leaves behind water more concentrated in the heavier isotope; however, transpiration does not result in substantial fractionation because the roots take up heavy isotopes at the same rate as the light isotopes, and evaporation at the leaf surface quickly adjusts to release the isotopes in the same proportions as the isotopes are taken up (Farquhar and others, 2007).

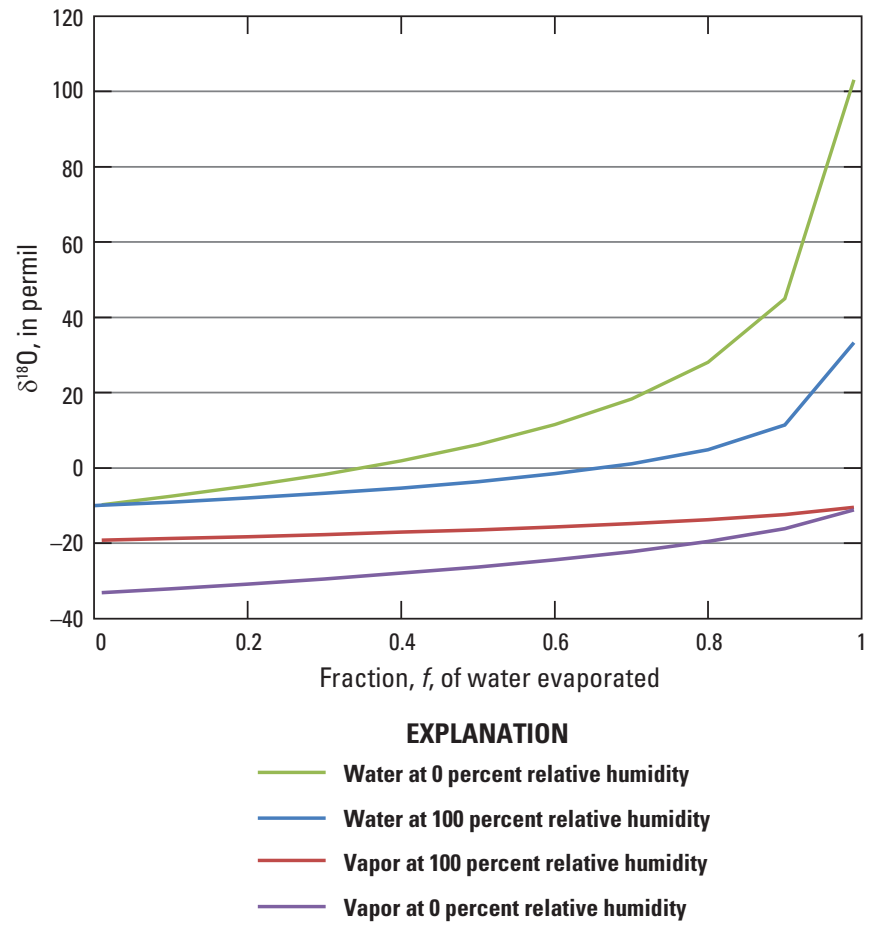

Figure 35. Delta value for oxygen-18 $\left(\delta^{18} 0\right)$ for water and vapor simulated for evaporation fractions from 0 to 1.0 at 0 percent and 100 percent relative humidity at 25 degrees Celsius. In this example, the initial $\delta^{18} 0$ for the water and the final $\delta^{18} 0$ for the vapor are -10 permil. 


\section{Example Problems}

Watershed modeling is difficult because the modeling is data intensive for hydrological and geochemical data and also because of the large numbers of parameters associated with the reservoirs of each MRU. The modeler should strive for parsimony, preferring a simple model that explains major variations in hydrology and geochemistry observed over many years rather than a complex model that closely matches observations for a single event but performs poorly for other periods. In addition, simple models run faster and, therefore, can be calibrated in less time than more complex models. The two models presented in this section represent endmembers for the types of hydrologic and geochemical simulations possible with WEBMOD. The first model is a 29-year simulation for the Andrews Creek watershed with complex geochemistry and simple hydrology, and the second model is an 18-year simulation for the DR2 watershed with simple geochemistry and complex hydrology (table 14).

Simulations of hydrology and geochemistry take approximately 3 hours for the Andrews Creek model and 10 minutes for the DR2 model on a current (2017) personal computer; hydrology alone for each model takes less than 10 seconds. The reason for the large discrepancy in run time is because, with the exception of solving the Green-Ampt infiltration equation to estimate overland flow, all hydrologic processes are reduced to systems of linear equations. On the other hand, the low-temperature aqueous geochemistry, which is simulated by PHREEQC, and the Green-Ampt infiltration equation use iterative numerical solutions of nonlinear equations that may require many iterations before converging (Parkhurst, 1997). In some cases, with poorly selected parameters, no solution for a hydrologic or geochemical process will be determined and the simulation stops.

Calibration of the two example models is limited to manual adjustments of the hydrologic parameters in the webmod.params file and geochemical parameters in the webmod.pqi file. In general, the user can start with default parameter values and then modify the values as more detailed input data become available. For example, lapse rates for daily maximum temperature are usually about $9{ }^{\circ} \mathrm{C} / \mathrm{km}$. This value could be used for all months; but, when additional data are available, as in the case of the Andrews Creek watershed, values tailored to the watershed of interest can and should be used. The narratives for the two examples do not discuss every parameter and variable; instead, the narratives focus on parameters that are key in the definition of the model topology or on parameters that differ from default values.

The first model simulates flows and water chemistry for Andrews Creek, which is fed by rain and snow that falls on the Continental Divide in the Rocky Mountains west of Estes Park, Colo. The mean altitude for the watershed is 3,500 meters above mean sea level (mamsl). The hydrology is simulated as 10 hillslopes, each with 11 TTI bins. The geochemistry describes daily variations in precipitation chemistry along with mineral weathering and precipitation of secondary minerals.

The second model simulates salinity and flows for DR2, which is a heavily modified catchment that drains agricultural fields southeast of Yakima, Wash. The geochemistry describes simple conservative mixing and transport of chloride from three constant-composition water sources-precipitation, the Sunnyside Canal that delivers water from the Yakima River, and upgradient groundwater. The hydrology is defined with 22 hillslopes, each with irrigation from the Sunnyside Canal, from a local well, or from the return flow in the DR2 drain. Irrigation is not pumped from wells or the DR2 drain, but the scenario is presented in this example to demonstrate how to include these transfers of water in a model. In addition to the irrigation, two groundwater inputs, each with different salinities, and tile drains (pipe flow) are simulated.

The ASCII-format control, hydrologic data, chemistry data, and parameter files (webmod.control, webmod.hydro.dat, webmod.chem.dat, and webmod.params, respectively) are distributed with the WEBMOD download. In addition, the data for these files are included in worksheets in Microsoft Excel workbooks (.|inputlandcrk.xlsm and . |input|dr2.xlsm). Any worksheet may be exported to ASCII format by running the macro "ExportText" and then naming and saving the file to the appropriate control or input directory. The workbooks are provided to facilitate entry and manipulation of data and parameters for each model, but only the ASCII-format files are used in a WEBMOD run.

\section{Hydrology, Weathering, and Isotopic Variations for the Andrews Creek Watershed}

Loch Vale fills with waters that fall on the eastern flank of the Continental Divide in Rocky Mountain National Park west of Estes Park, Colo. (fig. 36). The flux of water and major ions entering and leaving Loch Vale and its two primary tributaries, Andrews Creek and Icy Brook, have been a focus of small watershed research since 1983 (Baron, 1992; Clow and Mast, 1995, 1999, 2010). The watershed continues to be a research focus for the USGS WEBB program (Turk and others, 1993), the Western Mountain Initiative (Stephenson and others, 2006), the National Park Service (Baron, 1990), and the Natural Resource Ecology Laboratory at the Colorado State University (Newkirk, 1995). This example simulates the evolution of waters in Andrews Creek, a subbasin of Loch Vale, as a result of the interaction of precipitation with soils and regolith of the granitic terrane (Drever, 1997; Drever and Clow, 1995).

The construction of the Andrews Creek model involved the compilation of meteorology, watershed topology, mineralogy, and observations of discharge and water quality. 
Table 14. Overview of model configuration for the Andrews Creek and the DR2 watersheds.

The formatting convention used in this report is to present file names in italic font, dimension names in Courier New font, variable names in bold italic Courier New font, and parameter names in bold Courier New font. See tables 1 and 2 for descriptions of dimensions and parameters. MRU, model response unit; ET, evapotranspiration; PET, potential evapotranspiration; SNOTEL, Snow Telemetry; Ca, calcium; $\mathrm{Mg}$, magnesium; $\mathrm{Na}$, sodium; $\mathrm{K}$, potassium; $\mathrm{NH}_{4}$, ammonium; $\mathrm{Cl}$, chloride; $\mathrm{S}$, sulfur; $\mathrm{NO}_{3}$, nitrate; $\mathrm{Si}$, silica; $\delta^{18} \mathrm{O}$, delta oxygen-18; $\mathrm{mg} / \mathrm{L}$, milligram per liter; $\mu \mathrm{S} / \mathrm{cm}$, microsiemen per centimeter; $\left(\mathrm{mg} / \mathrm{m}^{2}\right) / \mathrm{d}$, milligram per square meter per day; $\mathrm{mg} / \mathrm{mol}$, milligram per mole]

\begin{tabular}{|c|c|}
\hline Directory/files & Andrews Creek watershed \\
\hline Project Directory & Andrews \\
\hline \multicolumn{2}{|l|}{ |control $\mid$} \\
\hline \multicolumn{2}{|l|}{ webmod.control } \\
\hline start/end of simulation & $10 / 1 / 1983-9 / 30 / 2012(29$ years $)$ \\
\hline Run Time Plots 1 & Observed and simulated discharge, in centimeters \\
\hline Run Time Plots 2 & Snowpack in MRU 3 and 10 \\
\hline Run Time Plots 3 & Concentrations of sodium at outlet, in milligrams per liter \\
\hline Run Time Plots 4 & Concentrations of silica at outlet, in milligrams per liter \\
\hline
\end{tabular}

Run Time Plots 5 . $\mid$ input $\mid$

webmod.params

webmod.hydro.dat

webmod.chem.dat

webmod.pqi

. $\mid$ output

webmod.topout

webmod.hydro.out

webmod.chem.out
Ten hillslopes with time varying chemical inputs

Discharge for Andrews Creek, Icy Brook, and the Loch; precipitation from Bear Lake SNOTEL station; precipitation, temperature, insolation, and relative humidity observed at Main Weather Station

Daily values for temperature, $\mathrm{pH}, \mathrm{Ca}, \mathrm{Mg}, \mathrm{Na}, \mathrm{K}, \mathrm{NH}_{4}$, alkalinity, $\mathrm{Cl}, \mathrm{S}, \mathrm{NO}_{3}, \mathrm{Si}$, and $\delta^{18} \mathrm{O}$, measured in precipitation and stream; the stream was sampled intermittently, so concentrations and delta values of analytes were set to zero on days with no sampling

Initial solutions, mineral phases, equilibrium phases, and kinetics to simulate weathering, secondary mineralization, and nitrification

Description of soils properties and time-delay ordinates for Clark unit hydrograph; all water exits the watershed in less than one day, so there is only a single stream reservoir

Basin detailed water balance

Volume-normalized temperature and $\mathrm{pH}$ for basin inputs and outputs; daily basin fluxes and final mass for water and 10 solutes; volumenormalized $\delta^{18} \mathrm{O}$ values for precipitation, discharge, evapotranspiration, and total volume
Model

DR2 watershed

$d r 2 \backslash$

10/1/1987-9/30/2003 (16 years)

Observed and simulated discharge, in centimeters

Inputs: precipitation, irrigation, leakage from Sunnyside Canal, and upgradient groundwater, in centimeters

Ouputs: ET, overland flow, direct flow, pipe flow, and baseflow, in centimeters

Water table, in meters above land surface, for MRU with precipitation, evapotranspiration, upgradient groundwater, pipe flow, and four irrigation scenarios: 1, no additional irrigation (MRU 19); 2, irrigation from Sunnyside Canal (MRU 1); 3, synthetic well irrigation (MRU 2); and 4, synthetic stream diversion (MRU 7)

Inputs and outputs of chloride, in grams

Twenty-two hillslopes with constant composition irrigation from canals and internally computed concentrations for irrigation from wells and return flow; pipe flow simulating tile drains included

Discharge from DR2 for 2003; temperature, precipitation, insolation, PET, and relative humidity from Harrah Agromet station, irrigation schedules, and

fluxes from upgradient groundwater; potential evapotranspiration, calculated using the Penman method with observations from the Harrah Agromet

station, is input to the model as the variable pan_evap

No webmod.chem.dat file as constant composition inputs defined in webmod.pqi

Constant values for chloride concentrations in precipitation, Yakima River water, and upgradient groundwater

Description of soil properties and time-delay ordinates for Clark unit hydrograph; all water exits the watershed in less than one day, so there is only a single stream reservoir

Basin detailed water balance

Daily basin fluxes for water and chloride 
Table 14. Overview of model configuration for the Andrews Creek and the DR2 watersheds.-Continued

[The formatting convention used in this report is to present file names in italic font, dimension names in Courier New font, variable names in bold italic Courier New font, and parameter names in bold Courier New font. See tables 1 and 2 for descriptions of dimensions and parameters. MRU, model response unit; ET, evapotranspiration; PET, potential evapotranspiration; SNOTEL, Snow Telemetry; Ca, calcium; $\mathrm{Mg}$, magnesium; $\mathrm{Na}$, sodium; $\mathrm{K}$, potassium; $\mathrm{NH}_{4}$, ammonium; $\mathrm{Cl}$, chloride; $\mathrm{S}$, sulfur; $\mathrm{NO}_{3}$, nitrate; $\mathrm{Si}$, silica; $\delta^{18} \mathrm{O}$, delta oxygen-18. Abbreviation of units: mg/L, milligram per liter; $\mu \mathrm{S} / \mathrm{cm}$, microsiemen per centimeter; $\left(\mathrm{mg} / \mathrm{m}^{2}\right) / \mathrm{d}$, milligram per square meter per day; $\mathrm{mg} / \mathrm{mol}$, milligram per mole]

Directory/files

webmod.statvar

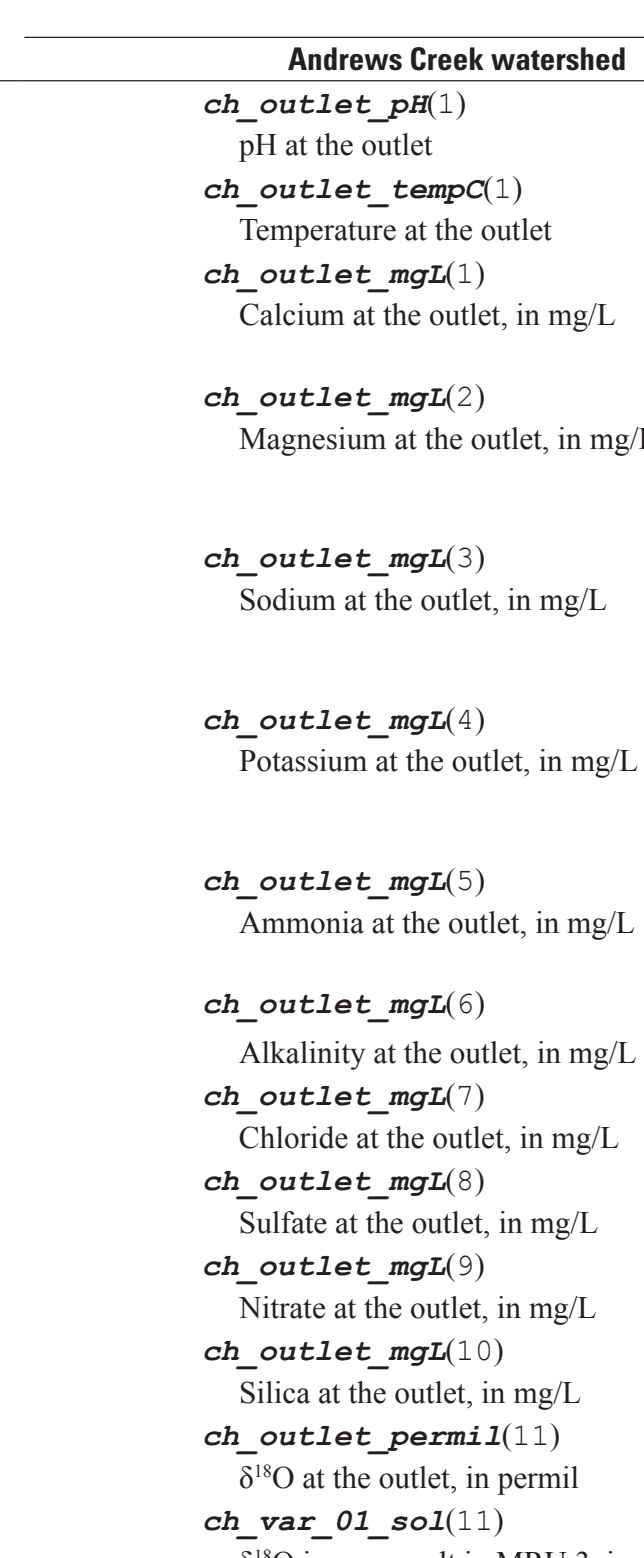

Model

ch basin in $\operatorname{mgL}(1)$

Chloride inputs, in $\mathrm{mg} / \mathrm{L}$

ch_outlet_mgL(1)

Chloride exports, in $\mathrm{mg} / \mathrm{L}$

ch_var_10_sol(1)

Chloride export from last stream segment, in units of convfactor(1)= $2,000,000 \mathrm{mg} / \mathrm{mol}$, set to approximate specific conductivity, in $\mu \mathrm{S} / \mathrm{cm}$

z_wt(2)

The altitude, in meters, of the water table above the land surface for MRU 2 that receives irrigation from a well into saturated zone in the same amount as MRU 6

z_wt(6)

The altitude, in meters, of the water table above the land surface for MRU 6 that receives irrigation from Sunnyside Canal in the same amounts as MRU 2

z_wt(9)

The altitude, in meters, of the water table above the land surface for MRU 9 that receives irrigation from the return flow in DR2 in the same amounts as MRU 14

$z_{-}$wt(14)

The altitude, in meters, of the water table above the land surface for MRU 14 that receives irrigation from Sunnyside Canal in the same amounts as MRU 9 ch_mru_mgL_out $(2,1)$

The concentration of chloride, in waters exported from MRU 2, in mg/L

ch_mru_mgL_out $(6,1)$

The concentration of chloride, in waters exported from MRU 6, in mg/L

ch_mru_mgL_out $(9,1)$

The concentration of chloride, in waters exported from MRU 9, in $\mathrm{mg} / \mathrm{L}$

ch_mru_mgL_out $(14,1)$

The concentration of chloride, in waters exported from MRU 14, in mg/L

$\delta^{18} \mathrm{O}$ in snowmelt in MRU 3 , in permil 
Table 14. Overview of model configuration for the Andrews Creek and the DR2 watersheds. - Continued

[The formatting convention used in this report is to present file names in italic font, dimension names in Courier New font, variable names in bold italic Courier New font, and parameter names in bold Courier New font. See tables 1 and 2 for descriptions of dimensions and parameters. MRU, model response unit; ET, evapotranspiration; PET, potential evapotranspiration; SNOTEL, Snow Telemetry; Ca, calcium; $\mathrm{Mg}$, magnesium; $\mathrm{Na}$, sodium; $\mathrm{K}$, potassium; $\mathrm{NH}_{4}$, ammonium; $\mathrm{Cl}$, chloride; $\mathrm{S}$, sulfur; $\mathrm{NO}_{3}$, nitrate; $\mathrm{Si}$, silica; $\delta^{18} \mathrm{O}$, delta oxygen-18. Abbreviation of units: $\mathrm{mg} / \mathrm{L}$, milligram per liter; $\mu \mathrm{S} / \mathrm{cm}$, microsiemen per centimeter; $\left(\mathrm{mg} / \mathrm{m}^{2}\right) / \mathrm{d}$, milligram per square meter per day; $\mathrm{mg} / \mathrm{mol}$, milligram per mole]

\begin{tabular}{|c|c|c|}
\hline \multirow[b]{2}{*}{ Directory/files } & \multicolumn{2}{|c|}{ Model } \\
\hline & Andrews Creek watershed & DR2 watershed \\
\hline \multirow{16}{*}{$\begin{array}{l}\text { webmod.statvar } \\
\text {-Continued }\end{array}$} & ch_var_02_sol(11) & \\
\hline & $\overline{\delta^{18}} \mathrm{O}$ in snowpack in MRU 3, in permil & \\
\hline & ch_var_03_sol(11) & \\
\hline & $\delta^{18} \mathrm{O}$ in the O-horizon in MRU 3, in permil & \\
\hline & ch_var_04_sol(11) & \\
\hline & $\delta^{18} \mathrm{O}$ in the unsaturated zone in MRU 3 , in permil & \\
\hline & ch_var_05_sol(11) & \\
\hline & $\delta^{18} \mathrm{O}$ in the saturated zone in MRU 3, in permil & \\
\hline & ch_var_06_sol( 8$)$ & \\
\hline & $\begin{array}{l}\text { Sulfate produced from pyrite oxidation in unsaturated zone } \\
\text { of MRU } 10 \text { (cold), in }\left(\mathrm{mg} / \mathrm{m}^{2}\right) / \mathrm{d}\end{array}$ & \\
\hline & ch_var_07_sol(8) & \\
\hline & $\begin{array}{l}\text { Sulfate produced from pyrite oxidation in saturated zone of } \\
\text { MRU } 10 \text { (cold), in }\left(\mathrm{mg} / \mathrm{m}^{2}\right) / \mathrm{d}\end{array}$ & \\
\hline & ch_var_08_sol(8) & \\
\hline & $\begin{array}{l}\text { Sulfate produced from pyrite oxidation in unsaturated zone of } \\
\text { MRU } 3 \text { (warm), in }\left(\mathrm{mg} / \mathrm{m}^{2}\right) / \mathrm{d}\end{array}$ & \\
\hline & ch_var_09_sol(8) & \\
\hline & $\begin{array}{l}\text { Sulfate produced from pyrite oxidation in saturated zone of } \\
\text { MRU } 3 \text { (warm), in }\left(\mathrm{mg} / \mathrm{m}^{2}\right) / \mathrm{d}\end{array}$ & \\
\hline
\end{tabular}



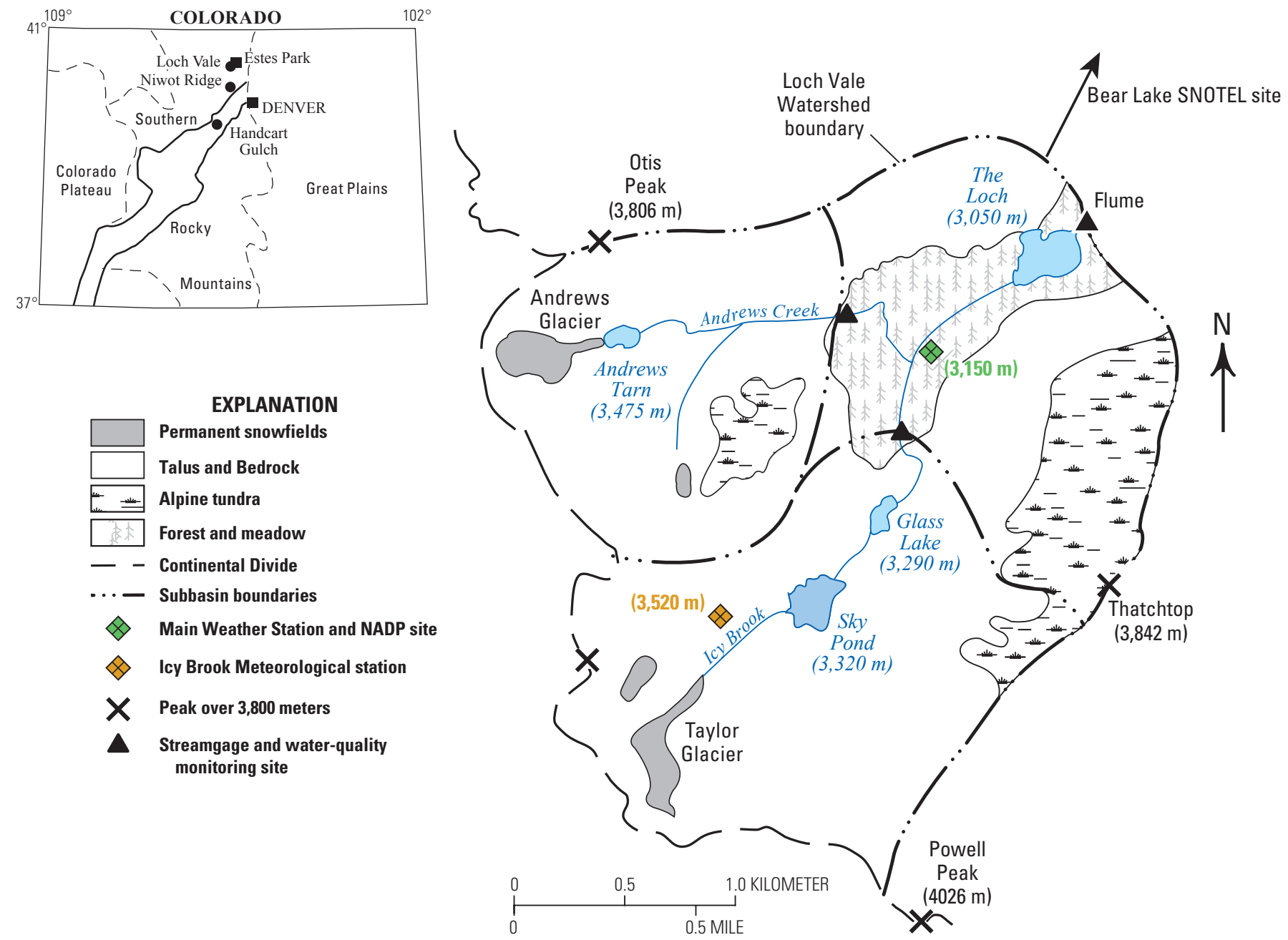

Figure 36. Descriptive map showing the location of the Loch, Andrews Creek, Icy Brook, and Main Weather Station in the Loch Vale watershed, Rocky Mountain National Park, Colorado. The Bear Lake snow telemetry (SNOTEL) site is 2.5 kilometers to the northeast of the Loch at an altitude of 2,896 meters above mean sea level. Handcart Gulch is in a naturally acidic watershed where the pyrite kinetics used in the Andrews Creek model were tested. (Modified from Campbell and others, 1995) (m, meter; NADP, National Atmospheric Deposition Program) 
Parameters describing the amount and form of precipitation, air and soil temperatures, soil transmissivity and moisture retention, and potential evaporation for a single-MRU representation of the Andrews Creek watershed were then manually calibrated to match variations of discharge, chloride concentrations, and $\delta^{18} \mathrm{O}$. Hydrologic parameters were then fixed, and geochemical parameters describing partial pressures of oxygen and carbon dioxide and surface-to-volume ratios for each mineral phase were then manually calibrated to match variations in concentrations of major ions. The manually calibrated parameters served as the starting point for model optimization using PEST (Doherty, 2004), where a variety of parameters were either fixed or allowed to recalibrate. Final values for temperature, $\mathrm{pH}, \delta^{18} \mathrm{O}$, and solute concentrations for reservoirs in the single-MRU model were occasionally copied to the SOLUTION blocks in webmod.pqi to provide better initial conditions so that the number of days needed for the hydrology and geochemistry to arrive at a dynamic equilibrium was reduced. Iterative manual and automated model calibration continued until a satisfactory fit between simulated and observed variations in hydrology and geochemistry was obtained. Parameters related to area, altitude, slope, aspect, and solar radiation, along with adjustments of temperature and undercatch of precipitation, were then distributed to a 10MRU model of the Andrews Creek model, and a final automated calibration with fixed relations between MRU parameters was completed.

\section{Hydrologic Simulations}

A 10-hillslope model is presented to simulate the hydrology and water chemistry observed for Andrews Creek, which is upstream from Loch Vale (fig. 10). The discretization of the watershed topology and the model variables are defined in webmod.hydro.dat and webmod.params.

\section{Hydrologic Data File (webmod.hydro.dat)}

The variables available to drive the hydrology of the simulation include the precipitation measured at the Bear Lake SNOTEL site (U.S. Department of Agriculture, 2016) and at Main Weather Station [precip(nrain=2)] along with the minimum temperature [tsta_min_f(ntemp=1)], maximum temperature [tsta_max_ $\bar{f}(\mathrm{ntemp}=1)]$, solar radiation $[\operatorname{sol} \mathrm{rad}(\mathrm{nsol}=1)]$, and relative humidity [relhum(nhum=1)] measured at the Remote Area Weather Station (Natural Resource Ecology Laboratory, 2011) or Main Weather Station. All 10 MRUs reference precipitation measured at the Bear Lake SNOTEL site [mru_psta(nmru) $=1]$ and temperature measured at Main Weather Station upstream from Loch Vale $[\mathrm{mru}$ tsta $(\mathrm{nmru})=1]$. Discharge measurements are included for three stations runoff(nobs=3). The three stations are Andrews Creek, Icy Brook, and the Loch outlet; however, only the Andrews Creek discharge is a target of calibration for this model. All meteorological data observed at Main Weather Station, discharge, water quality, and isotope results are available from the USGS National Water Information System (NWIS, https://doi.org/10.5066/F7P55KJN). The parameter qobsta(one) $=1$ indicates that Andrews Creek, the first of the three columns of discharge measurements, will be used to compute the objective functions [obj_func(five)] that describe the fit between observed and simulated discharge.

\section{Parameter File (webmod.params)}

The Andrews Creek watershed is configured as 10 hillslopes (nmru=10) within the $1.74-\mathrm{km}^{2}$ watershed with an average altitude of 3,540 mamsl; each hillslope is further discretized into 11 TTI bins $\left(\mathrm{nac}_{\mathrm{C}}=11\right)$ as listed in table 15 . Internally, WEBMOD uses a vector with 21 elements (nresinp) to track flows into, out of, and among the reservoirs of any hillslope. Therefore, the dimension of nac_nmru_nresinp must be set to $2310(=11 \times 10 \times 21)$.

Base-flow recession measured at the Andrews Creek gage, plotted with $1 \sqrt{\mathrm{Q}}$ (discharge as cubic meters per hour) on the $y$-axis and hours on the $\mathrm{x}$-axis, was more linear than recessions plotted as $1 / \mathrm{Q}$ or $\ln (\mathrm{Q})$, so the parabolic transmissivity model, T_decay (imru=1-10)=1, was used. Therefore, the TTI bin thresholds, st(nac,nmru), and the mean TTI values for each MRU, TL(nmru), use the transformation of $\sqrt{\mathrm{a} / \tan \beta}$. When using the parabolic transmissivity model, the ratio of transmissivity to the maximum saturation deficit varies as $\sqrt{T_{0}} / m=a \sqrt{A} \lambda_{r}$ (fig. 25; Ambroise, 1996a), where $T_{0}$ is To(nmru), the transmissivity at saturation; $m$ is the maximum saturation deficit, set to 0.35 meter for all MRUs; $\alpha$ is the computed slope of the recession plot, equal to $8.6 \times 10^{-5} ; \mathrm{A}$ is the drainage area above the point where the recession was measured, $1.74 \times 10^{6}$ square meters; and $\lambda_{r}$ is the mean TTI value for each MRU, TL(nmru). In this example, the mean TTI values, TL(nmru) — as derived by using GIS - were used to distribute transmissivity values, To(nmru), to each MRU, given a maximum saturation deficit of 0.35 (table 16).

Average slopes ranged from 0.65 to 1.025 ( $\tan \beta$, rise/run) (table 17). Slopes and aspects were derived by fitting a plane to the $\mathrm{X}, \mathrm{Y}, \mathrm{Z}$ coordinates of the perimeter of each MRU (Lee, 1963). Daily variations of incoming solar radiation were computed for each MRU by using solar radiation tools available in ArcGIS. Southern exposures (MRUs 1, 3, 5, 7, and 9) receive an annual average of $230 \mathrm{~W} / \mathrm{m}^{2}$ on clear-sky days compared to $150 \mathrm{~W} / \mathrm{m}^{2}$ for the hillslopes with northern exposures (MRUs 2, 4, 6, 8, and 10). When the Hamon method is 
Table 15. Dimensions of the Andrews Creek model.

[The formatting convention used in this report is to present dimension names in Courier New font. See table 1 for definitions of dimensions]

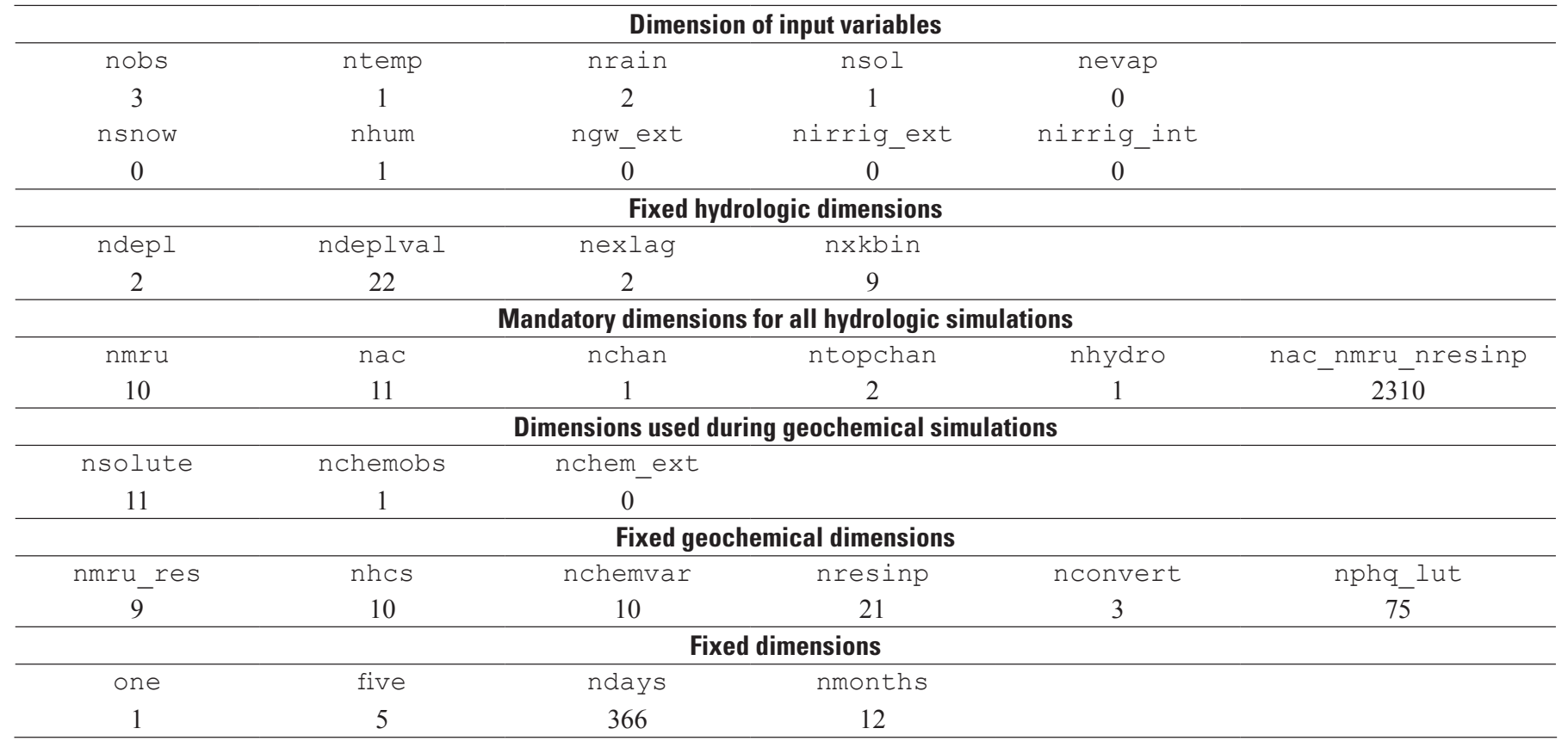

used to estimate PET, the main driver of PET is air temperature and not incoming solar radiation; the temperature adjustment parameters [tmax_adj(nmru) and tmin_adj(nmru)] are appropriate when simulating the temperature differences expected for MRUs with different exposures. Therefore, the assigned adjustment to maximum daily temperature, tmax_adj(nmru), ranged from $2.5^{\circ} \mathrm{C}$ for MRU 5, which is sunlit, to $-3.6{ }^{\circ} \mathrm{C}$ for MRU 10 , which lies in a topographically shaded canyon. Corrections to minimum temperatures were similar but not as extreme. These corrections are combined with temperature differences predicted by using vertical lapse rates [tmax_lapse(nmonths) and tmin_lapse(nmonths)] to distribute temperatures observed upstream from the Loch. Vertical lapse rates were computed from observed temperature differences between the site upstream from the Loch-Main Weather Station (altitude 3,150 mamsl) — and the weather stations installed at Andrews Meadow (altitude 3,215 mamsl) and Icy Brook (altitude 3,520 mamsl) during water year 1994. The temperature adjustments and lapse rates are listed in table 17. Main Weather Station provided reliable measurements of temperature and relative humidity, but the high winds there resulted in erratic measurements of the amount of snow and rain.

The hydrology simulated from October 1983 through September 2012 is driven with precipitation measured at the Bear Lake SNOTEL station and temperature and relative humidity measured at Main Weather Station. SNOTEL observations include direct estimates of SWE by weighing the snow deposited on a large pillow. At the site upstream from the Loch, a Remote Area Weather Station (RAWS) operated from 1982 through 1998, but sensors began to degrade in 1993. Main Weather Station was installed in 1992 at the same site as the RAWS. Main Weather Station and the RAWS operated together for approximately 1 year before the RAWS instrumentation started to produce poor data. Therefore, the official weather record consists of the RAWS observations from September 9, 1982, through December 30, 1992, (Natural Resource Ecology Laboratory, 2011) and Main Weather Station observations from January 1, 1993, through present. The minimum and maximum daily temperatures were derived from measurements made every hour (or more frequently for recent periods) at $6 \mathrm{~m}$ above land surface. When more than 12 hours of observations were missing for Main Weather Station, the temperature statistics from Niwot Ridge - a research watershed 27 kilometers south of Loch Vale and at a similar altitude - were used. If less than 12 hours of data were missing for a given day at the Main Weather Station, the missing minimum or maximum temperature was estimated by using an average daily temperature range of $8^{\circ} \mathrm{C}$ (for 1993-2010 at Loch Vale). For the 3 days that had temperature values missing at Main Weather Station and Niwot Ridge, minimum and maximum temperatures were linearly interpolated between the previous and following days. If 
Table 16. Topographic and transmissivity parameters for the Andrews Creek model.

[The formatting convention used in this report is to present dimension names in Courier New font and parameter names in bold Courier New font. See tables 1 and 2 for descriptions of dimensions and parameters. Some values in this table differ nominally from the values in the parameter file because of rounding. a, upslope contributing area; tan, tangent; $\beta$, slope.]

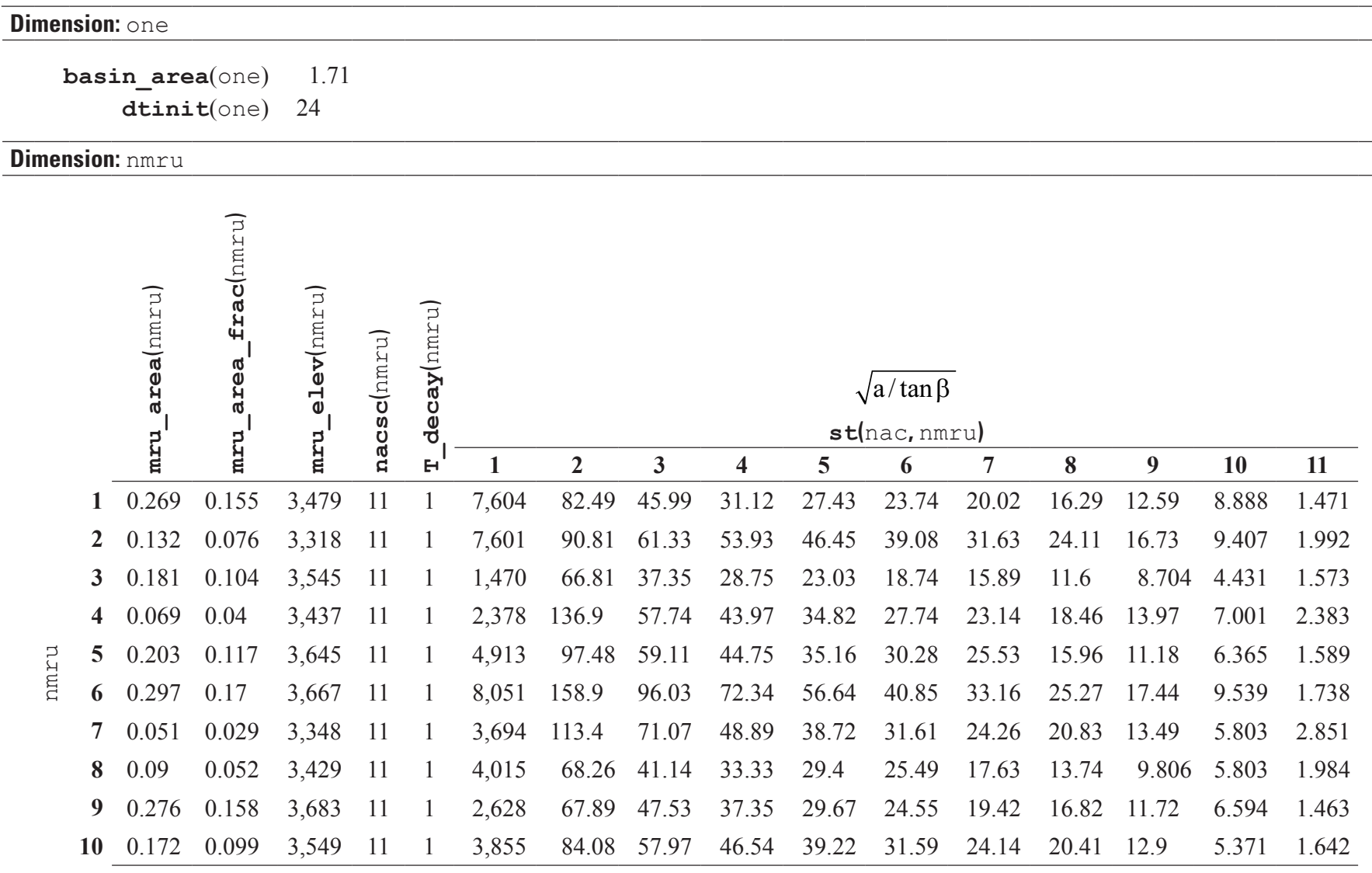

\begin{tabular}{|c|c|c|c|c|c|c|c|c|c|c|c|c|c|c|}
\hline & \multirow{2}{*}{ 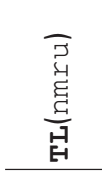 } & \multirow{2}{*}{ 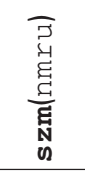 } & \multirow{2}{*}{ 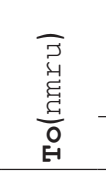 } & \multicolumn{11}{|c|}{ ac(nac, nmru) } \\
\hline & & & & 1 & 2 & 3 & 4 & 5 & 6 & 7 & 8 & 9 & 10 & 11 \\
\hline 1 & 78.00 & 0.35 & 9.59 & 0 & 0.1 & 0.1 & 0.1 & 0.1 & 0.1 & 0.1 & 0.1 & 0.1 & 0.1 & 0.1 \\
\hline 2 & 111.7 & 0.35 & 19.67 & 0 & 0.1 & 0.1 & 0.1 & 0.1 & 0.1 & 0.1 & 0.1 & 0.1 & 0.1 & 0.1 \\
\hline 3 & 36.5 & 0.35 & 2.1 & 0 & 0.1 & 0.1 & 0.1 & 0.1 & 0.1 & 0.1 & 0.1 & 0.1 & 0.1 & 0.1 \\
\hline & 125.9 & 0.35 & 24.99 & 0 & 0.1 & 0.1 & 0.1 & 0.1 & 0.1 & 0.1 & 0.1 & 0.1 & 0.1 & 0.1 \\
\hline 5 & 65.8 & 0.35 & 6.83 & 0 & 0.1 & 0.1 & 0.1 & 0.1 & 0.1 & 0.1 & 0.1 & 0.1 & 0.1 & 0.1 \\
\hline 6 & 84.0 & 0.35 & 11.12 & 0 & 0.1 & 0.1 & 0.1 & 0.1 & 0.1 & 0.1 & 0.1 & 0.1 & 0.1 & 0.1 \\
\hline 7 & 90.5 & 0.35 & 12.91 & 0 & 0.1 & 0.1 & 0.1 & 0.1 & 0.1 & 0.1 & 0.1 & 0.1 & 0.1 & 0.1 \\
\hline 8 & 102.6 & 0.35 & 16.59 & 0 & 0.1 & 0.1 & 0.1 & 0.1 & 0.1 & 0.1 & 0.1 & 0.1 & 0.1 & 0.1 \\
\hline 9 & 43.6 & 0.35 & 3 & 0 & 0.1 & 0.1 & 0.1 & 0.1 & 0.1 & 0.1 & 0.1 & 0.1 & 0.1 & 0.1 \\
\hline 10 & 54.3 & 0.35 & 4.65 & 0 & 0.1 & 0.1 & 0.1 & 0.1 & 0.1 & 0.1 & 0.1 & 0.1 & 0.1 & 0.1 \\
\hline
\end{tabular}


Table 17. Parameters to distribute incoming solar radiation, temperature, and precipitation in the Andrews Creek model.

[The formatting convention used in this report is to present dimension names in Courier New font and parameter names in bold Courier New font. See tables 1 and 2 for descriptions of dimensions and parameters]

Dimension: one

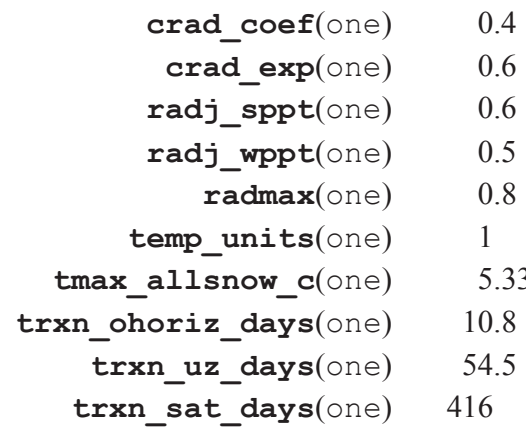

Dimension: ntemp

tsta_elev(ntemp) 3,150

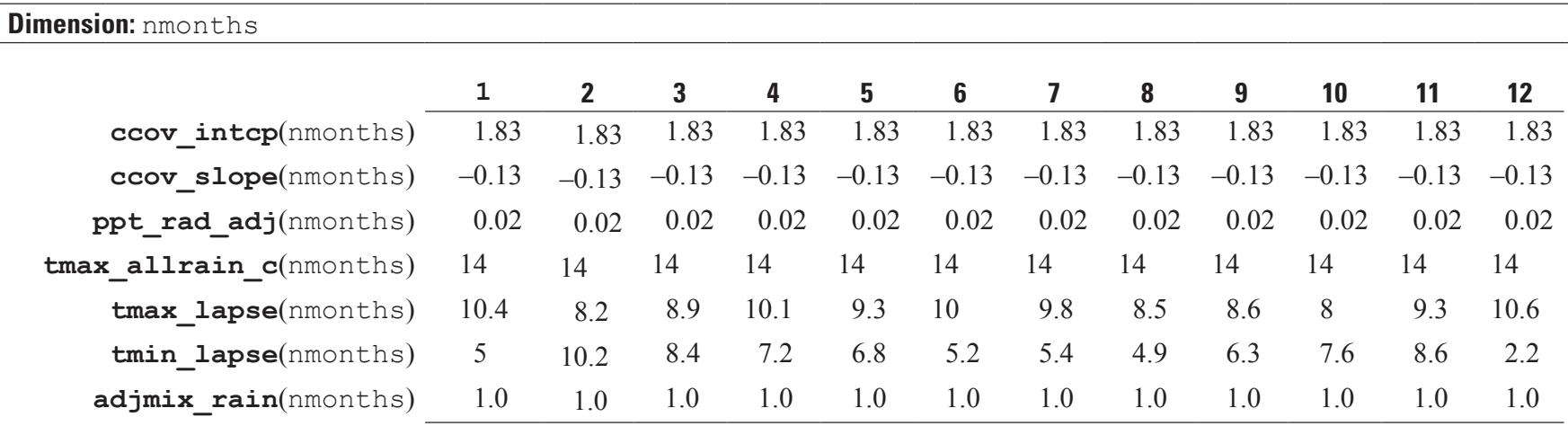

\begin{tabular}{|c|c|c|c|c|c|c|c|c|c|c|c|c|c|c|}
\hline & 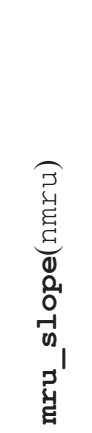 & 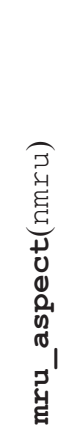 & 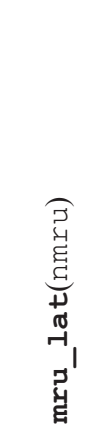 & 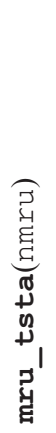 & 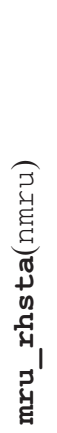 & 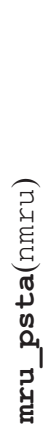 & 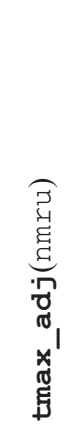 & 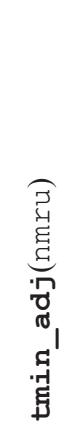 & 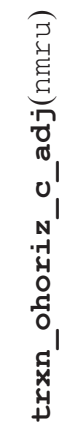 & 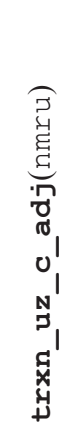 & 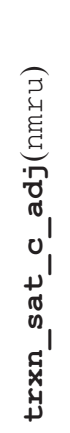 & 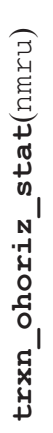 & 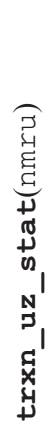 & 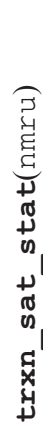 \\
\hline 1 & 1 & 135 & 40.292 & 1 & 1 & 1 & 2 & 1 & 7.49 & 1.16 & 8.0 & 1 & 1 & 1 \\
\hline 2 & 0.686 & 0 & 40.288 & 1 & 1 & 1 & -3 & -1.5 & 7.49 & 1.16 & 8.0 & 1 & 1 & 1 \\
\hline 3 & 1.022 & 135 & 40.291 & 1 & 1 & 1 & 2.2 & 1.1 & 7.49 & 1.16 & 8.0 & 1 & 1 & 1 \\
\hline 4 & 0.65 & 45 & 40.288 & 1 & 1 & 1 & -1.3 & -0.7 & 7.49 & 1.16 & 8.0 & 1 & 1 & 1 \\
\hline 5 & 0.717 & 155 & 40.290 & 1 & 1 & 1 & 2.5 & 1.2 & 7.49 & 1.16 & 8.0 & 1 & 1 & 1 \\
\hline 6 & 0.548 & 335 & 40.286 & 1 & 1 & 1 & -1.3 & -0.7 & 7.49 & 1.16 & 8.0 & 1 & 1 & 1 \\
\hline 7 & 0.445 & 75 & 40.287 & 1 & 1 & 1 & -0.9 & -0.5 & 7.49 & 1.16 & 8.0 & 1 & 1 & 1 \\
\hline 8 & 0.747 & 330 & 40.286 & 1 & 1 & 1 & -2.9 & -1.5 & 7.49 & 1.16 & 8.0 & 1 & 1 & 1 \\
\hline 9 & 1.025 & 67 & 40.284 & 1 & 1 & 1 & -2.1 & -1.1 & 7.49 & 1.16 & 8.0 & 1 & 1 & 1 \\
\hline 10 & 0.825 & 330 & 40.283 & 1 & 1 & 1 & -3.6 & -1.8 & 7.49 & 1.16 & 8.0 & 1 & 1 & 1 \\
\hline
\end{tabular}


Table 17. Parameters to distribute incoming solar radiation, temperature, and precipitation in the Andrews Creek model.-Continued

[The formatting convention used in this report is to present dimension names in Courier New font and parameter names in bold Courier New font. See tables 1 and 2 for descriptions of dimensions and parameters]

\begin{tabular}{|c|c|c|c|c|c|c|c|c|c|c|c|c|c|}
\hline \multicolumn{14}{|c|}{ Dimension: nmru,nmonths } \\
\hline \multicolumn{14}{|c|}{ rain_adj(nmru,nmonths) } \\
\hline \multirow{2}{*}{ 完 } & \multirow[b]{2}{*}{ 1-10 } & \multicolumn{12}{|c|}{ nmonths } \\
\hline & & 1.28 & 1.28 & 1.28 & 1.28 & 1.28 & 1.28 & 1.28 & 1.28 & 1.28 & 1.28 & 1.28 & 1.28 \\
\hline & & 1 & 2 & 3 & 4 & 5 & 6 & 7 & 8 & 9 & 10 & 11 & 12 \\
\hline & $1-4,7-10$ & 1.41 & 1.41 & 1.41 & 1.41 & 1.41 & 1.41 & 1.41 & 1.41 & 1.41 & 1.41 & 1.41 & 1.41 \\
\hline ઘ્વ & 5-6 & 2.21 & 2.21 & 2.21 & 2.21 & 2.21 & 2.21 & 2.21 & 2.21 & 2.21 & 2.21 & 2.21 & 2.21 \\
\hline
\end{tabular}

measurements of relative humidity were missing for 3 days or less, then values were filled with linear interpolation; longer periods of missing relative humidity were filled with day-ofyear averages computed for the period December 17, 1991, through November 7, 2013.

Discharge from Andrews Creek correlates better with precipitation measured at the Bear Lake SNOTEL site than with precipitation measured at Main Weather Station (Alisa Mast, U.S. Geological Survey, oral commun., 2013). The reason for the poor correlation of discharge with precipitation measured at Main Weather Station is that the station is in an open area with highly variable wind speeds and directions. By contrast, the Bear Lake site is in a forest clearing, which provides a natural windscreen that results in a more accurate measurement of snowfall amounts. Missing precipitation data at Bear Lake were filled with observations from Loch Vale or, if missing, from Niwot Ridge.

Precipitation measured at the Bear Lake SNOTEL site was adjusted for gage undercatch, orographic effect, and blownin snow. The two parameters rain_adj(nmru,nmonths) and snow_adj(nmru,nmonths) were calibrated so that simulated discharge best matched that of observed discharge. The amount of rain was multiplied by 1.28 , and the amount of snow was multiplied by 1.41 . These values are consistent with undercatch estimates by Fassnacht (2004) for windy areas in the Rocky Mountains and anecdotal accounts of additional snow being blown in from the western side of the Continental Divide. The two MRUs, 5 and 6, receive enough blown-in snow from the western side of the Continental Divide to sustain Andrews Glacier. Therefore, each of these MRUs was assigned a snow adjustment of 2.21, which is a calibrated value assigned to match observed variations of discharge, solute concentrations, and $\delta^{18} \mathrm{O}$ measured at the Andrews Creek gage.
Andrews Creek drains a pristine watershed at the Continental Divide; therefore, the watershed has no external inputs of water from irrigation or upgradient groundwater (tables 18 and 19).

Simulated evaporation accounts for approximately 30 percent of the adjusted precipitation deposited in the Andrews Creek watershed. The canopy interception plays no significant role because the basin is mostly above tree line; therefore, canopy density was set to only 5 percent for summer and 1 percent for winter for all MRUs. Parameters controlling estimates of PET and canopy interception (table 20) along with snowpack processes (table 21) were adjusted to match observed variations of discharge, $\delta^{18} \mathrm{O}$, and concentrations of chloride. The ratio of solar radiation on each MRU in winter to that in summer on each MRU was used as the ratio of MFMIN(nmru) to MFMAX(nmru), two of the major snowpack parameters (Mizukami and others, 2008). Fractionation of $\delta^{18} \mathrm{O}$ is simulated for maximum equilibrium and diffusive fractionation [iso_n $(i m r u=1-10)=0.5$; iso_theta $($ imru=1-10)=1.0] typical of fractionation over open water. Open water, springs, and seeps, occupy limited area in the Andrews Creek watershed, leading to a calibrated value for the areal adjustment factor equal to 5 percent of what would be expected for a lake with a size similar to that of the watershed [iso_fac $($ imru $=1-10)=0.05]$.

Because Hortonian overland flow is simulated for the Andrews Creek model [infex(one)=1], the amount of rain, throughfall, and snowmelt that exceeds the infiltration capacity is determined by using the vertical transmissivity $[\mathbf{x k} 0(n m r u)]$ and its coefficient of variation [ $\mathbf{x k} \mathbf{c v}(n m r u)]$ as listed in table 22. The Green-Ampt default values are used for the wetting front suction $[\mathrm{hf}(\mathrm{imru=1-10)=0.01]}$ and for the water content change across the front $[\operatorname{dth}($ imru $=1-10)=1.0]$. Internally, $\mathbf{h f}(\mathrm{nmru})$ and 
Table 18. Default parameters for irrigation; no irrigation is simulated in the Andrews Creek model (all irrigation dimensions are equal to zero), so these parameters are not included in the parameter file and are grayed out below.

[The formatting convention used in this report is to present dimension names in Courier New font and parameter names in bold Courier New font. See tables 1 and 2 for descriptions of dimensions and parameters]

\section{Dimension: nmru}

\begin{tabular}{|c|c|c|c|c|c|}
\hline & 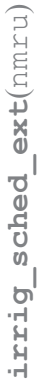 & 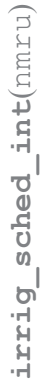 & 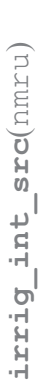 & 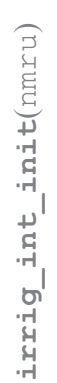 & 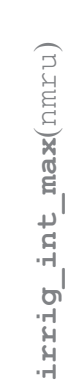 \\
\hline $1-10$ & 0 & 0 & 1 & 0.0 & 100.0 \\
\hline
\end{tabular}

Table 19. Default parameters for groundwater inputs; no inputs of upgradient groundwater are simulated in the Andrews Creek model. The dimension ngw ext equals zero, so the four groundwater parameters are not included in the parameter file and are grayed out below. The value of $11\left(10^{-11}\right)$ for gw_loss_k indicates no leakage into bedrock.

[The formatting convention used in this report is to present dimension names in Courier New font and parameter names in bold Courier New font. See tables 1 and 2 for descriptions of dimensions and parameters]

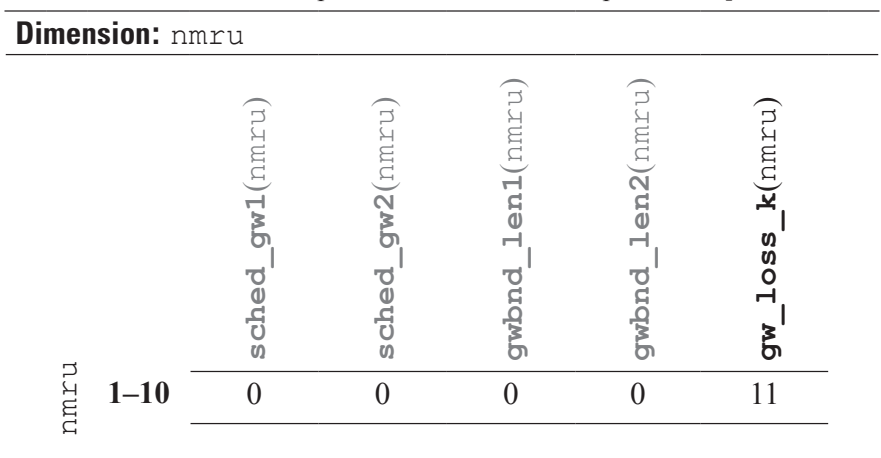

$\mathrm{dth}(\mathrm{nmru})$ are used only in a product, so if the product of the two is unchanged, there will be no change in the estimated Hortonian flow. After removing Hortonian overland flow, 27.8 percent of the available recharge bypasses the root zone [pmacro(imru $=1-10)=0.278$ ], and 80 percent of the recharge that bypasses the root zone is delivered directly to the saturated zone [pmacro_sat $($ imru $=1-10)=0.8$ ]. The depth of vertical preferential flow delivered from the surface directly to the saturated zone is tracked as qvpref(nmru). The calibrated values are reasonable for the talus-covered slopes of the Andrews Creek watershed. If pmacro_sat(nmru) was less than 1.0, then a fractionequal to 1.0-pmacro_sat(nmru) -would bypass the root zone and be delivered directly to the unsaturated zone storage [suz(nac,nmru)] of the TTI bin, if storage were available. No pipe flow [s_satpref_k $\mathbf{k m r u})=0$ ] is simulated in the Andrews Creek model.

Rain, throughfall, and snowmelt that does not run off as infiltration excess and does not bypass the root zone are available to replenish the root-zone deficit [srz(nac,nmru)] and the local saturation deficit [sd(nac,nmru)]. The local saturation deficit is a function of the saturated porosity [s_porosity(nmru)], the field capacity [s_theta_fc(nmru)], and the water already stored in the unsaturated zone above field capacity for a TTI bin [suz(nac,nmru)] (fig. 31). A good practice is to set the initial water content in the root zone [s_theta_0(nmru)] equal to the field capacity so that the soils respond immediately to precipitation events. Setting the initial moisture deficit [sbar_0(nmru)] to zero will result in a large initial pulse of hillslope discharge that will quickly slow as subsequent recharge and baseflow approach equilibrium.

By introducing a depth-to-bedrock parameter [s_rock_depth(nmru)] to the original TOPMODEL, a finite volume is assigned to the saturated zone, which enables computation of mixing ratios. During the course of the simulation, if the depth to the local water table [z_wt_local(nac,nmru)] exceeds the assigned depth to bedrock, a warning is printed and the user can adjust parameters to increase the depth to bedrock, increase recharge, or decrease losses from the saturated zone causing the water table to be closer to the surface. The depth-to-bedrock parameter is s_rock_depth(nmru). Recharge can be increased by increasing rain and snow adjustments [rain_adj(nmru,nmonths) and snow_adj(nmru,nmonths)] or reducing PET [pan_evap(nevap) or hamon_coef(nmonths)]. Losses from the saturated zone can be reduced by decreasing base flow [ $\mathbf{s z m}(\mathrm{nmru})$ and $\mathbf{T} \mathbf{0}(\mathrm{nmru})]$, pipe flow [s_satpref_k(nmru)], or losses into bedrock [gw_loss_k(nmru)]. Recall that when using the parabolic or linear transmissivity profiles, the parameters $\mathbf{s} \mathbf{z m}(\mathrm{nmru})$ and $\mathrm{TO}$ (nmru) are constrained by the slope of the transformed recession curve and the mean TTI. Irrigation withdrawels and additions can also have a large effect if poorly configured.

The maximum amount of soil water available for ET for a given TTI bin is referred to as the available water capacity, which is the field capacity [s_theta_fc(nmru)] minus the wilting point [s_theta_wp(nmru)] times the depth of the root zone [s_root_depth(nmru)]. Water in excess of field capacity in the unsaturated zone of each TTI bin will recharge the saturated zone at a rate of 1,129.5 hours 
Table 20. Evapotranspiration parameters for the Andrews Creek model.

[The formatting convention used in this report is to present dimension names in Courier New font and parameter names in bold Courier New font. See tables 1 and 2 for descriptions of dimensions and parameters]

\begin{tabular}{|c|c|c|c|c|c|c|c|c|c|c|c|c|}
\hline Dimension: nmont & & & & & & & & & & & & \\
\hline & 1 & 2 & 3 & 4 & 5 & 6 & 7 & 8 & 9 & 10 & 11 & 12 \\
\hline $\begin{array}{c}\text { epan_coef } \\
\text { (nmonths) }\end{array}$ & 1.0 & 1.0 & 1.0 & 1.0 & 1.0 & 1.0 & 1.0 & 1.0 & 1.0 & 1.0 & 1.0 & 1.0 \\
\hline $\begin{array}{c}\text { hamon_coef } \\
\text { (nmonths) }\end{array}$ & 0.015139 & 0.017308 & 0.017701 & 0.017118 & 0.014502 & 0.011317 & 0.010137 & 0.010811 & 0.013857 & 0.017759 & 0.020462 & 0.018364 \\
\hline
\end{tabular}

Dimension: nmru

\begin{tabular}{|c|c|c|c|c|c|c|c|c|c|c|c|c|}
\hline & 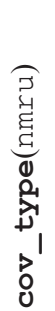 & 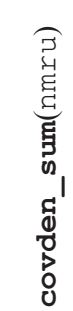 & 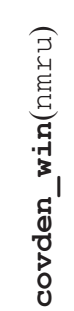 & 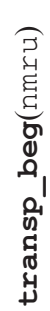 & 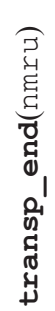 & 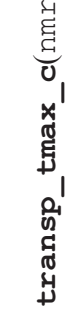 & 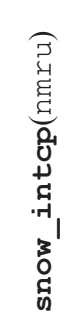 & 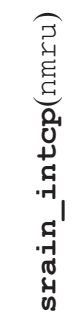 & 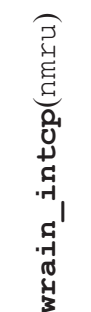 & 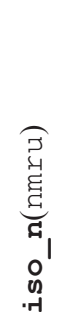 & 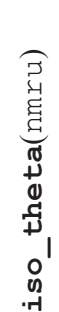 & 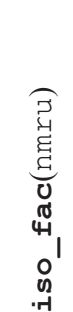 \\
\hline $1-10$ & 3 & 0.05 & 0.01 & 5 & 9 & 64.4 & 0.05 & 0.085 & 0.012 & 0.5 & 1 & 0.05 \\
\hline
\end{tabular}


Table 21. Snowpack parameters for the Andrews Creek model.

[The formatting convention used in this report is to present dimension names in Courier New font and parameter names in bold Courier New font. See tables 1 and 2 for descriptions of dimensions and parameters]

Dimension: one

ALAT(one) 40.29

Dimension: depval

\begin{tabular}{cccccccccccc} 
& $\mathbf{1}$ & $\mathbf{2}$ & $\mathbf{3}$ & $\mathbf{4}$ & $\mathbf{5}$ & $\mathbf{6}$ & $\mathbf{7}$ & $\mathbf{8}$ & $\mathbf{9}$ & $\mathbf{1 0}$ & $\mathbf{1 1}$ \\
\cline { 2 - 24 } & 0.05 & 0.24 & 0.4 & 0.52 & 0.65 & 0.75 & 0.82 & 0.88 & 0.93 & 0.99 & 1
\end{tabular}

\begin{tabular}{ccccccccccc}
$\mathbf{1 2}$ & $\mathbf{1 3}$ & $\mathbf{1 4}$ & $\mathbf{1 5}$ & $\mathbf{1 6}$ & $\mathbf{1 7}$ & $\mathbf{1 8}$ & $\mathbf{1 8}$ & $\mathbf{2 0}$ & $\mathbf{2 1}$ & $\mathbf{2 1}$ \\
\hline 0.02 & 0.047 & 0.114 & 0.212 & 0.318 & 0.416 & 0.498 & 0.56 & 0.592 & 0.604 & 0.604
\end{tabular}

\begin{tabular}{|c|c|c|c|c|c|c|c|c|c|c|c|c|c|c|c|}
\hline \multicolumn{16}{|c|}{ Dimension: nmru } \\
\hline \multirow{11}{*}{ 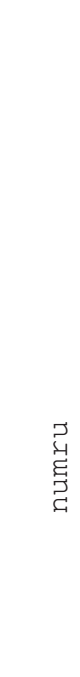 } & & 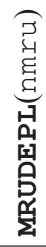 & 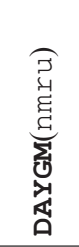 & 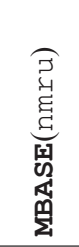 & 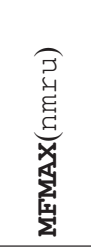 & 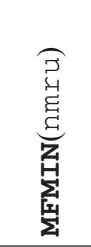 & 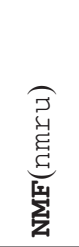 & 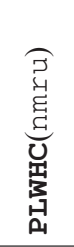 & 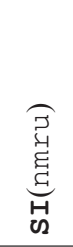 & 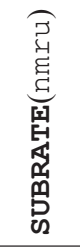 & 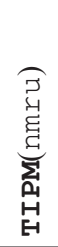 & 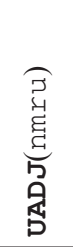 & 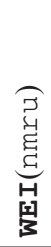 & 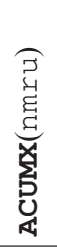 & 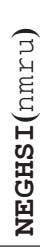 \\
\hline & 1 & 2 & 0.02 & 32.6 & 1.375 & 0.591 & 0.48 & 0.02 & 33.1 & 0.01 & 0.3 & 0.04 & 15 & 0 & 0 \\
\hline & 2 & 2 & 0.02 & 32.6 & 0.693 & 0.021 & 0.48 & 0.02 & 33.1 & 0.01 & 0.3 & 0.04 & 15 & 0 & 0 \\
\hline & 3 & 2 & 0.02 & 32.6 & 1.417 & 0.666 & 0.48 & 0.02 & 33.1 & 0.01 & 0.3 & 0.04 & 15 & 0 & 0 \\
\hline & 4 & 2 & 0.02 & 32.6 & 0.923 & 0.065 & 0.48 & 0.02 & 33.1 & 0.01 & 0.3 & 0.04 & 15 & 0 & 0 \\
\hline & 5 & 2 & 0.02 & 32.6 & 1.448 & 0.579 & 0.48 & 0.02 & 33.1 & 0.01 & 0.3 & 0.04 & 15 & 0 & 0 \\
\hline & 6 & 2 & 0.02 & 32.6 & 0.923 & 0.083 & 0.48 & 0.02 & 33.1 & 0.01 & 0.3 & 0.04 & 15 & 0 & 0 \\
\hline & 7 & 2 & 0.02 & 32.6 & 0.976 & 0.029 & 0.48 & 0.02 & 33.1 & 0.01 & 0.3 & 0.04 & 15 & 0 & 0 \\
\hline & 8 & 2 & 0.02 & 32.6 & 0.703 & 0.021 & 0.48 & 0.02 & 33.1 & 0.01 & 0.3 & 0.04 & 15 & 0 & 0 \\
\hline & 9 & 2 & 0.02 & 32.6 & 0.808 & 0.065 & 0.48 & 0.02 & 33.1 & 0.01 & 0.3 & 0.04 & 15 & 0 & 0 \\
\hline & 10 & 2 & 0.02 & 32.6 & 0.609 & 0.018 & 0.48 & 0.02 & 33.1 & 0.01 & 0.3 & 0.04 & 15 & 0 & 0 \\
\hline
\end{tabular}


Table 22. Hillslope parameters for the Andrews Creek model.

[The formatting convention used in this report is to present dimension names in Courier New font and parameter names in bold Courier New font. See tables 1 and 2 for descriptions of dimensions and parameters]

Dimension: one

infex(one)

Dimension: nmru

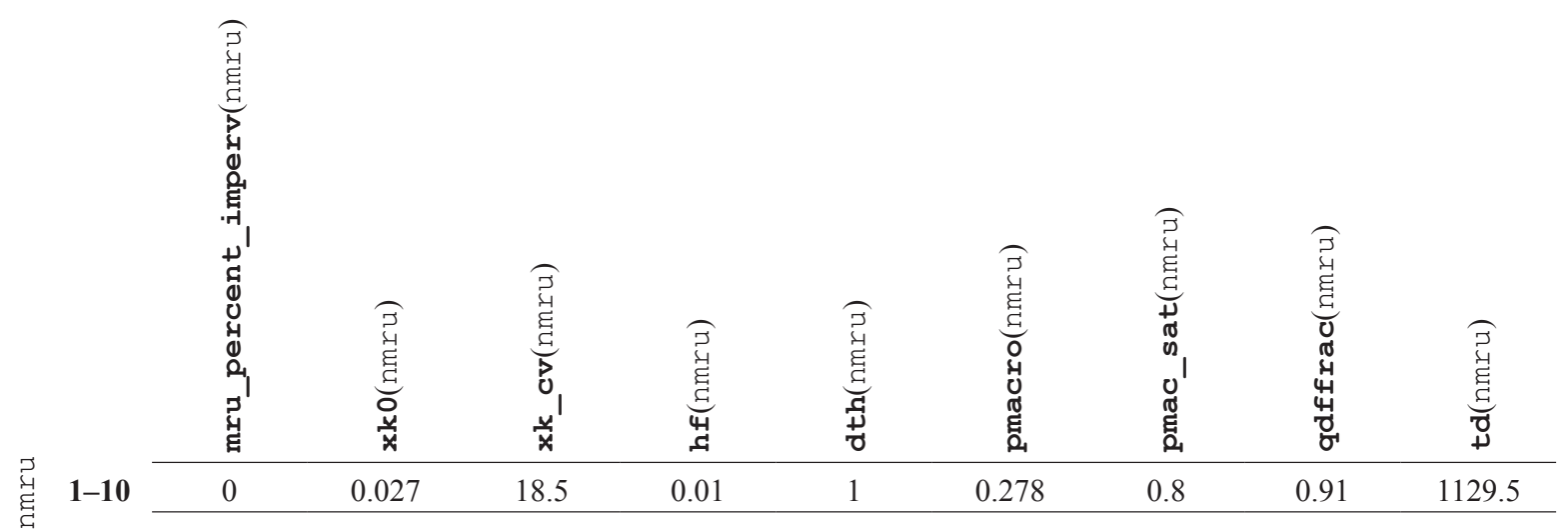

\begin{tabular}{|c|c|c|c|c|c|c|c|c|c|c|}
\hline & 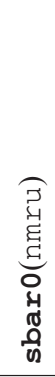 & 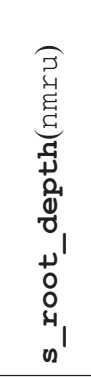 & 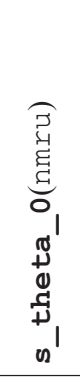 & 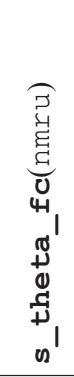 & 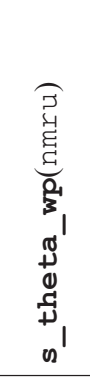 & 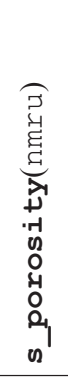 & 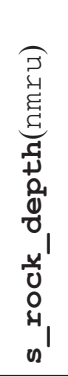 & 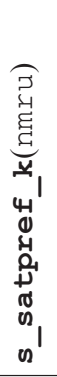 & 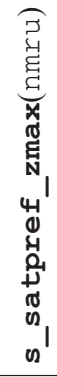 & 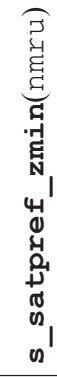 \\
\hline $1-10$ & 0 & 0.634 & 0.21 & 0.21 & 0.052 & 0.5 & 1.6 & 0 & -2 & -2 \\
\hline
\end{tabular}


per meter [td(nmru)] of local saturation deficit [sd(nac,nmru)]. On a given day, 91 percent of the total recharge [qdffrac(nmru) $=0.91]$ will be shunted from the unsaturated zone to a stream reservoir as direct flow [ $q d f(n m r u)]$, and the remaining 9 percent will be delivered to the saturated zone as matrix recharge [quz(nmru)].

Drainage from all hillslopes is assigned to a single channel (nchan=1) with an average channel velocity, $\operatorname{chv}(o n e)$, equal to $400 \mathrm{~m} / \mathrm{s}$ (table 23), a conservative estimate of the velocity measured during a continuous-injection tracer experiment in the fall of 1998 (Clow and others, 2003). Given this velocity, the runoff from all hillslopes mixes and reacts in a single stream reservoir (nhydro=1) before exiting past the Andrews Creek gage on the same day.

With all hydrologic parameters defined, simulations of the hydrology can be run in batch mode or by using the MMS Tool GUI. Hydrology alone is simulated when the switch to simulate geochemistry is turned off [chem_sim(one $)=0]$.

\section{Geochemical Simulations}

When geochemistry is simulated [chem_sim(one)=1], the files webmod.pqi and phreeqc.dat.lite are used to define all solutions and geochemical reactants for the watershed. Initial solutions and reactants are distributed throughout the watershed as specified in webmod.params, which also contains parameters to simulate the incongruent melting of snowpack. If the input solute concentrations vary with time as they do in the Andrews Creek model, initial solutions describing precipitation and other inputs will be superseded by solutions defined in webmod.chem.dat.

The Andrews Creek model tracks inputs, outputs, and change in storage for 11 solutes of interest (number of elements is nsolute=11). The nsolute indices, descriptive names, and dimension names as they appear in webmod.params (related to the second field in phreeq_lut) are the following: (1) calcium, $\mathrm{Ca}$; (2) magnesium, $\mathrm{Mg}$; (3) sodium, $\mathrm{Na}$; (4) potassium, K; (5) ammonia, Amm; (6) alkalinity, Alkalinity; (7) chloride, $\mathrm{Cl}$; (8) sulfate, $\mathrm{S}$; (9) nitrate, $\mathrm{N}(5)$; (10) silica, $\mathrm{Si}$; and (11) ${ }^{18} \mathrm{O}$, [18O] (table 24). The symbol S is used as the dimension name in webmod.params and in the species list in webmod.chem.dat to recognize all forms of sulfur, sulfate plus sulfide. $\mathrm{S}$ is used instead of S(6) - PHREEQC nomenclature for $\mathrm{SO}_{4}$ - to allow mole-balance accounting of all sources and sinks of sulfur, including reduced sulfur from pyrite. Stream discharge and the concentrations of the solutes in stream samples over time are the main calibration target for the Andrews Creek model. The nsolute solutes are a subset of the elements included in the chemistry calculations. In the Andrews Creek example, PHREEQC also tracks the masses (and redox states) of elements, such as iron and aluminum, that participate in the mineral dissolution and precipitation reactions, but because the elements are not included as solutes of interest, no WEBMOD variable is defined to track those elements.
Table 23. Channel routing parameters for the Andrews Creek model.

[The formatting convention used in this report is to present dimension names in Courier New font and parameter names in bold Courier New font. See tables 1 and 2 for descriptions of dimensions and parameters]

\begin{tabular}{|c|c|}
\hline Dimension: one & \\
\hline qobsta(one) & 1 \\
\hline chan loss rate(one) & 0.0 \\
\hline$-\operatorname{chv}(o n e)$ & 400.0 \\
\hline q0(one) & 0.06 \\
\hline Dimension: nmru & \\
\hline & 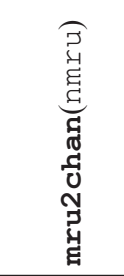 \\
\hline 壳 1-10 & 1 \\
\hline Dimension: nchan & \\
\hline & nchan \\
\hline & 1 \\
\hline ntopchan(nchan) & 2 \\
\hline
\end{tabular}
d(ntopchan, nchan)

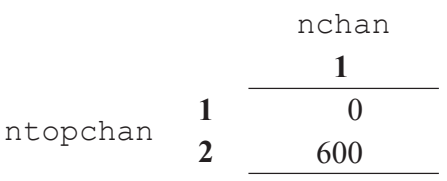

$\operatorname{ach}($ ntopchan, nchan)

\begin{tabular}{ccc} 
& & nchan \\
\cline { 2 - 2 } ntopchan & $\mathbf{1}$ & $\mathbf{1}$ \\
\cline { 3 - 3 } & $\mathbf{2}$ & 1 \\
\hline
\end{tabular}

The value of riparian_thresh(nmru) is used to assign each TTI bin to either riparian or upland. A value of riparian_thresh (imru $=1-10)=500$ (table 25) is less than the wet limit for the first TTI bin st (inac $=1$, imru $=1-10$ ) and greater than the wet limit for the second TTI bin, st (inac $=2$, imru $=1-10$ ), for all MRUs. Therefore, composite summary files of volumes, solutes, and entities in the unsaturated zone (if selected) will lump only the first TTI bin (5 percent of the area) into the riparian composite and the other 10 bins (95 percent of the area) into the uplands 
Table 24. Biogeochemical simulation switch and 11 solutes tracked in the Andrews Creek model.

[Solutes of interest and descriptors are listed in Dimensions section of the parameter file. The formatting convention used in this report is to present dimension names in Courier New font and parameter names in bold Courier New font. See tables 1 and 2 for descriptions of dimensions and parameters]

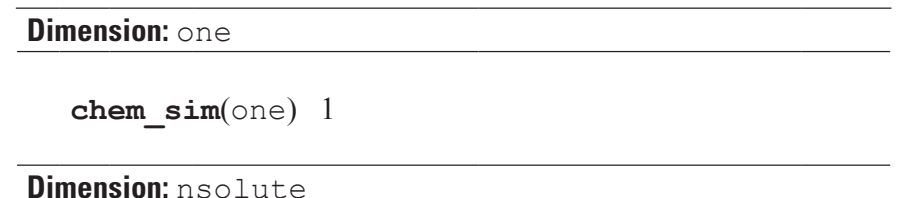
Dimension: nsolute

\begin{tabular}{|c|c|c|}
\hline & Species & Descriptor \\
\hline 1 & $\mathrm{Ca}$ & @Calcium \\
\hline 2 & $\mathrm{Mg}$ & @Magnesium \\
\hline 3 & $\mathrm{Na}$ & @Sodium \\
\hline 4 & $\mathrm{~K}$ & @Potassium \\
\hline 5 & Amm & @Ammonia \\
\hline 6 & Alkalinity & @,Alkalinity \\
\hline 7 & $\mathrm{Cl}$ & (a)Chloride \\
\hline 8 & $\mathrm{~S}$ & $@$ Sulfate \\
\hline 9 & $\mathrm{~N}(5)$ & @Nitrate \\
\hline 10 & $\mathrm{Si}$ & @.Silica \\
\hline 11 & [18O] & (a) Oxygen isotope \\
\hline
\end{tabular}

composite (s_mru002_uzrip and $s \_m r u 002 \_u z u p$, for example). The first TTI bin is always included in riparian composite variables, ch_uzrip_mgL_final(nmru,nsolute) for example, even if the riparian_thresh(nmru) exceeds the maximum value of st(nac,nmru).

\section{PHREEQC Input File (webmod.pqi) and Parameter File (webmod.params)}

Mast (1992) used the chemical composition of soils and bedrock combined with 4 years of chemical analyses of stream water to develop a weathering model consistent with the mole-balance method of Garrels and MacKenzie (1967). The mole-balance method provides a framework where the chemical composition of stream water can be accounted for by reactions among precipitation, atmospheric gases, and minerals in the soils and bedrock. With minor changes to Mast (1992), the predominant chemical reactions in the Andrews Creek watershed are assumed to be uptake or loss of the atmospheric gases $\mathrm{O}_{2}$ and $\mathrm{CO}_{2}$; weathering of primary granitic minerals — oligoclase, biotite, and chlorite; weathering of pyrite; dissolution or precipitation of calcite; formation of secondary minerals - kaolinite, goethite, gibbsite, and smectite-illite; and nitrification.
Table 25. Input dynamics, conversion factors, static reservoirs, and the transformed topographic index threshold that separates riparian from upland areas for the Andrews Creek model.

[The formatting convention used in this report is to present dimension names in Courier New font and parameter names in bold Courier New font. See tables 1 and 2 for descriptions of dimensions and parameters]

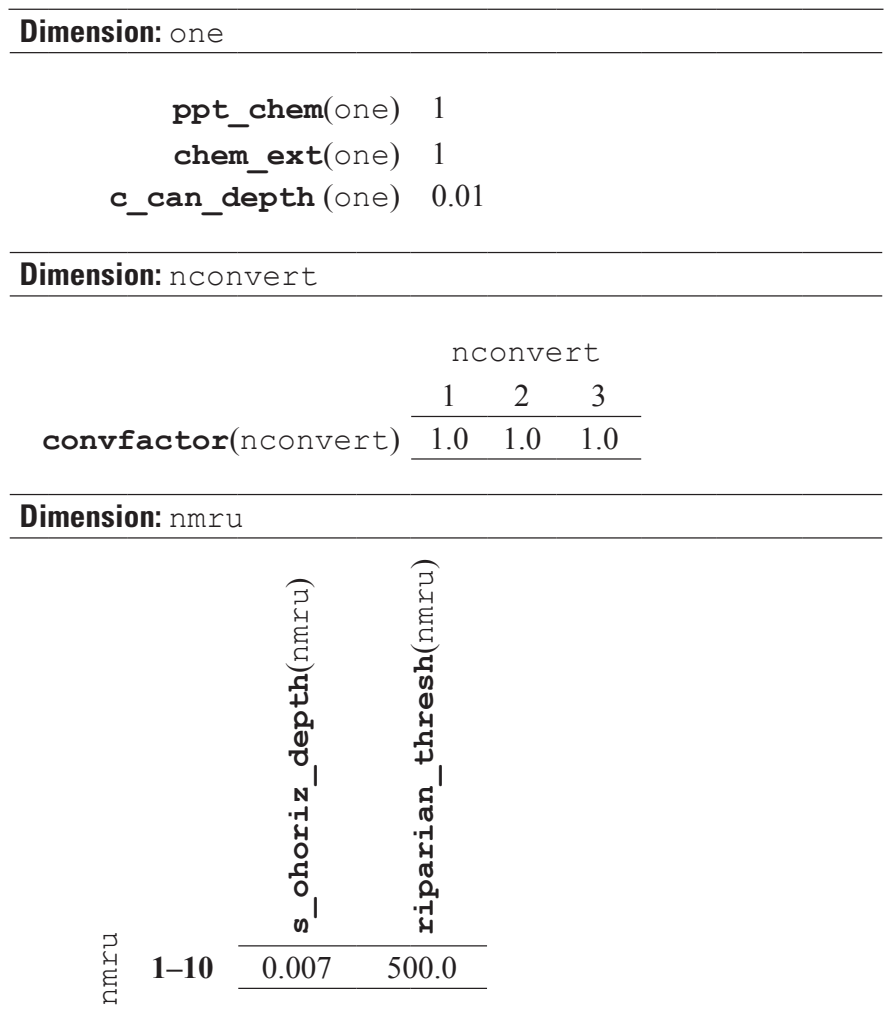

\section{Assignment of Initial Solutions to the Reservoirs}

The Andrews Creek model requires the initialization of solute chemistry for 182 reservoirs (precipitation, 180 hillslope, and 1 stream reservoir). During initialization, six solutions described in webmod.pqi are distributed to the 182 reservoirs as assigned in webmod.params with init_soln_ppt(one), init_solnset_mru(nmru), solnset_table(nmru_res,nhcs), and init_soln_hydro(nhydro). A seventh solution, consisting of pure water, is also initialized for simulating evaporation and fractionation of deuterium and oxygen-18. Indices for each MRU [init solnset mru(nmru)] point to one of the columns of solnset_table(nmru_res,nhcs) to define the initial solution composition for that hillslope. The parameter init_solnset_mru(imru=1-10) $=1$, so all MRUs point to the initial solution assignments in the first column of solnset_table(nmru_res,nhcs). Each row lists solution IDs (or a TTI rule) for the following individual hillslope reservoirs: (1) canopy, (2) snowpack, (3) impermeable 
surface (not used), (4) O-horizon, (5) unsaturated zone for first TTI bin, (6) TTI rule, (7) preferential flow through unsaturated zone, (8) saturated zone, and (9) preferential flow through the saturated zone. The columns are dimensioned at nhCS $=10$, which is an arbitrary number of unique hillslope chemistry sets. The table init_solnset mru is fixed at 9 rows (nmru_res) and 10 columns (nhcs), which allows for easy viewing of the parameter table with the Parameter Tool GUI. This layout is duplicated in table 26 .

Precipitation and stream water are sampled frequently so average properties can be used to initialize properties for these reservoirs. Other reservoirs have few to no sample results available, so final values for temperature, $\mathrm{pH}, \delta^{18} \mathrm{O}$, and solute concentrations simulated for the reservoirs in the single-MRU version of the Andrews Creek model were used as initial conditions. The seven solutions defined in the webmod.pqi file are numbered and described as follows:

SOLUTION 0.- This solution is assigned to precipitation [init_soln_ppt(one) $=0$ ] and is defined with the average concentrations measured in precipitation by the NADP at the site of Main Weather Station. Trace amounts $(0.001 \mathrm{mg} / \mathrm{L})$ of silica, aluminum, and iron are included although these analytes are not included in the suite of analytes measured by the NADP. Any element defined in a SOLUTION data block in the webmod.pqi file may be used as a solute of interest, so including silica, aluminum, and iron in SOLUTION 0 ensures that these elements can be used as solutes of interest. If one of the solutes of interest is an element that is not in a solution or any geochemical entity defined in the webmod.pqi file, then the run will terminate. A $\delta^{18} \mathrm{O}$ of -8.0 permil is close to the value of -8.5 permil for rain. SOLUTION 0 is used as part of the PHREEQC initialization but is not used again in the simulation because the parameter ppt_chem(one) $=1$ indicates that daily solute concentrations will be read from the webmod.chem.dat file.

SOLUTION 1.-This solution is pure water, which is removed from the canopy and soil by evaporation. No properties are assigned to this solution, so PHREEQC creates 1 kilogram of pure water at standard temperature and pressure. Internally, WEBMOD assigns daily isotopic signatures to SOLUTION 1 to simulate the appropriate amount of fractionation during evaporation or incongruent melting of the snowpack, or both. SOLUTION 1 must not be modified in webmod.pqi.

SOLUTION 2.-This solution is identical to SOLUTION 0 and is used to initialize the canopy and snowpack (and also the impervious surface reservoir that is not implemented) to a composition typical of average precipitation solnset_table (imru_res $=1-3$, ichemset $s=1$ ) $=2$ but with a $\delta^{18} \mathrm{O}$ of -15.6 permil, more typical of snow.

SOLUTION 3.- This solution was copied from the final O-horizon solution (September 30, 2012) for a single-MRU Andrews Creek model. SOLUTION 3 is assigned as the initial water composition for all O-horizon reservoirs for the 10-MRU Andrews Creek model solnset_table(imru_res $=4$, i chemset $s=1)=3$.

SOLUTION 30.-This solution was copied from the final solution (September 30, 2012) in the wettest TTI bin, st (inac $=1$, imru=1), for a single-MRU Andrews Creek model. Because the wettest bin is almost always simulated as saturated, with only evaporation and transpiration as outputs (no recharge to groundwater), solutes concentrate in this reservoir and are simulated to be several orders of magnitude higher than that simulated for the other 10 TTI bins. SOLUTION 30 is assigned as the initial water composition for all riparian TTI bins (in this case just the first TTI bin) following the TTI rule (table 13) of distinct positive integers for solnset_table(imru_res $=5$, i chemset $s=1)=30$ and solnset_table(imru_res $=6$, ichemset $s=1)=40$.

SOLUTION 40.- This solution is an average of the final solutions (September 30, 2012) in all but the wettest TTI bin, $\mathbf{s t}$ ( inac $=2-11$, imru=1), for a singleMRU Andrews Creek model. As discussed in the previous section, the upland TTI bins are flushed with rain and snowmelt, so the simulated concentrations are less than the concentrations simulated for the wettest TTI bin. SOLUTION 40 is assigned as the initial water composition for all upland riparian TTI bins [those with st(nac,nmru) value less than riparian_thresh(nmru)] and also all preferential flow reservoirs in the unsaturated zone, solnset_table(imru_res $=6,7$; i chemset $s=1)=40$.

SOLUTION 4.- This solution is an average of the final solution (September 30, 2012) in the saturated zone reservoir for a single-MRU Andrews Creek model. SOLUTION 4 is assigned as the initial water composition for all saturated zone reservoirs and all preferential flow reservoirs in the saturated zone, solnset_table(imru_res $=8,9$; i chemset $s=1)=4$.

Solution numbers used to initialize stream chemistry are listed individually for each of nhydro stream reservoirs. In this model, init_soln_hydro(ihydro $=1)=4$ is used to initialize the single stream reservoir with SOLUTION 4, which is also used to initialize the saturated zone reservoirs. This selection is reasonable at the end of the summer when base flow begins to dominate the hillslope contributions to the stream. The stream routing used in WEBMOD (Clark, 1945) involves only advection with no diffusion so that, after the first nhydro days (one day in this example), all water in stream reservoirs will have been replaced by hillslope discharge. Any PHREEQC entities other than SOLUTION, such as EQUILIBRIUM_PHASES definitions that specify reactions between each stream reservoir and atmospheric oxygen and carbon dioxide, remain associated with each stream reservoir. 
Table 26. Initial assignments of inputs, hillslope reservoirs, and stream segments in the Andrews Creek model to the entities defined in webmod.pqi.

[The formatting convention used in this report is to present file names in italic font, dimension names in Courier New font, and parameter names in bold Courier New font. See tables 1 and 2 for descriptions of dimensions and parameters. There is no irrigation or regional groundwater interaction simulated in the Andrews Creek model, so the following dimensions are set equal to zero: nchem_ext, nirrig_ext, nirrig_int, and ngw_ext. Parameters dependent on these dimensions are not included in the parameter file and are grayed out below]

Dimension: one

$$
\begin{array}{rr}
\text { init_soln_ppt(one) } & 0 \\
\text { atmos_eq_ph(one) } & 0
\end{array}
$$

Dimension: nchem ext

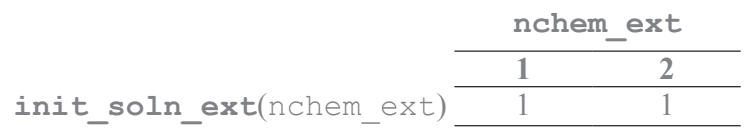

\begin{tabular}{|c|c|c|c|c|c|c|c|c|c|}
\hline & 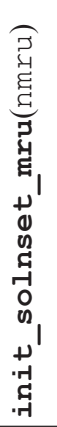 & 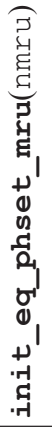 & 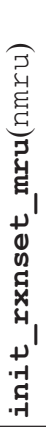 & 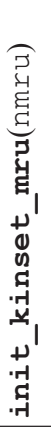 & 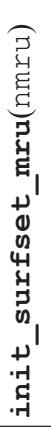 & 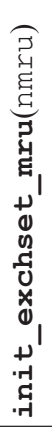 & 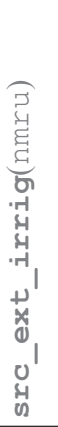 & 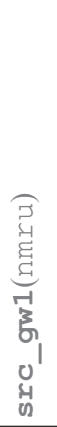 & 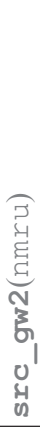 \\
\hline $1-10$ & 1 & 1 & 1 & 1 & 1 & 1 & 1 & 1 & 1 \\
\hline
\end{tabular}

Dimension: nmru

\begin{tabular}{|c|c|c|c|c|c|c|c|c|c|c|}
\hline \multirow[b]{3}{*}{1} & \multicolumn{10}{|c|}{ nhes } \\
\hline & 1 & 2 & 3 & 4 & 5 & 6 & 7 & 8 & 9 & 10 \\
\hline & 2 & 1 & 1 & 1 & 1 & 1 & 1 & 1 & 1 & 1 \\
\hline 2 & 2 & 1 & 1 & 1 & 1 & 1 & 1 & 1 & 1 & 1 \\
\hline 3 & 2 & 1 & 1 & 1 & 1 & 1 & 1 & 1 & 1 & 1 \\
\hline 4 & 3 & 1 & 1 & 1 & 1 & 1 & 1 & 1 & 1 & 1 \\
\hline 5 & 30 & 1 & 1 & 1 & 1 & 1 & 1 & 1 & 1 & 1 \\
\hline 6 & 40 & 1 & 1 & 1 & 1 & 1 & 1 & 1 & 1 & 1 \\
\hline 7 & 40 & 1 & 1 & 1 & 1 & 1 & 1 & 1 & 1 & 1 \\
\hline 8 & 4 & 1 & 1 & 1 & 1 & 1 & 1 & 1 & 1 & 1 \\
\hline 9 & 4 & 1 & 1 & 1 & 1 & 1 & 1 & 1 & 1 & 1 \\
\hline
\end{tabular}

Dimension: nmru res, nhcs: unique hillslope pointers to webmod.pqi file

eq_phset_table(nmru_res, nhcs)

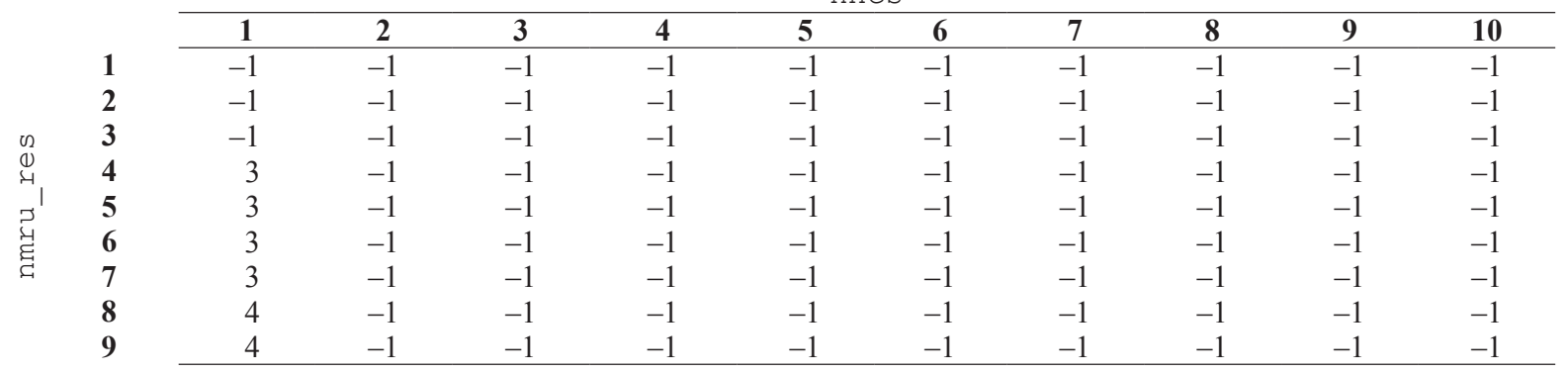


Table 26. Initial assignments of inputs, hillslope reservoirs, and stream segments in the Andrews Creek model to the entities defined in webmod.pqi.-Continued

[The formatting convention used in this report is to present file names in italic font, dimension names in Courier New font, and parameter names in bold Courier New font. See tables 1 and 2 for descriptions of dimensions and parameters. There is no irrigation or regional groundwater interaction simulated in the Andrews Creek model so the following dimensions are set equal to zero: nchem_ext, nirrig_ext, nirrig_int, and ngw_ext. Parameters dependent on these dimensions are not included in the parameter file and are grayed out below]

Dimension: nmru res, nhcs: unique hillslope pointers to webmod.pqifile-Continued

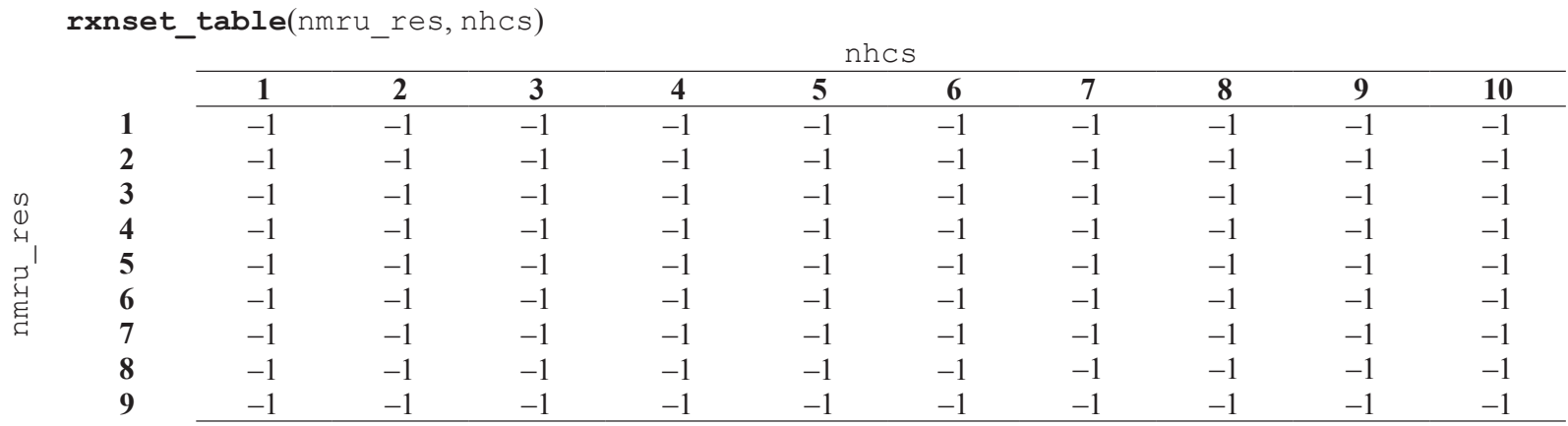

kinset_table(nmru_res, nhcs)

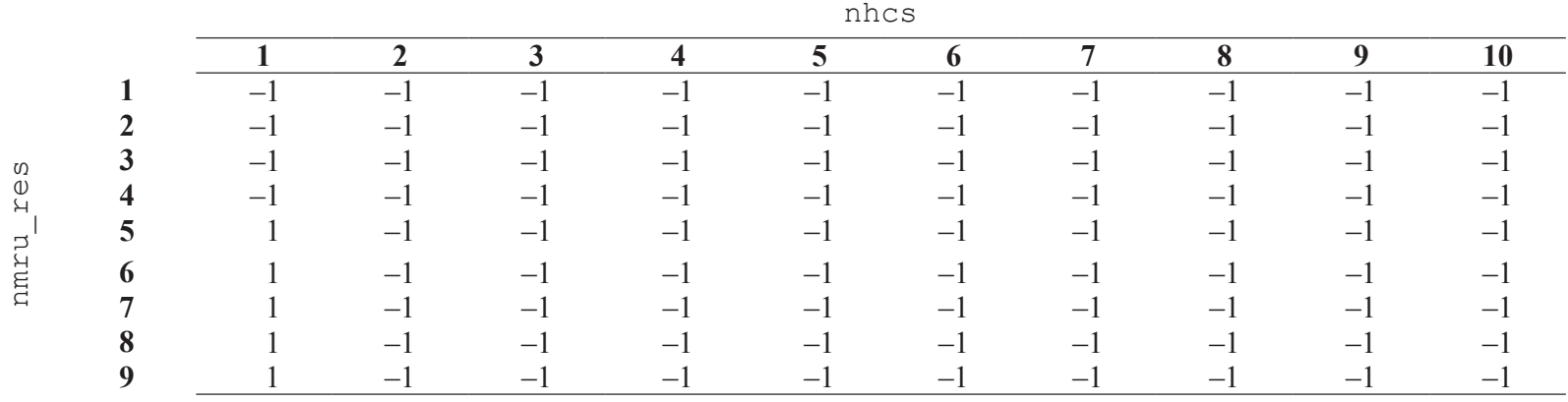

surfset_table(nmru_res, nhcs)

\begin{tabular}{|c|c|c|c|c|c|c|c|c|c|c|}
\hline & 1 & 2 & 3 & 4 & 5 & & & & & \\
\hline 1 & 1 & 1 & & & & & & & & \\
\hline 1 & -1 & -1 & -1 & -1 & -1 & -1 & -1 & -1 & -1 & -1 \\
\hline 2 & -1 & -1 & -1 & -1 & -1 & -1 & -1 & -1 & -1 & -1 \\
\hline 3 & -1 & -1 & -1 & -1 & -1 & -1 & -1 & -1 & -1 & -1 \\
\hline 4 & -1 & -1 & -1 & -1 & -1 & -1 & -1 & -1 & -1 & -1 \\
\hline 5 & -1 & -1 & -1 & -1 & -1 & -1 & -1 & -1 & -1 & -1 \\
\hline 6 & -1 & -1 & -1 & -1 & -1 & -1 & -1 & -1 & -1 & -1 \\
\hline 7 & -1 & -1 & -1 & -1 & -1 & -1 & -1 & -1 & -1 & -1 \\
\hline 8 & -1 & -1 & -1 & -1 & -1 & -1 & -1 & -1 & -1 & -1 \\
\hline 9 & -1 & -1 & -1 & -1 & -1 & -1 & -1 & -1 & -1 & -1 \\
\hline
\end{tabular}

Dimension: nhydro

\begin{tabular}{|c|c|c|c|c|c|c|}
\hline & 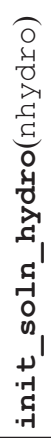 & 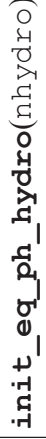 & 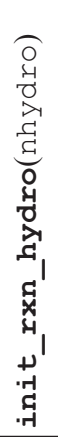 & 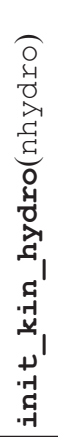 & 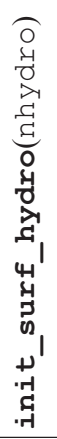 & 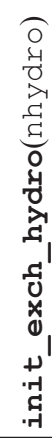 \\
\hline 1 & 3 & 2 & -1 & -1 & -1 & -1 \\
\hline
\end{tabular}


Assignment of Geochemical Reactions to the Reservoirs (webmod.pqi and phreeqc_web_lite.dat)

PHREEQC uses keyword data blocks to define different types of geochemical reactions. The Andrews Creek model uses two types of data blocks - the KINETICS and the EQUILIBRIUM PHASES data blocks. The KINETICS data block is used to define the weathering of primary granitic minerals, pyrite dissolution, calcite dissolution and precipitation, and nitrification. The EQUILIBRIUM_PHASES data block is used to define equilibrium exchange of gases between a reservoir and the atmosphere and to define equilibrium conditions for the formation of secondary minerals. To define additional information, three other data blocks are used. The RATES data block is used to define the rate expressions needed for KINETICS; the PHASES data block is used to define the reaction stoichiometry and equilibrium constants for mineral phases that are not defined in phreeqc_web_lite.dat; and the SOLUTION_SPECIES data block is used to simplify the nitrogen system to only two redox states, ammonium and nitrate. All of these keyword data blocks are defined in the webmod.pqi file.

\section{Kinetic Reactions}

The weathering of minerals identified by Mast (1992) in the bedrock under Andrews Creek-oligoclase, biotite, chlorite, pyrite, and calcite - are simulated as kinetic reactions. Weathering rates are commonly determined by measuring the increasing concentrations of solutes in waters of known composition containing known surface areas of pure minerals. It is impossible to know the surface area of each mineral disseminated throughout a watershed. Therefore, WEBMOD uses surface area per kilogram of water as a fitting parameter to match the simulated concentrations of solutes to the measured concentrations of solutes exiting the watershed. Some studies refer to surface area of minerals per bulk volume of soil or rock. The bulk volume of saturated soil or rock containing a kilogram of water is inversely proportional to porosity.

The composition of minerals found in the Loch Vale watershed are taken from the stoichiometric formulas given by Mast (1992), with slight simplifications to replace titanium with silica in some formulas and with adjustments to formulas to obtain charge-balanced chemical dissociation reactions (table 27). The rate expressions and corresponding parameters for the kinetic reactions of oligoclase, biotite, chlorite, and calcite were taken from Palandri and Kharaka (2004). The rate expression, normalized to the mass of water, is as follows:

$$
\begin{aligned}
\frac{d C}{d t} & =-S A\left[k_{\text {acid }} e^{-\frac{E_{\text {acid }}}{R}\left(\frac{1}{T}-\frac{1}{T_{r}}\right)} a_{H^{+}}^{n_{1}}\left(1-\Omega^{p_{1}}\right)^{q_{1}}\right. \\
& +k_{\text {neutral }} e^{-\frac{E_{\text {neutral }}}{R}\left(\frac{1}{T}-\frac{1}{T_{r}}\right)}\left(1-\Omega^{p_{2}}\right)^{q_{2}} \\
& \left.+k_{\text {base }} f^{n_{3}} e^{-\frac{E_{\text {base }}}{R}\left(\frac{1}{T}-\frac{1}{T_{r}}\right)}\left(1-\Omega^{p_{3}}\right)^{q_{3}}\right]
\end{aligned}
$$

where

$$
\begin{aligned}
& \frac{d C}{d t} \quad \text { is the rate, in moles per second per kilogram } \\
& \text { of water; } \\
& S A \text { is the surface area, in square meter per kilogram } \\
& \text { of water; }
\end{aligned}
$$

The Palandri and Kharaka expression allows for parameters to fit an acid, neutral, and base $\mathrm{pH}$ region and a carbonate mechanism for calcite. Rate adjustments as a function of temperature are included through the factor that includes the activation energy (Palandri and Kharaka, 2004). Pyrite weathering is particularly sensitive to amount of dissolved oxygen in the solution (Williamson and Rimstidt, 1994). Therefore, the rate expression used for pyrite was that of Williamson and Rimstidt modified from Webb and others (2011):

where

$$
\frac{d C}{d t_{2^{\circ} \mathrm{C}}}=10^{-9.14} \cdot \frac{S A a_{D O}^{0.5}}{a_{H^{+}}^{0.11}}
$$

$$
\frac{d C}{d t_{2^{\circ} \mathrm{C}}} \quad \begin{gathered}
\text { is the rate, in moles per second per kilogram } \\
\text { of water, at } 2{ }^{\circ} \mathrm{C} ;
\end{gathered}
$$


Table 27. Minerals, weathering reactions, equilibrium constants, enthalpies of reaction, and surface areas listed in phreeqc_web_lite.dat and webmod.pqi to simulate weathering and precipitation of secondary minerals in the Andrews Creek model.

[The stoichiometry of the minerals shown on the left side of the reaction varies from those shown in table 6.4 of Mast (1992) in the following ways: Silica was substituted for titanium in the composition of biotite, and the coefficient for calcium in smectite-illite was changed from 10.0 to 0.225 to achieve charge balance. The surface areas are calibrated values. log, logarithm base $10 ; \mathrm{K}_{25}$, equilibrium constant at 25 degrees Celsius; $\Delta H_{R}^{o}(\mathrm{kcal} / \mathrm{mol})$, enthalpy of reaction in kilocalories per mole; SA, surface area of mineral, in square meters per kilogram of water]

\begin{tabular}{|c|c|c|c|c|}
\hline Mineral & Reaction & $\log \left(K_{25}\right)$ & $\triangle H_{R}^{0}(\mathrm{kcal} / \mathrm{mol})$ & $\log S A$ \\
\hline Oligoclase & $\mathrm{Ca}_{0.27} \mathrm{Na}_{0.73} \mathrm{Al}_{1.27} \mathrm{Si}_{2.73} \mathrm{O}_{8}+8 \mathrm{H}_{2} \mathrm{O}=0.27 \mathrm{Ca}^{+2}+0.73 \mathrm{Na}^{+}+1.27 \mathrm{Al}(\mathrm{OH})_{4}^{-}+2.73 \mathrm{H}_{4} \mathrm{SiO}_{4}$ & -19.0 & & 0.603 \\
\hline Biotite & $\begin{array}{l}\left(\mathrm{K}_{0.98} \mathrm{Mg}_{1.00} \mathrm{Fe}_{1.33} \mathrm{Si}_{0.18} \mathrm{Al}_{0.33}\right)\left(\mathrm{Al}_{1.35} \mathrm{Si}_{2.65}\right) \mathrm{O}_{10}(\mathrm{OH})_{2}+10.68 \mathrm{H}_{3} \mathrm{O}^{+}=0.98 \mathrm{~K}^{+}+\mathrm{Mg}^{+2} \\
\quad+1.33 \mathrm{Fe}^{+2}+1.68 \mathrm{Al}(\mathrm{OH})_{4}^{-}+0.68 \mathrm{H}_{2} \mathrm{O}+10.68 \mathrm{H}_{2} \mathrm{O}\end{array}$ & 20.0 & & -0.1583 \\
\hline Chlorite & $\begin{array}{l}\left(\mathrm{Mg}_{1.81} \mathrm{Fe}_{2.72} \mathrm{Al}_{1.39}\right)\left(\mathrm{Al}_{1.23} \mathrm{Si}_{2.77}\right) \mathrm{O}_{10}(\mathrm{OH})_{8}+16.92 \mathrm{H}_{3} \mathrm{O}^{+}=1.81 \mathrm{Mg}^{+2}+2.72 \mathrm{Fe}^{+2} \\
\quad+1.39 \mathrm{Al}^{+3}+1.23 \mathrm{Al}^{+3}+2.77 \mathrm{H}_{4} \mathrm{SiO}_{4}+6.92 \mathrm{H}_{2} \mathrm{O}+16.92 \mathrm{H}_{2} \mathrm{O}\end{array}$ & 68.38 & -151.494 & 0.622 \\
\hline Pyrite $^{1}$ & $\mathrm{FeS}_{2}+2 \mathrm{H}_{3} \mathrm{O}^{+}+2 \mathrm{e}^{-}=\mathrm{Fe}^{+2}+2 \mathrm{HS}^{-}+2 \mathrm{H}_{2} \mathrm{O}$ & -18.479 & 11.3 & -2.33 \\
\hline Smectite-illite & $\begin{array}{l}\left(\mathrm{K}_{0.32} \mathrm{Ca}_{0.225}\right)\left(\mathrm{Fe}_{0.25} \mathrm{Mg}_{0.39} \mathrm{Al}_{1.47}\right)\left(\mathrm{Al}_{0.46} \mathrm{Si}_{3.54}\right) \mathrm{O}_{10}(\mathrm{OH})_{2}+9.88 \mathrm{H}_{2} \mathrm{O}+0.12 \mathrm{H}_{3} \mathrm{O}^{+}=0.32 \mathrm{~K}^{+} \\
\quad+0.225 \mathrm{Ca}^{+2}+0.25 \mathrm{Fe}^{+2}+0.39 \mathrm{Mg}^{+2}+1.47 \mathrm{Al}(\mathrm{OH})_{4}^{-}+0.46 \mathrm{Al}(\mathrm{OH})_{4}^{-}+3.54 \mathrm{HSiO}_{4} \\
\quad+0.12 \mathrm{H}_{2} \mathrm{O}\end{array}$ & -40.276 & 54.684 & \\
\hline Kaolinite $^{1}$ & $\mathrm{Al}_{2} \mathrm{Si}_{2} \mathrm{O}_{5}(\mathrm{OH})_{4}+6 \mathrm{H}_{3} \mathrm{O}^{+}=7 \mathrm{H}_{2} \mathrm{O}+2 \mathrm{H}_{4} \mathrm{SiO}_{4}+2 \mathrm{Al}^{+3}$ & 7.435 & -35.300 & \\
\hline
\end{tabular}

${ }^{1}$ Standard reactions included in phreeqc_web_lite.dat. All other reactions were derived from mineral compositions observed in the granite and gneiss bedrock of the Loch Vale watershed (Mast, 1992).

$10^{-9.14}$ is the rate constant, in moles per square meter of pyrite per second at $2^{\circ} \mathrm{C}$ (the exponent of -9.14 was computed by using the Arrhenius equation [Arrhenius, 1889] with an activation energy for pyrite of 65 kilojoules per mole to convert the rate constant of -8.19 at $25^{\circ} \mathrm{C}$ reported by Williamson and Rimstidt, 1994, to a rate constant at $2{ }^{\circ} \mathrm{C}$ - an average soil temperature at Handcart Gulch and Loch Vale];

$S A$ is the surface area, in square meters per kilogram of water;

$a_{D O}^{0.5} \quad$ is the activity of dissolved oxygen raised to the power 0.5 , unitless; and

$a_{H^{+}}^{0.11} \quad$ is the activity of hydrogen raised to the power 0.11 , unitless.

Using transition-state theory (Eyring, 1935), the computed kinetic reaction rate is further reduced as pyrite approaches saturation:

$$
\frac{d C}{d t}=\frac{d C}{d t_{2^{\circ} C}} \cdot\left(1-\Omega^{p}\right)
$$

where

$$
\begin{gathered}
\frac{d C}{d t} \quad \begin{array}{r}
\text { is the rate adjusted for pyrite saturation, in moles } \\
\text { per second, at } 2{ }^{\circ} \mathrm{C} ;
\end{array} \\
\frac{d C}{d t_{2^{\circ} \mathrm{C}}} \quad \text { is the rate, in moles per second, at } 2{ }^{\circ} \mathrm{C} \text {; }
\end{gathered}
$$

$\Omega \quad$ is the saturation ratio $I A P / K$, where $I A P$ is the ion activity product and $K$ is the equilibrium constant for the reaction (varies from 0.0 for no dissolved ions to 1.0 when the solution is in equilibrium with pyrite), unitless; and

$p \quad$ is the empirical exponent to account for other factors, set to 1 in this case.

For the kinetic reactants oligoclase, biotite, chlorite, calcite, and pyrite, the surface area of each reactant, in square meter per kilogram of water, was used as an adjustable parameter in WEBMOD. The surface areas were adjusted by trial and error and parameter optimization routines to calibrate the model and attain reasonable matches between modeled and observed discharge, $\mathrm{pH}$, temperature, and concentrations of major ions and oxygen-18 measured in stream water at the Andrews Creek streamgage location.

Rainwater and snowfall contain both ammonium and nitrate scavenged from the atmosphere, where they coexist in vapor phases and aerosols (Adams and others, 1999; Lehmann and others, 2005). Both species are measured in similar concentrations in rain and snow, even though nitrate is the more stable species in oxygenated waters at the earth's surface. Indeed, nitrate is the dominant form of nitrogen in streamflow exiting Andrews Creek. However, if concentrations of nitrate, $\mathrm{N}(5)$, and ammonium, $\mathrm{N}(-3)$, are assigned to the same PHREEQC solution with sufficient oxygen present, all the ammonium would be instantly converted to nitrate during the equilibrium calculations. To introduce the kinetics that are 
known to exist, concentrations of ammonium are identified as the nitrogen-bearing species "Amm" in phreeqc_web_lite.dat, phreeq_lut, webmod.pqi, webmod.chem.dat and as one of the nsolute dimension names in webmod.params. Both Amm and $\mathrm{N}(5)$ in snowfall remain unchanged until the snowpack melts. Incongruent melting may result in higher concentrations of both ions in meltwater than in the remaining snowpack. Although the absolute concentrations are higher, the ratio of the concentration of nitrate to the concentration of ammonium in the meltwater remains the same as that in the remaining snowpack. Once the rain or meltwater enters the soils, ammonium converts to nitrate as described by a kinetic reaction. The rate of the conversion is described by the following equation included as the BASIC code "Nitrification" in the RATES block of the webmod.pqi file:

$$
R_{A m m}=10^{p(1)}[\mathrm{Amm}]\left(\frac{\left[O_{2}\right]}{\left[O_{2}\right]+10^{-5}}\right),
$$

where

$R_{A m m} \quad$ is the rate that Amm is removed and $\mathrm{NH}_{3}$ is added to solution, in moles per second (the $\mathrm{NH}_{3}$ added to solution appears in solution as the aqueous species nitrate as dissolved oxygen is consumed);

$p(1) \quad$ is the exponent, in $\log$ (one per second), indicated as "-parms -3.25 " in the Nitrification block of KINETICS 1 in the webmod.pqi file;

$[\mathrm{Amm}]$ is the concentration of ammonium, in moles per liter; and

$\left[\mathrm{O}_{2}\right]$ is the concentration of dissolved oxygen.

The exponent $p(1)$ was used as a fitting parameter for nitrification in the streams and unsaturated zone during the calibration of the Andrews Creek model.

The KINETICS 1 data block in the webmod.pqi file defines six kinetic reactions - oligoclase, biotite, chlorite, calcite, pyrite, and nitrification. The parameters that are assigned to each MRU by the values of init_kinset_mru(nmru) point to a column of the table kinset_table (nmru_res, nhcs) that is to be used to assign KINETICS definitions to hillslope reservoirs. By setting init_kinset_mru(imru=1-10)=1, the values from column 1 of kinset_table are used to initialize the kinetic reactions for all $1 \overline{0}$ MRUs of the Andrews Creek model. This column assigns the KINETICS 1 data block to the O-horizon, the unsaturated-zone, and saturated-zone reservoirs of each MRU kinset_table(imru_res=4-9, ihcs $=1)=1$; kinetic reactions were not assigned to canopy and snowpack (column values of -1 ). The stream reservoir also was defined to have no kinetic reactants [init_kin_hydro $($ ihydro $=1)=-1$ ].

EQUILIBRIUM_PHASES define minerals and gases that react to maintain the water composition at a specified saturation index $(\mathrm{SI}=\log I A P / K$, where $I A P$ is the ion activity product and $K$ is the equilibrium constant) for a mineral or at a specified log partial pressure for a gas. For the Andrews Creek model, equilibrium phases are used to maintain reservoirs in equilibrium with secondary minerals kaolinite, goethite, gibbsite, and smectite-illite and the atmosphere. The atmosphere is approximately 78 percent nitrogen, 21 percent oxygen, and 0.04 percent carbon dioxide (log partial pressures in atmospheres, at sea level, are equal to $-0.11,-0.68$, and -3.40 , respectively).

The four EQUILIBRIUM_PHASES data blocks defined in the webmod.pqi file are numbered and described as follows:

EQUILIBRIUM_PHASES 0.- - This data block contains only $\mathrm{CO}_{2}$ and $\mathrm{O}_{2}$ gas and is used to allow for gas exchange between precipitation and the atmosphere [atmos_eq_ph $(o n e)=0]$. Log partial pressures at an altitude of $3,500 \mathrm{~m}$ are calculated to be -0.866 for oxygen and -3.59 for carbon dioxide. All rain and snow are equilibrated with these partial pressures, and in the absence of assigning equilibrium phases to canopy and snowpack or eq_phset_table $\left(i m r u \_r e s=1,2 ;\right.$ i hCs $\left.=1\right)=1$, all surface deposition and vertical preferential flow will also be in equilibrium with the atmosphere.

EQUILIBRIUM_PHASES 3.-This data block contains secondary minerals, $\mathrm{CO}_{2}$ gas, and $\mathrm{O}_{2}$ gas to represent equilibrium reactions in the $\mathrm{O}$-horizon, unsaturated zone, and preferential flow through the unsaturated zone for all MRUs, init_eq_phset_mru(imru=1-10)=1 and eq_phset_table(imru_res $=4-7$, ihcs $=1)=3$. The secondary minerals kaolinite, goethite, gibbsite, and smectite-illite and are required to precipitate to equilibrium $(\mathrm{SI}=0)$. In addition, $\mathrm{CO}_{2}$ gas is set to a log partial pressure $(-2.0)$ that is greater than the atmospheric partial pressure to account for respiration in the unsaturated zone; conversely, $\mathrm{O}_{2}$ gas is set to a log partial pressure (log partial pressure $=-1.0$, about 75 percent of saturation) that is less than the atmospheric log partial pressure to account for consumption of oxygen by biological processes and pyrite oxidation (Angert and others, 2015).

EQUILIBRIUM_PHASES 4.-This data block is used to represent equilibrium reactions in the saturated zone [eq_phset_table(imru_res $=8,9$; i hcs $=1)=4$ ]. The data block is identical to the EQUILIBRIUM_PHASES 3 data block with the key exception that no gas equilibria are assigned to the saturated zone. Therefore, no gas exchange from the gas phase of the unsaturated zone to the saturated zone through the capillary zone is simulated, such that, other than the dissolved gases in the initial condition, all dissolved gases are advected to the saturated zone as recharge from the surface [qvpref(nmru)] and the unsaturated zone [quz(nmru)].

EQUILIBRIUM_PHASES 2.-This data block contains only $\mathrm{CO}_{2}$ and $\mathrm{O}_{2}$ gas and is used to allow for gas exchange at the air-water interface of the stream. Partial degassing of carbon dioxide was required during calibration to match 
observed variations in stream $\mathrm{pH}$. The single stream segment of Andrews Creek was defined to have EQUILIBRIUM PHASES 2 by setting init_eq_ph_hydro $($ ihydro $=1)=2$.

\section{Incongruent Melting of Snowpack}

The model for Andrews Creek simulates fractionation of solutes and $\delta^{18} \mathrm{O}$ as the snowpack melts to water. To simulate the ionic pulse observed in the melting snowpack, the concentrations of solutes in the snowmelt are specified to be about 100 times the concentrations of the residual snowpack [snow_ion_factor(nmru) $=116.6$ ] as listed in table 28 . To simulate the fractionation of $\delta^{18} \mathrm{O}$, the snowmelt is specified to be 1.27 permil lighter than the snowpack [snowmelt_180_depl $(\mathrm{nmru})=-1.27]$. Fractionation of ions and isotopes is limited to days when the volume of melting water is less than 90 percent of the initial snowpack; when the melt fraction exceeds 90 percent, then the snowmelt is assigned the same composition as the remaining snowpack.

\section{Solute Concentration File (webmod.chem.dat)}

In the Andrews Creek model, the chemistry of the precipitation varies with time [ppt_chem(one)=1], as listed in table 25, and solution compositions are assigned in the webmod.chem.dat file. Initial solution compositions read from the webmod.pqi file that define constant compositions for precipitation [init_soln_ppt $(o n e)=0]$ and external sources [init_soln_ext(nchem ext) $=1$ ], as listed in table 26, are irrelevant. These initial input solution compositions are required to initialize the model; however, the initial compositions are overwritten with the daily-varying compositions at the beginning of each day, including the first day. The daily values in

Table 28. Parameters for incongruent melting of solutes and isotopes from snowpack for the Andrews Creek model.

[The formatting convention used in this report is to present dimension names in Courier New font and parameter names in bold Courier New font. See tables 1 and 2 for descriptions of dimensions and parameters]

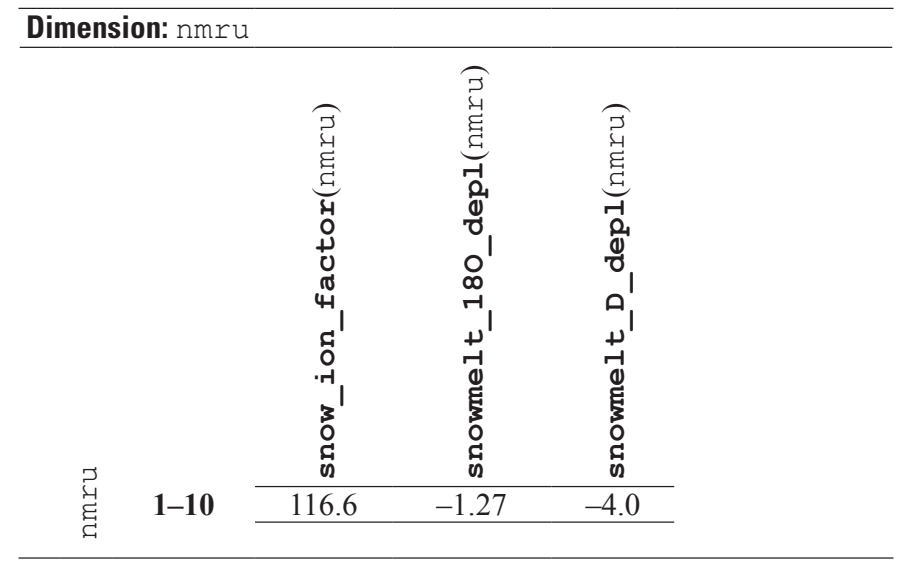

webmod.chem.dat also include the results from waters sampled from Andrews Creek. On days with no sample results (most days), concentrations were set to zero and $\mathrm{pH}$ was assigned a value of 7 .

Personnel of the NADP have made biweekly trips to site CO98 (Loch Vale) to sample precipitation and dry deposition since August 1983 (National Atmospheric Deposition Program, 2013). The deposition is collected in 5-gallon buckets that are either covered (dry deposition) or uncovered (wet deposition) during precipitation events. The concentrations measured in the wet-deposition bucket are included in the webmod.chem.dat file for each day of each sampled period, which defines an average concentration for all precipitation events in each sampled period. The CO98 site is adjacent to Main Weather Station just upstream from the Loch, and a co-located backup NADP site has been operated since September 2009 (fig. 36). Quality assurance of NADP data is rigorous, and samples or analyses may be rejected because of contamination or failure of field or laboratory personnel to adhere to strict protocols. In addition, many weeks have no results for major ions because little to no precipitation was collected during dry periods. Analysis and interpretation of the dry deposition has been problematic; therefore, only the water and solutes measured as wet deposition (rain and snow) are considered as inputs for the model. (If the user would like to simulate the deposition of additional mass of solutes due to dry deposition, then the concentrations of wet deposition would need to be increased.) Of the 1,402 samples collected during the 27 years, results were not available for 412 samples. Monthly mean $\mathrm{pH}$ values and concentrations of eight major ions $\left(\mathrm{Ca}, \mathrm{Mg}, \mathrm{Na}, \mathrm{K}, \mathrm{NH}_{4}\right.$, $\mathrm{Cl}, \mathrm{SO}_{4}$, and $\mathrm{NO}_{3}$ ) were used to fill in missing periods; alkalinity and silica are measured only in trace amounts in precipitation, so inputs for these species were assigned a nominal concentration of $0.001 \mathrm{mg} / \mathrm{L}$. Each element of interest must appear in the webmod.pqi file, a solution, an equilibrium phase, or another reaction entity to register as part of the PHREEQC model that simulates the geochemistry in WEBMOD.

Some samples from the stream and the snowpack were analyzed for $\delta^{18} \mathrm{O}$. Because the NADP program does not routinely measure stable isotopes, a series of $\delta^{18} \mathrm{O}$ values for input precipitation was synthesized and included in the webmod.chem.dat file. Stable isotopes of hydrogen and oxygen in the Loch Vale watershed were measured for 1,918 samples of precipitation, snowpack, snowmelt, soils, groundwater, springs, lakes, and streams collected from May 1992 through January 2000 (figs. 37, 38; Carol Kendall, U.S. Geological Survey, written commun., 2013). As expected, $\delta^{18} \mathrm{O}$ of the snowpack ( -20.5 permil, $\left.n=236, \sigma=2.0\right)$ was isotopically lighter than for bulk precipitation collected from May through September during the period of record ( -8.6 permil, $n=69, \sigma=4.5)$. Stream samples were intermediate between snow and rain, with an average $\delta^{18} \mathrm{O}=-16.7$ permil $(n=583$, $\sigma=1.8$ ). A simple two-endmember mixing equation results in 


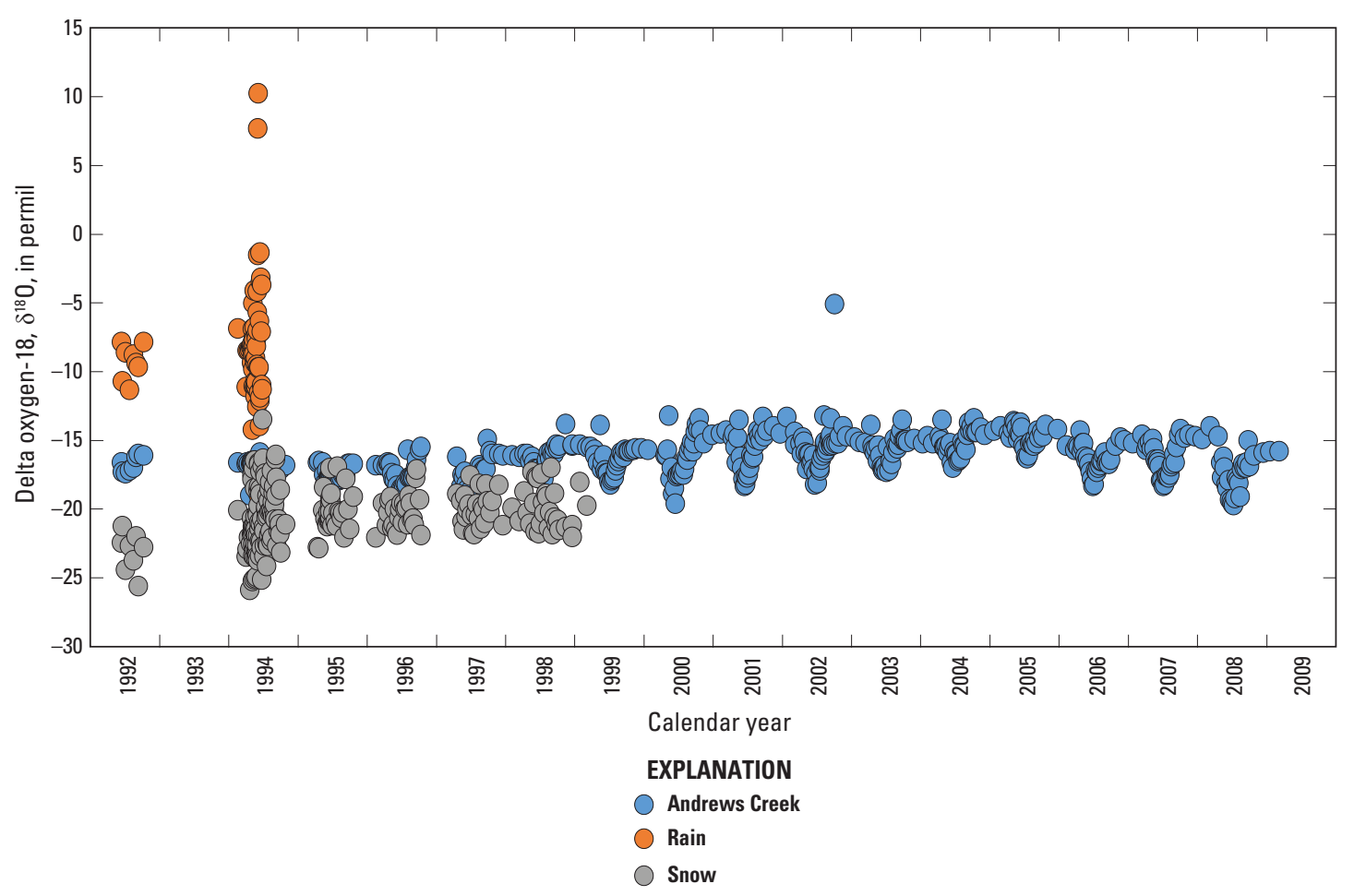

Figure 37. Delta oxygen-18 $\left(\delta^{18} 0\right)$, in permil, measured in Andrews Creek along with that measured in rain and snow falling in the Loch Vale watershed from 1992 through 2009.

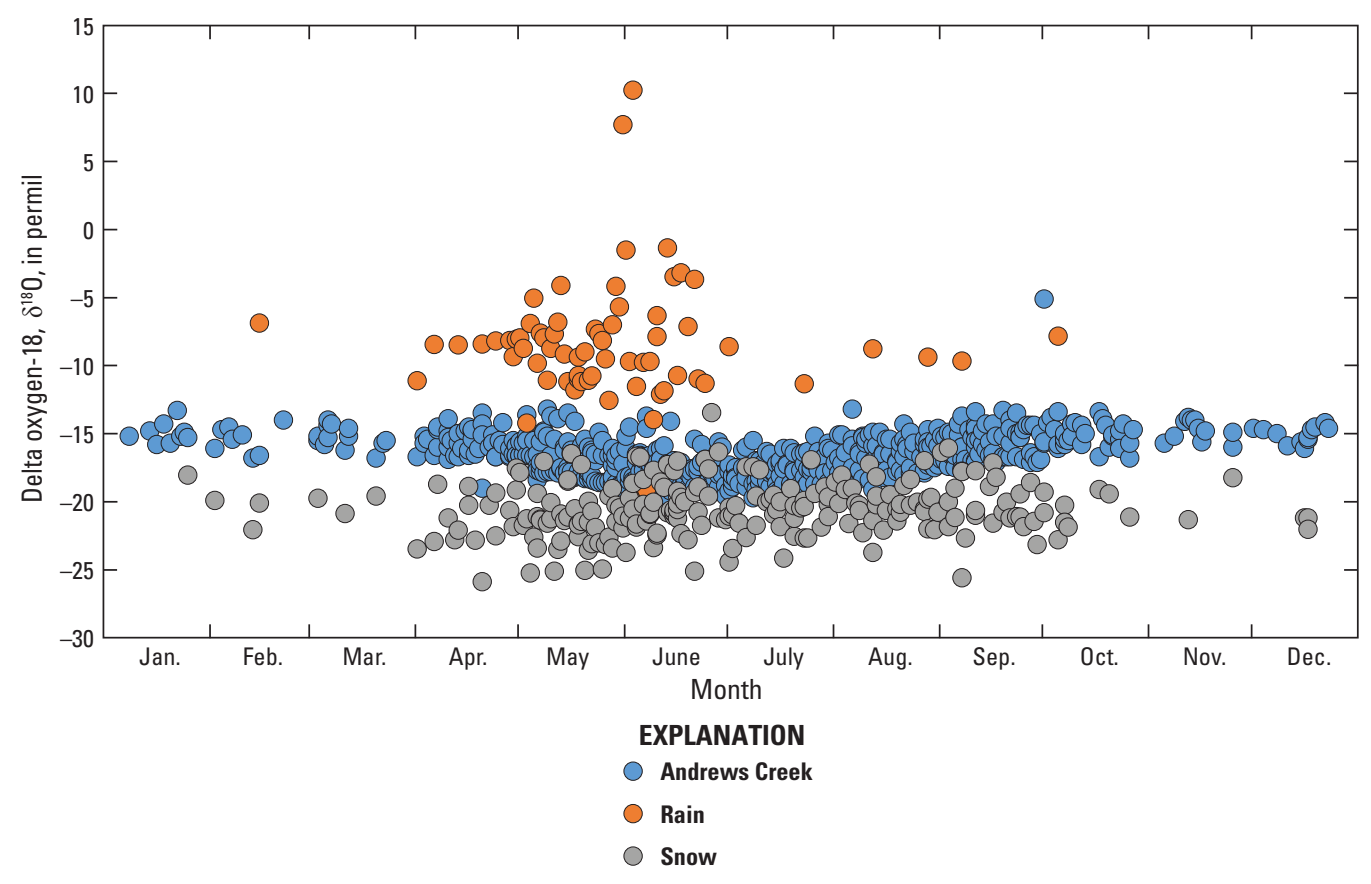

Figure 38. Seasonal variations in delta oxygen-18 $\left(\delta^{18} 0\right)$, in permil, measured in Andrews Creek along with that measured in precipitation and snow pits in the Loch Vale watershed from 1992 through 2009. 
an estimate of approximately 70 percent of precipitation falling as snow, in the absence of fractionation. If evaporation and sublimation result in approximately a 1 permil enrichment of $\delta^{18} \mathrm{O}$, then a volume-weighted mean value for $\delta^{18} \mathrm{O}$ of -17.7 is a reasonable target for precipitation for a synthetic series for the simulation period.

The synthetic series of daily $\delta^{18} \mathrm{O}$ values for precipitation was constructed by estimating rain and snow adjustments to match observed discharge and then a temperature for the rain-snow threshold was estimated to match the observed average stream $\delta^{18} \mathrm{O}$ value of -16.7 permil. An adjustment factor of 1.1 for rain [rain_adj(nmru,nmonths)] and 1.9 for snow [snow_adj(nmru,nmonths)] applied to precipitation measured at the Bear Lake SNOTEL station resulted in a reasonable water balance for a single-MRU model of Andrews Creek. A rain-snow threshold of $5.5^{\circ} \mathrm{C}$ for daily maximum temperature at Main Weather Station was determined by using the Microsoft Excel solver, such that, after application of the precipitation adjustment factors, the calculated volume-weighted mean isotopic signature of precipitation falling in the Loch Vale Watershed from 1984 through 2010 was -17.8 permil, very close to the desired target of -17.7 (see snow_threshold sheet in Andrews.xlsm). Therefore, on days when the daily maximum temperature at Main Weather Station was less than or equal to $5.3^{\circ} \mathrm{C}$, the $\delta^{18} \mathrm{O}$ of the precipitation falling on Andrews Creek was assigned the value -20.5 permil. This assignment is independent of the form of precipitation (rain or snow) assigned by the snowmelt module, which subdivides the day into four 6-hour periods. On days when the daily maximum temperature was greater than $5.3{ }^{\circ} \mathrm{C}$, the $\delta^{18} \mathrm{O}$ of the precipitation was assigned -8.6 permil. The Andrews Creek watershed is higher and colder than the location of Main Weather Station; therefore, the threshold value of $5.3^{\circ} \mathrm{C}$ at the altitude of the station $(3,150 \mathrm{~m})$ translates to $1.9^{\circ} \mathrm{C}$ at the average altitude of the Andrews Creek MRUs (3,540 m) after applying an average tmax_lapse(nmonths) of $9.3^{\circ} \mathrm{C} / \mathrm{km}$ and the tmax_adj(nmru) of $-0.03{ }^{\circ} \mathrm{C}$. The threshold of $1.9^{\circ} \mathrm{C}$ at the altitude of the MRU indicates that a value for tmax_allsnow_c(one $)=2.0^{\circ} \mathrm{C}$ is a reasonable approximation of the snow-rain threshold for all MRUs.

\section{Model Calibration and Discussion}

The WEBMOD model for Andrews Creek simulates flows and water chemistry that are calibrated to interannual and seasonal variations in discharge and stream concentrations observed at the Andrews Creek gage, which became operational on April 16, 1992. Operational flags for model output and specifications for chemvars describing $\delta^{18} \mathrm{O}$ and concentrations of major solutes in warm and cool hillslopes are listed in table 29 .
Table 29. Parameters for output and user-defined variables for the Andrews Creek model.

[The formatting convention used in this report is to present dimension names in Courier New font and parameter names in bold Courier New font. See tables 1 and 2 for descriptions of dimensions and parameters]

\begin{tabular}{|c|c|c|c|c|c|c|c|c|c|}
\hline \multicolumn{10}{|c|}{ Dimension: one } \\
\hline \multicolumn{5}{|c|}{ print_type(one) } & 2 & & & & \\
\hline \multicolumn{5}{|c|}{ print_freq(one) } & 9 & & & & \\
\hline \multicolumn{5}{|c|}{ print_objfunc(one) } & 0 & & & & \\
\hline \multicolumn{5}{|c|}{ print_explanation(one) } & 0 & & & & \\
\hline \multicolumn{5}{|c|}{ iout(one) } & 2 & & & & \\
\hline \multicolumn{5}{|c|}{ print_vse(one) } & 0 & & & & \\
\hline \multirow{2}{*}{\multicolumn{5}{|c|}{$\begin{array}{r}\text { xdebug_start }(o n e) \\
\text { xdebug_stop }(o n e)\end{array}$}} & 0 & & & & \\
\hline & & & & & 0 & & & & \\
\hline \multicolumn{10}{|c|}{ Dimension: nchemvar } \\
\hline \multirow{11}{*}{ 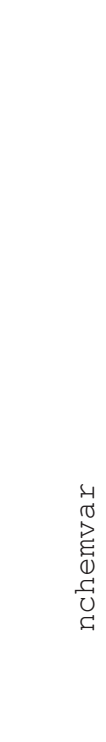 } & & 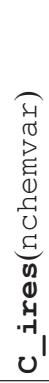 & 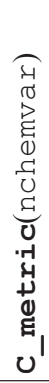 & 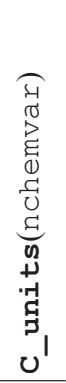 & 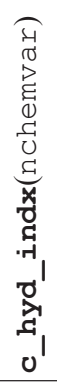 & 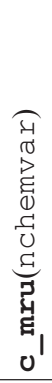 & 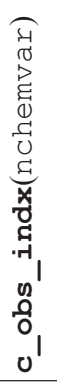 & 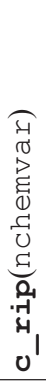 & 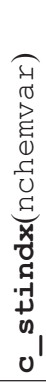 \\
\hline & 1 & 2 & 3 & 13 & 0 & 3 & 0 & 0 & 0 \\
\hline & 2 & 2 & 5 & 13 & 0 & 3 & 0 & 0 & 0 \\
\hline & 3 & 4 & 3 & 13 & 0 & 3 & 0 & 0 & 0 \\
\hline & 4 & 5 & 3 & 13 & 0 & 3 & 0 & 0 & 5 \\
\hline & 5 & 8 & 3 & 13 & 0 & 3 & 0 & 0 & 0 \\
\hline & 6 & 5 & 4 & 4 & 0 & 10 & 0 & 0 & 5 \\
\hline & 7 & 8 & 4 & 4 & 0 & 10 & 0 & 0 & 0 \\
\hline & 8 & 5 & 4 & 4 & 0 & 3 & 0 & 0 & 5 \\
\hline & 9 & 8 & 4 & 4 & 0 & 3 & 0 & 0 & 0 \\
\hline & 10 & 99 & 2 & 1 & 0 & 1 & 0 & 0 & 0 \\
\hline
\end{tabular}

To spin up the model, simulations begin in water year 1984, coincident with the initiation of data collection at the NADP site and the observations of discharge and stream concentrations at the Loch Vale outlet. Annual adjusted precipitation and simulated and observed discharge for Andrews Creek for water years 1984 through 2012 are shown in figure 39. The record includes the exceptional drought of 2000-2003 (Colorado Water Resources Research Institute, 2002).

The first phase of calibration focused on matching variations in streamflow. Parameters describing precipitation undercatch, PET, and snowmelt were adjusted to approximate volumes and timing of snowmelt, which is the dominant hydrologic process. In the spring, snowfall and snowpack reach an annual maximum, and then the melt begins as average temperatures rise above freezing in May and June 


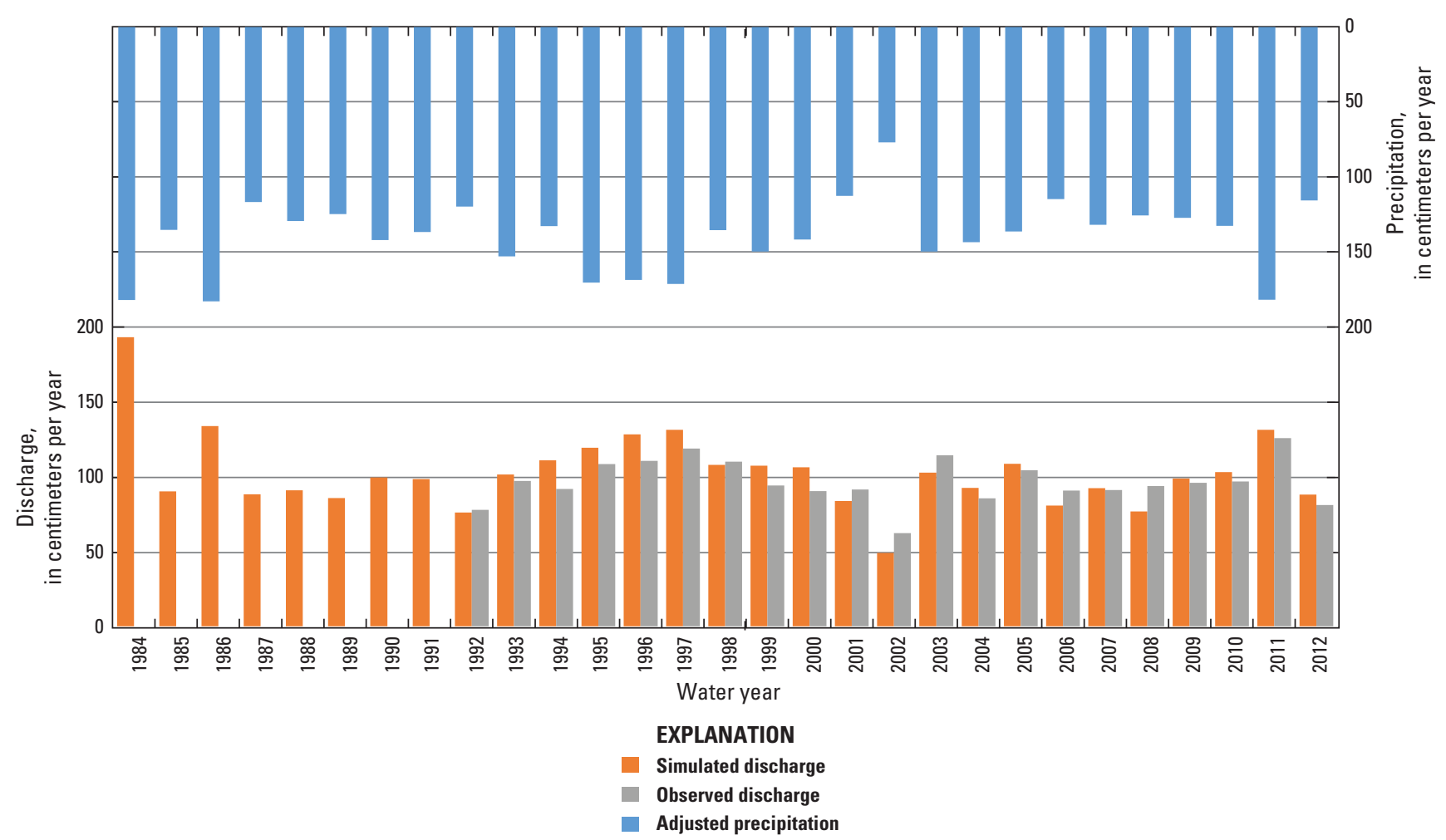

Figure 39. Simulated and observed discharge and adjusted precipitation for Andrews Creek for water years 1984 through 2012. The Andrews Creek gage was installed in April 1992. Observed values from October 1991 through April 1992 were copied from values simulated for the base-flow recession for the same period.

(fig. 40). Discharge in Andrews Creek usually peaks in June or July. The average of the simulated annual discharge at the Andrews Creek gage for water years 1993 through 2012 is 101 centimeters per year $(\mathrm{cm} / \mathrm{yr})$ compared to an average observed discharge of $98 \mathrm{~cm} / \mathrm{yr}$ for the same period. For water years 2001 through 2012, simulated discharge fit observed discharge for wet and dry years (fig. 41).

The second step of the calibration focused on matching variations of stream concentrations. The size of the hillslope reservoirs and the percentage of preferential flows were adjusted to match seasonal variations in $\delta^{18} \mathrm{O}$ (fig. 42). Next, the parameters used to simulate the incongruent melting of snowpack were adjusted to match the spikes in chloride and $\delta^{18} \mathrm{O}$ that are measured in early snowmelt samples (fig. 43). Finally, the mineral dissolution rates, nitrification rates, and equilibrium partial pressures of oxygen and carbon dioxide in the hillslopes were adjusted in the webmod.pqi file to match the annual and seasonal variations in the concentrations of major solutes and $\mathrm{pH}$. The $\mathrm{pH}$ sensor at the Andrews Creek gage began degrading in the summer of 2008; observations after that time were excluded from the set of observations used for calibration.

After adjusting parameters, the range of daily values and the timing of seasonal variations of isotopic values and concentrations were consistent with most of the observations. The $\delta^{18} \mathrm{O}$ for stream water was the lightest, or most similar to the snowpack, in the middle of the summer, although almost all precipitation at that time was isotopically heavy rain. Chloride, which has no internal sources or sinks, had an average stream concentration of $0.126 \mathrm{mg} / \mathrm{L}$, about 25 percent greater than the average concentration measured in the precipitation, reflecting concentration by evapotranspiration. Maximum concentrations of chloride coincided with the ionic pulse during spring snowmelt. Nitrate, which was derived from ammonium converted to nitrate and from nitrate in the precipitation and snow, also displayed maximum concentrations during the ionic pulse.

Concentrations of sodium, sulfate, and alkalinity were highest during base flow in the winter and lowest during the summer when snowmelt flushed the soils. Variations in $\mathrm{pH}$ were consistent with the alkalinity produced by the unsaturated- and saturated-zone reactions and degassing of $\mathrm{CO}_{2}$ from the stream. The drought ending in 2003 resulted in a period of increased winter concentrations of chloride, nitrate, and sulfate (coincident with a smaller variability in alkalinity) before returning to baseline concentrations near the end of the simulation period (fig. 43). Baron and others (2009) and Caine (2010) suggest warmer summers and melting permafrost on north-facing slopes as an explanation for the higher concentrations during the drought. 


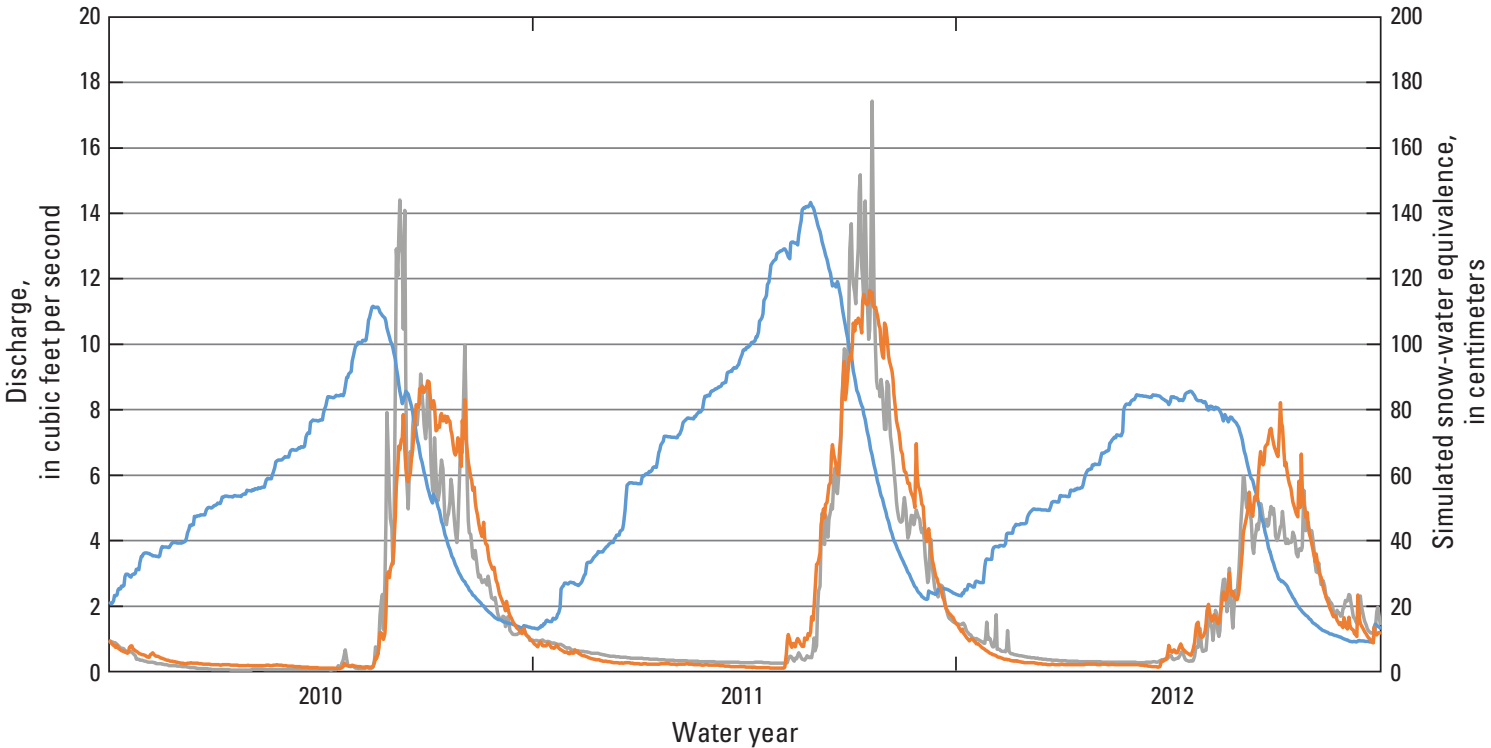

EXPLANATION

Simulated discharge

Observed discharge

Snow-water equivalence

Figure 40. Seasonal variations in snow-water equivalence and simulated and observed discharge for water years 2010 through 2012.

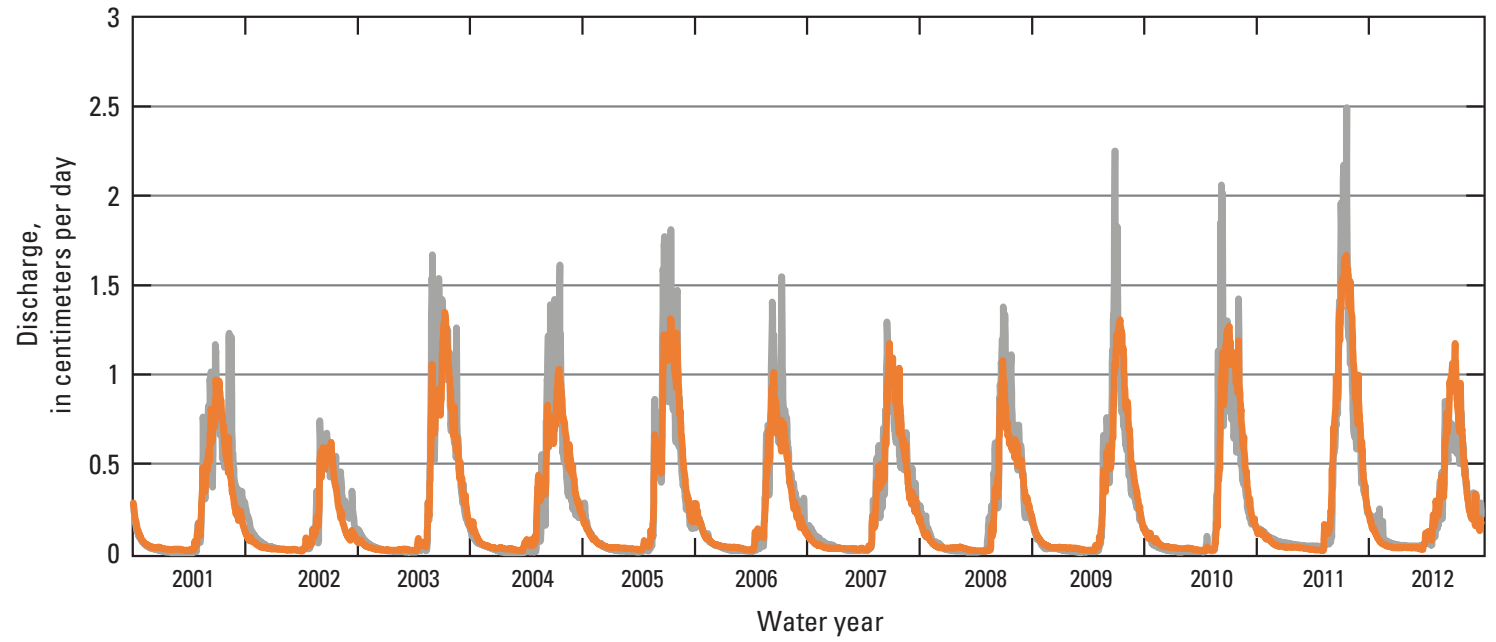

EXPLANATION

Simulated discharge

Observed discharge

Figure 41. Simulated and observed discharge for Andrews Creek for water years 2000 through 2012. 

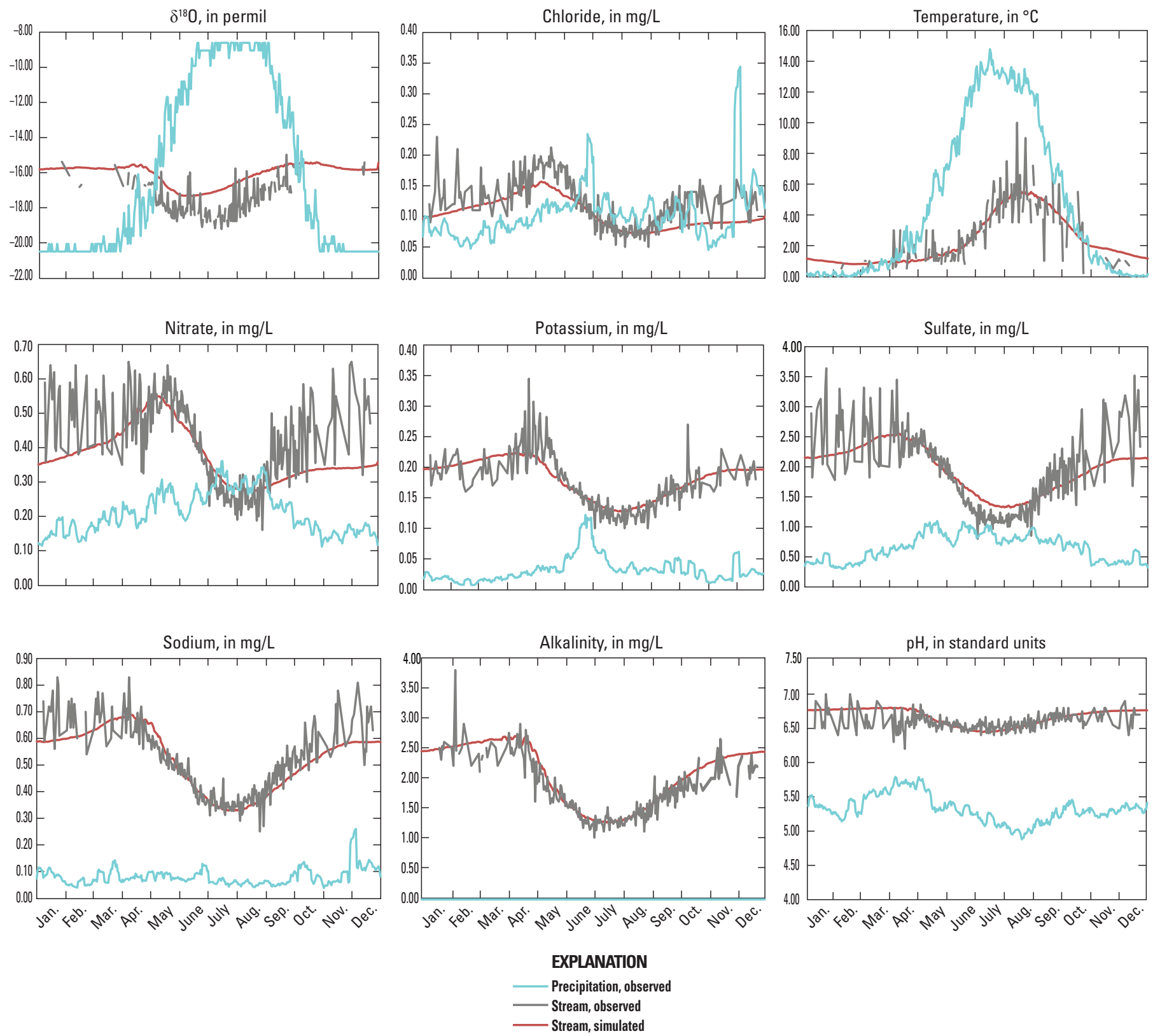

Figure 42. Seasonal variations in daily delta oxygen-18 $\left(\delta^{18} \mathrm{O}\right)$, temperature (degrees Celsius, ${ }^{\circ} \mathrm{C}$ ), pH, and solute concentrations (milligrams per liter, $\mathrm{mg} / \mathrm{L}$ ) for Andrews Creek averaged for water years 1993 through 2012; the Andrews Creek gage was installed in April 1992. The $\delta^{18} 0$ in precipitation shows a seasonal variation from a fixed signature of -20.5 permil during the winter when all precipitation was simulated as snow to a fixed value of -8.6 permil in the summer when all precipitation was simulated as rain. 

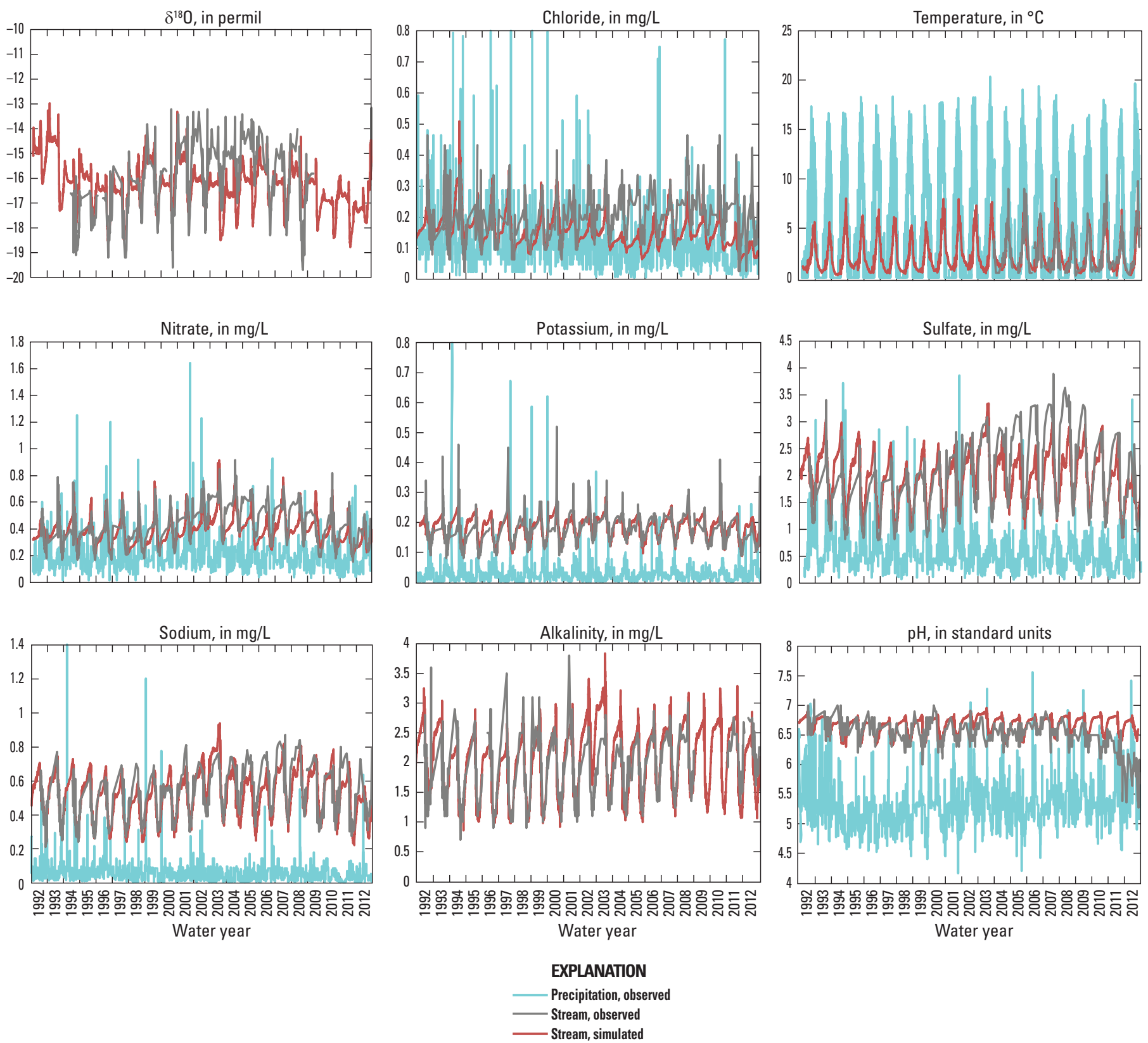

Figure 43. The delta oxygen-18 $\left(\delta^{18} 0\right)$, temperature (degrees Celsius, ${ }^{\circ} \mathrm{C}$ ), $\mathrm{pH}$, and solute concentrations (milligrams per liter, $\mathrm{mg} / \mathrm{L}$ ) for Andrews Creek for water years 1992 through 2012. The $\delta^{18} 0$ in precipitation is not shown because the input $\delta^{18} 0$ values were a synthetic binary distribution equal to -8.6 permil for rain and -20.5 permil for snow. 
Maximum concentrations of potassium were observed in the spring, which is contemporaneous with maximum concentrations of atmospherically derived cations such as nitrate, chloride, and sulfate. The concentration of potassium in rain and snow, however, is much lower than the concentrations of nitrate, chloride, and sulfate in rain and snow, so the high concentrations in spring likely result from a combination of the ionic pulse and flushing of potassium derived from weathering during the spring melt.

\section{Dryland Irrigation in the DR2 Watershed}

Yakima lies in the rain shadow of the Cascade Range, and although the many sunny days are favorable to agriculture, the area received an average of just less than 20 centimeters $(\mathrm{cm})$ of precipitation per year during 1988-2005, which is the time period simulated in this example. The Sunnyside canal was constructed through arid grasslands in the $1890 \mathrm{~s}$, and by $1907,40,000$ acres of land were irrigated by this large diversion of the Yakima River near Yakima, Wash. (Waring, 1913) (fig. 44). In the spring, the Bureau of Reclamation begins diverting water from the Yakima River into the Roza and Sunnyside Canals to provide approximately $1 \mathrm{~m}$ of irrigation water per growing season for the agricultural fields in the lower Yakima River valley (fig. 45). An irrigation season is contemporaneous with a growing season, usually from mid-March to mid-October. The diversions and drains, which are necessary to maintain optimal soil moisture, are managed and monitored by the Roza-Sunnyside Board of Joint Control (RSBOJC; Zuroske, 2009). Drains are manmade featuresfor example, tile drains and ditches - that capture surface and subsurface flow generated by precipitation and irrigation. Drainage systems drain areas ranging in size from hectares to fields and affect the flow of water in the watershed. Because of the value put on irrigation water, irrigation is applied to maximize water-use efficiency. Consequently, runoff is limited, and return flow to the Yakima River is highly concentrated in suspended sediments, major ions, nutrients, and agricultural chemicals.

Beginning in 1999, the NAWQA Program worked with individual irrigation districts, in general, and with RSBOJC, in particular, to better understand the timing and loads of pesticides, nutrients, and suspended sediments in the flows that return to the Yakima River downstream from the agricultural fields (Fuhrer and others, 2004). During water years 2003 and 2004, studies focused on hydrology and water quality in the $160-\mathrm{km}^{2}$ basin flowing to Granger Drain, hereafter referred to as Granger watershed (Payne and others, 2007), and in the $5-\mathrm{km}^{2}$ subbasin flowing to the DR2 Drain, hereafter referred to as DR2 watershed (McCarthy and Johnson, 2009). The terms
"Granger Drain" and "DR2 Drain" will refer to the actual canals that drain the watershed, and "Granger gage" and "DR2 gage" will refer to the locations of the drain outlets. The "DR2 model" refers to the WEBMOD model that includes the watershed, the drain, and the outlet.

The DR2 watershed was once arid grassland with no perennial drainage. With the annual application of a meter of irrigation, the DR2 watershed is now a surcharged system (Weiskel and others, 2007) that is far from equilibrium with natural conditions. This example shows that WEBMOD can be used to simulate many of the water-management options that are used in the DR2 watershed. Tracking water through multiple years of varying irrigation is complex in this example; however, the approach to geochemistry is simplistic-changes in concentration are the result of evaporation and conservative mixing of low-conductivity precipitation and irrigation water with high-conductivity groundwater.

\section{Hydrologic Simulations}

This example simulates the hydrology of the irrigated DR2 watershed by discretizing the land surface into 22 MRUs with areas from 9 to 56 hectares. The areas were discretized on the basis of drainage patterns and may contain one or more fields with a variety of crops. Model inputs include precipitation, irrigation, canal leakage, and inflow of upgradient groundwater. The sources of irrigation water include the Sunnyside Canal, a well, and ditch water. The well and ditch water are fictitious but are presented to demonstrate how to include these sources in a model simulation and to investigate how these sources affect hillslope processes. Excess soil moisture is reduced through the use of tile drains, which is also simulated by defining pipe flow parameters.

\section{Hydrologic Data File (webmod.hydro.dat)}

The source of the meteorological data for the simulation period January 1, 1988, through December 31, 2005, is the Harrah, Wash., station (HRHW) of the Pacific Northwest Cooperative Agricultural Weather Network (U.S. Department of the Interior, Bureau of Reclamation, Pacific Northwest Region; http://www.usbr.gov/pn/agrimet/agrimetmap/ hrhwda.html, accessed June 7, 2016) (fig. 44). Observations made at HRHW that are included in the hydrologic data file include precipitation [precip(nrain)]; temperature [tsta_max_f(ntemp) and tsta_min_f(ntemp)]; potential evaporation [pan_evap(nevap)] as calculated by the Penman equation modified for Kimberly, Idaho (Wright, 1982); and incoming solar radiation [sol rad(nsol)]. In addition, the hydrologic data file includes discharge [runoff(nobs)] measured from March 1, 2003, through September 30, 2004, 


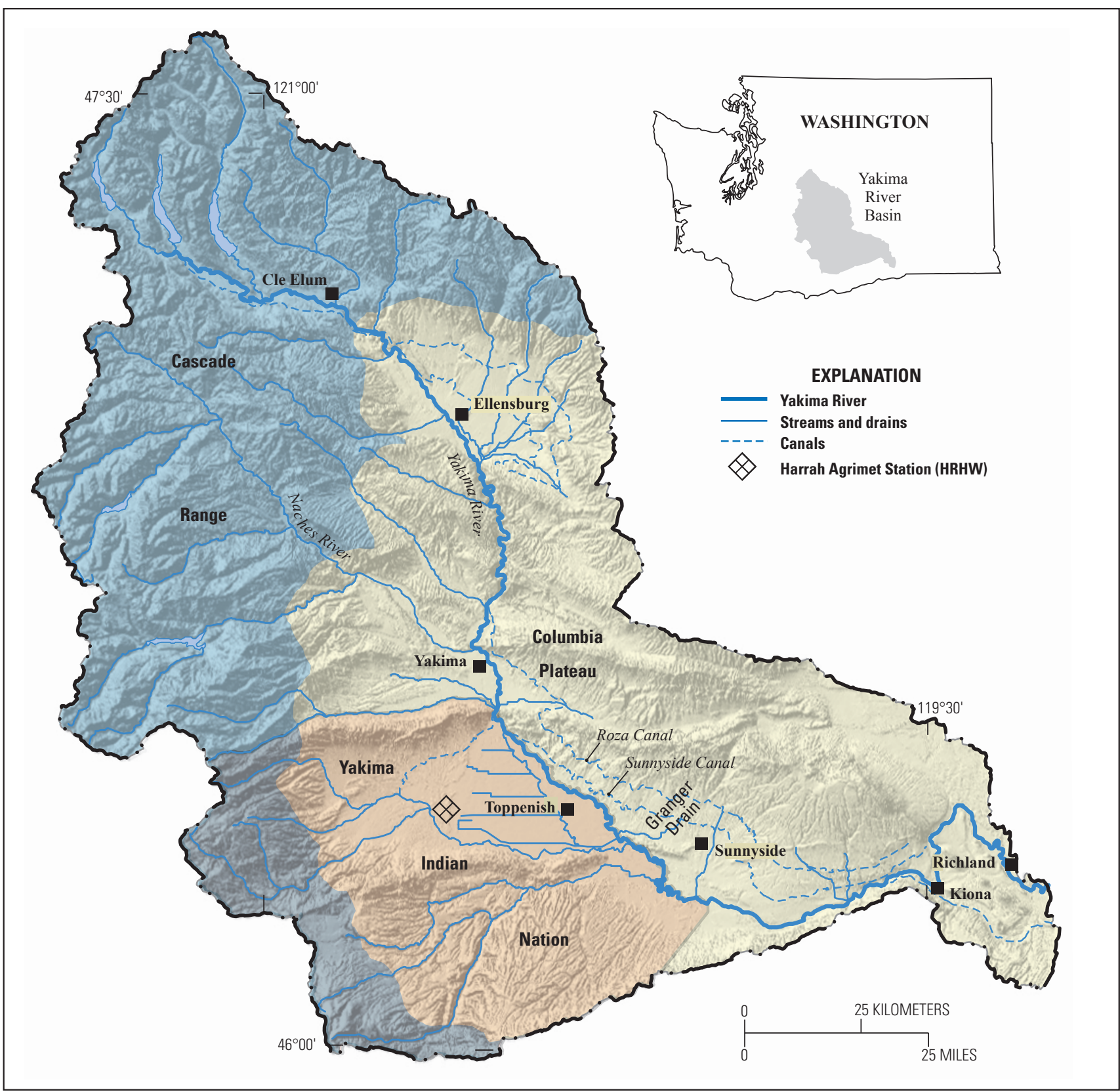

Figure 44. Map showing the Yakima River and the location of the Granger Drain. (Modified from Fuhrer and others, 2004) 


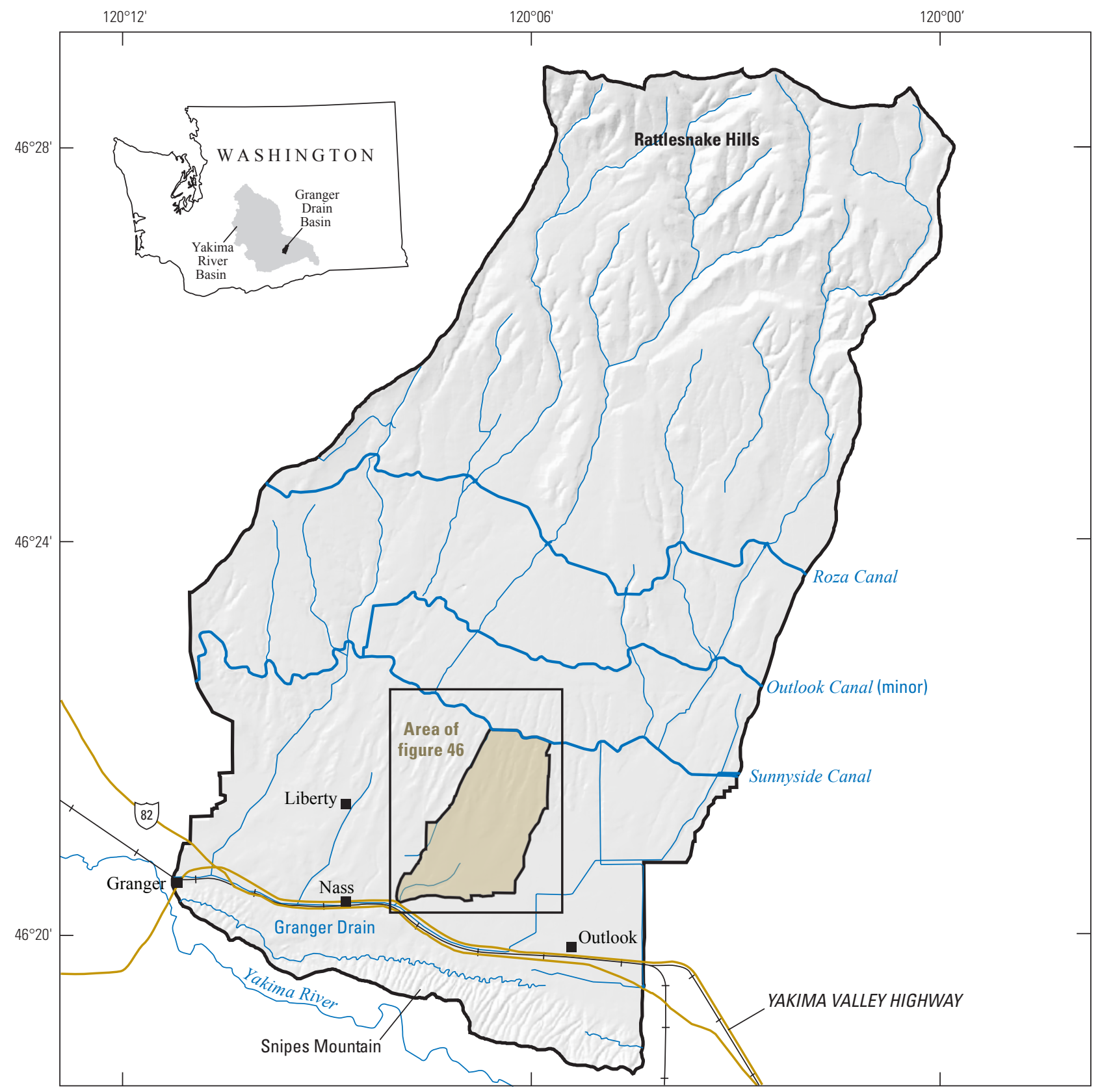

Albers projection, False_Easting: 0.00000000, False_Northing: 0.00000000 , Central_Meridian: -119.00000000, Standard_Parallel_1: 29.50000000, Standard_Parallel_2: 45.50000000, Latitude_Of_Origin: 23.00000000, Linear Unit: Meter. Shaded-relief base from 1:100,000-scale Digital Elevation Model based on the North American Datum of 1983

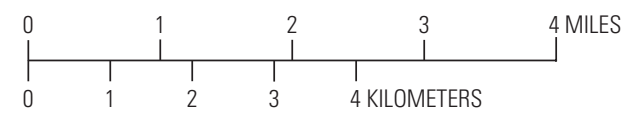

\section{EXPLANATION}

DR2 Basin

Granger Drain Basin boundary

Figure 45. Map showing the Roza, Sunnyside, and Outlook Canals and the watershed boundaries for the DR2 and Granger watersheds. (From Payne and others, 2007) 
at the DR2 gage (USGS station ID 462023120075200; https://doi.org/10.5066/F7P55KJN), seven schedules for daily external irrigation [irrig_ext(nirrig_ext)], two schedules for internal irrigation (wells or stream diversions) to be applied on the next day [irrig_int_next(nirrig_int)], and two schedules for groundwater inputs from external sources [gw_ext(ngw_ext)].

The Sunnyside Valley Irrigation District provided flow data from 2001 through 2005 (Don Schramm, written commun., 2006), in cubic foot per second, for seven weirs $(28.90,28.90$ A, $28.90 \mathrm{~B}, 29.15,29.38,29.58$, and 29.68) at the heads of the laterals that move water from Sunnyside Canal to the fields (fig. 46). Flows, in cubic foot per second, were converted to inches of irrigation by normalizing to the area of the fields where the water was applied. For purposes of this example, irrigation for each year from 1988 through 2000 was assigned the irrigation of one of the seasons from 2001 through 2005, whichever matched the Yakima River water availability best (fig. 47). The irrigation schedules observed from 2001 through 2005 were concatenated to the irrigation schedules synthesized for 1988 through 2000 to construct the schedules from 1988 through 2005 that are included in the webmod.hydro.dat file. The RSBOJC records indicate 11 years of drought between 1940 and 2005; this DR2 simulation of 18 years contains 4 years of drought—1993, 1994, 2001, and 2005.

Irrigation that is supplied by sources internal to the watershed is described by two schedules. The well and the stream diversions are fictitious but are presented to demonstrate how to configure internal sources and to demonstrate potential effects on water quality. In reality, all irrigated fields in the DR2 watershed draw water from Sunnyside Canal.

\section{Parameter File (webmod.params)}

The 5.02- $\mathrm{km}^{2}$ DR2 watershed is discretized into 11 stream channels (nchan=11) that receive water from the left and right banks, for a total of 22 hillslopes (nmru=22; table 30; fig. 48). Each hillslope is further discretized into five TTI bins ( nac $=5$; table 31 ). The convention used here is to assign hillslope indices (MRU ID) to the right and left bank hillslopes (looking downstream) as follows: the MRU ID of the right bank is assigned the value of the stream channel ID, and the MRU ID of the left bank is assigned the value of the stream channel ID plus the total number of stream channels. Thus, for the first stream channel of the DR2 model, the MRU ID of the right bank is 1, and the MRU ID of the left bank is $12(1+$ nchan $)$. Both MRUs are linked to the same one-dimensional stream channel; in this case, stream channel 1 [mru2 $\operatorname{chan}(i \operatorname{mru}=1,12)=1]$ as listed in table 32. The discretization of the DR2 model into 22 MRUs is needed to simulate distinct irrigation schedules for multiple fields. Having a separate stream channel between each pair of MRUs is not necessary for such a small watershed; all MRUs could point to a single stream channel that would mix all hillslope discharge at the end of the day. The 11 stream channels presented in this example demonstrate the MRU-to-stream-channel mapping that is ultimately used to map MRU discharge to stream reservoirs (time-delay ordinates).

The primary stream reservoirs in WEBMOD are dimensioned by nhydro, not nchan. Water chemistry can be reported for and irrigation can be taken from any of nhydro well-mixed reservoirs that represent the one-dimensional stream that collects discharge from the hillslopes in the watershed. Stream channels are used to discretize the watershed into MRUs and to distribute flow accumulation along the channel into the nhydro time-delay ordinates by using the distance and fractional area parameters for each stream channel [d(ntopchan,nchan) and ach(ntopchan,nchan)]. The number of points that will be assigned distance and flow accumulation fractions is the parameter nchan_d(nchan). The maximum value for nchan_d(nchan) is equal to ntopchan and nchan_d(ichan=1,5)=ntopchan=5 (table 30; fig. 48). Where channels are shorter, nchan_d(nchan) may be less than ntopchan as in nchan_d(ichan=2,7-9)=2. As explained in "Spatial Properties and Topology of the Watershed," the farthest distance on the channel network upstream from the outlet [d(ntopchan,nchan)] and the average channel velocity $[\mathbf{c h v}(\circ n e)]$ determine the maximum number of days that stream water remains in the watershed before being discharged at the outlet. When distances are greater or channel velocities are slower (as artificially set in the Andrews Creek model above), then nhydro will increase.

Meteorological observations drive the natural surface-water hydrology. All undercatch factors are set to 1.0 , which indicates that no correction is applied to the amount of precipitation measured at HRHW [rain_adj(imru $=1-22$, imonths $=1-12)=1.0$ and snow_adj(imru=1-22, imonths $=1-12)=1.0$ ] as listed in table 33 . When more than 0.02 inch 


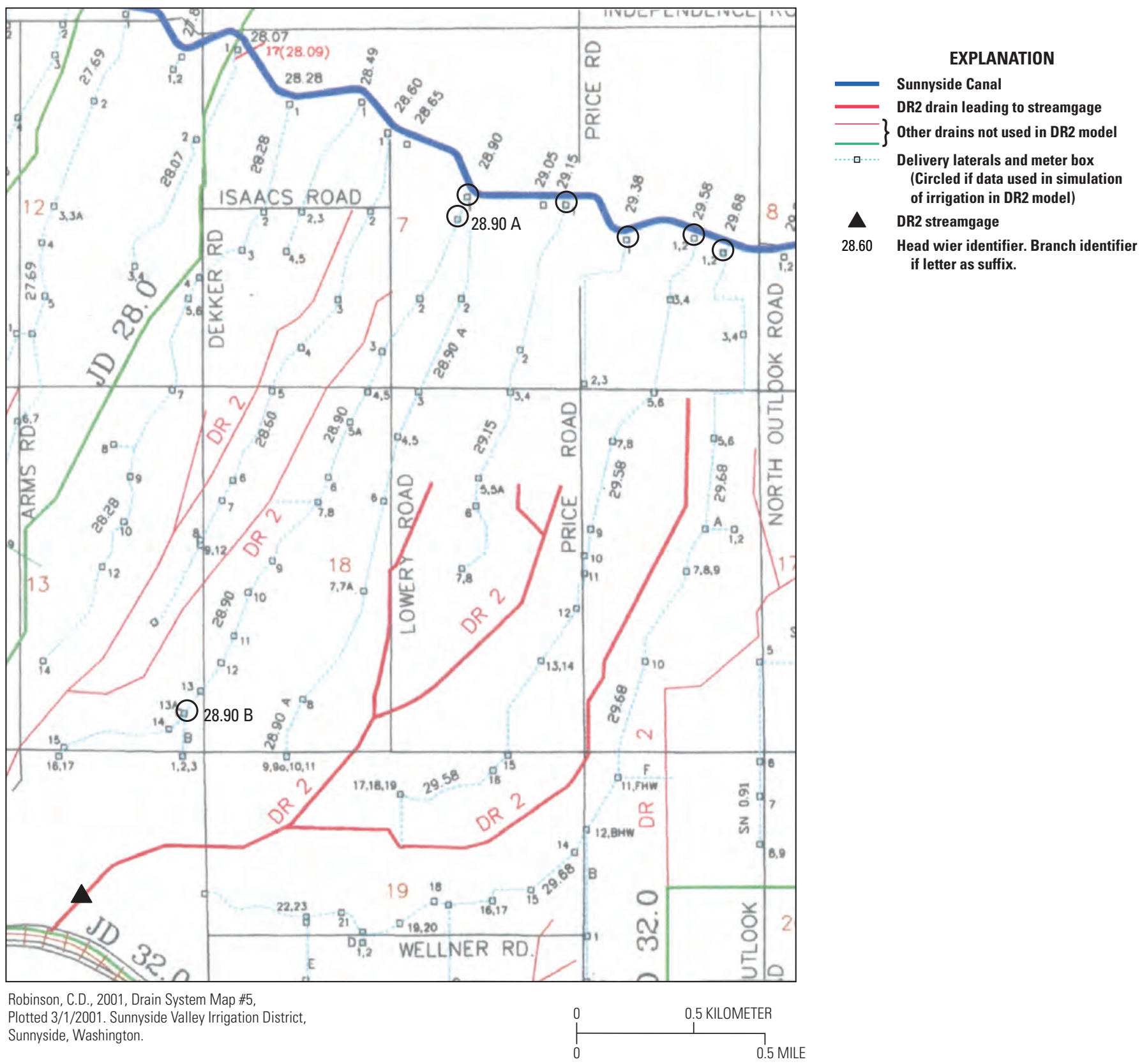

Figure 46. Map showing head weirs and delivery boxes used to regulate diversions of water from Sunnyside Canal to fields in the DR2 watershed. The DR2 drain joins the Granger drain in the lower left. (Base map from Robinson, 2001) 


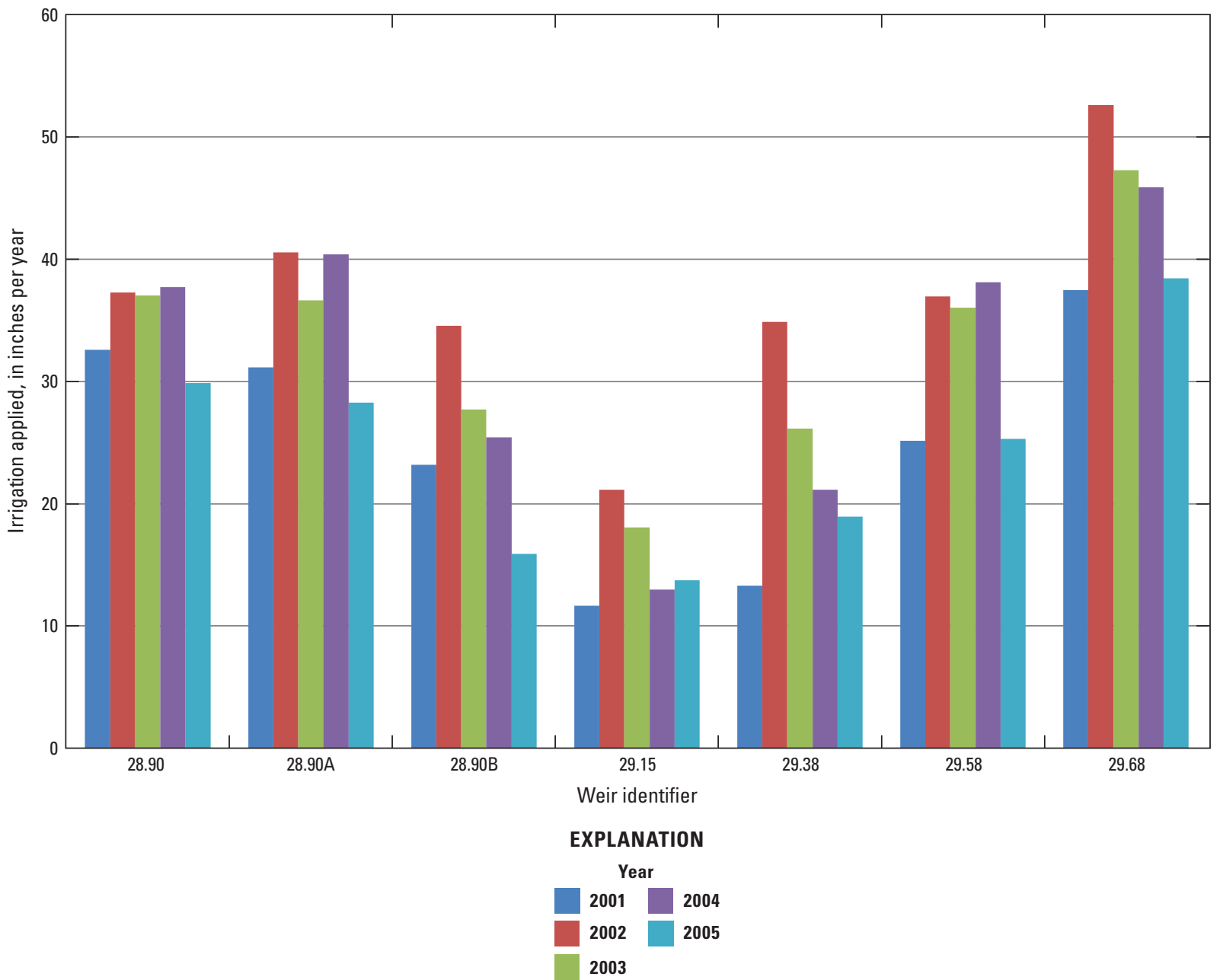

Figure 47. Depths of irrigation supplied by seven weirs that control deliveries of water from Sunnyside Canal to agricultural fields flowing to the DR2 drain from 2001 through 2005. (Weir locations and identifiers are shown in figure 46.)

Table 30. Dimensions for the DR2 model.

[The formatting convention used in this report is to present dimension names in Courier New font. See table 1 for definitions of dimensions]

\begin{tabular}{|c|c|c|c|c|c|}
\hline \multicolumn{6}{|c|}{ Dimension of input variables } \\
\hline nsnow & nhum & ngw ext & nirrig ext & nirrig int & \\
\hline 0 & 1 & 2 & $x^{-12}$ & $2^{+1+c}$ & \\
\hline \multicolumn{6}{|c|}{ Fixed hydrologic dimensions } \\
\hline ndepl & ndeplval & nexlag & nxkbin & & \\
\hline 2 & 22 & 2 & 9 & & \\
\hline \multicolumn{6}{|c|}{ Mandatory dimensions for all hydrologic simulations } \\
\hline \multicolumn{6}{|c|}{ Dimensions used during geochemical simulations } \\
\hline $\begin{array}{c}\text { nsolute } \\
1\end{array}$ & $\begin{array}{c}\text { nchemobs } \\
0\end{array}$ & nchem_ext & & & \\
\hline \multicolumn{6}{|c|}{ Fixed geochemical dimensions } \\
\hline nmru_res & nhes & nchemvar & nresinp & nconvert & nphq_lut \\
\hline$\overline{9}$ & 10 & 10 & 21 & 3 & 75 \\
\hline
\end{tabular}




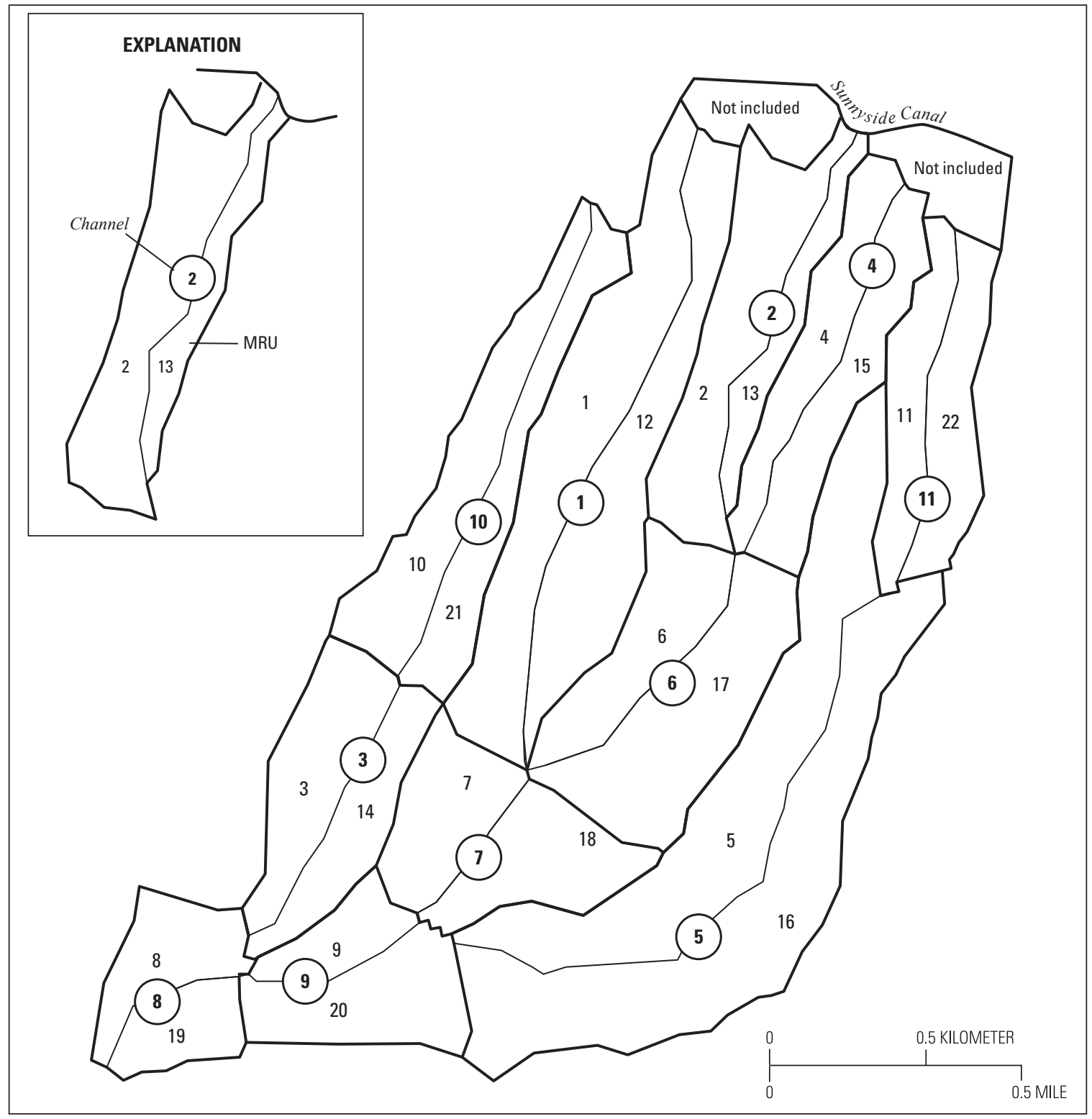

Figure 48. Diagram showing 22 model response units (MRUs) in the DR2 model (nmru=22). Thick lines on ridges surround a left and right bank of a channel (nchan=11). Thin lines follow the drainage and separate the MRUs by aspect. Although not required, this model uses a convention where left and right banks are offset by the total number of channels. 
Table 31. Topographic parameters for the DR2 model.

[The formatting convention used in this report is to present dimension names in Courier New font and parameter names in bold Courier New font. See tables 1 and 2 for descriptions of dimensions and parameters. ln, natural log; a, upslope contributing area; $\tan , \operatorname{tangent;} \beta$, slope]

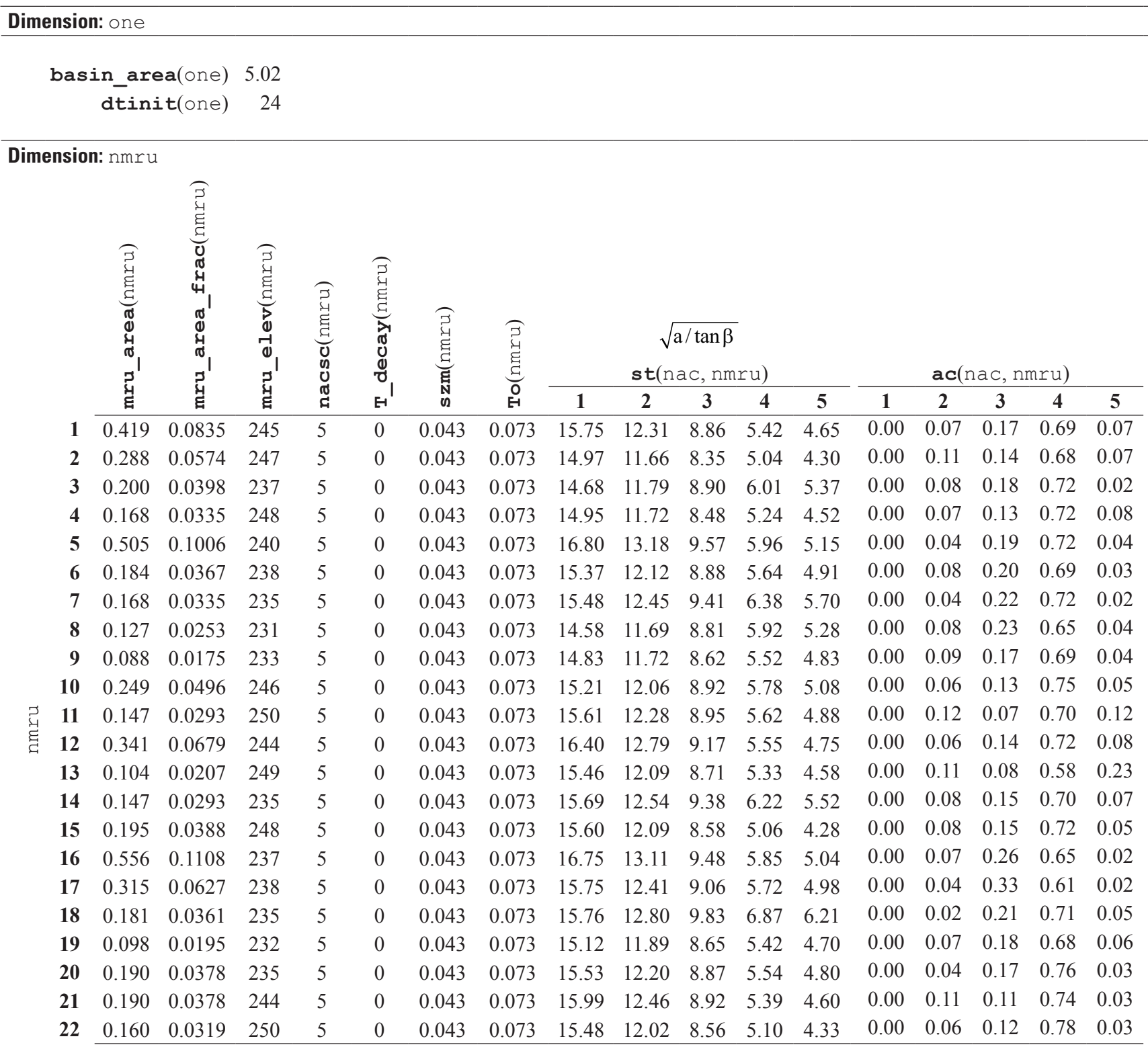


Table 32. Channel routing parameters for the DR2 model.

[The formatting convention used in this report is to present dimension names in Courier New font and parameter names in bold Courier New font. See tables 1 and 2 for descriptions of dimensions and parameters. Parameter values for $\mathbf{d}(n t o p c h a n, n c h a n)$ and ach(ntopchan, nchan) are grayed out where they exceed nchan_d(nchan), the number of $\mathbf{d}$, ach pairs used to assign time-delay ordinates for routing for each channel (minimum of two pairs). Grayed out zeros pad the $\mathbf{d}$ and ach parameter arrays as the parameter file must contain $n t o p c h a n \times$ nchan values]

Dimension: one

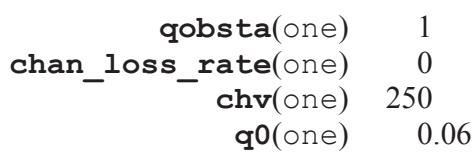

Dimension: nmru

\begin{tabular}{|c|c|c|c|c|c|c|c|c|c|c|c|c|c|c|c|c|c|c|c|c|c|}
\hline & \multicolumn{21}{|c|}{ nmru } \\
\hline & 1 & 2 & 3 & 4 & 5 & 6 & 7 & 8 & 9 & 10 & 11 & 12 & 13 & 14 & 15 & 16 & 17 & 18 & 19 & 20 & 21 \\
\hline $\operatorname{mru} 2 \operatorname{chan}(n m r u)$ & 1 & 2 & 3 & 4 & 5 & 6 & 7 & 8 & 9 & 10 & 11 & 1 & 2 & 3 & 4 & 5 & 6 & 7 & 8 & 9 & 10 \\
\hline
\end{tabular}

Dimension: nchan

\begin{tabular}{|c|c|c|c|c|c|c|c|c|c|c|c|}
\hline & \multicolumn{11}{|c|}{ nchan } \\
\hline & 1 & 2 & 3 & 4 & 5 & 6 & 7 & 8 & 9 & 10 & 11 \\
\hline chan d(nchan) & 5 & 2 & 4 & 3 & 5 & 3 & 2 & 2 & 2 & 3 & 3 \\
\hline
\end{tabular}

Dimension: ntopchan, nchan

d(ntopchan, nchan)

\begin{tabular}{|c|c|c|c|c|c|c|c|c|c|c|c|}
\hline & 1 & 2 & 3 & 4 & 5 & 6 & 7 & 8 & 9 & 10 & 11 \\
\hline 1 & 1880 & 2930 & 572 & 2940 & 1250 & 1880 & 1260 & 0 & 584 & 1720 & 3710 \\
\hline 2 & 2290 & 3520 & 946 & 3420 & 1840 & 2370 & 1850 & 542 & 1220 & 2230 & 4110 \\
\hline 3 & 2730 & 0 & 1310 & 3870 & 2450 & 2900 & 0 & 0 & 0 & 2740 & 4490 \\
\hline 4 & 3200 & 0 & 1680 & 0 & 3060 & 0 & 0 & 0 & 0 & 0 & 0 \\
\hline 5 & 3620 & 0 & 0 & 0 & 3660 & 0 & 0 & 0 & 0 & 0 & 0 \\
\hline
\end{tabular}

$\operatorname{ach}($ ntopchan, nchan)

\begin{tabular}{|c|c|c|c|c|c|c|c|c|c|c|c|}
\hline & 1 & 2 & 3 & 4 & 5 & 6 & 7 & 8 & 9 & 10 & 11 \\
\hline 1 & 0 & 0.0 & 0 & 0 & 0 & 0 & 0 & 0 & 0 & 0 & 0 \\
\hline 2 & 0.191 & 1 & 0.204 & 0.533 & 0.219 & 0.528 & 1 & 1 & 1 & 0.636 & 0.461 \\
\hline $\begin{array}{ll}0 & 3\end{array}$ & 0.543 & 0 & 0.543 & 1 & 0.506 & 1 & 0 & 0 & 0 & 1 & 1 \\
\hline 4 & 0.824 & 0 & 1 & 0 & 0.74 & 0 & 0 & 0 & 0 & 0 & 0 \\
\hline 5 & 1 & 0 & 0 & 0 & 1 & 0 & 0 & 0 & 0 & 0 & 0 \\
\hline
\end{tabular}


Table 33. Parameters to distribute incoming solar radiation, temperature, and precipitation in the DR2 model.

[The formatting convention used in this report is to present dimension names in Courier New font and parameter names in bold Courier New font. See tables 1 and 2 for descriptions of dimensions and parameters]

$\begin{aligned} \text { crad_coef(one) } & 0.2 \\ \text { crad_exp(one) } & 0.61 \\ \text { radj_sppt(one) } & 0.6 \\ \text { radj_wppt(one) } & 0.5 \\ \text { radmax(one) } & 0.62 \\ \text { temp_units(one) } & 0 \\ \text { tmax_allsnow_c(one) } & 2 \\ \text { trxn_ohoriz_days(one) } & 14.0 \\ \text { trxn_uz_days(one) } & 45.0 \\ \text { trxn_sat_days(one) } & 365.0\end{aligned}$

Dimension: ntemp

tsta_elev(ntemp) 250

\begin{tabular}{|c|c|c|c|c|c|c|c|c|c|c|c|c|}
\hline & \multicolumn{12}{|c|}{ nmonths } \\
\hline & 1 & 2 & 3 & 4 & 5 & 6 & 7 & 8 & 9 & 10 & 11 & 12 \\
\hline ccov_intcp(nmonths) & 1.83 & 1.83 & 1.83 & 1.83 & 1.83 & 1.83 & 1.83 & 1.83 & 1.83 & 1.83 & 1.83 & 1.83 \\
\hline ccov_slope(nmonths) & -0.13 & -0.13 & -0.13 & -0.13 & -0.13 & -0.13 & -0.13 & -0.13 & -0.13 & -0.13 & -0.13 & -0.13 \\
\hline ppt rad adj(nmonths) & 0.02 & 0.02 & 0.02 & 0.02 & 0.02 & 0.02 & 0.02 & 0.02 & 0.02 & 0.02 & 0.02 & 0.02 \\
\hline tmax_allrain_c(nmonths) & 5 & 5 & 5 & 5 & 5 & 5 & 5 & 5 & 5 & 5 & 5 & 5 \\
\hline tmax_lapse(nmonths) & 9 & 9 & 9 & 9 & 9 & 9 & 9 & 9 & 9 & 9 & 9 & 9 \\
\hline tmin_lapse(nmonths) & 9 & 9 & 9 & 9 & 9 & 9 & 9 & 9 & 9 & 9 & 9 & 9 \\
\hline adjmix_rain(nmonths) & 1 & 1 & 1 & 1 & 1 & 1 & 1 & 1 & 1 & 1 & 1 & 1 \\
\hline
\end{tabular}

Dimension: nmru

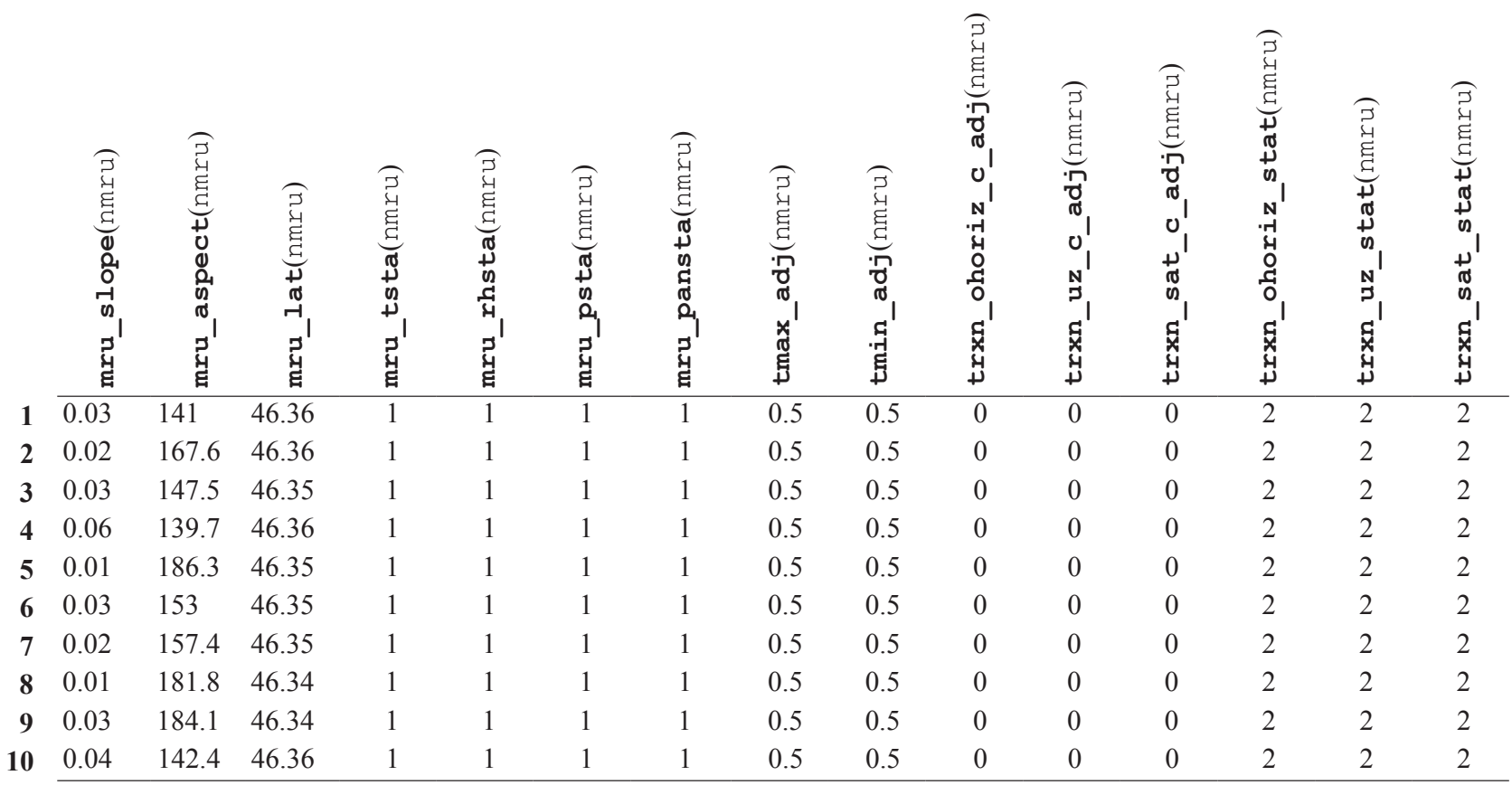


Table 33. Parameters to distribute incoming solar radiation, temperature, and precipitation in the DR2 model.-Conitnued

[The formatting convention used in this report is to present dimension names in Courier New font and parameter names in bold Courier New font. See tables 1 and 2 for descriptions of dimensions and parameters]

\begin{tabular}{|c|c|c|c|c|c|c|c|c|c|c|c|c|c|c|c|}
\hline \multicolumn{16}{|c|}{ Dimension: nmru-Continued } \\
\hline & 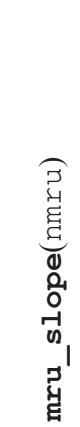 & 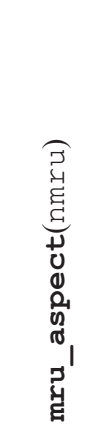 & 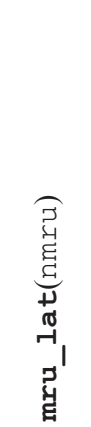 & 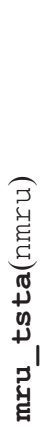 & 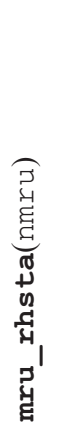 & 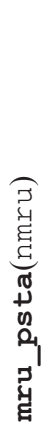 & 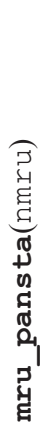 & 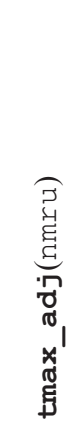 & 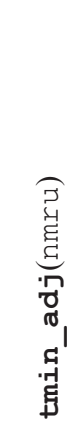 & 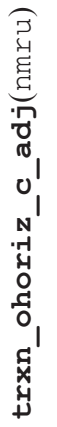 & 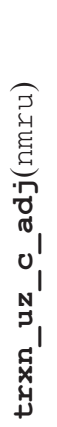 & 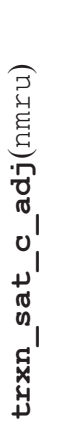 & 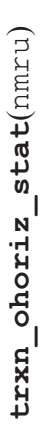 & 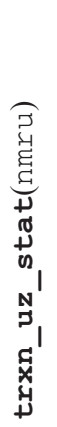 & 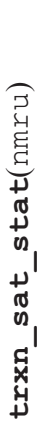 \\
\hline 11 & 0.04 & 130.6 & 46.36 & 1 & 1 & 1 & 1 & 0.5 & 0.5 & 0 & 0 & 0 & 2 & 2 & 2 \\
\hline 12 & 0.03 & 283.8 & 46.36 & 1 & 1 & 1 & 1 & -0.5 & -0.5 & 0 & 0 & 0 & 2 & 2 & 2 \\
\hline 17 & 0.02 & 309 & 46.35 & 1 & 1 & 1 & 1 & -0.5 & -0.5 & 0 & 0 & 0 & 2 & 2 & 2 \\
\hline 18 & 0.01 & 303.8 & 46.35 & 1 & 1 & 1 & 1 & -0.5 & -0.5 & 0 & 0 & 0 & 2 & 2 & 2 \\
\hline 19 & 0.03 & 330.5 & 46.34 & 1 & 1 & 1 & 1 & -0.5 & -0.5 & 0 & 0 & 0 & 2 & 2 & 2 \\
\hline 20 & 0.03 & 357.6 & 46.34 & 1 & 1 & 1 & 1 & -0.5 & -0.5 & 0 & 0 & 0 & 2 & 2 & 2 \\
\hline 21 & 0.03 & 283.8 & 46.36 & 1 & 1 & 1 & 1 & -0.5 & -0.5 & 0 & 0 & 0 & 2 & 2 & 2 \\
\hline 22 & 0.04 & 279 & 46.36 & 1 & 1 & 1 & 1 & -0.5 & -0.5 & 0 & 0 & 0 & 2 & 2 & 2 \\
\hline
\end{tabular}

Dimension: nmru, nmonths

rain_adj(nmru, nmonths)

\begin{tabular}{|c|c|c|c|c|c|c|c|c|c|c|c|c|}
\hline \multirow{3}{*}{ ક્ટ્y } & & & & & & & & & & & & \\
\hline & 1 & 2 & 3 & 4 & 5 & 6 & 7 & 8 & 9 & 10 & 11 & 12 \\
\hline & 1.0 & 1.0 & 1.0 & 1.0 & 1.0 & 1.0 & 1.0 & 1.0 & 1.0 & 1.0 & 1.0 & 1.0 \\
\hline
\end{tabular}

snow_adj(nmru, nmonths)

\begin{tabular}{|c|c|c|c|c|c|c|c|c|c|c|c|c|}
\hline & 1 & 2 & 3 & 4 & 5 & 6 & 7 & 8 & 9 & 10 & 11 & 12 \\
\hline $1-22$ & 1.0 & 1.0 & 1.0 & 1.0 & 1.0 & 1.0 & 1.0 & 1.0 & 1.0 & 1.0 & 1.0 & 1.0 \\
\hline
\end{tabular}


[ppt $\operatorname{rad} \operatorname{adj}($ imonth $s=1-12)=0.02$ ] of precipitation falls on a given day, cloudy conditions are assumed; therefore, simulated incoming solar radiation is reduced to 60 percent of clear-sky radiation on rainy days in the summer [radj_sppt(one) $=0.6]$ and to 50 percent in the winter $[$ radj_wppt $(o n e)=0.5]$. Irrigation does not affect radiation adjustments. The aspects [mru aspect(nmru)] of MRUs 1-11 are to the southeast; therefore, MRUs 1-11were assigned temperatures $0.5^{\circ} \mathrm{C}$ greater than expected by using lapse rate only [tmax_adj $(i \operatorname{mru}=1-11)=0.5$ and tmin_adj $($ imru $=1-11)=0.5]$. Similarly, MRUs $12-22$ were assigned slightly cooler temperatures to simulate northwestern aspects [tmax adj $(i m r u=12-22)=-0.5$ and tmin adj $(i m r u=12-22)=-0.5]$.

The Sunnyside Canal forms the northern boundary of the DR2 watershed. Water leaves the canal through calibrated head weirs, and each weir has an irrigation schedule in the data file. The seven head weirs (nirrig ext $=7$ ) included in this example are 28.90, 28.90A, 28.90B, 29.15, 29.38, 29.58, and 29.68 (fig. 46). Weirs are adjusted by RSBOJC ditchriders to deliver specific flow rates. These rates are normalized by the area of the irrigated fields to compute equivalent water depths. Water flowing through the lateral connected to weir 28.90 branches to fields where irrigation is controlled by weirs 28.90A and 28.90B, so the flows in the downstream weirs are subtracted from the flow measured at 28.90 to correctly apportion water to the fields served by $28.90,28.90 \mathrm{~A}$, and 28.90B. The equivalent water depths supplied by each weir, in inches, are the irrig_ext(nirrig_ext) variables in the data file. In this case, the external sources of irrigation refer to canal water, but an external source could be from any external source such as a well delivering water from a deep regional aquifer or a water-nutrient slurry delivered by truck. No upper limit applies to the irrigation applied from an external source on a given day.

This example includes two schedules (nirrig_int=2) for irrigation from internal sources. The values for irrig_int_next(nirrig_int) in the data file define the maximum depth to be supplied from an internal source. The maximum depths are reduced when insufficient water is available in the source (either saturated zone or stream) or when the pump capacity is insufficient to meet the requested demand. The irrigation from an external source [irrig_ext(nirrig_ext)] is applied on the indicated day; the irrigation from an internal source [irrig_int_next(nirrig_int)] is a watershed output on the indicated day but is then applied to an MRU as an input (along with any precipitation) on the following day. The reason for the one day offset is because the volume in the saturated zone or stream reservoir is not known until the end of the time step. If the demand for irrigation exceeds the available volume, then the actual volume to be delivered on the next day will be reduced.
The water passing over the weirs is gravity fed to delivery boxes along the crests of the interfluves (numbered boxes in figure 46). Water from the boxes is then siphoned or pumped to the heads of furrows for irrigation. In reality, each farmer adjusts the irrigation schedule to optimize crop yields on the basis of the recent weather, the crops, and the soils; in this example, all fields assigned to the same external weir receive the same daily depth of irrigation.

Each MRU receiving irrigation has a nonzero integer for the external or internal irrigation schedule parameters [irrig_sched_ext(nmru) orirrig_sched_int (nmru), respectively] (table 34). In this example, all MRUs except for MRU 19 have irrigation assigned. All but four MRUs receive irrigation from the Sunnyside Canal; the schedule of irrigation for each MRU is specified by the index of an irrigation schedule for a specific weir. For example, irrig_sched_ext $(i m r u=1)=2$ specifies that MRU 1 will be irrigated with the schedule irrig_ext(iirrig_ext=2); the inches of deposition for each day of the simulation are specified in the second column of external irrigation definitions in the data file, which is weir $28.90 \mathrm{~A}$.

For demonstration, two schedules for irrigation apply to internal sources (nirrig_int=2). When an internal schedule has been assigned, any positive integer assigned to irrig_int_src(nmru) indicates a stream reservoir that provides the irrigation water for the MRU; in this example, the number of stream reservoirs is one (nhydro=1) because all water leaves the watershed in less than 1 day. Internal sources are defined for MRUs 7 and 9, where irrig_sched_int $(\mathrm{imru}=7,9)=1$ indicates the first internal irrigation schedule will be used, and irrig_int_src $(i \operatorname{mru}=7,9)=1$ indicates irrigation water will be pumped from the first stream reservoir. When an internal schedule has been assigned and irrig_int_src(imru) equals zero, the irrigation is pumped from the saturated zone of that MRU, which is the case for MRU 2 [irrig_int_src $(i m r u=2)=0$ ]. The irrigation schedule is defined to be the second of the internal source schedules [irrig_sched_int $($ imru $=2)=2$ ]; values in the second column of internal source schedules [irrig_int_next(iirrig_int=2)] specify the inches of water that are taken from the saturated zone of MRU 2.

WEBMOD allows a maximum of two unique groundwater input sources for each MRU; the DR2 model uses both. The first source, with application depths described by sched_gw1(nmru), is leakage of low-ionic-strength canal water through the earthen bed of the Sunnyside Canal. The second source, with application depths described by sched gw2(nmru), is high-ionic-strength groundwater that enters the DR2 watershed from the north and flows underneath the Sunnyside Canal. The upgradient groundwater is derived from infiltration of precipitation on the Rattlesnake Hills and from irrigation applied to fields fed by Roza Canal and Outlook Canal, north of the Sunnyside Canal (fig. 45). Seepage runs 
Table 34. Parameters mapping irrigation for the DR2 model.

[The formatting convention used in this report is to present dimension names in Courier New font and parameter names in bold Courier New font. See tables 1 and 2 for descriptions of dimensions and parameters]

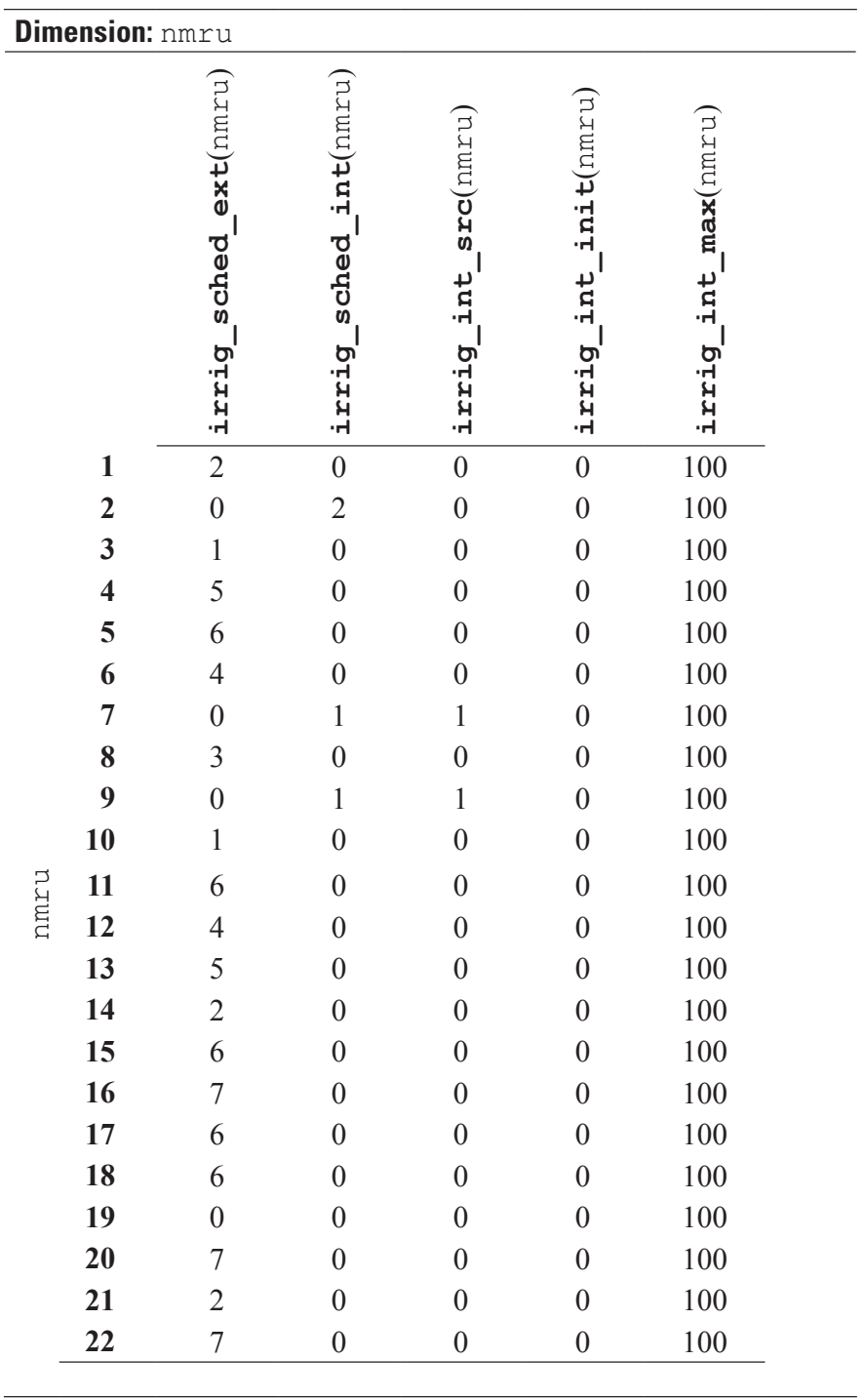

during the irrigation season have documented a loss of approximately 1 cubic foot per second per mile of canal $\left(\left(\mathrm{ft}^{3} / \mathrm{s}\right) / \mathrm{mi}\right)$ from Sunnyside Canal when it is in use (McCarthy and Johnson, 2009); the canal does not leak after mid-October because the canal is drained after the growing season. Similarly, using the measured hydrograph as the calibration target, the flux of upgradient groundwater underneath Sunnyside Canal is the source of an additional $6\left(\mathrm{ft}^{3} / \mathrm{s}\right) / \mathrm{mi}$ during the irrigation season decreasing to approximately $3\left(\mathrm{ft}^{3} / \mathrm{s}\right) / \mathrm{mi}$ from mid-October to mid-March during the nonirrigation season. The canal leakage and the upgradient groundwater fluxes for an MRU, in cubic feet per second per mile, are defined by an index to a schedule. For the DR2 model, the canal leakage is defined with sched_gw1(nmru) and the upgradient groundwater fluxes are defined with sched_gw2(nmru) (table 35). Both values of these parameters point to columns of groundwater schedules [gw_ext(ngw_ext)] in the hydrologic data file that contain the rates of inflow, in cubic feet per second per mile.

To compute the cubic meters of water entering the DR2 model domain from the leaky canal and the upgradient groundwater, the inflow rates, in cubic feet per second per mile, are converted to cubic meters of water per meter of boundary per day and multiplied by length of the boundary, in meters. Approximately 1,200 m of the Sunnyside Canal forms the boundary of the watershed north of MRUs $1,12,2,13,4,15,11$, and 22 (fig. 48). Assigning boundary lengths to these MRUs that sum to $1,200 \mathrm{~m}$ would provide the appropriate volume of water to the DR2 model domain. Unfortunately, WEBMOD has no mechanism to transfer groundwater from the saturated zone of an MRU to the saturated zone of an adjacent MRU. Therefore, the water tables for the MRUs that received groundwater inflow would be unrealistically high compared with adjacent MRUs that were not assigned groundwater inflow. To produce a more realistic simulation, the $1,200 \mathrm{~m}$ of boundary is assigned to all MRUs weighted by the MRU area [multiply 1,200 by the mru_area(nmru) and divide by the basin_area(one)]. These computed boundary lengths are the parameter values defined for gwbnd_len1(nmru), canal inflow, and 
Table 35. Parameters defining upgradient groundwater inputs for the DR2 model.

[The formatting convention used in this report is to present dimension names in Courier New font and parameter names in bold Courier New font. See tables 1 and 2 for descriptions of dimensions and parameters. The value of $11\left(10^{-11}\right)$ for $\mathbf{g w}$ _loss_k indicates no leakage into bedrock]

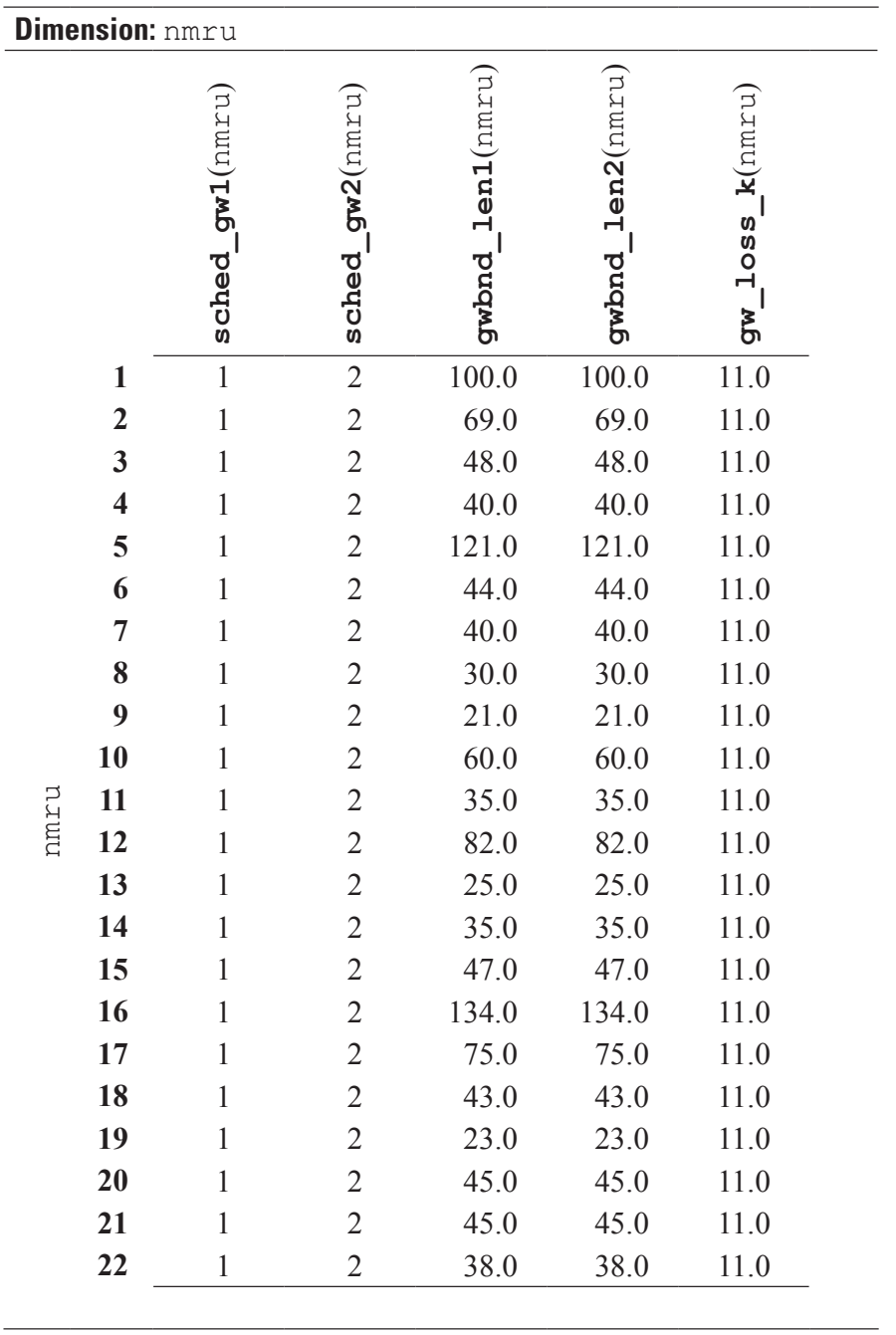

gwbnd len2(nmru), upgradient groundwater inflow, and are listed in table 35 . No groundwater loss through the bottom of the model domain is simulated. The parameters for groundwater loss are set to 11 [gw loss $\mathbf{k}(i \mathrm{mru}=1-22)=11$ ], which translates to a permeability of $10^{-11} \mathrm{~cm} / \mathrm{s}$. Any value of gw_loss_k $\mathbf{k m r u})$ equal to or greater than 11 results in zero leakage through the bottom of the saturated zone.

Parameters describing the seasonality of ET include canopy densities, dates for the beginning and end of the transpiration season, canopy interception rates, and Hamon coefficients. The canopy density is 60 percent in summer [covden sum(nmru $=0.6$ ] and 10 percent in winter [covden_win $\bar{n}(\mathrm{nmru})=0.1$ ] as listed in table 36 . Beginning on March $\overline{1}$ [transp_beg $(i m r u=1-22)=3$ ], daily maximum temperatures, in degrees Celsius, are summed until the day the sum exceeds 500 [transp_tmax_c $($ imru $=1-22)=500$ ].

On the day that the sum exceeds 500 , summer canopy density and increased transpiration rates begin. Winter canopy density and decreased transpiration rates are used beginning on November 1 [transp_end $($ imru=1-22) $=11$ ]. Typical canopy interception rates are used for summer rain [srain in tcp $(i \operatorname{mru}=1-22)=0.1]$, winter rain [wrain intcp $(i m r u=1-22)=0.15]$, and snow [snow_intcp $($ imru $=1-22)=0.2]$. The Hamon coefficient is set to 0.01 for all months

[hamon coef $($ imonths $=1-12)=0.01$ ].

Default values are used for most snowpack parameters, and no initial snowpack is assigned $[\mathrm{WEI}(\mathrm{imru}=1-22)=0]$ as listed in table 37 . Soil porosity [s_porosity $($ imru $=1-22)=0.45$ ], field capacity [s_theta_fc(imru=1-22) $=0.25]$, and wilting point [s_theta_wp $($ imru=1-22) $=0.12$ ] are typical of a sandy loam (table 38; Meyer and others, 1997) with limited vertical conductivity $[\mathbf{x k} 0($ imru $=1-22)=0.003$ and $\mathbf{x k} \mathbf{c v}($ imru=1-22)=14]. Of the water that infiltrates through the root zone to recharge the groundwater, 30 percent is diverted to preferential flow [qdffrac $(i \operatorname{mru}=1-22)=0.3]$. The remaining 70 percent of recharge will raise the water table when recharge exceeds the discharge of groundwater through pipe flow (tile drains) and base flow. 
Table 36. Parameters for evapotranspiration in the DR2 model.

[The formatting convention used in this report is to present dimension names in Courier New font and parameter names in bold Courier New font. See tables 1 and 2 for descriptions of dimensions and parameters]

Dimension: nmonths

\begin{tabular}{|c|c|c|c|c|c|c|c|c|c|c|c|c|}
\hline & 1 & 2 & 3 & 4 & 5 & 6 & 7 & 8 & 9 & 10 & 11 & 12 \\
\hline epan_coef(nmonths) & 1.00 & 1.00 & 1.00 & 1.00 & 1.00 & 1.00 & 1.00 & 1.00 & 1.00 & 1.00 & 1.00 & 1.00 \\
\hline hamon_coef(nmonths) & 0.01 & 0.01 & 0.01 & 0.01 & 0.01 & 0.01 & 0.01 & 0.01 & 0.01 & 0.01 & 0.01 & 0.01 \\
\hline
\end{tabular}

Dimension: nmru

\begin{tabular}{|c|c|c|c|c|c|c|c|c|c|c|c|c|}
\hline & 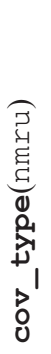 & 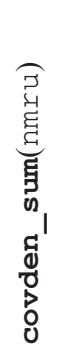 & 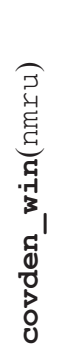 & 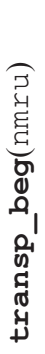 & 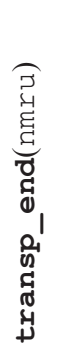 & 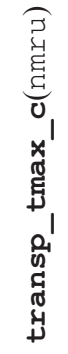 & 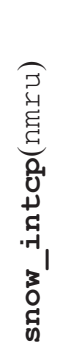 & 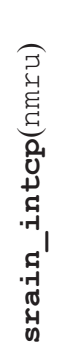 & 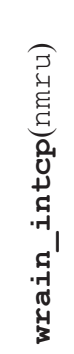 & 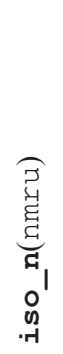 & 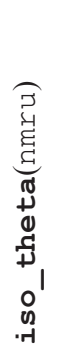 & 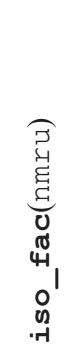 \\
\hline $1-22$ & 1 & 0.6 & 0.1 & 3 & 11 & 500 & 0.2 & 0.1 & 0.15 & 0.5 & 1 & 0.15 \\
\hline
\end{tabular}

Table 37. Snowpack parameters for the DR2 model.

[The formatting convention used in this report is to present dimension names in Courier New font and parameter names in bold Courier New font. See tables 1 and 2 for descriptions of dimensions and parameters]

Dimension: one

ALAT(one) $\quad 46.4$

Dimension: ndepval

\begin{tabular}{cccccccccccc}
$\operatorname{ADC}($ ndeplval) & $\mathbf{1}$ & $\mathbf{2}$ & $\mathbf{3}$ & $\mathbf{4}$ & $\mathbf{5}$ & $\mathbf{6}$ & $\mathbf{7}$ & $\mathbf{8}$ & $\mathbf{9}$ & $\mathbf{1 0}$ & $\mathbf{1 1}$ \\
\cline { 2 - 11 } & 0.05 & 0.24 & 0.4 & 0.52 & 0.65 & 0.75 & 0.82 & 0.88 & 0.93 & 0.99 & 1 \\
\cline { 2 - 12 } & $\mathbf{1 2}$ & $\mathbf{1 3}$ & $\mathbf{1 4}$ & $\mathbf{1 5}$ & $\mathbf{1 6}$ & $\mathbf{1 7}$ & $\mathbf{1 8}$ & $\mathbf{1 9}$ & $\mathbf{2 0}$ & $\mathbf{2 1}$ & $\mathbf{2 2}$ \\
\cline { 2 - 12 } & 0.02 & 0.047 & 0.114 & 0.212 & 0.318 & 0.416 & 0.498 & 0.56 & 0.592 & 0.604 & 0.604 \\
\hline
\end{tabular}

Dimension: nmru

\begin{tabular}{|c|c|c|c|c|c|c|c|c|c|c|c|c|c|c|}
\hline & 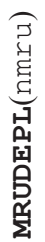 & 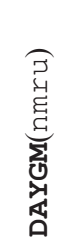 & 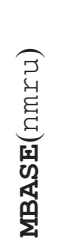 & 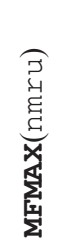 & 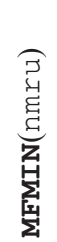 & 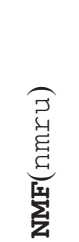 & 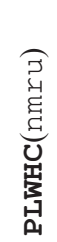 & 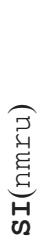 & 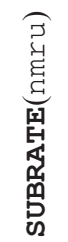 & 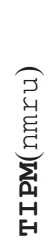 & 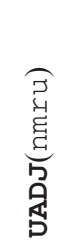 & 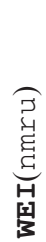 & 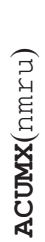 & 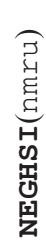 \\
\hline $1-22$ & 1 & 0.01 & 38 & 1.6 & 0.3 & 0.15 & 0.1 & 5 & 0.01 & 0.3 & 0.03 & 0 & 0 & 0 \\
\hline
\end{tabular}


Table 38. Hillslope parameters for the DR2 model.

[The formatting convention used in this report is to present dimension names in Courier New font and parameter names in bold Courier New font. See tables 1 and 2 for descriptions of dimensions and parameters]

Dimension: one

infex(one) 1

\section{Dimension: nmru}

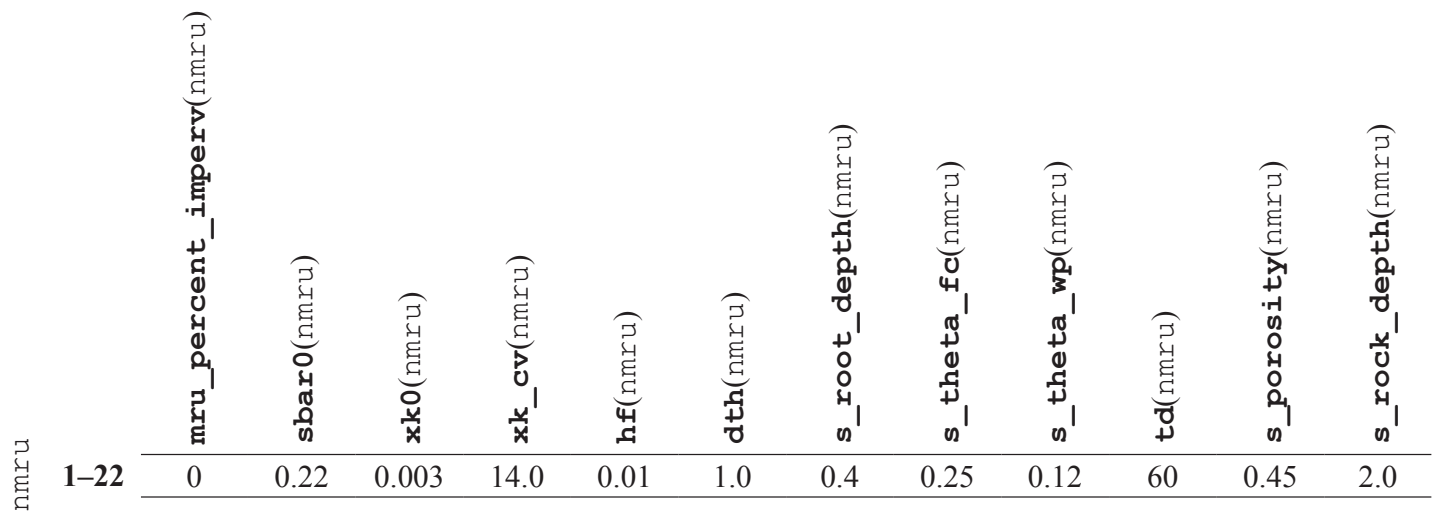

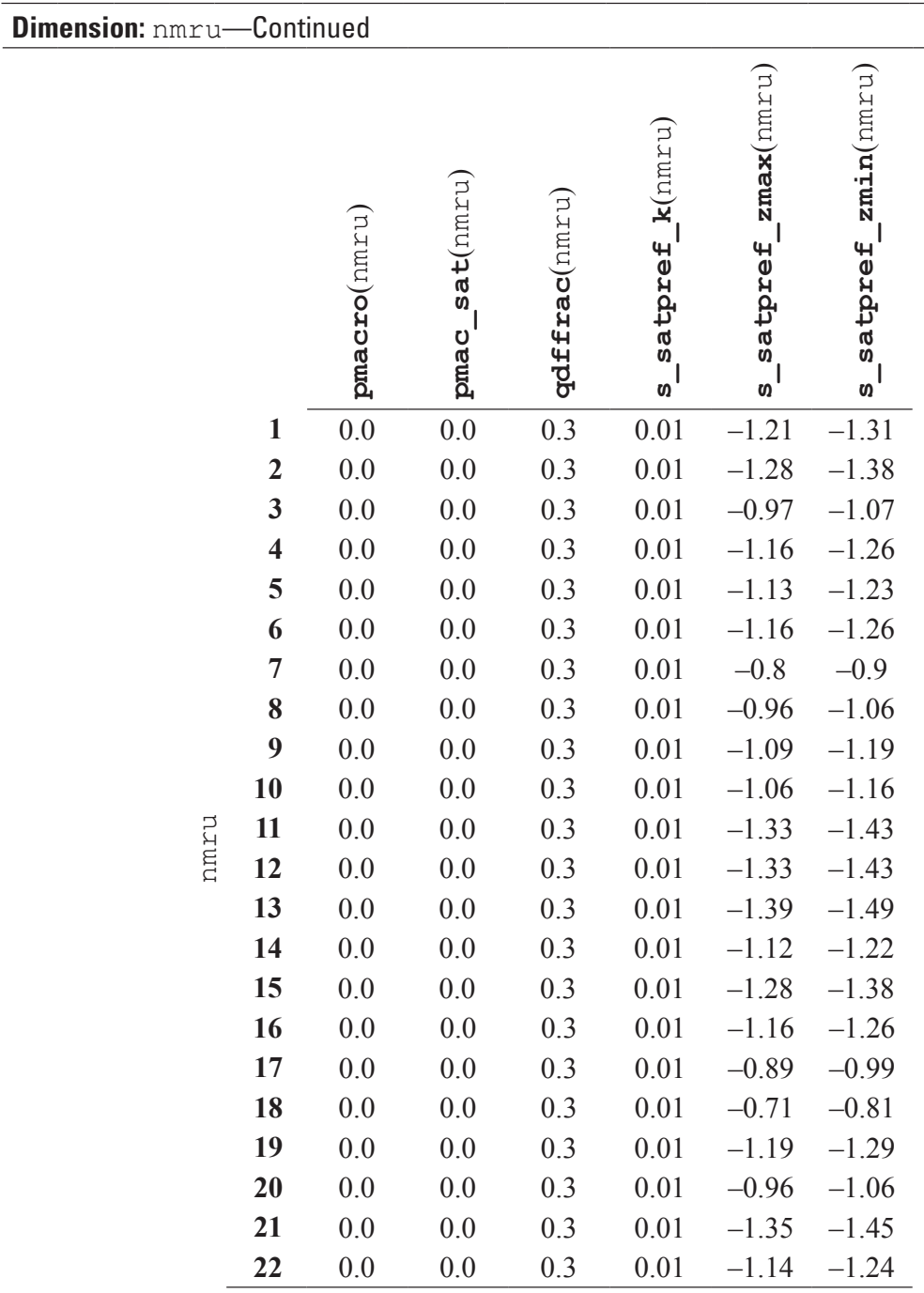


Tile drains are simulated to result in pipe flow [qpref $(\mathrm{nmru})>0.0]$ whenever the average water table [z_wt(nmru)] rises above the lower threshold [s_satpref_zmin(nmru)]. The altitude of the water table and the threshold are in meters above land surface, so both these values are always negative (or zero). The lower threshold was set to the mean water-table altitude simulated for each MRU with no tile drains in the simulation. As the water table rises during the irrigation season, pipe flow increases. The flow is dependent on the height of the water table above the lower threshold and the preferential-zone conductivity [s_satpref_k $($ imru $=1-22)=0.01 \mathrm{~cm} / \mathrm{s}]$; the maximum flow rate is attained when the water table reaches or exceeds the upper threshold [s_satpref_zmax(nmru)]. In this example, the upper threshold was assigned an altitude $10 \mathrm{~cm}$ $(0.1 \mathrm{~m})$ above the lower threshold, so the maximum pipe flow is $0.1 \times 0.01 \times 36=0.036 \mathrm{~m} / \mathrm{h}$.

\section{Geochemical Simulations}

The flows from the hydrologic model are used to simulate conservative mixing of chloride (nsolute $=1$ ), as listed in table 39, from multiple initial and inflowing solutions that are defined in the webmod.pqi file. WEBMOD reserves SOLUTION 1 for pure water removed from hillslope reservoirs by evaporation. Solutions 0,2 , and 3 , each with distinct concentrations of chloride, are defined to initialize all reservoirs and to act as constant composition sources for precipitation, canal water, and groundwater as follows:

$\begin{array}{ll}\text { SOLUTION } 0 & \text { Precipitation } \\ \text {-units } & \text { mg/kgw } \\ \text { Cl } & 0.2 \\ \text { SOLUTION 1 } & \text { Evaporation (pure } \\ & \text { water) } \\ \text { SOLUTION 2 } & \text { Irrigation, channel } \\ & \text { leakage and initial } \\ & \text { canopy, snow, and } \\ & \text { stream } \\ & \text { mg/kgw } \\ & 0.8 \\ \text {-units } & \text { All other hillslope } \\ \text { reservoirs and upslope } \\ \text { SOLUTION 3 }\end{array}$

Table 39. Biogeochemical simulation switch and single solute tracked for the DR2 model.

[Solutes of interest and descriptors are listed in the Dimensions section of the parameter file. The formatting convention used in this report is to present dimension names in Courier New font and parameter names in bold Courier New font. See tables 1 and 2 for definitions of dimensions and parameters]

\begin{tabular}{|c|c|c|}
\hline \multicolumn{3}{|l|}{ Dimension: one } \\
\hline \multicolumn{2}{|c|}{ chem_sim(one) } & 1 \\
\hline \multicolumn{3}{|l|}{ Dimension: nsolute } \\
\hline \multicolumn{3}{|c|}{ nsolute } \\
\hline & Species & Descriptor \\
\hline $\mathbf{1}$ & $\mathrm{Cl}$ & @Chloride \\
\hline
\end{tabular}

Constant compositions are specified for precipitation and external sources of groundwater by setting ppt_chem(one) and chem_ext(one) to zero (table 40). Initial assignments of geochemical entities to all hillslope and stream reservoirs are made as indicated in table 41 . The entities include the assignment of partial pressures of oxygen and carbon dioxide in the atmosphere in the block EQUILIBRIUM_PHASES 0 of webmod.pqi. Because input solution compositions do not vary with time, no webmod. chem.dat file is necessary. Inputs are of constant composition; however, WEBMOD will still simulate an ionic pulse for melting snowpack such that the chloride concentrations in the melt will be 10 times the concentration left in the remaining snowpack (table 42).

A water balance of inputs, ET, and discharge indicates that groundwater inputs from canal leakage and upgradient groundwater are approximately $7\left(\mathrm{ft}^{3} / \mathrm{s}\right) / \mathrm{mi}$ during the irrigation season and $3\left(\mathrm{ft}^{3} / \mathrm{s}\right) / \mathrm{mi}$ during the nonirrigation season. Seepage runs have indicated that $1\left(\mathrm{ft}^{3} / \mathrm{s}\right) / \mathrm{mi}$ leaks from Sunnyside Canal. The simulation assigns a chloride concentration of $0.8 \mathrm{mg} / \mathrm{L}$ to the canal leakage and $20 \mathrm{mg} / \mathrm{L}$ to the upgradient groundwater. The schedule of flows for the low-concentration canal leakage [gw_ext $\left.\left(i g w \_e x t=1\right)\right]$ is $1\left(\mathrm{ft}^{3} / \mathrm{s}\right) / \mathrm{mi}$ for the irrigation season and $0\left(\mathrm{ft}^{3} / \mathrm{s}\right) / \mathrm{mi}$ during the nonirrigation season. The schedule of flows for the high-concentration, upgradient groundwater inflow [gw_ext $\left(i g w_{-}\right.$ext $\left.\left.=2\right)\right]$ is $6\left(\mathrm{ft}^{3} / \mathrm{s}\right) / \mathrm{mi}$ during the irrigation season and $3\left(\overline{\mathrm{ft}^{3}} / \mathrm{s}\right) / \mathrm{mi}$ during the nonirrigation season. 
Table 40. Input dynamics, conversion factors, static reservoirs, and the transformed topographic index threshold that separates riparian from upland areas for the DR2 model.

[The formatting convention used in this report is to present dimension names in Courier New font and parameter names in bold Courier New font. See tables 1 and 2 for definitions of dimensions and parameters]

\begin{tabular}{|c|c|c|c|}
\hline \multicolumn{4}{|l|}{ Dimension: one } \\
\hline \multirow{2}{*}{$\begin{array}{l}\text { ppt_chem(one) } \\
\text { chem_ext }(o n e)\end{array}$} & \multicolumn{3}{|l|}{0} \\
\hline & 0 & & \\
\hline c_can_depth (one) & \multicolumn{3}{|l|}{0.001} \\
\hline \multicolumn{4}{|l|}{ Dimension: nconvert } \\
\hline & \multicolumn{3}{|c|}{ nconvert } \\
\hline & 1 & 2 & 3 \\
\hline convfactor(nconvert) & $1,410,000.0$ & 1.0 & 1.0 \\
\hline \multicolumn{4}{|l|}{ Dimension: nmru } \\
\hline \multirow{2}{*}{ 胥 1-22 } & 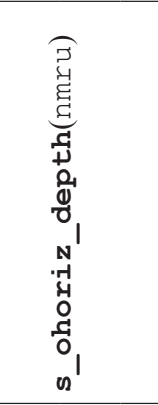 & 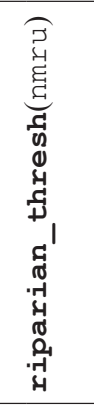 & \\
\hline & 0.005 & 10.0 & \\
\hline
\end{tabular}

Table 41. Initial assignments of inputs, hillslope reservoirs, and stream segments in the DR2 model to the entities defined in webmod.pqi.

[The formatting convention used in this report is to present file names in italic font, dimension names in Courier New font, and parameter names in bold Courier New font. See tables 1 and 2 for definitions of dimensions and parameters. *, file name]

Dimension: one

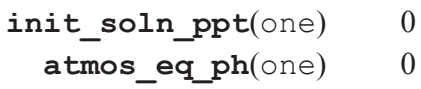

Dimension: $\mathrm{nchem}$ ext $=2$

\begin{tabular}{lll} 
& \multicolumn{2}{c}{ nchem_ext } \\
\cline { 2 - 3 } init_soln_ext(nchem_ext) & $\mathbf{1}$ & $\mathbf{2}$ \\
\cline { 2 - 3 } & 2 & 3
\end{tabular}

Dimension: nmru

\begin{tabular}{|c|c|c|c|c|c|c|c|c|c|}
\hline & 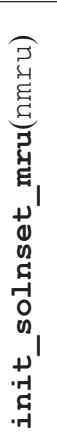 & 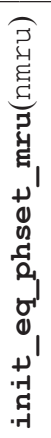 & 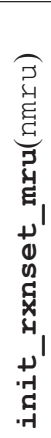 & 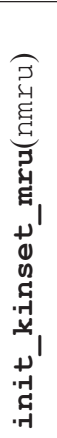 & 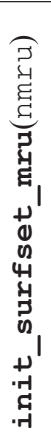 & 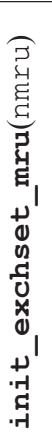 & 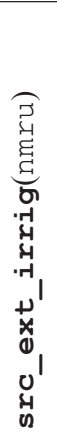 & 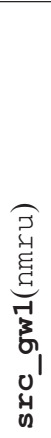 & 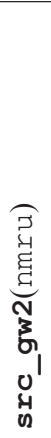 \\
\hline $1-22$ & 1 & 1 & 1 & 1 & 1 & 1 & 1 & 1 & 2 \\
\hline
\end{tabular}


Table 41. Initial assignments of inputs, hillslope reservoirs, and stream segments in the DR2 model to the entities defined in webmod.pqi. -Continued

[The formatting convention used in this report is to present file names in italic font, dimension names in Courier New font, and parameter names in bold Courier New font. See tables 1 and 2 for definitions of dimensions and parameters. *, file name]

Dimension: nmru_res, nhcs: unique hillslope pointers to *.pqi file

solnset_table(nmru_res, nhcs)

\begin{tabular}{|c|c|c|c|c|c|c|c|c|c|c|}
\hline & \multicolumn{10}{|c|}{ nhes } \\
\hline & 1 & 2 & 3 & 4 & 5 & 6 & 7 & 8 & 9 & 10 \\
\hline 1 & 2 & 1 & 1 & 1 & 1 & 1 & 1 & 1 & 1 & 1 \\
\hline 2 & 2 & 1 & 1 & 1 & 1 & 1 & 1 & 1 & 1 & 1 \\
\hline 3 & 3 & 1 & 1 & 1 & 1 & 1 & 1 & 1 & 1 & 1 \\
\hline 4 & 3 & 1 & 1 & 1 & 1 & 1 & 1 & 1 & 1 & 1 \\
\hline 5 & 3 & 1 & 1 & 1 & 1 & 1 & 1 & 1 & 1 & 1 \\
\hline 6 & 3 & 1 & 1 & 1 & 1 & 1 & 1 & 1 & 1 & 1 \\
\hline 7 & 3 & 1 & 1 & 1 & 1 & 1 & 1 & 1 & 1 & 1 \\
\hline 8 & 3 & 1 & 1 & 1 & 1 & 1 & 1 & 1 & 1 & 1 \\
\hline 9 & 3 & 1 & 1 & 1 & 1 & 1 & 1 & 1 & 1 & 1 \\
\hline
\end{tabular}

eq_phset_table(nmru_res, nhcs)

\begin{tabular}{|c|c|c|c|c|c|c|c|c|c|c|}
\hline & \multicolumn{10}{|c|}{ nhes } \\
\hline & 1 & 2 & 3 & 4 & 5 & 6 & 7 & 8 & 9 & 10 \\
\hline 1 & -1 & -1 & -1 & -1 & -1 & -1 & -1 & -1 & -1 & -1 \\
\hline 2 & -1 & -1 & -1 & -1 & -1 & -1 & -1 & -1 & -1 & -1 \\
\hline 3 & -1 & -1 & -1 & -1 & -1 & -1 & -1 & -1 & -1 & -1 \\
\hline 4 & -1 & -1 & -1 & -1 & -1 & -1 & -1 & -1 & -1 & -1 \\
\hline 5 & -1 & -1 & -1 & -1 & -1 & -1 & -1 & -1 & -1 & -1 \\
\hline 6 & -1 & -1 & -1 & -1 & -1 & -1 & -1 & -1 & -1 & -1 \\
\hline 7 & -1 & -1 & -1 & -1 & -1 & -1 & -1 & -1 & -1 & -1 \\
\hline 8 & -1 & -1 & -1 & -1 & -1 & -1 & -1 & -1 & -1 & -1 \\
\hline 9 & -1 & -1 & -1 & -1 & -1 & -1 & -1 & -1 & -1 & -1 \\
\hline
\end{tabular}

rxnset_table(nmru_res, nhcs)

\begin{tabular}{|c|c|c|c|c|c|c|c|c|c|c|}
\hline & \\
\hline & 1 & 2 & 3 & 4 & 5 & 6 & 7 & 8 & 9 & 10 \\
\hline 1 & -1 & -1 & -1 & -1 & -1 & -1 & -1 & -1 & -1 & -1 \\
\hline 2 & -1 & -1 & -1 & -1 & -1 & -1 & -1 & -1 & -1 & -1 \\
\hline 3 & -1 & -1 & -1 & -1 & -1 & -1 & -1 & -1 & -1 & -1 \\
\hline 4 & -1 & -1 & -1 & -1 & -1 & -1 & -1 & -1 & -1 & -1 \\
\hline 5 & -1 & -1 & -1 & -1 & -1 & -1 & -1 & -1 & -1 & -1 \\
\hline 6 & -1 & -1 & -1 & -1 & -1 & -1 & -1 & -1 & -1 & -1 \\
\hline 7 & -1 & -1 & -1 & -1 & -1 & -1 & -1 & -1 & -1 & -1 \\
\hline 8 & -1 & -1 & -1 & -1 & -1 & -1 & -1 & -1 & -1 & -1 \\
\hline 9 & -1 & -1 & -1 & -1 & -1 & -1 & -1 & -1 & -1 & -1 \\
\hline
\end{tabular}


Table 41. Initial assignments of inputs, hillslope reservoirs, and stream segments in the DR2 model to the entities defined in webmod.pqi. -Continued

[The formatting convention used in this report is to present file names in italic font, dimension names in Courier New font, and parameter names in bold Courier New font. See tables 1 and 2 for definitions of dimensions and parameters. *, file name]

kinset_table(nmru_res, nhcs)

\begin{tabular}{|c|c|c|c|c|c|c|c|c|c|c|}
\hline & 1 & 2 & 3 & 4 & 5 & 6 & 7 & 8 & 9 & 10 \\
\hline 1 & -1 & -1 & -1 & -1 & -1 & -1 & -1 & -1 & -1 & -1 \\
\hline 2 & -1 & -1 & -1 & -1 & -1 & -1 & -1 & -1 & -1 & -1 \\
\hline 3 & -1 & -1 & -1 & -1 & -1 & -1 & -1 & -1 & -1 & -1 \\
\hline 4 & -1 & -1 & -1 & -1 & -1 & -1 & -1 & -1 & -1 & -1 \\
\hline 5 & -1 & -1 & -1 & -1 & -1 & -1 & -1 & -1 & -1 & -1 \\
\hline 6 & -1 & -1 & -1 & -1 & -1 & -1 & -1 & -1 & -1 & -1 \\
\hline 7 & -1 & -1 & -1 & -1 & -1 & -1 & -1 & -1 & -1 & -1 \\
\hline 8 & -1 & -1 & -1 & -1 & -1 & -1 & -1 & -1 & -1 & -1 \\
\hline 9 & -1 & -1 & -1 & -1 & -1 & -1 & -1 & -1 & -1 & -1 \\
\hline
\end{tabular}

surfset_table(nmru_res, nhcs)

\begin{tabular}{|c|c|c|c|c|c|c|c|c|c|c|}
\hline & \multicolumn{10}{|c|}{ nhes } \\
\hline & 1 & 2 & 3 & 4 & 5 & 6 & 7 & 8 & 9 & 10 \\
\hline 1 & -1 & -1 & -1 & -1 & -1 & -1 & -1 & -1 & -1 & -1 \\
\hline 2 & -1 & -1 & -1 & -1 & -1 & -1 & -1 & -1 & -1 & -1 \\
\hline 3 & -1 & -1 & -1 & -1 & -1 & -1 & -1 & -1 & -1 & -1 \\
\hline 4 & -1 & -1 & -1 & -1 & -1 & -1 & -1 & -1 & -1 & -1 \\
\hline 5 & -1 & -1 & -1 & -1 & -1 & -1 & -1 & -1 & -1 & -1 \\
\hline 6 & -1 & -1 & -1 & -1 & -1 & -1 & -1 & -1 & -1 & -1 \\
\hline 7 & -1 & -1 & -1 & -1 & -1 & -1 & -1 & -1 & -1 & -1 \\
\hline 8 & -1 & -1 & -1 & -1 & -1 & -1 & -1 & -1 & -1 & -1 \\
\hline 9 & -1 & -1 & -1 & -1 & -1 & -1 & -1 & -1 & -1 & -1 \\
\hline
\end{tabular}

exchset_table(nmru_res, nhcs)

\begin{tabular}{|c|c|c|c|c|c|c|c|c|c|c|}
\hline & \multicolumn{10}{|c|}{ nhes } \\
\hline & 1 & 2 & 3 & 4 & 5 & 6 & 7 & 8 & 9 & 10 \\
\hline 1 & -1 & -1 & -1 & -1 & -1 & -1 & -1 & -1 & -1 & -1 \\
\hline 2 & -1 & -1 & -1 & -1 & -1 & -1 & -1 & -1 & -1 & -1 \\
\hline 3 & -1 & -1 & -1 & -1 & -1 & -1 & -1 & -1 & -1 & -1 \\
\hline 4 & -1 & -1 & -1 & -1 & -1 & -1 & -1 & -1 & -1 & -1 \\
\hline 5 & -1 & -1 & -1 & -1 & -1 & -1 & -1 & -1 & -1 & -1 \\
\hline 6 & -1 & -1 & -1 & -1 & -1 & -1 & -1 & -1 & -1 & -1 \\
\hline 7 & -1 & -1 & -1 & -1 & -1 & -1 & -1 & -1 & -1 & -1 \\
\hline 8 & -1 & -1 & -1 & -1 & -1 & -1 & -1 & -1 & -1 & -1 \\
\hline 9 & -1 & -1 & -1 & -1 & -1 & -1 & -1 & -1 & -1 & -1 \\
\hline
\end{tabular}


Table 41. Initial assignments of inputs, hillslope reservoirs, and stream segments in the DR2 model to the entities defined in webmod.pqi. -Continued

[The formatting convention used in this report is to present file names in italic font, dimension names in Courier New font, and parameter names in bold Courier New font. See tables 1 and 2 for definitions of dimensions and parameters. *, file name]

\begin{tabular}{|c|c|c|c|c|c|c|}
\hline & 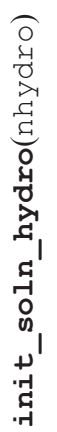 & 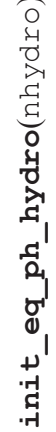 & 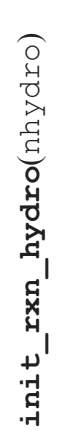 & 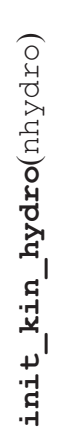 & 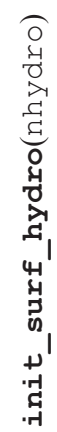 & 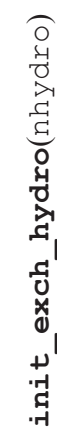 \\
\hline nhydro $\mathbf{1}$ & 2 & -1 & -1 & -1 & -1 & -1 \\
\hline
\end{tabular}

Table 42. Parameters for incongruent melting of solutes and isotopes from snowpack for the DR2 model.

[The formatting convention used in this report is to present dimension names in Courier New font and parameter names in bold Courier New font. See tables 1 and 2 for definitions of dimensions and parameters]

\begin{tabular}{|c|c|c|c|}
\hline \multicolumn{4}{|l|}{ Dimension: nmru } \\
\hline & 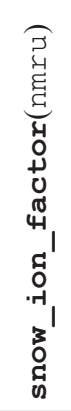 & 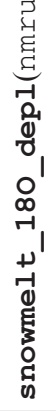 & 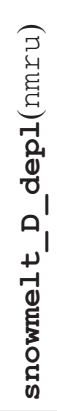 \\
\hline $1-22$ & 10 & 0 & 0 \\
\hline
\end{tabular}


To demonstrate how to use custom output units, a conversion factor was derived to estimate specific conductance from the simulated concentrations of chloride. From March 4, 2003, through October 24, 2004, a suite of other analytes including chloride and specific conductance were analyzed (McCarthy and Johnson, 2009). A line with a zero intercept was fit to data for specific conductance, in microsiemens per centimeter, and chloride, in milligrams per liter, for 64 samples collected at the DR2 gage (fig. 49). The slope of the line (39.678) is multiplied by the chloride formula weight of $35,453 \mathrm{mg} / \mathrm{mol}$ to compute a conversion factor [convfactor(1)] of 1,410,000 $(\mu \mathrm{S} / \mathrm{cm}) / \mathrm{mol}$.

The hydrologic output file is set to output daily fluxes [print freq(one)=8], and the chemvars is configured to output the concentration in hillslope reservoirs and streams for each day, in milligrams per liter (table 43).

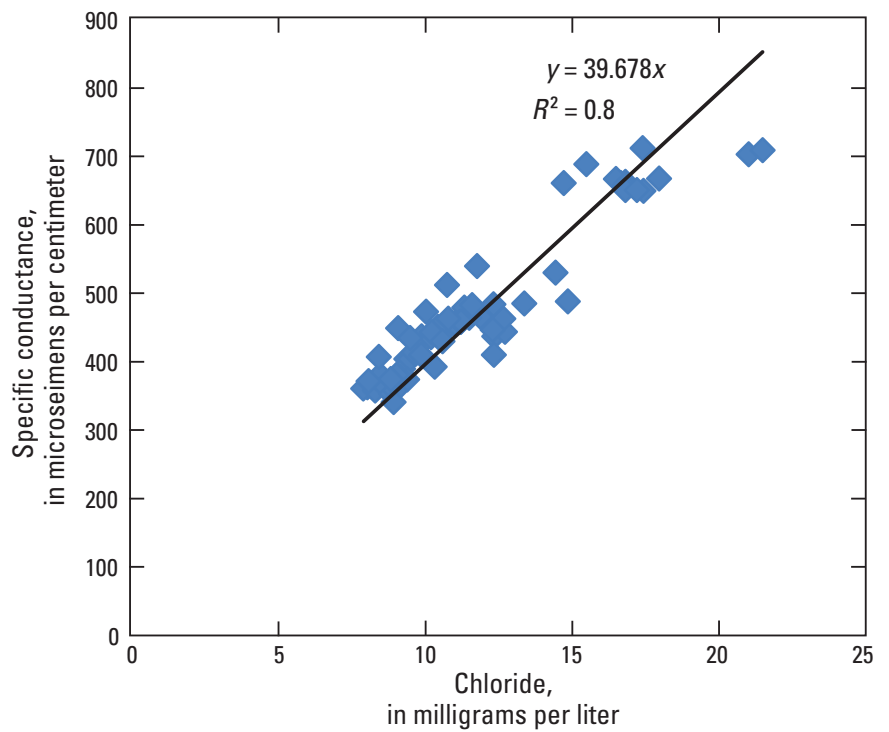

Figure 49. Specific conductance (y), in microsiemens per centimeter, versus chloride concentrations (x), in milligrams per liter, for water-quality samples collected at the DR2 gage at Yakima Highway from March 4, 2003, through October 24, 2004. The coefficient of determination $\left(\mathrm{R}^{2}\right)$ of the relation is 0.8 .
Table 43. Parameters for output and user-defined variables for the DR2 model.

[The formatting convention used in this report is to present dimension names in Courier New font and parameter names in bold Courier New font. See tables 1 and 2 for definitions of dimensions and parameters]

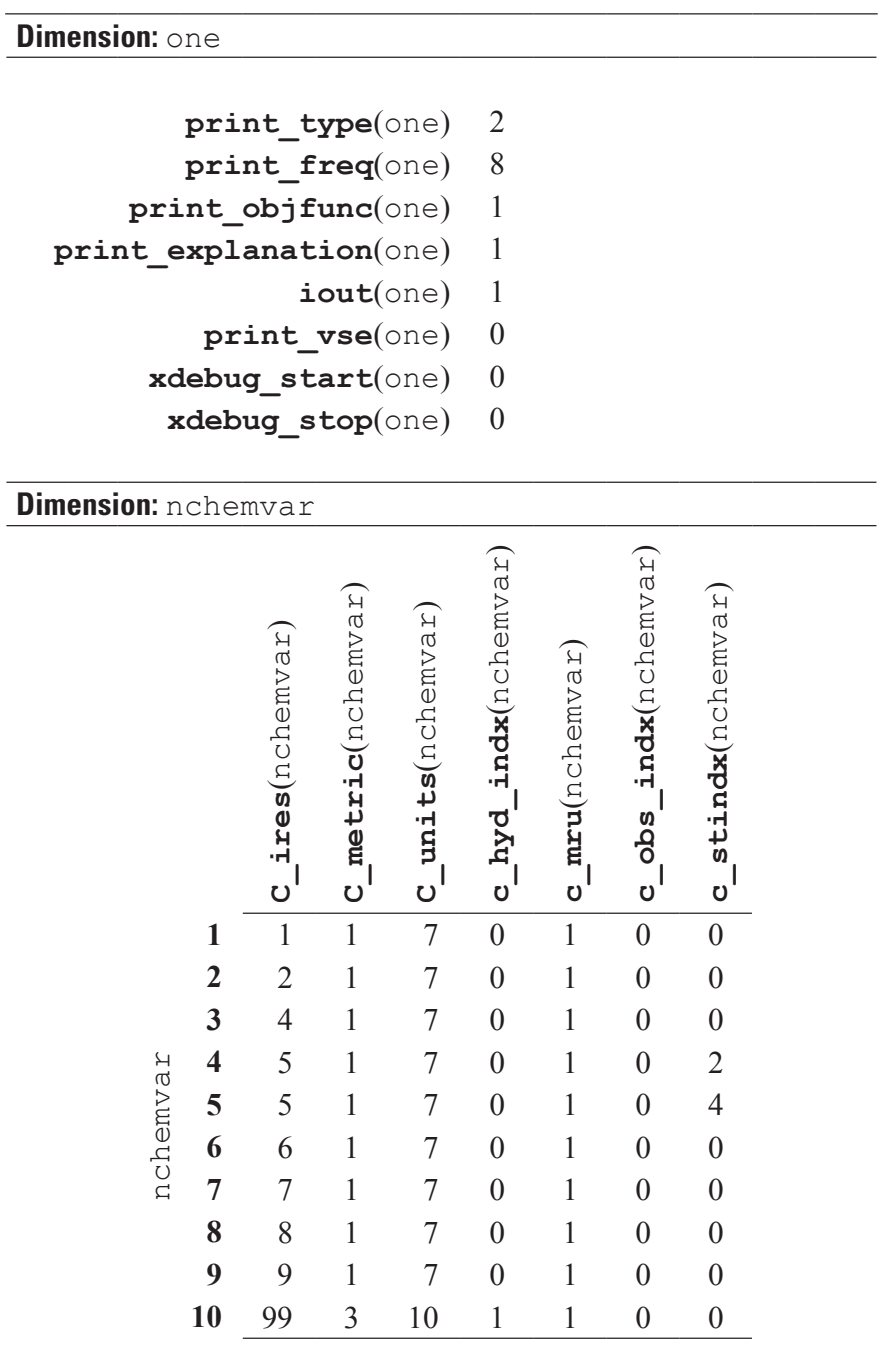




\section{Model Calibration, Results, and Discussion}

The DR2 model was run with observed meteorology, estimated irrigation inputs, and measured canal leakage for calendar years 1988 through 2005 (fig. 50). For simplicity, all hillslope and stream reservoirs were assigned one of three solutions representing precipitation, canal water, and upgradient groundwater.

Inputs, flow paths, and discharge simulated for 2004 and 2005 are shown in figure 51. The irrigation season 2005 was one of the most severe drought years.

Chloride concentrations of inputs were assigned values typical for precipitation $(0.2 \mathrm{mg} / \mathrm{L})$ and canal water $(0.8 \mathrm{mg} / \mathrm{L})$. The chloride concentration in the groundwater $(20 \mathrm{mg} / \mathrm{L})$ was adjusted to match the observed chloride concentrations at the outflow and is within the range of groundwater concentrations measured in the study area (McCarthy and Johnson, 2009). To better match the abrupt changes in specific conductance seen at the outlet, the fraction of recharge that becomes direct flow, qdffrac(nmru), was increased, and the active depth to bedrock, s_rock_depth(nmru), was decreased. The seasonal hydrology reached steady state after 2 years; however, seasonal variations in simulated chloride reached steady state after approximately 5 years. As an additional evaluation of model performance, simulated values of specific conductance and concentrations of chloride were compared with specific conductance measured by the RozaSunnyside Board of Joint Control since 1998 (Brian Jackson, written commun., 2004) and chloride values measured in 2003 and 2004 (McCarthy and Johnson, 2009;

https://doi.org/10.5066/F7P55KJN). Although the fit between simulated and observed hydrology and chemistry is adequate (fig. 52), the abrupt decrease in chloride concentrations observed during the first few days of irrigation is not simulated well. Substantial canal water is delivered directly to the DR2 drain through waste gates at the end of the laterals to adjust heads along the lateral and to dilute high concentrations of suspended sediments and nutrients for compliance with state water-quality standards. This large pulse of freshwater added directly to the DR2 drain is not simulated with WEBMOD. A workaround could include reducing vertical infiltration rates to produce large amounts of Hortonian overland flow of pure irrigation water with only minor modification during canopy throughfall and interaction with the O-horizon.

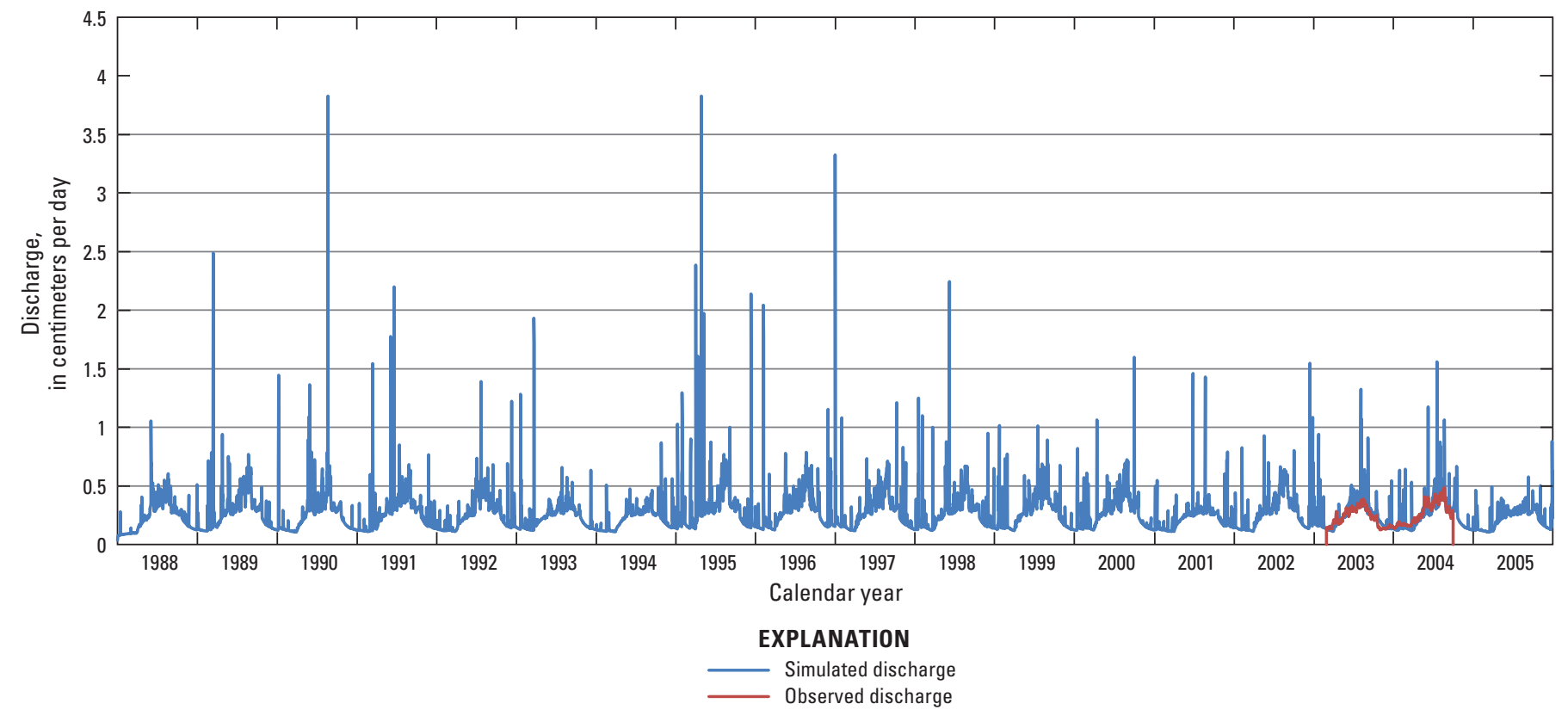

Figure 50. Simulated discharge of the DR2 drain for calendar years 1988 through 2005, and measured discharge from March 1, 2003, through September 30, 2004, using a flume installed at the outlet. During 2003 and 2004, farmers received their full allotment of irrigation. During the drought years of 1993, 1994, 2001, and 2005, allotments were reduced. 


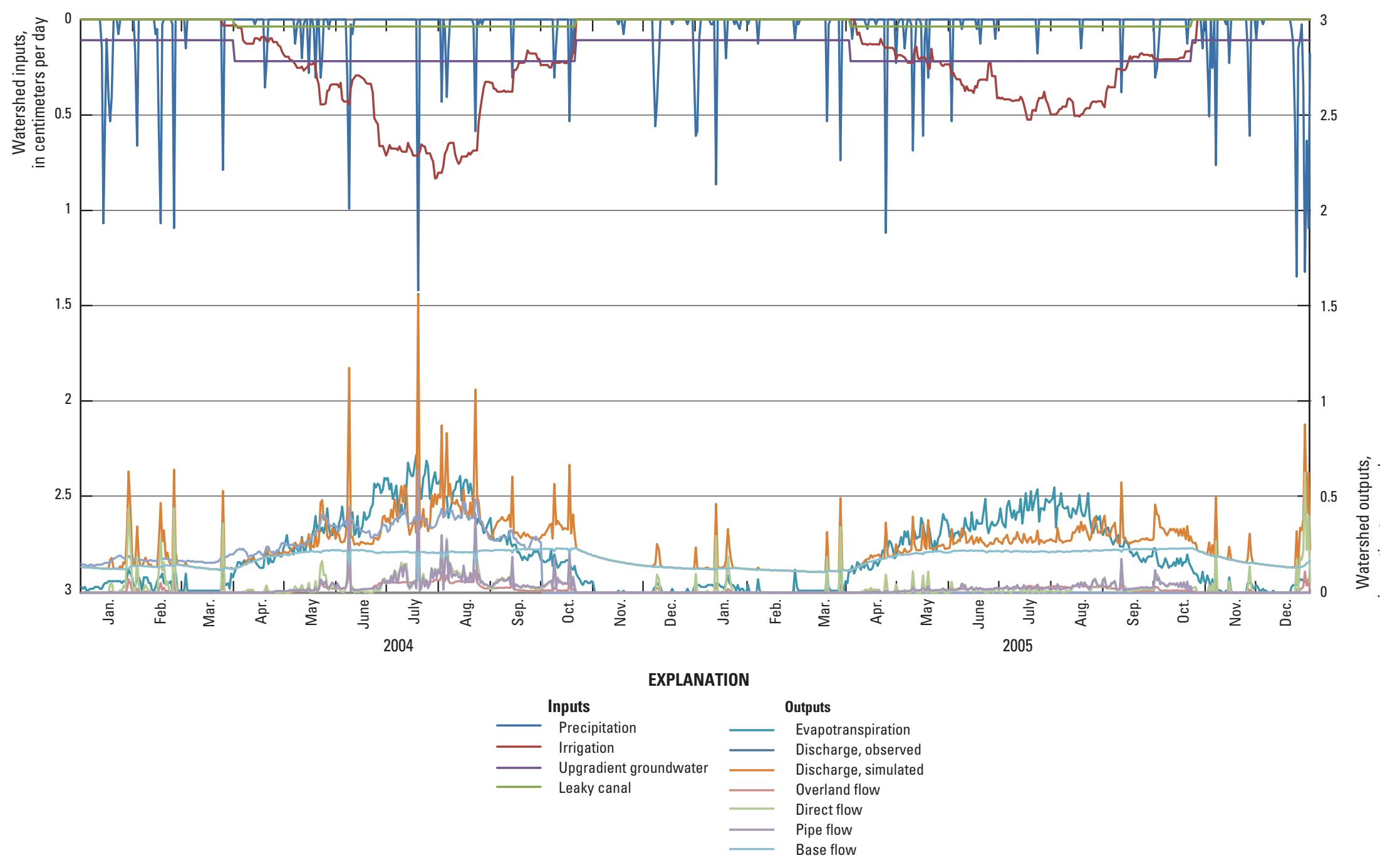

Figure 51. Inputs and outputs for the DR2 watershed simulated for 2004-05. Observations of discharge were discontinued on September 30, 2004. Drought conditions were prevalent in the Pacific Northwest during 2005, resulting in decreased irrigation allotments. Note that direct flow is active during the winter and early growing season. As the water table rises, the pipe flow drains excess water from the fields. 

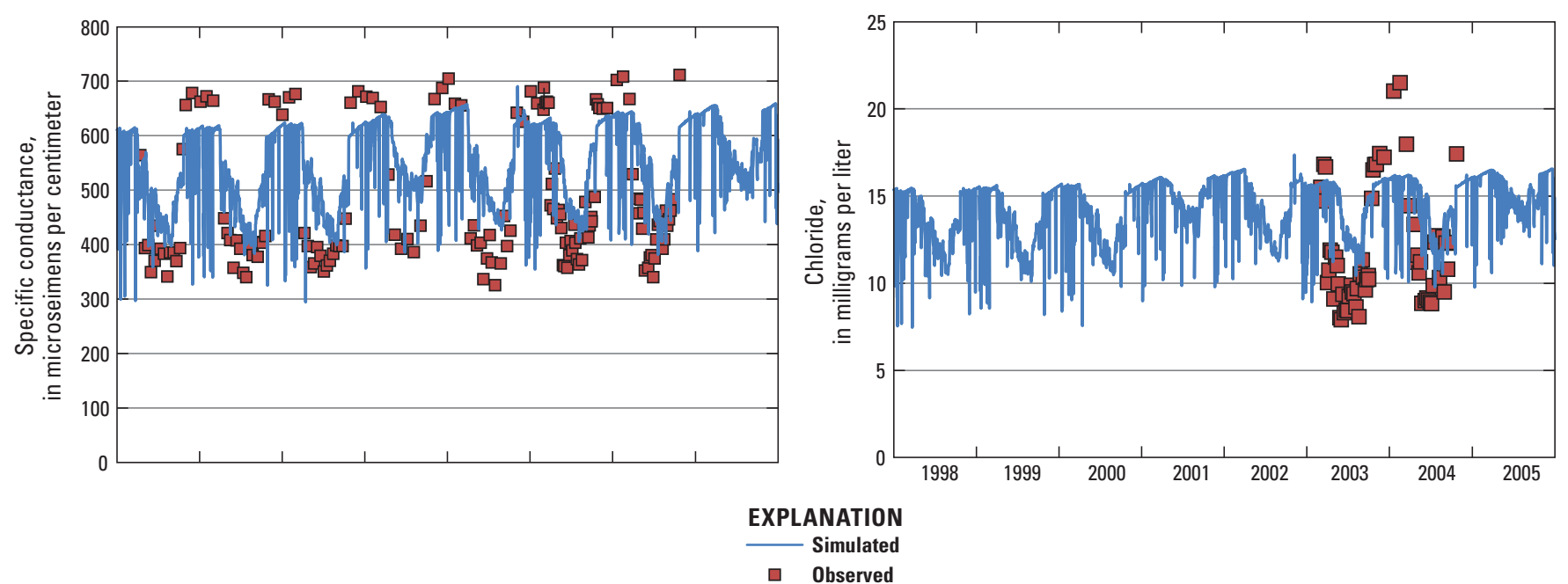

Figure 52. Simulated and observed variations in specific conductance and chloride for the DR2 gage for calendar years 1998 through 2005.

\section{Summary}

This manual documents the theoretical background of the hydrologic, geochemical, and management processes simulated by the Water, Energy, and Biogeochemical Model (WEBMOD) and provides descriptions of the software and file formats necessary to build, execute, and calibrate a WEBMOD model. Example applications for a pristine alpine watershed in Colorado and an irrigated agricultural watershed near Yakima, Washington, provide the user with templates to facilitate the modeling of other watersheds.

WEBMOD is a watershed model that simulates conservative and reactive transport of solutes that cycle among the atmosphere, soils, regolith, and streams. Originally developed to simulate the hydrology and geochemistry of pristine watersheds, WEBMOD has been enhanced to simulate the fluxes of water and solutes in heavily managed watersheds. With these additional capabilities, WEBMOD is a new-generation predictive model that can be used to identify combinations of landscapes and soils where impaired water quality can be expected as a result of changing deposition, climate, and land use. Watersheds susceptible to impairment can then be included in targeted monitoring programs to make the most efficient use of limited laboratory and human resources.

\section{References}

Abatzoglou, J.T., 2013, Development of gridded surface meteorological data for ecological applications and modelling: International Journal of Climatology, v. 33, p. 121-131, accessed November 2, 2016, at https://doi.org/10.1002/joc.3413.

Adams, P.J., Seinfeld, J.H., and Koch, D.M., 1999, Global concentrations of tropospheric sulfate, nitrate, and ammonium aerosol simulated in a general circulation model: Journal of Geophysical Research, v. 104, no. D11, p. 13791-13823.
Ambroise, B., Beven, K., and Freer, J., 1996a, Towards a generalization of the TOPMODEL concepts-Topographic indices of hydrological similarity: Water Resources Research, v. 32, no. 7, p. 2135-2145.

Ambroise, B., Beven, K., and Freer, J., 1996b, Application of a generalized TOPMODEL to the small Ringelbach catchment, Vosges, France: Water Resources Research, v. 32, no. 7, p. 2147-2159.

Anderson, E.A., 1968, Development and testing of snow pack energy balance equations: Water Resources Research, v. 4, no. 1, p. 19-38.

Anderson, E.A., 1973, National Weather Service river forecast system-Snow accumulation and ablation model: National Oceanic and Atmospheric Administration Technical Memorandum NWS-HYDRO-17, p. 3-7.

Anderson, E.A., 1976, A point energy and mass balance model of a snow cover: National Oceanic and Atmospheric Administration Technical Report NWS-19, $150 \mathrm{p}$.

Anderson, E.A., 2002, Calibration of conceptual hydrologic models for use in river forecasting: National Oceanic and Atmospheric Administration, Hydrology Laboratory, Technical Report NWS 45, accessed January 21, 2016, at www.nws.noaa.gov/oh/hrl/calb/calibration1102/main.htm.

Anderson, E.A., 2006, Snow accumulation and ablation model-SNOW-17, part 2 of chap. II.2 of NWSRFS [National Weather Service River Forecast System] user manual documentation-Adobe Acrobat format: National Oceanic and Atmospheric Administration, 61 p. [Also available at http://www.nws.noaa.gov/oh/hrl/nwsrfs/ users_manual/part2/_pdf/22snow17.pdf.]

Angert, A., Yakir, D., Rodeghiero, M., Preisler, Y., Davidson, E.A., and Weiner, T., 2015, Using $\mathrm{O}_{2}$ to study the relationships between soil $\mathrm{CO}_{2}$ efflux and soil respiration: Biogeosciences, v. 12, p. 2089-2099. 
Arrhenius, S., 1889, On the reaction velocity of the inversion of cane sugar by acids: Zeitschrift für Physikalische Chemie, v. 4, p. 96-116. [English translation in Back, M.H., and Laidler, K.J., eds., 1967, Selected readings in chemical kinetics: Oxford, Pergamon, p. 31-35.

Baedecker, M.J., and Friedman, L.C., 2000, Water, Energy, and Biogeochemical Budgets-A watershed research program: U.S. Geological Survey Fact Sheet 165-99. [Also available at http://pubs.er.usgs.gov/publication/fs16599.]

Bales, R.C., Davis, R.E., and Williams, M.W., 1993, Tracer release in melting snow-Diurnal and seasonal patterns: Hydrologic Processes, v. 7, p. 389-401.

Baron, J., 1990, Findings from ecological research program, in Highlights of natural resources management: National Park Service, Natural Resources Programs, Natural Resources Report NPS/NRPO/NRR-90/02.

Baron, J., ed., 1992, Biogeochemistry of a subalpine ecosystemLoch Vale watershed: New York, Springer-Verlag Ecological Study Series, no. 90, 247 p.

Baron, J.S., Schmidt, T.M., and Hartman, M.D., 2009, Climate-induced changes in high elevation stream nitrate dynamics: Global Change Biology, v. 15, no. 7, p. $1777-1789$.

Beven, K.J., 1984, Infiltration into a class of vertically nonuniform soils: Hydrological Sciences Journal, v. 29, no. 4, p. 425-434.

Beven, K., 1995, TOPMODEL demonstration program version 95.02: Lancaster, United Kingdom, Lancaster University.

Beven, K., 1997, TOPMODEL-A critique: Hydrologic Processes, v. 11, no. 9, p. 1069-1086.

Beven, K.J., and Kirkby, M.J., 1979, A physically based variable contributing area model of basin hydrology: Hydrology Science Bulletin, v. 24, no. 1, p. 43-69.

Beven, K.J., Kirkby, M.J., Schoffield, N., and Tagg, A.F., 1984, Testing a physically based flood forecasting model (TOPMODEL) for three UK catchments: Journal of Hydrology, v. 69, p. 119-143.

Bowen, I.S., 1926, The ratio of heat losses by conduction and by evaporation from any water surface: Physical Reviews, v. 27, p. $779-787$.

Caine, N., 2010, Recent hydrologic change in a Colorado alpine basin-An indicator of permafrost thaw?: Annals of Glaciology, v. 51, no. 56, p. 130-134.

Campbell, D.H., Clow, D.W., Ingersoll, G.P., Mast, M.A., Spaher, N.E., and Turk, J.T., 1995, Processes controlling the chemistry of two snowmelt-dominated streams in the Rocky Mountains: Water Resources Research, vol. 31, no. 11, p. 2811-2821.
Capel, P.D., Hamilton, P.A., and Erwin, M.L., 2004, Studies by the U.S. Geological Survey on sources, transport, and fate of agricultural chemicals: U.S. Geological Survey Fact Sheet 2004-3098. [Also available at http://pubs.usgs.gov/ fs/2004/3098/pdf/fs2004-3098.pdf.]

Charlton, S.R., and Parkhurst, D.L., 2011, Modules based on the geochemical model PHREEQC for use in scripting and programming languages: Computers and Geosciences, v. 37, no. 10, p. 1653-1663. [Also available at https://doi.org/10.1016/j.cageo.2011.02.005.]

Childs, E.C., and Bybordi, M., 1969, The vertical movement of water in stratified porous material-1. Infiltration: Water Resources Research, v. 5, no. 2, p. 446-459.

Clark, C.O., 1945, Storage and the unit hydrograph: American Society of Civil Engineers Transactions, v. 110, no. 1, p. 1419-1488.

Clark, I.D., and Fritz, P., 1997, Environmental isotopes in hydrogeology: Boca Raton, Fla., CRC Press, LLC, 331 p.

Clow, D.W., and Mast, M.A., 1995, Composition of precipitation, bulk deposition, and runoff at a granitic bedrock catchment in the Loch Vale Watershed, Colorado, USA, in Tonnessen, K.A., Williams, M.W., and Tranter, M., eds., Biogeochemistry of seasonally snow-covered catchments: International Association of Hydrological Sciences, p. 235-242.

Clow, D.W., and Mast, M.A., 1999, Long-term trends in stream water and precipitation chemistry at five headwater basins in the northeastern United States: Water Resources Research, v. 35, no. 2, p. 541-554.

Clow, D.W., and Mast, M.A., 2010, Mechanisms for chemostatic behavior in catchments-Implications for $\mathrm{CO}_{2}$ consumption by mineral weathering: Chemical Geology, v. 269 , p. $40-51$.

Clow, D.W., Schrott, L., Webb, R.M.T., Campbell, D.H., Torizzo, A., and Dornblaser, M., 2003, Groundwater occurrence and contributions to streamflow in an alpine catchment: Ground Water, v. 41, no. 7, p. 937-950.

Colorado Water Resources Research Institute, 2002, Colorado drought conference-Managing water supply and demand in the time of drought, Fort Collins, Colo., December 4, 2002, proceedings: Fort Collins, Colo., Colorado Water Resources Research Institute Information Series Report No. 96, 155 p. [Also available at http://www.cwi.colostate.edu/publications/ is/96.pdf.]

Craig, H., 1961, Isotope variations in meteoric waters: Science, v. 133, p. 1702-1703.

Craig, H., and Gordon, L.I., 1965, Deuterium and oxygen-18 variations in the ocean and marine atmosphere, in Tongiorgi, E., ed., Stable isotopes in oceanographic studies and paleotemperatures [Conferences in Nuclear Geology], Spoleto, Italy, 1965, proceedings: Pisa, Italy, V. Lishi e F., p. 9-130. 
Dalton, J., 1808, A new system of chemical philosophyPart I: Manchester, United Kingdom, S. Russell, 604 p.

Dansgaard, W., 1964, Stable isotopes in precipitation: Tellus, v. 16, p. 436-438.

Doherty J., 2004, PEST-Model-independent parameter estimation and uncertainty analysis: Brisbane, Australia, Watermark Numerical Computing. [Also available at http:// www.pesthomepage.org/getfiles.php?file=newpestman1.pdf.]

Doorenbos, J., and Pruitt, W.O., 1977, Calculation of crop water requirements, part I of Guidelines for predicting crop water requirements ( $2 \mathrm{~d}$ ed.): Rome, Italy, Food and Agriculture Organization of the United Nations, Irrigation and Drainage Paper No. 24, p. 1-66.

Drever, J.I., 1997, The geochemistry of natural watersSurface and groundwater environments: Upper Saddle River, N.J., Prentice-Hall, Inc., 436 p.

Drever, J.I., and Clow, D.W., 1995, Weathering rates in catchments, in White, A.F., and Brantley, S.L., eds., Chemical weathering rates of silicate minerals: Washington, D.C., Mineralogical Society of America, p. 463-483.

Dunne T., and Black, R.D., 1970a, An experimental investigation of runoff production in permeable soils: Water Resources Research, v. 6, p. 478-490.

Dunne T., and Black, R.D., 1970b, Partial area contributions to storm runoff in a small New England watershed: Water Resources Research, v. 6, p. 1296-1311.

ESRI, Inc., 2001, ArcInfo Workstation, version 8.1 [software]: ESRI, Inc.

Eyring, H., 1935, The activated complex in chemical reactions: Journal of Chemical Physics, v. 3, no. 2, p. 107-115.

Farquhar, G.D., Cernusak, L.A., and Barnes, B., 2007, Heavy water fractionation during transpiration: Plant Physiology, v. 143 , no. 1 , p. 11-18.

Fassnacht, S.R., 2004, Estimating Alter-shielded gauge snowfall undercatch, snowpack sublimation, and blowing snow transport at six sites in the conterminous United States, in Eastern Snow Conference, 61st, Portland, Maine, June 9-11, 2004, proceedings: Eastern Snow Conference, p. $15-26$.

Federer, A.C., and Lash, Douglas, 1978, BROOK-A hydrologic simulation model for eastern forests: Durham, N.H., University of New Hampshire, Water Resources Research Center, Research Report No. 19, 84 p.

Frank, E.C., and Lee, R., 1966, Potential solar beam radiation on slopes: U.S. Department of Agriculture, Forest Service Research Paper RM-18, 116 p.

Freeze, R.A., and Cherry, J.A., 1979, Groundwater: Englewood Cliffs, N.J., Prentice Hall, 604 p.

Fritschen, L.J., and Gay, L.W., 1979, Environmental instrumentation: New York, Springer-Verlag, 216 p.
Fritz, P., and Fontes, J.-Ch., eds., 1980, Handbook of environmental isotope geochemistry, volume 1-The terrestrial environment, A: Amsterdam, Netherlands, Elsevier, 545 p.

Fuhrer, G.J., Morace, J.L., Johnson, H.M., Rinella, J.F., Ebbert, J.C., Embrey, S.S., Waite, I.R., Carpenter, K.D., Wise, D.R., and Hughes, C.A., 2004, Water quality in the Yakima River Basin, Washington, 1999-2000: U.S. Geological Survey Circular 1237, 34 p. [Also available at http://pubs.usgs.gov/circ/2004/1237/.]

Garrels, R.M., and Mackenzie, F.T., 1967, Origin of the compositions of some springs and lakes, in Equilibrium concepts in natural water systems: American Chemical Society, Advances in Chemistry Series, no. 67, p. 222-242.

Gat, J.R., 1996, Oxygen and hydrogen isotopes in the hydrologic cycle: Annual Review of Earth and Planetary Sciences, v. 24, no. 1, p. 225-262.

Gat, J.R., Bowser, C.J., and Kendall, Carol, 1994, The contribution of evaporation from the Great Lakes to the continental atmosphere-Estimate based on stable isotope data: Geophysical Research Letters, v. 21, no. 7, p. 557-560.

Gilliom, R.J., Alley, W.M., and Gurtz, M.E., 1995, Design of the national water-quality assessment program-Occurrence and distribution of water-quality conditions: U.S. Geological Survey Circular 1112, 33 p. [Also available at http://pubs.usgs.gov/circ/circ1112/.]

Gonfiantini, R., 1971, Notes on isotope hydrology: Vienna, Austria, International Atomic Energy Agency, Isotope Hydrology section, internal publication.

Green, W.H., and Ampt, G.A., 1911, Studies on soil physics I-Flow of air and water through soils: Journal of Agricultural Science, v. 4, p. 1-24.

Hamon, W.R., 1961, Estimating potential evapotranspiration: Proceedings of the American Society of Civil Engineers, Journal of the Hydraulic Division, v. 87(HY3), p. 107-120.

Hancock, T.C., Sandstrom, M.W., Vogel, J.R., Webb, R.M.T., Bayless, E.R., and Barbash, J.E., 2008, Pesticide fate and transport throughout unsaturated zones in five agricultural settings, USA: Journal of Environmental Quality, v. 37, p. 1086-1100.

Hendrickx, J.M.H., and Flury, M., 2001, Uniform and preferential flow mechanisms in the vadose zone, in Conceptual models of flow and transport in the fractured vadose zone: Washington D.C., National Academy Press, p. 149-187, accessed April 5, 2012, at http:/www.nap.edu/catalog/10102.html.

Holtan, H.N., England, C.B., Lawless, G.P., and Schumaker, G.A., 1968, Moisture-tension data for selected soils on experimental watersheds: U.S. Department of Agriculture, Agricultural Research Service, ARS 41-144, 609 p.

Horton, R.E., 1939, Approach toward a physical interpretation of infiltration capacity: Soil Science Society of America Proceedings, v. 5, p. 399-417. 
Horton, R.E., Leach, H.R., and Van Vliet, R., 1934, Laminar sheet flow: Transactions of the American Geophysical Union, v. 15 , no. 2, p. 393-404.

Jensen, M.E., and Haise, H.R., 1963, Estimating evapotranspiration from solar radiation: American Society of Civil Engineers, Journal of Irrigation and Drainage Engineering Division, v. 89, p. 15-41.

Johannessen, M., and Henriksen, A., 1978, Chemistry of snow meltwater - Changes in concentration during melting: Water Resources Research, v. 14, p. 615-619.

Kendall, Carol, and McDonnell, J.J., eds., 1998, Isotope tracers in catchment hydrology: Amsterdam, Netherlands, Elsevier, 839 p.

Kirkby, M.J., 1975, Hydrograph modelling strategies, in Peel, R., Chisholm, M., and Haggett, P., eds., Processes in physical and human geography: London, Heinemann, p. 69-90.

Kirkby, M.J., 1976, Tests of the random network model, and its application to basin hydrology: Earth Surface Processes, v. 1, no. 3, p. 197-212.

Leavesley, G.H., Lichty, R.W., Troutman, B.M., and Saindon, L.G., 1983, Precipitation-runoff modeling system-User's manual: U.S. Geological Survey Water-Resources Investigations Report 83-4238, 207 p. [Also available at http://pubs.er.usgs.gov/publication/wri834238.]

Leavesley, G.H., Markstrom, S.L., Brewer, M.S., and Viger, R.J., 1996, The Modular Modeling System (MMS)—The physical process modeling component of a database-centered decision support system for water and power management: Water, Air, and Soil Pollution, v. 90, p. 303-311.

Leavesley, G.H., Markstrom, S.L., Viger, R.J., and Hay, L.E., 2005, USGS Modular Modeling System (MMS) Precipitation-Runoff Modeling System (PRMS) MMSPRMS, in Singh, V.P., and Frevert, D., eds., Watershed models: Boca Raton, Fla., CRC Press, p. 159-177.

Leavesley, G.H., Restrepo, P.J., Markstrom, S.L., Dixon, M., and Stannard, L.G., 1996, The Modular Modeling System (MMS) - User's manual: U.S. Geological Survey Open-File Report 96-151, 142 p.

Lee, R., 1963, Evaluation of solar beam irradiation as a climatic parameter of mountain watersheds: Fort Collins, Colo., Colorado State University, Hydrology papers no. 2, 50 p.

Lehmann, C.M.B., Bowersox, V.C., Larson, S.M., 2005, Spatial and temporal trends of precipitation chemistry in the United States, 1985-2002: Environmental Pollution, v. 135, p. $347-361$.

Linard, J.I., Wolock, D.M., Webb, R.M.T., and Wieczorek, M.E., 2009, Identifying hydrologic processes in agricultural watersheds using precipitation-runoff models: U.S. Geological Survey Scientific Investigations Report 2009-5126, 22 p. [Also available at http://pubs.usgs.gov/sir/2009/5126/.]
Lowe, P.R., 1976, An approximating polynomial for the computation of saturation vapor pressure: Journal of Applied Meteolorolgy, v. 16, no. 1, p. 100-103.

Majzoub, M., 1971, Fractionnement en oxygen-18 et en deuterium entre l'eau et sa vapeur: Journal de Chimie Physique, v. 68 , p. $1423-1436$.

Markstrom, S.L., and Koczot, K.M., 2008, User's manual for the object user interface (OUI) - An environmental resource modeling framework: U.S. Geological Survey Open-File Report 2008-1120, 39 p. [Also available at http://pubs.usgs.gov/of/2008/1120/.]

Markstrom, S.L., Regan, R.S., Hay, L.E., Viger, R.J., Webb, R.M.T., Payn, R.A., and LaFontaine, J.H., 2015, PRMS-IV, the precipitation-runoff modeling system, version 4: U.S. Geological Survey Techniques and Methods, book 6, chap. B7, 158 p. [Also available at https://doi.org/10.3133/tm6B7.]

Mast, M.A., 1992, Geochemical characteristics, in Baron, Jill, ed., Biogeochemistry of a subalpine ecosystem-Loch Vale Watershed: New York, Springer-Verlag, p. 93-107.

McCabe, G.J., and Wolock, D.M., 2008, Joint variability of global runoff and global sea surface temperatures: Journal of Hydrometeorology, v. 9, p. 816-824.

McCabe, G.J., and Wolock, D.M., 2010, Century-scale variability in global annual runoff examined using a water balance model: International Journal of Climatology, v. 31, no. 12, p. 1739-1748.

McCabe, G.J., Hay, L.E., Bock, A., Markstrom, S.L., and Atkinson, R.D., 2015, Inter-annual and spatial variability of Hamon potential evapotranspiration model coefficients: Journal of Hydrology, v. 521, p. 389-394. [Also available at https://doi.org/10.1016/j.jhydrol.2014.12.006.]

McCarthy, K.A., and Johnson, H.M., 2009, Effect of agricultural practices on hydrology and water chemistry in a small irrigated catchment, Yakima River Basin, Washington: U.S. Geological Survey Scientific Investigations Report 2009-5030, 22 p. [Also available at http://pubs.usgs.gov/ sir/2009/5030/.]

Meeus, J., 1998, Astronomical algorithms: Richmond, Va., Willmann-Bell, Inc., 477 p.

Mein, R.G., and Larson, C.L., 1973, Modeling infiltration during a steady rain: Water Resources Research, v. 9, no. 2, p. 384-394.

Merlivat, L., 1978, Molecular diffusivities of $\mathrm{H}_{2}{ }^{16} \mathrm{O}, \mathrm{HD}^{16} \mathrm{O}$, and $\mathrm{H}_{2}{ }^{18} \mathrm{O}$ in gases: Journal of Chemical Physics, v. 69, no. 6, p. 2864-2871.

Merlivat, L., and Nief, G., 1967, Fractionnement isotopique lors des changements d'état solide-vapeur et liquide-vapeur de l'eau à des températures inférieures à $0{ }^{\circ} \mathrm{C}$ : Tellus, v. 19 , no. 1, p. 122-127. 
Meyer, P.D., Rockhold, M.L., and Gee, G.W., 1997, Recommended distributions for describing uncertainty in soil hydraulic parameters, chap. 2 of Uncertainty analyses of infiltration and subsurface flow and transport for SDMP sites: U.S. Nuclear Regulatory Commission NUREG/ CR-6565, PNNL-11705, prepared by Pacific Northweast National Laboratory, p. 3-14.

Mizukami, N., Koren, V., and Smith, M., 2008, SNOW-17 a priori parameterization update, in National Development and Operations Hydrologist (DOH) Workshop, Silver Spring, Md., July 15-17, 2008, proceedings: National Oceanic and Atmospheric Administration, accessed March 7, 2016, at http://www.nws.noaa.gov/ohd/rfcdev/docs/ Snow-17_A_priori_parm_estimates.pdf.

Mook, W.G., 2000, Environmental isotopes in the hydrological cycle-Principles and applications. Volume 1, Introduction - Theory, methods, review: International Atomic Energy Agency [IAEA], United Nations Educational, Scientific and Cultural Organization [UNESCO], IHP-V Technical Documents in Hydrology, no. 39, accessed February 17, 2011, at http://www-naweb.iaea.org/napc/ih/ IHS_resources_publication_hydroCycle_en.html.

Morel-Seytoux, H.J., and Khanji, J., 1974, Derivation of an equation of infiltration: Water Resources Research, v. 10, no. 4, p. 795-800.

Murray, F.W., 1967, On the computation of saturation vapor pressure: Journal of Applied Meteorology, v. 6, p. 203-204.

National Atmospheric Deposition Program, 2013, AMoN Site CO98: National Atmospheric Deposition Program, accessed November 14, 2013, at http://nadp.isws.illinois.edu/data/ sites/siteDetails.aspx?net=AMON\&id=CO98.

National Atmospheric Deposition Program, 2014, Ammonia Monitoring Network (AMoN) Web site: National Atmospheric Deposition Program, accessed November 2, 2016, at http://nadp.sws.uiuc.edu/AMoN/.

National Renewable Energy Laboratory, 1995, Final Technical Report, National solar radiation data base (1961-1990): Golden, Colo., National Renewable Energy Laboratory, NREL/TP-463-5784.

Natural Resource Ecology Laboratory, 2011, Loch Vale Watershed: Fort Collins, Colo., Natural Resources Ecology Laboratory, Long-term Ecological Research and Monitoring Program, accessed June 2, 2016, at http://www.nrel.colostate.edu/ projects/lvws/data.html.

Newkirk, B.K., 1995, Loch Vale Watershed methods manual: Fort Collins, Colo., Colorado State University Natural Resource Ecology Laboratory, 124 p.

O'Loughlin, E.M., 1981, Saturation regions in catchments and their relations to soil and topographic properties: Journal of Hydrology, v. 53, p. 229-246.
O'Neil, J.R., 1968, Hydrogen and oxygen isotope fractionation between ice and water: Journal of Physical Chemistry, v. 72, p. 3683-3684.

Palandri, J.L, and Kharaka, Y.K., 2004, Compilation of rate parameters of water-mineral interaction kinetics for application to geochemical modeling: U.S. Geological Survey Open-File Report 2004-1068, 64 p. [Also available at http://pubs.usgs.gov/of/2004/1068/.]

Parkhurst, D.L., 1997, Geochemical mole-balance modeling with uncertain data: Water Resources Research, v. 33, no. 8, p. 1957-1970.

Parkhurst, D.L., and Appelo, C.A.J., 1999, User's guide to PHREEQC (version 2)-A computer program for speciation, batch-reaction, one-dimensional transport and inverse geochemical calculations: U.S. Geological Survey WaterResources Investigations Report 99-4259, 312 p. [Also available at http://pubs.er.usgs.gov/publication/wri994259.]

Parkhurst, D.L., and Appelo, C.A.J., 2013, Description of input and examples for PHREEQC version 3-A computer program for speciation, batch-reaction, one-dimensional transport, and inverse geochemical calculations: U.S. Geological Survey Techniques and Methods, book 6, chap. A43, 497 p., accessed October 18, 2016, at http://pubs.usgs.gov/ tm/06/a43.

Parkhurst, D.L., Thorstenson, D.C., and Plummer, L.N., 1980, PHREEQE - A computer program for geochemical calculations: U.S. Geological Survey Water-Resources Investigations Report 80-96, 195 p. [Also available at http://pubs.er.usgs.gov/publication/wri8096.]

Payne, K.L., Johnson, H.M., and Black, R.W., 2007, Environmental setting of the Granger Drain and DR2 Basins, Washington, 2003-04: U.S. Geological Survey Scientific Investigations Report 2007-5102, 26 p. [Also available at http://pubs.usgs.gov/sir/2007/5102/.]

Peters, N.E., Shanley, J.B., Aulenbach, B.T., Webb, R.M., Campbell, D.H., Hunt, R., Larsen, M.C., Stallard, R.F., Troester, J., and Walker, J.F., 2006, Water and solute mass balance of five small, relatively undisturbed watersheds in the U.S.: Science of the Total Environment, v. 358, nos. 1-3, p. 221-242.

Piñol, J., Beven, K., and Freer, J., 1997, Modeling the hydrological response of Mediterranean catchments, Prades, Catalonia-The use of distributed models as aids to hypothesis formulation: Hydrological Processes, v. 11, p. 1287-1306.

Robinson, C.D., 2001, Drain system map \#5, plotted 3/1/2001: Sunnyside, Wash., Sunnyside Valley Irrigation District.

Simon, Andrew, Larsen, M.C., and Hupp, C.R., 1990, The role of soil processes in determining mechanisms of slope failure and hillslope development in a humid-tropical forestEastern Puerto Rico, in Kneuper, P.L.K., and McFadden, L.D. eds., Soils and landscape evolution: Geomorphology, v. 3, p. 263-286. 
Stannard, D.I., Gannett, M.W., Polette, D.J., Cameron, J.M., Waibel, M.S., and Spears, J.M., 2013, Evapotranspiration from marsh and open-water sites at Upper Klamath Lake, Oregon, 2008-2010: U.S. Geological Survey Scientific Investigations Report 2013-5014, 66 p.

Stephenson, N., Peterson, D., Fagre, D., Allen, C., McKenzie, D., Baron, J.S., and O'Brian, K., 2006, Response of western mountain ecosystems to climatic variability and changeThe Western Mountain Initiative: Park Science, v. 24, no. 1, p. 24-29.

Stone, W.W., and Wilson, J.T., 2006, Preferential flow estimates to an agricultural tile drain with implications for glyphosate transport: Journal of Environmental Quality, v. 35 , no. 5 , p. 1825-1835.

Swift, L.W., Jr., 1976, Algorithm for solar radiation on mountain slopes: Water Resources Research, v. 12, no. 1, p. 108-112.

Tallaksen, L.M., 1995, A review of baseflow recession analysis: Journal of Hydrology, v. 165, no. 1, p. 349-370.

Tangborn, W.V., 1978, A model to predict short-term snowmelt runoff using synoptic observations of streamflow, temperature, and precipitation, in Colbeck, S.C., and Ray, M., eds., Workshop on modeling of snow cover runoff, Hanover, N.H., September 26-28, 1978, proceedings: Hanover, N.H., U.S. Army Cold Regions Research and Engineering Laboratory, v. 26, p. 28.

Thompson, E.S., 1976, Computation of solar radiation from sky cover: Water Resources Research, v. 12, no. 5, p. 859-865.

Turk, J.T., Spahr, N.E., and Campbell, D.H., 1993, Planning document of water, energy, and biogeochemical-budget (WEBB) research project, Loch Vale watershed, Rocky Mountain National Park, Colorado: U.S. Geological Survey Open-File Report 92-628, 18 p. [Also available at http://pubs.er.usgs.gov/publication/ofr92628.]

U.S. Department of Agriculture, 2016, Bear Lake (322) [SNOTEL site]: U.S. Department of Agriculture, Natural Resources Conservation Service, National Water and Climate Center, accessed June 2, 2016, at http://wcc.sc.egov.usda.gov/nwcc/ site? sitenum $=322$.

U.S. Geological Survey, 2011, USGS NED ned19_n40×50_ w105×75_co_grandco_2010 1/9 arc-second 2011 $15 \times 15$ minute IMG: U.S. Geological Survey: Reston, VA, http://ned.usgs.gov/, http://nationalmap.gov/viewer.html.

Viger, R.J., and Leavesley, G.H., 2007, The GIS Weasel user's manual: U.S. Geological Survey Techniques and Methods, book 6, chap. B4, 201 p. [Also available at http://pubs.usgs.gov/tm/2007/06B04/.]
Vogt, H.J., 1978, Isotopentrennung bei der Verdünstung von Wasser: University of Heidelberg, Institute of Environmental Physics, thesis.

Waring, G.A., 1913, Geology and water resources of a portion of south-central Washington: U.S. Geological Survey Water-Supply Paper 316, 46 p. [Also available at http://pubs.er.usgs.gov/publication/wsp316.]

Webb, R.M.T., Mast, M.A., Manning, A.H., Clow, D.W., Campbell, D.H., 2011, Potential climate change effects on water tables and pyrite oxidation in headwater catchments in Colorado, in Medley, C.N., Patterson, Glenn, and Parker, M.J., eds., Observing, studying, and managing for change-Proceedings of the Fourth Interagency Conference on Research in the Watersheds: U.S. Geological Survey Scientific Investigations Report 2011-5169, p. 23-33. [Also available at http://pubs.usgs.gov/sir/2011/5169/ SIR11-5169_508.pdf.]

Webb, R.M.T, Peters, N.J., Aulenbach, B.T., and Shanley, J.B., 2003, Relations between hydrology and solute fluxes at the five water, energy, and biogeochemical budget (WEBB) watersheds of the U.S. Geological Survey, in Renard, K.G., McElroy, S.A., Gburek, W.J., Canfield, H.E., and Scott, R.L., eds., First Interagency Conference on Research in the Watersheds, Benson, Ariz., October 27-30, 2003: U.S. Department of Agriculture, Agricultural Research Service, p. 332-339.

Weiskel, P.K., Vogel, R.M., Steeves, P.A., Zarriello, P.J., DeSimone, L.A., and Ries, K.G., III, 2007, Water use regimes - Characterizing direct human interaction with hydrologic systems: Water Resources Research, v. 43, no. 4, W04402, 11 p.

Williamson, M.A., and Rimstidt, J.D., 1994, The kinetics and electrochemical rate-determining step of aqueous pyrite oxidation: Geochimica et Cosmochimica Acta, v. 58, no. 24, p. 5443-5454.

Wolock, D.M., 1993, Simulating the variable-source-area concept of streamflow generation with the watershed model TOPMODEL: U.S. Geological Survey Water-Resources Investigations Report 93-4124, 33 p. [Also available at http://pubs.er.usgs.gov/publication/wri934124.]

Wright, J.L., 1982, New evapotranspiration crop coefficients: American Society of Civil Engineers, Journal of Irrigation and Drainage Division, v. 108, no. 1, p. 57-74.

Zuroske, M., 2009, Water quality conditions in irrigation waterways within the Roza and Sunnyside Valley Irrigation Districts, Lower Yakima Valley, Washington, 1997-2008: Roza-Sunnyside Board of Joint Control, 68 p. 
Publishing support provided by:

Denver Publishing Service Center, Denver, Colorado

For more information concerning this publication, contact:

Chief, National Research Program, Central Branch

U.S. Geological Survey

Box 25046, Mail Stop 418

Denver, C0 80225

Or visit the National Research Program Web site at: https://water.usgs.gov/nrp

This publication is available online at: https://doi.org/10.3133/tm6B35 

